MAriv TEXILA

AMERICAN

UNIVERSITY

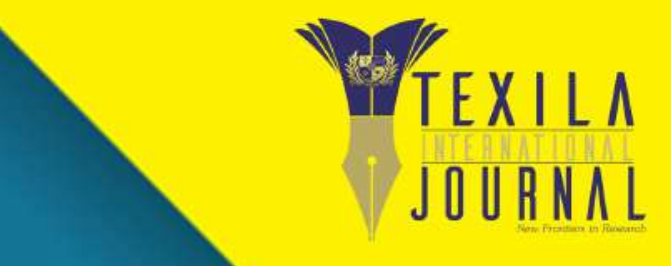

HIIIIIIII 


\section{EDITORIAL POLICY}

Papers must be submitted with the understanding that they have not been published elsewhere (except in the form of an abstract or as part of a published lecture, review, or thesis) and are not currently under consideration by another journal published or any other publisher. The submitting (Corresponding) author is responsible for ensuring that the article's publication has been approved by all the other coauthors. It is also the authors' responsibility to ensure that the articles coming from a particular institution are submitted with the approval of the necessary institution. Only an acknowledgment from the editorial office officially establishes the date of receipt. It is a condition for submission of a paper that the authors permit editing of the paper for readability. All enquiries concerning the publication of accepted papers should be addressed to ejournal.assist@tau.edu.gy

\section{CHIEF EDITOR}

Dr. T. Selvankumar, Professor and Head, Mahendra Arts \& Science College.

\section{EDITORIAL BOARD MEMBERS}

Dr. Neerja Sood, Assistant Professor in School of Health Sciences, Indira Gandhi National Open University, New Delhi.

Dr Nirmallya Chatterjee, Lecturer, Ma Sarada College of Nursing.

Dr. Sunil Kumar D, Associate professor in the Department of Community Medicine, JSS.

Dr. Jitendra Kumar Chaudhary, College of Veterinary Sciences, Mizoram.

Dr. Rahul Diliprao Suryawanshi, Department of Veterinary Public Health and Epidemiology, College of Veterinary and Animal Sciences, Udgir, Dist. Latur.

Dr. Atulomah, Nnodimele Onuigbo, Babcock University, School of Public and Allied Health, Department of Public Health, Nigeria. 


\section{ABOUT PLAGIARISM}

Plagiarism is the use or close imitation of the language and ideas of another author and representation of them as one's own original work. Duplicate publication, sometimes called self-plagiarism, occurs when an author reuses substantial parts of his or her own published work without providing the appropriate references. This can range from getting an identical paper published in multiple journals, where authors add small amounts of new data to a previous paper.

Plagiarism can be said to have clearly occurred when large chunks of text have been cut and pasted. Such manuscripts would not be considered for publication in TIJPH Journal. But minor plagiarism without dishonest intent is relatively frequent, for example when an author reuses parts of an introduction from an earlier paper. The editors will judge any case of which they become aware (either by their own knowledge of and reading about the literature, or when alerted by referees) on its own merits.

The paper containing the plagiarism will be obviously returned back to the author's for review, but we earnestly request the authors to avoid submitting plagiarized. 


\section{DISCLAIMER}

Texila International Journal of Public Health (TIJPH) make every effort to ensure the accuracy of all the information (the "Content") contained in its publications. However, the TIJPH and its agents make no representations or warranties whatsoever as to the accuracy, completeness or suitability for any purpose of the Content and disclaim all such representations and warranties whether express or implied to the maximum extent permitted by law. Any views expressed in this publication are the views of the authors and are not necessarily the views of the Editor's or Texila International Journal of Public Health. 


\section{TABLE OF CONTENT}

1 Validity of Ziehl-Neelsen and LED Fluorescence Microscopy Technique in the Diagnosis of Mycobacterium Tuberculosis Infection among HIV Patients in Lafia, Nigeria, 2017

Ubong Akpan Okon

2 Adverse Drug Reactions Reporting among Health Professionals in 10 Government Hospitals in Katsina State, Nigeria

Ayuba Daniel

3 Asymptomatic Bacteriuria among Pregnant Women Attending Antenatal 24 Clinic at the Akuapem North District of the Eastern Region of Ghana

Aquel Rene Lopez

4 Antibiotics Resistance, Sensitivity Pattern and Development of Antibiogram to Support Empirical Prescription in Health Facilities in South Senatorial District of Kwara State, Nigeria

\section{Joseph Gbenga Solomon}

5 Evaluation of Health Risks of Improper Biomedical Waste Management 46 among Health Workers in Selected Hospitals in Abuja, Nigeria

Edith C Okechukwu

6 Review and Critical Evaluation of Cognitive Behavioural Therapy for the 56 Treatment of Post-Traumatic Stress Disorder

Azubuike Chidozie Precious

7 Knowledge, Perception, and Practice of DMPA-SC/Self-Injectable Contraceptive among Women: Findings from Mixed-Method Study in South-West and North-Central, Nigeria

Kehinde Osinowo

8 Factors Associated with Distribution of Pre-Eclampsia and Eclampsia 81 Among Rural and Urban Women in Child Bearing Age - A Case of Mbala General Hospital, Northern Province, Zambia

Daniel Sinkala 
9 An Assessment of Factors Influencing Job Satisfaction of Healthcare 92 Professionals in Ogun State Hospitals, Nigeria

Ahmed Babatunde Jimoh

10 Assessment of Coagulopathy, Inflammation and LDH Activity in SARS- 107 CoV-2-infected Patients

Ajibola Adisa

11 In Hypertension Patients is Diet and Exercise more Effective in Lowering High Blood Pressure Compared to Exercise Alone

Gift Himwaaba

12 Access to Healthcare and Health Seeking Behaviour among Female Head 136 Porters in Kumasi, Ghana: The Impact on Public Health

Justice Ofori-Amoah

13 Strengthening Capacities of Ward Development Committees to Promote Health in Nigeria: A Case Study of Osun State

Helen U. Ekpo

14 Factors Contributing to Community None Acceptance for Indoor Residual Spraying (IRS) for Malaria prevention in Chipushi Area of Mpika, Zambia

Elemiya Tembo

15 Factors Determining the Choice of Place of Delivery among Antenatal Attendees in Primary Health Care Centres in Lafia Nigeria

Bello Surajudeen Oyeleke

16 Partner Notification Services (PNS) Among HIV Positive Key Populations: An Important Strategy Towards Achieving UNAIDS 95.95.95 Goals by the Year 2030

Ugbena, Eneojo Richard

17 Health Seeking Behaviour among Past and Current Tuberculosis Patients in 194 a Low-Income Country

Gokul Mishra

18 Analyzing the Magnitude of Global Epidemiological Transition in SubSaharan Africa: A Need to Review the Current Healthcare Management Approach

$$
\text { Abiodun Bamidele Adelowo }
$$

19 Determinants of Hesitancy to Childhood Immunizations in a Peri -Urban Settlement; A Case Study of Nansana Municipality, Uganda 
20 Financial Health Affects Medical Outcomes; the Case of Some Mission

Hospitals in Ghana

Ebenezer Kenneth Abban

21 Route of Administration of Corticosteroids and Asthma Relapse after Acute 238 Care; Appraisal of Evidence on Effectiveness and Safety

Sogunle P.T

22 The Impact of COVID-19 Pandemic on Pharmacy Practices in the Tropics:

247 Nigeria as a Case Study

Nnenna Genevieve Ekechukwu

23 The Influence of Social Support on the Academic Performance/SelfEfficacy of Students in Methodist University College Students, Ghana

Peter Worlanyo Abomah

24 Assessing the Challenges of Pharmaceutical Practices during COVID-19

Pandemic in Nigeria

Nnenna Genevieve Ekechukwu

25 Attitude, Knowledge, and Use of Self-Medication with Antibiotics by Outpatients of Gbagada General Hospital Gbagada Lagos 


\title{
Validity of Ziehl-Neelsen and LED Fluorescence Microscopy Technique in the Diagnosis of Mycobacterium Tuberculosis Infection among HIV Patients in Lafia, Nigeria, 2017
}

\author{
Ubong Akpan Okon ${ }^{1,2 *}$, Ahmed Saad ${ }^{3}$, Adebola Olayinka ${ }^{1,4}$, Muhammad Shakir Balogun ${ }^{1}$, \\ Elizabeth Adedire ${ }^{1}$, Patrick Mboya Nguku ${ }^{1}$ \\ ${ }^{I}$ Nigeria Field Epidemiology and Laboratory Training Program, Abuja, Nigeria \\ ${ }^{2}$ Nigeria Police Medical Service, Benue State \\ ${ }^{3}$ Department of Pathology, Ahmadu Bello University Teaching Hospital, Zaria, Nigeria \\ ${ }^{4}$ Department of Microbiology, Ahmadu Bello University Teaching Hospital, Zaria, Nigeria
}

\begin{abstract}
Tuberculosis (TB) is a public health problem caused by the Mycobacterium tuberculosis complex. An estimated $70 \%$ of TB patients living with HIV are from sub-Saharan Africa largely depends on direct smear microscopy light microscopy for TB diagnosis, which has low Sensitivity, especially among HIV patients. Hence, we conducted this study to evaluate the Performance of Auramine O LED Fluorescence microscopy and the Ziehl-Neelsen technique in Tuberculosis among HIV-positive patients. The study was conducted using a cross-sectional design among 107 consecutively selected HIV/AIDS patients with presumptive Tuberculosis attending ART clinic in Dalhatu Araf Specialist Hospital (DASH), Lafia, Nasarawa State. Three samples were collected from each patient in two visits. Each sample was examined using ZN, LED FM, and Gene-Xpert. Data on socio-demographic characteristics was collected from the subject participant. Univariate and bivariate analyses were done using MS Excel and Epi Info. The Sensitivity and Specificity were compared using McNemar's chi-square. Seventythree (68\%) patients were female, 33 (30.8\%) were in the age group 28-32 years, and 61 (56\%) were employed. Ziehl-Neelsen and LED fluorescent microscopy respectively yielded 11 (10.3\%) and 15 (14.0\%) positive results, while Gene-Xpert gave 18 (16.3\%). The Sensitivity for direct ZN and LED FM were $61.1 \%$ and $83.3 \%$, respectively (P-value 0.01 ) with $100 \%$ specificity for both methods. LED microscopy has a much higher sensitivity than ZN microscopy and would be a better alternative in the diagnosis of Tuberculosis in high HIV settings where the use and expertise with culture and Gene-Xpert are limited.
\end{abstract}

Keywords: HIV, LED Fluorescence, Sensitivity, Specificity, Ziehl-Neelsen.

\section{Introduction}

Tuberculosis (TB) is a public health problem caused by infection with the Mycobacterium tuberculosis complex. It is more common in developing countries and is associated with poverty and poor housing conditions $[1,2]$. Large household size, overcrowding and consumption of animal products like unpasteurized milk and milk products have been documented as risk factors for Tuberculosis [3,
4]. Tuberculosis affects the lungs and other organs of the body which are known as pulmonary and extra-pulmonary Tuberculosis, respectively. Pulmonary Tuberculosis (PTB) accounts for $80 \%$ of all TB cases [5, 6]. TB is spread from person to person through the air containing the bacilli from the cough, sneeze, or spit of an infected person. The most important source of infection is an untreated PTB patient people ill with TB can infect up to 10-15 other people through close contact [6]. The case

*Corresponding Author: itdo4christ@yahoo.com 
definition of PTB is any person presenting with cough lasting 2 weeks or more, accompanied with one or more of the following symptoms: weight loss, tiredness, fever, night sweats, chest pain, shortness of breath, loss of appetite, coughing without or without blood [7]. HIV increases the risk of acquiring TB with a $10 \%$ chance of developing active Tuberculosis yearly. Tuberculosis causes a third of global HIV/AIDS deaths. Without treatment, TB mortality rates are higher than HIV; and about $70 \%$ of pulmonary TB cases died within 10 years of infection [7]. However, according to WHO reports, only $2.4 \%$ of all people living with HIV or AIDS have been tested for TB [8]. In 2013, it was estimated that TB-HIV deaths were about 360,000 and 400,000 in 2014 , and about $41 \%$ of the deaths occurred in Africa, where $38 \%(170,000)$ of the deaths was recorded in Nigeria [7].

The most important control strategy for TB is the early detection and appropriate treatment of TB cases. Globally the Case Detection Rate (CDR) of TB has been estimated at only $64 \%$ against the $70 \%$ target set by the World Health Assembly in 2005. This means that about 36\% of the incident TB cases are not detected [9]. "This leaves a gap of approximately 3.3 million people worldwide with TB who were "missed," either because they were not diagnosed or because they were diagnosed but not reported" [7]. Tuberculosis diagnosis in Nigeria is largely dependent on direct smear microscopy, and hence the TB case detection rate in Nigeria was about $15 \%$ in 2014 [7], very low when compared to other nations in the world.

The Sensitivity of $\mathrm{ZN}$ microscopy is low, ranging from 52 to $70 \%$. The conventional light microscopy sensitivity is grossly compromised in the diagnosis of TB among HIV patients and other cases where the bacterial load is less than 10,000 organisms $/ \mathrm{ml}$ sputum sample such as children and extra-pulmonary TB cases $[10,11$, 12]. Due to the low $\mathrm{ZN}$ sensitivity, many cases TB cases go undetected, thereby making TB control more challenging, and this has contributed to the challenges in TB control.
Mercury fluorescence has been shown to improve tuberculosis diagnosis by $10 \%$ with a good turnaround time when compared with conventional bright-field microscopy [13, 14]. However, the cost of maintenance due to the short life span of mercury, equipment cost, the requirement for the dark room, and high skilled required have made the use of fluorescence microscopy challenging in developing countries like Nigeria [15]. Due to challenges associated with the use of mercury fluorescence microscopy, Light-emitting diodes (LEDs) have been identified as an alternative to conventional FM, and having been distributed across most Nigeria health centres, and its Performance has been limitedly studied among HIV patients; hence, our study was aimed to evaluate the validity of LED Microscopy in the diagnosis of tuberculosis infection among HIV patients attending Dalhatu Araf Specialist Hospital, Lafia.

\section{Methods}

\section{Study Area and Site}

Nasarawa State, with Lafia as its capital, is in the North-Central geopolitical zone of Nigeria. Its population is 2,523,400 according to the 2016 projection. The study was conducted at Dalhatu Araf Specialist Hospital, a 300-bed facility in Lafia. It serves clients within Lafia, local Government Area and the neighboring states. The facility has about 13,780 adult and pediatric HIV patients receiving HAART. DASH laboratory is an accredited laboratory by the Medical Laboratory Council of Nigeria and serves as a referral centre for the neighboring laboratories.

The DASH laboratory has different departments like the Hematology, Microbiology, ART Laboratory, Gene-Xpert services, Clinical Chemistry and Histopathology.

\section{Study Design and Population}

This was a cross-sectional study among HIV patients with presumptive pulmonary TB visiting Dalhatu Araf Specialist Hospital. 


\section{Inclusion Criteria}

All HIV patients with presumptive TB who are able to give sputum and are not on any antituberculosis drugs.

\section{Exclusion Criteria}

HIV patients with presumptive TB who are critically ill or admitted for other illnesses.

\section{Sample Size Determination}

The sample size was calculated using the formula for sample size determination [16, 17].

\section{Sample size (n)based on Specificity $n$}

$$
=\frac{\mathbf{Z}_{\propto / 2}^{2} \times S_{\mathbf{P}}\left(\mathbf{1}-\mathbf{S}_{\mathbf{P}}\right)}{\mathbf{L}^{2} \times P}
$$

Description:

$$
\begin{aligned}
& \mathrm{n}=\text { required sample size for this } \\
& \text { study. } \\
& \mathrm{P}=\text { Estimated prevalence of } \\
& \text { pulmonary TB in TB suspects } \\
& \text { attending health facility }=0.5 \text {. } \\
& S_{P}=\text { anticipated specificity }= \\
& \text { (0.965) [18]. } \\
& \propto \quad=\quad \text { size of the critical region }(1- \\
& \alpha \text { is the confidence level })= \\
& 0.05 \text {. } \\
& Z \propto / 2=\text { standard normal deviate } \\
& \text { corresponding to the specified } \\
& \text { size of the critical region }(\propto) \\
& =1.96 \text {, and } \\
& n=\frac{1.96^{2} \times 0.965(1-0.965)}{0.05^{2} \times 0.5}=\frac{0.12975}{0.00125} \\
& =103.8 \sim 107
\end{aligned}
$$

\section{Sampling Technique}

Samples were collected consecutively during clinic days. Monday and Thursday-from every HIV-positive subject with a suspected TB infection until the sample size was reached.

\section{Data Collection Technique}

\section{Socio-demographic Characteristics}

A proforma was developed to abstract data on the study subjects from source documents. Clinicians diagnosed patients presenting at the HIV clinic to be presumptive tuberculosis patients after a clinical examination. A maximum of 10 patients were recruited on a daily basis over a period of 6 weeks after informed consent was received from them to participate in the study.

\section{Specimen Collection}

Three early morning sputum samples were collected for testing from 107 participants using wide-mouthed sterile containers. Two early morning sputum samples were collected during the patient's first visit, and the remaining sample was collected at the second visit. The subject was briefed on how and when to collect the samples. The sputum was labeled with an identification number corresponding to the identifier on the proforma. The physical appearance of the sample was examined and documented as salivary, mucoid, muco-purulent, purulent, or blood-stained.

\section{Smear Preparation}

A small portion of purulent or muco-purulent material was collected with the stick/loop and transferred to the slide. A spread was made in an area equal to about 2-3 x 1-2 cm using repeated circular movements and allowed to air dry at room temperature. The flame was passed under the slides slowly in about three consecutive times without overheating the slides.

\section{Gene-Xpert Procedure}

Sputum was liquefied and inactivated with 2:1 sample reagent dilution, then $2 \mathrm{ml}$ of the liquefied material was transferred into test cartridge and then inserted into MTB-RIF platform. The sample was automatically filtered 
and washed. Ultrasonic lysis filtered captured organisms released DNA molecules. The DNA molecule released mixed with the dry PCR reagents. Hemi-nested real-time amplification and detection occurred in an integrated reaction tube and result.

\section{Data Management}

Slides were reading, recording, and reporting: Slides were blindly examined by two trained laboratorians who had worked for more than five years on the TB bench for both Ziehl-Neelsen microscopy and fluorescence microscopy. The slides were scanned and systematically ready from one side to the other and back again using 100 objectives for $\mathrm{ZN}$ microscopy, while $40 \mathrm{x}$ objectives was used for confirmation of AFB for fluorescence microscopy.

The result was considered positive or negative when confirmed by the supervisor and are quantified using the WHO/IUATLD scale. Data Entering, Storage, and Confidentiality: The test results were recorded in the data form and entered in Microsoft Excel, followed by data cleaning. Socio-demographic characteristics such as age, sex, address, educational status, and employment status were collected. Data collected were kept in lockable cabinets and database pass-worded to maintain limited access and confidentiality. Study identification numbers identified all records to maintain confidentiality.

\section{Statistical Analysis}

All data were analyzed using open Epi Info version 7 at a $5 \%$ level of significance and $95 \%$ confidence level. Frequencies and proportions were calculated. The Sensitivity and Specificity of smear microscopy were calculated using the positive Gene-Xpert as the gold standard. The Sensitivity and Specificity were compared using the McNemar Chi-square test.

The following formula was used to calculate Sensitivity (Se), Specificity (SP), positive and Negative predictive valve, and the $95 \%$ confidence interval.

$$
\begin{aligned}
S e & =\frac{\mathrm{TP}}{\mathrm{TP}+\mathrm{FN}} \\
S P & =\frac{\mathrm{TN}}{\mathrm{TN}+\mathrm{FP}} \\
N P V & =\frac{\mathrm{TN}}{\mathrm{TN}+\mathrm{FN}} \\
P P V & =\frac{\mathrm{TP}}{\mathrm{TP}+\mathrm{FP}}
\end{aligned}
$$

$95 \%$,

C.L $1.96 \sqrt{\frac{P(1-P)}{n}} \leq \pi \gg p+1.96 \sqrt{\frac{P(1-P)}{n}}$

Where Se: Sensitivity, Sp: Specificity, TP: True positive results; TN: True negative results; FN: False-negative results; FP: False-positive results.

\section{Ethical Consideration}

Ethical approval was obtained from the Dalhatu Araf Specialist Hospital Research Ethical Committee. Verbal informed consent was obtained from these participants of age $>17$ years and emancipated minors. Assent was also obtained from subjects less than 17 years.

\section{Limitation}

Gene-Xpert was used in this study as a gold standard in place of culture due to the cost, time constraint, and also the challenges of transporting viable samples to the National Tuberculosis Reference Laboratory. Challenge of missing data since data abstraction was used in the study. Challenges were resolved by triangulation from the different source documents.

\section{Result}

Three sputum samples were collected from 107 study subjects in two consecutive days, giving a total of 321 sputum specimens collected from 107 subjects with a mean age of $34 \pm 11.9$. Thirty-eight percent of the participants were within the age group 28-32 years.

There were 73 (65\%) females, 53 (50\%) with secondary education, and $60(56 \%)$ urban dwellers (Table 1).

Each of the 107 sputum specimens was tested with Ziehl-Neelsen, LED fluorescence 
microscopy, and Gene-Xpert. Out of this, ZN direct smear yielded $11(10.3 \%)$ positive MTB results, while 15 (14.0\%) were positive for LED FM direct smear. Out of the 96 (98.7\%) of ZN AFB-negative, $7(7.3 \%)$ were positive with Gene-Xpert. The Sensitivity for direct $\mathrm{ZN}$ was $61.1 \%$ and Specificity of $100 \%$ with the percent agreement Cohen's kappa 0.72 and (p-value:
0.01) (Table 2). Out of the $92(86.0 \%)$ LED FM AFB Negative, $3(3.3 \%)$ were positive with Gene-Xpert. The Sensitivity for direct LED FM was $83.3 \%$ and Specificity of $100 \%$. The percent agreement Cohen's kappa was 0.89 (p-value: 0.13) (Table 3). The incremental Sensitivity between $\mathrm{ZN}$ and LED FM was 22.2\% (Table 4).

Table 1. Socio-demographic Characteristics of HIV Patients with Presumptive Tuberculosis Infections

\begin{tabular}{|c|c|c|}
\hline Variables & Frequency & Percent \\
\hline \multicolumn{3}{|l|}{ Age (Years) } \\
\hline$\leq 17$ & 6 & 5.6 \\
\hline $18-22$ & 5 & 4.7 \\
\hline $23-27$ & 14 & 13.1 \\
\hline $28-32$ & 33 & 30.8 \\
\hline $33-37$ & 15 & 14.0 \\
\hline $38-42$ & 17 & 15.9 \\
\hline $43-47$ & 6 & 5.6 \\
\hline $48-52$ & 4 & 3.7 \\
\hline $53-57$ & 2 & 1.9 \\
\hline$\geq 58$ & 5 & 4.7 \\
\hline \multicolumn{3}{|l|}{ Occupation } \\
\hline Employed & 61 & 57 \\
\hline Unemployed & 46 & 43 \\
\hline \multicolumn{3}{|l|}{ Location } \\
\hline Urban & 60 & 56 \\
\hline Rural & 47 & 44 \\
\hline \multicolumn{3}{|l|}{ Educational Level } \\
\hline No Formal Education & 24 & 22 \\
\hline Primary Education & 18 & 17 \\
\hline Secondary Education & 53 & 50 \\
\hline Tertiary Education & 12 & 11 \\
\hline \multicolumn{3}{|l|}{ Gender } \\
\hline Male & 34 & 32 \\
\hline Female & 73 & 68 \\
\hline
\end{tabular}

Table 2. Validity of Ziehl-Neelsen Technique against Gene-xpert in the Diagnosis of Tuberculosis Infection among HIV-Positive Patients

\begin{tabular}{|c|c|c|c|c|c|c|c|}
\hline \multirow[t]{3}{*}{$\mathbf{Z N}$} & \multicolumn{2}{|c|}{ Gene-xpert } & \multirow[t]{3}{*}{ Total } & \multirow{2}{*}{$\begin{array}{l}\text { Sensitivity/CL } \\
61.1 \% \\
\end{array}$} & \multirow{2}{*}{$\begin{array}{l}\text { Specificity/CL } \\
100 \%\end{array}$} & \multirow{3}{*}{$\begin{array}{l}\text { Kappa } \\
0.72\end{array}$} & \multirow{3}{*}{$\begin{array}{l}\text { P-value } \\
0.01\end{array}$} \\
\hline & \multirow[t]{2}{*}{ Positive } & \multirow[t]{2}{*}{ Negative } & & & & & \\
\hline & & & & $(60.8-94.2)$ & $(95.9-100)$ & & \\
\hline Positive & 11 & 0 & 11 & - & - & - & - \\
\hline Negative & 7 & 89 & 96 & - & - & - & - \\
\hline Total & 18 & 89 & 107 & - & - & - & - \\
\hline
\end{tabular}


Table 3. Validity of LED Fluorescence Technique against Gene-Xpert in the Diagnosis of Tuberculosis Infection among HIV-Positive Patients.

\begin{tabular}{|c|c|c|c|c|c|c|c|}
\hline \multirow[t]{3}{*}{ LED FM } & \multicolumn{2}{|c|}{ Gene-xpert } & \multirow[t]{3}{*}{ Total } & \multirow{2}{*}{$\begin{array}{l}\text { Sensitivity/CL } \\
83.3 \% \\
\end{array}$} & \multirow{2}{*}{$\begin{array}{l}\text { Specificity/CL } \\
100 \%\end{array}$} & \multirow{3}{*}{$\frac{\text { Kappa }}{0.89}$} & \multirow{3}{*}{$\frac{\text { P-value }}{0.13}$} \\
\hline & \multirow[t]{2}{*}{ Positive } & \multirow[t]{2}{*}{ Negative } & & & & & \\
\hline & & & & $(60.8-94.2)$ & $(95.9-100)$ & & \\
\hline Positive & 15 & 0 & 15 & - & - & - & - \\
\hline Negative & 3 & 89 & 92 & - & - & - & - \\
\hline Total & 18 & 89 & 107 & - & - & - & - \\
\hline
\end{tabular}

Table 4. Comparison of Validity of ZN and LED FM Technique in the Diagnosis of Tuberculosis Infection among HIV-Positive Patients at DASH, Lafia, 2017

\begin{tabular}{|l|l|l|l|l|}
\hline Validity & $\begin{array}{l}\text { ZN Technique } \\
\text { (Percent) }\end{array}$ & $\begin{array}{l}\text { LED FM Technique } \\
\text { (Percent) }\end{array}$ & Incremental Yield & P-value \\
\hline Sensitivity & 61.1 & 83.3 & $22.2 \%$ & 0.01 \\
\hline Specificity & 100 & 100 & & \\
\hline
\end{tabular}

\section{Discussion}

Our study has shown the Performance of FM Microscopy to be better than ZN Microscopy with an incremental sensitivity of $21.2 \%$. FM Microscopy has also yielded more positives than ZN Microscopy among gender, with the male having a higher yield than females. There is also more AFB Positive among the employed, those residing in the rural setting, and participants within the age group 28-30 years. The study shows a similar sensitivity of ZN Microscopy with the previous studies conducted among HIV patients with suspected pulmonary $\mathrm{TB}$ in Kampala, Uganda, with a Sensitivity of $51 \%$ [19] and also among pulmonary and extrapulmonary TB patients in South India with a Sensitivity of $61.1 \%$ [20]. The results of our study differ from other studies that recorded a high sensitivity of $82.6 \%, 71 \%$, and $95.6 \%$ [21, 22]. The difference observed in other studies may be because the studies were conducted among non-HIV patients' presumptive TB as the study population. Although other factors like study design, operational design, and gold standard may have also contributed to this discrepancy observed in this study. Our results showed that $\mathrm{ZN}$ has a lower sensitivity in the diagnosis of TB amongst HIV patients. This result agrees with a study conducted among HIV subjects in Thailand which shows ZN microscopy has a low sensitivity in the diagnosis of TB among HIV patients [23]. ZN low sensitivity also applied in extrapulmonary TB and in the use of other specimen likes cerebrospinal fluid or other body fluids.

Our findings also revealed that LED FM has a high sensitivity of $83.3 \%$. This may be due to the large area seen by the objectives Len and less time required by the microscopes to read a slide. The use of a trained microscopic with the previous experience in using LED microscopy in their routine diagnosis of Tuberculosis, may have also contributed to this high Sensitivity of LED FM. Studies have shown that LED fluorescence microscopy performs better than mercury fluorescence microscopy. Hence, the use of LED Technology, which may have also contributed to the increase in Sensitivity in fluorescence microscopy, has been demonstrated among HIV-positive subjects in various studies [20,21]. The result of our study was similar with other studies, which reported $95.2 \%, 83.1 \%$ among non-HIV positive, however, high Sensitivity of fluorescence microscopy had been demonstrated among HIV positive subjects in many studies [20, 21]. Our study showed a significant difference between $\mathrm{ZN}$ microscopy and LED FM with an increase in 
Sensitivity of $22.2 \%(\mathrm{P}<0.01)$. This is similar to other studies conducted in Kenya, were the Sensitivity of FM methods, and $\mathrm{ZN}$ were statistically significant (FM-80\%, ZN-65\%) [24]. Our findings differ from the study among non-HIV patients, which reported no statistically significant difference between LED Fluorescence Microscopy and $\mathrm{ZN}$ in the diagnosis of pulmonary tuberculosis [25]. There was a perfect concordance agreement (unweighted kappa $=0.89 \%$ ) between $\mathrm{ZN}$ and LED FM. Contrarily to our study, many have shown a good concordance agreement between $\mathrm{ZN}$ and LED microscopy [25]. Fluorescence microscopy offers well-described benefits and improves the diagnostic value of the sputum smear, especially among those with a low density of bacilli missed by $\mathrm{ZN}$ microscopy. Moreover, fluorescence microscopy allows more rapid screening of sputum specimens than $\mathrm{ZN}$.

The findings from our study showed a similar specificity of $100 \%$ for ZN and LED FM. The result may be due to the choice of gold standard other than culture used by other studies. GeneXpert has high sensitivity and able to detect even fragments of RNA virus. Studies have shown that gene-Xpert has a similar sensitivity with the culture [26, 27], and due to the limitations involved in the use of culture, gene-Xpert was used as a gold standard. Another reason would be the use of experienced microscopists. They examined the slides independently of the value

\section{Reference}

[1] Clark M, Riben P, Nowgesic E., (2002), The association of housing density, isolation and Tuberculosis in Canadian First Nations communities. Int J Epidemiol. $31 \quad$ (5): 940-5. https://pubmed.ncbi.nlm.nih.gov/12435764/.

[2] Wanyeki I, Olson S, Brassard P, Menzies D, Ross N, Behr M, et al. (2006), Dwellings, crowding, and Tuberculosis in Montreal. Soc sci med. 63(2): 16480805

https://pubmed.ncbi.nlm.nih.gov/16480805/. of the Gene-Xpert result. Moreover, it may also be likely that high magnification was used for both methods, which led to the increase in Specificity for both methods. The result was similar to Mohammad, who evaluated ZN's performance and found the Specificity to be $100 \%$ for the $\mathrm{ZN} \mathrm{[22].} \mathrm{However,} \mathrm{the} \mathrm{study}$ results were different from the Specificity obtained from other studies that reported 80$90 \%[24,28,29]$.

\section{Conclusion}

The Sensitivity of ZN microscopy is low, and LED microscopy has a higher sensitivity than $\mathrm{ZN}$ and would serve as a better replacement for $\mathrm{ZN}$ in the diagnosis of TB in high HIV setting where there are limited use of culture GeneXpert.

\section{Acknowledgement}

I want to express my gratitude to God for his mercy, my family for their support during the work. My appreciation also goes to my supervisors, Prof Ahmed Saad, Prof. Adebola Olayinka, and my mentor Dr. Muhammad Shakir Balogun. Most importantly to CDC and NFELTP family for the training offered to me to become an epidemiologist.

\section{Conflict of Interests}

The authors have not declared any conflict of interest.

[3] Ndadilnasiya Endie Waziri, Simeon Cadmus, Patrick Nguku, Olufunmilayo Fawole, Olajide Adewale Owolodun, Hyelshilni Waziri, Luka Ibrahim, Oladayo Biya, Saheed Gidado, Samuel Badung, Peterside Kumbish, Peter Nsubugan, (2014), Factors associated with tuberculosis among patients attending a treatment centre in Zaria, North-west Nigeria, Pan Afr Med J. 18 (Suppl 1) https://www.ncbi.nlm.nih.gov/pmc/articles/PMC419 9345/. 
[4] Mangtani P, Jolley DJ, Watson JM, Rodrigues LC. London during 1982-91. BMJ. 1995;310 (April):963-6.

https://www.bmj.com/content/310/6985/963.short.

[5] World Health Organization. Global Tuberculosis Report, (2012) Available from: http://apps.who.int/iris/bitstream/10665/75938/1/978 9241564502_eng.pdf accessed 15 February 2017.

[6] March R, Goal MD, Tb T, Strategy STB. Fact sheet $\mathrm{N}^{\circ} 104$ Reviewed March (2014). Vol. 2014. https://www.who.int/tb/publications/global_report/gt br15_main_text.pdf.

[7] Global tuberculosis report (2014), WHO Library Cataloguing in Publication Data Global tuberculosis report (2014).

https://www.who.int/tb/publications/global_report/gt br14_main_text.pdfs.

[8] Mardani M. (2003), TB-HIV Co-Infection. Vol. 2, https://www.sid.ir/en/Journal/ViewPaper.aspx?ID=1 68548.

[9] Teran R, Waard JH de (2015), Recent Advances in the Laboratory Diagnosis of Tuberculosis. J Int Fed Clin Chem Lab Med.26(4):295-309. https://www.ifcc.org/media/334114/eJIFCC2015Vol 26No4pp295-309.pdf.

[10]Desikan P.2013, Sputum smear microscopy in Tuberculosis: Is it still relevant? Indian J Med Res.137(3):442-4.

https://www.ncbi.nlm.nih.gov/pmc/articles/PMC370 $5651 /$.

[11] Steingart KR, Ng V, Henry M, Hopewell PC, Ramsay A, Cunningham J, et al.2006, Sputum processing methods to improve the sensitivity of smear microscopy for tuberculosis: a systematic review. Lancet Infect Dis.6(10):664-74. https://pubmed.ncbi.nlm.nih.gov/17008175/.

[12] Kakkar F, Allen UD, Ling D, Pai M, Kitai IC, Society CP, et al.2010, Tuberculosis in children: New diagnostic blood tests. Can Paediatr Soc.15(8):52933.

https://academic.oup.com/pch/article-

abstract/15/8/529/2639309.

[13] Steingart KR, Ramsay A. 2007, Optimizing sputum smear microscopy for the diagnosis of. Expert Rev Anti Infect Ther.5(3):327-31. https://pubmed.ncbi.nlm.nih.gov/17547496/.
[14] Holani AG, Ganvir SM, Shah NN, Bansode SC, Shende V, Jawade R, et al., (2014), Demonstration of Mycobacterium Tuberculosis in sputum and saliva smears of tuberculosis patients using Ziehl Neelsen and fluorochromes staining - A comparative study. J Clin Diagnostic Res. 8(7):42-5. https://pubmed.ncbi.nlm.nih.gov/25177636/.

[15] Prevention $\mathrm{C}$ for DC and. Chapter 2 Transmission and Pathogenesis of Tuberculosis. In p. 19-44.

https://www.cdc.gov/tb/education/corecurr/pdf/chapt er2.pdf.

[16] Buderer NM. (1996), Statistical methodology: I. Incorporating the prevalence of disease into the sample size calculation for Sensitivity and. Acad Emerg Med. 3(9):8870764. https://pubmed.ncbi.nlm.nih.gov/8870764/.

[17] Malhotra RK, Indrayan A. (2007), Research Methodology A simple nomogram for the sample size for estimating Sensitivity and Specificity of medical tests. Indian J Ophthalmol.105:110-3. https://pubmed.ncbi.nlm.nih.gov/20952837/.

[18] Cuevas LE, Al-sonboli N, Lawson L, Yassin MA, Arbide I, Al-aghbari N, et al. (2011), LED Fluorescence Microscopy for the Diagnosis of Pulmonary Tuberculosis: A Multi-Country CrossSectional Evaluation. PLoS Med.8(7). https://journals.plos.org/plosmedicine/article?id=10. 1371/journal.pmed.1001057.

[19] Cattamanchi A, Dowdy DW, Davis JL, Worodria W, Yoo S, Joloba M, et al. (2009), Sensitivity of direct versus concentrated sputum smear microscopy tuberculosis. $5: 1-9$. https://pubmed.ncbi.nlm.nih.gov/19419537/.

[20]Daley P, Michael JS, Kalaiselvan S, Latha A, Mathai D, John KR, et al. (2009), A pilot study of short-duration sputum pretreatment procedures for optimizing smear microscopy for Tuberculosis. PLoS One.4(5).

https://journals.plos.org/plosone/article?id=10.1371/ journal.pone.0005626.

[21] Shenai S, Minion J, Vadwai V, Tipnis T, Shetty S, Salvi A, et al. (2011), Evaluation of light-emitting diode-based fluorescence microscopy for the detection of mycobacteria in a tuberculosis-endemic 
region. Int $\mathrm{J}$ Tuberc Lung Dis.15(4):483-8. https://pubmed.ncbi.nlm.nih.gov/21396207/.

[22] Uddin MKM, Chowdhury MR, Ahmed S, Rahman MT, Khatun R, van Leth F, et al., (2013), Comparison of direct versus concentrated smear microscopy in detection of pulmonary Tuberculosis. BMC Res Notes 6:291. https://pubmed.ncbi.nlm.nih.gov/23885922/.

[23] Monkongdee, P., McCarthy, K. D., Cain, K. P., Tasaneeyapan, T., Nguyen, H. D., Nguyen, T. N., Nguyen, T. B., Teeratakulpisarn, N., Udomsantisuk, N., Heilig, C., \& Varma, J. K. (2009), Yield of acidfast smear and mycobacterial culture for tuberculosis diagnosis in people with human immunodeficiency virus. American journal of respiratory and critical care medicine, 180(9), 903-908. https://pubmed.ncbi.nlm.nih.gov/19628775/.

[24] Githui W, Kitui F, Juma ES, Obwana DO, Mwai J, Kwamanga D. (1993), A comparative study on the reliability of the fluorescence microscopy and ZiehlNeelsen method in the diagnosis of pulmonary tuberculosis. East AfrMed J.70:263-6. https://europepmc.org/article/med/8306899.

[25]Bhalla M, Sidiq Z, Sharma PP, Singhal R, Myneedu VP, Sarin R. (2013), Performance of lightemitting diode fluorescence microscope for diagnosis of Tuberculosis. Int $\mathbf{J}$ Mycobacteriology http://www.ijmyco.org/article.asp?issn=22125531;y ear $=2013$; volume $=2 ;$ issue $=3$; spage $=174$; epage $=178$; aulast $=$ Bhalla.
[26] Sharma SK, Kohli M, Yadav RN, Chaubey J, Bhasin D, Sreenivas V, et al. (2015), Evaluating the diagnostic accuracy of Xpert MTB/RIF assay in pulmonary Tuberculosis. PLoS One.10(10):1-9. https://pubmed.ncbi.nlm.nih.gov/26496123/. [27] Agrawal M, Bajaj A, Bhatia V, Dutt S. (2016), Comparative study of GeneXpert with $\mathrm{ZN}$ stain and culture in samples of suspected pulmonary Tuberculosis. J Clin Diagnostic Res.10(5): DC09DC12. https://pubmed.ncbi.nlm.nih.gov/27437212/. [28] Rahman F, Munshi SK, Kamal SMM, Rahman ASMM, Rahman MM, Noor R. (2011), Comparison of Different Microscopic Methods with Conventional TB Culture. Stamford J Microbiol.1(1):1-5. https://www.banglajol.info/index.php/SJM/article/vi ew/9133.

[29] Cuevas LE1, Al-Sonboli N, Lawson L, Yassin MA, Arbide I, Al-Aghbari N, et al, (2011), s LED fluorescence microscopy for the diagnosis of pulmonary Tuberculosis: a multi-country crosssectional evaluation. PLoS Med. 2011;8(7). https://journals.plos.org/plosmedicine/article?id=10. 1371/journal.pmed.1001057. 


\title{
Adverse Drug Reactions Reporting among Health Professionals in Government Hospitals in Katsina State, Nigeria
}

\author{
Ayuba Daniel $^{1 *}$, Abdullahi Sabo Muhammad ${ }^{2}$ \\ ${ }^{1}$ Department of Public Health, Texila American University, Guyana \\ ${ }^{2}$ Department of Physical and Health Education, College of Technical and Vocational \\ Education, Kaduna polytechnic, Kaduna Nigeria
}

\begin{abstract}
Medicines have the potential to cause Adverse Drug Reactions (ADRs) and therefore the need for health professionals to detect and spontaneously report to the National Agency for Food and Drug Administration and Control (NAFDAC) for further actions to ensure patients and public safety. The study was conducted to ascertain the proportion and reporting procedures of ADRs reported by health professionals in the Government Hospitals in Katsina State, Nigeria. This was a crosssectional survey of 392 health professionals randomly selected from the 19 secondary hospitals in Katsina state. Data were collected through a self-administered structured questionnaire from 18th January to 19th February 2021 with a $98.7 \%$ and 1.3\% response rate. Data were analyzed using STATA software Version 15.0. Descriptive statistics were used to describe the background characteristics of respondents, and the outcome, such as the proportion of ADR reported summarized in percentages, frequencies, and charts. There was only a $28.3 \%$ ADRs reporting rate, and $25.1 \%$ of health professionals who saw an ADRs case reported it by completing the ADRs form. The level of knowledge on ADRs reporting procedures was $58.3 \%$ among respondents. The main systemic challenge with ADRs reporting was the lack of access to the reporting form for ADRs. Therefore, there is a need to improve access to the reporting form in all the hospitals.
\end{abstract}

Keywords: Adverse Drug Reaction Reporting, Government Hospitals, Health Professionals, Katsina state, Nigeria, Reporting Rate.

\section{Introduction}

Adverse Drug Reactions (ADRs) are global public health problems. In its severe form, it may cause hospital admission, morbidity, and mortality [1]. Adverse Drug Reaction (ADR) is an untoward response to a medicinal product that is noxious and unintended, including the absence of efficacy, and that happens at any dose and may result from the use of the product under the terms of the marketing authorization, the use of the product outside the terms of the marketing authorization, including overdose, off-label use, misuse, abuse and mistakes in medication [2].
Out of the several methods of detecting ADRs, the Spontaneous system of reporting is widely used and is the cheapest system for monitoring the safety of a medicine in real life [3]. This method is largely dependent on ADR reporting by healthcare providers. Data gathered from drug monitoring activities enable drug regulatory authorities to make evidencebased decisions with regard to the safety and rational use of drugs.

Previous studies from different regions in Nigeria have concentrated on the perception and practice of ADRs reporting among physicians only while excluding other cadres of 
healthcare workers $[4,5 ; 6]$. The achievement of safe medicine and patient safety is not within the jurisdiction of one discipline. For instance, ADR has an economic burden on the health system and the patients [7]. Therefore, effective pharmacovigilance is achievable where a team with the requisite training, knowledge, and responsibility for it is aware of its expected public health roles in that regard and is willing, able, and disposed to work together to perform it [8]. The conduct of this study assesses only the ADR aspect of the pharmacovigilance system. The findings, in part, will contribute to the provision of relevant information on ADR reporting and how responsive the system is. It will also identify some possible challenges with the system to inform policymakers about suggestive ways to strengthen or improve the current guidelines or policy direction.

The World Health Organization has laid series of emphasis on pharmacovigilance [9]. Despite this and locally directed efforts such as the National ADR reporting scheme in Nigeria, there is still a low rate of ADRs reporting by health care providers [10].

\section{Methods}

\section{The study Area/Setting}

Katsina State was created on September 23rd, 1987. It has an area of 23,938 square kilometers and a population of 5.97 million people based on 2003 population census figures at a $3.0 \%$ constant annual growth rate in 2007 , and this indicates a population density of about 249 persons per square kilometre [11]. It is located approximately between latitude 11007 ' $49 "$ and 13020 ' 00 " $\mathrm{N}$ and between longitude 60 52' 03 " and 9002 ' 40" E. it is boarded to the North by the Niger Republic, to the East by Jigawa and Kano States, to the south by Kaduna State and the West by Zamfara State. The State covers an area of about $24,192 \mathrm{~km} 2$.

In 2003, there was 18 Hospital in Katsina State with 1,643 beds and a bed/population ratio of 1:3:13. By the end of 2007, the total number of hospitals in the State increase to 19 , representing a $5.5 \%$ increase, while the available beds increased to $2885 \quad(76.6 \%$ increase) and the bed/population rate stood at $1 / 2,068$ persons [11].

\section{Study Design}

A cross-sectional descriptive approach was employed to undertake the study among health professionals in Government hospitals in Katsina state using a structured questionnaire to collect quantitative data. The type of data collected was tightly pre-specified on the questionnaires before the data collection. It focused on pre-defined variables to be measured.

\section{The Study Population}

The study population was healthcare professionals in the 19 secondary hospitals in Katsina state. These include Doctors, Nurses, Midwives, and Pharmacy staff who practiced in the hospital for the past twelve months at the time of the conduct of this study.

\section{Sampling Procedure}

Simple random sampling was done to select the respondents. The investigator visited all the Departments and units where the various cadre of the health professionals work and folded papers with "YES" and "NO" inscriptions on them. The folded papers were put in a container and presented to prospective respondents to select. Those that select "YES" during each visit were included in the study. Those that picked "NO" had the chance to be selected in the subsequent sampling procedure. This procedure was done two times in each ward for the period of the data collection. Due to the small numbers of prescribers, pharmacy staff and midwives, all those that were at the post during the period of data collection were all included in the study.

\section{Inclusion and Exclusion Criteria}

Doctors, Nurses, Midwives, and pharmacy staff (pharmacist, pharmacy technicians, and dispensing assistants), who have been involved 
in clinical care for at least twelve months at the time of this study were included. Other cadres and those who were less than a year in clinical practice were excluded. Students and personnel on internship under the categories stated above were also excluded.

\section{Sample Size Determination}

Three hundred and ninety-two (392) health professionals are estimated to take part in the study. The minimum sample size for the research was calculated using the Cochran, 1963 [12] formula as follows:

$$
S S=\frac{Z^{2} p(1-p)}{C^{2}}
$$

ss $=$ sample size

$\mathrm{Z}=\mathrm{Z}$ value (1.96 for $95 \%$ confidence level).

$\mathrm{p}=$ percentage picking a choice, expressed as decimal.

$\mathrm{c}=$ confidence interval, expressed as decimal.

Using a $36.6 \%$ ADR reporting rate among health professional in Nigeria (Fadare et al, 2011), $\mathrm{p}=0.366$ Allowable margin of error $(\mathrm{C})$ is $5 \%=0.05$.

The $\mathrm{z}$ value corresponding to a $95 \%$ confidence interval $=1.96$.

The above parameters were substituted into the formula to get the minimum sample size required for the study as follows;

$$
N=\frac{1.96^{2}(0.366)(1-0.366)}{0.05^{2}}=356.5
$$

Adjusting for a non-response rate of $10 \%$, a minimum sample size of 392 was finally obtained.

\section{Data Collection Instrument and Procedure}

Structured questionnaires were used as a tool to collect the data. Each questionnaire consisted of five sections. Part "A" covered the sociodemographic data of the respondents, section " $\mathrm{B}$ " comprised of nine knowledge questions with two options of "YES" for having knowledge and "NO" for not knowing ADR reporting, section " $\mathrm{C}$ " covered the proportion of
ADR reported by health professionals, section "D" sought data on challenges of ADR reporting and the last section solicited data on how to improve ADR reporting. Since all respondents were literates, the questionnaires were distributed to participants, and clarifications made on questions that respondents did not understand and later be retrieved by the principal investigator. Respondents that had time and answered the questionnaires outright were retrieved the same day. Those that could not be given at most 72 hours to answer and return them.

\section{Pretest and Validation of the Instrument}

The questionnaires were pretested at the Alheri Clinic, Katsina though no changes were made apart from few typographical errors that were corrected. The literature and the research objectives guided the validity of the design of the questionnaire. No data collection assistant was recruited. Participants that were busy and could not immediately answer the questionnaire were given a maximum of three days to return the answered questionnaire.

\section{Ethical Approval}

The Katsina state ministry of Health Ethics Committee has approved (MOH/ADM/SUB/1152/1/419) the conduct of the study. Written permission was obtained from Hospital services management Board, Katsina to use the hospitals as the study site and their health professionals as the study participants.

\section{Data Analysis}

The unit of analysis was the cadre of health professionals. Questionnaires were sorted and screened for errors. Data were first entered into Microsoft Excel, cleaned and coded before being exported to STATA software version 15.0 for analysis. The characteristics of respondents such as age were described in mean and standard deviation. All background characteristics were also summarized and 
presented in frequencies and percentages. The outcome variable was described in frequencies and proportions.

\section{Results}

\section{Background \\ Respondents}

Characteristics

of

A total of 387 health professionals took part in the study. Table 1 shows that most health professionals were within the 30-39 age category representing $48 \%(n=186)$ of the total respondents. The 20-29 age category formed $32.8 \%(\mathrm{n}=127)$. The least age group (19\% $\mathrm{n}=74$ ) was those that were 40 years and above. Over half $(62.5 \% \mathrm{n}=242)$ were females, with the males forming less than half (37.5 $n=145)$. Over half of them were married $(85 \% \mathrm{n}=331)$, while the rest were not married. Out of the three hundred and eighty-seven participants, the highest $(39 \%, \mathrm{n}=151)$ were nurses, $9.3 \%(\mathrm{n}=36)$ midwives, $22.7 \%(\mathrm{n}=88)$ pharmacy staff and (28.9\%, $\mathrm{n}=112$ ) being the Medical Doctors. A good number of the health professionals were young in practice with 4-6 years of work experience and constituted $32.6 \%(n=126)$ of the total respondents. An appreciable number $(\mathrm{n}=73,18.9 \%),(\mathrm{n}=71,18.3 \%)$ had also worked for 1-3 and 7-9 years respectively, while 14\% $(n=54)$ had worked for sixteen or more years at the time of this study.

Table 1. Background Characteristics of Respondents

\begin{tabular}{|l|l|l|}
\hline Variable name & Frequency $(\mathbf{n}=\mathbf{3 8 7})$ & Percentage (\%) \\
\hline Age (years) & 127 & 33 \\
\hline $20-29$ & 186 & 48 \\
\hline $30-39$ & 74 & 19 \\
\hline$>=40$ & 145 & 37.5 \\
\hline Sex & 242 & 62.5 \\
\hline Male & \multicolumn{2}{|l|}{} \\
\hline Female & 14.5 \\
\hline Marital status & 56 & 85.5 \\
\hline Not married & 56 \\
\hline Married & 331 & 28.9 \\
\hline Cadre of staff & \multicolumn{2}{|l|}{} \\
\hline Medical Doctor & 112 & 22.7 \\
\hline Pharmacy staff & 88 & 39 \\
\hline Nurses & 151 & 9.3 \\
\hline Midwives & 36 & 18.9 \\
\hline Years of practice & 32.6 \\
\hline $1-3$ & 73 & 18.3 \\
\hline $4-6$ & 126 & 16.2 \\
\hline $7-9$ & 71 & 14 \\
\hline $10-15$ & 63 & \\
\hline$>=16$ & 54 & \\
\hline
\end{tabular}

\section{ADR Reporting}

The summary in Table 2 and Table 3 shows that in the past twelve months $117(30.2 \%)$ patients reported ADR to the health professionals, while patients did not approach almost $70 \%$ on issues related to ADR. About 1,239 cases of ADR were reported by patients to the HCPs within the months under review. 
Table 2. Proportion of Adverse Drug Reaction Reported by Patients through the HCPs.

\begin{tabular}{|l|l|l|}
\hline Variable Name & Frequency $(\mathbf{n = 3 8 7})$ & Percentage (\%) \\
\hline \multicolumn{2}{|c|}{ Any patient reported an ADR to you in the past year } \\
\hline No & 270 & 69.8 \\
\hline Yes & 117 & 30.2 \\
\hline
\end{tabular}

Table 3. Cases of Adverse Drug Reaction Reported by Patients to HCPs

\begin{tabular}{|l|c|c|c|}
\hline Response & Frequency $\mathbf{( n = 3 8 7 )}$ & Cumulative Response & Percentage (\%) \\
\hline 0 & 103 & 0 & 0 \\
\hline 1 & 35 & 35 & 2.8 \\
\hline 2 & 53 & 106 & 8.6 \\
\hline 3 & 50 & 150 & 12.1 \\
\hline 4 & 47 & 188 & 15.2 \\
\hline 5 & 23 & 115 & 9.3 \\
\hline 6 & 15 & 90 & 7.3 \\
\hline 7 & 5 & 35 & 2.8 \\
\hline 8 & 9 & 72 & 5.8 \\
\hline 9 & 2 & 18 & 1.5 \\
\hline 10 & 7 & 70 & 5.6 \\
\hline 11 & 1 & 11 & 0.9 \\
\hline 12 & 4 & 48 & 3.9 \\
\hline 13 & 1 & 13 & 1.0 \\
\hline 14 & 1 & 14 & 1.1 \\
\hline$>=15$ & 31 & 274 & 22.1 \\
\hline Total & 387 & 1,239 & 100 \\
\hline
\end{tabular}

The summary in Table 4 shows that 322 $(83.2 \%)$ of health professionals ever encountered a patient with suspected ADR in the past twelve months. Out of 322 participants who saw ADR cases, only $(25.1 \%, \mathrm{n}=97)$ reported it by completing the ADR form, while the majority $(74.9 \%, \mathrm{n}=290)$ however did not report it.

Table 4. The Proportion of Adverse Drug Reaction Reported by a Health Professional

\begin{tabular}{|l|l|l|}
\hline Variable Name & Frequency $(\mathbf{n}=\mathbf{3 8 7})$ & Percentage (\%) \\
\hline \multicolumn{2}{|l|}{ Ever seen a patient with ADR for the past year } \\
\hline No & 65 & 16.8 \\
\hline Yes & 322 & 83.2 \\
\hline \multicolumn{2}{|l|}{ Ever reported ADR $(\mathbf{n = 3 2 2})$} \\
\hline No & 290 & 74.9 \\
\hline Yes & 97 & 25.1 \\
\hline
\end{tabular}

In Figures 1 and 2, the majority $(n=322)$ of health professionals saw a patient with adverse drug response in the past twelve months. More Medical Doctors $(89.28 \%, \mathrm{n}=100)$ than, Pharmacy staff $(73.86 \%, \quad \mathrm{n}=65)$, Nurses $(59.60 \%, \mathrm{n}=90)$, and midwives $(47.22 \%, \mathrm{n}=17)$ ever saw adverse drug reaction cases at the time of this study. Less than 30\% ( $\mathrm{n}=97)$ of all cadres reported the ADR they saw. The proportion among the pharmacy staff was highest $(87.69 \%, n=57)$, and that of the Nurses was lowest $(55.55 \% \mathrm{n}=50)$ relative to the other cadres. 


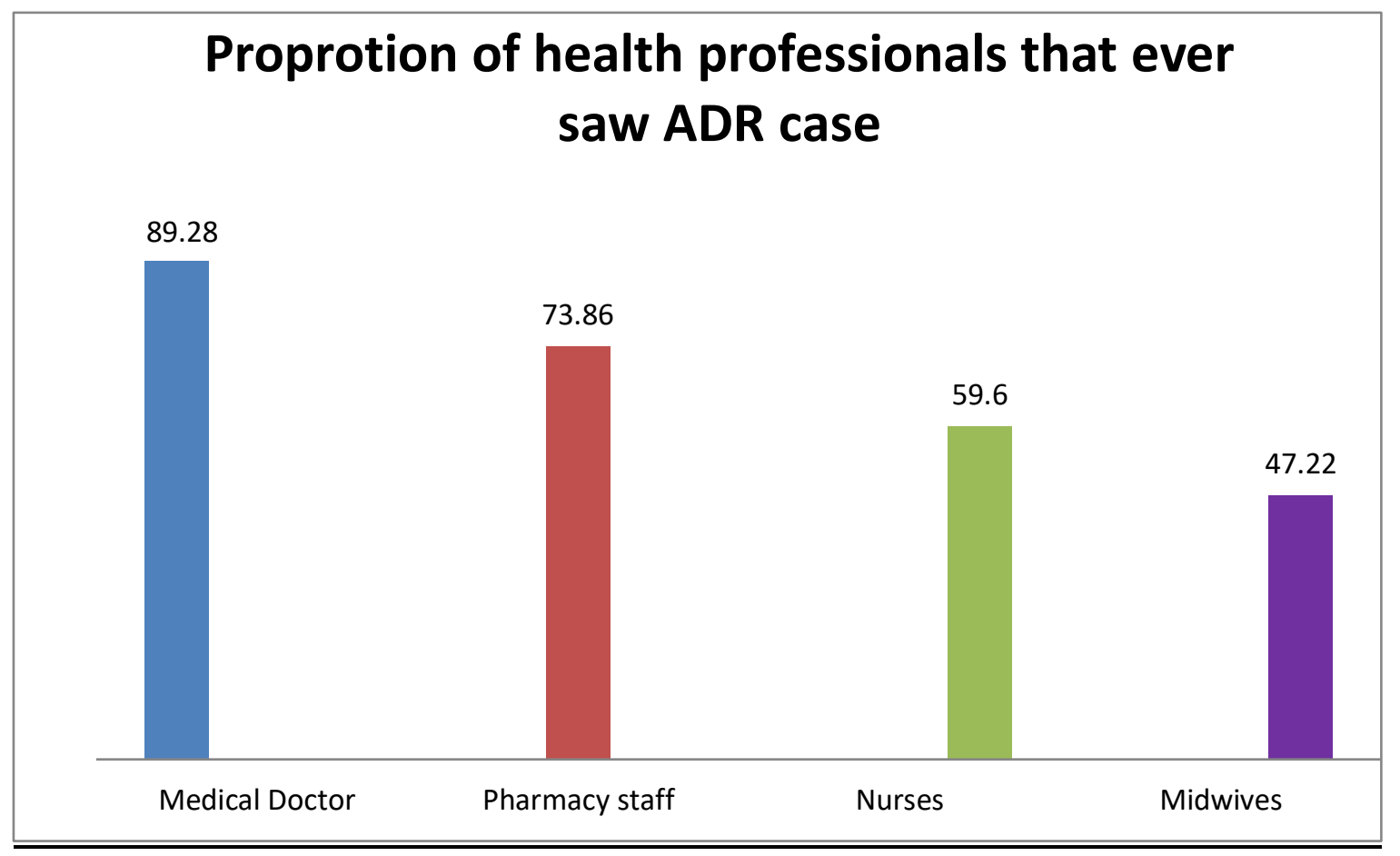

Figure 1. Proportion of ADR Seen by a Cadre

\section{Proprotion of health professionals that ever reproted ADR case}

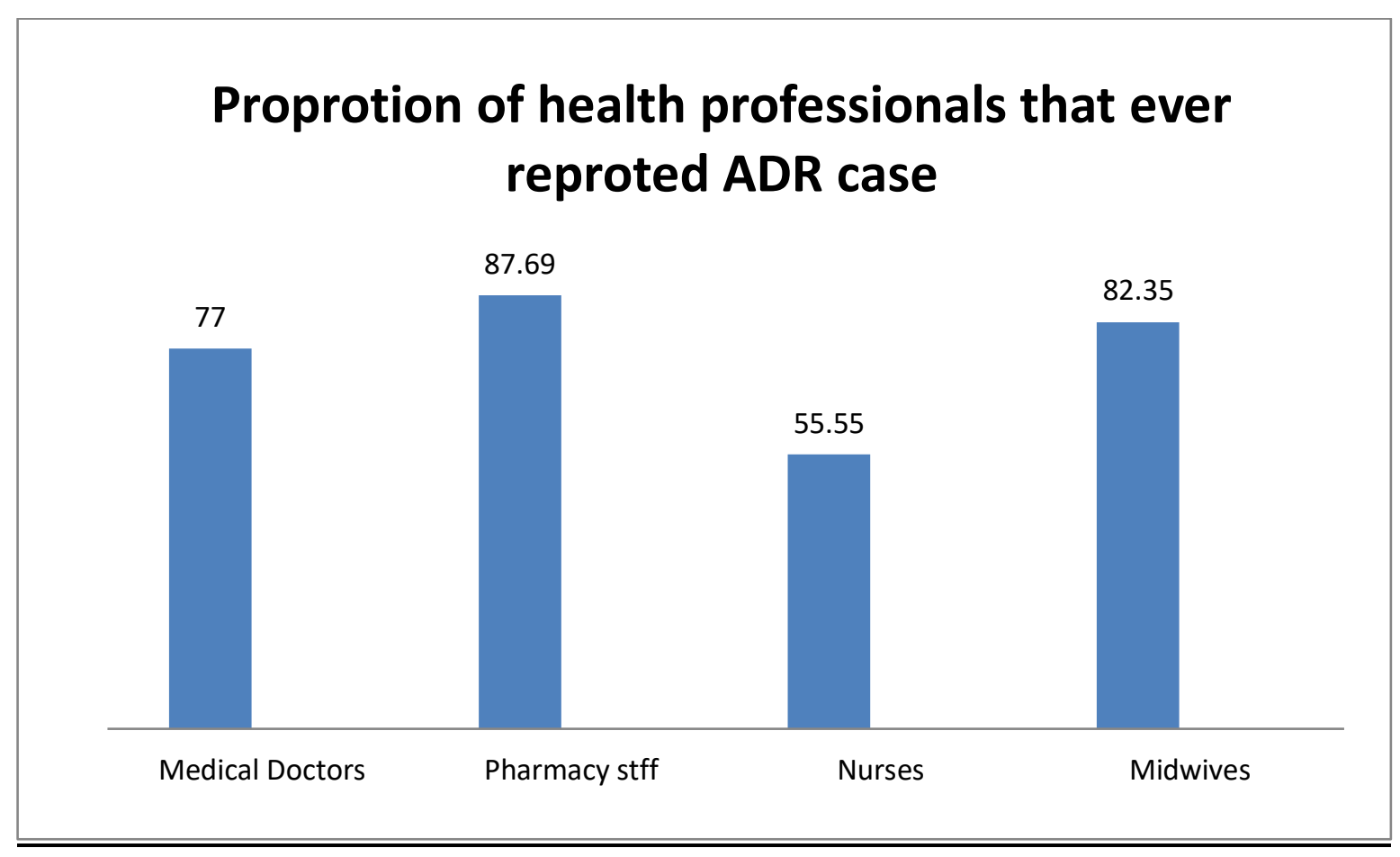

Figure 2. The Proportion of ADR Reported by a Cadre

In Figure 3, only 103(28.3\%) out of 364 adverse drug reaction cases seen for the past year were reported by participants using the
ADR forms. The remaining 261(71.7\%) were not reported. 


\section{Proportion of ADR reported by health professionals}

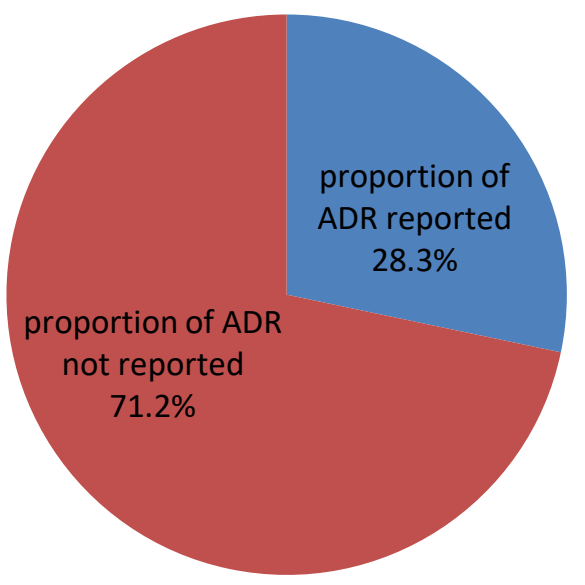

Figure 3. The Proportion of Total ADRs Reported

Respondents ascribed different reasons when they were asked the question of why some ADR cases were not reported. The most $(89.96 \%, n=242)$ cited reason for not reporting ADR was non-availability of the ADR forms followed by not knowing the reporting procedure $(3.72 \%, n=10)$. About $3.35 \%(n=9)$ indicated that they did not report because they considered the reaction to be normal and commonly associated with that medicine. Almost 2.23\% ( $\mathrm{n}=6)$ said they did not know they were supposed to report it. Not thinking that the ADR reporting was important or serious was not a reason for non-reporting. The least $(0.74 \%, \mathrm{n}=2)$ reason for non-reporting was lack of time.

Table 4. Reasons for not Reporting Adverse Drug Reaction

\begin{tabular}{|l|l|l|}
\hline Reasons for not reporting ADR & Frequency & Percent \\
\hline I did not know I was supposed to report & 6 & 2.23 \\
\hline The reporting form was not available & 242 & 89.96 \\
\hline I do not know the reporting procedure & 10 & 3.72 \\
\hline I did not have time to report & 2 & 0.74 \\
\hline I did not think it was important/serious & 0 & 0.00 \\
\hline $\begin{array}{l}\text { I considered it "normal because it is a } \\
\text { common reaction with that medicine }\end{array}$ & 9 & 3.35 \\
\hline
\end{tabular}

\section{Knowledge on Adverse Drug Reaction Reporting}

The summary in Table 5 and 6 regarding the knowledge on ADR reporting procedures portrayed that majority $(88.1 \%, \mathrm{n}=340)$ of respondents ever heard of adverse drug reaction reporting in Nigeria. More Medical Doctors
(100\%, $\mathrm{n}=112)$ and pharmacy staff $(100 \%$, $\mathrm{n}=88$ ) than the other cadres heard about ADR reporting in Nigeria and knew that all health professionals are obliged to report ADRs. Midwives were the least $(94.44 \%, n=34,80.55$, $n=29$ ) that heard of the ADR reporting in Nigeria and also knew that ADR reporting is a professional obligation to all health 
professionals. Cumulatively, 41.5\% ( $\mathrm{n}=160)$ of total respondents knew the tools for reporting ADR in Nigeria. By cadre, all pharmacy staff (88) and nurses (151) knew the ADR reporting tools while $98.21 \%$ and $61.11 \%$ of Medical Doctors and midwives, respectively, also knew the ADR reporting tools. Moreover, 55.2\% knew the types of ADR to be reported. In terms of the reporting procedure, $55.2 \%$ knew where to obtain the ADR forms. More Medical Doctors $(62.50 \%)$ knew where to obtain the ADR forms compared to the pharmacy staff (68.18\%), nurses $(35.76 \%)$, and midwives (52.77\%). About $52.1 \%$ knew the information to put on the ADR form. Also, 37.0\% knew where to submit the filled forms. About $98.21 \%$ of Medical Doctors knew where to return the filled ADR form to, but fewer nurses (39.73) relative to the other cadres knew where to submit the filled ADR form. Generally, as much as $85.0 \%$ thought it was necessary to report ADRs, and $86.3 \%$ knew the reasons for reporting them. By cadre, all Medical Doctors and pharmacy staff thought it necessary to report ADRs and knew the reasons for reporting.

Overall, more than half $(58.3 \%, \mathrm{n}=225)$ of respondents had a high level of knowledge about adverse drug reaction reporting with those that had a low level of knowledge constituting for less than $10 \%$ of the total respondents. Moderately $31.9 \%$ of health professionals knew adverse drug reaction reporting.

Table 5. Knowledge of Health Professionals on ADR Reporting

\begin{tabular}{|l|l|l|}
\hline Level of knowledge criteria & Positive response & Percentage (\%) \\
\cline { 2 - 3 } & Frequency n=386 & \\
\hline $\begin{array}{l}\text { Have you heard about adverse drug reaction } \\
\text { reporting in Nigeria? }\end{array}$ & 340 & 88.1 \\
\hline $\begin{array}{l}\text { Do you know that all health professionals who } \\
\text { directly take care of patients are responsible for } \\
\text { reporting ADRs? }\end{array}$ & 304 & 78.8 \\
\hline $\begin{array}{l}\text { Do you know the tools for reporting ADR in } \\
\text { Nigeria? }\end{array}$ & 160 & 41.5 \\
\hline $\begin{array}{l}\text { Do you know the type of ADRs that are supposed to } \\
\text { be reported? }\end{array}$ & 213 & 55.2 \\
\hline $\begin{array}{l}\text { Do you know where to obtain the reporting tools for } \\
\text { reporting ADRs in your hospital? }\end{array}$ & 137 & 35.5 \\
\hline $\begin{array}{l}\text { Do you know the information that is required on the } \\
\text { ADR form? }\end{array}$ & 201 & 52.1 \\
\hline Do you know where to send the filed ADR form? & 143 & 37.0 \\
\hline Do you think it is necessary to report ADR? & 328 & 85.0 \\
\hline Do you know the reason for reporting ADR? & 333 & 86.3 \\
\hline Level of knowledge on ADR reporting & 38 & 9.8 \\
\hline Low knowledge & 123 & 31.9 \\
\hline Average knowledge & 225 & 58.3 \\
\hline High knowledge & $1-3$ “Y & \\
\hline
\end{tabular}

The level of knowledge was measured using a total score of nine responses. Seven to nine "YES" responses were graded high knowledge, 5-6 "Yes" was graded moderate knowledge, and 1-3 "YES" was considered a low level of knowledge about ADR reporting. 
Table 6. Awareness of Respondents on ADR Reporting Procedures

\begin{tabular}{|l|l|l|l|l|}
\hline \multirow{2}{*}{ Knowledge Questions } & Medical Doctors & Pharmacy Staff & Nurses & Midwives \\
\cline { 2 - 5 } & $\mathbf{n = 1 1 2}$ & $\mathbf{n = 8 8}$ & $\mathbf{n = 1 5 1}$ & $\mathbf{n = 3 6}$ \\
\cline { 2 - 5 } & $\mathbf{f r e q u e n c y ~ ( \% )}$ & frequency (\%) & frequency (\%) & frequency (\%) \\
\hline Have you heard about adverse drug reaction reporting in Nigeria? & $112(100)$ & $88(100)$ & $145(96.02)$ & $34(94.44)$ \\
\hline $\begin{array}{l}\text { Do you know that all health professionals who directly take care of } \\
\text { patients are responsible for reporting ADRs? }\end{array}$ & $112(100)$ & $88(100)$ & $140(92.71)$ & $29(80.55)$ \\
\hline Do you know the tools for reporting ADR in Nigeria? & & & \\
\hline Do you know the type of ADRs that are supposed to be reported? & $110(98.21)$ & $88(100)$ & $100(66.22)$ & $26(61.11)$ \\
\hline $\begin{array}{l}\text { Do you know where to obtain the reporting tools for reporting ADRs } \\
\text { in your hospital? }\end{array}$ & $70(62.50)$ & $65(96.59)$ & $81(53.64)$ & $22(61.11)$ \\
\hline Do you know the information that is required on the ADR form? & $112(100)$ & $75(35.18)$ & $54(35.76)$ & $19(52.77)$ \\
\hline Do you know where to send the filed ADR form? & $110(98.21)$ & $85(96.59)$ & $60(39.73)$ & $18(50.00)$ \\
\hline Do you think it is necessary to report ADR? & $112(100)$ & $88(100)$ & $120(79.47)$ & $35(97.22)$ \\
\hline Do you know the reason for reporting ADR? & $112(100)$ & $88(100)$ & $130(86.09)$ & $29(80.55)$ \\
\hline
\end{tabular}


Though the level of knowledge was generally high among respondents, further analysis showed that Medical Doctors particularly had the highest (100\%) level of knowledge. Nurses had moderate (39.37\%) knowledge while midwives had the least knowledge on ADR reporting procedures with $14.29 \%$ compared to the other cadres, as shown in figure 4 below.

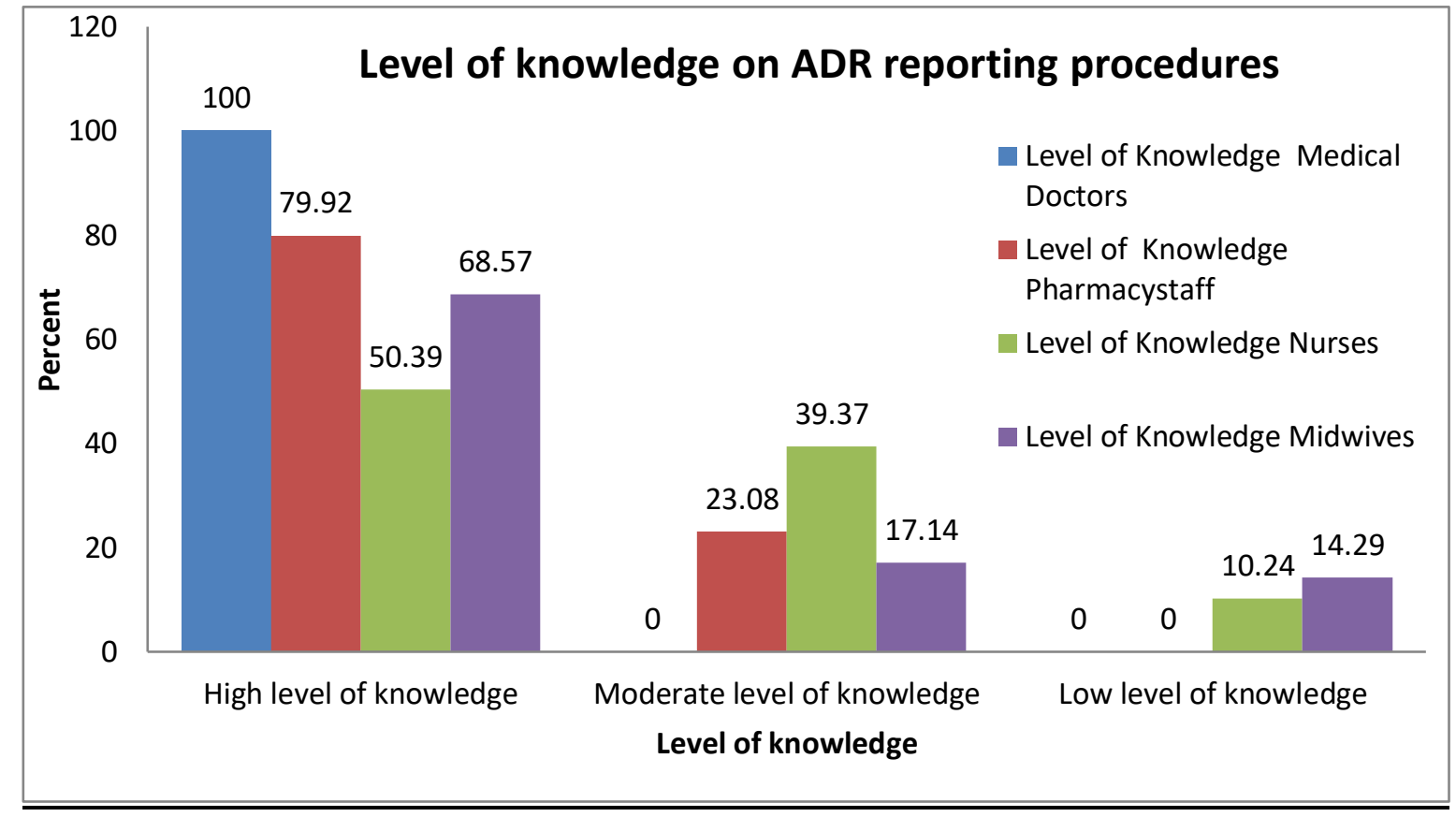

Figure 4. Level of Knowledge of Health Professionals on ADR Reporting Procedures

\section{Challenges with ADR Reporting}

Regarding the question on the challenges with ADR reporting, it was found that Patient's poor knowledge about ADRs (77.4), Lack of campaigns to promote patients ADR reporting to HCPs (84.0), lack of access to the internet
ADR reporting portal (57.9\%), non-availability of the ADR forms (97.2\%), lack of training (70.4\%), and no extrinsic motivation (94.8) were the major challenges in Government hospitals in Katsina state, Nigeria.

Table 7. Systemic Challenges with ADR Reporting

\begin{tabular}{|l|l|l|}
\hline Systemic Challenges & Frequency & Percent \\
\hline Patient's poor knowledge about ADRs & 280 & 72.4 \\
\hline Bias in ADRs reporting by consumers or patients & 159 & 41.2 \\
\hline $\begin{array}{l}\text { Lack of campaigns to promote consumers or patients ADR } \\
\text { reporting to HCPs }\end{array}$ & 375 & 84.0 \\
\hline Non-availability of the ADR forms & 376 & 97.2 \\
\hline Lack of access to the online reporting portal & 224 & 57.9 \\
\hline Internet connectivity & 119 & 30.7 \\
\hline No extrinsic motivation & 367 & 94.8 \\
\hline Lack of in-service training/orientation on ADR reporting & 272 & 70.4 \\
\hline
\end{tabular}

As shown in Table 8, closed to $88 \%$ of respondents thought the WhatsApp platform should be added to existing ADR channels for
ADR. About $30 \%$ chose E-mail as an additional mode of reporting ADR. The majority (97.4\%) of respondents indicated that giving phone 
recharge cards for online reporting will help improve the ADR reporting rate. Less than 3\% (36) did not know whether giving the recharge cards will improve the reporting rate or not. Closed to $100 \%$ indicated that patient education on ADR would further improve ADR reporting. All (100\%) respondents said training of health staff would improve ADR reporting rate. As many as 379 (97.9\%) respondents further thought that the availability of ADR forms is a way of improving ADR reporting whilst only $2.1 \%$ didn't think so. The results also showed that a greater proportion $(93.8 \%)$ of respondents were of the view that integrating ADR reporting into the monthly cases and deaths (CD1) reporting system for diseases under surveillance will also improve the reporting system of ADR.

Table 8. Suggested Ways to Improve ADR Reporting

\begin{tabular}{|l|l|l|}
\hline Ways to improve ADR reporting & Frequency $(\mathbf{n}=\mathbf{3 8 7})$ & Percent \\
\hline Reporting through WhatsApp platform & 340 & 87.9 \\
\hline Reporting through E-mail & 116 & 30 \\
\hline $\begin{array}{l}\text { Giving phone recharge cards as motivation report ADR } \\
\text { online }\end{array}$ & 377 & 97.4 \\
\hline $\begin{array}{l}\text { Patient education on the need to visit the health facility } \\
\text { in times ADR }\end{array}$ & 381 & 98.4 \\
\hline Training of health professionals on ADR reporting & 387 & 100 \\
\hline Availability of ADR forms in all wards & 379 & 97.9 \\
\hline $\begin{array}{l}\text { Will integration of ADR into the weekly cases and } \\
\text { death (CD1) reporting system improves ADR reporting }\end{array}$ & 363 & 93.8 \\
\hline
\end{tabular}

\section{Discussion}

This study revealed that $83.2 \%(n=322)$ of respondents ever saw adverse drug reaction cases, out of which $25.1 \% \quad(n=97)$ reported them by filling the ADR forms. More proportion of prescribers than the other cadres ever saw and reported ADR cases among the different cadres. In contrast, a study conducted in the Volta regional hospital of Ghana on knowledge and attitude among health professionals on pharmacovigilance found that only $16.7 \%$ and $24 \%$ of doctors and nurses had ever reported ADRs by using the blue form [13]. Further studies on healthcare professionals' knowledge on pharmacovigilance and ADR reporting behaviour and factors determining the reporting rates also found a contrasting proportion of ADR reported by healthcare professionals compared to the current studies. About $41 \%$ of ADR seen were reported in their study compared to $25.1 \%$ in the present study [14]. The $89.28 \%(\mathrm{n}=100)$ of Medical Doctors that ever saw ADR aligns with the finding by [15] that showed that more than $50 \%$ of doctors ever saw ADR cases. The proportion $(77.00 \%)$ of Medical Doctors that reported ADRs from the current study, however, differs from the $20 \%$ that [15] observed in their study. In the Indian Maharashtra rural tertiary hospital, more doctors $(59 \%)$ than nurses $(18 \%)$ ever reported ADR [16]. This is similar to the findings from the present study, where more Medical Doctors than nurses reported ADRs in the past 12 months. Only 3\% of respondents who ever encountered ADRs in Saudi Arabia reported it [17]. This is dissociated with about $25 \%$ proportion of health professionals reporting ADRs as documented in this study.

This study found that the proportion of the total number of ADRs reported by respondents was low (28.3\%). This observation agrees with earlier findings from Sokoto that showed as low as 7.0\% ADR reporting rate by clinicians [18]. Patients' failure to report ADRs to their healthcare Providers accounts for the high proportion of ADR not reported by health 
professionals in the past 12 months preceding this study.

Generally, there was high knowledge (88.1\%) on ADR reporting across all cadres of respondents. This supports earlier studies by Adosome in the Volta Regional Hospital of Ghana, which found that Doctors, Pharmacists, and Nurses Prescribers are knowledgeable in pharmacovigilance in Ghana [13]. However, the $78.8 \%$ awareness of the ADR reporting system described in the current study does not support a $39.6 \%$ awareness of healthcare professionals about the domestic pharmacovigilance system documented by Al-Madinah Al-Munawwarah Kingdom of Saudi Arabia [14]. Approximately $70 \%$ of pharmacists in Nigeria did not know where to get the ADR reporting forms [17]. This is not in correlation with findings from the current study where $68.18 \%$ of pharmacy staff knew where to get the ADR reporting forms. Studies elsewhere recorded generally poor knowledge in ADR reporting among healthcare professionals, contrary to what this current study found [19]. The high level of knowledge on ADR reporting from the present study might be due to the interventions that were instituted by the NAFDAC in 2015 to improve the ADR reporting in Katsina and Kano state, Nigeria. It could also be due to sensitization of health professionals during public health programs like the mass drug administration and the Seasonal Malaria Chemoprevention (SMC) which staff of the hospitals under study were part.

This study documented varied reasons for not reporting negative drug reactions. Relative to those that saw ADRs but did not report, the major reasons were the non-availability of the reporting forms and the not knowing the reporting procedure $(89.96 \%$ and $3.72 \%)$. Related outcomes were observed in other studies among pharmacists [20]. This calls for NAFDAC to ensure the provision of ADR forms to health facilities and the need to continuously orient health staff on ADR reporting.
The online reporting portal and the ADR forms were not accessible to almost 58\% and $89.96 \%$, respectively, of the respondents, and most of them were not trained or oriented on pharmacovigilance though most of them ever reported ADRs. The present study found similarities with a study in Uganda that found $56 \%$ of health professionals to have lacked training on ADR reporting [21]. Qassim also documented related findings among pharmacists [20]. These observations may be attributed to the fact that the ADR system is still developing, and the hospital has not assumed full responsibility for pharmacovigilance activities. It could also be due to inadequate policy direction or dissemination on making ADR reporting an integral part of the health system.

Respondents' perspective of how to improve ADR reporting was through training (100\%), patient education (98.4\%), ensuring the availability of ADR forms (97.9\%), and integrating ADR reporting into the monthly cases and deaths (CD1) reporting system (93.8\%). Patients that were aware and knew about the ADR reporting system reported the ADRs they experienced to a health professional [22].

\section{Limitations of the Study}

The study did not cover all health professionals due to financial and time constraints; hence sample was drawn from the target population for the study. There could be a recall and personal bias by respondents that could have an effect on the data and the outcome of this study.

Data provided about the number of ADR ever seen and reported could not be independently verified and authenticated. Findings from the study are limited to only the nineteen [19] Government hospitals in Katsina state, Nigeria, and should therefore be interpreted with the above limitations in mind. 


\section{Conclusion}

The Government hospitals in Katsina state, Nigeria, has a low ADR reporting rate. Medical Doctors and pharmacy staff reported more ADR cases than the nurses and midwives. Most health professionals that saw ADR in the past year reported it by completing the ADR reporting form. Knowledge of ADR reporting was generally high. The main systemic challenges with ADR reporting were the lack of access to ADR reporting form and an online portal on ADR reporting though it was one of the strategies to improve ADR reporting in Nigeria. Training and access to the ADR reporting tools are relevant to increasing the current ADR reporting rate of the Government hospitals in Katsina state, Nigeria.

\section{Recommendations}

1. All health professionals in close contact with the patient should be given access to the online reporting portal for ADR.

2. The NAFDAC should ensure regular training of all clinical cadres of health staff to

\section{References}

[1] Smith-Marsh, D. E. (2016), Adverse Drug Reactions (Adverse Drug Effects). Merck Sharp \& Dohme Corporation, 42(1), 12-16. Retrieved from http://www.msdmanuals.com/professional/clinicalpharmacology/adverse-drug-reactions/adverse-drugreactions.

[2] Nwokike, J., \& Eghan, K. (2010), Pharmacovigilance in Ghana: A Systems Analysis.

[3] Dodoo, A., \& Olsson, S. (2011), The world medicines situation 2011 pharmacovigilance and safety of medicines. WHO/EMP/MIE/2011.2.7.

[4] Oshikoya, K. A., Awobusuyi, J.O., (2009), Perceptions of doctors to adverse drug reaction reporting in a teaching hospital in Lagos, Nigeria. BMC Clin Pharmacol. 2009 Aug 11; 9:14. doi: 10.1186/1472-6904-9-14.

[5] Okezie, O.O., Fawole, O.I., (2008), Adverse drug reactions reporting by physicians in Ibadan, Nigeria. Pharmaco Epidemiol Drug Saf. 2008; 17: 517-522. improve the rate of ADR reporting in hospitals.

3. NAFDAC should consider linking the online reporting system to WhatsApp to facilitate reporting of ADR.

4. Hospital management should include ADR reporting in the appraisal of its staff to compile them look out for, and report ADRs.

5. Future research could be done to evaluate the whole pharmacovigilance system in the Katsina State focusing on the minimum requirement and what is currently practiced.

\section{Conflicts of Interest}

The authors declare that they have no conflicts of interest.

\section{Acknowledgements}

We wish to acknowledge Katsina State Ministry of Health, the Hospital Services Management Board, the 19 General Hospitals where the research was conducted, and the respondents.

[6] Ohaju-Obodo, J.O., Iribhogbe, O.I., (2010), Extent of pharmacovigilance among resident doctors in Edo and Lagos states of Nigeria. Pharmaco Epidemiol Drug Saf. 2010; 19: 191-195.

[7] Güner, M. D., (2017)' Incentives to Increase Pharmacovigilance Practices from an Educational and Ethical Point of View. Journal of Pharmacology \& Clinical Research, 3(5).

[8] Ezeuko, A.Y., Ebenebe, U.E., Nnebue, C.C., Ndu, O.O., (2015), Adverse Drug Reaction Reporting by Different Categories of Healthcare Workers in Nnewi, Nigeria: Awareness, Knowledge and Attitudes; BJMMR, 7(11): 932-941, 2015.

[9] World Health Organization. (2002), The Importance of Pharmacovigilance - Safety Monitoring of medicinal products. World Health Organization, $1-52$. https://doi.org/10.1002/0470853093. 
[10]Hazell, L., Shakir, S.A., (2006). Underreporting of adverse drug reactions: A systematic review. Drug Saf. 2006; 29:385-396.

[11] State News Letter (SNL) (2005), Addressing Maternal Mortality. Aminia 14: 5-13.

[12] Cochran, W.G., (1963), Sampling Techniques, Wiley, New York.

[13] Amedome, S.N., (2017), Pharmacovigilance Practices: Knowledge and Attitudes among the Healthcare Professionals at the Volta Regional Hospital of Ghana. https://doi.org/10.4172/23296887.1000229.

[14]Ekmekci, P. E., (2019), Healthcare professionals' pharmacovigilance knowledge and adverse drug reaction reporting behavior and factors determining the reporting rates. 8(1), 13-20. https://doi.org/10.1080/21556660.2019.1566137.

[15] Sabblah, G. T., Akweongo, P., Darko, D. M., Dodoo, A. N. O., \& Sulley, A. M. (2014), Adverse drug reaction reporting by doctors in a developing country: a case study from Ghana. Ghana Medical Journal, 48(4), 189-193. https://doi.org/10.4314/gmj.v48i4.4.

[16]Bahekar, S. E., \& Patil, S. M., (2018), Evaluation of knowledge, attitude, and practice of adverse drug reactions reporting among doctors and nursing staff of a rural tertiary care teaching hospital of

Maharashtra.

https://doi.org/10.4103/JMISR.JMISR.

[17] Kopciuch, D., Paczkowska, A., \& Ratajczak, P., (2019), Safety of medicines — Pharmacists' knowledge, practice, and attitudes toward pharmacovigilance and adverse drug reactions reporting process. (August 2018), 1-9. https://doi.org/10.1002/pds.4792.

[18]Bello, S., Tukur, U. M., (2011), Original Article Knowledge and attitudes of physicians relating to reporting of adverse drug reactions in Sokoto, northwestern Nigeria. https://doi.org/10.4103/15963519.76563 .

[19]Almandil, N.B, (2016), Healthcare professionals' awareness and knowledge of adverse drug reactions and pharmacovigilance. Saud Med J.;37(12):1359-64.

[20] Qassim, S., Metwaly, Z., Shamsain, M., and AlHariri, Y., (2014), Spontaneous Reporting of Adverse Drug Reactions in UAE: Obstacles and Motivation among Community Pharmacists. Qassim et al., 5(10), 4203-4208. https://doi.org/10.13040/IJPSR.09758232.5(10).4203-08.

[21] Katusiime, B., Semakula, D., \& Lubinga, S., (2015), Adverse drug reaction reporting among healthcare workers at Mulago National Referral and Teaching hospital in Uganda. Afri Health Sci., 15(4):1308-1317. [Online] Available at http://dx.doi.org/10.4314/ahs.v15i4.34.

[22] Jacobs, T. G., Hilda Ampadu, H., Hoekman, J., Dodoo, A. N. O., \& Mantel-Teeuwisse, A. K., (2018), The contribution of Ghanaian patients to the reporting of adverse drug reactions: A quantitative and qualitative study. BMC Public Health, 18(1), 111. https://doi.org/10.1186/s12889-018-6285-9. 


\title{
Asymptomatic Bacteriuria among Pregnant Women Attending Antenatal Clinic at the Akuapem North District of the Eastern Region of Ghana
}

\author{
Eli Dzandu ${ }^{1}$, Ernest Kenu ${ }^{1}$, Aquel Rene Lopez ${ }^{2 *}$, Sampson Mark Amegayie ${ }^{3}$, Clement \\ Amdor $^{4}$, Tanko Rufai ${ }^{5}$, Julia Kwakoa Karikari ${ }^{6}$ \\ ${ }^{1}$ School of Public Health, University of Ghana, Ghana \\ ${ }^{2}$ Department of Haematology, Tetteh Quarshie Memorial Hospital, Mampong, Ghana \\ ${ }^{3}$ Librarian, University of Ghana, Ghana \\ ${ }^{4}$ Department of Bacteriology, Tamale Teaching Hospital. Tamale, Ghana \\ ${ }^{5}$ Medical Laboratory Scientist, Koforidua Policlinic, Koforidua \\ ${ }^{6}$ Department of Obstetrics and Gynaecology Sinel Specialist Hospital, Tema, Ghana
}

\begin{abstract}
Asymptomatic bacteriuria is a condition in which urine culture reveals the presence of more than $10^{5}$ bacteria per millilitre but without the patient showing signs and symptoms of urinary tract infection (UTI). In many of the health care facilities in Ghana, routine screening for ASB among pregnant woman is not done despite overwhelming evidence clearly demonstrating its benefits in preventing UTI and the associated adverse pregnancy outcome. It is a common problem in pregnant women, which usually results in maternal and fetal complications. The majority of the participant were in the age range of 25 years to 34 years, and all the participants had basic education. Out of the 134 sterile urine samples cultured, 11 of the participants had bacteria isolated from their urine, given a prevalence of $8.2 \%$. Escherichia coli were $63.6 \%$, Nitrofurantoin was $81.8 \%$ sensitive to all bacteria isolated, and Cotrimoxazole was the most resistant antibiotic with $72.7 \%$. Factors associated with ASB in Akuapem North District were toilet facility, multiple pregnancy, and any medical condition, which were statistically significant at the bivariate analysis level. After adjusting these factors with the multiple logistics regression, only multiple pregnancy was statistically significant. The study revealed an $8.2 \%$ prevalence of ASB among pregnant women with E. coli, the predominate bacteria with $63.6 \%$. Nitrofurantoin, $81.8 \%$ sensitive, and Cotrimoxazole was the most resistant antibiotics with $72.7 \%$. Multiple pregnancy was associated with Asymptomatic bacteriuria among pregnant women at Akuapem North District.
\end{abstract}

Keywords: Asymptomatic Bacteriuria, Pregnant Women, Urine Culture, Urinary Tract Infection.

\section{Introduction}

Asymptomatic bacteriuria is a condition in which urine culture reveals the presence of more than $10^{5}$ colony forming unite of bacteria per millilitre $(\mathrm{CFU} / \mathrm{mL})$, but the client is showing no signs and symptoms of urinary tract infection [1].

An early study by [2] revealed that the apparent reduction in immunity of pregnant women appears to encourage the growth of both commensal and pathogenic microorganisms. During pregnancy, there is a physiological increase in plasma volume and a decrease in urine concentration up to about $70 \%$ that developed glycosuria which encourages bacteria growth in the urine [3]. Again, in their study, although all women are prone to the development of UTIs, pregnant women are at increased risk because of the numerous changes in the woman's body caused by pregnancy. In support of [3] findings, [4] also came out that 
pregnant women have hormonal and anatomical changes that contribute to ureteral dilatation and urinary stasis. These changes include shortness of the urethra and difficulty with hygiene due to a distended belly that increases UTI frequency in pregnant women.

To [5], women with Asymptomatic bacteriuria show a variable degree of the local urinary, immune response. This is almost onethird to half of the elderly women with Asymptomatic bacteriuria having elevated antibody levels compared with non-bacteriuria women. Further findings of [5] revealed that Asymptomatic bacteriuria, which is urinary cytokines, has been shown to be more frequently present in women when they become pregnant. In Africa, [6] reported that the prevalence of Asymptomatic bacteriuria among pregnant women and their effect on the reduction in immunity has increased risk factors such as infection of the foetus.

In Ghana, [7] reported that the prevalence of Asymptomatic bacteriuria was associated with sexual activity during pregnancy but not with sexual frequency. [7] also disagree that urinary infection does not affect the foetus being carried but reported that the commonest organism isolated was Enterococcus spp, although the Enterobacteriaceae formed the majority of isolated organisms. [7] also contended that nitrofurantoin was the antibiotic with the highest sensitivity to all the isolated organisms." [8] and [9] in their studies mentioned that pregnancy increases the progression from asymptomatic to symptomatic bacteriuria, leading to pyelonephritis and obstetric outcomes such as prematurity, low birth weight, and higher foetal mortality rates. [8] again added that the adverse effects of Asymptomatic undiagnosed bacteriuria on mother and child have made researchers to recommend routine urine culture for all pregnant women attending the antenatal clinic to prevent mother and child from any form of complication that may arise due to infection. Briefly, extensive work has not been done when it comes to Asymptomatic bacteriuria and its associated factors in the study area of Akuapem North District. Therefore, this study aims to screen for Asymptomatic bacteriuria and its antibiotic susceptibility patterns of the isolated bacteria among antenatal women that visited the health care facilities at the Akuapem North District.

\section{Materials and Methods}

The research employed a cross-sectional study between May to June 2019 to collect both qualitative and quantitative data on pregnant women attending antenatal clinics at Akuapem North District.

\section{Study Site}

The study was conducted at Akuapem North District, which is located at the south-eastern part of the Eastern Region, which is about $58 \mathrm{~km}$ from Accra, the capital city of Ghana. The Akuapem North Municipal shares boundaries to the northeast with Yilo Krobo, north with New Jauben Municipal, southeast with Dangbe West, southwest with Akuapem South District, and in the west with Suhum-Kraboa-Coaltar District. The district covers a land area of about $450 \mathrm{sq}$. $\mathrm{km}$ representing 2.3 percent of the total area of the Eastern Region and has about 230 settlements [9]. 


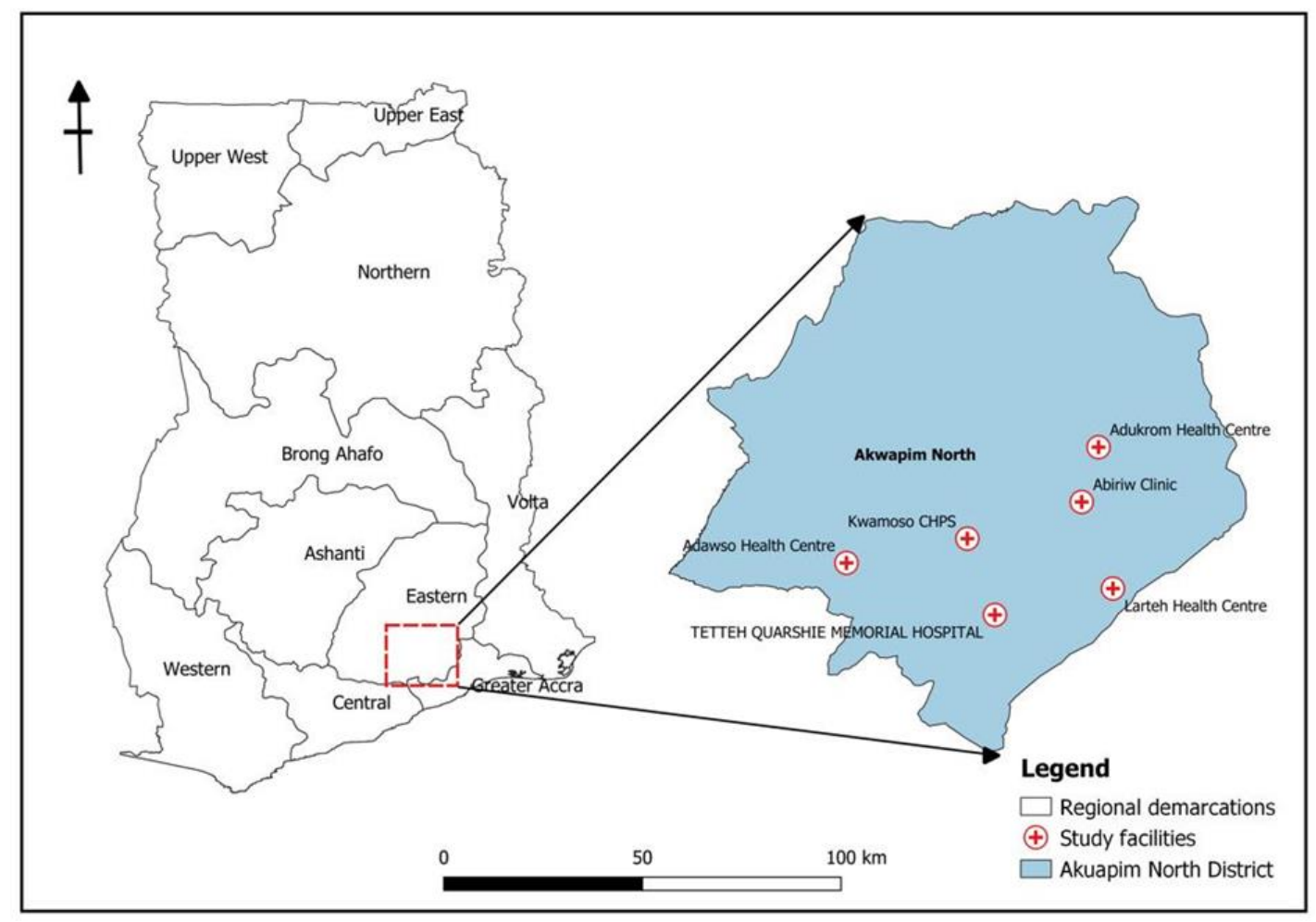

Figure 1. Map of Akuapem North

\section{Study Population}

The study population was all pregnant women who were attending antenatal clinics at any of the six selected health facilities at Akuapem North District from May to June 2019.

\section{Sampling}

\section{Sample Size Determination}

The sample size was calculated from Cochran's formula.

$$
n=Z^{2} p(1-p) / e^{2}
$$

Where $\mathrm{n}$ is the minimum sample size, $\mathrm{Z}$ is the standard $\mathrm{z}$ score that corresponds with a $95 \%$ confidence interval, which is $1.96, \mathrm{p}$ is the proportion of pregnant women with ASB and e is the allowable error margin set at $5 \%$.

$$
n=Z^{2} p(1-p) / e^{2}
$$

this implies that,

\section{$\mathrm{Z}=95 \% \mathrm{CI}$ is 1.96}

$\mathrm{p}=$ proportion of pregnant women with Asymptomatic bacteriuria in Akuapem North District. In Akuapem North District, the proportion of is u Figure 2: Map of Akuapem
North known but a similar study was carried out at Komfo Anokye with the prevalence of $7.3 \%$ [10] was used for the calculation of the minimum sample size for the study.

$$
\begin{aligned}
& \mathrm{p}=7.3 \%=0.073 \\
& \mathrm{e}=5 \%=0.05 \\
& \quad n=Z^{2} p(1-p) / e^{2} \\
& =1.96^{2} * 0.073(1-0.073) / 0.05^{2}=3.8416 * \\
& 0.073(0.927) / 0.0025 \\
& =3.8416 * 0.073(0.927) / 0.0025=3.8416 * \\
& 0.067671 / 0.0025 \\
& =\quad 3.8416 \quad * \quad 0.067671 / 0.0025 \\
& =0.2599649136 / 0.0025 \\
& =103.985 \sim 104 \text { participants. }
\end{aligned}
$$

\section{Sampling Method}

A five-year antenatal attendance book was used to calculate the mean attendance for each of the 23 health facilities in the district. Six health facilities were selected for the study based on the highest number of antenatal attendances. Samples were proportionately allocated to the six health facilities based on their five-year attendance. Those who consented to be part of the study had their urine specimens screened 
with the routine urine examination test to exclude those with protein, leucocyte, nitrate, glucose, and pus cells in their urine. Based on the number that was negative for protein, leucocyte and nitrate, and pus cells in their urine, the pregnant women were randomly selected by picking YES or NO, which was written on pieces of paper, folded, and put into a bowl. All those who picked YES were selected for the study. In instances where only a pregnant woman's result was negative on a particular day, that person was selected automatically for the study. The procedure was repeated on another antenatal day for those who were not already screened until they require a number from each stratum was gotten.

\section{Selection of Participants}

Routine urine examination was used as a baseline after they had satisfied the inclusion criteria and consented to be part of the study. Urine specimens from the pregnant women were collected and screened for the presence of protein, nitrate, glucose, leucocytes, and pus cell. All those who were negative after the routine urine examination test were randomly selected by picking YES or NO to give an equal chance of been included into the study.

\section{Data Collection Techniques and Tools}

\section{Review of Patients Records}

Maternal and child health record book (antenatal book) was used to retrieve information on clinical and pregnancy history such as gestational age, previous delivery with any birth defects, any medical condition, and outcome of the previous delivery.

\section{Laboratory Analysis}

\section{Culture and Antimicrobial Susceptibility}

Each urine specimen was well mixed by swirling the container. A sample was plated (cultured) in a labelled petri dishes containing a media of Cystine Lactose Electrolyte Deficient (CLED) and 5\% sheep blood agar media for the primary isolation of uropathogen using a sterile calibrated wire loop $(0.002 \mathrm{~mL})$ to inoculate a loopful of urine onto a half plate of each of the agars.

The culture plates were incubated between $35^{\circ} \mathrm{C}-37^{\circ} \mathrm{C}$ aerobically for $18-24$ hours. When there is bacterial growth after 18-24 hours of incubation morphological identification, biochemical test, colony count, and sensitivity were performed.

\section{Data Analysis}

The data was analysed using STATA software version 15 .

\section{Results and Discussion}

134 urine specimens were analyzed from pregnant women in six selected health facilities in the Akuapem North District who came for their antenatal clinic during the period of the study. Routine urine examination was performed, and those pregnant women whose results were negative for protein, leucocytes, nitrite, glucose, and pus cells less than 4 HPF and consented were enrolled in the study. A microbiological culture method was performed to determine the proportion of Asymptomatic bacteriuria among pregnant women at Akuapem North District. The ages of participants ranged from a minimum of 17 years to 43 years with an average age of 29.9 years (SD \pm 6.3 ). The majority of the pregnant women, 72 representing $53.7 \%$, were in the age range of 25-34 years, and $24.6 \%$ pregnant women were above 35 years.

All participants and the fathers of the inborn babies (foetus) had some level of education. 73 pregnant women representing $54.5 \%$, had basic education, while 79 representing $58.9 \%$ of the baby's (foetus) father, had advanced education. More than $78 \%$ of the participants were working at the time of the study, but only 17 , representing $12.7 \%$, earned a monthly income above one thousand Ghana cedis. More than $50 \%$ of the pregnant woman were married, 57(42.5\%) were co-habiting, and the remaining 5 representing $3.8 \%$, were single. 55 of the respondents representing $41.0 \%$, were yet to have their first 
child/twins, and 18 representing $13.5 \%$, had a total family size of more than five. The prevalence of Asymptomatic bacteriuria among the study sample was $8.2 \%(4.2 \%-14.2 \%)$.

In this study, urine culture and sensitivity, which is the gold standard, was randomly ran for 134 pregnant women who visited any of the six selected health facilities in the Akuapem North District. 134 pregnant women were screened with the current technique routine urine examination that is normally employed at these health facilities. A routine urine examination method was performed, and the results for those who were negative were assumed free from bacterial infection. However, a sterile urine container was given to all those participants to produce another urine specimen for culturing. 11 turned up with bacteria growth representing 8.2\% CI (4.2-14.2) that were negative from the earlier test performed. This, therefore, meant that they actually had Asymptomatic bacteriuria. Figure 2 below gives the pictorial view of the isolated bacteria. In order to check how significant this proportion of the number of pregnant women who actually had Asymptomatic bacteriuria a binomial test was run as shown in Table 1.

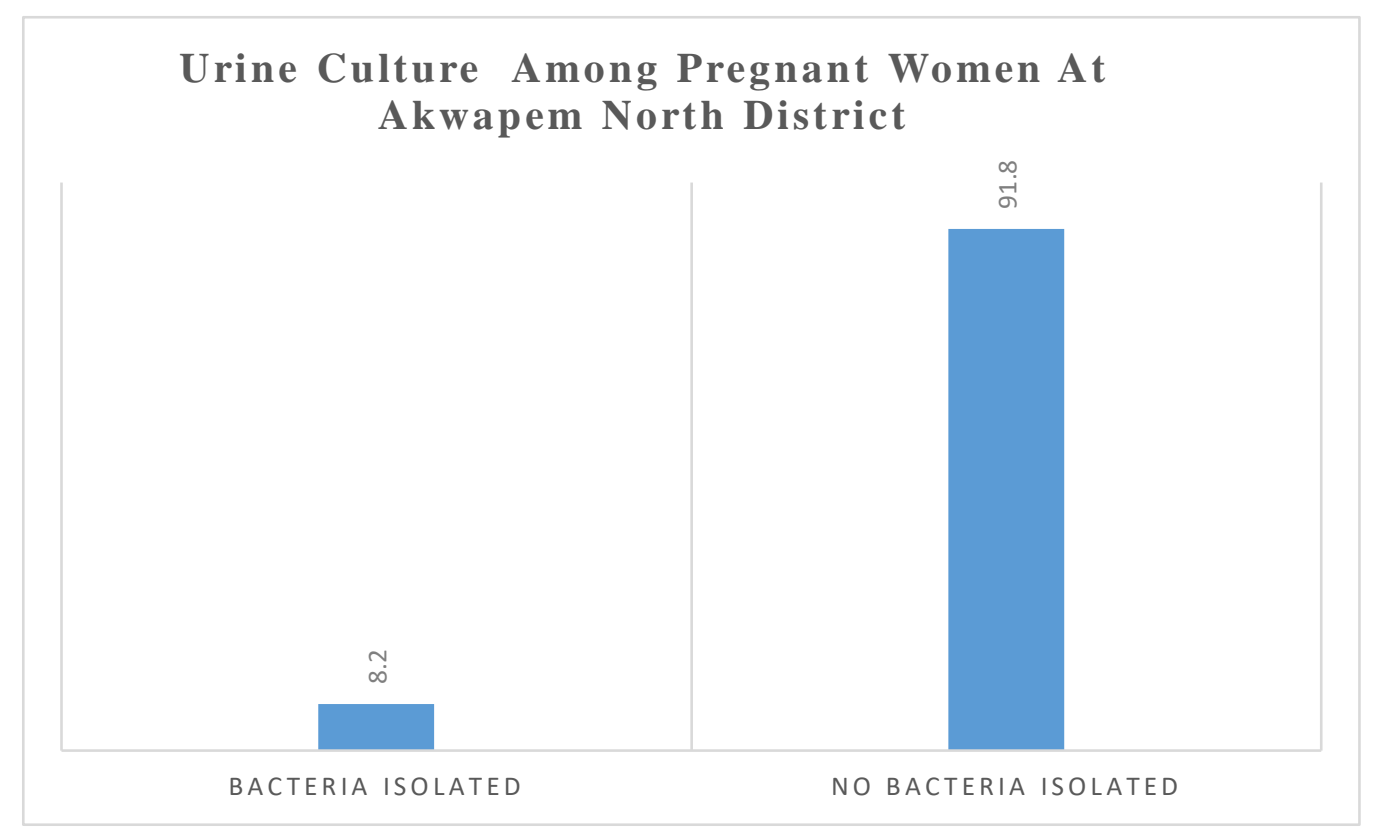

Figure 2. Urine Culture among Pregnant Women at Akuapem North District

Table 1. Binomial Test for Sample Proportion

\begin{tabular}{|l|l|l|l|l|l|c|}
\hline \multicolumn{3}{|c|}{ Category } & N & Observed Prop. & Test Prop. & P-value \\
\hline \multirow{3}{*}{ Bacteria growth } & Group 1 & No bacteria growth & 123 & 0.918 & .999 & $0.000^{\mathrm{a}}$ \\
\cline { 2 - 7 } & Group 2 & Bacteria Growth & 11 & 0.082 & - & - \\
\cline { 2 - 7 } & Total & 134 & 1.000 & - & - \\
\hline \multirow{2}{*}{ a. Alternative hypothesis states that the proportion of cases in the first group < .999 } \\
\hline
\end{tabular}

The Binomial Test in Table 1 revealed that the proportion (0.082) of pregnant women who were really having Asymptomatic bacteriuria was very significant since the p-value $(0.000)$ which is less than 0.05 . This, therefore, means that, out of every 1000 pregnant women who were initially declared to be free from urinary tract infection Asymptomatic bacteriuria, 82 of them were actually having Asymptomatic bacteriuria at Akuapem North District at 95\% confidence level. 
Table 2. Isolated Bacteria from Asymptomatic Bacteriuria

\begin{tabular}{|c|c|c|c|c|c|}
\hline \multirow[b]{2}{*}{ Bacteria isolated } & E. coli & Klebsiella spp & Proteus spp & Staph. aureus & Total \\
\hline & $\mathrm{n}(\%)$ & $\mathrm{n}(\%)$ & $\mathrm{n}(\%)$ & n $(\%)$ & n $(\%)$ \\
\hline Total bacteria isolated & $7(63.6)$ & $2(18.2)$ & $1(9.1)$ & $1(9.1)$ & $11(100)$ \\
\hline \multicolumn{6}{|l|}{ Antibiotics } \\
\hline \multicolumn{6}{|l|}{ Ampicillin } \\
\hline Sensitive & $5(71.4)$ & $2(100)$ & $0(0)$ & $0(0)$ & $7(63.6)$ \\
\hline Resistant & $2(28.6)$ & $0(0)$ & $1(100)$ & $1(100)$ & $4(36.4)$ \\
\hline \multicolumn{6}{|l|}{ Cotrimoxazole } \\
\hline Sensitive & $2(28.6)$ & $0(0)$ & $0(0)$ & $1(100)$ & $3(27.3)$ \\
\hline Resistant & $5(71.4)$ & $2(100)$ & $1(100)$ & $0(0)$ & $8(72.7)$ \\
\hline \multicolumn{6}{|l|}{ Cefuroxime } \\
\hline Sensitive & $4(57.1)$ & $1(50)$ & $0(0)$ & $0(0)$ & $5(45.5)$ \\
\hline Resistant & $3(42.9)$ & $1(50)$ & $1(100)$ & $1(100)$ & $6(54.6)$ \\
\hline \multicolumn{6}{|l|}{ Gentamicin } \\
\hline Sensitive & $6(85.7)$ & $1(50)$ & $1(100)$ & $0(0)$ & $8(72.7)$ \\
\hline Resistant & $1(14.3)$ & $1(50)$ & $0(0)$ & $1(100)$ & $3(27.3)$ \\
\hline \multicolumn{6}{|l|}{ Nalidixic Acid } \\
\hline Sensitive & $5(71.4)$ & $1(50)$ & $1(100)$ & $0(0)$ & $7(63.6)$ \\
\hline Resistant & $2(28.6)$ & $1(50)$ & $0(0)$ & $1(100)$ & $4(36.4)$ \\
\hline \multicolumn{6}{|l|}{ Nitrofurantoin } \\
\hline Sensitive & $5(71.4)$ & $2(100)$ & $1(100)$ & $1(100)$ & $9(81.8)$ \\
\hline Resistant & $2(28.6)$ & $0(0)$ & $0(0)$ & $0(0)$ & $2(18.2)$ \\
\hline \multicolumn{6}{|l|}{ Pipemidic Acid } \\
\hline Sensitive & $4(57.1)$ & $1(50)$ & $1(100)$ & $1(100)$ & $7(63.6)$ \\
\hline Resistant & $3(42.9)$ & $1(50)$ & $0(0)$ & $0(0)$ & $4(36.4)$ \\
\hline \multicolumn{6}{|l|}{ Tetracycline } \\
\hline Sensitive & $4(57.1)$ & $2(100)$ & $0(0)$ & $0(0)$ & $6(54.6)$ \\
\hline Resistant & $3(42.9)$ & $0(0)$ & $1(100)$ & $1(100)$ & $5(45.5)$ \\
\hline
\end{tabular}

Asymptomatic bacteriuria pregnant women at Akuapem Mampong and its antimicrobial susceptibility pattern. Source: Fieldwork, 2019

Table 2 showed the antimicrobial susceptibility patterns of 4 bacteria isolated from 11 pregnant women at Akuapem North District. The bacteria were three Gram-negatives namely Escherichia coli, Klebsiella spp and Proteus spp, and Staphylococcus aureus as the only Gram-positive bacteria isolated from the study. Also, from Table 2 above, the study showed that $E$. coli was the highest bacteria isolated from seven pregnant women representing 63.6\%, followed by Klebsiella spp which was isolated from 2 pregnant women representing 18.2\%. The other two bacteria were Proteus spp and
Staphylococcus aureus, which were isolated from two pregnant women representing $9.1 \%$ each.

From the study, Nitrofurantoin was the most effective antibiotic, which was sensitive to $81.8 \%$ of the bacteria isolated, followed by Gentamicin $72.7 \%$ sensitive. Cotrimoxazole was the highest resistant antibiotic to the isolated four (4) bacteria among the pregnant women in Akuapem North District, representing 72.7\%. Tetracycline was the second antibiotic with a resistance of $45.5 \%$. 
Table3. Multiple Logistic Regression Results for Factors Associated with Asymptomatic Bacteriuria

\begin{tabular}{|c|c|c|c|c|c|c|}
\hline \multirow[b]{2}{*}{ Variables } & \multicolumn{2}{|l|}{ Bacteria } & \multicolumn{2}{|c|}{ Unadjusted Model } & \multicolumn{2}{|l|}{ Adjusted Model } \\
\hline & No Growth & Growth & cOR $(95 \% \mathrm{CI})$ & P-value & aOR $(95 \% \mathrm{CI})$ & P-value \\
\hline \multicolumn{7}{|c|}{ Toilet facility } \\
\hline Private & $94(94.95)$ & $5(5.05)$ & 1.00 (reference) & \multirow[t]{2}{*}{0.04} & 1.00(reference) & \multirow[t]{2}{*}{0.06} \\
\hline Public & $29(82.86)$ & $6(17.14)$ & $3.9(1.1-13.8)$ & & $4.03(0.93-17.5)$ & \\
\hline \multicolumn{7}{|c|}{ Multiple pregnancy } \\
\hline No & $118(93.6)$ & $8(6.4)$ & 1.00 (reference) & \multirow[t]{2}{*}{0.01} & 1.00(reference) & \multirow[t]{2}{*}{0.01} \\
\hline Yes & $5(62.5)$ & $3(37.5)$ & $8.85(1.7-44.2)$ & & $9.52(1.7-51.9)$ & \\
\hline \multicolumn{7}{|c|}{ Any medical condition } \\
\hline No & $115(93.5)$ & $8(6.5)$ & $1.00($ reference) & \multirow[t]{2}{*}{0.03} & 1.00(reference) & \multirow[t]{2}{*}{0.09} \\
\hline Yes & $8(72.7)$ & $3(27.3)$ & $5.4(1.19-24.5)$ & & $2.0(0.26-16.9)$ & \\
\hline
\end{tabular}

cOR-crude odds ratio aOR-adjusted odd ratio CI-confidence interval.

Multiple logistic regression analysis was conducted on all the associated factors that were statistically significant at 95\% CI and P-value $\leq$ 0.05 at the bivariate level. These factors were toilet facility, multiple pregnancies, and any medical condition. Out of the three associated factors that were significantly associated with at t Asymptomatic bacteriuria he bivariate analysis, only one was statistically significant and strongly associated with the development of Asymptomatic bacteriuria at the multiple logistic regression analysis levels (P-value $\leq$ 0.05). This is shown on Table 3 above.

The study investigated the proportion of Asymptomatic bacteriuria among a study population of one 134 pregnant women from six selected health facilities in Akuapem North District during a period of May to July 2019. Urine specimens were cultured from pregnant women whose initial results with routine urine examination were negative for protein, nitrite, leucocytes, and pus cells less than 5/ HPF. The results of the study showed that 11 out of one hundred and thirty-four 134 pregnant women had had ASB giving a proportion of $8.2 \%$ (4.314.6). The prevalence is almost close to similar work done by [11]. This study is in agreement with what several researchers said about the prevalence of Asymptomatic bacteriuria among pregnant women that is from $2.5 \%$ to over $10 \%$ [12].
In contrast to this study, the study done in Nigeria by [13] had a much higher prevalence of $86.6 \%$, which may be due to the difference geographical area of the study population or the screening method used in selecting the participants. Asymptomatic bacteriuria rarely causes serious problems however, in pregnancy, if this condition is left untreated, more than $30 \%$ of the pregnant women will develop serious complications [14].

From the Binomial Test in Table 1 show that the proportion 11/134 (0.082) of pregnant women who were really having Asymptomatic bacteriuria was very significant since the $p$-value $(<0.001)$ is less than 0.05. This, therefore, means that, out of every 1000 pregnant women who were initially declared free from urinary tract infection with the routine urine examination technique used in Akuapem North District among the participants, 82 will have Asymptomatic bacteriuria, and out of that, more than 25 of them will develop serious complications. Some of these consequences of Asymptomatic untreated bacteriuria in pregnant women may lead to pyelonephritis, low birth weight, premature labor, eclampsia, premature rupture of the membrane, mental retardation, fatal death, pregnancy-induced hypertension, anaemia [15]. This can be a great worry to families since more resources will be spent to treat these conditions or even spend the whole 
lifetime looking after a human being from infancy through adulthood to old age if he/ she has developed a mental condition. Life can also be lost since this condition can result into fatality on the part of either child or mother.

According to [16], in Turkey, the prevalence of Asymptomatic bacteriuria was $8.5 \%$ which has a difference of $0.3 \%$ from this study. Similar studies were conducted in the same country Ghana but in different geographical regions. These studies were conducted in Ashanti Region at Komfo Anokye Teaching Hospital, Kumasi by [10] and had a prevalence of 7.2\%. At Korlebu Teaching Hospital in the Greater Accra Region, the capital city of Ghana, the prevalence of Asymptomatic bacteriuria was 5.5\% [7]. This research was also carried out at Akuapem North District from May-July, 2019 in the Eastern Region of Ghana and had a result of $8.2 \%$ prevalence of Asymptomatic bacteriuria among pregnant women. These variations in prevalence can be attributed to several factors, some of them are sociodemographic factors, environmental factors, clinical/pregnancy history, and health facilities. Four different types of bacteria were isolated from the study. These were E. coli 7(63.6\%), Klebsiella spp 2(18.1\%), Proteus spp $1(9.1 \%)$ and Staphylococcus aureus $1(9.1 \%)$.

Comparing the study to similar studies done in Ghana, the commonest bacteria isolated was in line with the one conducted by [10] at Komfo Anokye Teaching Hospital, Kumasi, which had E. coli- 6(37.5\%). In Greater Accra Region, [7] had Enterococcus spp of $4(26.7 \%)$ as the common bacteria isolated at the Korle-Bu Teaching Hospital. Studies were done in different countries all confirmed $E$ coli to be the most causative bacteria causing Asymptomatic bacteriuria among pregnant women. This can be affirmed by [17] in Babol city, [18], Jahrom, [19] in Tanzania [20] in Yemen [21] in Gorgan, and all had E. coli as the most causative bacteria in their studies. This is consistent with the work done at Akuapem North District. Antibiotics are among the most frequently prescribed types of medication during pregnancy and lactation [22].
The study showed the antimicrobial susceptibility patterns of four different types of bacteria isolated from eleven pregnant women. The bacteria were three Gram-negatives: Escherichia coli, Klebsiella spp and Proteus spp, and Staphylococcus aureus, the only Grampositive bacteria isolated from the study.

Table 2 showed E. coli was the most predominant bacteria isolated from 7 pregnant women representing $63.6 \%$, followed by Klebsiella spp. it was isolated from 2 pregnant women representing $18.2 \%$. The other two bacteria were Proteus spp and Staphylococcus aureus. Proteus spp was isolated from one pregnant woman, and Staphylococcus aureus was from another pregnant woman representing 9.1\% each.

From the study, Nitrofurantoin was the most effective antibiotic, which was $81.8 \%$ sensitive to the bacteria isolated. This was in agreement to the study done by [7] and went further to explain that antibiotics is not commonly used for the treatment of UTI in Ghana; therefore, their abuse is limited. From this study, Gentamicin was $72.7 \%$ sensitive to the isolated bacteria, and from the researcher's point of view, this antibiotic is an injectable; therefore, the use of it might be limited unless prescribed by a clinician or a pharmacist and also the pain in injecting one's self with a needle.

Cotrimoxazole was the highest resistant antibiotic to the isolated four bacteria among the pregnant women in Akuapem North District, representing $72.7 \%$. It is very common in Ghana, and both the injection and the tablet, so the abuse of it is high. Cefuroxime is also gradually becoming resistant since this is given to pregnant women to treat urinary tract infections [23]. When routine urine examination results suggest urinary tract infection, it must be confirmed by culture and sensitivity to know its susceptibility pattern and epidemiology. Epidemiological studies carried out among pregnant women in different populations worldwide have identified a diverse range of factors for asymptomatic bacteriuria [24]. The result of this study showed 
that there were no statistically significant associations with the development of Asymptomatic bacteriuria between most of the factors. [7] reported, the prevalence of Asymptomatic bacteriuria was associated with sexual activity during pregnancy, but not with sexual frequency, their finding affirmed in the current study.

The frequency of sexual intercourse per week was not statistically significant (p-value 0.353 ). At the bivariate level, only four of these factors were statistically significant at $95 \% \mathrm{CI}$ and Pvalue $\leq 0.05$. The results from the analysis indicate that toilet kind ( $\mathrm{p}$-value $=0.03$ ), multiple pregnancy $(\mathrm{p}$-value $=0.01)$, family history of medical condition ( $p$-value $=0.04$ ) and UTI previous experience $(\mathrm{p}$-value $=0.03)$ were associated with Asymptomatic bacteriuria. This means that there is a possibility of pregnant women having Asymptomatic bacteriuria based on these factors.

According to [25], women who have many children before the present pregnancy and it has been reported that multiparity is associated with Asymptomatic bacteriuria. In this study, the number of births was not statistically significant, but it was multiple pregnancies that were strongly associated with 9.5 folds greater odds of getting Asymptomatic bacteriuria compared to those with no multiple pregnancies in both bivariate and multivariate analysis 8.9 and 9.2 respectively.

\section{Conclusion}

The prevalence of asymptomatic bacteriuria among pregnant women is $8.2(4.3 \%-14-6 \%)$ at Akuapem North District. E. coli was the most predominate bacteria isolated with $63.6 \%$. Quantitative urine culture is the ideal test for the detection of asymptomatic bacteriuria.

The culture method helps to identify the bacteria and per its susceptibility pattern in order to reduce the antibiotics resistance, which has now become a public health problem globally. Early detection and treatment are essential to safeguard the health of the mother and fetus. In this study, Nitrofurantoin was the most sensitive with a percentage of 81.8 , and Cotrimoxazole was the most resistant of $72.7 \%$. Screening of Asymptomatic bacteriuria with the gold standard will help in knowing the bacteria causing the infection and deciding the best choice of antibiotics treatment.

\section{Recommendation}

Medical laboratories in the district need to be upgraded to enable them to screen for Asymptomatic bacteriuria for all pregnant women with a more sensitive technique instead of the routine urine examination, which is not sensitive in detecting Asymptomatic bacteriuria among pregnant women.

\section{Conflict of Interest}

The authors declare that they have no competing interests.

\section{Acknowledgement}

We will like to express our gratitude to all medical and non-medical staff of the various health facilities for their contribution towards this work. 


\section{References}

[1] Szweda, H., \& Jóźwik, M. J. D. P. M. (2016). Urinary tract infections during pregnancy-an updated overview. 20(4), 263-272.

[2] Scort, JR., E.D.whitefeaded and H.M Naghes, 1990. Dan Forty Obstertrics and Gynaecology.6th Edn, McGraw Hill Boston,pp:60-80.

[3] Ortega-González, Y., \& Castro-Diaz, D. J. C. B. D. R. (2014). Antibiotic considerations for urinary tract infections in pregnancy. 9(3), 167-174.

[4] Samuel, O., Victoria, O., \& Ifeanyi, O. J. U. J. o.

C. M. (2016). Prevalence of asymptomatic bacteriuria among the pregnant women receiving antenatal care at federal medical centre Owerri, Nigeria. 4(1), 1-5.

[5] Akerele, P. A., F. Okonofua, J , \& Gynaecology. (2001). Prevalence of asymptomatic bacteriuria among pregnant women in Benin City, Nigeria. Journal of Obstetrics Gynaecology, 21(2), 141-144.

[6] Ugbogu, O. (2007). Asymptomatic bacteriuria among pregnant women in Abakaliki, Ebonyi State Nigeria. Med. Sci., 7(4), 698-700.

[7] Labi, A., Yawson, A., Ganyaglo, G., \& Newman, M. (2015). Prevalence and associated risk factors of asymptomatic bacteriuria in ante-natal clients in a large teaching hospital in Ghana. Ghana medical journal, 49(3), 154-158.

[8] Blomberg, B., Olsen, B. E., Hinderaker, S. G., Langeland, N., Gasheka, P., Jureen, R., Midtvedt, T. (2005). Antimicrobial resistance in urinary bacterial isolates from pregnant women in rural Tanzania: implications for public health. Scandinavian journal of infectious diseases, 37(4), 262-268.

[9] http://www.easternregion.gov.gh/index.php/profi le/.

[10] Turpin, C., Minkah, B., Danso, K., \& Frimpong, E. J. G. m. j. (2007). Asymptomatic bacteriuria in pregnant women attending antenatal clinic at komfo anokye teaching hospital, Kumasi, ghana. 41(1), 26.

[11] Debebe, S. (2005). Asymptomatic Bacteriuria in Pregnant Women in Harar, South Eastern Ethiopia. Addis Ababa University.

[12] Abdullahi, H. I., \& Thairu, Y. J. I. J. o. P. (2015). Asymptomatic bacteriuria among pregnant women attending antenatal: evaluation of screening test. 5(8), 41-47.
[13] Schnarr, J., \& Smaill, F. J. E. j. o. c. i. (2008). Asymptomatic bacteriuria and symptomatic urinary tract infections in pregnancy. 38, 50-57.

[14] Mohamed, N. R., Omar, H. H. H., \& Abd-Allah, I. M. J. I.-J. (2017). Prevalence and Risk Factors of Urinary Tract Infection among Pregnant Women in Ismailia City, Egypt. 6(3), 62-72.

[15] Çelen, Ş., Oruç, A. S., Karayalçin, R., Saygan, S., Ünlü, S., Polat, B., . . . gynecology. (2011). Asymptomatic bacteriuria and antibacterial susceptibility patterns in an obstetric population. 2011.

[16] Amiri, M., Lavasani, Z., Norouzirad, R., Najibpour, R., Mohamadpour, M., Nikpoor, A. R., . . . Marzouni, H. Z. (2015a). Prevalence of urinary tract infection among pregnant women and its complications in their newborns during the birth in the hospitals of Dezful city, Iran, 2012-2013. Iranian Red Crescent Medical Journal, 17(8).

[17] Emamghorashi, F., Mahmoodi, N., Tagarod, Z., \& Heydari, S. T. (2012). Maternal urinary tract infection as a risk factor for neonatal urinary tract infection. Iranian journal of kidney diseases, 6(3), 178.

[18] Masinde, A., Gumodoka, B., Kilonzo, A., \& Mshana, S. (2009). Prevalence of urinary tract infection among pregnant women at Bugando Medical Centre, Mwanza, Tanzania. Tanzania journal of health research, 11(3).

[19] Abdullahi, H. I., \& Thairu. (2015). Asymptomatic bacteriuria among pregnant women attending antenatal: evaluation of screening test. IOSR Journal of Pharmacy, 5(8), 41-47.

[20] Mobsheri, E., Tabbraei, A., Ghaemei, E., Moujerlou, M., Vakili, M., Dastforooshan, M., \& Gholamei, S. (2002). Distribution of Asymptomatic Bacteriuria in Pregnant Women Referring to Dezyani Hospital in Gorgan.

[21] Mobsheri, E., Tabbraei, A., Ghaemei, E., Moujerlou, M., Vakili, M., Dastforooshan, M., \& Gholamei, S. (2002). Distribution of Asymptomatic Bacteriuria in Pregnant Women Referring to Dezyani Hospital in Gorgan.

[22] Nahum, G. G., Uhl, K., Kennedy, D. L. J. O., \& Gynecology. (2006). Antibiotic use in pregnancy and 
lactation: what is and is not known about teratogenic and toxic risks. 107(5), 1120-1138.

[23] Sorlozano, A., Jimenez-Pacheco, A., del Castillo, J. d. D. L., Sampedro, A., Martinez-Brocal,

A., Miranda-Casas, C., Gutiérrez-Fernández, J. (2014). Evolution of the resistance to antibiotics of bacteria involved in urinary tract infections: a 7-year surveillance study. American journal of infection control, 42(10), 1033-1038.

[24] Tellapragada, C., Eshwara, V. K., Bhat, P., Acharya, S., Kamath, A., Bhat, S., Health, P. (2016).
Risk factors for preterm birth and low birth weight among pregnant Indian women: a hospital-based prospective study. Journal of Preventive Medicine, 49(3), 165.

[25] Andabati, G., \& Byamugisha, J. J. A. h. s. (2010). Microbial aetiology and sensitivity of asymptomatic bacteriuria among ante-natal mothers in Mulago hospital, Uganda. 10(4). 


\title{
Antibiotics Resistance, Sensitivity Pattern and Development of Antibiogram to Support Empirical Prescription in Health Facilities in South Senatorial District of Kwara State, Nigeria
}

\author{
Gbenga Solomon Joseph ${ }^{1 *}$, Adekunle Ganiyu Salaudeen ${ }^{2}$ \\ ${ }^{1}$ School of Public Health, Texila American University, Georgetown, Guyana, South America \\ ${ }^{2}$ Department of Epidemiology and Community Health, University of Ilorin Teaching \\ Hospital, Ilorin, Nigeria
}

\begin{abstract}
A major concern in public health is Antibiotic resistance among pathogenic microorganisms. There are several organisms developing resistance to commonly used antibiotics in different locations and time. This study assessed patterns of antibiotic resistance in line with the WHO classification of antibiotics. A cross-sectional study was carried out from September 2020 to January 2021 in 4 randomly selected hospitals. Of all 442 patients recruited for this study, twenty-seven percent (122) were randomly selected for Antimicrobial Susceptibility Testing using the modified Kirby-Bauer disk diffusion method, and SPSS version 23 was used for analysis. The most predominant isolate was Staphylococcus aureus. Resistance by Staphylococcus aureus was noted against Amoxicillin, Trimethoprim-Sulfamethoxazole, Amoxicillin clavulanic acid, Gentamicin, and Cefuroxime. Resistance by E. coli against Chloramphenicol 80\%, cefuroxime 100\%, Trimethoprim-Sulfamethoxazole $83.3 \%$, Resistance by Klebsiella spp; against Ampicillin Second and third-generation cephalosporin and Gentamicin 100\%. Resistance by Streptococcus spp; Ampicillin 100\% and Ampicillin cloxacillin 100\%, cefuroxime 100\%, and Ciprofloxacin 100\%. Ciprofloxacin and levofloxacin were active against Salmonella species, Pseudomonas species, klebsiella, and Escherichia coli. Azithromycin, imipenem, and meropenem with high susceptibility to local bacterial isolates sample tested. The access group antibiotics showed a low susceptibility rate to local bacteria isolate with increase resistance to the watch group. Antibiogram was developed to guide empirical treatment type that is predominant in the district. Most bacteria isolated from health facilities in Kwara South were resistant to the access group. The resistance to watch a group of WHO antibiotics classification is building very fast.
\end{abstract}

Keywords: Antibiotic Resistance, Empirical Treatment, Susceptible.

\section{Introduction}

The most commonly used and abused antimicrobial agent in the management of bacterial infection globally is antibiotics agents [1]. A major concern in public health is Antibiotic resistance among pathogenic microorganisms. The increasing prevalence of antimicrobial resistance is putting pressure on the healthcare system, and this has become a threat to public health. It has increased resistance to first-line antibiotics and increased resistance to second-line antibiotics in the community, with consequences increasing deaths and costly treatment [2]. There are several organisms developing resistance to commonly used antibiotics in different locations and times. Antibiotic resistance (ABR) impedes the effective prevention and treatment of a continuous increasing range of bacterial infections [1].

Resistance in Klebsiella pneumoniae resulted in life-threatening infections to reserve a group of antibiotics. K. pneumoniae is the main cause 
of hospital-acquired infections such as pneumonia, bloodstream infections, and infections in newborns and intensive-care unit patients [3]. In a study conducted in 2019 in Brazil intensive care unit of the hospital, the author observed Klebsiella pneumoniae developed resistance to beta-lactam antibiotics: ampicillin/sulbactam, piperacillin/tazobactam, cefuroxime, cefoxitin, ceftazidime, ceftriaxone, cefepime, ertapenem, imipenem and meropenem. This revealed that Klebsiella pneumoniae isolates demonstrate different degrees of resistance to other antibiotics like gentamicin (80\%), Ciprofloxacin (64\%), TGC (52\%), CST (36\%), and amikacin (4\%) [4].

In a study conducted in Ibadan, Nigeria, the author observed, resistance to a common antibiotic is increasing; the author documented E. coli isolates showed resistance to ciprofloxacin $(92.86 \%), \quad$ cotrimozazole $(92.86 \%)$, and ceftriazone $(78.58 \%)$. He also observed a lower susceptibility to oflaxacin $(28.57 \%)$ in the study [5]. Similarly, in another study in southwestern Nigeria, among food sellers on the campus of the University of AdoEkiti, the antibiotic resistance pattern of the isolates showed six out of the eight antibiotics tested was resistance to commonly bacteria isolate [6]. This shows a higher resistance by microorganisms in Nigeria. In a study conducted in Kano and Borno University Teaching Hospitals among the patients on admission, it was observed that Staphylococcus aureus develops resistance very quickly and successfully to different antimicrobials over a period. The highest frequency of S. aureus occurred with susceptibility to antimicrobial agent Levofloxacin (100\%) followed by Ciprofloxacin (78.9\%), while the least was Penicillin (7.1\%) [7].

The situation report presented by Nigeria Centre for Disease Control revealed a trend of the wide spread of resistance strain to watch a group of antibiotics according to World Health Organization categorization [7]. In a study in Port Harcourt, Rivers State, Nigeria, it was observed that the Upper respiratory tract infection $(83.7 \%)$ and diarrhoea $(55.9 \%)$ were significantly associated with empirical antibiotic prescription $(\mathrm{P}=0.05$ and 0.002 [8]. Empirical prescription contributes greatly to antibiotic resistance.

Several factors have been found to contribute to antimicrobial resistance epidermic, especially in poor resource settings: the triple threat of unfettered access, minimal product regulation and failure to ensure appropriate guideline on antibiotic prescription is followed, and Lack of clinical diagnostic tools to support antibiotic resistance control amongst others [9]. Antibiotics resistance epidermic in Nigeria is facilitated by inappropriate medicine use, poor infection prevention, and control, Lack of government commitment to control of antimicrobial resistance and poor AMR surveillance system in place, and Lack of antimicrobial stewardship in both private and public sectors. In Nigeria, antimicrobial surveillance is weak. Antibiotics are prescribed unnecessarily and empirically for complaints where no antibiotic is needed or where culture and sensitivity results could safely be awaited (AMR use and situation analysis 2017). The empirical prescription is not guided by an antibiotic's stewardship instrument like an antibiogram that tracked and monitored resistance and susceptible strains in a given time and location.

Antimicrobial use and situation analysis in Nigeria identify setting up a national surveillance system for AMR, strengthen institutional capacities for early AMR detection and trends monitoring in the country, build laboratory capacity to produce high-quality microbiological data across all sectors, and implement a research agenda for AMR burden as a solution to the current antibacterial resistance burden in Nigeria. The strategic solution was to promote research in Government and private hospital and strengthen institutional capacities for early AMR detection and trends monitoring in the country. The monitoring of antibiotic use 
in Nigeria is still weak in many institutions in Nigeria. Though a lot has been done to create awareness to promote antibiotic's rational use, The Lack of research to quantify the resistance burden at the institution and subnational level and data to support antibiotic monitoring is still a challenge in Nigeria.

To optimize the use of antimicrobials and to pave the way for the implementation of antibiotic stewardship in the hospital [10], the World Health Organization (WHO) in 2017 updated the Essential Medicine List (EML) and categorized antibiotics into three groupsAccess, Watch and Reserve (AWaRe). This strategy aimed to ensure that antibiotics are available when needed and that the appropriate antibiotics are prescribed for the right infections. It would improve treatment outcomes, reduce the development of drug-resistant bacteria, and preserve the effectiveness of "last resort" antibiotics that are needed when all others failed [10].

In the face of the growing burden of antibiotics resistance, there is a dearth in research and data on this subject in Kwara State and Nigeria, a resource-limited setting [7]. A study to determine antibiotics resistance burden and sensitivity pattern to develop an antibiogram that will improve empirical treatment outcome and inform the development of appropriate policies for establishing antibiotics stewardship is required in this setting.

Therefore, this study was carried out to investigate the prevalence of antibiotics resistance and susceptibility patterns of bacteria isolated from samples collected from Government and Private hospitals in Kwara south senatorial district to develop an antibiogram that can be updated continuously to guide empirical treatment and rational use of antibiotics.

Estimating antibiotics resistance and sensitivity using (AWaRe) WHO classification to develop an antibiogram for the hospital is a new concept in Kwara south senatorial district. Antibiogram is a tool that guides empirical treatment type and antibiotic formulary for the hospital in the Kwara south with the goal of improving clinical outcomes.

\section{Material and Methods}

A cross-sectional study of antibiotics resistance and sensitivity pattern to the bacterial pathogen in Kwara south senatorial district was carried out on 442 patients between September 2020 and January 2021. Approval from the State Ministry of Health Research and Ethical Committee was obtained prior to the commencement of the study. A multistage sampling technique was used. Out of three senatorial districts in Kwara State, Kwara South senatorial district was selected using simple random sampling by balloting. The list of the Government secondary health facility and Private secondary health facility located in Kwara senatorial was obtained from the State Ministry of Health and used as the sampling frame. Two hospitals from the Government and private hospitals were selected from the Government and private hospitals list using simple random sampling. Using eligibility criteria, hospital patient registers from private and secondary health facilities selected were screened to have a list of eligible respondents for the sampling frame for this study. Systematic Sampling techniques were used to select respondents. The first respondent was selected by simple random sampling, while the subsequent respondents was selected using sampling interval.

A proportionate sampling method was used to determine the number of respondents from private and Government health facilities using the patient load in the four selected health hospitals. Of all 442 patients recruited for this study, twenty-seven percent (122) were randomly selected for Antimicrobial Susceptibility Testing (AST) WHO questionnaire on antibiotic resistance prevalence survey was modified and adopted to collect data regarding the socio-demographic data of the respondents. 
All bacteria were identified by standard microbiologic methods. The antibiotic susceptibility testing was done by using the modified Kirby-Bauer disk diffusion method. The antibiotic disks which were used were ampicillin, ampicillin/ sulbactam, ceftazidime, cefotaxime, cefuroxime, cefaperazone/ sulbactam, nitrofurantoin, co-trimoxazole, gentamicin, amikacin, norfloxacin, ciprofloxacin, piperacillin, piperacillin/ tazobactum, imipenem, and meropenem.

The zone size around each antimicrobial disk was interpreted as sensitive, intermediate, or resistant according to the Clinical and Laboratory Standards Institute (CLSI) criteria. Organisms sensitive and resistant to the drug were documented. Data regarding culture and sensitivity of the organisms isolated from different sources from urine, blood, wound swab/pus, stool, sputum, and tracheal aspirations were collected from both out-patients (OP) and in-patients (IP). All data were tabulated and analyzed. Descriptive and inferential statistics were used for analysis, and the results were expressed.

\section{Description of the study Area}

This study was conducted in Kwara South Senatorial District (KSSD) of Kwara State. The Language of the people of Kwara south senatorial district is mainly Yoruba with three sub-ethnic nationalities, namely, Ekiti, Ibollo, and Igbomina. There are other ethnic groups like Bassa, Fulani, Hausa, Igbo, Nupe, and Tiv living in the area. Kwara south senatorial district has guinea savannah vegetation. This senatorial district geographically shared boundaries with Kwara central senatorial district to the west, Kwara north senatorial district to the North, Kogi State to the east, and with the duo of Ekiti and the Osun States to the South.

The levels of care in the public sector are primary, secondary. The primary level is financed and managed by the local government, and the secondary is by the state. Primary health care (PHC) facilities exist at all the Local
Government Areas (LGAs); they form the entry point of the community into the health care system. PHC facilities provide preventive, curative, promotive, and pre-referral care to the population. PHC facilities are typically staffed by nurses, community health workers, community health extension workers (CHEWs), junior CHEWs, and environmental health officers. They are headed technically and administratively by the PHC coordinator, normally the Medical Officer of Health (MOH) where one exists who is assisted by program officers and unit heads.

The secondary health facilities referred to as general hospitals provide medical and laboratory services, as well as specialized health services such as surgery, paediatrics, obstetrics, and gynaecology to patients referred from the PHC level. Medical officers, nurses, midwives, pharmacists, laboratory specialists, and community health officers are the typical staff at secondary health facilities. They are headed by Medical Directors.

The study was conducted in four secondary health facilities selected by simple random sampling: General Hospital Omu-Aran and General Hospital, Offa (representing public health facilities) and Private Hospital are ESquare Hospital, Oro and Olalomi Hospital, Erin-ile. These health facilities are located in four LGAs of the seven LGAs in the senatorial district.

\section{Results}

Over a quarter $(27.6 \%)$ of participants had sample collection for culture, and $98.4 \%$ of participants that had sample collection had their results reported. Almost two-thirds (62.3\%) of the sample taken had growth of different types of microorganisms. Over eight different types of specimens were taken, with urine having the highest proportion (42.6\%). This was distantly followed by a sputum/respiratory tract sample that accounted for $13.1 \%$. The blood sample was the least with a $0.8 \%$ proportion (Table 1 ). 
Table 1. Specimen taken for Culture and Results before Antibiotics Prescription

\begin{tabular}{|l|l|l|}
\hline Variable & Frequency & Percent \\
\hline Culture sample taken $(\mathbf{n}=442)$ & \multicolumn{2}{|l|}{} \\
\hline Yes & 122 & 27.6 \\
\hline No & 320 & 72.4 \\
\hline Specimen type (n= 122) & 1 & 0.8 \\
\hline Blood & \multicolumn{2}{|l|}{} \\
\hline Urine & 52 & 42.6 \\
\hline Sputum/Respiratory sample & 16 & 13.1 \\
\hline Wound & 12 & 9.8 \\
\hline High Vaginal Swab & 14 & 11.5 \\
\hline Pus & 13 & 10.7 \\
\hline Stool & 4 & 3.3 \\
\hline Semen & 3 & 2.5 \\
\hline Others & 7 & 5.7 \\
\hline Culture results $(\mathbf{n}=\mathbf{1 2 2})$ & & 62.3 \\
\hline Growth & 76 & 36.1 \\
\hline No growth & 44 & 1.6 \\
\hline Not available & 2 & \\
\hline
\end{tabular}

The highest number (24) of growth reported The least reported were pseudomonas specie and was for Staphylococcus aureus 24 (31.58), salmonella specie $1(1.32 \%)$. closely followed by the coliform organism (22).

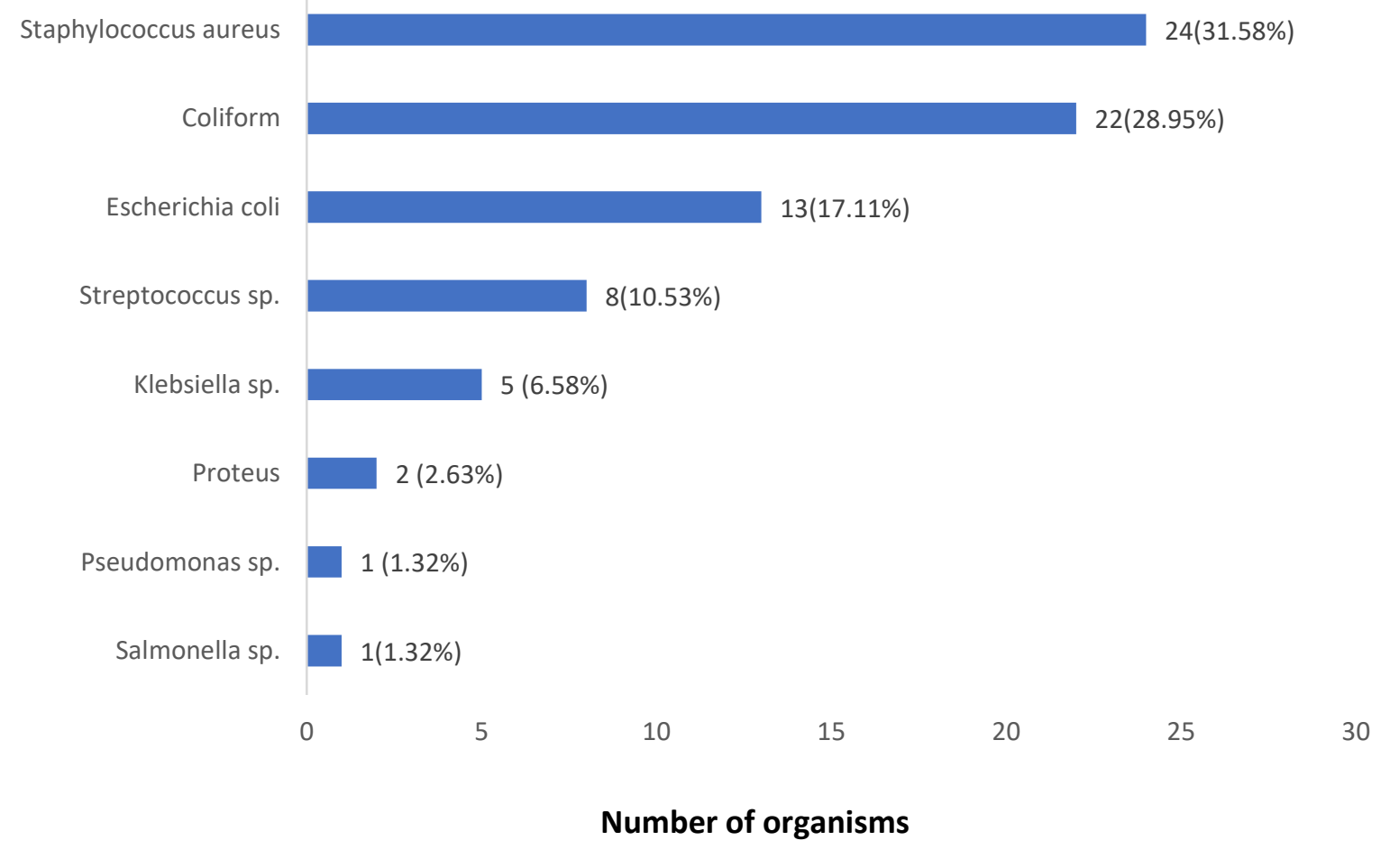

Figure 1. Distribution of Bacterial Organisms Grown from Samples 
Table 2. Different Bacterial Organisms Grown in the Culture Test of the Specimen

\begin{tabular}{|c|c|c|c|c|c|c|c|c|c|c|c|c|c|c|c|c|}
\hline & \multicolumn{2}{|c|}{$\begin{array}{l}\text { Streptococcus } \\
s p\end{array}$} & \multicolumn{2}{|c|}{$\begin{array}{l}\text { Staph. } \\
\text { aureus }\end{array}$} & \multicolumn{2}{|c|}{$\begin{array}{l}\text { Salmonella } \\
\text { sp }\end{array}$} & \multicolumn{2}{|c|}{$\begin{array}{l}\text { Pseudomonas } \\
\text { sp }\end{array}$} & \multicolumn{2}{|c|}{ Proteus } & \multicolumn{3}{|c|}{ Coliform } & \multicolumn{2}{|c|}{$\begin{array}{l}\text { Klebsiella } \\
\text { sp }\end{array}$} & \multirow[t]{2}{*}{ Escherichia } \\
\hline Antibiotics tested & $\mathbf{R}$ & & $\mathbf{R}$ & & $\mathbf{R}$ & & $\mathbf{R}$ & & $\mathbf{R}$ & & $\mathbf{R}$ & & & $\mathbf{R}$ & & \\
\hline Ampicillin Cloxacillin & $3 / 3$ & 100 & $2 / 2$ & 100 & - & - & - & - & - & - & $6 / 7$ & 85.7 & $1 / 1$ & 100 & $2 / 2$ & 100 \\
\hline Ampicillin & - & - & - & - & - & - & - & - & - & - & $1 / 1$ & 100 & & & $1 / 1$ & 100 \\
\hline Amoxicillin & $5 / 5$ & 100 & $10 / 12$ & 83.3 & - & - & - & - & $2 / 2$ & 100 & $1 / 3$ & 33.3 & $4 / 4$ & 100 & $4 / 9$ & 44.4 \\
\hline Amoxicillin Clavulanic acid & $1 / 3$ & 33.3 & $9 / 14$ & 64.3 & - & - & - & - & $2 / 2$ & 100 & $11 / 13$ & 84.6 & $3 / 3$ & 100 & $5 / 9$ & 55.6 \\
\hline Azithromycin & - & - & & & - & - & - & - & - & - & - & - & - & - & - & - \\
\hline Ceftazidime & - & - & $1 / 1$ & 100 & - & - & - & - & - & - & - & - & $1 / 1$ & 100 & - & - \\
\hline Cefixime & - & - & - & - & - & - & - & - & - & - & $1 / 2$ & 50.0 & - & - & - & - \\
\hline Cefazolin & - & - & - & - & - & - & - & - & - & - & & & $3 / 3$ & 100 & - & - \\
\hline Chloramphenicol & $2 / 5$ & 40.0 & $3 / 5$ & 60.0 & $1 / 1$ & 100 & $1 / 1$ & 100 & - & - & $4 / 4$ & 100 & & & $4 / 5$ & 80.0 \\
\hline Ciprofloxacin & $3 / 3$ & 100 & $1 / 14$ & 7.1 & - & - & - & - & - & - & $2 / 11$ & 18.2 & $1 / 5$ & 20.0 & $1 / 7$ & 14.3 \\
\hline Clarithromycin & - & - & - & 0.0 & - & - & - & - & - & - & - & - & - & - & - & - \\
\hline Cefuroxime & $3 / 3$ & 100 & $2 / 4$ & 50.0 & - & - & - & - & - & - & - & - & $1 / 1$ & 100 & $5 / 5$ & 100 \\
\hline Ceftriaxone & $2 / 4$ & 50.0 & $3 / 8$ & 37.5 & - & - & - & - & - & - & - & - & - & - & - & - \\
\hline Erythromycin & $1 / 3$ & 33.3 & $7 / 11$ & 63.6 & - & - & - & - & - & - & $3 / 6$ & 50.0 & - & - & - & - \\
\hline Nitrofurantoin & - & - & $3 / 4$ & 75.0 & - & - & - & - & - & - & $4 / 8$ & 50.0 & - & - & - & - \\
\hline Gentamicin & $3 / 3$ & 50.0 & $11 / 17$ & 64.7 & - & & $1 / 1$ & 100 & $1 / 2$ & 50.0 & $10 / 17$ & 58.8 & $2 / 2$ & 100 & $3 / 8$ & 37.5 \\
\hline Imipinem & - & - & - & - & - & - & - & - & - & - & - & & - & - & - & - \\
\hline Levofloxacin & - & - & - & - & - & - & - & - & - & - & $1 / 8$ & 12.5 & - & - & - & - \\
\hline Meropinem & - & - & - & - & - & - & - & - & - & - & - & - & - & - & - & - \\
\hline Metronidazole & - & - & - & - & - & - & - & - & - & - & - & - & - & - & - & - \\
\hline Ofloxacin & $2 / 6$ & 33.3 & $9 / 18$ & 50.0 & - & & $1 / 1$ & 100 & $1 / 2$ & 50.0 & $3 / 16$ & 18.8 & $1 / 4$ & 25.0 & $1 / 7$ & 14.3 \\
\hline Streptomycin & - & - & $4 / 12$ & 33.3 & $1 / 1$ & 100 & - & - & - & - & $4 / 4$ & 100 & $1 / 3$ & 33.3 & $2 / 6$ & 33.3 \\
\hline Tetracycline & - & - & - & - & - & - & - & - & - & - & $1 / 1$ & 100 & $1 / 1$ & 100 & - & - \\
\hline Trimethoprim - Sulfamethoxazole & $3 / 5$ & 60.0 & $12 / 13$ & 92.3 & $1 / 1$ & 100 & $1 / 1$ & 100 & - & - & $5 / 7$ & 71.4 & $3 / 3$ & 100 & $5 / 6$ & 83.3 \\
\hline
\end{tabular}


Table 3. Antibiogram for the Health Facilities

\begin{tabular}{|c|c|c|c|c|c|c|c|c|c|c|c|c|c|c|c|c|}
\hline \multirow[b]{2}{*}{ Antibiotics tested } & \multicolumn{2}{|c|}{$\begin{array}{l}\text { Streptococcus } \\
s p\end{array}$} & \multicolumn{2}{|c|}{$\begin{array}{l}\text { Staph. } \\
\text { aureus }\end{array}$} & \multicolumn{2}{|c|}{$\begin{array}{l}\text { Salmonella } \\
\text { sp }\end{array}$} & \multicolumn{2}{|c|}{$\begin{array}{l}\text { Pseudomonas } \\
\text { sp }\end{array}$} & \multicolumn{2}{|c|}{ Proteus } & \multicolumn{2}{|c|}{ Coliform } & \multicolumn{2}{|c|}{ Klebsiella sp } & \multicolumn{2}{|c|}{ Escherichia } \\
\hline & $\mathbf{R}$ & $\mathbf{S}$ & $\mathbf{R}$ & $\mathbf{S}$ & $\mathbf{R}$ & $\mathbf{S}$ & $\mathbf{R}$ & $\mathbf{S}$ & $\mathbf{R}$ & $\mathbf{S}$ & $\mathbf{R}$ & $\mathbf{S}$ & $\mathbf{R}$ & $\mathbf{S}$ & $\mathbf{R}$ & $\mathbf{S}$ \\
\hline Ampicillin Cloxacillin & 100 & 0.0 & 100 & 0.0 & - & - & - & - & - & - & 85.7 & 14.3 & 100 & 0.0 & 100 & 0.0 \\
\hline Ampicillin & - & - & - & - & - & - & - & - & - & - & 100 & - & - & - & 100 & 0.0 \\
\hline Amoxicillin & 100 & 0.0 & 83.3 & 16.2 & 0.0 & 100 & - & - & 100 & 0.0 & 33.3 & 66.7 & 100 & 0.0 & 44.4 & 55.6 \\
\hline Amoxicillin Clavulanic acid & 33.3 & 66.7 & 64.3 & 35.7 & - & - & - & - & 100 & 0.0 & 84.6 & 15.4 & 100 & 0.0 & 55.6 & 44.4 \\
\hline Azithromycin & - & - & - & - & - & - & - & - & - & - & 0.0 & 100 & - & - & - & - \\
\hline Ceftazidime & - & - & 100 & 0.0 & - & - & - & - & - & - & - & - & 100 & 0.0 & - & - \\
\hline Cefixime & - & - & - & - & - & - & - & - & - & - & 50.0 & 50.0 & - & - & - & - \\
\hline Cefazolin & - & - & - & - & - & - & - & - & - & - & - & - & 100 & 0.0 & - & - \\
\hline Chloramphenicol & 40.0 & 60.0 & 60.0 & 40.0 & 100 & 0.0 & 100 & - & - & - & 100 & 0.0 & 0.0 & 100 & 80.0 & 20.0 \\
\hline Ciprofloxacin & 100 & 0.0 & 7.1 & 92.9 & - & - & - & 100 & 0.0 & 100 & 18.2 & 81.8 & 20.0 & 80.0 & 14.3 & 85.7 \\
\hline Clarithromycin & - & - & 0.0 & 100 & - & - & - & - & - & - & - & - & - & - & - & - \\
\hline Cefuroxime & 100 & 0.0 & 50.0 & 50.0 & - & - & - & - & - & - & 0.0 & 100 & 100 & 0.0 & 100 & 0.0 \\
\hline Ceftriaxone & 50.0 & 50.0 & 37.5 & 62.5 & - & - & - & - & - & - & - & - & 0.0 & 100 & - & - \\
\hline Erythromycin & 33.3 & 66.7 & 63.6 & 36.4 & - & - & - & - & - & - & 50.0 & 50.0 & - & - & - & - \\
\hline Nitrofurantoin & - & 100 & 75.0 & 25.0 & - & - & - & - & - & - & 50.0 & 50.0 & - & - & 0.0 & 100 \\
\hline Gentamicin & 50.0 & 50.0 & 64.7 & 35.3 & - & - & 100 & 0.0 & 50.0 & 50.0 & 58.8 & 41.2 & 100.0 & 0.0 & 37.5 & 62.5 \\
\hline Imipinem & - & - & - & - & - & - & - & - & - & - & - & - & - & - & 0.0 & 100 \\
\hline Levofloxacin & 0.0 & 100 & 0.0 & 100 & - & - & - & - & - & - & 12.5 & 87.5 & - & - & - & - \\
\hline Meropinem & - & - & - & - & - & - & - & - & - & - & - & - & - & - & 0.0 & 100 \\
\hline Metronidazole & 0.0 & 100 & - & - & - & - & - & - & - & - & - & - & - & - & 0.0 & 100 \\
\hline Ofloxacin & 33.3 & 66.7 & 50.0 & 50.0 & 0.0 & 100 & 100 & 0.0 & 50.0 & 50.0 & 18.8 & 81.3 & 25.0 & 75.0 & 14.3 & 85.7 \\
\hline Streptomycin & 0.0 & 100 & 33.3 & 66.7 & 100 & 0.0 & 0.0 & 100 & - & - & 100 & 0.0 & 33.3 & 66.7 & 33.3 & 66.7 \\
\hline Tetracyclin & - & - & - & - & - & - & - & - & - & - & 100 & 0.0 & 100 & 0.0 & - & - \\
\hline Trimethoprim - Sulfamethoxazole & 60.0 & 40.0 & 92.3 & 7.7 & 100 & 0.0 & 100 & 0.0 & - & - & 71.4 & 28.6 & 100 & 0.0 & 83.3 & 16.7 \\
\hline
\end{tabular}


The highest resistance by Staphylococcus aureus was noted against Amoxicillin 100\%, Ampicillin cloxacillin 100\%, Ciprofloxacin $100 \%$, Cefuroxime $100 \%$, and TrimethoprimSulfamethoxazole $60 \%$. Resistance by E. coli was noted against to Ampicillin 100\% and Ampicillin cloxacillin 100\%, Chloramphenicol $80 \%$, cefuroxime $100 \%$, TrimethoprimSulfamethoxazole $\quad 83.3 \% \quad$ Amoxicillin Clavulanic acid 55.6\%. Resistance by Klebsiella $s p$ was observed against Ampicillin 100\% and Ampicillin cloxacillin 100\%, Second and thirdgeneration cephalosporin, TrimethoprimSulfamethoxazole and Gentamicin 100\%. The least resistance by $E$. coli was observed in this study against Ciprofloxacin $14.3 \%$, Gentamicin $37.5 \%$, Ofloxacin 14.3\%. Resistance by Streptococcus spp was noted against Ampicillin $100 \%$ and Ampicillin cloxacillin 100\%, cefuroxime $100 \%$, Ciprofloxacin $100 \%$, and Trimethoprim-Sulfamethoxazole $60 \%$. The new generation macrolide (clarithromycin and azithromycin) experienced no resistance to a microorganism with known activity, unlike older generation macrolide (erythromycin) that shown acquired resistance to Streptococcus and staphylococcus aureus.

The antibiotic susceptibility pattern results to Staphylococcus aureus showed levofloxacin $100 \%$, Nitrofurantoin 100\%, Amoxicillin clavulanic acid $64 \%$. The least resistance by $E$. coli was observed in this study against Ciprofloxacin 14.3\%, Gentamicin 37.5\%, Ofloxacin $14.3 \%$. Sensitivity by Streptococcus spp was observed in levofloxacin 100\%, Nitrofurantoin 100\%, Amoxicillin Clavulanic acid $66.7 \%$, Erythromycin $66.7 \%$, and Ofloxacin $66 \%$. Ciprofloxacin and levofloxacin were active against Salmonella species, Pseudomonas species, klebsiella, and Escherichia coli. Azithromycin, imipenem, and meropenem with high susceptibility to local bacterial isolates sample tested. The access group of antibiotics, according to WHO classification, showed a low susceptibility rate to local bacteria isolate compared to the watch group with a high susceptibility rate.

\section{Discussion}

Estimating bacterial profile and its antibiotic resistance pattern is critical in establishing antibiotics stewardship, one of the key interventions necessary to curb the further emergence and spread of antimicrobial resistance (AMR). WHO in 2017 announced the Access, Watch, Reserve ("AWaRe") classification of antibiotics. The categorization is a tool for antibiotic stewardship at local, national, and global levels with the aim of decreasing antimicrobial resistance.

Urinary Tract Infection (UTI) has been found to be one of the most common bacterial infections seen in medical practice, especially in developing countries. The most predominant isolate was Staphylococcus aureus, followed by coliform (28.50\%) and Escherichia coli (17.11\%). This is consistent with findings from studies conducted in Anambra and Zaria [11], which showed that these were common pathogenic organisms of UTI [12]. One of the key factors predisposing to UTI is poor personal hygiene [12].

The highest resistance by Staphylococcus aureus was noted against Ampicillin cloxacillin, Amoxicillin, Trimethoprim-Sulfamethoxazole, Amoxicillin clavulanic acid, Gentamicin, and Cefuroxime in this study. In a study conducted in Abuth, Zaria, Nigeria had reported a pattern of resistance to ampicillin $100 \%$, ceftriaxone $72.2 \%$, and ciprofloxacin 51.5\% [13]. [14] had reported in Kuwait, MSRA isolates were resistant to ciprofloxacin (42.7\%), erythromycin, and clindamycin (42.4\%), gentamicin (38.5\%), tetracycline $(2,652$; $38.3 \%)$, and trimethoprim (33.5\%). This reflected that resistance patterns differ in a different location and the need to have an antibiogram to guide empirical treatment type and pave the way for hospital antibiotics policy programs to promote rational use of antibiotics. 
Poor hygienic environments and the absence of a relevant antibiotic policy are potential reasons for high resistance to commonly used first lines antibiotics.

High antibiotic susceptibility patterns by Staphylococcus aureus to levofloxacin, Ciprofloxacin, and Ceftriaxone were reported in this study. Previously, Nwankwo had reported a susceptibility pattern of Levofloxacin $93.7 \%$ and Amoxicillin clavulanic acid 63\% in Kano, Nigeria [15]. This may suggest that Quinolones are effective in managing Staphylococcus aureus infections and should be considered for empirical treatment in the antibiogram.

The highest resistance by $E$. coli was noted against Ampicillin 100\% and Ampicillin cloxacillin 100\%, Chloramphenicol 80\%, cefuroxime $\quad 100 \%, \quad$ TrimethoprimSulfamethoxazole $\quad 83.3 \% \quad$ Amoxicillin Clavulanic acid 55.6\%. This pattern of resistance has been shown in studies by [16], and the authored reported $100 \%$ resistance to amoxicillin/ clavulanate, cotrimoxazole, and amoxicillin in Southwest, Nigeria in 2011. Okeke observed that E. coli isolates showed resistance to ciprofloxacin (92.86\%), cotrimozazole $(92.86 \%)$, and ceftriazone (78.58\%) [5]. This was a prove that antibiotics resistance to the first choice of antibiotics to treat $E$. coli infection were growing, there was a steadily increased in resistance pattern. This finding suggests the need to develop antibiotic policies to guide the implementation of a costeffective antibiotic stewardship program in the Kwara south senatorial district.

Least resistance by E. coli was observed in this study against Ciprofloxacin 14.3\%, Gentamicin $37.5 \%$, Ofloxacin $14.3 \%$, which is consistent with Okeke N.I et al. 2007, he also observed a lower susceptibility to ofloxacin (28.57\%) [5]. On the contrary, [16] found that high resistance rates to ofloxacin, gentamycin, nalidixic acid, and tetracycline were $70 \%, 92 \%$, $96 \%$, and $88 \%$, respectively. This shows that organisms developed resistance to commonly used antibiotics in different locations and time.
This suggests the need to have an antibiogram for location and periodically update.

Resistance by Klebsiella $s p$ was observed against Ampicillin 100\% and Ampicillin cloxacillin $100 \%$, Second and third-generation cephalosporin, Trimethoprim-Sulfamethoxazole and Gentamicin $100 \%$. The least resistance was observed in this study against ciprofloxacin $20 \%$ and ofloxacin $25 \%$. This is consistent with the reports from a study conducted in 2019 in the Brazil intensive care unit of the hospital, and the author observed Klebsiella pneumoniae developed resistance to beta-lactam antibiotics, cefuroxime, cefoxitin, ceftazidime, ceftriaxone, cefepime, gentamicin, and Ciprofloxacin [4].

The authored, in a study conducted in Ebonyi State University Teaching Hospital Abakaliki, Nigeria, in 2005, observed that the most sensitive antimicrobial in his study was Ciprofloxacin with (49.4\%) followed by Gentamicin with $38.8 \%$ than Ceftazidime with $36.7 \%$ [17]. The sensitive rate demonstrated by ciprofloxacin and ofloxacin in this study and consistent with another study in eastern Nigeria suggests that these two molecules should be considered for empirical treatment in the antibiogram of the hospitals in Kwara South Senatorial district of Kwara State.

The highest resistance by Streptococcus spp was noted against Ampicillin 100\% and Ampicillin cloxacillin 100\%, cefuroxime 100\%, Ciprofloxacin 100\%, and TrimethoprimSulfamethoxazole $60 \%$. Sensitivity by Streptococcus spp was observed in levofloxacin $100 \%$, Nitrofurantoin 100\%, Amoxicillin Clavulanic acid $66.7 \%$, Erythromycin $66.7 \%$, and Ofloxacin $66 \%$.

This study was at variance to the 1997 U.S. Surveillance Study published in 1999 that reported $94 \%$ of Streptococcus. pneumoniae isolates were susceptible to amoxicillin and amoxicillin-clavulanate, $69 \%$ to azithromycin and clarithromycin, $63 \%$ cefuroxime, and $52 \%$ to cefixime [18]. The reason for this variance may be due to the Lack of a surveillance system in the Kwara senatorial district because the 
National surveillance system for antimicrobial resistance started in 2018 in Nigeria with 12 sites. Lack of AMR surveillance has promoted indiscriminate and inappropriate use of an antibiotic that led to an increase in resistance to commonly used antibiotics with the direct consequence of increases cost of health care.

This study reflected that resistance was high in the access and watched a group of antibiotics classification by WHO. The empirical antibiotic use in these hospitals is still a problem. Antibiotics are prescribed unnecessarily and empirically for complaints where no antibiotic is needed or where culture and sensitivity results could safely be awaited.

The criteria for the selection of antimicrobial agents should be determined based on the most likely pathogen and its expected resistance pattern in the locality.

Hence, there is a need for periodic monitoring of bacteria isolate and their resistance/susceptibility pattern in a locality by constantly updating antibiogram to support empirical treatment, especially for the critically ill patient before cultures result is released.

\section{References}

[1] World Health Organization (WHO). (2016). WHO | Antimicrobial resistance: global report on surveillance 2014 [Internet]. Antimicrobial resistance: global report on surveillance 2014. Available from: http://www.who.int/drugresistance/d http://www.who.int/drugresistance/documents/survei llancereport/en/\%0A

http://www.who.int/antimicrobial-

resistance/publications/surveillancereport/en/\%0A.

[2] Costelloe C, Metcalfe C, Lovering A, Mant D, Hay AD. (2010). Effect of antibiotic prescribing in primary care on antimicrobial resistance in individual patients: Systematic review and meta-analysis. Vol. 340, BMJ (Online). p. 1120.

[3] Bbosa GS, Mwebaza N, Odda J, Kyegombe DB, Ntale M. (2014). Antibiotics/antibacterial drug use, their marketing and promotion during the postantibiotic golden age and their role in emergence of

\section{Conclusion}

Most bacteria isolated from health facilities in Kwara South were resistant to the access group. The resistance to watch a group of WHO antibiotics classification is building very fast. The empirical treatment should consider antibiotics with high sensitivity to local bacterial isolates. Stakeholders should support the development of antibiogram to guide prescriptions, prevent irrational use and improve the clinical outcome of patients. Additionally, there is a need for a more sophisticated study that will encapsulate the concerns highlighted above.

\section{Acknowledgements}

The author wishes to acknowledge the Heads of departments in the units in all the hospitals. I also wish to appreciate nurses and medical officers in the wards who allow us to collect data and medical laboratory scientists to collect the data on sensitivity and resistance tests.

\section{Conflict of Interest}

The Author declares that there is no conflict of interest.

bacterial resistance. Health (Irvine Calif); 06(05): 410-25.

[4] Ferreira RL, Da Silva BCM, Rezende GS, Nakamura-Silva R, Pitondo-Silva A, Campanini EB, et al. (2019). High prevalence of multidrug-resistant klebsiella pneumoniae harboring several virulence and $\beta$-lactamase encoding genes in a brazilian intensive care unit. Front Microbiol; 10 (JAN).

[5] Okeke IN, Aboderin OA, Byarugaba DK, Ojo KK, Opintan JA. (2007). Growing problem of multidrug-resistant enteric pathogens in Africa. Emerg Infect Dis.; 13(11):1640-6.

[6] Oluyege AO, Dada AC, Ojo AM, Oluwadare E. (2009). Antibiotic resistance profile of bacterial isolates from food sold on a university campus in south western Nigeria. Vol. 8, African Journal of Biotechnology. p. 5883-7.

[7] Egwuenu A, Obasanya J, Okeke I, Aboderin O, Olayinka A, Kwange D, et al. (2018). Antimicrobial 
use and resistance in Nigeria: situation analysis and recommendations, 2017. Pan African Med J Conf Proc;2.

[8] Onubogu U, Anochie I. (2014). Empiric antibiotic prescription among febrile under-five Children in the University of Port Harcourt Teaching Hospital, Rivers State, Nigeria. Vol. 41, Nigerian Journal of Paediatrics. p. 234.

[9] Das P, Horton R. (2016). Antibiotics: Achieving the balance between access and excess. Vol. 387, The Lancet. p. 102-4.

[10] Bebell LM, Muiru AN. (2014). Antibiotic use and emerging resistance: How can resource-limited countries turn the tide? Vol. 9, Global Heart. p. 34758.

[11] Al PAE. (2016). Antimicrobial Evaluation of Bacterial Isolates from Urine Specimen of Patients with Complaints of Urinary Tract Infections in Awka, Nigeria. Int J Microbiol; 9740273. Article ID 9740273, 6 pages http://dx.doi.org/10.115, (Article ID $9740273, \quad 6 \quad$ pages http://dx.doi.org/10.1155/2016/9740273).

[12] Ehinmidu JO. (2005). Antibiotics susceptibility patterns of urine bacterial isolates in Zaria, Nigeria. Trop J Pharm Res; 2(2):223-8.

[13] Udobi CE, Obajuluwa AF, Onaolapo JA. (2013).

Prevalence and antibiotic resistance pattern of methicillin-resistant staphylococcus aureus from an Orthopaedic hospital in Nigeria. Vol. 2013, BioMed Research International.

[14] Udo EE, Boswihi SS. (2017). Antibiotic Resistance Trends in Methicillin-Resistant Staphylococcus aureus Isolated in Kuwait Hospitals: 2011-2015. Med Princ Pract; 26(5):485-90.

[15] Nwankwo EO, Nasiru MS. (2011). Antibiotic sensitivity pattern of Staphylococcus aureus from clinical isolates in a tertiary health institution in Kano, Northwestern Nigeria. Pan Afr Med J.; 8:4.

[16] Okesola, A. O., \& Aroundegbe TI. (2011). Antibiotic resistance pattern of uropathogenic Escherichia coli in South West Nigeria. African J Med Med Sci.; 40(3):235-238.

[17]CN A. (2005). Antimicrobial susceptibility pattern of Klebsiella species from Ebonyi State University Teaching Hospital Abakaliki, Nigeria. Niger J Clin Pract; 8(2):90-93.

[18] Jacobs MR, Bajaksouzian S, Zilles A, Lin G, Pankuch GA, Appelbaum PC. (1999). Susceptibilities of Streptococcus pneumoniae and Haemophilus influenzae to 10 oral antimicrobial agents based on pharmacodynamic parameters: 1997 U.S. surveillance study. Antimicrob Agents Chemother; 43(8):1901-8. 


\title{
Evaluation of Health Risks of Improper Biomedical Waste Management among Health Workers in Selected Hospitals in Abuja, Nigeria
}

\author{
Edith C Okechukwu ${ }^{1 *}$, Azuka C Oparah ${ }^{2}$, Sunday O Aguora ${ }^{3}$,Jeffrey S Soni ${ }^{4}$ \\ ${ }^{1,3}$ School of Public Health, Texila American University, Georgetown, Guyana, South \\ America \\ ${ }^{2,4}$ Department of Pharmacy and Pharmacy Practice, Faculty of Pharmacy, University of \\ Benin, Benin City, Nigeria
}

\begin{abstract}
Improper biomedical wastes management could lead to health risks and environmental hazards. The study aimed to evaluate the health risks of improper biomedical wastes management among health workers. A descriptive cross-sectional study was conducted among 400 health workers across private and public hospitals in Abuja, Nigeria, using a self-developed and administered questionnaire. Analysis of the data involved descriptive and inferential statistics. The Nurses were the predominant respondents (28\%), and many respondents had bachelor's degree qualifications (86\%). The respondents agreed that health workers are exposed to several health risks following poor handling of biomedical wastes from the point of generation, transport, treatment, and disposal. The study revealed satisfactory practices of precautionary measures while experience, gender, and type of hospital were significantly associated with the transmission of blood-borne infections such as Human Immunodeficiency Virus (HIV) and Hepatitis B Virus $(H B V)$ through needle pricks and injuries from sharps $(p<0.0001)$. Gender and hospital type were significantly related to environmental pollution ( $p<0.0001)$, and work experience was significantly linked to water and foodborne infections such as cholera and typhoid ( $p<0.0003)$. Work experience and hospital type were significantly associated with the public health risks of improper biomedical wastes management $(p<0.0001)$. Training of health workers on appropriate safety procedures of biomedical waste management is essential to prevent occupational health hazards, achieve a safe working environment, and efficient health service delivery. Government and hospital management should enforce appropriate safety measures.
\end{abstract}

Keywords: Biomedical Wastes, Health Risks, Infections, Injuries, Occupational Health Hazards.

\section{Introduction}

In developing nations like Nigeria, biomedical waste issues have not been given merited attention because of the limited resources competing for several national needs $[1,2,3]$. As a result, governments and health institutions have neglected biomedical waste management. Moreover, the populace is unaware of the potential health risks and environmental pollution caused by poorly handled biomedical wastes [4].
Biomedical wastes have been characterized as infectious and hazardous [5] that harbour pathogens sufficient to transmit diseases on exposure to them [6]. A relatively small portion $10-25 \%[7,8]$ of the total waste stream generated is regarded as hazardous characterized as toxic, genotoxic, reactive, radioactive [9] to body cells, tissue, and systems, corrosive to skin, inflammable, explosive and shock sensitive [10]. Accident, carelessness, negligence, ignorance could lead to exposure to hazardous wastes with 
negative health impacts with different or same outcomes. Therefore, if biomedical wastes are not appropriately managed, they can be detrimental to workers, patients, waste handlers, and the community as they are predisposed to infections, toxic effects, injuries, and environmental pollution. Consequently, the segregation of biomedical wastes at the point of generation is pivotal to proper biomedical waste management $[11,12]$.

Some health risks associated with improper handling of biomedical wastes include gastroenteric, respiratory, skin infections [13], and nosocomial infections. Pathogenic viruses such as Human Immunodeficiency Virus (HIV) infection, Hepatitis B and C viruses [14] have been discovered to be associated with poor management of biomedical wastes due to pricks and injuries of sharps. Biomedical wastes usually contain heavy loads of pathogenic and antibiotic-resistant microorganisms, if not properly treated and disposed of, can spread the infection to persons and the immediate environment. Skin punctures, abrasions, and cuts from sharps, including exposure to chemical irritants [5], are health hazards encountered. It is estimated that about 5.2 million people, including 4 million children die as a result of wastes related diseases [15].

World Health Organization estimates that each year there are about 8-16 million infections (32\% of all new cases) of Hepatitis B virus (HBV), 2.3-4.7 million infections (40\% of all new cases) of Hepatitis $\mathrm{C}$ virus (HCV), and 80,000 to 160,000 infections of HIV (5\% of all new cases) due to injections with contaminated syringes and needles owing to improper biomedical waste management systems [16, 17].

Exposure to chemicals and radioactive wastes originating from radiotherapy, if not disposed of properly, can lead to death and severe radiation burns [18]. Also, health risks are associated with improperly treated and disposed pharmaceutical wastes such as leftovers/expired medicines and vaccines from homes and hospitals [18, 19]. Attenuated live microbes from expired vaccines could infect waste handlers rather than cause immunity; long exposure to pharmaceuticals from the environment can harm pregnant women and children [20]. Pharmaceutical wastes have been found to contaminate surface water, drinking water, and cause acute and chronic health issues together with reproductive and cell damage [21, 22].

Often health risks and environmental hazards are associated with the release of toxic fumes like dioxins and heavy metals from disposal methods such as burning and incineration of biomedical wastes. These fumes are carcinogenic, with mutagens capable of producing adverse effects in humans even at low doses $[23,24]$.

The impact of health risks caused by poor management cannot be over-stressed. Health workers (e.g., doctors, nurses, sanitary staff, maintenance personnel) are not the only ones affected. Even out-patients, caregivers, visitors, support services staff (laundry), wastes handling and transportation services, workers in waste disposal facilities, and the public are all high-risk groups $[6,18,12]$. Occupational health hazards among health care workers increase morbidity, mortality, and socioeconomic loss.

Accordingly, identifying health risks associated with improper biomedical wastes management is important to create awareness about occupational health hazards, formulate occupational health safety policies and waste management policies. Therefore, it is imperative to ensure proper hygiene and sanitation in the health institutions and the safety of workers and environs [2]. These biomedical wastes require proper treatment to minimize direct exposure and harm to humans and the environment [25].

This study seeks to evaluate the health risks of improper biomedical wastes management among health workers and determine the association (if any) with gender, work experience, type of hospital, and membership in waste management teams across the public and private hospitals surveyed. 


\section{Methods}

\section{Study Area}

The study took place in Abuja, Nigeria. According to United Nations Fund for Population Activities, UNFPA, [26] Federal Capital Territory is estimated to have a population of 3,324,000 people. Abuja consists of six Area Councils, of which Abuja Municipal Area Council is a densely populated area as the seat of government and the public services. The city harbour many private and public (district) hospitals to serve the sprawling population.

\section{Sample Size Determination}

The researcher used Cochran's formula for calculating sample size for an infinite population [27].

$$
\left(n_{0=Z^{2} p q / e^{2}}\right)
$$

\section{Where:}

$$
\begin{aligned}
& \mathrm{n}_{0}=\text { sample size } \\
& \mathrm{z}=\mathrm{a} \text { selected critical value of } \\
& \text { desired confidence level } \\
& \mathrm{p}=\text { represents estimated proportion } \\
& \text { of an attribute present in the } \\
& \text { study population } \\
& q=1-p \\
& \mathrm{e}=\text { represents the desired level of } \\
& \text { precision taking } 95 \% \\
& \text { confidence level with } \pm 5 \% \\
& \text { precision } \\
& p=0.5 ; \text { hence } q=1-0.5=0.5 ; e=0.05 ; z=1.96 \\
& \left(n_{0=Z^{2} p q / e^{2}}\right) \\
& \mathrm{n}_{0}=(1.96)^{2}(0.5)(0.5) /(0.05)^{2} \\
& \mathrm{n}_{0}=384.16
\end{aligned}
$$

An overage of $12 \%$ was added to the minimum sample size (384) to offset nonresponse, incomplete response, and late response in order to have the acceptable minimum response size for the study.

\section{Sampling Technique}

Six (6) hospitals were randomly selected for the study, such that each hospital had a fair chance of being selected. The hospitals were stratified into two groups, private and public, based on the ownership and management system. The hospitals were lettered alphabetically to ensure anonymity/confidentiality.

\section{Data Collection}

Structured self-administered and selfcompleted questionnaires were used to collect data. The study and the questionnaire were explained to the individual participants, and their consent to participate in the study was obtained. Participation was voluntary, and participants were free to withdraw at any time during the study. Confidentiality was assured by excluding all the names of the hospitals and respondents.

\section{Data Analysis}

Structured self-administered and selfcompleted questionnaires were administered to participants to collect data for the study. The questionnaires retrieved from the respondents were verified for completeness, accuracy, and consistency. Usable questionnaires were numbered serially and coded. All items were responded to on a Likert scale of 1-5 (5-point scale), where $5=$ strongly agree and $1=$ strongly disagree for positive items and reverse score so that the opposite is true (i.e., $1=$ strongly agree and $5=$ strongly disagree) for negative questions [28]. The ordinal data were converted to interval data (numerical data) and subjected to statistical analysis. Statistical Package for Social Sciences (SPSS Version 20.0) was used for inferential analysis.

\section{Results and Discussion}

The study showed that the respondents were medical staff that included doctors, nurses, pharmacists, medical laboratory scientists, and other healthcare professionals. However, the predominant respondents were nurses $(29.0 \%)$. This finding is consistent with the previous studies [29, 30, 31, 32] that nurses counted as the majority of the respondents. The greater proportion of the respondents were bachelor's degree holders $(86 \%)$, and the finding is in conformity with the report of an earlier study [29]. The majority of the respondents work with 
public hospitals, and this finding is similar to the result of previous work [33], and about half of the respondents were members of the biomedical waste management team.

The study revealed that the respondents are aware of the potential health risks, environmental hazards, and public health issues associated with improper biomedical wastes management in the hospitals. This finding is similar to the work conducted in Ondo, Osun, and Uganda respectively [30, 12, 29, 34]. The health workers may have received training that improved their knowledge and produced satisfactory practices towards biomedical waste management [35, 36] and use of job aids [29].

Human Immunodeficiency Virus (HIV), Hepatitis B Virus (HBV), Hepatitis C Virus (HCV) infections, chemical irritation, Tetanus, and physical injury are health risks that health workers encounter as a result of needle pricks, injuries from sharps, spills of chemicals and negligence of safety measures. These health risks are consistent with previous reports $[12,18$, 29, 37, 38].

The years of working experience significantly impacted the health risks domain of the proliferation of rodents, parasites, and vectors. The respondents with 1 to 5 years of working experience believed that rodents, parasites, and vectors are health risks associated with improper biomedical management. Regardless of gender, hospital type, and participation in the waste management team, health workers may have encountered this hazard within their few years of working in the hospital. This finding agrees with the report [33] that vector-borne disease is a health risk encountered by health workers.

The gender, years of working experience, and hospital type had an effect on the health risks domain of transmission of typhoid and cholera, while membership of the biomedical wastes management team did not affect the apparent transmission of typhoid and cholera. The result showed that male health workers with more than 15 years of working experience in public hospitals believed that the transmission of typhoid and cholera are health risks associated with improper biomedical wastes management. Typhoid and cholera are classified as health hazards that could occur due to the long exposure of health workers to contaminated food, water, and poor hygienic practices in the working environment [34].

The gender, years of experience, and type of hospital had an effect on the risk domain of hepatitis and HIV through injuries from sharps and needle pricks contaminated with human blood, while membership of the hospital waste management team did not. The result showed that male health workers with more than 15 years of experience in public hospitals believed that hepatitis and HIV through injuries from sharps and needle pricks contaminated with human blood are health risks associated with improper biomedical wastes management. This finding is consistent with the previous reports [14, 29, 39] that health workers are at high risks of bloodborne infections. Health workers are unavoidably exposed to poorly managed sharps and needle pricks [33, 30]. Hepatitis B Virus (HBV) infection was among the early occupational health hazards that affected health workers, and its incidence rate was 386 cases per 100,000 populations which implies higher risk [40].

The health risk domain of environmental pollution and the unpleasant smell was affected by gender, type of hospital, and membership of the hospital waste management team, while years of experience did not. The result showed that male health workers in public hospitals that are not members of the waste management team believed that environmental pollution and unpleasant smell are among health risks of improper biomedical wastes management. This finding agrees with the reports from previous studies conducted in Tanzania, and Nigeria [3, $24,41]$ that improper treatment and disposal practices of biomedical wastes can cause environmental pollution. The male workers, irrespective of years of working experience, may be at higher risk as they are typically involved in 
the handling of biomedical wastes, especially the treatment and disposal procedures.

Working experience, type of hospital, and membership of waste management team had an effect on the domain of public health risks while gender did not. The result showed that health workers with over 15 years of experience in public hospitals that are not members of the waste management team believed that public health risks are associated with improper biomedical waste management.

Both male and female health workers who have worked over the years, especially in public hospitals, would have experienced either biological or non-biological risks. Notably, hospital-acquired infections (nosocomial infections) and blood-borne infections have increased the incidence of hospital stay and morbidity among the general population [3]. The study showed that the respondents were highly aware of the safety and precautionary measures. The respondents agreed that training on proper biomedical waste management was important and agreed to using personal protective equipment (PPE). The finding agrees with the reports of previous work $[29,34]$ that health workers were trained, aware of the safety and precautionary measures, and exhibited satisfactory practices in order to forestall occupational health risks.

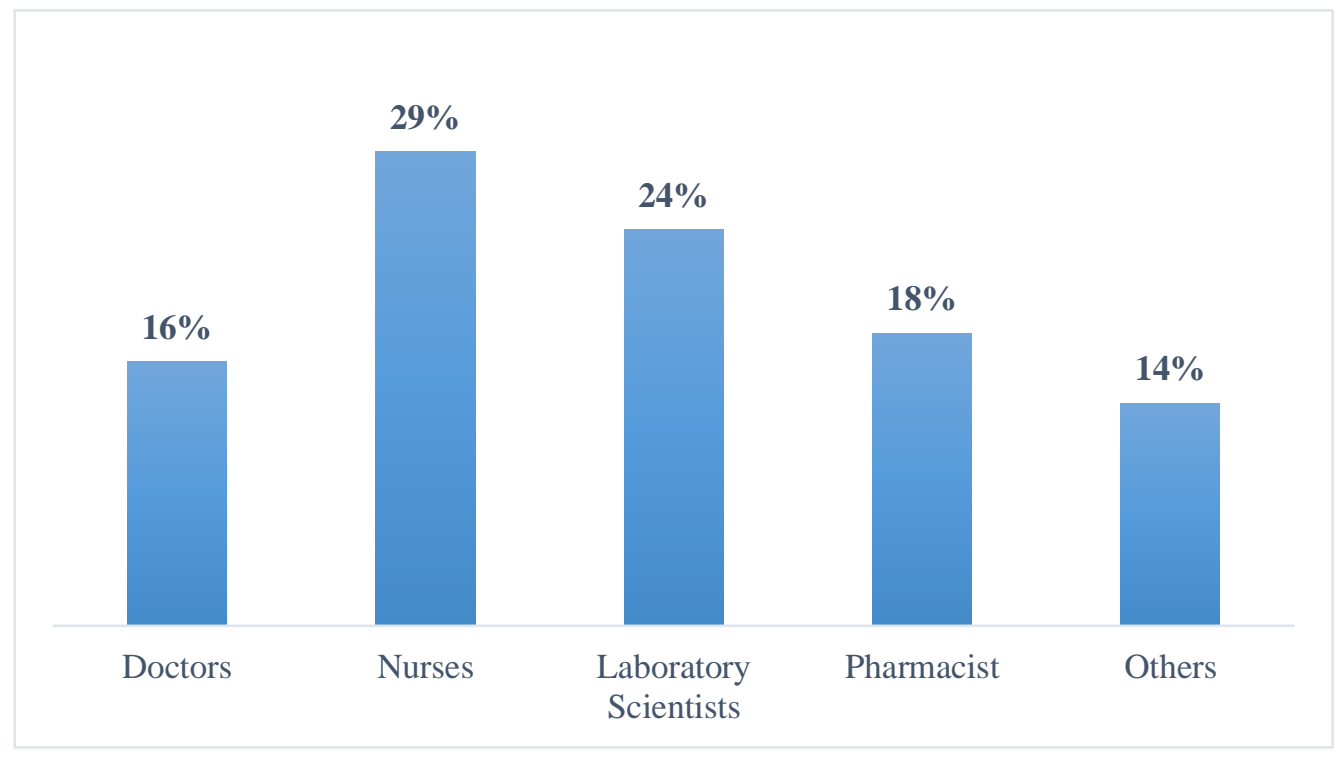

Figure 1. Job Category/ Profession of Respondents ( $N=400)$

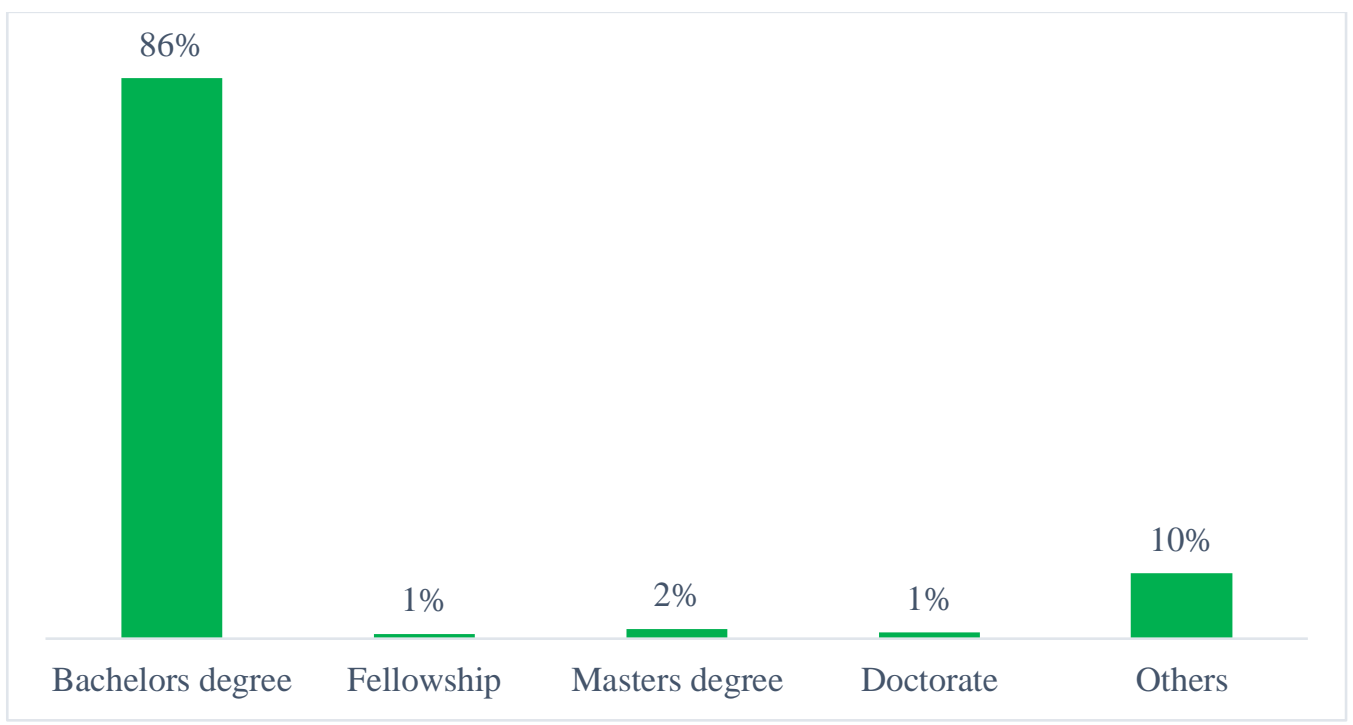

Figure 2. Highest Educational Qualification of Respondents ( $N=400)$ 


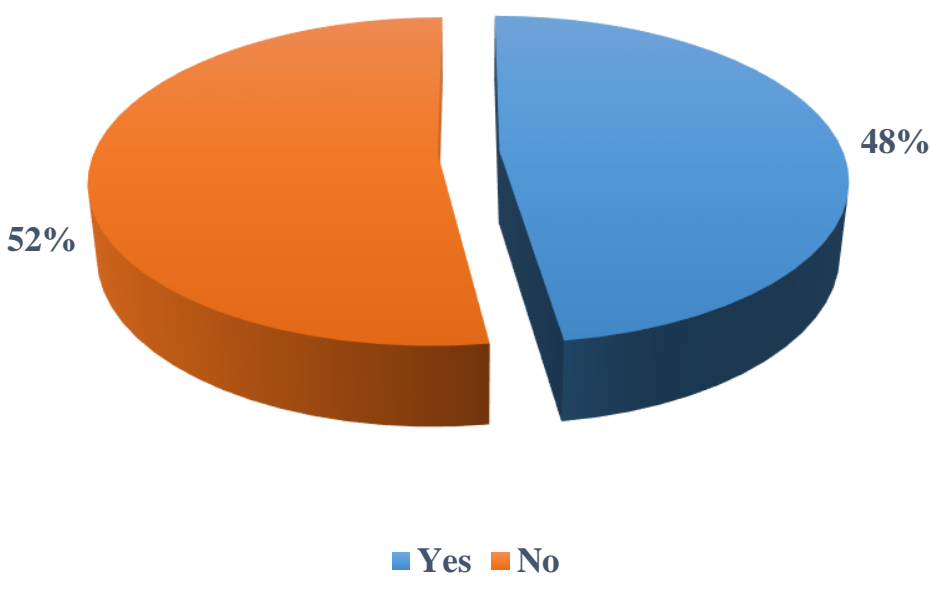

Figure 3. Membership of Biomedical Waste Management Team (N=400)

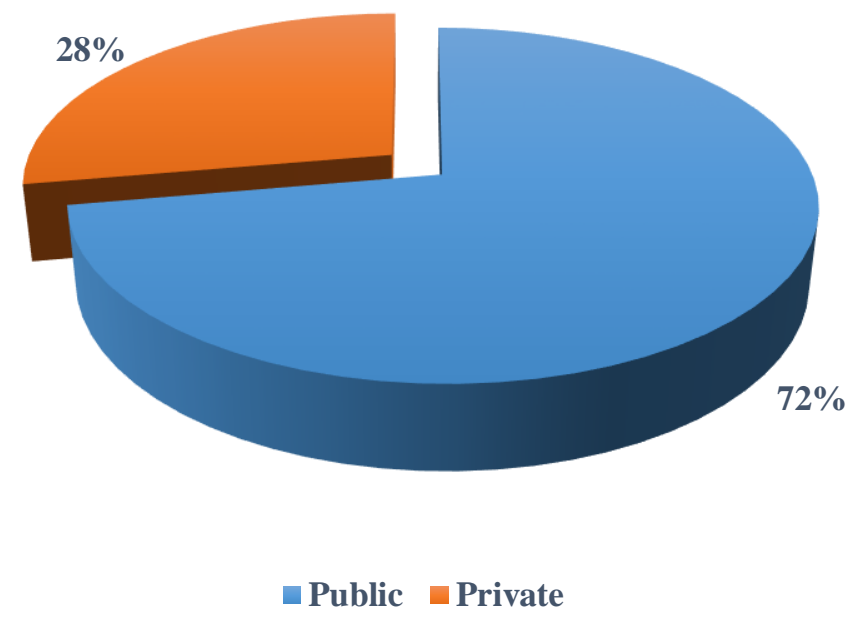

Figure 4. Types of Hospital where Respondents are Working ( $N=400)$

Table1. Health Risks of Improper Biochemical Wastes Management (N=400)

\begin{tabular}{|l|l|}
\hline Items & Positive Responses \\
\cline { 2 - 2 } & Frequency N (\%) \\
\hline Growth and multiplication of vectors like insects, rodents and parasites & $392(98.0)$ \\
\hline Transmission of diseases like typhoid, cholera & $350(87.5)$ \\
\hline $\begin{array}{l}\text { Hepatitis and AIDS through injuries from syringes and needles } \\
\text { contaminated with human blood }\end{array}$ & $392(98.0)$ \\
\hline Environmental pollution and unpleasant odour & $386(96.5)$ \\
\hline Public health risk & $370(92.5)$ \\
\hline
\end{tabular}

Positive responses $=$ Agree/ Strongly Agree 
Table 2. Effect of Socio-Demographic Characteristics on Health Risks of Improper Biomedical Wastes Management (N=400)

\begin{tabular}{|c|c|c|c|c|c|c|c|c|c|c|c|}
\hline Items & & \multicolumn{2}{|c|}{ Gender } & \multicolumn{4}{|c|}{ Years of Experience } & \multicolumn{2}{|c|}{ Hospital Setting } & \multicolumn{2}{|c|}{$\begin{array}{l}\text { Membership of Biomedical } \\
\text { Waste Management Team }\end{array}$} \\
\hline \multirow{4}{*}{$\begin{array}{l}\text { Growth and } \\
\text { multiplication of vectors } \\
\text { like insects, rodents, and } \\
\text { parasites }\end{array}$} & & female & male & $1-5$ & 6-10 & $11-15$ & 16\&above & Public & Private & Non-member & Member \\
\hline & No & 13 & 13 & 13 & 40 & 67 & 72 & 143 & 55 & 51 & 45 \\
\hline & Yes & 167 & 207 & 80 & 41 & 27 & 60 & 146 & 56 & 158 & 146 \\
\hline & $\mathrm{P}$-value & \multicolumn{2}{|l|}{0.4143} & \multicolumn{4}{|c|}{$<0.0001$} & \multicolumn{2}{|l|}{$=1.000$} & \multicolumn{2}{|l|}{0.4752} \\
\hline \multirow{3}{*}{$\begin{array}{l}\text { Transmission of diseases } \\
\text { like typhoid, cholera }\end{array}$} & No & 13 & 13 & 13 & 27 & 26 & 14 & 41 & 52 & 39 & 40 \\
\hline & Yes & 167 & 207 & 80 & 54 & 68 & 118 & 248 & 59 & 170 & 151 \\
\hline & P-value & \multicolumn{2}{|c|}{$<0.0001$} & \multicolumn{4}{|c|}{0.0003} & \multicolumn{2}{|c|}{$<0.0001$} & \multicolumn{2}{|l|}{0.4508} \\
\hline \multirow{3}{*}{$\begin{array}{l}\text { Hepatitis and AIDS } \\
\text { through injuries from } \\
\text { syringes and needles } \\
\text { contaminated with } \\
\text { human blood }\end{array}$} & No & 34 & 14 & 13 & 27 & 26 & 14 & 27 & 52 & 62 & 54 \\
\hline & Yes & 146 & 206 & 80 & 54 & 68 & 119 & 267 & 59 & 147 & 137 \\
\hline & $\mathrm{P}$-value & \multicolumn{2}{|c|}{$<0.0001$} & \multicolumn{4}{|c|}{$<0.0001$} & \multicolumn{2}{|c|}{$<0.0001$} & \multicolumn{2}{|l|}{0.6630} \\
\hline \multirow{3}{*}{$\begin{array}{l}\text { Environmental pollution } \\
\text { and unpleasant smell }\end{array}$} & No & 26 & 15 & 27 & 27 & 26 & 28 & $69 \backslash$ & 52 & 53 & 45 \\
\hline & Yes & 154 & 205 & 66 & 54 & 68 & 91 & 220 & 59 & 156 & 146 \\
\hline & $\mathrm{P}$-value & \multicolumn{2}{|c|}{$<0.0001$} & \multicolumn{4}{|c|}{0.4733} & \multicolumn{2}{|c|}{$<0.0001$} & \multicolumn{2}{|l|}{0.0003} \\
\hline \multirow[t]{3}{*}{ Public health risk } & No & 13 & 14 & 13 & 41 & 26 & 13 & 41 & 52 & 48 & 45 \\
\hline & Yes & 167 & 206 & 80 & 40 & 68 & 119 & 248 & 59 & 161 & 146 \\
\hline & $\mathrm{P}$-value & \multicolumn{2}{|l|}{0.6880} & \multicolumn{4}{|c|}{$<0.0001$} & \multicolumn{2}{|l|}{0.0001} & \multicolumn{2}{|l|}{0.0003} \\
\hline
\end{tabular}




\section{Conclusion}

The study has revealed that health workers are aware of the health risks of improper biomedical wastes management and the precautionary measures. The health risks of improper biomedical wastes management affect male health workers in public hospitals with long years of working experience than others. Thus, indicating that the male health workers are more involved in the handling of biomedical wastes, making them vulnerable to infections and other health hazards.

\section{Recommendations}

Health managers and health policymakers should organize training and workshops for health workers on safety measures and the

\section{References}

[1] Diaz, L.F., Eggerth, L.L., Enkhtsetse, S.H. and Savage G.M. (2008) Characteristics of healthcare. Waste. Management Research vol 28:1219-26.

[2] Patwary MA, Harare TW, Sarker MH. (2011) Assessment of occupational and environmental safety associated with medical waste disposal in developing countries. A qualitative approach. Saf Science; 49:89.

[3] Kuchibanda, K. and Mayo, A.W. (2015) Public Health Risks from Mismanagement of Healthcare Wastes in Shinyanga Municipality Health Facilities, Tanzania. Scientific World Journal vol 2015 pp 1-11. [4] Awodele, O., Adewoye, A. A and Oparah, A. C. (2016) Assessment of medical waste management in seven hospitals in Lagos, Nigeria. BioMedical Central Public Health (16)-269 pp 1-11.

[5] Wahab, A.B.and Adesanya, D.A. (2011). Medical Waste Generation in Hospitals and Associated Factors in Ibadan Metropolis, Nigeria. Research Journal of Applied Sciences, Engineering, and Technology 3(8):746-751.

[6] Ngwuluka N, Ochekpe N, Odumosu P, John SA (2009). Waste Management in health care establishment within Jos metropolis, Nigeria. African consequences of improper biomedical wastes management. Hospital management should ensure an adequate supply of personal protective equipment and enforce their use. The vaccination, use of personal protective equipment, and practicing universal precautionary measures is crucial in health risks prevention and control.

\section{Acknowledgments}

The authors are thankful to the study participants who provided important information that enabled the successful completion of this study.

\section{Conflicts of Interest}

The authors declare that no conflicts of interest exist.

Journal of Environmental Science and Technology 3(12):459-465.

[7] World Health Organization (WHO), (2005) Management of Solid Healthcare Waste at Primary Healthcare Centre-A Decision-Making Guide, World Health Organization (WHO), Geneva, Switzerland, 2005, http://www.who.int/water sanitation health/ publications/manhcwm.pdf.

[8] Dinesh, M.S. Geetha, K.S., Vaishmavi, V., Kale, R.D. and Krishna-Murthy, V. (2010) "Eco-friendly treatment of biomedical wastes using epigeic earthworms," Journal of Indian Society of Hospital Waste Management, vol. 9, no. 1, pp. 5-20, 2010.

[9] World Health Organization (2000) Hazardous Wastes from Health Care Facilities. WHO, Rome, Italy.

[10]Pruss, A., Giroult, E. and P. Rushbrook, P. (1999) Safe Management of Wastes from Health care Activities, Handbook, World Health Organisation, Geneva, Switzerland, 1999.

[11] WHO (2011). Healthcare waste management: Healthcare waste needs sound management, including alternatives to incineration.

[12] Afolabi O. T., Aluko O. O., Afolabi B. K. and Fehintola F. O. (2018) Healthcare waste management practices and risk perception of healthcare workers in private healthcare facilities in an urban community in 
Nigeria. African Journal of Environmental Science and Technology 12 (9) 305-311.

[13]Rao H.P. (2008) "Report: Hospital waste management- awareness and practices: a study of three states in India". Waste Management \& Research, Vol.26, pp297-303.

[14] Goniewicz, M., Włoszczak-Szubzda, A. Niemcewicz, M. Witt, M. Marciniak-Niemcewicz, A. and Jarosz, M.J. (2012) "Injuries caused by sharp instruments among healthcare workersinternational and Polish perspectives," Annals of Agricultural and Environmental Medicine, 19 (3) pp. 523-527, 2012.

[15]Akter, N. "Medical Waste Management: A Review." Asian Institute of Technology y, 2000.Thailand.

[16] World Health Organization (2012) "Safe health care-waste management policy paper. Available at www.healthcarewaste.org. Accessed 20th March 2012.

[17] World Health Organization (2015) Safe management of wastes from healthcare activities $\left(2^{\text {nd }}\right.$ edition). Geneva, Switzerland: WHO Press, pp 102, 136-138 and 181-190.

[18] Babanyara, Y. Y., Ibrahim D. B., Garba T., Bogoro A. G., Abubakar, M. Y. (2013) Poor Medical Waste Management (MWM) Practices and Its Risks to Human Health and the Environment: A Literature Review. International Journal of Health and Medical Engineering 7(11) pp 780-787.

[19]Denloye, A.A., Ojuromi, O.T., Ochei, K. and Ade-Serrano, E.A. (2018) Bio safety Knowledge, Waste Disposal Practices and Identification of Parasites in Biomedical Wastes from Healthcare Establishments in Lagos and Abuja, Nigeria. Biomedical journal of scientific and Technical Research 5(4) pp 4759-64.

[20] Radhakrishna, L., Nagarajan, P., Vijayanandhan, S. S., \& Ponniah, T. (2014). Knowledge, Attitude, and practice (KAP) towards disposal of medicines: A qualitative study among health care professionals in South India. Wild J Pharm Res, 3, 1955-63.

[21] Alam, M.Z., Islam, M.S. \& Islam, M.R. (2013). Medical Waste Management: A Case Study on Rajshahi City Corporation in Bangladesh. Journal of
Environmental Science and Natural Resources., 6(1), 173-178.

[22] Patneedi, C. B., Prasadu, D., Sharma, R. S. K., Sekhar, D. C., \& Rao, D. V. (2015). Microwave Mediated Synthesis in pharmaceutical Chemistry.

[23] Saad, S.A. (2013). Management of hospitals solid waste in Khartoum state. Environmental Monitoring Assessment 185(10) pp 8567-8582.

[24] Gambo, J., Ahmed, G., Hadiza, Z. H., Idris, M.A., Babura, B.S. and Yusuf A.Y. (2018) Assessing the Impacts of Improper Medical Waste Disposal and Residents Perception of their Disposal Practices in Hadejia Metropolis, Jigawa State, Nigeria. Nigerian Research Journal of Chemical Sciences vol 4 pp 2637.

[25] Rahman, H.A. (2013) "Incineration in Malaysia: really needs?" International Journal of Chemical, Environmental and Biological Sciences, vol 1(4) pp. 678-681.

[26] United Nations Fund for Population Activities (2015) UNFPA in FCT, Abuja.

[27] Glenn, I. D. (1992) Sampling the Evidence of Extension Program Impact. Program Evaluation and Organizational Development, IFAS, University of Florida. PEOD-5. October pp 1-5.

[28] Sullivan G.M. and Artino A.R. (2013) Journal of Graduate Medical Education. Pp 541-542.

[29]Aluko, O.O. Adebayo, A.E., Adebisi, T.F., Ewegbemi,M.K. Abidoye, A.T. and Popoola, B.F. (2016) Knowledge, attitudes and perceptions of occupational hazards and safety practices in Nigerian healthcare workers. Bio Medical Central Research Notes 9 (71) pp 1-14.

[30] Osungbemiro, B.W. Adejumo O.A., Akinbodewa, A.A. and Adelosoye, A.A. (2016) Assessment of Occupational Health Safety and Hazard among Government Health Workers in Ondo City, Southwest Nigeria. British Journal of Medicine \& Medical Research 13(8): 1-8.

[31] Sheshi, I. M., Agbana, EB. (2018) Prevalence of Occupational Diseases and Practice of Safety Control Measures Among Health Workers of General Hospital Minna. Working and Living Environmental Protection 15(2) pp 147 - 165

[32] Mugabi, B. Hattingh, S. Chima, S. C. (2018) Assessing Knowledge, Attitudes, and Practices of 
Healthcare Workers Regarding Medical Waste Management at a Tertiary Hospital in Botswana: A Cross-Sectional Quantitative Study. Nigerian Journal of Clinical Practice 21(12) pp 1627-37.

[33] Ndejjo, R. Musinguzi, G. Yu, X., Buregyeya, E. Musoke, D. Wang, J.S., Halage, A.A., Whalen, C. Bazeyo, W., Williams, P. and Ssempebwa, J. (2015) Occupational Health Hazards among Healthcare Workers in Kampala, Uganda. Journal of Environmental and Public Health.

[34] Wafula, S.T. Julian Musiime, J., and Oporia, F. (2019) Health care waste management among health workers and associated factors in primary health care facilities in Kampala City, Uganda: a cross-sectional study. Bio Medical Central Public Health 19 (203) pp $1-10$.

[35] Kumar, R., Somrongthong, R., and Shaikh, B.T. (2015) Effectiveness of intensive healthcare waste management training model among health professionals at teaching hospitals of Pakistan: a quasi-experimental study. Biomedical Central Health Services Research 15:81.

[36] Al-Khatib IA. (2014) Problems of management of medical, solid waste at primary health care centres in the Palestinian territory and their remedial measures. East Mediterrean Health Journal 19(Suppl 3): S152-8.

[37] Manyele, S.V., Ngonyani, H.A.M., Eliakimu, E. (2008). The status of occupational safety among health service providers in hospitals in Tanzania. Tanzania Journal of Health Research 10(3):159-165. [38] Amosun AM, Degun AM, Atulomah NOS, Olanrewaju MF, Aderibigbe KA. Level of knowledge regarding occupational hazards among nurses in Abeokuta, Ogun State, Nigeria. Curr Res J Biol Sci. 2011;3(6):586-90.

[39] Rodriguez-Morales A.J. (2013) Current topics in public health. Rijeka: InTech.

[40]Allen, O.T., Nwaogazie, I.L. and Douglas, K. (2019) Analyses and Assessment of Health Care Workers (HCWs) towards Occupational Hygiene $(\mathrm{OH})$ and Infection Control (IC) Practices in Selected Tertiary Healthcare Facilities within Parts of Niger Delta, Nigeria. Asian Journal of Research in Nursing and Health 2(2): 1-14.

[41] Saraf Y, Shinde M, and Tiwari SC. Study of awareness status about hospital waste management among personnel and quantification. Indian Journal Community Medicine 2006;31(2):111. 


\title{
Review and Critical Evaluation of Cognitive Behavioural Therapy for the Treatment of Post-Traumatic Stress Disorder
}

\author{
Gina Marie Piane ${ }^{1}$, Precious Chidozie Azubuike ${ }^{2 *}$ \\ ${ }^{1}$ Department of Community Health, College of Professional Studies, National University, San \\ Diego, California \\ ${ }^{2}$ Department of Reproductive Health Sciences, Institute of Life and Earth Sciences, Pan \\ African University, Ibadan, Nigeria
}

\begin{abstract}
This systematic analysis seeks to describe the evidence regarding cognitive-behavioral therapy (CBT) for the treatment of post-traumatic stress disorder (PTSD) in the recent, published, professional literature. This systematic review addressed the question of the efficacy of and evidence for CBT for the treatment of PTSD. The review incorporates a comprehensive literature review, addresses the methodological quality of the papers, and synthesizes the results by themes. After evaluation of the published and professional literature, five themes; Result of CBT for PTSD, Alternatives to CBT for PTSD, CBT in practice, Treatment of children, and CBT in tandem with medication. 11 published studies including qualitative interviews, randomized control trials, and meta-analyses were examined. CBT proved to be instrumental in alleviating PTSD symptoms in men who have been exposed to combat trauma, women who have experienced violence, veterans who have gone through combat trauma and also have disorders due to addictions, and young adults and children who have experienced trauma. Studies have shown that CBT works quite well in the case of couples where one has been diagnosed with PTSD. CBT for PTSD can be delivered face-to-face or by using telepsychiatry. CBT tends to have a higher success rate when carried out while administering appropriate drugs. Also, carrying out CBT for PTSD can bring about stronger relationships and posttraumatic stress growth.
\end{abstract}

Keywords: Cognitive Behavioral Therapy, Post-Traumatic Stress Disorder, Treatment.

\section{Introduction}

Formerly grouped under anxiety disorder alongside generalized anxiety, phobia, and panic, Post-Traumatic Stress Disorder (PTSD) has in recent times been classified as Stressor and Trauma-Related Disorders since it is associated with traumatic events [1]. To be diagnosed with PTSD, "a person must have experienced, witnessed, or been confronted with an event so traumatizing that it results in symptoms or re-experiencing, hyperarousal, cognitive alterations or avoidance" [1].

Cognitive Behavioral Therapy (CBT), originated by Dr. Aaron T. Beck in the 1960s, has often been employed to treat PostTraumatic Stress Disorder (PTSD) [1]. CBT seeks to annul the undesirable, abnormal thoughts resulting from the trauma in order to enhance adaptation to cognition and behaviors [2]. This systematic analysis demonstrates the approval of CBT for PTSD in the recent, published, professional literature. According to [3], the traumatic events that lead to PTSD include violent personal assaults, natural or human-caused disasters, accidents, combat, and other forms of violence. Although PTSD stands at a figure of just $3.6 \%$ per year and $6.8 \%$ over the lifetime, about half of the adults of the world population have experienced it. The 
prevalence is higher among females and people aged 45-59 years. Variants of a gene, FKBP5, can predispose an individual to PTSD [1]. Also, early childhood trauma or abuse can also play a part in making one susceptible to PTSD [1].

Psychological therapies for PTSD include psychodynamic treatment, CBT, counselling, and family-based therapy. CBT has been found to be particularly effective [2]. There have been analysis of PTSD treatments, and conclusions have been drawn that successful treatment includes five components; addressing safety, calming, efforts to support self and collective efficacy, fostering connectedness, and instilling hope [1]. Treatment for PTSD has been described as psychotherapy, medications, or both [3]. The psychotherapy described includes CBT, particularly the components of exposure therapy and cognitive restructuring.

\section{Aim/Purpose}

This systematic analysis serves as proof that cognitive-behavioral therapy (CBT) is effective in the treatment of PTSD. This systematic review answered the questions being asked concerning the potency and evidence of CBT in the treatment of PTSD. The review incorporates a thorough literature review, gives the methodological rating of the papers, and produces the outcomes by themes.

\section{Review Question}

Does the published professional literature support the potency of CBT for PTSD?

\section{Materials and Methods}

This systematic review cleared the doubts about the treatment of PTSD using CBT. It entailed a comprehensive search of the literature, stated the methodological quality of the papers, and produced the results by themes. In March 2019, an examination of the professional published articles in CINAHL, Health Source, Medline in EBSCO, ProQuest Health, Medical Complete, and the Cochrane Collaboration was carried out. 'Cognitive Behavioral Therapy for PTSD' and 'Cognitive
Behavioral Therapy for PTSD Cochrane' were searched for on the databases. Journal articles published between 2002 and 2019 were included in the search, which also was restricted to articles published in English. Given the fact that this is a systematic review of the published literature, approval by the National University Institutional Review Board was not warranted.

\section{Results}

Five themes emerged from the analyzed, published, professional literature, and the articles were sorted accordingly; Results of CBT for PTSD, Alternatives to CBT for PTSD, CBT in practice, Treatment of children, and CBT together with medication.

\section{Outcomes of CBT}

A randomized control trial that comprised of 150 women diagnosed with PTSD and symptoms of depression was conducted by [4]. From their tests, they discovered that CBT for women who were at risk for Intimate Partner Violence (IPV) could break what they refer to as the 'vicious cycle of abuse'. Their manualbased treatment included detailed written accounts, daily readings of these accounts, and helping the clients identify cognitive distortions and to promote balanced thinking. The treatment group was at lower risk for subsequent IPV than the controls. They posit that CBT may lower the risk by increasing positive outcomes such as accurate perceptions of situations and increased safety behaviors.

In the descriptive case studies produced by [5], there is preliminary evidence that CBT enhanced by the inclusion of significant others (SOs) can be a promising approach for veterans with both PTSD and alcohol use disorders. The sample was drawn from those who served in Operation Enduring Freedom (OEF) and Operation Iraqi Freedom (OIF). The intervention entailed psychoeducation about PTSD, alcohol misuse, the signs of PTSD that lead to social stigmatisation and emotional 
numbing, and also the need for social support. The SOs were included to offer support consistent with the veteran's treatment goals. Some examples included helping the veteran to avoid alcohol use, practicing new coping skills, engaging in alternative activities, communication skills, and problem-solving.

In 2012, A Study added to the numerous proofs regarding partner inclusion in the remedy of PTSD [6]. Their randomized control trial, which drew clients from a Veteran's Affairs (VA) hospital and a university research center, offered a 15-session cognitivebehavioral therapy for couples with one partner who was diagnosed with PTSD. They labeled this intervention as disorder-specific couple therapy' and found significant improvement in PTSD symptom severity in the intervention as compared to the wait-list. The cognitivebehavioral couple treatment began with psychoeducation regarding PTSD and its effect on constituents of the relationship. It went ahead to the evaluation of avoidance of feelings and enhanced communication. In time the couple was guided to approach rather than avoid specific people, places, situations, and emotions that have been evaded as a couple because of PTSD. In the final phase of treatment, the couples were guided to challenge their cognitions and strong tenets that maintain PTSD, specifically, trust, control, emotional closeness, and physical intimacy.

Further analyses of the same randomized control trial with couples were conducted [7] and [8]. The 2014 analysis found that the partners too benefitted from the couple therapy. Those who presented with clinical levels of distress at pre-treatment benefitted significantly, as shown by improvements in psychological functioning [7]. In the 2016 analysis, the investigators took a very different approach in measuring post-traumatic growth and not the traditional approach of measuring distress decrease. The measurement of posttraumatic growth involved perceptions about relations to others, perceptions of new possibilities, personal strength, spiritual change, and appreciation of life [8]. They discovered that CBT Couple Therapy for PTSD not only diminished symptoms and misery but also brought about a significant increase in posttraumatic growth.

Benitez and colleagues focused their investigation on the efficacy of CBT for PTSD in reducing somatization [9]. Using the Clinician Global Impression of Change Scale, which addresses headaches, fatigue, shortness of breath, nausea, and musculoskeletal symptoms, they measured the extent of somatization. Their research demonstrated that CBT was acceptable and feasible for their Latino clients. In addition, the effect size, preand post-treatment, was higher for the reduction of somatic symptoms than for the reduction of PTSD severity.

It is estimated that more than half of individuals with PTSD experience disturbed sleep. Some speculate that insomnia may be caused by nightmares associated with fear and arousal conditioning. [10] examined the persistence of insomnia after CBT for PTSD. They discovered that even when the nightmares and hypervigilance that come with PTSD cease, insomnia continued in $48 \%$ of their client's post-treatment. Added to this, if the initial trauma was sleep-related, the clients faired worse. This may imply that a specialized intervention for insomnia post-CBT for PTSD is needed.

\section{Alternative Treatments}

Another option to CBT for PTSD that has been used for approximately 20 years is an approach known as psychological debriefing or Critical Incident Stress Debriefing. These techniques, which use a single session, originated in the military unit's post-combat to maintain group morale and to reduce psychiatric distress among soldiers. The National Institute of Mental Health performed a meta-analysis for the Cochrane Collaboration of 15 RCTs measuring how effective debriefing 
sessions are [11]. They concluded that just one session debriefing for an individual is not a supported technique and hence, is not a feasible alternative to CBT for PTSD.

Another alternative to CBT for PTSD is Eye Movement Desensitization and Reprocessing (EMDR), which the World Health Organization (WHO) has determined to be among the best therapies for PTSD. EMDR is effective in combatting undesirable feelings, arousal, despondency, and agitation [12]. In a metaanalysis of 14 RCTs of EMDR for PTSD, Khan and colleagues came to realize that the participants who were administered EMDR experienced reduced symptoms of PTSD significantly more than those treated with CBT. This difference, however, was not evident at the 3-month follow-up. They conclude that more robust clinical trials of EMDR are warranted, seeing that it is likely to be a superior treatment for PTSD.

\section{CBT in Practice}

CBT for PTSD may be administered in the traditional manner, face-to-face, or employing teleconferencing technology. To determine if either means had more fidelity with the manualized CBT, [13] in 2013 performed a confirmatory analysis from an RCT where some clients were treated using telepsychiatry while others were counseling face-to-face in a single room. Their results indicate that the therapists in either setting adhered to the manual and were equally competent in delivering CBT [13].

\section{Treatment of Children}

PTSD is common among children and adolescents who have experienced trauma. In a Cochrane collaboration, the credibility of psychological therapies for treating PTSD in young adults and children was the subject of a meta-analysis. After realizing the outcomes of 14 RCTs, they concluded that psychotherapies for young adults and children with PTSD are effective [2]. However, they did not find CBT to be superior to any other psychological treatment method such as exposure-based therapy, psychodynamic therapy, narrative therapy, supportive counselling, family-based therapy, and eye movement desensitization and reprocessing [2].

\section{CBT Combined with Medication}

A Study [14] reported on an RCT that compared treatments of CBT with sertraline and CBT with pill placebo. They measured a significantly greater improvement in PTSD symptoms in the CBT combined with the medication group. This improvement persisted at the 6-month follow-up, indicating a longterm decrease in symptoms.

\section{Discussion}

The evidence regarding the effectiveness of CBT for PTSD is robust. There is consistency among the meta-analyses, randomized clinical trials, qualitative interviews, and case studies. Experiencing traumatic events is very rampant, and approximately 12.6 million individuals in the United States are diagnosed with PTSD each year. The prevalence is higher among females and people ages 45-59 years. The samples contained genders, age groups, minorities, and international samples, and many individuals across different sectors benefitted from the therapy. Women have a few times higher danger of suffering post-traumatic stress disorder (PTSD) contrasted with men, and few components are included clarifying this distinction [15]. Both psychosocial and organic clarifications (for example, oxytocin related) have been proposed in different articles. Nonetheless, a requirement for genderand sex-sensitive examination and announcing still exists. [12] had uncovered that the lifetime predominance of PTSD is around $10-12 \%$ in ladies and 5-6\% in men. There are comparative contrasts between the genders for (comorbid) issues, for instance, significant depression and nervousness issues. PTSD subcluster scores have been discovered to be expanded in ladies, 
for instance, for re-encountering and anxiousness [16]. People experience various kinds of trauma, both in private life and at work (for example, cops) [17], with ladies being exposed to high impact trauma (for example, sexual trauma) than men are, at a much younger age. Injury from the get-go in life has more effect, particularly when it includes type II injury meddling with the neurobiological turn of events and character. [18] adds that traumatic stress influences various spaces of the cerebrums of young men and young ladies at various ages.

CBT for PTSD was also shown to be effective with children, adolescents, and female victims of intimate partner violence (IVP). Therapy for teenagers or children who have gone through trauma or abuse may be especially crucial since these experiences in childhood predispose the child to PTSD later in life. Treatment of ladies who experienced IPV also has a preventive component in that those treated with CBT are not likely to experience PTSD later on in life. CBT for PTSD not only treats the present trauma and symptoms but has benefits throughout the client's lifespan. Studies have discovered that CBT assists with diminishing self-announced PTSD seriousness and related nervousness and that members do not consult experts for a PTSD conclusion at follow-up evaluations, showing supported improvement [19]. Curiously, it has been reported that $\mathrm{CBT}$ affects the physiological boundaries associated with PTSD, recommending improvement. Numerous examinations have investigated these zones and detailed a more prominent abatement of pulse reactivity and significant increase of systolic circulatory strain reaction to orthostasis after CBT in PTSD patients [18]. CBT has likewise been proven to be the frighten reaction in PTSD. A huge decrease in electromyographic reactivity to all upgrades was seen, either CBT or steady treatment, either CBT or supportive therapy, compared with wait-list controls [18]. Given this, alarm reactions are suggested as a
PTSD treatment result list [18]. Also, neuropsychological working in people with PTSD have been taken into consideration. Nonresponders to treatment had altogether less fortunate execution on proportions of verbal memory contrasted and responders and further showed account encoding shortages. Verbal memory deficiencies appear to lessen the adequacy of CBT and ought to be considered in its execution.

Among the psychological therapies for PTSD, CBT has been reported to be very effectual. The components of CBT that were taken note of in the research articles varied from study to study. However, the most occurring were: psychoeducation, cognitive restructuring, exposure, communication, anger management, relaxation, and coping skills. Upon the mentioning of the CBT duration, the clients were treated with 10-15 sessions. PTSD also includes five therapeutic components; addressing safety, calming, efforts to support self and collective efficacy, fostering connectedness, and instilling hope.

\section{Limitations of the Review}

This detailed report of the literature is limited by publication bias. Reports in any language other than English were restricted. The date range of published literature to be included was 2002-2019. Therefore, research previously published and currently under review was not included and may represent incongruent conclusions. Publication bias may manifest itself in the absence of publication of research that shows no major discrepancies among treatment groups.

\section{Conclusion}

It has been shown that CBT is quite potent in abating PTSD symptoms in women who have undergone brutality or coercion, men who have passed combat trauma, veterans who have had a taste of combat trauma and have substance use problems, and children and adolescents who have gone through trauma. Studies have shown 
that CBT is quite efficacious with couples where one is diagnosed with PTSD. CBT for PTSD can be administered face-to-face or via telepsychiatry. It may be more promising when combined with medication. In addition, CBT for PTSD can bring about relationship enhancement and post-traumatic growth. CBT is currently the preferred treatment method for therapists treating clients with PTSD.

\section{Conflict of interest(s)}

The authors declare no conflict of interest.

Table 1. Summary of Articles included in the Analysis

\begin{tabular}{|c|c|c|c|}
\hline Author, Title & Theme & Methods & Summary \\
\hline $\begin{array}{l}\text { Iverson, K. M., Gradus, J. L., Resick, } \\
\text { P. A., Suvak, M. K., Smith, K. F., \& } \\
\text { Monson, C. M. (2011). Cognitive-- } \\
\text { behavioral therapy for PTSD and } \\
\text { depression symptoms reduces risk for } \\
\text { future intimate partner violence } \\
\text { among interpersonal trauma survivors. }\end{array}$ & $\begin{array}{l}\text { Outcomes } \\
\text { of CBT }\end{array}$ & $\begin{array}{l}\text { Randomized } \\
\text { Control Trial } \\
(\mathrm{n}=150 \text { women })\end{array}$ & $\begin{array}{l}\text { Decrease in PTSD } \\
\text { symptoms in the course of } \\
\text { treatment were related with } \\
\text { a reduction of Intimate } \\
\text { Partner Violence } \\
\text { victimization. }\end{array}$ \\
\hline $\begin{array}{l}\text { Mcdevitt-Murphy, M., Roberts, M., } \\
\text { Barnett, J., \& Sherman, M. (2011). } \\
\text { Significant Other Enhanced } \\
\text { Cognitive-Behavioral Therapy for } \\
\text { PTSD and Alcohol Misuse in } \\
\text { OEF/OIF Veterans. }\end{array}$ & $\begin{array}{l}\text { Outcomes } \\
\text { of CBT }\end{array}$ & $\begin{array}{l}\text { Descriptive } \\
\text { Case-Studies } \\
(n=2 \text { men })\end{array}$ & $\begin{array}{l}\text { Preliminary findings show } \\
\text { that integrative treatments } \\
\text { for treating OEF/OIF } \\
\text { veterans with co-occurring } \\
\text { PTSD and alcohol misuse. }\end{array}$ \\
\hline $\begin{array}{l}\text { Monson CM, Fredman SJ, Macdonald } \\
\text { A, Pukay-Martin ND, Resick PA, } \\
\text { Schnurr PP. Effect of Cognitive- } \\
\text { Behavioral Couple Therapy for PTSD: } \\
\text { A Randomized Controlled Trial. }\end{array}$ & $\begin{array}{l}\text { Outcomes } \\
\text { of CBT }\end{array}$ & $\begin{array}{l}\text { Randomized } \\
\text { Control Trial } \\
(\mathrm{n}=40 \text { couples }) *\end{array}$ & $\begin{array}{l}\text { Couples with one partner } \\
\text { diagnosed with PTSD } \\
\text { decreased PTSD symptoms } \\
\text { after disorder-specific } \\
\text { couple therapy. }\end{array}$ \\
\hline $\begin{array}{l}\text { Pérez Benítez, C., Zlotnick, C., } \\
\text { Gomez, J., Rendón, M., \& Swanson, } \\
\text { A. (2013). Cognitive behavioral } \\
\text { therapy for PTSD and somatization: } \\
\text { an open trial. }\end{array}$ & $\begin{array}{l}\text { Outcomes } \\
\text { of CBT }\end{array}$ & $\begin{array}{l}\text { Pre and post } \\
\text { evaluation of a } \\
\text { therapeutic } \\
\text { intervention } \\
(\mathrm{n}=7 \text { women, } 1 \\
\text { man) }\end{array}$ & $\begin{array}{l}\text { Adapted cognitive } \\
\text { behavioral therapy and } \\
\text { abridged somatization } \\
\text { resulted in a small to } \\
\text { moderate reduction in } \\
\text { PTSD severity, and a } \\
\text { moderate to large reduction } \\
\text { of depressive symptoms } \\
\text { and physical functioning. }\end{array}$ \\
\hline $\begin{array}{l}\text { Shnaider, P., Pukay, M. N. D., } \\
\text { Fredman, S. J., Macdonald, A., \& } \\
\text { Monson, C. M. (2014). Effects of } \\
\text { Cognitive-Behavioral Conjoint } \\
\text { Therapy for PTSD on Partners' } \\
\text { Psychological Functioning. }\end{array}$ & $\begin{array}{l}\text { Outcomes } \\
\text { of CBT }\end{array}$ & $\begin{array}{l}\text { Randomized } \\
\text { Control Trial } \\
(\mathrm{n}=40 \text { couples }) \\
*\end{array}$ & $\begin{array}{l}\text { Partners of individual with } \\
\text { PTSD may benefit from } \\
\text { couple treatment for PTSD } \\
\text { and relationship } \\
\text { enhancement. }\end{array}$ \\
\hline $\begin{array}{l}\text { Wagner, A., Torbit, L., Jenzer, T., } \\
\text { Landy, M., Pukay-Martin, N., } \\
\text { Macdonald, A., .. Monson, C. } \\
\text { (2016). The Role of Posttraumatic }\end{array}$ & $\begin{array}{l}\text { Outcomes } \\
\text { of CBT }\end{array}$ & $\begin{array}{l}\text { Randomized } \\
\text { Control Trial } \\
(\mathrm{n}=40 \text { couples }) *\end{array}$ & $\begin{array}{l}\text { Individuals who received } \\
\text { treatment had a significant } \\
\text { increase in Post-Traumatic } \\
\text { Growth. }\end{array}$ \\
\hline
\end{tabular}




\begin{tabular}{|c|c|c|c|}
\hline $\begin{array}{l}\text { Growth in a Randomized Controlled } \\
\text { Trial of Cognitive-Behavioral } \\
\text { Conjoint Therapy for PTSD. }\end{array}$ & & & \\
\hline $\begin{array}{l}\text { Zayfert, C., \&Deviva, J. (2004). } \\
\text { Residual insomnia following } \\
\text { cognitive behavioral therapy for } \\
\text { PTSD. }\end{array}$ & $\begin{array}{l}\text { Outcomes } \\
\text { of CBT }\end{array}$ & $\begin{array}{l}\text { Pre and post } \\
\text { evaluation of a } \\
\text { therapeutic } \\
\text { intervention } \\
(\mathrm{n}=24 \text { women, } 3 \\
\text { men) }\end{array}$ & $\begin{array}{l}\text { CBT for PTSD did not } \\
\text { result in reduction in } \\
\text { insomnia. }\end{array}$ \\
\hline $\begin{array}{l}\text { Rose SC, Bisson J, Churchill R, } \\
\text { Wessely S. Psychological debriefing } \\
\text { for preventing post-traumatic stress } \\
\text { disorder (PTSD). }\end{array}$ & $\begin{array}{l}\text { Alternate } \\
\text { treatments }\end{array}$ & $\begin{array}{l}\text { Meta-Analysis } \\
\text { of Randomized } \\
\text { Control Trials } \\
(15 \text { trials; } n=396 \\
\text { women and } \\
\text { men }) \\
\end{array}$ & $\begin{array}{l}\text { The routine use of single } \\
\text { session debriefing for } \\
\text { trauma victims is not } \\
\text { supported. }\end{array}$ \\
\hline $\begin{array}{l}\text { Khan, A. M., Dar, S., Ahmed, R., } \\
\text { Ramya, B., Mahwish, A., \&Kotapati, } \\
\text { V. P. (2018). Cognitive behavioral } \\
\text { therapy versus eye movement } \\
\text { desensitization and reprocessing in } \\
\text { patients with post-traumatic stress } \\
\text { disorder: Systematic review and meta- } \\
\text { analysis of randomized clinical trials. }\end{array}$ & $\begin{array}{l}\text { Alternate } \\
\text { treatments }\end{array}$ & $\begin{array}{l}\text { Systematic } \\
\text { Review and } \\
\text { Meta-Analysis } \\
\text { of Randomized } \\
\text { Control Trials } \\
\text { (14 trials; } \mathrm{n}=389 \\
\text { women, } 286 \\
\text { men) }\end{array}$ & $\begin{array}{l}\text { Eye Movement } \\
\text { Desensitization and } \\
\text { Reprocessing was more } \\
\text { effective than CBT in } \\
\text { reducing PTSD symptoms. }\end{array}$ \\
\hline $\begin{array}{l}\text { Frueh, B. C., Monnier, J., Grubaugh, } \\
\text { A. L., Elhai, J. D., Yim, E., \& Knapp, } \\
\text { R. (2007). Therapist Adherence and } \\
\text { Competence with Manualized } \\
\text { Cognitive-Behavioral Therapy for } \\
\text { PTSD Delivered via } \\
\text { Videoconferencing Technology. }\end{array}$ & $\begin{array}{l}\mathrm{CBT} \text { in } \\
\text { practice }\end{array}$ & $\begin{array}{l}\text { Secondary } \\
\text { Analysis of a } \\
\text { Randomized } \\
\text { Control Trial } \\
\text { (n=38 men) }\end{array}$ & $\begin{array}{l}\text { CBT can effectively and } \\
\text { competently be delivered } \\
\text { by means of telepsychiatry. }\end{array}$ \\
\hline $\begin{array}{l}\text { Gillies D, Taylor F, Gray C, O'Brien } \\
\text { L, D'Abrew N. Psychological } \\
\text { therapies for the treatment of post- } \\
\text { traumatic stress disorder in children } \\
\text { and adolescents. }\end{array}$ & $\begin{array}{l}\text { Treatment } \\
\text { of children }\end{array}$ & $\begin{array}{l}\text { Meta-Analysis } \\
\text { of Randomized } \\
\text { Control Trials } \\
\text { ( } 60 \text { trials; } n= \\
758 \text { adults, } \\
1,155 \text { children) } \\
\end{array}$ & $\begin{array}{l}\text { Fair evidence for the } \\
\text { effectiveness of } \\
\text { psychological therapies, } \\
\text { particularly CBT. }\end{array}$ \\
\hline $\begin{array}{l}\text { Hien, D., Levin, F., Ruglass, L., \& } \\
\text { Lopez-Castro, T. (2015). Enhancing } \\
\text { the effects of cognitive behavioral } \\
\text { therapy for PTSD and alcohol use } \\
\text { disorders with antidepressant } \\
\text { medication: A randomized clinical } \\
\text { trial. }\end{array}$ & $\begin{array}{l}\text { CBT } \\
\text { combined } \\
\text { with } \\
\text { medication }\end{array}$ & $\begin{array}{l}\text { Qualitative } \\
\text { Interviews } \\
\text { (n=69 adults) }\end{array}$ & $\begin{array}{l}\text { Participants treated with } \\
\text { 'Seeking Safety' (SS) and } \\
\text { sertraline have greater } \\
\text { improvement than those } \\
\text { treated with SS alone or } \\
\text { placebo. }\end{array}$ \\
\hline
\end{tabular}

*Same trial, various analyses 


\section{Authors Contribution}

Dr. Piane conceptualized the analysis and developed the themes to be included as well as the majority of the writing. Mr. Azubuike contributed to the conceptualization and writing, and editing.

\section{Bio of Authors}

Dr. GinaMarie Piane, Ph.D., is a Professor of Community Mental Health at the Department of Community Health, College of Professional

\section{References}

[1] Broderick, P.C.\& Blewitt, P. (2015). The Life Span: Human Development for Helping Professionals ( $4^{\text {th }}$ ed.) Pearson, Upper Saddle River, New Jersey.

[2] Charak R., Armour C., Elklit A., Angmo D., Elhai J. D., \& Koot H. M. (2014). Factor structure of PTSD, and relation with gender in trauma survivors from India. European Journal of $\begin{array}{lll}\text { Psychotraumatology, } & 5, & 1 .\end{array}$ doi:10.3402/ejpt.v5.25547.

[3] Foa, E.B., Zoellner, L.A. \&Feeny, N. C. (2006). An evaluation of three brief programs for facilitating recovery after an assault. J Trauma Stress, 19(1), 29-43.

[4] Frueh, B. C., Monnier, J., Grubaugh, A. L., Elhai, J. D., Yim, E., \& Knapp, R. (2007). Therapist Adherence and Competence with Manualized Cognitive-Behavioral Therapy for PTSD Delivered via Videoconferencing Technology. Behavior Modification, 31(6), 856-866. https://doi.org/10.1177/0145445507302125.

[5] Gillies D, Taylor F, Gray C, O'Brien L, D'Abrew N. Psychological therapies for the treatment of post-traumatic stress disorder in children and adolescents. Cochrane Database of Systematic Reviews 2012, Issue 12. Art. No.: CD006726. DOI: 10.1002/14651858.CD006726.pub2.

[6] Hien, D., Levin, F., Ruglass, L., \& Lopez-Castro, T. (2015). Enhancing the effects of Cognitivebehavioral therapy for PTSD and alcohol use
Studies, National University, San Diego, California.

Precious Chidozie Azubuike, $\mathrm{BScPH}$, is a Research Assistant and Master of Health Sciences student at the Pan African University of Earth and Life Sciences, Ibadan, Nigeria.

\section{Acknowledgment/Sponsorship}

This was a self-sponsored research/review, and there are no conflicts of interest between the authors.

disorders with antidepressant medication: A randomized clinical trial. Drug and Alcohol Dependence, 146, e142-e142.

[7] Iverson, K. M., Gradus, J. L., Resick, P. A., Suvak, M. K., Smith, K. F., \& Monson, C. M. (2011). Cognitive-behavioral therapy for PTSD and depression symptoms reduces risk for future intimate partner violence among interpersonal trauma survivors. Journal of Consulting and Clinical Psychology, 79(2), 193-202. https://doiorg.nuls.idm.oclc.org/10.1037/a0022512.

[8] Khan, A. M., Dar, S., Ahmed, R., Ramya, B., Mahwish, A., \&Kotapati, V. P. (2018). Cognitive-behavioral therapy versus eye movement desensitization and reprocessing in patients with post-traumatic stress disorder: Systematic review and meta-analysis of randomized clinical trials. Cureus, 10(9) doi: http://dx.doi.org.nuls.idm.oclc.org/10.7759/cureus.3250.

[9] Mcdevitt-Murphy, M., Roberts, M., Barnett, J., \& Sherman, M. (2011). Significant Other Enhanced Cognitive-Behavioral Therapy for PTSD and Alcohol Misuse in OEF/OIF Veterans. Professional Psychology: Research and Practice, 42(1), 40-46. https://doi.org/10.1037/a0022346.

[10]Monson CM, Fredman SJ, Macdonald A, Pukay-Martin ND, Resick PA, Schnurr PP. Effect of Cognitive-Behavioral Couple Therapy for PTSD: A Randomized Controlled Trial. JAMA. 2012;308(7):700-709. doi:10.1001/jama.2012.9307.

[11]National Institute for Mental Health (2019). Post-Traumatic Stress Disorder. Accessed at: 
https://www.nimh.nih.gov/health/statistics/posttraumatic-stress-disorder-ptsd.shtml Accessed on March 27, 2019.

[12] Olff M. (2016). Five years of European Journal of Psychotraumatology. European Journal of Psychotraumatology, $\quad 7, \quad 31350$. doi:10.3402/ejpt.v7.31350.

[13]Pérez Benítez, C., Zlotnick, C., Gomez, J., Rendón, M., \& Swanson, A. (2013). Cognitivebehavioral therapy for PTSD and somatization: an open trial. Behaviour Research and Therapy, 51(6), 284-289. https://doi.org/10.1016/j.brat.2013.02.005. [14] Prochaska, J.O., Norcross, J.C. (2018). Systems of Psychotherapy ( $9^{\text {th }}$ Ed.) New York, NY: Oxford University Press.

[15]Christiansen, D.M., Hansen, M. and Elklit, A. (2014) Correlates of Coping Styles in an Adolescent Trauma Sample. Journal of Child \& Adolescent Trauma, 7, 75-85.

[16]Rose SC, Bisson J, Churchill R, Wessely S. Psychological debriefing for preventing posttraumatic stress disorder (PTSD). Cochrane Database of Systematic Reviews 2002, Issue 2. Art. No.: CD000560.

DOI: 10.1002/14651858.CD000560.
[17] Shnaider, P., Pukay, M. N. D., Fredman, S. J., Macdonald, A., \& Monson, C. M. (2014). Effects of Cognitive-Behavioral Conjoint Therapy for PTSD on Partners' Psychological Functioning. Journal of Traumatic Stress, 27(2), 129-136. https://doiorg.nuls.idm.oclc.org/10.1002/jts.21893.

[18] van der Meer C. A. I., Bakker A., Smit A. S., van Buschbach S., den Dekker M., Westerveld G. J., Olff M. (2017). Gender and age differences in trauma and PTSD among Dutch treatment-seeking police officers. Journal of Nervous \& Mental Disease, 205(2), 87-2. doi:10.1097/NMD.0000000000000562.

[19] Wagner, A., Torbit, L., Jenzer, T., Landy, M., Pukay-Martin, N., Macdonald, A., Monson, C. (2016). The Role of Posttraumatic Growth in a Randomized Controlled Trial of CognitiveBehavioral Conjoint Therapy for PTSD. Journal of Traumatic Stress, 29(4), 379-383. https://doi.org/10.1002/jts.22122.

[20]Zayfert, C., \&Deviva, J. (2004). Residual insomnia following cognitive behavioral therapy for PTSD. Journal of Traumatic Stress, 17(1), 69-73. https://doi.org/10.1023/B:JOTS.0000014679.31799. e7. 


\title{
Knowledge, Perception, and Practice of DMPA-SC/Self-Injectable Contraceptive among Women: Findings from Mixed-Method Study in South-West and North-Central, Nigeria
}

\author{
Kehinde Osinowo ${ }^{1,2^{*}}$, Sambo-Donga Fintirimam ${ }^{1}$, Oluwaseun Ojomo ${ }^{1}$, Oladapo Ladipo ${ }^{1}$, \\ Peculiar Ojo $^{3}$, Tolulope Majiyagbe ${ }^{6}$, Esther Ishaya ${ }^{4}$, Landry Sagbo ${ }^{5}$ \\ ${ }^{1}$ Association for Reproductive and Family Health, Abuja Trade and Convention Center, \\ Behind Abuja Chamber of Commerce and Industry, Airport Road, Lugbe, Abuja-Nigeria \\ ${ }^{2}$ Department of Public Health, Texila American University, Guyana \\ ${ }^{3}$ Association for Reproductive and Family Health, RASuDiN project, Plateau State \\ ${ }^{4}$ Association for Reproductive and Family Health, RASuDiN project, Niger State \\ ${ }^{5}$ Association for Reproductive and Family Health, RASuDiN project, Lagos State \\ ${ }^{6}$ Association for Reproductive and Family Health, RASuDiN project, Oyo State
}

\begin{abstract}
Depot-Medroxyl-Progesterone-Acetate-Subcutaneous/Self Injection (DMPA-SC/SI) is an intentional approach used by the Nigerian government to improve the coverage rate of contraceptives method-mix. In this study, the knowledge, practice, and determinants of use of DMPA-SC/SI among women in NorthCentral and South-West, Nigeria, was assessed. A cross-sectional health facility study was conducted across four Nigerian states. Structured pretested questionnaires were used to elicit information from 844 women within reproductive age. Twenty focused group discussions and 40 In-depth interviews (IDIs). Descriptive statistics were used to analyze the characteristics of the women. Multivariate logistic regression was used to examine the determinants of the current use of DMPA-SC /SI. Statistical analyses were set at 5\%. Recorded voices were transcribed in full and analyzed using literary methods. About $89.5 \%$ of respondents reported ever heard family planning; $97.6 \%$ reported heard DMPA-SC; 83.2\% reported ever use family planning; $95.7 \%$ reported current use of family planning; $94.3 \%$ reported ever use DMPA-SC, and 46.5\% reported ever use DMPA-SC/SI. The reason for the use of DMPA-SC/SI was because it was easy to use, effective and self-administered. The factors that discourage women from using DMPA-SC/SI were mainly fears associated with side effects, for and fear of SI-self-injury. The logistic regression results showed that those residing in a rural part of the country were less likely to use DMPA-SC/SI. The government should scale up this model nationally, including rural and hard-to-reach communities with public awareness programmes, public sensitization, and refresher training to improve on Provider's counselling skills.
\end{abstract}

Keywords: Knowledge, Practice, Self-injectable contraceptive.

\section{Introduction}

Family planning and contraception can have a significant impact on avoiding unintended pregnancies, ensuring adequate birth spacing, improving maternal and child health indicators, and empowering women to improve their own and their families' health $[1,2]$.
Despite the established benefits of contraception, new information suggests that by the end of 2019, over 190 million women of reproductive age in the world had not used any form of contraception and that unintended pregnancy accounted for almost 45 percent of all conceptions $[1,3,4]$. 
Recently, there has been a noticeable increase in global funding and an emphasis on boosting contraceptive use [2]. The global contraceptive prevalence rate increased from 55 percent to 64 percent during the Millennium Development Goals (MDGs) period (1990-2015) [5]. However, not all parts of the world improved at the same rate.

For example, whereas the prevalence of contraception has increased dramatically in other parts of the world, Sub-Saharan Africa has lagged behind [1]. Contraception use has increased in Sub-Saharan Africa, although at a glacial pace. According to evidence, the contraceptive prevalence rate for SSA was barely 18.4 percent in 2015 [6]. Furthermore, contraception in SSA is higher among urbanbased households and those in resource-rich communities $[7,8]$.

Nigeria is one of the countries where all forms the contraceptive prevalence rate has minimally increased from 15.1 percent in 2013 to 16.6 percent in 2018, falling short of the government aim of 27 percent by 2020 [9]. However, as in other SSA nations, there is a difference in the use of modern contraception depending on where you live and the dichotomy between rural and Urban area. According to the National Demographic and Health Survey (2018), the prevalence of contraception in urban and rural Nigeria is 26.3 percent and 10.0 percent, respectively. In addition, the prevalence rate of injectable contraception was found to be 4.5 percent in the urban area and 2.5 percent in the rural area. Furthermore, the high contraceptive prevalence rate was recorded for South-West Nigeria (35.1\%) and lowest for North-West $(6.7 \%)$ [9].

When compared to South Asia (52\%) and East Asia (78\%) regions with high population density, Sub-Saharan Africa, particularly Nigeria, has high fertility rates and the lowest contraceptive prevalence rate in the world, with an average modern contraceptive prevalence rate (mCPR) of 30 percent and Nigeria at 12 percent [10]. Nigeria's population has been steadily increasing over the last decade, while the mCPR has remained stable [11]. The contraceptive prevalence rate (CPR) among currently married women aged 15 to 49 is 17 percent. The majority of currently married women who use contraception choose a modern method (12\%), whereas 5\% use a traditional method. The Federal Government of Nigeria, through the $\mathrm{FMoH}$, has set a target of 27 percent modern contraception prevalence by 2020 .

The government has established a national guidelines and training manuals for the introduction and scale-up of DMPA-SC selfinjection, among other things, to achieve this goal. Self-injection of DMPA-SC is an intentional strategy of the Nigerian government's national family planning goals to address the unmet need for contraception, and it has the potential to be a game-changer in terms of increasing and scaling up DMPA-SC. DMPASC/SI has been demonstrated to improve contraceptive prevalence rates in studies, although there is a gap in the predictors of method uptake and continuance across selfinjecting and provider-administered customers in Nigeria [12-14]. This study explored the knowledge, practice, and determinants of selfinjectable contraceptives among reproductiveage women in South West and North-Central Nigeria.

\section{Materials and Methods}

\section{Study Settings}

The study is conducted among women in South-West and North-Central Nigeria. Both political regions account for one-third of the population of women within the reproductive ages in Nigeria [15].

North-Central has six states (Niger, Kogi, Benue, Plateau, Nasarawa, and Kwara), including the Federal Capital Territory (FCT), and South-West has six states which are Ekiti state, Ondo states, Lagos state, Osun states, Ogun states, and the Oyo States. While the population of South West was put at 32.5 million 
people, that of North-Central is put at 45 million people.

\section{Study Design}

We conducted a descriptive cross-sectional health facility study among 844 women within reproductive age who registered for Family planning Clinics in four Nigerian States. The study population services is all the women within the reproductive age group who registered for Family planning Clinics in the selected health facilities at the time of the study.

\section{Sample Size Calculation}

Assuming a $50 \%$ health facility delivery in study area due to lack of reliable information, a z-score value of 1.96 for $95 \%$ confidence interval (CI), an error margin of 0.05 , a nonresponse rate of $10 \%$ a, a minimum sample size of 844 was worked out using the Cochrane's [16] formula for a single proportion.

\section{Sampling Procedure}

A multi-stage sampling procedure was used in selecting respondents for the study. In stage 1, we purposively selected two geopolitical zones, which are north-central and southwest. In stage 2 , a simple random sampling technique was used to select two states in each of the geopolitical zones.

In north-central, we selected Niger and Plateau States, while in the northwest, we selected Oyo and Lagos States. In stage 3, we obtained the lists of all the LGAs in each of the selected States, out of which $50 \%$ of the LGAs were selected, ensuring an equitable percentage of half-drawn from urban and a half from rural. In stage 4, simple random sampling was used to select 10 Primary Healthcare Centres in each of the LGA. In the final stage, respondents were selected from the health facility register. Reliability of the instrument was determined by pretesting of the instrument in another LGA among Women of reproductive age with similar demographic characteristics of the main Study site. After the Pretest the data was subjected to
Cronbach Alpha test to determine the reliability coefficient which gave a value of 0.5 .

\section{Inclusion/Exclusion Criteria}

The eligibility criteria include women within the reproductive ages that are 15-49 years, who were sexually active and mentally stable. We considered only women who were currently residing in the communities.

\section{Research Instrument}

Three research instruments were used for the study, and they are focused group discussion (FGDs); In-depth Interviews (IID), and a structured questionnaire. The questionnaire was self-structured and was administered in the English language. The questionnaire elicited information on women's socioeconomic characteristics; husband's socio-demographic data; women's reproductive characteristics; awareness, knowledge, and practice of family planning, experience with self-injected DMPA$\mathrm{SC}$, reasons for the use of self-injection, barriers to use of self-injection, negative influence to using DMPA-SC, what factors influence the use of DMPA-SC, what prompted women to take their last DMPA-SC, perception of quality of information given on DMPA-SC and description of the respondent experience of service delivery on DMPA-SC attitude of healthcare workers to respondent. The questionnaire was pretested by administering it to 20 women in a health centre that was not included in the study. The questionnaire was administered through face-toface interviews with respondents. However, where face-to-face contacts were not possible, mobile phones were used for data collection. The questionnaire was administered using an open data kit (ODK) in which the questionnaire called form was scripted into a computer and uploaded into a server. The completed forms were saved on the tablet and later uploaded into the server. The uploaded data were ready for error checking. A total of 20 FGDs were held among women of reproductive age in the four states. Each of the FGDs lasted between 45 minutes and 
an hour, and an end was put to each of the discussions when no further issue was raised. Each of the discussion featured between 10 and 12 participants who share similar socioeconomic characteristics. The number of participants were small enough to allow cordial conversation but large enough to allow divergent views [17].

The FGDs were held in Pidgin English and was recorded after permission was sought from participants.

Also, a total of 40 IDIs (10 per state) were conducted among family planning providers. IDIs lasted between 45 minutes and an hour. They were one-on-one interviews conducted with identified stakeholders and persons relevant to the focus of the research. Well-detailed FGDs and IDIs guides were used in conducting the interviews. The guides were structured to promote uniformity in the discussions. Some of the issues discussed in the FGDs and KIIs were the perception of women on DMPA-SC, the perception of the community on DMPA-SC, family planning practice, place of the utilization of DMPA-SC, motivation to use DMPA-SC, who decides about the number of children, factors that encourage the use of DMPA-SC; internal and external triggers to use DMPA-SC and factors that influence the ability to demand for DMPA-SC and availability of the products in the health facilities. Both FGDs and IDIs were audiotaped using NVIVO 12.0. In addition to the recording, a research assistant took notes using a template.

\section{Data Collection Procedure}

Trained field research assistants were used in collecting the data. Five research assistants, which comprised 3 community resource persons and 2 other persons with B.Sc. Degrees in health-related disciplines were recruited for data collection.

Research assistants were given training on the following areas: an overview of family planning, explanation of the study goals and objectives, study locations-urban and rural LGAs, study data collection, and ethics in the field survey.
Each of the research assistants was allocated 40 questionnaires, 3 IDIs, and 1 FGD.

\section{Dependent Variable}

The outcome indicator used in this study is the use of DMPA-SC. The outcome indicator is binary; hence women who reported current use of DMPA-SC were coded 1, while those who reported otherwise were coded 0 .

\section{Independent Variables}

For the dependent variable, we assessed the predictive value of several independent variables (covariate), which include maternal age, marital status, maternal education, occupation, place of residence, parity (number of children), number of children alive, desire for more children and geopolitical zones of residence were examined. Maternal age examined the respondents' current age, and we considered the following age groups: $<19 ; 20-29 ; 30-39$ and $\geq 40$ years. Marital status is considered the marital status of the respondents. We considered five marital categories which were married, single, separate, divorced, and widowed. Maternal education was considered the highest educational attainment of the respondents, and we considered the following groups: no formal education, primary, secondary and tertiary education. For occupation, we examined the following categories: housewife, artisan, farming, civil servant, trading, and student. Place of residence categorized the women into rural and urban. Parity examined the number of children the woman had ever given birth to, and the following categories were considered: none, 1-3, 4-6, and $\geq 7$. The number of children alive is considered the actual number of children alive out of the number of children to which the woman has given birth to. We considered the following categories: none, 1-3, 4-6, and $\geq 7$. A desire for more children considered whether the woman desire more children or not. Those who desire more children were coded 1 while otherwise coded 0 . The geopolitical zone categorized the women into South West and North Central. 
These variables were used by past studies that examined the determinants of family planning in Nigeria and elsewhere [18-22].

\section{Statistical Analysis}

Descriptive statistics was used to analyze the categorical and continuous variables of the socioeconomic characteristics of women of reproductive age. Cross-tabulation analysis was conducted to establish an association between dependent variables and selected independent variables. The Chi-square test was used to set variables that were statistically significant at $10 \%$. The binary logistic regression was used to examine determinants of the current use of DMPA-SC/SI among the women. Audio-taped voices were transcribed verbatim. Important themes related to the discussion were highlighted. Recorded voices were reported using translated quotations, which were denoted using brackets. The literal translation gave credibility to the reports. The In-depth Interview (IDI) and Focus Group Discussion were subjected to descriptive and inferential statistics using NVIVO version 12. Quantitative data collected was analyzed using Statistical Package for Service Solution (SPSS).

\section{Ethical Clearance and Approval}

Approval to conduct the study was gotten from the Nigerian Health Research Ethics Committee in line with the established guidelines of the Federal Ministry of Health. Approval was sought from the health facilities where the study was conducted. Informed consent was gotten from individual participants, having provided detailed information about the survey to them.

\section{Results}

Table 1. Socio-demographic Characteristics of the Respondents

\begin{tabular}{|l|l|l|}
\hline Variables & Frequency $(\mathbf{n}=\mathbf{8 4 4})$ & Percent \\
\hline Maternal age (years) & 2.1 \\
\hline$\leq 19$ & 18 & 40.4 \\
\hline $20-29$ & 341 & 41.3 \\
\hline $30-39$ & 348 & 16.2 \\
\hline$\geq 40$ & 137 & 85.1 \\
\hline Marital status & 9.5 \\
\hline Married & 718 & 2.6 \\
\hline Single & 80 & 1.3 \\
\hline Separate & 22 & 1.5 \\
\hline Divorced & 11 & \\
\hline Widowed & 13 & 9.6 \\
\hline Maternal education & 16.5 \\
\hline None & 81 & 47.4 \\
\hline Primary & 139 & 26.5 \\
\hline Secondary & 400 & \\
\hline Tertiary & 224 & 11 \\
\hline Occupation & 93 & 12.8 \\
\hline Housewife & 93 & 9 \\
\hline Artisan & 108 & 15.8 \\
\hline Farmer & 76 & 42.1 \\
\hline Civil Servant & 133 & \\
\hline Trading & 355 & \\
\hline
\end{tabular}




\begin{tabular}{|l|l|l|}
\hline Student & 79 & 9.4 \\
\hline \multicolumn{2}{|l|}{ Place of residence } & 45.6 \\
\hline Rural & 385 & 54.4 \\
\hline Urban & 459 & \\
\hline Parity (number of children) & 7.5 \\
\hline None & 63 & 49.5 \\
\hline $1-3$. & 418 & 37.2 \\
\hline $4-6$. & 314 & 5.8 \\
\hline$\geq 7$ & 49 & \\
\hline Number of children alive & 7.5 \\
\hline None & 63 & 53.9 \\
\hline $1-3$. & 455 & 35.7 \\
\hline $4-6$. & 301 & 3 \\
\hline$\geq 7$ & 25 & \\
\hline Desire for more children & 50.4 \\
\hline No & 425 & 49.6 \\
\hline Yes & 419 & 54 \\
\hline Geopolitical zone of residence \\
\hline Southwestern & 456 & 46 \\
\hline North central & 388 & \\
\hline
\end{tabular}

The respondents comprise of women between the ages of nineteen and forty-nine years. However, the majority of them, 689 (81.6\%), were women of age 20-39 years. Most of the respondents, $718(85.1 \%)$, were married women, about three quarter $73.9 \%$ of them had at least secondary level of education, 355 (42.2\%) were traders, while $385(45.6 \%)$ were rural dwellers. More so, 456 (54.0\%) were from the southwestern part of Nigeria, while 388 (46.0\%) were from the north-central part. About half 418 $(49.5 \%)$ of the women had 1-3 children, while about the same number of women still desire more children.

Table 2. Knowledge and Practice of DMPA-SC/SI among the Women

\begin{tabular}{|l|l|l|}
\hline Variables & Frequency $(\mathbf{n}=\mathbf{8 4 4})$ & Percent \\
\hline \multicolumn{2}{|l|}{ Ever heard of modern family planning method } \\
\hline No & 89 & 10.5 \\
\hline Yes & 755 & 89.5 \\
\hline Ever heard of DMPA-SC & 2.4 \\
\hline No & 20 & 97.6 \\
\hline Yes & 824 & 11.5 \\
\hline Ever heard of Self- Injection as a FP methods \\
\hline No & 97 & 88.5 \\
\hline Yes & 747 & 16.8 \\
\hline Ever used any modern family planning method \\
\hline No & 142 & 83.2 \\
\hline Yes & 702 & 4.3 \\
\hline Current use of family planning method (n= 702) \\
\hline No & 30 & \\
\hline
\end{tabular}




\begin{tabular}{|c|c|c|}
\hline Yes & 672 & 95.7 \\
\hline \multicolumn{3}{|c|}{ Ever used DMPA-SC $(n=702)$} \\
\hline No & 40 & 5.7 \\
\hline Yes & 662 & 94.3 \\
\hline \multicolumn{3}{|c|}{ Ever used Self-Injected DMPA-SC (n= 662) } \\
\hline No & 354 & 53.5 \\
\hline Yes & 308 & 46.5 \\
\hline \multicolumn{3}{|c|}{ The FP Method currently used $(n=672)$} \\
\hline DMPA-SC/SI & 620 & 92.3 \\
\hline Other modern FP & 52 & 9.7 \\
\hline
\end{tabular}

In Table 2, 89.5\% reported ever heard of the modern family planning method, and $97.6 \%$ reported ever heard DMPA-SC. About 83\% reported ever use of modern family planning methods. Also, $95.7 \%$ reported the current use of the family planning method. The result showed that $94.3 \%$ reported ever used DMPA-SC and $46.5 \%$ reported ever use of self-injectable DMPA-SC (see Figure 1). The majority of the respondents reported that they used selfinjectable DMPA-SC.

\section{Ever used DMPA-SC}

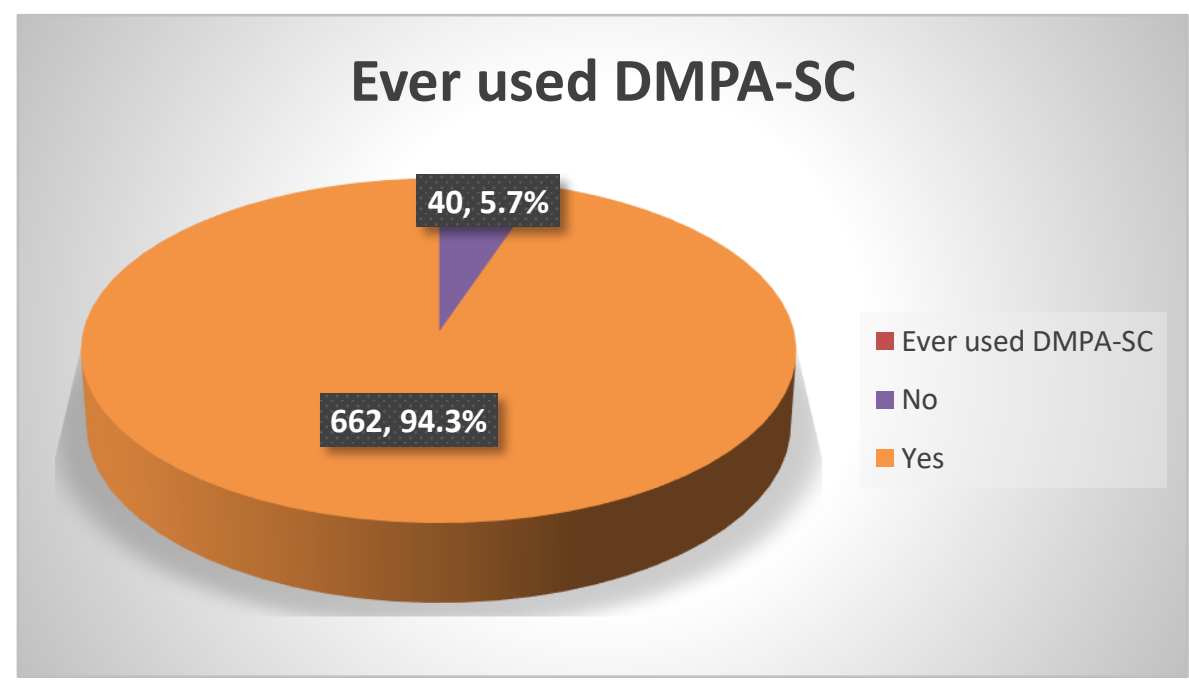

Figure 1. The Proportion of Mothers who Reported ever Use of DMPA-SC

\section{Ever self-injected DMPA-SC}

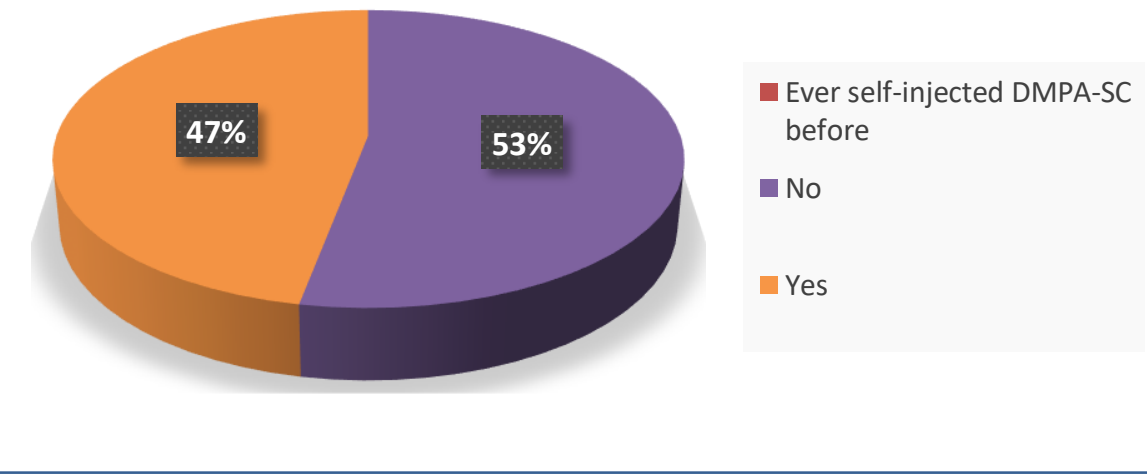

Figure. 2. The Proportion of Mothers who Reported ever Use of DMPA-SC/SI 
Table 3. Reasons for Use and Non-use of DMPA-SC/SI

\begin{tabular}{|l|l|l|}
\hline Variables & Frequency & Percent \\
\hline Negative influence to DMPA-SC/SI* & 424 & 51.5 \\
\hline Negative side effects of the method & 289 & 35.1 \\
\hline External influence from partner & 242 & 29.4 \\
\hline Religious reasons & 210 & 25.5 \\
\hline External influence from family members & \multicolumn{2}{l|}{} \\
\hline Positive influence to using DMPA-SC /SI & 298 & 45.0 \\
\hline Health benefits & 153 & 23.1 \\
\hline Financial implications & 118 & 17.9 \\
\hline Family and friends & 73 & 11.0 \\
\hline The effectiveness, safety and availability of the products & 20 & 3.0 \\
\hline Proximity of community Providers & \multicolumn{2}{l}{} \\
\hline Benefits associated with Self-injection & 278 & 42.0 \\
\hline It is easy to use and self-administered & 135 & 20.4 \\
\hline It is safe and dependable & 116 & 17.5 \\
\hline It helps in child spacing and prevention of unwanted pregnancy & 75 & 11.3 \\
\hline It is available, accessible and affordable & 58 & 8.8 \\
\hline It is provided free of charge & \multicolumn{2}{l}{} \\
\hline Fears associated with self-injection & 247 & 37.3 \\
\hline No fear at all & 101 & 15.3 \\
\hline Phobia for injection & 89 & 13.4 \\
\hline Fear of side effects & 88 & 13.3 \\
\hline Fear of self-injury & 79 & 11.9 \\
\hline Fear of wrong administration & 34 & 5.1 \\
\hline Fear of poor handling and storage & 15 & 2.3 \\
\hline Fear of husband approval & 9 & 1.4 \\
\hline Fear of availability & \multicolumn{2}{l}{} \\
\hline & 24 \\
\hline
\end{tabular}

*Multiple Responses

In Table 3, in order of hierarchy, the negative influence to use of injectable DMPA-SC are negative side effects of the method, husband discouragement, religious reasons, and discouragement from family members. On the other hand, positive influences to self-injectable DMPA-SC are health benefits and financial associated with self-injectable contraceptives are it is easy to use, and self-administered, it is safe and dependable and adequately helps in childbirth spacing. The fears associated with self-injectable contraceptives are phobia for selfinjection, fear of side effects, and fear of selfinjury from self-injection. implications. Furthermore, the benefits

Table 4a. Socio-demographic Characteristics of the Respondents and Current Use of DMPA-SC

\begin{tabular}{|l|l|l|l|}
\hline \multicolumn{5}{|c|}{ Current use DMPA-SC } \\
\hline Variables & Yes (n= 620) & No (n=52) & P-value \\
\hline Age (years) & $13(92.9)$ & $1(7.1)$ & 0.566 \\
\hline$\leq 19$ & $223(91.0)$ & $22(9.0)$ & \\
\hline $20-29$ &
\end{tabular}




\begin{tabular}{|l|l|l|l|}
\hline $30-39$ & $269(92.1)$ & $23(7.9)$ & \\
\hline$\geq 40$ & $115(95.0)$ & $6(5.0)$ & \\
\hline Marital status & \multicolumn{5}{|l|}{} \\
\hline Married & $544(92.7)$ & $43(7.3)$ & 0.500 \\
\hline Single & $41(87.2)$ & $6(12.8)$ & \\
\hline Separate & $16(94.1)$ & $1(50.9)$ & \\
\hline Divorced & $8(88.9)$ & $1(11.1)$ & \\
\hline Widowed & $11(91.7)$ & $1(8.3)$ & \\
\hline Highest educational level & & \\
\hline None & $52(89.7)$ & $6(10.3)$ & 0.381 \\
\hline Primary & $114(95.8)$ & $5(4.2)$ & \\
\hline Secondary & $276(91.7)$ & $25(8.3)$ & \\
\hline Tertiary & $178(91.8)$ & $16(8.2)$ & \\
\hline Occupation & $73(98.6)$ & $1(1.4)$ & $\mathbf{0 . 0 2 0}$ \\
\hline Housewife & $77(85.6)$ & $13(14.4)$ & \\
\hline Artisan & \multicolumn{5}{|l|}{} \\
\hline Farmer & $47(92.2)$ & $4(7.8)$ & \\
\hline Civil Servant & $116(95.9)$ & $5(4.1)$ & \\
\hline Trading & $268(91.5)$ & $25(8.5)$ & \\
\hline Student & $39(90.7)$ & $4(9.3)$ & \\
\hline Type of residence & & \multicolumn{1}{|l|}{} \\
\hline Rural & $202(85.6)$ & $34(14.4)$ & $<\mathbf{0 . 0 0 1}$ \\
\hline Urban & $418(96.9)$ & $18(4.1)$ & \\
\hline State of residence & $1439100.0)$ & $0(0.0)$ & $<\mathbf{0 . 0 0 1}$ \\
\hline Lagos & $129(79.6)$ & $33(20.4)$ & \\
\hline Oyo & $145(88.4)$ & $19(11.6)$ & \\
\hline Niger & $203(100.0)$ & $0(0.0)$ & \\
\hline Plateau & & \\
\hline
\end{tabular}

Table 4b. Socio-demographic Characteristics of the Respondents and Current Use of DMPA-SC

\begin{tabular}{|l|l|l|l|}
\hline \multicolumn{5}{|c|}{ Current use DMPA-SC } \\
\hline Variables & Yes (n= 620) & No (n=52) & P-value \\
\hline Geopolitical zone \\
\hline Southwest Nigeria & $272(89.2)$ & $33(10.8)$ & $\mathbf{0 . 0 0 9}$ \\
\hline Northcentral Nigeria & $348(94.8)$ & $19(5.2)$ & \\
\hline \multicolumn{5}{|l|}{} & \\
\hline Epe & $12(100.0)$ & $0(0.0)$ & $<\mathbf{0 . 0 0 1}$ \\
\hline Ifako Ijaiye & $131(100.0)$ & $0(0.0)$ & \\
\hline IBNE & $102(87.2)$ & $15(12.8)$ & \\
\hline Ido & $27(60.0)$ & $18(40.0)$ & \\
\hline Bassa & $83(100.0)$ & $0(0.0)$ & \\
\hline Jos South & $119(100.0)$ & $0(0.0)$ & \\
\hline Bosso & $84(95.5)$ & $4(4.5)$ & \\
\hline Tafa & $62(80.5)$ & $15(19.5)$ & \\
\hline Parity (number of children) & & \\
\hline
\end{tabular}




\begin{tabular}{|l|l|l|l|}
\hline None & $26(86.7)$ & $4(13.3)$ & 0.321 \\
\hline $1-3$ & $317(93.8)$ & $21(6.2)$ & \\
\hline $4-6$ & $240(90.9)$ & $24(9.1)$ & \\
\hline$\geq 7$ & $37(92.5)$ & $3(7.5)$ & \\
\hline Number of children alive & $26(86.7)$ & $4(13.3)$ & 0.103 \\
\hline None & $352(93.9)$ & $23(6.1)$ & \\
\hline $1-3$ & $224(90.0)$ & $25(10.0)$ & \\
\hline $4-6$ & $18(100.0)$ & $0(0.0)$ & \\
\hline$\geq 7$ & $301(91.5)$ & $28(8.5)$ & 0.474 \\
\hline Desire for more children & $319(93.0)$ & $24(7.0)$ & \\
\hline No & $1(33.3)$ & $2(66.7))$ & $\mathbf{0 . 0 1 7}$ \\
\hline Yes & $619(92.5)$ & $50(7.5)$ & \\
\hline Ever heard of DMPA-SC & & \\
\hline No & $35(81.4)$ & $8(18.6)$ & $\mathbf{0 . 0 1 3}$ \\
\hline Yes & $585(93.0)$ & $44(7.0))$ & \\
\hline Ever heard of self-injection &
\end{tabular}

Tables $4 \mathrm{a}$ and $4 \mathrm{~b}$ show the factors that are associated with respondents' current use of DMPA-SC. Respondents' occupation ( $\mathrm{p}=$ $0.020)$, type of residence ( $p<0.001)$, state of residence $(<0.001)$, geopolitical zone of residence $(\mathrm{p}=0.009)$, LGA of residence $(\mathrm{p}<$ $0.001)$, ever heard of DMPA-SC $(p=0.017)$, and ever heard of self-injection ( $p=0.013$ ) were found to be statistically significantly associated with current use of DMPA-SC.

Table 5. Logistic Regression Analysis to Determine the Predictors of Current Use of DMPA-SC among Respondents

\begin{tabular}{|l|l|l|l|}
\hline \multicolumn{5}{|c|}{ Current use of DMPA-SC } \\
\hline Predictors & Regression coefficient & AOR (95\% CI) & P-value \\
\hline Age (years) & 0.897 & $2.45(0.12-52.40)$ & 0.566 \\
\hline$\leq 19$ & 1.062 & $2.89(1.00-8.38)$ & $\mathbf{0 . 0 5 0}$ \\
\hline $20-29$ & 0.477 & $1.612(0.59-4.44)$ & 0.356 \\
\hline $30-39$ & \multicolumn{3}{|l|}{} \\
\hline$\geq 40$ & 1.311 & 1 & \\
\hline Highest educational level & $0.71(0.94-14.71)$ & 0.062 \\
\hline None & -0.607 & $0.57(0.16-1.81)$ & 0.322 \\
\hline Primary & -0.569 & 1 & 0.200 \\
\hline Secondary & \multicolumn{4}{|l}{} \\
\hline Tertiary & -0.673 & $0.51(0.04-6.26)$ & 0.599 \\
\hline Occupation & 1.966 & $7.14(1.47-34.69)$ & $\mathbf{0 . 0 1 5}$ \\
\hline Housewife & 0.749 & $2.1290 .30-14.77)$ & 0.450 \\
\hline Artisan & 0.964 & $2.62(0.49-14.13)$ & 0.262 \\
\hline Farmer & 1.363 & $3.91(0.88-17.25)$ & 0.072 \\
\hline Civil Servant &
\end{tabular}




\begin{tabular}{|c|c|c|c|}
\hline Student & & 1 & \\
\hline \multicolumn{4}{|l|}{ Type of residence } \\
\hline Rural & 2.407 & $11.10(5.12-24.10)$ & $<0.001$ \\
\hline Urban & & 1 & \\
\hline \multicolumn{4}{|l|}{ Geopolitical zone } \\
\hline Southwest Nigeria & 1.365 & $3.91(1.82-8.42)$ & $<0.001$ \\
\hline Northcentral Nigeria & & 1 & \\
\hline \multicolumn{4}{|c|}{ Ever heard of DMPA-SC } \\
\hline No & 3.521 & $33.80(2.22-515.64)$ & 0.011 \\
\hline Yes & & 1 & \\
\hline \multicolumn{4}{|c|}{ Ever heard of self-injection } \\
\hline No & 1.509 & $4.52(1.57-13.05)$ & 0.005 \\
\hline Yes & & 1 & \\
\hline
\end{tabular}

Respondents who were between the ages of $20-29$ years were found to be about 3 times statistically significantly more likely to be a current user of DMPA-SC when compare with those who were 40 years and above (AOR, 2.89; 95\% CI, 1.00-8.38; $\mathrm{P}=0.050$ ). Those who are artisans were 7 times statistically significantly more likely to be a current user of DMPA-SC when compare with those who are students (AOR, 7.14; 95\% CI, 1.47-34.69); $\mathrm{P}<0.015$ ). Respondents from the rural areas were 11 times statistically as likely to currently use DMPA-SC when compared with those from the urban areas (AOR, 11.10 95\% CI, 5.12-24.10; p <0.001). Respondents from the southwestern geopolitical zone $(3.91 ; 95 \%$ CI, 1.82-8.42; $\mathrm{p}<0.001)$, when compared with those from the north-central geopolitical zone, were found to be about 4 times more likely to currently using DMPA-SC. Those who have not heard about DMPA-SC (33.80; 95\% CI, 2.22-515.64; $p=0.011)$, compared to those who have heard about it, were statistically significantly more likely to currently use DMPA-SC/SI.

\section{In-depth Interview /Focused Group Discussion Sessions}

Two important themes were drawn from the FGDs and IIDs. The themes are: (i) Motivation to use IDIs (ii) Potential internal and external triggers that influence demand and uptake of modern FP methods, including DMPA selfinject.

\section{Motivation to Use DMPA-SC}

From the FGDs and IDIs, we gathered that there are some factors that serve as motivators to respondents who reported the use of selfinjectable contraceptive. Prominent among the factors were it is self-administered, costeffective, easy to use, and users do not need to frequently visit health facilities. In an in-depth interview, one of the participants has this to say:

"self-injectable contraceptive is effective, no complain of bleeding, and It reduces the number of the visit of clients to health facilities" [IDI Oyo State].

In another discussion, a participant remarked that the method was cheap, hence cost-effective.

"It saves cost; it is free and gives confidences to the women" [IDI- Oyo State].

We also noted that DMPA-SC appears to be more available that than contraceptive methods such as implants. This was reported by participants in the FGDs:

"When I was using the implant, access to the commodity was a problem because you have to go to and queue and wait you have to also pay, but this DMPA SC is easy because it does not take time and it does not waste time" [FGD-Plateau State]. 
Another motivating drive to use DMPA-SC/SI was that it has less issues of complication. Participants compared it with other methods and found it more attractive. It is less complicated. In one of the FGDs, a participant emphasized it:

"Self-injectable contraceptive is easy, and its complication are less, women complain about it less unlike the pills that you can forget, the loop you will bleed others are headache and what have you, in the ratio of women in the community of women using family planning method is the least women complain about its complications" [FGD-Plateau State].

Another participant has this to say:

"The absence of bleeding, overweight, DMPA$S C$ is good" [FGD-Tafa].

\section{Potential Internal and External Triggers that Influence Demand and Uptake of Modern FP Methods including DMPA Self-inject}

We also gathered from the FGDs and IDIs that there are both internal and external triggers that can influence the uptake of self-injectable DMPA-SC. Some of the triggers are costeffectiveness, the time it saves the respondents, partner/husband encouragement, and the anticipated benefits from its use. In one of the FGDs, a participant reported its costeffectiveness and that the method is cheap:

'The cost it is cost-effective; it is free, so there's no money attached to it. Then the proximity too is one of it, but probably because of the self-injection" [IDI- Lagos State].

Another participant remarked that the use of self-injectable DMPA-SC reduces the number of times the user visits health facilities:

"It's because of the method then the distance as well" [IDI- Lagos State].

'I think the only thing that makes them use it is that by the time they plan their family, they will be at rest, there will not be the issue of unwanted pregnancy, they will enjoy their husband, and they will enjoy their wife. I think that is one of the things that make them to turn out" [IDI-Oyo State].
Spousal encouragement was also reported in the FGDs:

"My husband encourages me." [IDI - Oyo].

\section{Discussion}

This study explored the knowledge, attitude, practice, and determinants of Depot Medroxyl Progesterone-Acetate-Subcutaneous/Self-

Injection (DMPA-SC/SI) among women in two geopolitical zones of Nigeria. The selected states were two (Lagos and the Oyo States) from the South Western geopolitical zone and two (Niger and Plateau States) from the North Central geopolitical zone. The result showed that $97.6 \%$ of the women reported they had heard of DMPASC, and $88.5 \%$ had heard of DMPA-SC/SI. However, this study is a follow-up to an aggressive campaign on family planning utilization among women and key decisionmakers in the northern part of the country. This may account for the high overall knowledge of DMPA-SC among the respondents. The focused group discussions showed that the majority of the respondents have heard of DMPA-SC and even self-injectable contraceptives.

The results demonstrated that contraceptive prevalence among the study participants was high (95.7\%), whereas current users of DMPASC were $92.3 \%$, while those who have ever selfinjected DMPA-SC $46.5 \%$. The usage rate of DMPA-SC recorded in this study is higher than national estimates $(21.8 \%)$ and the usage rate reported by past studies [23-26]. According to current scientific evidence, DMPA use has risen dramatically in Sub-Saharan Africa, and it is quickly becoming the most widely used modern method of contraception in many health facilities and reproductive and family health centers in Nigeria [27]. This could indicate that DMPA-SC is most commonly used for terminal contraception by women who have reached the end of their reproductive careers and want to stop having children [27]. This is not surprising given that the surgical method of contraception is not widely accepted by women in this society for cultural and religious [29, 30]. 
It was observed that reasons such as fear of self-injecting, fear of needle/ injection, and being unaware that one can actually self-inject herself were among the reasons more than half of the study participants never self-injected themselves. All these fears can be addressed or at least alleviated through appropriate training. The local government area in which the study areas are situated should organize periodic training where women are trained on how to inject themselves and handle the DSPA-SC in order to avoid self-injury. With the training, most of the women will become expertise, and that will avert all the fears that have been discouraging the use of injectable contraceptives. Men should also be trained so that they can assist women who cannot inject themselves.

When the usage of DMPA-SC was compared in terms or place of residence and geopolitical zones, it was observed that participants from urban areas and those from the North-Central region of the country respectively used the DMPA-SC method much more than their rural and southern dwelling counterparts. Availability of products, technically competent reproductive health practitioners, and health facilities may have helped in the higher rate of usage in the urban arrears compared to the rural areas, where there is the dearth of facility, professionals, and products due mainly because of security reasons, poor or non-existence of access road, and other infrastructures that can make life a bit easier and convenient for health care providers.

However, this study is a follow-up to an aggressive campaign on family planning utilization among women and key decisionmakers in the northern part of the country. Also, looking at the evidence from our findings that more than three-quarters of the participants from the northwestern zone started using DMPA-SC and other modern family planning methods less than three years ago (analysis withheld from the tables). We can deduce that these campaigns and other social mobilization and public enlightenments programs being carried out by non-profit organizations in the country and the effort of the government are yielding positive results among the targeted population. This could serve as a foundation for highlighting the study's findings. Lower fertility rates and longer birth spacing, which includes contraceptive use, can help to reduce maternal and child mortality rates. Other factors that can help are increased women's participation in the labor force, protection from abuse and violence, increased knowledge, improved decision-making power, and socioeconomic status. In addition, favorable trade policies and banking institutions should aid the expansion of profitable medium and smallscale firms. Women's economic empowerment could be improved by promoting it through local support groups, philanthropic organizations, well-off individuals, trade initiatives, and effective policies [31].

Though various factors were discovered to impact the use of DMPA-SC, both the household survey and the qualitative interviews show that cost-effectiveness, free charges for DMPA-SC, safety, effectiveness, self-administered, there are no cases of complications, and side effects (that is, bleeding, overweight and underweight), availability of services, lack of financial hardship and the fact that users do not need to visit health centres frequently were the motivating factors to use of DMPA-SC. Several other reasons were identified to promote or influence the use of modern contraceptive methods by the study participants. This study's findings suggest that efforts to promote healthy interpregnancy intervals are needed to reduce negative child health outcomes [23]. Furthermore, healthcare stakeholders would find the study's findings fascinating and useful as a foundation for policy design and implementation.

The result showed that appointment cards, telephone calls from healthcare providers, and the use of short messages were very helpful in motivating the women to initiate the use of DMPA-SC in particular and family planning in general. It is therefore important that these 
strategies be deployed in encouraging mothers to initiate contraception. Healthcare workers should have a list of women who are under their watch for contraceptives and send periodic messages to remind them of the initiation of contraception and progression.

Despite the utility from the results of this study, it has noteworthy limitations. First, the report analyzed was gotten through verbal reporting, and they were not validated using objective sources such as the use of health facility cards. Just like any other household survey, it is possible for respondents to give socially desirable responses. More so, because of the cross-sectional nature of the data, we could not explore the dynamic intertemporal relationship between the socio-demographic characteristics of the women and the use of family planning. Third, the number of observations used for the analysis is few; hence we cannot generalize the findings for the entire Nigerian population.

\section{Conclusion}

The results of the study showed a high contraceptive utilization rate $(95.7 \%)$ that far exceeds national estimates (22\%). Also, we noted that a high proportion of the women have heard of DMPA-SC and that slightly below average $(46.5 \%)$ reported ever use of DMPASC/SI. The utilization of self-injectable DMPASC recorded in this study is far above national estimates. This may be due to an earlier awareness campaign in the study area. The primary reasons why most respondents subscribed to the use of self-injectable DMPASC was because it is safe, easy to use, effective, and self-administered. Fears were associated with the use of self-injectable DMPA-SC, and common among the fears were phobias associated with self-injection, fear of side effects, and fear of self-injury. It will be helpful for an intervention programme to be conducted in the study area that will use health education, awareness, and public sensitization to educate mothers on the benefits of self-injectable contraceptives. Training programmes to help mothers learn how to inject themselves will allay the fear of self-injury associated with the method.

Furthermore, the result showed that respondents were drawn from South-West Nigeria, those residing in rural parts of the country and those who have not heard of selfinjectable DMPA-SC were less likely to report its use it. Intervention programme design to increase coverage use of this method of contraceptive must focus more on rural women and those from South-West Nigeria. Awareness programmes should be launched that educate mothers on the benefit of this method. The Government of Nigeria Should explore replicating this model across the $36+1$ states, as it has been perceived with evidence to be the Game Changer for increasing FP uptake.

\section{Acknowledgement}

The author appreciates the approval of the Association for Reproductive and Family Health for allowing this study to be conducted in four of the ten project states of Implementation. The contribution of all stakeholders and study participants in the four states is sincerely acknowledged.

\section{Ethics Approval and Consent to Participate}

Ethical clearance was obtained from the National Health Research Ethics Committee, Nigeria, for $\mathrm{PhD}$ primary research study in the four study sites.

\section{Consent for Publication}

No consent to publish was needed for this study as the author did not use any details, images, or videos related to individual participants.

\section{Conflict of Interest}

There was no conflicting interest in this study as it was a sole $\mathrm{PhD}$ primary Research by the author. 


\section{References}

[1] Moon TD, Okoth V, Starnes JR, et al. Determinants of modern contraceptive prevalence and unplanned pregnancies in Migori County, Kenya: results of a cross-sectional household survey. Afr $J$ Reprod Health 2021; 25: 29.

[2] Mochache V, Lakhani A, El-Busaidy H, et al. Pattern and determinants of contraceptive usage among women of reproductive age from the Digo community residing in Kwale, Kenya: results from a cross-sectional household survey. BMC Women's Health 2018; 18: 10.

[3] Ameyaw EK, Budu E, Sambah F, et al. Prevalence and determinants of unintended pregnancy in subSaharan Africa: A multi-country analysis of demographic and health surveys. PLoS ONE 2019; 14: e0220970.

[4] United Nations Department of Economic and Social Affairs. Family Planning and the 2030 Agenda for Sustainable Development (Data Booklet). United Nations. Epub ahead of print September 20, 2019. DOI: $10.18356 / \mathrm{e} 154 \mathrm{e} 49 \mathrm{~d}-\mathrm{en}$.

[5] Dasgupta ANZ, Wheldon M, Kantorova V, et al. Progress in Family Planning: Did the Millennium Development Goals Make a Difference? In: Population Association of America. Austin: Population Division, United Nations, Department of Economic and Social Affairs, 2019, p. 10.

[6] Ba DM, Ssentongo P, Agbese E, et al. Prevalence and predictors of contraceptive use among women of reproductive age in 17 sub-Saharan African countries: A large population-based study. Sex Reprod Health c 2019; 21: 26-32.

[7] Prata N, Weidert K, Fraser A, et al. Meeting Rural Demand: A Case for Combining Community-Based Distribution and Social Marketing of Injectable Contraceptives in Tigray, Ethiopia. PLoS ONE 2013; 8: e68794.

[8] Sileo KM, Wanyenze RK, Lule $\mathrm{H}$, et al. Determinants of family planning service uptake and use of contraceptives among postpartum women in rural Uganda. Int J Public Health 2015; 60: 987-997. [9] National Population Commission (NPC) [Nigeria] and ICF. 2019. Nigeria Demographic and Health Survey

2018 ,
https://www.dhsprogram.com/pubs/pdf/FR359/FR35 9 pdf (2019, accessed October 24, 2020).

[10] Total Fertility Rate in Nigeria Decreases Slightly as the Contraceptive Prevalence Rate Increases | JHU Advance Family Planning, https://www.advancefamilyplanning.org/totalfertility-rate-nigeria-decreases-slightlycontraceptive-prevalence-rate-increases (accessed July 10, 2021).

[11] National Population Commission. Nigeria Demographic and Health Survey 2018. Key Indicators Report, Nigeria: The DHS Program ICF Rockville, Maryland, USA.

[12] Cover J, Namagembe A, Tumusiime J, et al. Continuation of injectable contraception when selfinjected vs. administered by a facility-based health worker: a nonrandomized, prospective cohort study in Uganda. Contraception 2018; 98: 383-388.

[13] Kohn JE, Simons HR, Della Badia L, et al. Increased 1-year continuation of DMPA among women randomized to self-administration: results from a randomized controlled trial at Planned Parenthood. Contraception 2018; 97: 198-204.

[14]Liu J, Shen J, Diamond-Smith N. Predictors of DMPA-SC continuation among urban Nigerian women: the influence of counseling quality and side effects. Contraception 2018; 98: 430-437.

[15]Ahuru RR. The influence of women empowerment on maternal and childcare use in Nigeria. Int J Healthc Manag 2019; 1-10.

[16] Cochran WG. Professor of Statistics, Emeritus Harvard University. 10.

[17] Yaya S, Uthman OA, Ekholuenetale M, et al. Women empowerment as an enabling factor of contraceptive use in sub-Saharan Africa: a multilevel analysis of cross-sectional surveys of 32 countries. Reprod Health 2018; 15: 214.

[18] Aliyu AA, Dahiru T. Reproductive Health and Family Planning Services in Africa: Looking beyond Individual and Household Factors. In: Amarin Z, Abduljabbar $\mathrm{H}$ (eds) Family Planning and Reproductive Health. IntechOpen. Epub ahead of print December 2, 2020. DOI: 10.5772/intechopen.92138.

[19] Solanke BL. Factors influencing contraceptive use and non-use among women of advanced 
reproductive age in Nigeria. J Health Popul Nutr 2017; 36: 1 .

[20] Adebowale SA, Ajiboye BV, Arulogun O. Patterns and Correlates of Condom Use among Unmarried Male Youths in Nigeria: NDHS 2008. Afr J Reprod Health 2017; 17: 149-159.

[21] Kanwal N, Muttappallymyalil J, Al-Sharbatti S, et al. Contraceptive Utilisation Among Mothers of Reproductive Age in Ajman, United Arab Emirates. Sultan Qaboos Univ Med J 2017; 17: e50-e58.

[22] Olugbenga-Bello AI, Adebimpe WO, Akande RO, et al. Health risk behaviors and sexual initiation among in-school adolescents in rural communities in southwestern Nigeria. Int $\mathrm{J}$ Adolesc Med Health 2014; 26: 503-510.

[23] Burke HM, Chen M, Buluzi M, et al. Effect of self-administration versus provider-administered injection of subcutaneous depot medroxyprogesterone acetate on continuation rates in Malawi: a randomised controlled trial. Lancet Glob Health 2018; 6: e568-e578.

[24] Ezegwui H, Ikeako L, Obiora-Okafor N. The use of Depot Medroxyprogesterone Acetate (DMPA) Injectable Contraceptive in Enugu, Nigeria. Niger J Med 2012; 21: 6 .

[25] Prabhakaran S, Sweet A. Self-administration of subcutaneous depot medroxyprogesterone acetate for contraception: feasibility and acceptability. Contraception 2012; 85: 453-457.

[26]Beasley A, White KO, Cremers S, et al. Randomized clinical trial of self-versus clinical administration of subcutaneous depot medroxyprogesterone acetate. Contraception 2014; 89: 352-356.

[27] Mairiga AG, Kyari O, Audu B, et al. Socioclinical characteristics of modern contraceptives users at the University of Maiduguri Teaching Hospital. Niger J Clin Pract 2007; 10: 152-155.

[28] Abasiattai A, Udoma E, Ukeme E. Depot medroxyprogesterone injectable contraception at the University of Uyo Teaching Hospital, Uyo. Ann Afr Med 2010; 9: 81.

[29]Ross J, Hardee K. Access to contraceptive methods and prevalence of use. J Biosoc Sci 2013; 45: 761-778.

[30]Ross J, Keesbury J, Hardee K. Trends in the Contraceptive Method Mix in Low- and MiddleIncome Countries: Analysis Using a New "Average Deviation" Measure. Glob Health Sci Pract 2015; 3 : $34-55$.

[31]Ross JA, Agwanda AT. Increased use of injectable contraception in sub-Saharan Africa. Afr $\mathbf{J}$ Reprod Health 2012; 16: 68-80. 


\title{
Factors Associated with Distribution of Pre-Eclampsia and Eclampsia Among Rural and Urban Women in Child Bearing Age - A Case of Mbala General Hospital, Northern Province, Zambia
}

\author{
Daniel Sinkala $^{1^{*}}$, Ellen Munyati ${ }^{2}$, Kousalya, $\mathrm{R}^{1,2}$ \\ ${ }^{1}$ District Health Director, Ministry of Health, Mbala, Zambia \\ ${ }^{2}$ Public Health, College of Nursing, Ndola, Zambia
}

\begin{abstract}
Preeclampsia and eclampsia cases continue to rise in northern Zambia as people search for babies and continuity of clans' survival. Due to the competitive nature of cultural demands/ myths on pregnancy and maternal socio-demographic factors (low-age, low socio-economic status, and poor health-seeking behaviour), women in rural prefer unprofessional primary health care services that are presumably affordable to them thereby, delaying in seeking for professional healthcare services. High levels of poverty in resource-limited areas have put many female adolescents at risk of falling pregnant. Thus, this study probed on the interaction between these maternal socio-demographic factors and disease distribution in both rural and urban areas with respect to various pregnancy outcomes. The study used retrospective quantitative methods in eliciting information from data sources (women, registers) in Mbala, Mpulungu, Senga, and Mungwi districts covering 3-year period (2017-2019). In all, 202 female respondents from Northern Zambia were interviewed through selfadministered questionnaires. Thereafter, data were analysed using a statistical package for the social sciences (SPSS v16). Findings indicate severe; socio-economic status and low maternal age affect pre-eclampsia disease distribution coupled with adverse pregnancy outcomes more in rural than urban areas. The better the socio-demographic conditions, the lower the disease distribution with good pregnancy outcomes. However, worsening maternal socio-demographic conditions may increase the incidence of pre-eclampsia among pregnant women of northern Zambia. The study recommended interventions tarred towards public health programmes such as social behaviour change and communication (SBCC) towards adolescent women and socio-economic empowerment of pregnant women in resource-limited areas.
\end{abstract}

Keywords: Average ANC timing, Preeclampsia, Residency, Socio-economic, Teenage pregnancy.

\section{Introduction}

The increasing obstetrical/ gynaecological skilled quality health service provision at Mbala general hospital keep on attracting more pregnant women from all parts of Senga, Mbala, Mpulungu, and Mungwi (kayambi) districts. Among these are women with hypertensive disorders in pregnancy and the most prevalent being pre-eclampsia that had shown a constant increase of cases over the period under this study [1]. In the struggle to cope with standard healthcare services, some women fall into vulnerable socio-demographic conditions leading to poor health for both mother and baby.

Pre-eclampsia is a pregnancy-related hypertensive disorder that usually occurs after 20 weeks of gestation, and if treatment delays, it progresses to eclampsia which is basically fitting in patients with severe forms of preeclampsia [2]. Therefore, pre-eclampsia and eclampsia are not distinct disorders but the manifestation of the spectrum of clinical signs 
and symptoms of the same condition. Pregnancy-induced hypertension is the mildest disorder in this continuum which becomes preeclampsia, when proteinuria appears, and the addition of convulsions changes the condition to eclampsia [3]. However, the pathogenesis of eclamptic convulsions remains unknown. Cerebral imaging suggests that cerebral abnormalities in eclampsia are similar to hypertensive encephalopathy that are vasogenic in nature. The convulsions can occur in antepartum (38-53\%), intrapartum (18-36\%), or postpartum (11-44\%) periods [4]. Recent data reveal an increase in the proportion of women who develop eclampsia beyond 48 hours after delivery [5]. There are no reliable tests or symptoms for predicting the development of eclampsia other than early detection of pre-eclampsia. In developed countries, the majority of cases reported in recent series are considered unpreventable [6]. $5-7 \%$ of all pregnancies are complicated by preeclampsia. In the pathogenesis of preeclampsia, proteinuria and hypertension dominate the clinical picture because the chief target organ is the kidney, and it suffers from glomerular endotheliosis [7]. The pathogenesis of pre-eclampsia is complex; numerous genetic, immunologic, and environmental factors interact. It has been suggested that preeclampsia is a two-stage disease. Stage I: (Placentation Abnormalities) - this stage is asymptomatic, characterized by abnormal placental development during the first trimester resulting in placental insufficiency and the release of excessive amounts of placental materials into the maternal circulation [7]. Stage II: (Maternal Syndrome) - this stage is symptomatic, and the pregnant woman develops characteristic hypertension, renal impairment, and proteinuria and is at risk for the hemolysis, elevated liver function enzymes and low platelets (HELLP syndrome), eclampsia, and other end-organ damage [5]. Therefore, abnormal placentation in stage I, resulting from the failure of trophoblastic remodelling of uterine spiral arterioles, leads to the release of secreted factors that enter the mother's circulation, which give rise to clinical signs and symptoms of pre-eclampsia. Thus, all the clinical manifestations of pre-eclampsia are due to malfunctioning of kidneys resulting from glomerular endotheliosis, increased vascular permeability, systemic inflammatory response, and hypoperfusion that results in end-organ damage [5]. These clinical manifestations typically occur after the 20th week of pregnancy [5, 7]. Scholars have shown in several studies that risk factors for preeclampsia include; body mass index raised systolic blood pressure, raised diastolic blood pressure, black race, clinical centre, and smoking [6,7]. Adjusted odds ratios computed with a Logistic regression model revealed that body mass index (odds ratio 3.22 for $\geq 35 \mathrm{~kg} / \mathrm{m} 2$ vs. $<19.8 \mathrm{~kg} / \mathrm{m} 2$ ), systolic blood pressure (odds ratio 2.66 for $\geq 120$ vs. $<101 \mathrm{~mm} \mathrm{Hg}$ ), diastolic blood pressure (odds ratio 1.72 for $\geq 61 \mathrm{~mm} \mathrm{Hg}$ vs. $<60 \mathrm{~mm} \mathrm{Hg}$ ), and clinical centre (odds ratio 1.85 for Memphis vs. the other clinical centres) were statistically significant predictors of preeclampsia [5]. Results of the final model fit revealed that pre-eclampsia risk increases significantly $(\mathrm{p}<0.0001)$ with increased body mass index at randomization, as well as with increased systolic and diastolic blood pressure at randomization [5]. The other strong risk in another study was the history of pre-eclampsia in a previous pregnancy, this was found to lead to high disease recurrence. Risks for the baby include poor growth and prematurity. Although the outcome is often good, pre-eclampsia can be devastating and life-threatening [8]. Preventive measures for pre-eclampsia are vast according to world health organization scholars that emphasize on the following:

I. In areas where dietary calcium intake is low, calcium supplementation during pregnancy (at doses of 1.5-2.0 g elemental calcium/day) is recommended for the prevention of pre-eclampsia in all women, 
but especially those at high risk of developing pre-eclampsia [9].

II. Use of low-dose acetylsalicylic acid (aspirin, $75 \mathrm{mg}$ ) for the prevention of preeclampsia and its related complications initiated before 20 weeks of pregnancy [8].

III. Treating women with severe hypertension during pregnancy with antihypertensive drugs.

IV. The use of magnesium sulphate to prevent eclampsia in women with severe preeclampsia instead of other anticonvulsants $[8,9]$.

Thus, scholars have shown that proven preventive interventions for pre-eclampsia so far include; use of antiplatelet agents, primarily low dose aspirin, calcium supplementation, Magnesium sulphate, and use of antihypertensive drugs, especially in women with pre-existing hypertension [8]. Women with a history of eclampsia are at increased risk of eclampsia (1-2\%) and pre-eclampsia (22$35 \%)$ in subsequent pregnancies. Recommendations for diagnosis, prevention, management, and counselling of these women are provided based on results of recent studies and my own clinical experience [10]. Management of pre-eclampsia is largely dependent on signs and symptoms. Antihypertensive drugs are mandatory for very high blood pressure above - systolic of 150/ diastolic of 100 millimeters of mercury [10]. Plasma volume expansion, corticosteroids, and antioxidant agents have been suggested for severe pre-eclampsia, but trials to date have not shown benefit. Optimal timing for delivery of women with severe pre-eclampsia before 32 to 34 weeks' gestation remains a dilemma [8]. Magnesium sulphate is the drug of choice for reducing the rate of eclampsia developing intrapartum and immediately postpartum [11]. Scholars conducted 4 large randomized trials comparing magnesium sulphate with no treatment or placebo in patients with severe preeclampsia. The study showed that the rate of eclampsia was significantly lower in those assigned to magnesium sulphate $(0.6 \%$ versus $2.0 \%$, relative risk $0.39,95 \%$ confidence interval 0.28-0.55), [8]. Thus, Magnesium sulphate is the drug of choice to prevent recurrent convulsions in eclampsia. The development of eclampsia is associated with an increased risk of adverse outcomes for both mother and foetus, particularly in developing nations [3]. Thus, pregnancies complicated by eclampsia require a well-formulated management plan that should be holistic in nature, covering all the symptoms on the patient. Pre-eclampsia can lead to severe complications in the end-organs such as; liver, kidneys, and brain. It also complicates the blood clotting system leading to disseminated intravascular coagulopathy (DIC), in which the clotting factors get consumed, and bleeding becomes uncontrollable, which usually leads to the death of both the mother and the unborn baby. The end-organ damage complicates into HELP syndrome, which is a very serious condition where there is massive damage to red blood cells (hemolysis), elevated liver enzymes, and reduced platelets. HELLP syndrome is a life-threatening form of pre-eclampsia with a typical laboratory triad. The incidence of the disease is reported as being $0.17-0.85 \%$ of all live births [12]. As a result of endothelial dysfunction, activation of intravascular coagulation occurs with fibrin deposition in the capillaries and consecutive microcirculation disorders. The disease manifests itself on average between 32-34 weeks' gestation. About $30 \%$ of cases of HELLP syndrome occur in the postpartum period [12] 2005. The cardinal clinical symptom of the disease is right upper quadrant (epigatric) pain accompanied with nausea, vomiting, and malaise. The increase of the aspartate transaminase (AST) and the alanine transaminase (ALT) often precedes a decrease in platelets $[9,12]$. Thus, in many low-income countries, complications of pre-eclampsia are the leading cause of death amongst women of reproductive years and perinatal deaths. Perinatal mortality is high 
following pre-eclampsia (9-10\%) and even higher following eclampsia (14-15\%) [3]. Preeclampsia is still a significant major factor of public health concern in both developed and developing countries, and it is one of the top three medical conditions that contribute to maternal and perinatal morbidity and mortality ratios globally [10]. However, the impact of the disease is felt more severely in developing countries, where, unlike other more prevalent causes of maternal mortality (such as haemorrhage and sepsis), medical interventions may be ineffective due to the late presentation of cases [6]. The problem is confounded by the continued mystery of the aetiology and the unpredictable nature of the disease. Thus, the purpose of this paper was to highlight the maternal socio-demographic factors associated with distribution and pregnancy outcome of pre-eclampsia/ eclampsia in developing countries and suggest measures that could be used to address them within the local context. The study used Mbala General Hospital as a pivotal referral health facility [13].

Preeclampsia and eclampsia seemed to be a huge challenge at Mbala General Hospital and its four referring districts over 3-year period with a disease trend of 33 (2017), 149 (2018), and 195 (2019) absolute cases reported. As a result of this, it had been very difficult to control maternal deaths (284/ 100,000 LB), preterm births, and perinatal deaths in the area under study [1]. Mbala General Hospital, through the ministry of health, with support from partners (CHAI, RBF, WVI, and HID), has been implementing robust interventions on FANC and EmOC services in order to reduce morbidity and improve on pregnancy outcomes. But this could not yield a desirable reduction in pre-eclampsia and eclampsia cases in the region under study. Thus, solutions to this problem should be directed towards studying factors affecting disease distribution among rural and urban women, of which factors associated with SBCC such as early ANC booking, good health-seeking behavior, and social economy could provide the best solution base. The major limitations have been longer distances and poor social-economic factors among many expecting women with known risk factors of preeclampsia (very difficult to sustain them in waiting for mother's shelters). The other limitation was demotivated CHW such as TBAs and SMAGs due to lack of provision of survival incentives by implementing entities. However, the presence of CHWs (TBAs \& SMAGs), competent workforce, and mother's shelters in all the four districts is a great achievement towards the fight to reduce pre-eclampsia and eclampsia disease burden.

\section{Significance of the Study}

Information on the effect of maternal factors (age, health-seeking behaviour, and socioeconomic status) on pre-eclampsia distribution with respect to residency and pregnancy outcome is important in containing disease burden, especially in rural areas. The outcome of this study will also bridge the scientific knowledge gap and contribute to a paradigm shift in the prevention and management of preeclampsia a public health perspective. Lastly, it will contribute to the debate on providing socio-economic assistance to vulnerable groups such as risk pregnant women, especially adolescents in resource-limited areas. This will provide the adequate scientific evidence needed by policy-makers for robust decision-making.

\section{Problem Statement}

The desire to reproduce and grow clans has seen an increase in the number of "women of childbearing age (WCBA) in northern Zambia. Pregnancy is something that communities treasure in northern Zambia, and it signifies life, and the district is mainly occupied by Christian denominations (mostly Roman Catholics) of different tribes. It is a respected expectation of the outcome of every marriage, as it is considered the source of pride for every family. To cope with this demand in the presence of various maternal socio- 
demographic variables, women are increasingly suffering from pre-eclampsia [14]. This is compounded by strong cultural belief (Amagini) that negatively affects professional health-seeking behaviour among these vulnerable eclamptic women with a three-year upward trend of 33, 149, and 195 cases [14, 15]. In northern Zambian culture, 'fitting in pregnancy' is considered a 'spiritual possession' called “Amagini”- a popular name given to eclampsia by traditional healers to mean 'water' or 'snake-like spirits'. The word "ma" is singular for mother, "Ama" plural. While "gini" means 'evil spirits', hence "Amagini" to denote mothers with evil spirits moving in the body like a snake [14].

Henceforth, despite the robust interventions done by the ministry of health with support from partners (CHAI, RBF, WVI, and HID), the cases of pre-eclampsia and eclampsia still seem to be a huge challenge at Mbala General Hospital and its four referring districts. As a result of this, it had been very difficult to control maternal mortality (284/ 100,000 LB), preterm births, and perinatal deaths in this region [1]. Thus, the need for this study that would enhance surveillance of more factors that could be contributing to these escalating cases by looking at low maternal age (teenage pregnancy), maternal residency, maternal socioeconomic status, and health seeking behaviour (antenatal care services) in relation to distribution of pre-eclampsia and eclampsia.

\section{Materials and Methods}

\section{Research Design and Study Population}

We conducted a retrospective structured study, quantitative and comparative in nature, at Mbala General Hospital and the four referring districts from 2017 to 2020. The primary exposure was pre-eclampsia/ eclampsia hospitalized, using clinical assessment method. The secondary exposure was residential area. The primary outcomes included pregnancy outcomes, evaluated using Mayo clinic assessment schedule on pre-eclampsia. While the secondary outcome was disease distribution among rural and urban women with respect to study selected factors namely; maternal - age, socioeconomy, and health seeking behaviour (ANC visits/ timing).

The study involved sample of 202 respondents calculated (eq. 1) and selected using systematic/ simple random sampling. Data was collected in two months from November to December 2020 using; a check list (ANC/ delivery, referral), structured questionnaire, and structured personal interviews. The study used a statistical package for social sciences (SPSS) version 16 in analysing data using binary logic regression in which residency (rural/ urban) and pregnancy outcome (abnormal/ normal) were used as dependent variables while maternal socioeconomy, maternal age, and antenatal timing were covariates.

\section{Ethical Considerations}

In compliance with the ethical guidelines of the University of Zambia - School of Medicine and ERES Ethics Review Board, the researcher clearly stated the purpose of the research, duration, methods used, and data collection instruments which were approved. Participants' consent was sought before interviews all the time. Interviews were made short in order to preserve time for research respondents.

\section{Sample Size Determination}

The study first used systematic sampling in which all the women treated with preeclampsia/ eclampsia from 2017 to 2019 at the hospitals were recruited to create a sampling frame of 377, from which the final representative sample of 202 for the study were selected using simple random sampling. This meant that participants were randomly selected to participate in the research after accessing sufficient information and an adequate understanding of both the proposed research and the implications of participating in the research. The final sample size of a selected 
woman was then subjected to structured personal interviews.

\section{Data collection}

Data was collected using; a checklist and structured questionnaire (ANC/ delivery, referral), structured personal interviews, and collateral personal interviews for the dead women was used. The interview questionnaire was administered during the scheduled visits to all the rural health facilities where sampled respondents came from. The questionnaire targeted maternal factors; age, socio-economic status, residency, health-seeking behaviour, and pregnancy outcome. The questionnaire was in English; thus, research assistants were multilingual with proficiency in Mambwe, Lungu, Namwanga, and Bemba for easy translation whenever needed.

The collected data was cleaned and analysed using descriptive statistics. Adjusted Odds and percentages were used to describe the effects of maternal factors on pre-eclampsia distribution between rural and urban and how they affect pregnancy outcomes using binary logistic regression model, under statistical package for social sciences (SPSS) version 16.
A total of 202 patients met eligibility criteria and were enrolled into the study. Of these patients, 1 died after 4 days of hospitalization, but was included in the primary analysis using collateral data from the caretaker by then.

Objective 1: To determine whether maternal socio-demographics factors (age, economic status, health-seeking behaviour) are associated with pre-eclampsia distribution with respect to residency in northern Zambia.

Hypothesis 1: The study rejects the Null Hypothesis (H0) that "none" of the maternal socio-demographic factors (age, economic status, health-seeking behaviour) are associated with pre-eclampsia distribution with respect to 'residency' and accepts the Alternate Hypothesis (H1) that at "least one" of the maternal socio-demographic factors (age, economic status, health-seeking behaviour) is associated with pre-eclampsia distribution with respect to 'residency', because the adjusted odds ratios produced by binary logic regression model for age [1.171 (CI 95\%, $1.106-1.240, \mathrm{p}$ $<0.05)$, and socio-economic status [0.246 (CI $95 \%, 0.133-0.455, \mathrm{p}<0.05)]$, are statistically significant at $95 \%$ confidence level.

\section{Results}

Table 1. Binary Logic Regression of Residency *Age, Occupation, ANC Timing Variables in the Equation

\begin{tabular}{|l|l|l|l|l|l|l|l|l|}
\hline Variables & B & SE & Wald & Df & Sig. & $\operatorname{Exp}(\mathbf{B})$ & \multicolumn{2}{|l|}{ 95\%CI for EXP(B) } \\
\cline { 6 - 9 } & & & & & & & Upper & Lower \\
\hline Age & .158 & .029 & 29.347 & 1 & .000 & 1.171 & 1.106 & 1.240 \\
\hline Occ/w & -1.404 & .314 & 19.93 & 1 & .000 & .246 & .133 & .455 \\
\hline ANC/t & .131 & .225 & .339 & 1 & .560 & 1.140 & .733 & 1.772 \\
\hline Constant & -4.070 & 1.026 & 15.737 & 1 & .000 & .017 & & \\
\hline
\end{tabular}

\section{Results 1}

1. Age - Adjusted Odds Ratio 17.1\%, CI 10.6 - $24.0 \%$, statistically significant at $95 \%$ $\mathrm{CL}, \mathrm{p}=0.000$.

2. Maternal Occupation - Adjusted Odds Ratio $24.6 \%$, CI $13.3-45.5 \%$, statistically significant at $95 \% \mathrm{CL}, \mathrm{p}=0.000$.
3. ANC timing - Adjusted Odds Ratio $14.0 \%$, CI $73.3-77.2 \%$, statistically insignificant at $95 \% \mathrm{CL}, \mathrm{p}=0.560$.

Objective 2: To determine whether maternal socio-demographics factors (age, economic status, health-seeking behaviour) are associated with pre-eclampsia distribution with respect to pregnancy outcome in northern Zambia. 
Hypothesis 2: The study rejects the Null Hypothesis (H0) that "none" of the maternal socio-demographic factors (age, economic status, health-seeking behaviour) are associated with pre-eclampsia distribution with respect to 'pregnancy outcome' and accepts the Alternate Hypothesis (H1) that at "least one" of the maternal socio-demographic factors (age, economic status, health-seeking behaviour) is associated with pre-eclampsia distribution with respect to 'pregnancy outcome' because the adjusted odds ratios produced by binary logic regression model for age [1.162 (CI 95\%, 1.099 $-1.228, \mathrm{p}<0.05)]$, and socio-economic status [0.261 (CI 95\%, $0.143-0.477, \mathrm{p}<0.05)]$, are statistically significant at $95 \%$ confidence level.

Table 2: Binary Logic Regression of Pregnancy Outcome *Age, Occupation, ANC Timing Variables in the Equation

\begin{tabular}{|l|l|l|l|l|l|l|l|l|}
\hline Variables & B & SE & Wald & Df & Sig. & $\operatorname{Exp}(\mathbf{B})$ & \multicolumn{2}{|l|}{ 95\%CI for $\operatorname{EXP(B)}$} \\
\cline { 6 - 9 } & & & & & & & Upper & Lower \\
\hline Age & .150 & .028 & 27.706 & 1 & .000 & 1.162 & 1.099 & 1.228 \\
\hline Occ/w & -1.343 & .307 & 19.111 & 1 & .000 & .261 & .143 & .477 \\
\hline ANC/t & .224 & .220 & 1.034 & 1 & .309 & 1.251 & .812 & 1.927 \\
\hline Constant & -4.188 & 1.019 & 16.901 & 1 & .000 & .015 & & \\
\hline
\end{tabular}

\section{Results 2}

4. Age - Adjusted Odds Ratio $16.2 \%$, CI 9.9 $22.8 \%$, statistically significant at $95 \% \mathrm{CL}$, $\mathrm{p}=0.000$.

5. Maternal Occupation - Adjusted Odds Ratio $26.1 \%$, CI $14.3-47.7 \%$, statistically significant at $95 \% \mathrm{CL}, \mathrm{p}=0.000$.

6. ANC timing - Adjusted Odds Ratio 25.1\%, CI $81.2-92.7 \%$, statistically insignificant at $95 \% \mathrm{CL}, \mathrm{p}=0.309$.

\section{Findings $1 \& 2$}

Findings show that those aged 20 years and below, 15-19 years, and 25-29 years, for instance, were about three-fold at risk of developing pre-eclampsia with complications to either mother or baby and likely to be in rural set up. Therefore, low maternal age and low socio-economic status were associated with high levels of pre-eclampsia and dictated the disease distribution and pregnancy outcome as we found more women with lower ages and lower social economic status in rural where preeclampsia distribution was more prevalent with various pregnancy outcome complications. While health-seeking behavior was not associated with pre-eclampsia distribution with respect to neither residency nor pregnancy outcome in northern Zambia.

\section{Discussion}

This retrospective study found that disease distribution and pregnancy outcome were significantly and independently associated with lower maternal age and lower maternal socioeconomy among hospitalized women with preeclampsia at Mbala general hospital and its four referring districts (Mbala, Mpulungu, Senga, and Mungwi) in the northern part of Zambia. A total of $37.1 \%$ of patients in this population were teenagers, who were distributed as $37.1 \%$ rural and $00.0 \%$ urban. $31.7 \%$ were for the age group 16 to 19 years old teenagers and was the most affected teenage population. While $5.4 \%$ consisted 10 to 15 years old group. This is actually consistent with findings by other scholars that a significant difference between pregnant adolescents and adult women do occur with up to $20 \%$ more pre-eclampsia events in pregnant adolescents than in adult women [16]. When compared pregnancy outcomes between rural and urban, using the age groups, the study found that pregnancy complications (preterm, low birth weight, perinatal and maternal deaths) were higher in rural compared to urban, with a 
peak at 19 years old $6.93 \%$, and started decreasing exponentially approaching zero after age 40 (eq. 2).

Maternal socio-economy was also found to be significantly and independently related to pregnancy outcomes with odds of 1.261 (CI $95 \%, 1.143-1.473, \mathrm{p}<\mathrm{P})$ among patients. The study estimated that $64.4 \%$ of women that suffered pre-eclampsia were housewives that survived on less than US\$ 1 per day, while only $3.5 \%$ were found to be living on US\$2.5 per day. The pregnancy complications among women in the study were more common and severe among house-wives but turned to be stable among both those in informal and formal employment. Women in rural were three-fold more affected when compared to urban after adjusting for relevant covariates. To my knowledge, this is the first retrospective study of hospitalized pre-eclampsia patients in a rural-urban setup looking at maternal socioeconomy as one of the factors affecting disease distribution and determining pregnancy outcomes. Thereby providing new and robust data regarding comprehensive communitybased management of pre-eclampsia through use of preventive public health interventions, especially in low-resource countries like Zambia.

In 2008, it was shown that Low maternal socio-economic status is a strong risk factor for pre-eclampsia. Only a small part of this association could be explained by the mediating effects of established risk factors for preeclampsia [17]. However, further research was needed to disentangle the pathway from low socio-economic status to pre-eclampsia and its effect on disease distribution in rural-urban set ups and command on pregnancy outcomes.

However, the study found that antenatal timing (early or late booking) had no significant and independent association with neither distribution nor command on pregnancy outcomes with adjusted odds of Odds Ratio 1.14 (CI 95\%, $1.733-1.772, \mathrm{p}>\mathrm{P}$ ), and 1.251 $(\mathrm{CI} 95 \%, 1.812-1.927, \mathrm{p}>\mathrm{P})$ respectively and rendered it to be statistically insignificant. Thus, the study proved that improving early antenatal bookings among women with the risk of pre-eclampsia does not affect the distribution of disease nor improve the pregnancy outcomes. Other Scholars have argued that early antenatal booking could be used to assess risks so that a suitable surveillance routine to detect pre-eclampsia can be planned for the rest of the pregnancy [18]. However, no study has shown the association between early antenatal booking and pregnancy outcome among women with pre-eclampsia so far. Thus, further research is needed to study specific pathways on how low maternal age (teenage) and low socio-economic status (house-wife) determines the distribution of pre-eclampsia between ruralurban areas and command pregnancy outcomes.

The mean age of this Zambian cohort is generally lower (22 years old) than most cohorts of patients included in developed countries like the US (38) and European (35) studies of pre-eclampsia [19], which has important public health implications with regard to the high rates of death and disability seen in this younger patient population. There are several reasons for this; firstly, Zambia has a younger overall population with lower life expectancy compared to those in found developed countries. Secondly, the county is medically and socioeconomically vulnerable with high rates of poverty, malnutrition, and other comorbidities, which, combined with inequitable access to quality healthcare, likely contributed to an overall younger cohort with 79 teenagers out of 202, all coming from rural areas [19].

Primary health care in Zambia is undergoing a rapid transformation with an aim toward implementing the Sustainable Development Goals and advancing universal health coverage. However, the health system faces challenges associated with inequitable access and affordability of healthcare for those living in rural and poverty-stricken areas, as well as insufficient human resources, frequent drug 
stock outs, and shortages of medical equipment, technology, and transportation. Further exploration of whether structural issues in the healthcare system, including gaps in primary health care, led to the high abnormal pregnancy outcomes and significant disease burden of preeclampsia on hospitalization would be an objective of a future study.

This study had several other strengths. The sample size was large for a retrospective study of hospitalized patients $(\mathrm{N}=202)$ and included both medical (gave birth vaginally) and surgical (underwent caesarian) admissions. The admission criteria was evaluated using a validated tool for pre-eclampsia assessment. All outcome assessment of participants was blinded to their pre-eclampsia exposure.

\section{Equations}

$$
\begin{aligned}
& E S S_{20 \%}=Z 2 Q P / D 2(1-0.2)(1) \\
& \int_{0}^{r_{\mathrm{z}}} F(r, \phi) d r d \phi=\left[\frac{\sigma r_{2}}{2 \mu_{0}}\right]
\end{aligned}
$$

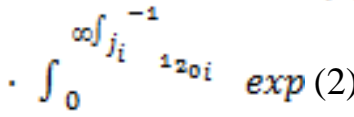

\section{Competing Interests}

The authors declare no competing interests for this manuscript.

\section{Conclusion}

This study examined the factors affecting the distribution of pre-eclampsia between rural and urban areas of northern Zambia, using a retrospective approach and quantitative method.

Findings indicate severe; socio-economic status and low maternal age among preeclamptic women. These socio-demographic characteristics have implications on disease distribution and pregnancy outcomes. The better the socio-demographic conditions, the lower the disease distribution coupled with good pregnancy outcomes.

Preeclampsia disease burden among hospitalized rural women was higher compared to urban areas of Northern Province of Zambian with a significant burden of teenage pregnancies and poverty. Pregnancy outcome was a strong independent predictor of maternal and neonatal morbidity. This data speaks to the fact that maternal-age and maternalsocioeconomic status are important in predicting pregnancy outcomes in hospitalized preeclamptic patients admitted to Maternal and Child Health wards in the northern province of Zambia. Since these two factors are not routinely included in the prevention and management of pre-eclampsia in sub-Saharan African countries, there is an unmet driving need to understand better the public health interventions directed to reduce disease burden and improve maternal and child health outcomes among women and children affected by pre-eclampsia in resource-limited settings. We must build on these data to understand whether detection, prevention, and appropriate management of pre-eclampsia (most of which consists of non-pharmacological interventions) can improve patient outcomes.

Our results also demonstrate that focusing on Social Behavioural Change and Communication (SBCC) on reducing teenage pregnancies, child-marriages and introducing financial empowerment of vulnerable pregnant women such as 'pregnant women social cash transfer' would reduce the prevalence and improve pregnancy outcomes among risk population in second and third world countries like Zambia, and this is in line with assertions by other scholars [20]. Thus, robust measures must be directed towards addressing the major findings of the study through social intervention packages by the government, the ministry of health, and its partners.

\section{Research Funding}

There was not any external funding for this study. The Principal Investigator covered all the costs needed by the study.

\section{Acknowledgements}

I take this opportunity to thank the Research Committee members that worked tirelessly: Dr. Ellen Munyati, Dr. Felix Silwimba, Dr. Sume 
Chisha, and Mr. John Phiri.

I extend my gratitude to Thesis supervisors/ guides Dr. Ellen Milimo Munyati (external) and Ms. R Kousalya (internal).

I also thank members of the Thesis guidelines formulation committee and the research scholars who helped in preparing this guideline at Texila American University on time in this challenging period of the Covid 19 pandemic.

I thank the Provincial Health Director, Dr. Lawrence Phiri, for granting me the authority to pursue a Doctorate degree in Public Health and

\section{References}

[1] Northern HIMS. (2019). Provincial Health Information Management System: PHO. Kasama. Zambia.

[2] Chowa P. E. et al. (2011). Prevalence of Hypertension among Women of Child-Bearing Age in Zambia: Medical Journal of Zambia, 38 (3), 1-6, Retrieved from https://www.ajol.info/index.php/mjz/article/view/81 443.

[3] Andrea $\quad$ P. M. (2001). Pregnancy-related mortality from pre-eclampsia and eclampsia: The American College of Obstetricians and Gynecologists. Elsevier Inc. 97 (4), 533-8, Retrieved from https://pubmed.ncbi.nlm.nih.gov/11275024/.

[4] Sibai. B. M. (2005). Diagnosis, Prevention, and Management of Eclampsia: The American College of Obstetricians and Gynecologists. Elsevier, 105(2), 402-410, Retrieved from https://pubmed.ncbi.nlm.nih.gov/15684172/.

[5] Sibai. B. M. (1997). Risk factors associated with pre-eclampsia in healthy nulliparous women: American Journal of Obstetrics and Gynaecology. Elsevier, 177 (5), 1003-1010, Retrieved from https://www.ajog.org/article/S0002-9378(97)700048/fulltext.

[6] Kayode O. Et al. (2011). Public Health Perspectives of Preeclampsia in Developing Countries: Implication for Health System Strengthening. Journal of Pregnancy, Hindawi, 1 for allowing me to conduct a Thesis in the Northern Province of Zambia.

I extend my sincere thanks to my beloved wife Christabel Mwitwa, my three daughters (Salifyanji, Mwizukanji, \& Sankananji), and my son (Suwilanji Daniel Jr.) for according me the much-needed social family support during thesis preparation through to completion.

Lastly but not least, I thank all members of Mbala DHO, Mpulungu DHO, Senga DHO, Mungwi DHO, and Mbala general hospital for the support rendered to the research team throughout the thesis process.

(1), 1-6, $\quad$ Retrieved from https://www.hindawi.com/journals/jp/2011/481095/. [7] Hladunewich. M. Et al. (2007). Pathophysiology of the Clinical Manifestations of Preeclampsia. Clinical Journal of the American Society of Nephrology. Google Scholar, 2 (3), 543-549, Retrieved from https://cjasn.asnjournals.org/content/2/3/543.

[8] Duley. L. (2009). The Global Impact of Preeclampsia and Eclampsia: Seminars in Perinatology. 33 (3), 130-137, Retrieved from https://doi.org/10.1053/j.semperi.2009.02.010.

[9] WHO. (2015). Recommendations for Prevention and treatment of pre-eclampsia and eclampsia. WHO Press, Geneva 27, Switzerland, human reproduction programme, 1-38 Retrieved from http://apps.who.int/iris/bitstream/handle/10665/4470 3/9789241548335_eng.pdf?sequence $=1$.

[10] Chisoko. E. C et al. (2013). Pre-eclampsia: Maternal and Fetal outcomes according to symptomatology and proteinuria at University Teaching Hospital, Lusaka, 1 (1), 26-29, Retrieved from http://dspace.unza.zm/handle/123456789/3145. [11] Yasuhiro, M. (2019). Significance of prehospital care to reduce the morbidity of eclampsia in rural Zambia: International Society for the Study of Hypertension in Pregnancy. Elsevier B.V, 17 (1), 100-103, Retrieved from https://pubmed.ncbi.nlm.nih.gov/31487623/. 
[12] Rath. W. Et al. (2005). HELLP syndrome. Journal of Perinatal Medicine, 28 (4), 249-260, Retrieved from https://pubmed.ncbi.nlm.nih.gov/11031696/.

[13] Mbala General Hospital HMIS. (2019). Hospital Health Information Management System: Mbala GH. Zambia.

[14] Mbala DHMIS. (2019). District Health Information Management System: Mbala DHO. Zambia.

[15]Chansa. R. et al. (2009). Childbirth Complications among Adolescent Mothers at Mbala General Hospital in Mbala District, Zambia. Open Journal of Nursing, 9 (7), 629-675, Retrieved from https://www.scirp.org/journal/paperinformation.aspx ?paperid $=93777$.

[16] Rosales-Ortiz. S. Et al. (2019). Adolescence and Pre-eclampsia: Prediction of Maternal and Fetal syndrome of Preeclampsia. Retrieved from https://www.intechopen.com/books/prediction-ofmaternal-and-fetal-syndrome-ofpreeclampsia/adolescence-and-preeclampsia.
[17] Silva, Lindsay M. Et al. (2008). Low socioeconomic status is a risk factor for pre-eclampsia: the Generation R Study. Journal of Hypertension, 26 (6), 1200-8, Retrieved from https://pubmed.ncbi.nlm.nih.gov/18475158/.

[18] Kirsten. D. et al. (2005). Risk factors for preeclampsia at antenatal booking: a systematic review of controlled studies. BMJ, 330 (7491), 565, Retrieved from https://pubmed.ncbi.nlm.nih.gov/15743856/.

[19] Abalos. E. et al. (2013). Global and regional estimates of pre-eclampsia and eclampsia: a systematic review. European Journal of Obstetrics \& Gynaecology and Reproductive Biology. Elsevier, $170 \quad(1), \quad 1-7, \quad$ Retrieved from https://pubmed.ncbi.nlm.nih.gov/23746796/.

[20] Namakau C. M. et al. (2015). Cultural and health beliefs of pregnant women in Zambia regarding pregnancy and childbirth. PMC, 38 (1), 788-793, Retrieved from https://www.ncbi.nlm.nih.gov/pmc/articles/PMC609 $1768 /$. 


\title{
An Assessment of Factors Influencing Job Satisfaction of Healthcare Professionals in Ogun State Hospitals, Nigeria
}

\author{
Ahmed Babatunde Jimoh ${ }^{1 *}$, Oluwafemi Tinuola ${ }^{2}$ \\ ${ }^{1}$ State Hospital, Ilaro, Ogun State Hospitals Management Board, Nigeria \\ ${ }^{2}$ School of Public Health Programs, Texila American University, Guyana, South America
}

\begin{abstract}
In the healthcare sector, the job satisfaction of professionals and/or healthcare workers plays a profound role in their performance and is further reflected in the health and satisfaction of the patient. In recent times, the healthcare workers in Nigeria were not seen to be gratified with the organizational policies. The various industrial unions of the health care professionals have engaged in several industrial strike actions over the years in an attempt to demand for better remuneration, improved working conditions, increased staff strength, reduction of work overload, and the likes. This situation among the healthcare professional has become worrisome in Ogun State. This study assessed factors influencing job satisfaction of healthcare professionals in Ogun State Hospitals, Nigeria. The study was conducted with a sample of 729 healthcare professionals from the five zonal offices comprising ThirtyNine (39) Health facilities across the study area. Data and/or items that assessed job satisfaction with management, supervision, nature of work/profession, work environment, salary, benefits, and promotion were subjected to exploratory factor analysis in order to group the major constraints variables. The results showed two orthogonal factors in management, two factors in supervision, five factors in nature of work/profession, three factors in a work environment, and three factors in rewards/compensation, which were derived with total explanations of $50.54 \%, 61.30 \%, 58.32 \%$, $58.82 \%$, and $68.68 \%$ respectively, of the Variance. Only variables with constraints loadings of 0.60 and above were used in naming the factors. The results further revealed that rewards, opportunities for career development, working conditions, and promotional schemes of the organizations have high associations with job satisfaction, whereas work environment was found to have low significance towards job satisfaction. This study concludes that the Ogun State Hospitals Management Board needs to improve the work environment; attractive rewards/compensation, opportunities for career development, and promotions.
\end{abstract}

Keywords: Factors, Healthcare Professionals, Job satisfaction, Nigeria, Ogun State Hospitals.

\section{Introduction}

Globally, health policies are necessary to satisfy with efficiency the requirements of quality management in the health sector [1]. By 2030, optimal health care cannot be delivered as nations commit to achieve universal health coverage by simply ensuring the coexistence of infrastructure, medical supplies, and health care providers. Improving the quality of health services is a continuing challenge to managers in the health system [2]. In the healthcare sector, the job satisfaction of professionals and/or healthcare workers plays a profound role in their performance and is further reflected in the health and satisfaction of the patients [3,4]. One study state that positive or favourable attitudes towards the job indicate job satisfaction while negative or unfavourable attitudes towards their job indicate job dissatisfaction [5]. For the optimum performance and quality of service delivery, the workforce needs to be regularly motivated 
through either financial or non-financial incentives to get satisfied to their work $[6,7,8$, $9,10]$.

There are factors influencing job satisfaction among healthcare workers/professions all over the world. In Sub-Sahara African, increased turnovers, inadequacy, retention, and the perpetual weakening quality of services delivery continue to frustrate healthcare workers, making it difficult for the realization of the health indicators in most African countries [11, 12]. Nigeria has been facing a certain shortage of professionals in the healthcare sector. Workforce dissatisfaction has a negative impact on the performance of the facilities [13].

In recent times, the healthcare workers in Nigeria are not gratified with the organizational policies. For example, thirty-nine (39) Hospitals under the management of the Ogun State Hospitals Management board currently provide secondary care across the State. The various industrial unions of the health care professionals have engaged in several industrial strike actions over the years in an attempt to demand for better remuneration, improved working conditions, increased staff strength, reduction of work overload, and the likes.

The migration of healthcare professionals from the Ogun State HMB to Tertiary Hospitals owned by the Federal Government within the State has become worrisome. Surveys have shown that the numbers of healthcare professionals employed by the State's HMB would decline by half within a year of their employment due to seeking greener pastures elsewhere. This has led to progressive staff attrition with resulting work overload and stress for the healthcare professionals left in the service that cannot efficiently and effectively deliver quality healthcare service to the populace.

In addition, patients visiting the hospital on delay in accessing services have made several complaints, as they have to wait for long hours, cope with the attitude of overstretched healthcare professionals, lack of doctors on sit and many more, which could be attributed to acute shortage of human resources.

Studies also showed that when health service providers are dissatisfied, despite the efforts and energy they put into their work, they tend to reveal this factor when interacting with patients and other staff members. A dissatisfied health service provider poses a potential risk for healthcare-related accidents, and this may negatively influence the mental health and quality of care delivery of such workers [14]. Few studies have recently been conducted on job satisfaction in Nigeria, but little or no studies have been conducted on the factors influencing job satisfaction of healthcare workers and/or professionals in Ogun State Hospitals Management Board. This study assessed the factors influencing job satisfaction among the healthcare professionals in Ogun State Hospitals, Nigeria.

\section{Materials and Methods}

The study area was confined to Ogun State Hospitals Management Board, Ogun State, Nigeria. Ogun State is one of the fastest developing states in the country. It lies in the southwestern part of the country between latitudes $6.2^{\circ} \mathrm{N}$ and $7.8^{\circ} \mathrm{N}$ of the equator and longitudes $3.0^{\circ} \mathrm{E}$ and $5.0^{\circ}$ East of the Greenwich Meridian (Figure. 1). Ogun State occupies an area of $16,980.55 \mathrm{~km}^{2}$ and a population of $3,751,140$, with a density of $220 / \mathrm{km}^{2}$ [15]. The geographical location of the State makes it accessible to the economically developed regions in Nigeria. Ogun State is made up of 20 Local Government Areas (Figure. 1).

The Ogun State Hospitals Management Board's headquarters is situated at Block A, State Secretariat Complex, Oke-Mosan, Abeokuta. The military Government with the objective to provide effective, qualitative, and quantitative healthcare services to the people of Ogun State, established the agency in 1978. The Ogun HMB has five (5) zonal offices (Abeokuta, Ijebu Ode, Ota, Sagamu, and Ilaro Health Zones). The Ogun HMB has under it Five (5) 
State Hospitals, Five (5) Dental Centres, Four (4) Community Mental Health Centres, and Twenty-five (25) General Hospitals with a total of Thirty-Nine (39) Health facilities [16].

The method employed in this study involved a cross-sectional descriptive study design, and it was conducted among the healthcare professionals in Ogun State Hospitals Management Board. A multi-stage sampling technique was adopted to obtain relevant information from the healthcare professionals in the study area. Data were collected mainly with a self-administered structured and unstructured questionnaire in the five (5) zonal offices which comprising all the twenty (20) Local
Government Areas in Ogun State, Nigeria. When the actual number of healthcare workers was insufficient, all the available healthcare workers (729) were given the questionnaires to fill, which were retrieved, coded in excel Microsoft Package. Descriptive and inferential statistics were employed, and exploratory factor was used in grouping the job satisfaction variables into major factors. However, only variables with loadings of 0.60 and above were used in naming the factors. Analysis was done using Statistical Package for Social Sciences (SPSS) version 23, while the results were presented in frequencies tables, graphs, and pie charts.

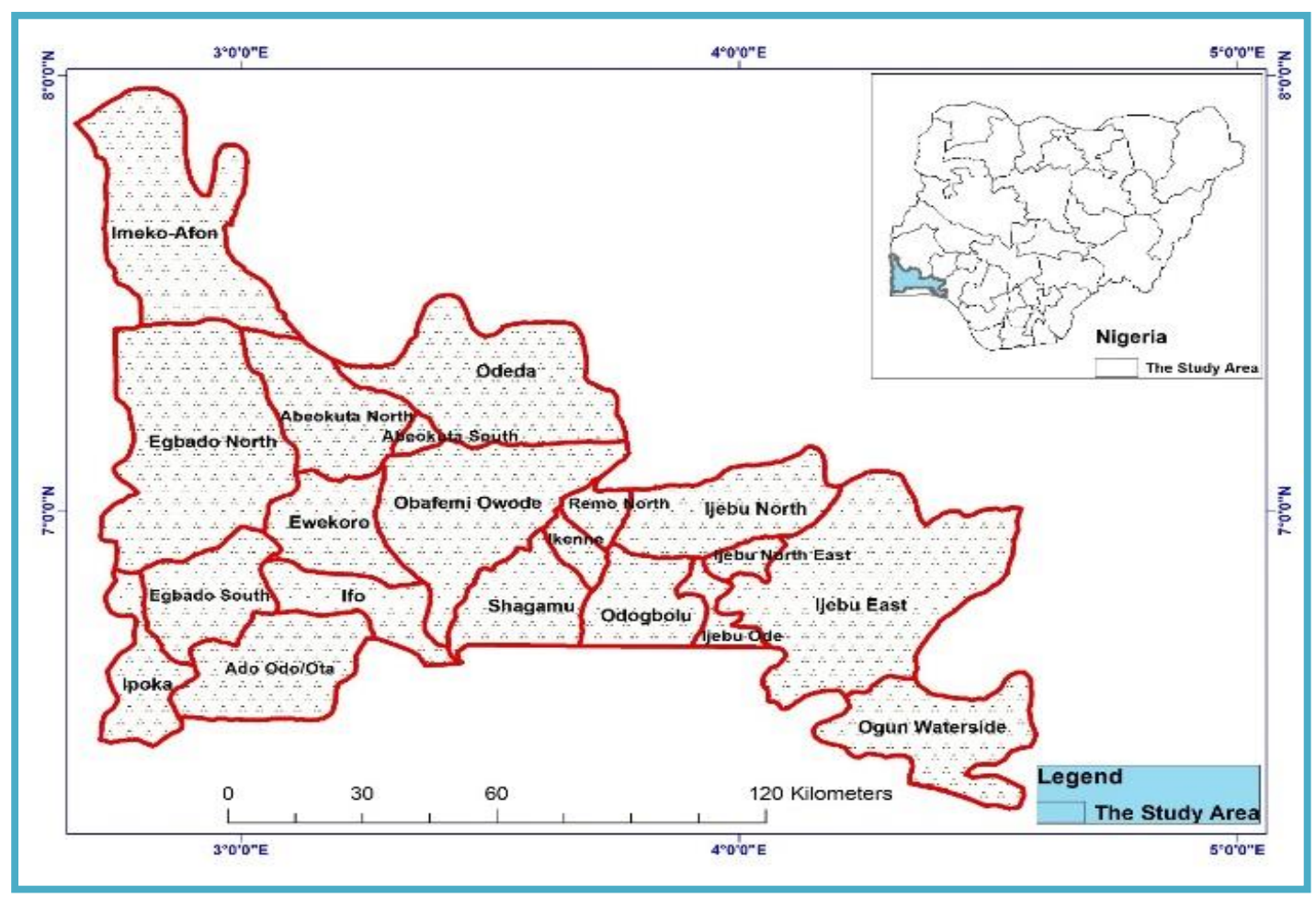

Figure 1. Ogun State, the Study Area

\section{Results}

\section{Demographic Characteristics of the Respondents in the Study Area}

Table 1-2 and Figure. 2-3 present the demographic characteristics of the respondents in the study area. In table 4.1, most participants were female $(73.5 \%)$; and $83.0 \%$ of them were married. The majority of the respondents, 261 (35.8\%) were between the ages 31 and 40, while
$249(34.2 \%)$ were between 41 and 50 years. Of the total respondents, $606(83.1 \%)$, were single (unmarried) and the least percentage of the respondents constituted those who have divorced with the percentage of 1.2 (Figure. 2). The number of respondents with university education constituted larger percentage with $56.5 \%$; the least number of respondents which represents only $16.5 \%$, had postgraduate 
education, while non-graduate respondents constituted a total of 197 (27.0\%).

The Nurses were the majority of the healthcare workers, constituting a total of 388 (53.2\%) of the respondent, followed by the Doctors $110(15.1 \%)$ and other professionals in Ogun State Hospitals Management Board (Table 1). A very small number of respondents which represents $11.2 \%$, have spent more than 20 years, while $36.1 \%$ and $30.0 \%$ of the respondents indicated to have spent between 10-
20 and less than 5 years in the study area (Figure. 3). Table 2 shows the distribution of the healthcare workers across the 39 health facilities under the management of the Ogun State Hospital Management Board (the study area). The results of this study showed that the healthcare workers were not evenly distributed, while Ijaiye had the highest number of healthcare workers with a total of 167 , which represent $22.9 \%$.

Table 1. Demographic Characteristics of the Respondents

\begin{tabular}{|c|c|c|c|}
\hline \multicolumn{2}{|c|}{ Demographic Characteristics } & \multirow{2}{*}{$\begin{array}{l}\text { Frequency } \mathbf{N}=\mathbf{7 2 9} \\
193\end{array}$} & \multirow{2}{*}{$\begin{array}{l}\text { Percent } \\
26.5\end{array}$} \\
\hline Gender & Male & & \\
\hline & Female & 536 & 73.5 \\
\hline \multirow[t]{4}{*}{ Age Bracket } & Less than 30 & 112 & 15.4 \\
\hline & $31-40$ & 261 & 35.8 \\
\hline & $41-50$ & 249 & 34.2 \\
\hline & 50 and above & 107 & 14.7 \\
\hline \multirow[t]{4}{*}{ Marital Status } & Married & 606 & 83.1 \\
\hline & Unmarried & 99 & 13.6 \\
\hline & Divorced & 9 & 1.2 \\
\hline & Widowed & 15 & 2.1 \\
\hline \multirow[t]{3}{*}{ Education Level } & Diploma & 197 & 27.0 \\
\hline & Graduate & 412 & 56.5 \\
\hline & Postgraduate & 120 & 16.5 \\
\hline \multirow[t]{15}{*}{ Profession } & Doctor & 110 & 15.1 \\
\hline & Dentist & 20 & 2.7 \\
\hline & Nurse & 388 & 53.2 \\
\hline & Pharmacist & 37 & 5.1 \\
\hline & Medlab Scientist & 35 & 4.8 \\
\hline & Physiotherapist & 16 & 2.2 \\
\hline & Dietician/Nutritionist & 13 & 1.8 \\
\hline & Lab Technician & 44 & 6.0 \\
\hline & Pharm. Technician & 38 & 5.2 \\
\hline & Dental Assistant/Therapist & 14 & 1.9 \\
\hline & Radiographer & 4 & 0.5 \\
\hline & Dental Technologist & 5 & 0.7 \\
\hline & Optometrist & 2 & 0.3 \\
\hline & X-ray Technician & 3 & 0.4 \\
\hline & Total & 729 & 100.0 \\
\hline
\end{tabular}




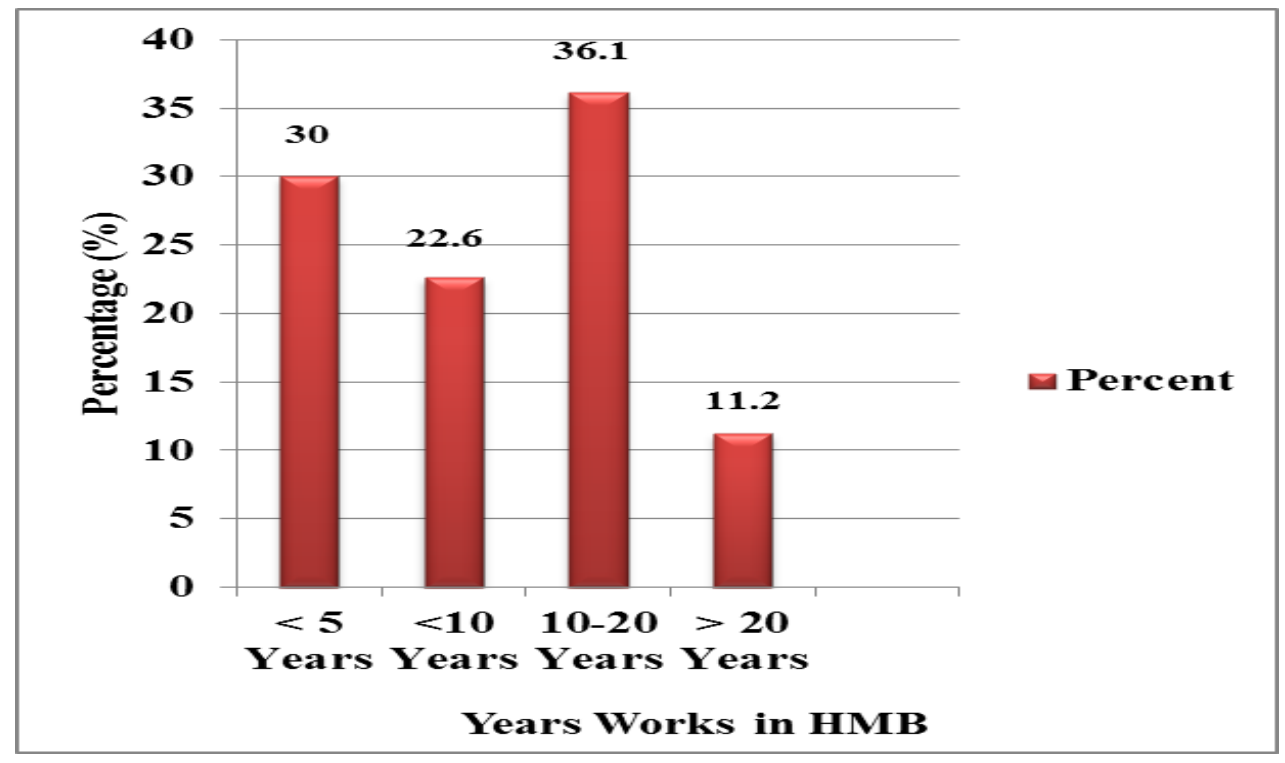

Figure 2. Distribution of the Years spent in service of the HMB

Table 2. Distribution of Healthcare Workers across the Health Facilities

\begin{tabular}{|l|l|l|}
\hline Name of Facility & Frequency & Percent (\%) \\
\hline Community Hospital Ilisan & 7 & 1.0 \\
\hline Community Hospital Isaga Orile & 4 & 0.5 \\
\hline Community Mental Health Centre Ijebu-Ode & 3 & 0.4 \\
\hline Community Mental Health Centre Ilaro & 3 & 0.4 \\
\hline Community Psychiatric Centre Ota & 4 & 0.5 \\
\hline Community Psychiatry Abeokuta & 9 & 1.2 \\
\hline Dental Centre Abeokuta & 17 & 2.3 \\
\hline Dental Centre Ayetoro & 2 & 0.3 \\
\hline Dental Centre Ijebu-ode & 9 & 1.2 \\
\hline Dental Centre OTA & 5 & 0.7 \\
\hline Dental Centre Sagamu & 7 & 1.0 \\
\hline General Hospital Ala-idowa & 10 & 1.4 \\
\hline General Hospital Atan & 7 & 1.0 \\
\hline General Hospital Ayetoro & 18 & 2.5 \\
\hline General Hospital Iberekodo & 9 & 1.2 \\
\hline General Hospital Ibiade & 8 & 1.1 \\
\hline General Hospital Idiroko & 15 & 2.1 \\
\hline General Hospital IFO & 26 & 3.6 \\
\hline General Hospital Ijebu-ife & 11 & 1.5 \\
\hline General Hospital Ijebu-igbo & 15 & 2.1 \\
\hline General Hospital Ikenne & 10 & 1.4 \\
\hline General Hospital Imeko & 10 & 1.4 \\
\hline General Hospital Iperu & 12 & 1.6 \\
\hline General Hospital Ipokia & 5 & 0.7 \\
\hline General Hospital Itori & 10 & 1.4 \\
\hline General Hospital Ode-Lemo & 5 & 0.7 \\
\hline General Hospital Odeda & 13 & 1.8 \\
\hline
\end{tabular}




\begin{tabular}{|l|l|l|}
\hline General Hospital Odogbolu & 10 & 1.4 \\
\hline General Hospital Ogbere & 5 & 0.7 \\
\hline General Hospital Omu-ijebu & 9 & 1.2 \\
\hline General Hospital owode-egba & 16 & 2.2 \\
\hline Hansen Clinic Iberekodo & 8 & 1.1 \\
\hline Oba Ademola Maternity Abeokuta & 24 & 3.3 \\
\hline Olikoye Ransom Kuti Memorial Hospital, Abeokuta & 34 & 4.7 \\
\hline State Hospital Ijaiye & 167 & 22.9 \\
\hline State Hospital Ijebu-Ode & 68 & 9.3 \\
\hline State Hospital Ilaro & 38 & 5.2 \\
\hline State Hospital Isara & 37 & 5.1 \\
\hline State Hospital Ota & 59 & 8.1 \\
\hline Total & $\mathbf{7 2 9}$ & $\mathbf{1 0 0}$ \\
\hline
\end{tabular}

\section{Factors Responsible for Job Satisfaction or Job Dissatisfaction of Healthcare Professionals in the Study Area}

The data and/or items that evaluate job satisfaction with management, supervision, nature of work/profession, work environment, salary, benefits, and promotion were subjected to exploratory factor analysis in order to group the constraints variables. The results of the rotated component matrix showing the extracted factors based on the responses of respondents are shown in Table 3-7 below. The results showed two orthogonal factors in management, two factors in supervision, five factors in nature of work/profession, three factors in work environment, and three factors in rewards, which were derived with total explanations of $50.54 \%$, $61.30 \%, 58.32 \%, 58.82 \%$, and $68.68 \%$ respectively, of the Variance. Only variables with constraints loadings of 0.60 and above were used in naming the constraints. The Eigen values, percentage of Variance, and cumulative percentage of the Variance explained are also presented in Table 3-7. In the management aspect of job satisfaction in Ogun State HMB (Table 3), Factor I is tagged "staff development factor" while Factor II is tagged "leadership policy factor". These two factors have an impact on job satisfaction and qualities of healthcare delivery in Ogun State HMB. The eigenvalue of Factor I is 4.95 with $41.28 \%$ of the Variance.
Factor I has very high significant loading on the variable 'The HMB provides for a career opportunity and growth of employees' (0.73) and "The HMB provides for additional training and education support" (0.72), and moderately high loading on the variables 'HMB provide for orientation and training of new employees' (0.69). Factor II has an Eigen value of 1.11 and contributed $9.26 \%$ to the Variance in the management of job satisfaction and quality of healthcare workers in Ogun State HMB. Factor II has the highest loading on 'I am satisfied with the leadership and management style of the HMB', 'The HMB value her employees', and 'HMB's many rules and procedures make doing a good job difficult' with loading points 0.72 , 0.62 and -0.62 respectively.

The two factors extracted from the supervision of job satisfaction and quality of healthcare delivery in Ogun State HMB was designated as supervisory and subordinates (Table 4). The factor I called supervisory is highly loaded in almost all the variables except "My supervisor shows little interest in the feelings of subordinates' and 'My supervisor holds me and other workers accountable for performance'. Factor II is highly loaded on the one constraint variable, namely 'My supervisor shows little interest in the feelings of subordinates' (0.85) and with an Eigen value of 1.12 and contributed $9.34 \%$ to the Variance in 
the supervision of job satisfaction and quality of healthcare workers in the study area.

Regarding the nature of work/profession, five factors were derived with total explanation of $58.32 \%$ of the Variance (Table 5). The extracted five factors were named 'job qualities, resources, job pressure, reward and training'. The factor I, which is named 'job qualities', contributes $28.13 \%$ explanation, and this factor is highly loaded on only two variables: 'I have opportunity to improve my professional skill and knowledge at work' (0.75), 'I am able to provide the best services at my workplace' $(0.70)$ and moderately loaded on six variables. Factor II has very high significant loading on the variable 'My department provides all equipment, supplies, and resources necessary to work with' (0.68) and "I have the autonomy to make decisions in the execution of my work according to the best clinical judgment" (0.72). Factor II has an Eigen value of 2.12 and contributed $10.82 \%$ to the Variance in the profession of job satisfaction and quality of healthcare workers in the study area. Factor III has an eigenvalue of 1.53 with $7.66 \%$ of Variance. The variables are related to job pressure. It has very high significant loadings on the variables 'The job adds significant pressure and anxiety to my life' (0.75) and 'the job demand is too much (physically, emotionally and mentally)' (0.76). Factor IV of the nature of work is related to rewards. It is highly loaded on two variables; 'I would consider leaving my better pay' (0.78) and 'I would consider leaving my job for greater opportunity for advancement' (0.69), with an Eigen value of 1.25 and contributed $6.26 \%$ to the Variance. The variables 'There are services we need to offer that we currently do not' (0.69) and 'I believe I need extra training to perform optimally' (0.68) are significantly loaded with Eigen value of 1.09.

In addition, three factors derived from the work environment as related to job satisfaction of healthcare workers in Ogun State HMB were facility, relationship, and employees' attitudes (Table 6). These factors have 35.02, 16.41, and 7.38 total \% of Variance. All these factors have an effect on healthcare worker's job satisfaction in the study area with total explanations of $58.82 \%$ contribution.

Finally, promotion, salary, and benefits were three major factors derived from the rewards as it has an impact on job satisfaction of healthcare workers in Ogun State HMB (Table 7). It has a total Cumulative \% of Variance Explained of 68.68 (4.13). The factor I named 'promotion 'contributes $37.04 \%$ explanation and this factor is positively and highly loaded on 'I am satisfied with my chances of promotion', 'I am satisfied with regards to illness benefits, disability benefits and life insurance', 'I am satisfied with my retirement plan benefits', and 'I am satisfied with my salary'. Factor II has an eigenvalue of 1.68 with $18.69 \%$ of Variance. The variables are related to job salary. It has very high significant loadings on the variables 'The salary received is good as most other organizations offers' $(0.86)$ and 'I get decent salary for the job I perform' (0.81). The third factor is benefits. It has high loadings on three variables such as 'I don't feel my efforts are rewarded the way they should, 'there are benefits we don't have which we should', and 'The influence of trade union contract on the existing salary system' with loading values of $0.79, \quad 0.76$ and 0.67 respectively.

Table 3. Managerial Factors for Job Satisfaction in HMB

\begin{tabular}{|l|l|l|}
\hline Items Description & Factor 1 & Factor 2 \\
\hline $\begin{array}{l}\text { Policies of HMB to create a conducive work } \\
\text { environment }\end{array}$ & 0.545 & 0.391 \\
\hline $\begin{array}{l}\text { HMB's many rules and procedures make doing } \\
\text { a good job difficult }\end{array}$ & 0.493 & -0.616 \\
\hline The HMB is supportive of her employees & 0.533 & 0.463 \\
\hline
\end{tabular}




\begin{tabular}{|l|l|l|}
\hline $\begin{array}{l}\text { HMB provide for orientation and training of } \\
\text { new employees }\end{array}$ & 0.688 & 0.224 \\
\hline $\begin{array}{l}\text { The HMB provides for career opportunity and } \\
\text { growth of employees }\end{array}$ & 0.725 & 0.286 \\
\hline $\begin{array}{l}\text { The HMB provides for additional training and } \\
\text { education support }\end{array}$ & 0.721 & 0.27 \\
\hline The HMB value her employees & 0.514 & 0.622 \\
\hline The HMB provide steady employment & 0.36 & 0.455 \\
\hline $\begin{array}{l}\text { The HMB provide periodic measurement of } \\
\text { individual efficiency }\end{array}$ & 0.315 & 0.534 \\
\hline I believe my job is secured with the Agency & 0.237 & 0.563 \\
\hline $\begin{array}{l}\text { I am satisfied with the leadership and } \\
\text { management style of the HMB }\end{array}$ & 0.344 & 0.72 \\
\hline $\begin{array}{l}\text { I am satisfied with the employee's transfer } \\
\text { policy }\end{array}$ & 0.33 & 0.53 \\
\hline Factor Description & Staff Development & Leadership Policies \\
\hline Eigenvalues & 4.954 & 1.111 \\
\hline \% Of Variance & 41.285 & 9.258 \\
\hline Cumulative \% of Variance Explained & 41.285 & 50.543 \\
\hline
\end{tabular}

Extraction Method: Principal Component Analysis

Rotation Method: Varimax with Kaiser Normalization

a. Rotation converged in 3 iterations

Table 4. Supervision Factors for Job Satisfaction in HMB

\begin{tabular}{|c|c|c|c|c|c|}
\hline \multirow[t]{2}{*}{ Items Description } & \multicolumn{5}{|c|}{ Factors } \\
\hline & 1 & 2 & 3 & 4 & 5 \\
\hline I have an accurate written job description & 0.68 & 0.078 & 0.054 & -0.246 & 0.096 \\
\hline $\begin{array}{l}\text { I have the opportunity to improve my } \\
\text { professional skill and knowledge at work }\end{array}$ & 0.746 & 0.052 & 0.084 & -0.151 & 0.009 \\
\hline $\begin{array}{l}\text { I am provided with the necessary } \\
\text { training to perform to satisfaction }\end{array}$ & 0.675 & 0.181 & 0.162 & -0.074 & -0.282 \\
\hline $\begin{array}{l}\text { I feel overwhelmed by my } \\
\text { responsibilities at work }\end{array}$ & 0.526 & -0.06 & 0.502 & -0.003 & -0.073 \\
\hline $\begin{array}{l}\text { The job adds significant pressure and } \\
\text { anxiety to my life }\end{array}$ & -0.112 & 0.02 & 0.75 & 0.226 & 0.044 \\
\hline $\begin{array}{l}\text { The job demand is too much (physically, } \\
\text { emotionally and mentally) }\end{array}$ & -0.051 & 0.02 & 0.762 & 0.205 & 0.15 \\
\hline $\begin{array}{l}\text { I am fully able to use my skill in the } \\
\text { present position. }\end{array}$ & 0.614 & 0.241 & 0.032 & 0.039 & -0.112 \\
\hline $\begin{array}{l}\text { I am satisfied at the level of quality } \\
\text { services delivered in my facility }\end{array}$ & 0.525 & 0.576 & 0.087 & -0.053 & -0.133 \\
\hline $\begin{array}{l}\text { My department provides all equipment, } \\
\text { supplies, and resources necessary to } \\
\text { work with. }\end{array}$ & 0.369 & 0.684 & 0.058 & -0.046 & -0.167 \\
\hline
\end{tabular}




\begin{tabular}{|l|l|l|l|l|l|}
\hline $\begin{array}{l}\text { I have autonomy to make decisions in } \\
\text { execution of my work according to the } \\
\text { best clinical judgment. }\end{array}$ & 0.101 & 0.716 & 0.105 & -0.225 & 0.323 \\
\hline $\begin{array}{l}\text { I believe I need extra training to perform } \\
\text { optimally }\end{array}$ & 0.173 & -0.046 & 0.018 & 0.039 & 0.683 \\
\hline I feel positive and happy doing my work & 0.692 & 0.091 & -0.132 & -0.097 & 0.33 \\
\hline I would consider leaving my better pay & -0.05 & 0.067 & 0.192 & 0.779 & 0.018 \\
\hline $\begin{array}{l}\text { I would consider leaving my job for } \\
\text { greater opportunity for advancement }\end{array}$ & 0.006 & -0.129 & 0.25 & 0.688 & 0.165 \\
\hline $\begin{array}{l}\text { I have energy at the end of workday to } \\
\text { engage in personal interest }\end{array}$ & 0.183 & 0.57 & -0.242 & 0.273 & -0.048 \\
\hline $\begin{array}{l}\text { I have ample opportunities for } \\
\text { advancement in my career. }\end{array}$ & 0.566 & 0.286 & -0.144 & 0.206 & 0.094 \\
\hline $\begin{array}{l}\text { I am able to live a happy home-life with } \\
\text { realization of my aspirations }\end{array}$ & 0.627 & 0.223 & -0.288 & 0.261 & 0.181 \\
\hline $\begin{array}{l}\text { I am able to command respect and } \\
\text { dignity from my job. }\end{array}$ & 0.625 & 0.276 & -0.234 & 0.15 & 0.298 \\
\hline $\begin{array}{l}\text { I am able to provide the best services at } \\
\text { my workplace }\end{array}$ & 0.704 & 0.215 & -0.209 & 0.165 & 0.091 \\
\hline $\begin{array}{l}\text { There are services we need to offer that } \\
\text { we currently do not. }\end{array}$ & -0.057 & 0.029 & 0.129 & 0.107 & 0.688 \\
\hline Factor Description & Job Qualities & Resources & Job Pressure & Reward & Training \\
\hline Eigenvalues & 5.625 & 2.164 & 1.532 & 1.252 & 1.092 \\
\hline \% Of Variance & 28.125 & 10.819 & 7.659 & 6.258 & 5.462 \\
\hline Cumulative \% of Variance Explained & 28.125 & 38.943 & 46.603 & 52.860 & 58.322 \\
\hline
\end{tabular}

Extraction Method: Principal Component Analysis

Rotation Method: Varimax with Kaiser Normalization

a. Rotation converged in 3 iterations

Table 5. Work Environment and Job Satisfaction of Healthcare Workers in HMB

\begin{tabular}{|l|l|l|l|}
\hline \multirow{2}{*}{ Items Description } & \multicolumn{2}{l|}{ Factors } \\
\cline { 2 - 5 } & $\mathbf{1}$ & $\mathbf{2}$ & $\mathbf{3}$ \\
\hline $\begin{array}{l}\text { Availability of aesthetically pleasant physical } \\
\text { environment }\end{array}$ & 0.687 & 0.089 & -0.062 \\
\hline $\begin{array}{l}\text { Provision of water, lighting, ventilation at } \\
\text { workplace }\end{array}$ & 0.735 & 0.096 & -0.137 \\
\hline Availability of security for life and property & 0.796 & 0.026 & 0.004 \\
\hline $\begin{array}{l}\text { Provision of ergonomic comfortability at work } \\
\text { e.g., ergonomic chairs, comfortable call rooms, } \\
\text { etc. }\end{array}$ & 0.762 & 0.011 & 0.123 \\
\hline $\begin{array}{l}\text { Availability of efficient equipment and tools } \\
\text { workplace. }\end{array}$ & 0.797 & 0.105 & 0.061 \\
\hline There is the provision of sanitary facilities. & 0.719 & 0.173 & -0.032 \\
\hline $\begin{array}{l}\text { The building, work area (floor), and layout are } \\
\text { adequate to work efficiently. }\end{array}$ & 0.768 & 0.113 & 0.008 \\
\hline
\end{tabular}




\begin{tabular}{|l|l|l|l|}
\hline $\begin{array}{l}\text { There is an implementation of safety norms in } \\
\text { my workplace }\end{array}$ & 0.762 & 0.204 & -0.058 \\
\hline I have a safe workplace & 0.793 & 0.211 & 0.01 \\
\hline I look forward to going to work daily & 0.534 & 0.381 & -0.158 \\
\hline There is mutual cooperation among co-workers. & 0.291 & 0.563 & -0.308 \\
\hline $\begin{array}{l}\text { I am satisfied with my relationship with my } \\
\text { immediate supervisor }\end{array}$ & 0.078 & 0.817 & -0.075 \\
\hline $\begin{array}{l}\text { I am satisfied with my relationship with my } \\
\text { subordinate }\end{array}$ & -0.045 & 0.833 & -0.008 \\
\hline $\begin{array}{l}\text { I am satisfied with my relationship with other } \\
\text { workers }\end{array}$ & 0.05 & 0.849 & -0.09 \\
\hline $\begin{array}{l}\text { There is a non-threatening way of } \\
\text { communicating the weakness of workers }\end{array}$ & 0.172 & 0.656 & -0.011 \\
\hline $\begin{array}{l}\text { Communications seem good within this } \\
\text { organization }\end{array}$ & 0.214 & 0.7 & -0.133 \\
\hline There is too much bickering and fighting at work & -0.034 & -0.144 & 0.818 \\
\hline $\begin{array}{l}\text { I have the opportunity to give input on decisions } \\
\text { affecting my work }\end{array}$ & 0.155 & 0.571 & 0.076 \\
\hline $\begin{array}{l}\text { I have to work harder at my workplace because } \\
\text { of the incompetence of the people I work with. }\end{array}$ & 0.023 & -0.03 & 0.822 \\
\hline Factor Description & Facility & Relationship & Employee's attitudes \\
\hline Eigenvalues & 6.655 & 3.118 & 1.402 \\
\hline \% Of Variance & 35.027 & 16.412 & 7.381 \\
\hline Cumulative \% of Variance Explained & 51.440 & 58.821 \\
\hline
\end{tabular}

Extraction Method: Principal Component Analysis

Rotation Method: Varimax with Kaiser Normalization

a. Rotation converged in 3 iterations

Table 6. Work Environment and Job Satisfaction of Healthcare Workers in HMB

\begin{tabular}{|l|l|l|l|}
\hline \multirow{2}{*}{ Items Description } & Factors & \multicolumn{2}{l|}{} \\
\cline { 2 - 4 } & $\mathbf{1}$ & $\mathbf{2}$ & $\mathbf{3}$ \\
\hline $\begin{array}{l}\text { Availability of aesthetically pleasant } \\
\text { physical environment }\end{array}$ & 0.687 & 0.089 & -0.062 \\
\hline $\begin{array}{l}\text { Provision of water, lighting, ventilation at } \\
\text { workplace }\end{array}$ & 0.735 & 0.096 & -0.137 \\
\hline $\begin{array}{l}\text { Availability of security for life and } \\
\text { property }\end{array}$ & 0.796 & 0.026 & 0.004 \\
\hline $\begin{array}{l}\text { Provision of ergonomic comfortability at } \\
\text { work e.g., ergonomic chairs, comfortable } \\
\text { call rooms, etc. }\end{array}$ & 0.762 & 0.011 & 0.123 \\
\hline $\begin{array}{l}\text { Availability of efficient equipment and } \\
\text { tools workplace. }\end{array}$ & 0.797 & 0.105 & 0.061 \\
\hline There is a provision of sanitary facilities. & 0.719 & 0.173 & -0.032 \\
\hline $\begin{array}{l}\text { The building, work area (floor), and layout } \\
\text { are adequate to work efficiently. }\end{array}$ & 0.768 & 0.113 & 0.008 \\
\hline
\end{tabular}




\begin{tabular}{|l|l|l|l|}
\hline $\begin{array}{l}\text { There is an implementation of safety } \\
\text { norms in my workplace }\end{array}$ & 0.762 & 0.204 & -0.058 \\
\hline I have a safe workplace & 0.793 & 0.211 & 0.01 \\
\hline I look forward to going to work daily & 0.534 & 0.381 & -0.158 \\
\hline $\begin{array}{l}\text { There is mutual cooperation among co- } \\
\text { workers. }\end{array}$ & 0.291 & 0.563 & -0.308 \\
\hline $\begin{array}{l}\text { I am satisfied with my relationship with } \\
\text { my immediate supervisor }\end{array}$ & 0.078 & 0.817 & -0.075 \\
\hline $\begin{array}{l}\text { I am satisfied with my relationship with } \\
\text { my subordinate }\end{array}$ & -0.045 & 0.833 & -0.008 \\
\hline $\begin{array}{l}\text { I am satisfied with my relationship with } \\
\text { other workers }\end{array}$ & 0.05 & 0.849 & -0.09 \\
\hline $\begin{array}{l}\text { There is a non-threatening way of } \\
\text { communicating the weakness of workers }\end{array}$ & 0.172 & 0.656 & -0.011 \\
\hline $\begin{array}{l}\text { Communications seem good within this } \\
\text { organization }\end{array}$ & 0.214 & 0.7 & -0.133 \\
\hline $\begin{array}{l}\text { There is too much bickering and fighting at } \\
\text { work }\end{array}$ & -0.034 & -0.144 & 0.818 \\
\hline $\begin{array}{l}\text { I have the opportunity to give input on } \\
\text { decisions affecting my work }\end{array}$ & 0.155 & 0.571 & 0.076 \\
\hline $\begin{array}{l}\text { I have to work harder at my workplace } \\
\text { because of the incompetence of the people } \\
\text { I work with. }\end{array}$ & 0.023 & -0.03 & 0.822 \\
\hline Factor Description & Facility & Relationship & Employee's attitudes \\
\hline Eigenvalues & 6.655 & 3.118 & 1.402 \\
\hline$\%$ Of Variance & 35.027 & 16.412 & 5.381 \\
\hline Cumulative \% of Variance Explained & 58.821 \\
\hline
\end{tabular}

Extraction Method: Principal Component Analysis

Rotation Method: Varimax with Kaiser Normalization

a. Rotation converged in 3 iterations

Table 7. Rewards and Job Satisfaction of Healthcare Workers in HMB

\begin{tabular}{|l|l|l|l|}
\hline Items Description & \multicolumn{2}{l}{ Factors } \\
\cline { 2 - 4 } & $\mathbf{1}$ & $\mathbf{2}$ & $\mathbf{3}$ \\
\hline I get a decent salary for the job I perform & 0.312 & 0.813 & 0.059 \\
\hline $\begin{array}{l}\text { The salary received is good as most other } \\
\text { organizations offers }\end{array}$ & 0.093 & 0.858 & 0.125 \\
\hline There are benefits we don't have which we should. & -0.077 & 0.118 & 0.76 \\
\hline $\begin{array}{l}\text { The influence of trade union contract on the } \\
\text { existing salary system. }\end{array}$ & 0.024 & 0.261 & 0.666 \\
\hline $\begin{array}{l}\text { I don't feel my efforts are rewarded the way they } \\
\text { should. }\end{array}$ & 0.129 & -0.179 & 0.793 \\
\hline I am satisfied with my chances of promotion & 0.786 & 0.162 & 0.056 \\
\hline $\begin{array}{l}\text { I am satisfied with regard to illness benefits, } \\
\text { disability benefits, and life insurance. }\end{array}$ & 0.875 & 0.09 & 0 \\
\hline
\end{tabular}




\begin{tabular}{|l|l|l|l|}
\hline I am satisfied with my retirement plan benefits & 0.886 & 0.109 & 0.025 \\
\hline I am satisfied with my salary. & 0.647 & 0.485 & -0.004 \\
\hline Factor Description & Promotion & Salary & Benefits \\
\hline Eigenvalues & 3.334 & 1.682 & 1.166 \\
\hline \% Of Variance & 37.042 & 18.689 & 12.953 \\
\hline Cumulative \% of Variance Explained & 37.042 & 55.731 & 68.684 \\
\hline
\end{tabular}

Extraction Method: Principal Component Analysis

Rotation Method: Varimax with Kaiser Normalization

a. Rotation converged in 3 iterations

\section{Discussion}

Job satisfaction of health care providers plays a great role in providing quality healthcare. From the present study, healthcare professionals were largely sampled with the ratio of male and female of 0.26 to 0.74 . This is because the study was conducted in Ogun State Hospitals, and the population of females was more than males. Most of the healthcare professionals were found to be between the ages of 31 and 50, which corresponds to the report of $[17,18,19]$. Being a Gateway State and one of the foremost educated States in Nigeria, the results of this study showed that the majority of the people in the study are educated, with a very large number of nurses and medical doctors with formal education. Uneven distribution of healthcare works might be attributed to the distribution of health facilities, where the State Hospital Ijaiye had the highest number of healthcare workers.

Findings obtained from this study revealed that there are determinant factors influencing job satisfaction and quality of healthcare delivery in Ogun State Hospitals. The findings of this study clearly showed that many healthcare workers believed that management, nature of work/profession, work environment, and rewards have a great impact on job satisfaction. The findings of this study corroborate with the study of [20]. This study found out two major variables in management, two factors in supervision, five factors in nature of work/profession, three factors in the work environment, and three factors in rewards, which were derived with total explanations of $50.54 \%$, $61.30 \%, 58.32 \%, 58.82 \%$, and $68.68 \%$ respectively, of the Variance. The physical infrastructures being the basic requirement for the effective functioning of an organization, have an important bearing on the job satisfaction of healthcare professionals.

One of the studies revealed that motivators (such as assurance of better working conditions, effective and efficient support system, opportunities for career development, financial incentives, better living conditions, and family support) are required for working in rural communities [21]. These findings are consistent with researches which have documented the need to improve working conditions and salary in a bid to motivate health workers and improve their job satisfaction $[22,23]$. The findings of the working condition and/or work environment were similar to the findings in studies conducted in Ethiopia [11] and Greece [24]. Further, the findings of this study also revealed that healthcare workers have a decent and receive a good salary, satisfied with the chances of promotion and the plan they have towards the retirements.

Based on the findings of this study, health workers were satisfied with the pay and promotion potentials of their workplaces. This finding was similar to the study conducted in Ogun state, Nigeria, where $38.2 \%$ of the workers liked their job because of the pay [21]. In contrast, the study conducted in Iran by [25] revealed that majority of healthcare workers were dissatisfied with their salaries. Pay and income plays a significant role in how health workers derive pleasure from their job, as relatively low pay can cause dissatisfaction and 
loss of motivation. The same applies to emigration towards higher-paying jobs. [18] also concluded a study and found that a healthy work environment for nurses in the primary health care settings is an important factor in improving work satisfaction, reducing turnover intention, and improving nursing care outcomes. A study concludes that workload, time pressures, and job control are to maintain morale among general practitioners [26].

\section{Conclusion and Recommendation}

Job satisfaction among healthcare professionals have significant effects on service delivery and healthcare professionals' lives. The results of the study have assessed that the job satisfaction in healthcare professionals in Ogun State Hospitals is highly associated with certain factors which need to be developed and focused on by the healthcare management. The study concludes that rewards or compensation (including attractive promotional schemes) have a great influence on the job satisfaction of healthcare professionals. In addition, other major factors that influence job satisfaction of healthcare workers in Ogun State Hospitals

\section{References}

[1] Tshamba, H.M., Yav, G.D., Didier, V., and Malonga, K.F., 2014, The assessment of job satisfaction for the healthcare providers in university clinics of Lubumbashi, Democratic Republic of Congo. Pan African Medical Journal, 19 (265), 1-12. doi:10.11604/pamj.2014.19.265.3138.

[2] Tzeng, H.M., 2002, The influence of nurses' working motivation and job satisfaction on intention to quit: An empirical investigation in Taiwan. International Journal of Nursing Studies, 39, 867878.

[3] Getnet, G., Yetnayet, S., Animut, A., and Yihalem, A.B., 2018, Level of Job Satisfaction and Associated factors among health care Professionals working at University of Gonder Referral Hospital, Northwest Ethiopia: A cross-sectional study. BMC include supervision, work environment, nature of work, and organizational management, respectively.

The management of public healthcare institutions of Ogun State needs to improve the Work Environment. In addition, healthcare professionals must be given attractive compensation, opportunities for career development, and promotions. This research was conducted on a small sample which limits its generalizability. Future researchers need to expand the scope of this study by focusing on a large sample so that its results can be generalized to the entire public health care sector of Nigeria.

\section{Conflicts of Interest}

There is no conflict of interest between the authors.

\section{Acknowledgements}

The author expresses his gratitude to all healthcare workers and the Department of Research Planning and Statistics (HMB) for their willingness and cooperation to participate in this study.

Res Notes, 11, 824. https://doi.org/10.1186/s13104018-3918-0.

[4] Raja, M.A., and Faraz, A.W., 2013, Factors influencing job satisfaction in public healthcare sector of Pakistan. Global Journal of Management and Business Research Administration and Management, 13(8), 60-66.

[5] Aziri, B., 2011, Job Satisfaction: A literature review. Management Research and Practice, 3, 7786.

[6] Ajayi K., 2004, Leadership, motivation, team work and information management for organizational efficiency. Niger J Soc Sci., 74(6), 1-16.

[7] International Council of Nurses-ICN, 2007, Positive practice environment: Quality workplaces quality patient care. Information and Action Tool Kit. Geneva: International Council of Nurses. Retrieved 
from: http://www.icn.ch/indkit2007pdf , accessed on 26/10/2020.

[8] Bjork, I.T., Samdal, G.B., Hansen, B.S., Torstad, S., and Hamilton, G.A., 2007, Job satisfaction in a Norwegian population of nurses: a questionnaire survey. International Journal of Nursing Studies, 44 (5), $747-757$.

[9] El - Jardali, F., Dimassi, H., Dmit, N., Jamal, D., and Muo, G., 2009, A national cross-sectional study on nurses' intent to leave and job satisfaction in Lebanon: Implications for policy and practice. $B M C$ Nursing, 8 (3), 1-13. https://doi.org/10.1186/14726955-8-3.

[10] Park, J.S., and Kim, T.H., 2009, Do types of organizational culture matter in nurses' job satisfaction and turnover intention. Leadership in Health Services, 22 (1), 20 - 38.

[11] Asegid, A., Belachew, T., and Yimam, E., 2014, Factors influencing job satisfaction and anticipated turnover among nurses in Sidama Zone public health facilities, South Ethiopia. Nursing Research and Practice, 2014 (Article ID 909768), 1-26. Doi:10.1155/2014/909768.

[12] Chang, E., Cohen, J., Koethe, B., Smith, K., and Bir, A., 2017, Measuring job satisfaction among healthcare staff in the United States: A confirmatory factor analysis of the Satisfaction of Employees in Health Care (SEHC) survey. International Journal for Quality in Health care, 29 (2), 262-268. DOI: 10.1093/intqhc/mzx012.

[13] Ayele, G., Negga, B., Gudina, E.A., and Yadeta, D., 2015, Job satisfaction and associated factors among health care providers at public health institutions in Harari region, eastern Ethiopia: a cross-sectional study. BMC Res Notes, 8, 1-7. DOI 10.1186/s13104-015-1368-5.

[14]Ali Khan Khuwaja 1, Riaz Qureshi, Marie Andrades, Zafar, F., Khan, N.K., 2004, Comparison of job satisfaction and stress among male and female doctors in teaching hospitals of Karachi. J Ayub Med Coll Abbottabad, 16,23-7.

[15] National Population Commission, 2006, Federal Republic of Nigeria 2006 Population and Housing Census, Priority Tables, Vol. VII Abuja, Nigeria.

[16]Department of Planning Research and Statistics (DPRS), 2019, Ogun State Hospitals Management
Board, Ogun State, Nigeria. https://www.ogunstate.gov.ng/ohmb/.

[17] Yakasai, I.A., Ugwa, E.A., and Abubakar, I.S., 2013, Job Satisfaction among Resident Doctors in a Tertiary Healthcare Facility in Northern Nigeria; A Cross-Sectional Survey. Trop J Obstet Gynecol. 2013; 30 (1), 89 - 96.

[18] Ayamolowo, S.J., Irinloye, O., and Oladoyin, M.O., 2013, Job Satisfaction and Work Environment of Primary Health Care Nurses in Ekiti State, Nigeria: An Exploratory Study. International Journal of Caring Sciences, 6 (3), 531-542.

[19]Ezeja, E.B., Azodo, C.C., Ehizele, A.O., Ehigiator, O., and Oboro, H.O., 2010, Assessment of job satisfaction and working conditions of Nigerian oral health workers. International Journal of Biomedical and Health Sciences, 6(3).143-150. Retrieved from http://www.klobex.org/journals/ijbhs/ijbhs6/ijbhs63 0610054.pdf. Accessed on 20/09/20.

[20] Olusegun, E.A., and Olusoji, J.G., 2020, Work environment and job satisfaction among nurses in government tertiary hospitals in Nigeria. Rajagiri Management Journal, 14(1), 71-92. https://doi.org/10.1108/RAMJ-01-2020-0002.

[21]Ebuehi, O.M., and Campbell, P.C., 2011, Attraction and retention of qualified health workers to rural areas in Nigeria: A case study of four Local Government Areas in Ogun State, Nigeria. Rural and Remote Health, 11, 1515. (online), www.rrh.org.au [22] Jathanna, R., Melisha, R.D., Mary, G., and Latha, K.S., 2011, Determinants of job satisfaction among health care workers at a tertiary care hospital. Online Journal of Health and Allied Sciences, 10 (3). 5 .

[23] Peters, D.H., Chakraborty, S., Mahapatra, P., and Steinhardt, L., 2010, Job satisfaction and motivation of health workers in public and private sectors: Cross-sectional analysis from two Indian states. Hum Resour Health, 8, 27. DOI: 10.1186/1478-4491-8-27. [24] Malliarou, M., Sarafis, P., Moustaka, E., Kouvela, T., and Constantinidis, T.C., 2010, Greek registered nurses' job satisfaction in relation to workrelated stress. A Study on Army and Civilian Rns. Global Journal of Health Science, 2, 1. DOI: 10.5539/gjhs.v2n1p44. 
[25] Kebriaei, A., and Moteghedi, M.S., 2009, Job satisfaction among community health workers in Zahedan District, Islamic Republic of Iran. East Mediterr Health J., 15(5), 1156-63.
[26]Diane, W., Chris, B., Hugh, G., and Bonnie, S., 2006, GP job satisfaction in view of contract reform: A national survey. Br J Gen Pract., 56(523), 87-92. 


\title{
Assessment of Coagulopathy, Inflammation and LDH Activity in SARS- CoV-2-infected Patients
}

\author{
Ajibola Adisa $^{1 *}$, Moses Akiibinu ${ }^{2}$ \\ ${ }^{1}$ Department of Publich Health, Texila American University, Guyana \\ ${ }^{2}$ Department of Chemistry and Biochemistry, Caleb University, Lagos, Nigeria
}

\begin{abstract}
The patho-physiology of COVID19 is still not clear. This study investigated the status of coagulation, LDH activity, and inflammation in SARS-CoV-2 infected patients. One hundred and thirty-four newly diagnosed COVID19 infected patients (age ranged65-82years) attending Mullingar Regional Hospital, Mullingar, Republic of Ireland, volunteered to participate in this study. They all presented with a pulmonary disorder, pyrexia, vomiting, body pains, etc. SARS-CoV-2 confirmatory test was done with RT-PCR molecular test using Cepheid Genexpert System. The data of another 121 plasma samples of apparently normal, non-COVID19 infected individuals taken before the emergence of COVID19 served as controls. Levels of blood platelets was determined in the participants using Siemen ADVIA 2120 Haematological System, and plasma D-dimer was determined in the participants using Star MaxStago-Automatic Coagulation Analyzer LDH activity, plasma ferritin, and C-reactive protein (CRP) were determined in the participants using Beckman AU680-Chemistry Analyser. SARS-CoV-2 -infected patients showed significantly $(p<0.001)$ higher levels of D-dimer $(1522.95 \pm 1395.45 \mathrm{ng} / \mathrm{ml}), C R P$ $(125.3 \pm 116.4 \mathrm{mg} / \mathrm{l})$, ferritin $(488.5 \pm 514.9 \mathrm{pg} / \mathrm{l})$, and LDH activity $(574.4 \pm 446.7 \mathrm{iu} / \mathrm{l})$ compared to controls $(78.8 \pm 18.1 \mathrm{ng} / \mathrm{ml}, 2.4 \pm 1.7 \mathrm{mg} / \mathrm{l}, 61.3 \pm 58.2 \mathrm{pg} / \mathrm{l}, 304.1 \pm 76.6 \mathrm{iu} / \mathrm{l}$ respectively). The blood platelet count did not show significant $(p>0.05)$ change in the COVID19 patients $\left(252.2 \times 10^{9} \pm 101 x\right.$ $\left.10^{9}\right)$ compared to controls $\left(256.4 \times 10^{9} \pm 63.2 \times 10^{9}\right)$. Elevated LDH activity could indicate tissue breakdown in the SARS-Cov-2 infected patients. Hyper-coagulation and inflammation are imminent in the COVID19 patients. Adjuvant anticoagulant and anti-inflammatory therapies may be useful as part of therapeutic regimen in the SARS-CoV-2 infected patients.
\end{abstract}

Keywords: COVID19, Coagulopathy, CRP and ferritin, LDH.

\section{Introduction}

COVID-19 is a disease caused by severe acute respiratory syndrome coronavirus-2 (SARS-CoV-2). The virus has the ability to spread via natural aerosols from human to human and mother to child during pregnancy [1]. SARS-CoV-2 has been found in stool, aerosols, and blood. Sustained human-to-human transmission through inhalation or contact with infected droplets enhances the pandemicity with an incubation period ranging from 2 to 14 days [2]. The disease is mild (asymptomatic) in most people; and may progress to pneumonia, acute respiratory distress syndrome (ARDS), septic shock, metabolic acidosis, and multi-organ dysfunction in some (usually the elderly and those with co-morbidities) [3]. The virus binds to the angiotensin-converting enzyme-2 molecule, highly expressed on the epithelium of the nasopharyngeal airway, type II pneumocytes of the alveoli, vascular endothelial cells, and the macrophages of the lung tissue of the host [3]. Increased levels of pro-inflammatory cytokines, such as tumour necrosis factor- $\alpha$ (TNF- $\alpha)$ and interleukins (IL), IL-1, and IL-6, have been reported as products of cellular activation in severe SARS-Cov-2 infection $[4,5]$. The 
interplay between blood coagulation, immune cells, and platelets restricts the dissemination of pathogens during infection [6, 7]. The activation of the coagulation system and leucocytes during infection are associated with the release of IL-1, IL-6 which enhances inflammation [4]. Apart from the direct interaction of a typical virus with platelets and other cells, endothelial injury through the interaction of SARS-CoV-2 specifically activates the lectin pathway of complement on the endothelial cell surface [8]. A vast body of literature shows that cellular activation enhances cytokine release and induction of tissue factor (TF) expression on mononuclear cells that subsequently initiates coagulation activation and thrombin generation $[6,9]$.

Transmembrane protein TF secreted by subendothelial cells or induced by pathogenassociated molecular patterns, bacterial lipopolysaccharides, and viral dsRNA can also initiate and enhance the coagulation process $[10$, 11]. The TF can be complex with the plasma coagulation protease (FVII/FVIIa) to enhance the coagulation process during infection by converting FX to FXa [6, 7]. The FXa then forms the prothrombinase complex with FVa to initiate the conversion of prothrombin to thrombin. The FXa, FVa, and thrombin consequently form a pathway that leads to thrombin-mediated cleavage of fibrinogen to fibrin that is crosslinked by activated FXIII to form a stable clot [4].

Excessive coagulation could initiate the recruitment of leukocytes and enhance inflammation characterized by changes in the plasma levels of acute-phase proteins (APPs) in the infected individuals. Plasma levels of APPs increase (positive APPs) or decrease (negative APPs) in response to inflammation [12]. Activation of the hepatocytes by cytokines such as interleukin-1 (IL-1), interleukin-6 (IL-6), and tumour necrosis factor- $\alpha$ has been reported to play critical roles in the production of the APPs [13].
The consequences of inflammation have been associated with several pathological conditions, including tissue or organ damage. This study was designed to assess the tissue damage by determining the plasma activity of lactate dehydrogenase (LDH), an index of tissue injury. Since coagulopathy, inflammation, and tissue damage have been suspected to be contributing factors in the pathogenesis of COVID19, and this study was designed to assess the levels of coagulopathy, inflammation, and tissue damage in COVID19 patients by determining the plasma levels of D-dimer, C-reactive protein, plasma ferritin, $\mathrm{LDH}$, and blood platelets count in SARS-CoV-2 infected patients.

\section{Materials and Methods}

\section{Materials}

One hundred and thirty-four newly diagnosed COVID19 infected patients presenting directly to Mullingar Regional Hospital, Mullingar, the Republic of Ireland with the pulmonary disorder, pyrexia, vomiting, pains, etc., volunteered to participate in this study. Another 121 plasma samples of apparently normal, non-COVID19 infected individuals taken before the emergence of COVID19 served as controls. Informed consent was obtained from every participant before the commencement of this study. This study was approved by the Institutional Review Board, and ethical approval was obtained from the Texila American University Ethical Committee.

\section{Selection of the Area}

This study was carried people living in Mullingar metropolis and its environs, where Covid 19 prevalence was $2 \%$ at the time the study was conducted. Analyses of samples were carried out at Mullingar Regional Hospital, Mullingar, Republic of Ireland.

\section{Sample Size Determination}

The sample size was determined using the following formula. 


$$
N=\frac{Z \alpha^{2} p q}{d^{2}}
$$

Where:

$\begin{array}{lll}\mathrm{N} & = & \text { required sample size } \\ \mathrm{Z} \alpha / 2 & =\begin{array}{l}\text { Standard deviation at } 95 \% \\ \text { confidence interval }=1.96\end{array} \\ \mathrm{=} & \text { the degree of precision } \\ \mathrm{d} & \text { expected }(3 \%) \\ = & \text { prevalence is } 2 \% \\ \mathrm{p} & 1.96, \mathrm{p}=2 \%, \mathrm{q}=1-\mathrm{p}, \mathrm{d}= \\ \mathrm{Z} & 0.03 \\ = & 1.96 \times 1.96 \times 0.02 \times 0.98= \\ \mathrm{N} & 0.03^{2} \\ & \text { Sample size = } & 83.7\end{array}$

Sampling techniques: A simple random technique was employed to recruit the COVID19 patients for this study.

\section{Data Collection}

Participants were asked to respond to a questionnaire for information about the clinical presentation such as pulmonary disorder, pyrexia, vomiting, body pains after confirmation of COVID19 status. Six milliliters (ml) of venous blood sample were taken from the anticubital vein of every participant. $4 \mathrm{ml}$ was put into lithium heparin was for the determination of LDH activity, ferritin, C-reactive protein and Ddimer. Another $2 \mathrm{ml}$ of blood was put into an ethylene diamine tetra acetic acid (EDTA) bottle for the determination of platelet count. After centrifugation of the sample in a lithium heparin bottle, the plasma was separated and stored at $20^{\circ} \mathrm{C}$ until ready for analysis.

\section{Study Location}

This study was carried out at Mullingar Regional Hospital, Mullingar, Republic of Ireland.

\section{Methods}

For confirmation of COVID19, RT-PCR Molecular Test was carried out using Cepheid Genexpert System. Another 121 apparently normal, non-COVID19 infected individuals whose blood samples have been stored before the emergence of COVID19 served as controls. Levels of blood platelets were determined in the participants using Siemen ADVIA 2120 Haematological System, and plasma D-dimer were determined in the participants using Star Max-Stago-Automatic Coagulation Analyzer LDH activity, plasma ferritin, and C-reactive protein (CRP) were determined in the participants using Beckman AU680-Chemistry Analyser.

\section{Statistical Analysis}

Statistical analyses were performed using Statistical Package for Social Sciences (SPSS) for Windows, version 21.0 (SPSS Inc. Chicago, USA). Data were expressed as Mean \pm SD. Student (T) test was used for comparison of COVID19 patients and controls. The changes were considered as significant when p-values were less than 0.05 .

\section{Results}

As demonstrated in Figs. 1-4, COVID19 patients showed significantly $(\mathrm{p}<0.05)$ higher levels of D-dimer $(1522.95 \pm 1395.45 \mathrm{ng} / \mathrm{ml})$, CRP $\quad(125.3 \pm 116.4 \mathrm{mg} / \mathrm{l}), \quad$ ferritin $(488.5 \pm 514.9 \mathrm{pg} / \mathrm{l}), \quad$ and $\mathrm{LDH}$ activity $(574.4 \pm 446.7 \mathrm{iu} / \mathrm{l})$ compared to controls $(78.8 \pm 18.1 \mathrm{ng} / \mathrm{ml}, \quad 2.4 \pm 1.7 \mathrm{mg} / \mathrm{l}, \quad 61.3 \pm 58.2 \mathrm{pg} / \mathrm{l}$, $304.1 \pm 76.6 \mathrm{iu} / \mathrm{l}$ respectively). The blood platelet count (Fig. 5) did not show significant ( $>0.05)$ change in the COVID19 patients (252.2 $\mathrm{x}$ $\left.10^{9} \pm 101 \times 10^{9}\right)$ compared to controls $(256.4 \times$ $\left.10^{9} \pm 63.2 \times 10^{9}\right)$. 


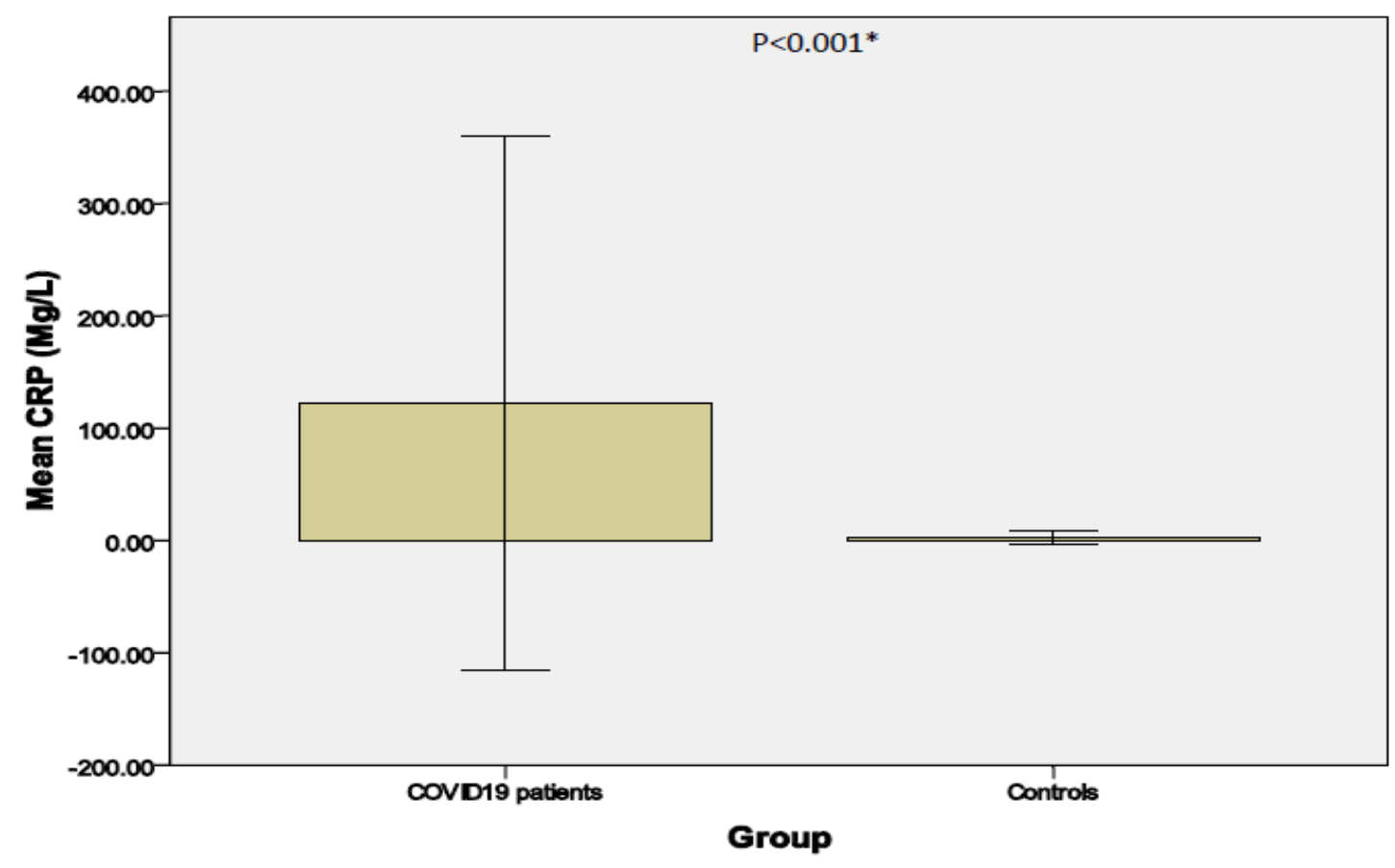

Error Bars: +/- 2 SD

*Significantly different from controls

Figure. 1. Levels of CRP in COVID19 Patients and Controls

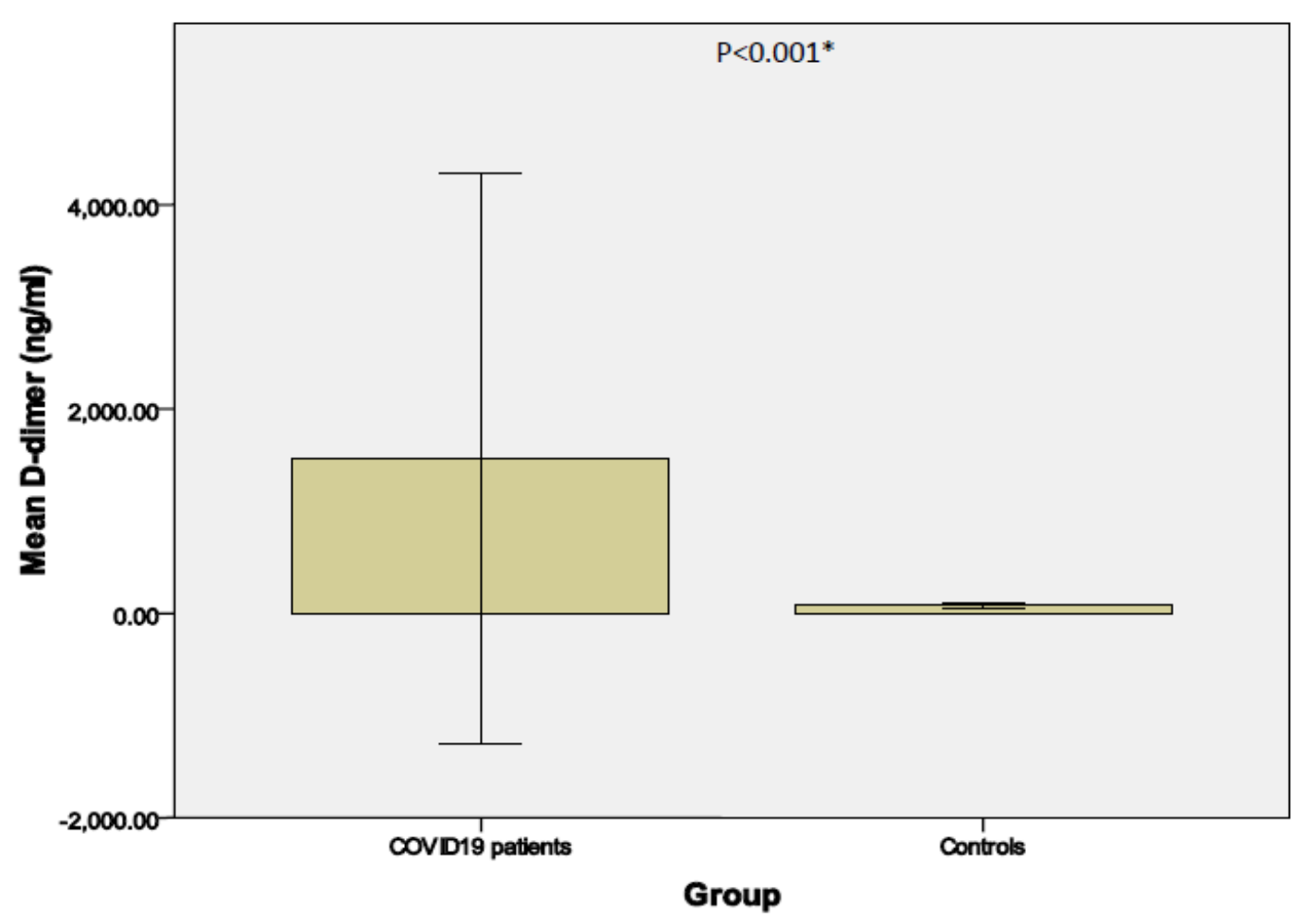

Error Bars: +/- 2 SD

*Significantly different from controls

Figure. 2. Plasma Levels of D-dimer in COVID19-Infected Patients and Controls 


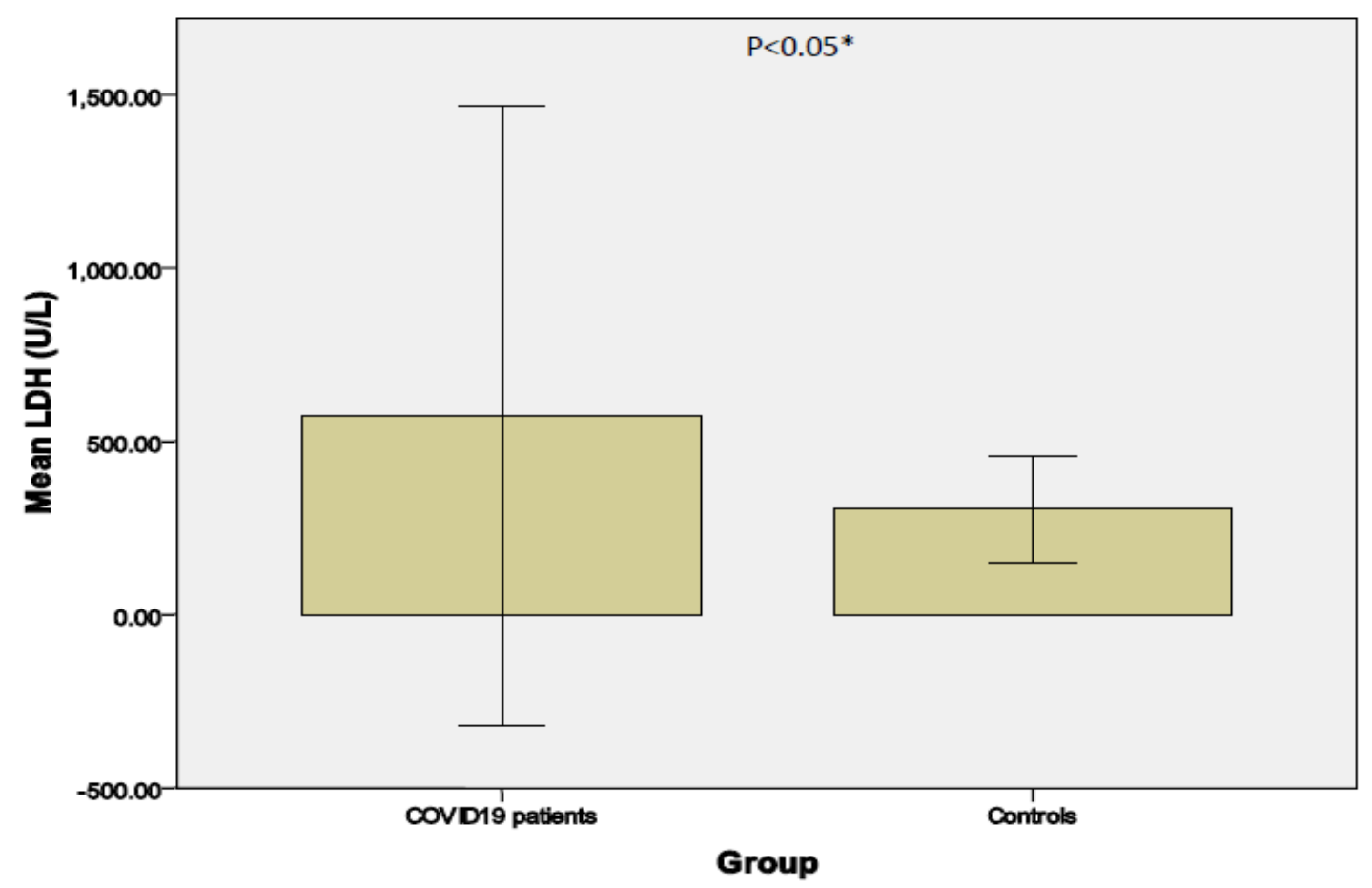

Error Bars: +/- 2 SD

*Significantly different from controls

Figure.3. Plasma Levels of LDH in COVID19-Infected Patients and Controls

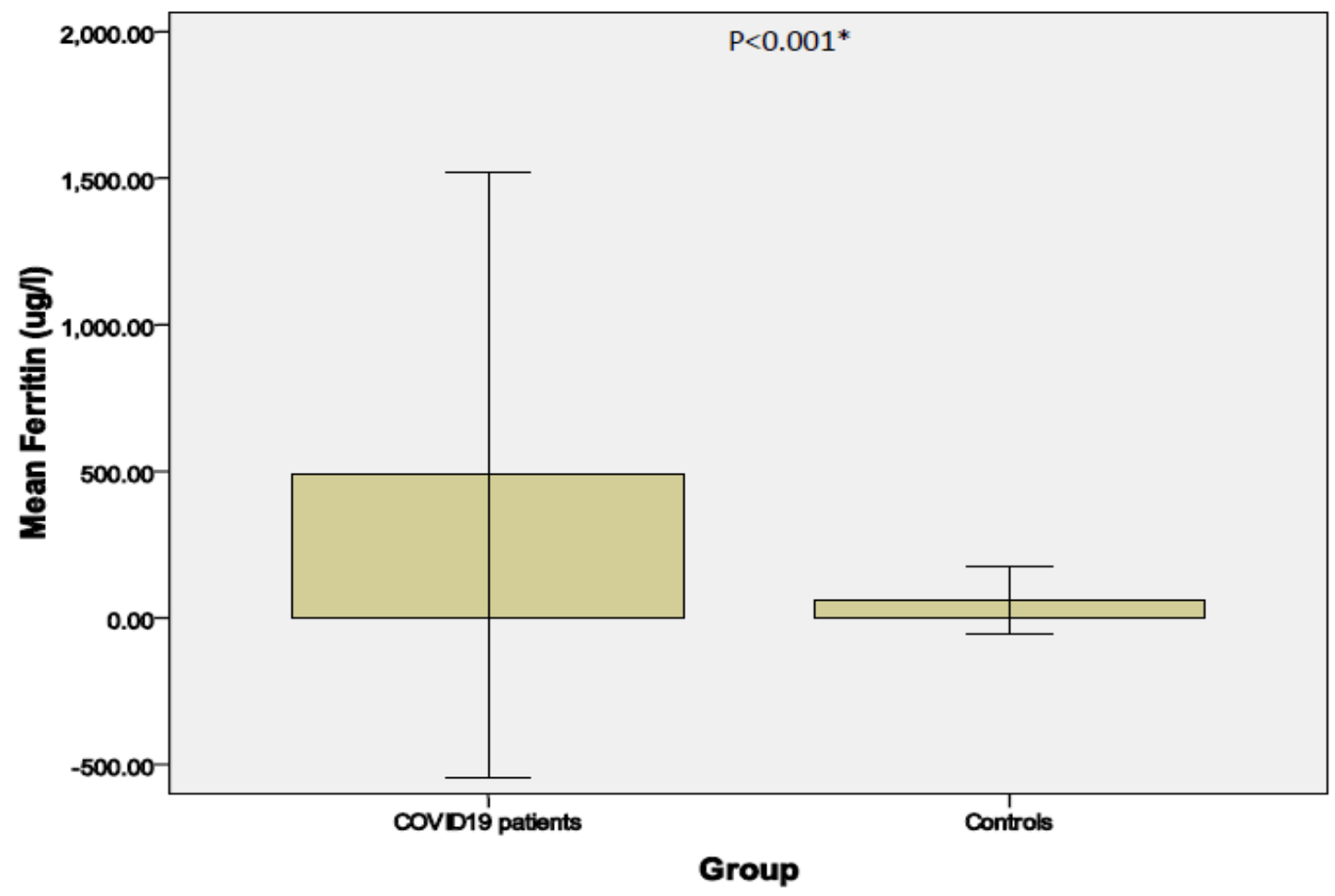

Error Bars: +/- 2 SD

*Significantly different from controls

Figure. 4. Plasma Levels of Ferritin in COVID19-infected Patients and Controls 


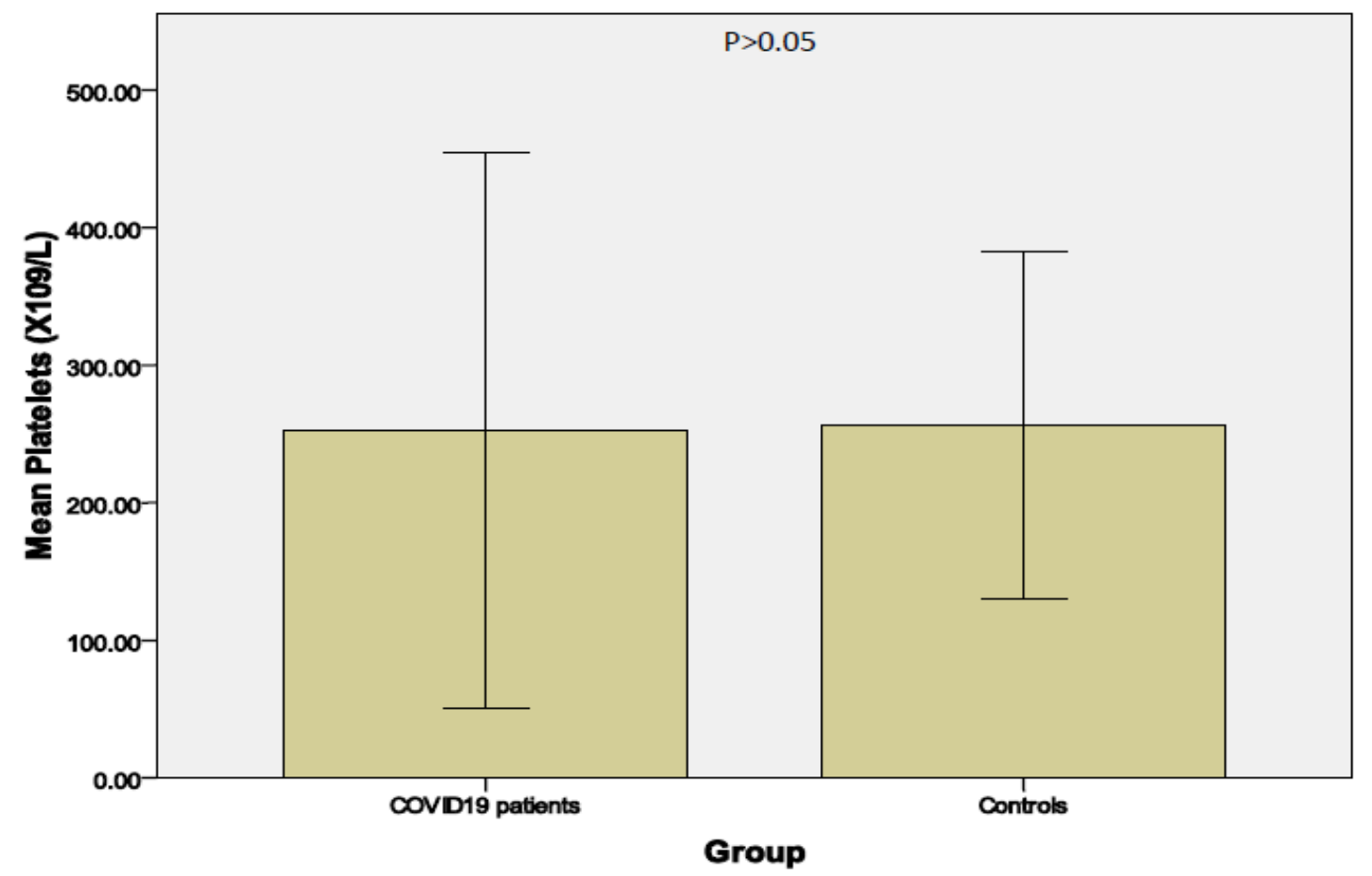

Error Bars: +/- 2 SD

Figure. 5. Levels of Platelets in COVID19-infected Patients and Controls

\section{Discussion}

The pathophysiology of COVID-19 has not been well documented. Available literature shows that respiratory disorder, intra-vascular coagulation, and hypoxia are major consequences of the SARS-Cov-2 infection. Other studies have reported lower levels of CD4+ T-cells and CD8+ T-cells in nearly all the COVID19 patients (14), with significantly higher circulating endothelial cell counts, serum levels of interleukin-6 (IL-6), and interleukin-8 (IL-8) in the COVID19 patients [15]. This present study confirmed the possibility of disseminated intravascular coagulation as proved by a significantly higher level of Ddimer, a product of cross-linked fibrin degradation and an index of hyper-coagulation in our COVID19 patients. The elevated level of D-dimer in this could be due to excessive activation of platelets and inflammation in the COVID19 patients.

This could also be evidence of the excessive intravascular coagulation commonly reported in SARS-CoV-2 infected patients. Previous studies show that under physiological conditions, a balance of coagulation and fibrinolysis maintains the D-dimer generated in the blood of most healthy individuals at a range of $<250$ $\mathrm{ng} / \mathrm{ml}$ [16, 17]. Meanwhile, in this study, a plasma level of $1522.95 \pm 1395.45 \mathrm{ng} / \mathrm{ml}$ was observed in COVID19 patients. A similarly higher level of D-dimer $(2950 \mathrm{ng} / \mathrm{mL})$ has been reported in COVID19 patients by previous workers $[18,19]$. The present finding could be due to the aberration of coagulation and fibrinolysis processes in the COVID19 patients. Since a high degree of fibrin degradation produces an increased level of D-dimer in the SARS-Cov-2 infected patients, this study confirms the clotting complications, such as microvascular thrombi and disseminated intravascular coagulation commonly reported in COVID19 patients by previous studies.

Interleukin-1, interleukin-6 and interferongamma released during cellular activation in COVID19 disease can induce the hepatocytes to produce a large array of acute phase proteins including CRP and ferritin [20]. The changes in 
plasma levels of APPs observed in this study could therefore be due to excessive activation of hepatocytes in response to viremia during SARS-Cov-2 infection [13]. The two APPs (CRP and ferritin) determined in this study are positive acute phase reactants and indices of markers of inflammation that increase in response to infection and trauma. A significantly higher level of CRP in the COVID19 patients recruited for this study could be due to their responses to SARS-CoV-2 infection or inflammation.

The immunological roles of CRP include initiation of opsonization, phagocytosis, and lysis of invading organisms such as bacterial and viruses. It can also activate macrophages, prevents damage to tissues, modulates phagocytic cell functions, enhances the removal of harmful molecules and pathogens, possesses anti-proteolytic activity, and presumably blocks the migration of cells into the lumen of blood vessels, thus preventing the establishment of a generalized systemic inflammation [21]. Therefore, an increased level of CRP in this study might be a protective strategy employed by the system to fight against possible invading pathogens. Our study agrees with the report of previous workers who also observed significantly higher levels of CRP during infections [22, 23]. CRP has therefore been proposed to be an index of severity of COVID19 in emergency cases [24, 25].

A significantly higher level of plasma ferritin observed in our COVID19 patients complements our report of possible inflammation in COVID19 patients. This significant increase in the plasma level of ferritin could be a physiological defense strategy to bind iron and deprive the pathogen from getting enough iron for its metabolic activities. This study corroborates previous reports that serum ferritin concentration increases in response to infections or inflammatory process [22, 23]. This study, therefore, confirm the elevated level of plasma ferritin reported in COVID19 patients by previous researchers [26].
LDH is a cytoplasmic, unilocular enzyme that is present in almost all tissues but at high concentrations in the muscle, liver, and kidney. The function of the enzyme is to catalyze the reversible conversion of lactate to pyruvate with the reduction of NAD+ to NADH and vice versa [27]. The enzyme is also involved in the anaerobic metabolism of glucose when oxygen is absent or in limited supply, a process that could be beneficial in hypoxic COVID19 patients. The activity increases in tissue injury, organ damage, haemolysis, infections, and cancers. High serum LDH activity observed in this study agrees with a previously reported study that presented high LDH activity as a risk factor in younger patients with COVID19 disease [28, 29]. Our study also agrees with other researchers who reported higher levels of LDH in COVID19 patients [15, 25]. The significantly higher LDH activity in our COVID19 patients could be due to tissue or organ damage. Since $\mathrm{LDH}$ is a cytoplasmic enzyme, acute tissue breakdown in the SARS-CoV-2 infected patients could enhance the liberation of the enzyme into the plasma.

Platelet's activation has been implicated in COVID19 pathogenesis, although the functions have not been well defined. A study has reported a significantly lower level of platelets in patients with severe SARS-CoV-2 infection [30]. An early study hypothesized that mild thrombocytopenia with a decreased platelet could be associated with a poor prognosis of COVID19 [31]. Another report demonstrates changes in platelet gene expression and function in COVID-19 patients [32]. The present study did not show any significant change in the platelet status of the COVID19 patients recruited for this study.

Meanwhile, other studies have highlighted that platelet hyperactivity in COVID-19 contributes to the coagulopathy and activation of monocytes, leading to the release of tissue factor, the principal regulator of the coagulation cascade [32, 33]. 


\section{Conclusion}

Increased levels of fibrin degradation product (D-dimer) and CRP are imminent in the COVID19 patients. Elevated LDH activity could indicate tissue breakdown in the SARS-Cov-2 infected patients. Adjuvant anticoagulant and anti-inflammatory therapies may be useful as part of a therapeutic regimen in the SARS-CoV2 infected patients.

\section{References}

[1] Hinojosa-Velasco A, Bobadilla-Montes de Oca VP, García-Sosa LE, Mendoza-Durán JD, PérezMéndez MJ, Eduardo Dávila-González, Dolores G Ramírez-Hernández, Jaime García-Mena, ZárateSegura P, Reyes-Ruiz JM, Bastida-González F., 2020. A Case Report of Newborn Infant with Severe COVID-19 in Mexico: Detection of SARS-CoV-2 in Human Breast Milk and Stool. Int J Infect Dis. 26; S1201-9712(20)30684-6.

DOI: $10.1016 /$ j.ijid.2020.08.055. Online ahead of print.

[2] Guo Y, Qing-Dong Cao, Zhong-Si Hong, YuanYang Tan, Shou-Deng Chen, Hong-Jun Jin, Kai-Sen Tan, De-Yun Wang, Yan Jinn 2020. The origin, transmission and clinical therapies on coronavirus disease 2019 (COVID-19) outbreak - an update on the status. Mil Med Res. 13;7(1):11. doi: 10.1186/s40779-020-00240-0.

[3] Singhal T. 2020. A Review of Coronavirus Disease-2019 (COVID-19). Indian J Pediatr. 87(4):281-286. doi: 10.1007/s12098-020-03263-6. Epub 2020.

[4] Boermeester MA, van Leeuwen PAM, Coyle SM, et al., 1995. Interleukin-1 receptor blockade in patients with sepsis syndrome: evidence that interleukin-1 contributes to the release of interleukin6 , elastase phospholipase A2, and to the activation of the complement, coagulation, and fibrinolytic systems, Arch Surg, vol. 130 (pg. 739-48).

[5] Ur A and Verma K. 2020. Cytokine Storm in Covid19: A Neural Hypothesis ACS Chemical Neuroscience. 11 (13), 1868-1870.

\section{Conflict of Interest}

Author declares there is no conflict of interest.

\section{Acknowledgement}

We appreciate the Mullingar Regional Hospital, Mullingar, the Republic of Ireland, for allowing us to the samples collected from their SARS-CoV-2 infected patients.

[6] Gaertner F, Massberg S., 2016. Blood coagulation in immunothrombosis-At the frontline of intravascular immunity. Semin Immunol. 28: 561- 9. [7] Antoniak S, Nigel Mackman., 2014. Multiple roles of the coagulation protease cascade during virus infection. Bood. 123 (17): 2605-2613. https://doi.org/10.1182/blood-2013-09-526277.

[8] Collard C.D., Vakeva A., Morrissey M.A., Agah A., Rollins S.A., Reenstra W.R., Buras J.A., Meri S., Stahl G.L. 2000. Complement activation after oxidative stress: role of the lectin complement pathway. Am. J. Pathol. 156:1549-1556.

[9] Antoniak S, Owens AP, Baunacke M, et al., 2013. PAR-1 contributes to the innate immune response during viral infection. J Clin Invest. 123:3; 13101322.

[10] Grover SP, Mackman N. 2018. Tissue factor: an essential mediator of hemostasis and trigger of thrombosis. Arterioscler Thromb Vasc Biol. 38: 70925.

[11]Drake TA, Morrissey JH, Edgington TS. 1989. Selective cellular expression of tissue factor in human tissues. Implications for disorders of hemostasis and thrombosis. Am J Pathol. 134: 1087- 97.

[12] Herpers BL, Endeman H, de Jong BA, de Jongh BM, Grutters JC, Biesma DH, van Velzen-Blad H 2009. "Acute-phase responsiveness of mannosebinding lectin in community-acquired pneumonia is highly dependent upon MBL2 genotypes". Clin Exp Immunol. 156 (3): 488-94. doi:10.1111/j.13652249.2009. 03929.x. PMC 2691978. PMID 19438602.

[13]Feelders RA et al. 1998. Regulation of iron metabolism in the acute phase response: interferon $\mathrm{g}$ tumour necrosis factors a induce hypoferraemia, 
ferritin production, and a decrease in circulating transferrin receptors in cancer patients. European Journal of Clinical Investigation, 28:520-527.

[14]Chen G, Di Wu, Wei Guo, Yong Cao, Da Huang, Hongwu Wang, Tao Wang, Xiaoyun Zhang, Huilong Chen, Haijing Yu, Xiaoping Zhang, Minxia Zhang, Shiji Wu, Jianxin Song, Tao Chen, Meifang Han, Shusheng Li, Xiaoping Luo, Jianping Zhao, Qin Ning., 2020. Clinical and immunological features of severe and moderate coronavirus disease 2019. J Clin Invest. $\quad 1 ; 130(5): 2620-2629 . \quad$ DOI: 10.1172/JCI137244.

[15]Rambaldi A, Giuseppe Gritti, Maria Caterina Micò, Marco Frigeni, Gianmaria Borleri, Anna Salvi, Francesco Landi, Chiara Pavoni, Aurelio Sonzogni, Andrea Gianatti, Francesca Binda, Stefano Fagiuoli, Fabiano Di Marco, Luca Lorini, Giuseppe Remuzzi, Steve Whitaker, Gregory Demopulos. 2020. Endothelial injury and thrombotic microangiopathy in COVID-19: Treatment with the lectin-pathway inhibitor narsoplimab. Immunobiology. 225(6):152001. doi: 10.1016/j.imbio. 152001. Epub 2020 Aug 9.

[16] Pagana KD, Pagana TJ, Pagana TN. 2019. Mosby's Diagnostic \& Laboratory Test Reference. 14th ed. St. Louis, Mo: Elsevier.

[17] Rostami M, Mansouritorghabeh H., 2020. Ddimer level in COVID-19 infection: a systematic review. Expert Rev Hematol. 13(11):1265-1275. DOI: 10.1080/17474086. 2020. 1831383. Epub 2020 Oct 12 .

[18] Al-Samkari H, Rebecca S Karp Leaf, Walter H Dzik, Jonathan C T Carlson, Annemarie E Fogerty, Anem Waheed, Katayoon Goodarzi, Pavan K Bendapudi, Larissa Bornikova, Shruti Gupta, David E Leaf, David J Kuter, Rachel P Rosovsky., 2020. COVID-19 and coagulation: bleeding and thrombotic manifestations of SARS-CoV-2 infection. Blood. 23; 136 (4):489-500. DOI: 10.1182/blood.2020006520.

[19] Bousquet G, Falgarone G, Deutsch D, Derolez S, Lopez-Sublet M, Goudot F, Amari K, Uzunhan Y, Bouchaud O, and Pamoukdjian F. 2020. ADLdependency, D-Dimers, LDH, and absence of anticoagulation are independently associated with one-month mortality in older inpatients with Covid19. Aging (Albany NY). 30; 12(12): 11306-11313.
[20] Watkins LR, Milligan ED, Maier SF., 2003.

Glial proinflammatory cytokines mediate exaggerated pain states: implications for clinical pain. Adv Exp Med Biol. 521:1-21. [PubMed].

[21]Xiang-Hua Y, et al., 2020. severe acute respiratory syndrome and venous thromboembolism in multiple organs. Am. J. respire. Crit. Care Med. $182,436-437$.

[22] Rienhoff HY Jr., 1990. Molecular and cellular biology of serum amyloid A. Molecular Biology and Medicine. 7: 287-298.

[23] Birgegård G, Hällgren R, Killander A, Venge P, Wide. 1979. Serum ferritin during infection. A longitudinal study in renal transplant patients. L.Acta Med Scand. 205 (7):641-5.

[24] Gómez-Pastora J, Weigand M, Kim J, Wu X, Strayer J, Palmer AF, Zborowski M, Yazer M, Chalmers JJ., 2020. Hyperferritinemia in critically ill COVID-19 patients - Is ferritin the product of inflammation or a pathogenic mediator? Clin Chim Acta. 2020 Oct; 509:249-251. DOI: 10.1016/j.cca. 06.033. Epub 2020 Jun 21.

[25] Assandri R, Buscarini E, Canetta C, Scartabellati A, Viganò G, Montanelli A., 2020. Laboratory Biomarkers Predicting COVID-19 Severity in the Emergency Room. Arch Med Res. 51 (6):598-599. DOI: 10.1016/j.arcmed.2020.05.011.

[26] Guan WJ, Ni ZY, Hu Y, et al. 2020. Clinical characteristics of coronavirus disease 2019 in China. N Engl J Med. 382: 1708-20.

[27]Feld J , Douglas Tremblay, Santiago Thibaud, Alaina Kessler, Leonard Naymagon . 2020. Ferritin levels in patients with COVID-19: A poor predictor of mortality and hemophagocytic lymphohistiocytosis. Int J Lab Hematol. 42 (6):773779. DOI: 10.1111/ijlh.13309. Epub 2020 Aug 13.

[28] Schumann G, Bonora R, Ceriotti F, ClercRenaud P, Ferrero CA, Férard G, Franck PF, Gella FJ, Hoelzel W, Jørgensen PJ, Kanno T, Kessner A, Klauke R, Kristiansen N, Lessinger JM, Linsinger TP, Misaki H, Panteghini M, Pauwels J, Schimmel HG, Vialle A, Weidemann G, Siekmann L. 2002. IFCC primary reference procedures for the measurement of catalytic activity concentrations of enzymes at 37 degrees C. Part 3. Reference procedure for the measurement of catalytic concentration of 
lactate dehydrogenase. Clin Chem Lab Med. 40(6):643-8.

[29] Li X, Xu S, Yu M, Wang K, Tao Y, Zhou Y, Shi J, Zhou M, Wu B, Yang Z, Zhang C, Yue J, Zhang Z, Renz H, Liu X, Xie J, Xie M, Zhao J., 2020. Risk factors for severity and mortality in adult COVID-19 inpatients in Wuhan. J Allergy Clin Immunol. 146(1):110-118.

[30]Zhou F, Yu T, Du R, Fan G, Liu Y, Liu Z, Xiang J, Wang Y, Song B, Gu X, Guan L, Wei Y, Li H, Wu X, Xu J, Tu S, Zhang Y, Chen H, Cao B. 2020. Clinical course and risk factors for mortality of adult inpatients with COVID-19 in Wuhan, China: a retrospective cohort study. Lancet. 28; 395(10229):1054-1062. (PubMed).

[31] Tang $N$ et al. 2020. Anticoagulant treatment is associated with decreased mortality in severe coronavirus disease 2019 patients with coagulopathy. J. Thromb. Haemost.

http://doi.org/10.1111/jth.14817.

[32] Yang W., Lee H.W., Hellinga H., Yang J.J., 2002. Structural analysis, identification, and design of calcium-binding sites in proteins. Proteins. 47:344-356.

[33] Manne BK, Denorme F, Middleton EA, et al., 2020. Platelet gene expression and function in patients with COVID-19. Blood. 136 (11):13171329.

[34] Hottz ED, Azevedo-Quintanilha IG, Palhinha L, et al., 2020. Platelet activation and platelet-monocyte aggregate formation trigger tissue factor expression in patients with severe COVID-19. Blood. 136(11):1330-1341. Google Scholar. 


\title{
In Hypertension Patients is Diet and Exercise more Effective in Lowering High Blood Pressure Compared to Exercise Alone
}

\author{
Himwaaba Gift ${ }^{1,2}$ \\ ${ }^{1}$ Ph.D. Public Health, Texila American University, Zambia \\ ${ }^{2}$ Zambia Correctional Service, Lusaka Regional Medical Coordinator
}

\begin{abstract}
The objective of this systematic review was to explore ways of using diet and regular exercise as a means of reducing of reducing high blood pressure levels the world over. High blood pressure is fundamentally associated with high morbidity, mortality rates, and disability. Generally, lifestyle modifications such as exercise and a healthy diet have been seen to lower blood pressure in hypertensive and normotensive. A search of the literature was conducted on the Medline database to identify articles related to the research question. We also obtained the primary studies from the reference list of the retrieved review articles. The search was performed using the following key terms combination; hypertension, diet, and exercise, regular exercise, exercise alone, and lowering high blood pressure. For this project, the Medline database was searched under EBSCO host on $29^{\text {th }}$ of April 2013, and there was no restriction on the years covered by the search. A total of eight articles were found to be relevant. Of all these articles reviewed, three addressed the issue of diet, and the other five addressed the issue of exercise as an intervention. Lifestyle modifications using exercise and diet was found to have a great effect in reducing blood pressure in hypertensive patients and normotensive in all the reviewed articles. There is evidence that diet and exercise have a substantial effect in reducing blood pressure in hypertensive patients and the normotensive in all the reviewed articles.
\end{abstract}

Keywords: Diet and Exercise, Exercise alone, Hypertension, Lowering High Blood Pressure.

\section{Introduction}

Hypertension is a disorder marked by an intermittent or sustained elevation of diastolic (90 $\mathrm{mm} \mathrm{Hg}$ or more) or systolic $(140 \mathrm{~mm} \mathrm{Hg}$ or more) blood pressure [1]. Despite people having interest and knowledge on the use of nonpharmacological therapy in managing hypertension, such as exercise and healthy diet, this has not been promoted at a larger scale to the general population at large. This may be due to a lack of agreement or knowledge on the type of diet and exercise to be used. Traditionally, approaches to control the epidemic of high blood pressure-related atherosclerotic cardiovascular disease (ASCVD) have concentrated on drug therapy. Despite this, still, non-pharmacological therapy such as diet and exercise have an important and expanding role [2], to play in the management of hypertension.

\section{Highlights on the Importance of Topic}

The importance of this review is to bring on board cheaper means of managing raised blood pressure such as lifestyle modifications (diet and exercise) the world over. By so doing, there will be a reduced burden of complications due to hypertension and improved quality of life at the national and individual level. Hypertension is also known as high blood pressure, is a global public health issue; it contributes to the burden of heat diseases, stroke, kidney failure [3]. It is also a leading cause of ill health, premature mortality, and disability [4]. Hypertension is a major health problem throughout the world because of its high prevalence and its association 
with increased risk of cardiovascular diseases. Hypertension is also a leading cause of morbidity and mortality among noncommunicable diseases. It has shown a rapid increase in prevalence affecting the urban more than the rural population in sub-Saharan Africa [5]. Hypertension contributes to cardiac and renal failure [6], and it is a major cause of cerebral vascular accidents (CVA) [7]. Cardiovascular diseases are a major cause of disability and premature death throughout the world [8]. Hypertensive disorders of pregnancy are an important cause of sever morbidity, longterm disability, and deaths among both mothers and their babies [9]. Hypertensive disorders of pregnancy account for 12 to $20 \%$ of the total maternal death in the world and other complications such as small for gestational age babies because of impaired growth [10]. Uncontrolled hypertension will result in significant economic costs in addition to the burden of other diseases such as AIDS/HIV, malaria, and tuberculosis [10]. This disease has a severe negative impact on economic development, such as high cost of treatment, limited productivity [11], and the other economic impact of this chronic disease include the cost of illness, individual and family are affected, labor market performance, and human capital accumulation [12]. Treating the complications of hypertension entails reducing costly interventions such as cardiac bypass, carotid artery surgery, and dialysis, which drains individual and government budgets [3]. There are many consequences of hypertension, such as premature death, disability, personal and family disruption, loss of income, and health care expenditure due to this scourge and takes a toll on families, communities, and national finances [3]. If no action is taken to tackle hypertension, the economic losses are projected to outstrip public spending on health [3]. With the researches going on to bring onboard the cheaper means of managing this illness using exercise and diet, we hope to reduce all the related costs of managing this scourge.

\section{Research Papers and Government Documents with Statistical Figures}

There are about 970 million people with elevated blood pressure worldwide, of these, 330 million are in developed countries, and 640 million are in developing countries [3]. In Zambia, hypertension affects all ages and classes and has risk factors that are mainly attributable to lifestyles such as physical inactivity and unhealthy diets [13]. During the past years for the period 2009, 2010, and 2011 hypertension has been the highest cause of visitation among non-communicable diseases to health facilities [13]. Table 1 below shows the number of hypertension patients in relation to the number of non-communicable diseases within this particular period in Zambia 2009-2011.

Table 1. Hypertension Disease for all Age Groups in Zambia for 209 to 2011

\begin{tabular}{|l|l|l|l|l|l|l|l|l|}
\hline \multicolumn{7}{|l|}{ Hypertension disease for all age groups combined in Zambia for 2009 to 2011} \\
\hline All ages 2009 & \multicolumn{7}{|c|}{ All ages 2010 } & All ages 2011 \\
\hline disease & number & $\%$ & disease & number & $\%$ & disease & number & $\%$ \\
\hline hypertension & 101181 & 43 & hypertension & 118549 & 34.8 & hypertension & 144071 & 35 \\
\hline
\end{tabular}

\section{Signs and Symptoms of Hypertension}

Hypertension is called a silent killer, and it is a very serious disease since the symptoms are only known when it becomes serious. If overlooked, it may lead to serious consequences, sometimes even fatal. It is an invisible killer that rarely causes symptoms [3]. Aside from characteristic high blood pressure, hypertension is classified according to its cause, severity, and type; the two major types are essential (also called primary or idiopathic) hypertension, the most common (90\% to $95 \%$ of cases), and secondary hypertension which results from renal 
disease or another identifiable cause [1]. Commonly asymptomatic and the patient is usually unaware that she or he has a disease, raised blood pressure may be discovered on routine medical examination and when complications occur such as a stroke [7]. In severe cases, patients complain of headache, palpitations, dizziness, exertional dyspnea, chest pains, and convulsions [7]. Complications due to hypertension occur late and can attack any organ system such as; cardiac complications due to hypertension occur late and can attack any organ system such as; cardiac complications may include coronary artery disease, angina, myocardial infarction, heart failure arrhythmias, and sudden death; neurologic complications may include cerebral infarctions and hypertensive encephalopathy; hypertension retinopathy can cause blindness, and renal vascular hypertension can lead to renal failure [1]. Other signs and symptoms of hypertension include fatigue, sudden loss of balance, abdominal discomfort due to high congestion in the liver, oliguria due to reduced renal perfusion, peripheral edema, cyanosis, peripheral vasoconstriction, jugular venous distension, systolic murmur in mitral or tricuspid regurgitation can be heard and pulmonary crackles due to fluid transudation, especially pulmonary congestion.

\section{Epidemiological Data}

Prevalence trends and incidence are important epidemiological considerations for hypertension, the leading cause of cardiovascular diseases [14]. Hypertension is prevalent all around the world, with one in three adult's lives with hypertension [11]. The largest deaths due to non-communicable diseases are due to hypertension accounting for $48 \%$ due to the adoption of western lifestyle by people in developing countries, and it is said to have led to a sharp rise in the incidence of hypertension [10]. Hypertension affects more than 60 million adults in the United States of America, blacks are twice as likely as whites to be affected, and they are four times as likely to die of the disorder [1]. In 2008 , worldwide, approximately $40 \%$ of adults aged 25 years and above had been diagnosed with hypertension; the number of people with the condition rose from 600 million in 1980 to 1 billion in 2008, the prevalence of hypertension is highest in the African region at $46 \%$ of adults aged thirty and above, while the lowest prevalence at $35 \%$ is found in the Americans [3]. The increasing prevalence of hypertension is attributed to population growth, aging, and behavioral risk factors, such as unhealthy diet, lack of physical activity [3].

\section{Age, Gender Affected by Hypertension}

Hypertension is associated with identifiable behavioral and biological risk factors such as race, obesity, diabetes, age, sex, alcoholism, sedentary lifestyles, diet (salt), and family history of hypertension [4]. Age is a major risk factor for hypertension, in that blood pressure increases with age in both men and women. Blacks are twice as likely as whites to be affected, and they are four times likely to die of the disorder [1]. Before the age of 55 years, men are more affected with hypertension than women, and after this age, the reverse is true [15]. African Americans are six times more likely to develop end-stage renal disease from hypertension than whites. More than $40 \%$ of African men and women have hypertension and accounts for over $40 \%$ of all death in this group. Hypertension is also becoming more common in children and teenagers, among young people; boys are at higher risk for high blood pressure than girls.

\section{Pathophysiology}

Most cases are idiopathic, and a few cases (less than 5\%) may be caused by other diseases [7]. Increased blood volume, cardiac rate, stroke volume, or arteriolar vasoconstriction that increases peripheral resistance causes blood pressure to rise [1]. Abnormalities in the neurohormonal activation and water and electrolyte balance also play a central role in the cascade that leads from hypertension to heart failure [14]. Angiotensin 2 is an important initiator of extracellular matrix remodeling, 
which contributes to the pathogenesis of atherosclerosis and cardiac hypertrophy [14]. The heightened sympathetic nervous system predisposes to vasoconstriction, sodium retention, and ventricular hypertrophy; the latter occurs as increased noradrenaline release results in myocyte hypertrophy, increased apoptosis of cardiomyocytes, and deficits in cardiomyocyte contractility; these changes are facilitated by B adrenoceptor hyperactivity [14].

\section{Risk Factors}

The risks factors for hypertension include Tobacco use, physical inactivity, unhealthy diet (rich in salt, fat, and calorie), high blood pressure, cholesterol, diabetes, overweight, and stress.

\section{How the Disease is Managed in Practice}

The purpose of treatment is to prevent complications [7]. Management is according to the cause and type of hypertension condition. Blood pressure drugs work in several ways by removing excess salt and fluid from the body, slowing the heartbeat, or relaxing and widening the blood vessels [3].

Although hypertension has no cure, drugs and modifications in diet and lifestyle can control it. Generally, non-drug treatment, such as lifestyle modification, is tried first, especially in early and mild cases [1].

If the diastolic pressure remains above $90 \mathrm{~mm}$ hg despite at least six months of non-drug treatment, monotherapy may begin, thiazide diuretic or a beta-blocker is the drug of choice; initially, this therapy is preferred because studies have demonstrated a decrease in morbidity with this therapy [1].

\section{The General Outcome Measures}

Early detection, lifestyle modifications such as healthy diet and regular exercises play a significant role in better hypertension outcomes. If hypertension is left untreated it causes severe complications such as coronary heart artery disease, angina, myocardial infarction, heart failure, arrhythmias, sudden death, and stroke [1].

\section{The Effects on Patients' Lives}

Cardiovascular diseases are a major cause of disability and premature death throughout the world [8]. Treating the complications of hypertension entails costly interventions such as cardiac bypass, carotid artery surgery, and dialysis, hence draining individual budgets [3]. Premature death, disability, personal and family disruption, loss of income, and health care expenditure due to hypertension take a toll on families, communities [3]. The results of complications due to hypertension have negative impacts on the patient's life, such as reduced quality of life, psychological disturbance, disability, and pain, increased deformity due to stroke, and also sexual disturbances due to erectile dysfunction.

\section{The Significance of this Study}

The major importance of doing this study was to find ways of incorporating diet and exercise in our daily life in order to reduce; high blood pressure, the likely complications, and also to reduce the prevalence and incidence of raised blood pressure.

By introducing diet and exercise as a means of lowering raised blood pressure which is less costly, there is hope to reduce the huge budgets spent on procuring these conventional drugs by governments and the donor community with diet and exercise; there is anticipation that the severe side effects from conventional drugs such as erectile dysfunction would be reduced. Furthermore, the economic consequences and biological uncertainties of long-term pharmacological treatment of hypertensive persons urge that alternative treatments should be examined, such as reduced salt in food and exercising [16].

\section{Objectives of the Study}

The objective of this review was to investigate the effect of diet and exercise as 
interventions on blood pressure in hypertension patients. Specifically, this review aimed;

1. At synthesizing evidence from research papers assessing the effectiveness of healthy diet and exercise in lowering high blood pressure in hypertension patients compared to exercise alone.

2. Discussing how diet and exercise can be developed in order to reduce raised blood pressure in hypertensive patients.

3. At assessing the relationship between exercise and diet with hypertension.

\section{Methodology}

\section{Creating Criteria for Selecting Evidence into this Review}

It has been said that high-quality systematic review should have inclusion criteria that is vigorously and transparently reported so that the search targets articles that will provide answers to the review question, leaving the irrelevant ones [17]. The criteria for selecting these studies followed from the research question and the identified PICO (population, intervention, comparison, and outcome) components [17]. This well-formulated question had key components that were used in the criteria for selecting studies for this review [18]; these key components of interest are population, interventions, comparison, and outcome. The clinical question was "in hypertension patients, is diet and exercise more effective in lowering high blood pressure compared to exercise alone." Since the clinical question was formulated, the next step was to find relevant evidence that would answer the clinical question [19].

The first stage in selecting studies involved the checking of results from electronic search and assessing the titles and abstracts to assess whether they met the predetermined criteria for eligibility [18]. Table 2. Shows articles that were relevant to the aims of the focused question that were also identified by checking the reference list of retrieved articles in order to identify the primary studies.

\section{Types of Studies}

The articles included or that were relevant for this focused question are randomized controlled trial articles because, looking at the hierarchy of evidence, they are said to be the best. The other reason for inclusion is that they were addressing the question to be reviewed [18]. A randomized controlled trial is also exhaustive in addressing a clearly defined question [20].

These should have the population of interest, which is hypertension patients, the intervention of interest, which is diet and exercise, the comparison, which is exercise alone, and the outcome of interest is reduced blood pressure. All the studies that have mentioned the intervention of interest, either diet or exercise, were included in order not to miss some articles that may be relevant, and also in that it may be difficult to find studies that have this type of combination intervention.

\section{Types of Participants or What is the Problem}

Looking at the research question on the population of interest, "hypertension patients," there was no restriction on age, sex, race because hypertension affects all.

\section{Types of Interventions/Issues}

The type of intervention that was of interest in this focused question was all types of diet and exercises. There was no restriction on the type of diet or exercise but a duration of two to fifty-two weeks.

\section{Types of Comparison}

The comparison of interest in this focused question was exercise alone in reducing high blood pressure. All types of exercises were considered duration two to fifty-two weeks.

\section{Types of Outcome Measures}

The desired outcome in this clinical research question was lowering elevated blood pressure or preventing hypertension hence reducing incidences and severity of this disease. The other outcomes of importance that were desired are 
reduced deaths, improved physical and and also improved social-economic outcomes emotional wellbeing, improved quality of life [21].

Table 2. Summary of Inclusion and Exclusion Criteria

\begin{tabular}{|l|l|l|}
\hline & Inclusion & Exclusion \\
\hline Population & All hypertension patients & $\begin{array}{l}\text { All studies that did not include } \\
\text { hypertension patients }\end{array}$ \\
\hline Intervention & All types of diet and exercises & $\begin{array}{l}\text { All studies that did not include } \\
\text { either of the two interventions }\end{array}$ \\
\hline comparison & Exercise alone & $\begin{array}{l}\text { If the method of outcome } \\
\text { assessment were inadequately } \\
\text { described. }\end{array}$ \\
\hline Outcome & Reduced high blood pressure & $\begin{array}{l}\text { Commentaries, review } \\
\text { documents, case studies }\end{array}$ \\
\hline Types of studies & All randomised controlled trials (RCTs) \\
\hline
\end{tabular}

\section{The Search Strategy}

Search strategy was very important so that relevant articles are not omitted [20]. The research question was "in hypertension patients is diet and exercise more effective in lowering high blood pressure compared to exercise alone". Since the search question was in place the next step was to focus on the key components of the question for initial search strategy [18]. Since the clinical question is health related a health-related electronic bibliographic database was searched. The databases used to search were
Medline because they include abstracts for majority of recent records and it is considered as one of the richest sources of trials [18]. Medline is the most widely used database for searching the biomedical literature and it is freely available on the internet, it is also updated regularly and is relatively user friendly [19]. For this project Medline database was searched under EBSCO host on the $29^{\text {th }}$ April 2013, there was no restriction on the years covered by the search [18]. The PICO elements of the focused question are shown in Table 3 below.

Table 3. PICO Elements (Keywords) of the Focused Question

\begin{tabular}{|l|l|l|l|}
\hline Population & Intervention/issue & comparison & Outcome \\
\hline Hypertension patients & diet and exercise & Exercise alone & Lowering high blood pressure \\
\hline
\end{tabular}

Since the PICO elements (keywords) in the focused question have already been identified, these are population (hypertension patients), intervention (diet and exercise), comparison (exercise alone) and outcome (lowering high blood pressure). The next thing was to find relevant evidence to the clinical question [19].

The Table 4 below shows the synonyms to the keywords in the research question.

Table 4. Synonyms to the Key Words

\begin{tabular}{|l|l|l|l|l|}
\hline PIO & $\mathbf{P}$ & $\mathbf{I}$ & $\mathbf{C}$ & $\mathbf{O}$ \\
\hline Keywords & hypertension & Diet and exercise & Exercise alone & Lowering high blood pressure \\
\hline Synonyms & $\begin{array}{l}\text { 1. High blood } \\
\text { pressure patients }\end{array}$ & 1.Food and workout & 1.workout & 1.Reduce hypertension \\
\cline { 2 - 5 } & $\begin{array}{l}\text { 2.Cardiovascular } \\
\text { patients }\end{array}$ & 2.Meals and training & 2.training & 2.Cut cardiovascular disease \\
\hline
\end{tabular}


Since all the synonyms related to keywords in the focused question have been generated, then the keywords and the generated synonyms are combined using Boolean operators "OR" and "AND". Boolean operators AND allows only articles containing both terms to be retrieved, while OR allows articles containing either term to be retrieved [19]. The CINAHL database was used in line with the focused question, which was medical in nature. Boolean operators "AND" and "OR" were used to narrow (specificity) and broaden (sensitivity) the search, respectively.

The ability to search databases effectively is an important aspect of evidence-based research; this is dependent upon a well-focused question and the ability to break it down into PICO terms and finding synonyms.

\section{Assessing the Methodological Quality of the Evidence}

The quality of evidence generated depends on the quality of the primary studies that make up the review [17]. The types of study design for this clinical question are randomized controlled trials. Assessing the methodological quality of the included studies is an important part in evidence-based practice. Since all relevant articles on the subject have been obtained, the next step was to appraise the evidence for its validity and clinical usefulness [19]. The most important component of critical appraisal is an evaluation of the appropriateness of the study design for the research question and careful assessment of key methodological features of the design [22]. The assessment of the validity, both internal validity (the degree to which the study provides valid evidence for the population and setting in which it was conducted) and external validity (the extent to which the evidence is relevant and generalizable to the population and conditions of typical primary care practice) has an important role throughout the process and is evident in the detailed reporting of individual quality items of all included studies. Validity means the extent the research study actually measures that which it is designed to measure. To do all this, several tools are available for appraising different research articles/designs; these are CASP [23]. The tools are simple, easy to use, and freely available on the internet. For this project, randomized controlled trial frameworks were be used; different studies use different frameworks according to research design.

\section{Results}

\section{Search Results}

The number of retrieved articles from the search strategy was eight; all were reviews and from the reference list of these retrieved articles was forty-three. After applying inclusion and exclusion criteria at the title and abstract level, eight articles were identified as relevant. This search was conducted on the Medline database under EBSCO host using keywords and generated synonyms. Only the eight randomized controlled trials from the reference list were included because they were primary studies and had the PICO components of the research question. Table 5 below shows the search results of the included articles.

\section{Summary of the Evidence that has been Included in the Project}

The summary of the evidence included in this project is shown in Table 6 .

\section{Summary of the methodological quality of the evidence}

The methodological quality of all included articles was assessed; these are randomized controlled trials. A critical appraisal skill program scale or tool was used to assess the quality of all the articles that met the inclusion criteria. The methodological quality looks at internal and external validity, reliability, and overall rigor. The (Table 7.) below shows a summary of the methodological quality of included articles. These tools assess the quality of all the articles that met the inclusion criteria. 
Table 5. Search Results, Data Base, Searched and Number of Articles

\begin{tabular}{|c|c|c|c|c|c|}
\hline Data base or method & $\begin{array}{l}\text { Number of articles } \\
\text { found from search }\end{array}$ & $\begin{array}{l}\text { Number of articles } \\
\text { discarded due to } \\
\text { irrelevant title }\end{array}$ & $\begin{array}{l}\text { Number of articles } \\
\text { duplicated from } \\
\text { another database }\end{array}$ & $\begin{array}{l}\text { Number of articles } \\
\text { discarded at abstract }\end{array}$ & $\begin{array}{l}\text { Number of articles to } \\
\text { review by title and abstract }\end{array}$ \\
\hline Medline (EBSCO HOST) & 8 & 1 & 0 & 7 & 0 \\
\hline Checking of the reference list & 43 & 35 & 0 & 0 & 8 \\
\hline
\end{tabular}

Table 6. Summaries of Evidence of the Included Articles in this Review

\begin{tabular}{|c|c|c|c|c|}
\hline Study by & Main aim & method & Main findings & conclusion \\
\hline $\begin{array}{l}\text { Svetkey L.P., } \\
\text { Simons-Morton } \\
\text { D.G., Vollmer } \\
\text { W.M., Appel L.J., } \\
\text { Conlin P.R., Ryan } \\
\text { D.H., Ard J. and } \\
\text { Kennedy B.M., } \\
\text { 1999. }\end{array}$ & $\begin{array}{l}\text { To determine the effects of dietary } \\
\text { patterns on blood pressure in } \\
\text { subgroups. }\end{array}$ & $\begin{array}{l}\text { The study design was a randomised } \\
\text { controlled trial. This was done at four } \\
\text { academic centres. Sample size was } 459 \\
\text { adult hypertensive patients. The sampling } \\
\text { method was by probability sampling } \\
\text { (simple random) computer generated. } \\
\text { Study duration was } 8 \text { weeks. Data } \\
\text { collection method was completing a daily } \\
\text { diary and direct observation. }\end{array}$ & $\begin{array}{l}\text { The combination diet } \\
\text { significantly lowered both } \\
\text { systolic and diastolic in all } \\
\text { subgroups. The DASH diet } \\
\text { lowered systolic blood } \\
\text { pressure significantly more } \\
\text { in African American than in } \\
\text { whites. }\end{array}$ & $\begin{array}{l}\text { The DASH combination diet } \\
\text { may be an effective strategy } \\
\text { for preventing and treating } \\
\text { hypertension across all } \\
\text { population groups. }\end{array}$ \\
\hline $\begin{array}{l}\text { Sacks F.M., Svetkey } \\
\text { L.P., Vollmer W.M., } \\
\text { Appel L.J., Bray } \\
\text { G.A., Harsha D., } \\
\text { Obarzanek E., } \\
\text { Conlin P.R., Miller } \\
\text { Iii E.R., Simons- } \\
\text { Morton D.G., } \\
\text { Karanja N. and Pao- } \\
\text { Hwa Lin, 2001. }\end{array}$ & $\begin{array}{l}\text { The aim was to study the effects of } \\
\text { different levels of dietary sodium } \\
\text { in conjunction with the dietary } \\
\text { approaches to stop hypertension } \\
\text { (DASH) diet which is rich in } \\
\text { vegetables, fruit and low-fat dairy } \\
\text { products in persons with and those } \\
\text { without hypertension. }\end{array}$ & $\begin{array}{l}\text { The study design was randomised } \\
\text { controlled multicentre. Sample size was } \\
412 \text { hypertensive and none hypertensive. } \\
\text { Duration of the study was from September } \\
1997 \text { to November } 1999 \text {. The sampling } \\
\text { method was by simple random. Data } \\
\text { collection method was by questionnaires, } \\
\text { daily food dairies, measuring of } 24 \text { hours } \\
\text { urinary excretion. }\end{array}$ & $\begin{array}{l}\text { Reduction in sodium intake } \\
\text { significantly lowered } \\
\text { systolic and diastolic blood } \\
\text { pressure both in the control } \\
\text { and DASH diet. }\end{array}$ & $\begin{array}{l}\text { Reduction of sodium intake to } \\
\text { levels below the current } \\
\text { recommendation of } 100 \mathrm{mmol} \\
\text { per day and the DASH diet } \\
\text { both lower blood pressures } \\
\text { substantially, with greater } \\
\text { effects in combination than } \\
\text { singly. }\end{array}$ \\
\hline
\end{tabular}




\begin{tabular}{|c|c|c|c|c|}
\hline $\begin{array}{l}\text { Margetts B.M., } \\
\text { Berlin L.J., } \\
\text { Vandongen R. and } \\
\text { Armstrong B.K., } \\
1986 .\end{array}$ & $\begin{array}{l}\text { Was to examine the effects of a } \\
\text { vegetarian diet in subjects with } \\
\text { mild hypertension and also to as } \\
\text { nearly as possible the diet of long- } \\
\text { term vegetarians. }\end{array}$ & $\begin{array}{l}\text { Randomised trial of } 58 \text { hypertension } \\
\text { patients aged } 30 \text { to } 64 \text { years. Duration six } \\
\text { weeks. Sampling method was simple } \\
\text { random. Data collection method was } \\
\text { dietary records, standiometer for height, } \\
\text { weight using beam scale, questionnaires } \\
\text { were completed }\end{array}$ & $\begin{array}{l}\text { There was fall in blood } \\
\text { pressure in vegetarian diet of } \\
\text { about } 5 \mathrm{~mm} \text { hg in untreated } \\
\text { subjects with hypertension. }\end{array}$ & $\begin{array}{l}\text { The study has shown that in } \\
\text { untreated subjects with mild } \\
\text { hypertension, changing to } \\
\text { vegetarian diet may bring } \\
\text { about a worthwhile fall in } \\
\text { systolic blood pressure. }\end{array}$ \\
\hline $\begin{array}{l}\text { Moreira W.D., } \\
\text { Fuchs F.D., } \\
\text { Lawrence J., Iberia } \\
\text { J.P. and Appel, } \\
\text { 1999. }\end{array}$ & $\begin{array}{l}\text { The main aim was to assess the } \\
\text { effect of six months of resistance } \\
\text { or endurance exercise training on } \\
\text { blood pressure in health } 70-79 \\
\text { years old men and women with } \\
\text { normal and elevated blood } \\
\text { pressure. }\end{array}$ & $\begin{array}{l}\text { The design was randomised controlled } \\
\text { trial. Location was at the hypertension unit } \\
\text { of the hospital de Clinicas de Ponto } \\
\text { Alegre. The sample size was } 28 \text { sedentary } \\
\text { hypertension patients; the duration was ten } \\
\text { weeks physical training. Sampling method } \\
\text { was probability sampling. Data collection } \\
\text { method was recording heart rate and blood } \\
\text { pressure from particular measuring } \\
\text { instruments. }\end{array}$ & $\begin{array}{l}\text { Across all participants, a } \\
\text { reduction in systolic blood } \\
\text { pressure was significant. }\end{array}$ & $\begin{array}{l}\text { The conclusion is that aerobic } \\
\text { training programs at } 20 \% \text { and } \\
60 \% \text { of the maximum work } \\
\text { capacity have similar effects } \\
\text { on ambulatory blood pressure. }\end{array}$ \\
\hline $\begin{array}{l}\text { Cononie C.C., } \\
\text { Graves J.E., Pollock } \\
\text { M.L., Philips M.I., } \\
\text { Sumners C., and } \\
\text { Hagberg J.M. 1991. }\end{array}$ & $\begin{array}{l}\text { The main aim was to assess the } \\
\text { effect of six months of resistance } \\
\text { or endurance exercise training on } \\
\text { blood pressure in health } 70-79 \\
\text { years old men and women with } \\
\text { normal and elevated blood } \\
\text { pressure. }\end{array}$ & $\begin{array}{l}\text { Design was randomised controlled trial. } \\
\text { Sample size was } 56 \text { male and female. } \\
\text { Duration was six months. Sampling } \\
\text { method was by stratified random. Data } \\
\text { collection method was by objectively } \\
\text { measuring using different instruments such } \\
\text { as random-zero sphygmomanometer. }\end{array}$ & $\begin{array}{l}\text { Endurance exercise training } \\
\text { produces modest reduction } \\
\text { in blood pressure in } 70-79 \\
\text { years old individuals. }\end{array}$ & $\begin{array}{l}\text { It appears that healthy men } \\
\text { and women in their seventies } \\
\text { with moderate hypertension } \\
\text { can lower their blood pressure } \\
\text { with endurance exercises to } \\
\text { the same degree as can young } \\
\text { and middle-aged hypertensive. }\end{array}$ \\
\hline $\begin{array}{l}\text { Martin J.E., Dubbert } \\
\text { P.M. and Cushman } \\
\text { W.C., } 1990 .\end{array}$ & $\begin{array}{l}\text { To determine the antihypertensive } \\
\text { efficacy of aerobic exercise } \\
\text { training in mild essential } \\
\text { hypertension. }\end{array}$ & $\begin{array}{l}\text { This was a randomised controlled trial } \\
\text { crossover. This was done at an outpatient } \\
\text { research clinic in a university-affiliated } \\
\text { veteran's administration medical centre. } \\
\text { Sample size was } 27 \text { men with untreated }\end{array}$ & $\begin{array}{l}\text { The study provides evidence } \\
\text { for the independent } \\
\text { antihypertensive effect of } \\
\text { aerobic exercise in mildly }\end{array}$ & $\begin{array}{l}\text { This study demonstrates that } \\
\text { moderate aerobic exercise } \\
\text { lowers blood pressure in } \\
\text { hypertensive subjects and } \\
\text { might be an important }\end{array}$ \\
\hline
\end{tabular}




\begin{tabular}{|c|c|c|c|c|}
\hline & & $\begin{array}{l}\text { diastolic blood pressure of } 90 \text { to } 104 . \\
\text { Duration was } 10 \text { weeks sampling method } \\
\text { was simple random. Data collection } \\
\text { method was by objectively measuring by } \\
\text { different instruments such as random-zero } \\
\text { sphygmomanometer. }\end{array}$ & $\begin{array}{l}\text { essential hypertensive men } \\
\text { who were not on medication. }\end{array}$ & $\begin{array}{l}\text { modality in the control of } \\
\text { hypertension. }\end{array}$ \\
\hline $\begin{array}{l}\text { Gunjal S., Shinde } \\
\text { N., Kazi A. and } \\
\text { Khatri S., } 2013\end{array}$ & $\begin{array}{l}\text { The aim was to study the effect of } \\
\text { aerobic interval training on blood } \\
\text { pressure and myocardial function } \\
\text { in hypertensive patients. }\end{array}$ & $\begin{array}{l}\text { The design was an experimental (pre-post) } \\
\text { design. Location of the study was at } \\
\text { department of cardiorespiratory } \\
\text { physiotherapy pravara rural hospital, loni, } \\
\text { India. Participants were } 30 \text { hypertensive } \\
\text { patients. Duration of the study was } 12 \\
\text { weeks. Sampling method was non- } \\
\text { probability. Data collection method by B } \\
\text { mode images was recorded and by } \\
\text { modified biplane Sampson's method. }\end{array}$ & $\begin{array}{l}\text { There was significant } \\
\text { reduction in blood pressure } \\
\text { and there was improvement } \\
\text { in ejection fraction, stroke } \\
\text { volume, cardiac output and } \\
\text { peripheral resistance } \\
\text { decreased by } 17 \% \text { after } \\
\text { aerobic interval training. }\end{array}$ & $\begin{array}{l}\text { The study indicates that } \\
\text { aerobic interval training is } \\
\text { effective to reduce blood } \\
\text { pressure and heart rate and } \\
\text { improves myocardial function } \\
\text { in hypertensive patients and } \\
\text { that moderate to high intensity } \\
\text { of the three weekly bouts of } \\
\text { interval training for } 12 \text { weeks } \\
\text { reduced blood pressure and } \\
\text { improved cardiac function. }\end{array}$ \\
\hline $\begin{array}{l}\text { Liu S., Goodman J., } \\
\text { Nolan R., Shawn } \\
\text { L.S. and Scott G., } \\
2012 \text {. }\end{array}$ & $\begin{array}{l}\text { The main aim was to assess the } \\
\text { relation between the degrees of } \\
\text { post exercise hypotension with } \\
\text { acute exercise and also to examine } \\
\text { the correlates of blood pressure } \\
\text { reduction after chronic exercise in } \\
\text { both sexes. }\end{array}$ & $\begin{array}{l}\text { The design was quasi experimental study } \\
\text { we are told the study benefited from a } \\
\text { longitudinal study design. Location was at } \\
\text { university of Toronto athletic centre. } 17 \\
\text { participant's duration } 8 \text { weeks. Sampling } \\
\text { method was non-probability. Data } \\
\text { collection method questionnaires were } \\
\text { completed, training was recorded in a } \\
\text { weekly log. }\end{array}$ & $\begin{array}{l}\text { Blood pressure was } \\
\text { significantly reduced relative } \\
\text { to the baseline after } 30 \\
\text { minutes of acute and chronic } \\
\text { exercises. }\end{array}$ & $\begin{array}{l}\text { The magnitude of the acute } \\
\text { blood pressure lowering with } \\
\text { exercise may predict the extent } \\
\text { of blood pressure lowering } \\
\text { after chronic training } \\
\text { intervention in } \\
\text { prehypertension individual and } \\
\text { that lifestyle intervention and } \\
\text { in particular chronic aerobic } \\
\text { exercises may prevent or delay } \\
\text { the development of } \\
\text { hypertension. }\end{array}$ \\
\hline
\end{tabular}


Table 7. Summaries of Methodological Quality of Included Articles

\begin{tabular}{|c|c|c|c|c|}
\hline Study by & Internal validity & External validity & reliability & Overall rigour \\
\hline $\begin{array}{l}\text { Svetkey L.P., Simons- } \\
\text { Morton D.G., Vollmer } \\
\text { W.M., Appel L.J., } \\
\text { Conlin P.R., Ryan D.H., } \\
\text { Ard J. and Kennedy } \\
\text { B.M., 1999. }\end{array}$ & $\begin{array}{l}\text { Was high due to random allocation of } \\
\text { participants, similarity of groups at } \\
\text { baseline, computer generated random } \\
\text { allocation, blinding of staff, } \\
\text { concealment of allocation, data } \\
\text { analysis was done on an intention to } \\
\text { treat analysis, control of variables, } \\
\text { adequacy of follow ups, data collection } \\
\text { methods through questionnaires, } \\
\text { observation and completed dairies. }\end{array}$ & $\begin{array}{l}\text { High due to the following sample } \\
\text { size was } 459 \text {, probability sampling } \\
\text { method, cluster eligibility was } \\
\text { followed, acceptability of } \\
\text { intervention, outcome measures } \\
\text { were considered such as change in } \\
\text { systolic and diastolic blood } \\
\text { pressure, exclusion and inclusion, } \\
\text { power analysis. The article did not } \\
\text { mention anything on dropout. }\end{array}$ & $\begin{array}{l}\text { High due to use of } \\
\text { standard tools such as } \\
\text { random zero } \\
\text { sphygmomanometer, data } \\
\text { analysis instruments such } \\
\text { as SAS software package. }\end{array}$ & $\begin{array}{l}\text { Strong due to } \\
\text { intervention and } \\
\text { intended } \\
\text { outcome. }\end{array}$ \\
\hline $\begin{array}{l}\text { Sacks F.M., Svetkey } \\
\text { L.P., Vollmer W.M., } \\
\text { Appel L.J., Bray G.A., } \\
\text { Harsha D., Obarzanek } \\
\text { E., Conlin P.R., Miller } \\
\text { Iii E.R., Simons-Morton } \\
\text { D.G., Karanja N. and } \\
\text { Pao-Hwa Lin, 2001. }\end{array}$ & $\begin{array}{l}\text { High due to random allocation of } \\
\text { participants, concealment of allocation, } \\
\text { blinding of participants and dietary } \\
\text { staff, similarity of groups at baseline, } \\
\text { intention to treat analysis, adequacy of } \\
\text { follow ups, data collection (diaries and } \\
\text { questionnaires) methods, statistical } \\
\text { analysis and there was control of } \\
\text { variables. }\end{array}$ & $\begin{array}{l}\text { High due to sample size of } 412 \\
\text { participants, probability sampling } \\
\text { method, cluster eligibility } \\
\text { (exclusion and inclusion), cluster } \\
\text { generalizability, outcome of } \\
\text { systolic and diastolic blood } \\
\text { pressure. The study did not } \\
\text { mention anything on dropouts, and } \\
\text { acceptability of intervention and } \\
\text { power analysis. }\end{array}$ & $\begin{array}{l}\text { High due to the use of } \\
\text { standard tools such as } \\
\text { random zero } \\
\text { sphygmomanometer. }\end{array}$ & strong \\
\hline $\begin{array}{l}\text { Margetts B.M., Berlin } \\
\text { L.J., Vandongen R. and } \\
\text { Armstrong B.K., } 1986 .\end{array}$ & $\begin{array}{l}\text { High due to control of variables, } \\
\text { random allocation, concealment of } \\
\text { allocation, similarity of groups at } \\
\text { baseline, intention to treat analysis, } \\
\text { adequacy of follow ups, data collection } \\
\text { methods such as questionnaires, }\end{array}$ & $\begin{array}{l}\text { High due to sample size } 58 \\
\text { participants, probability sampling } \\
\text { method, cluster eligibility } \\
\text { (exclusion and inclusion), cluster } \\
\text { generalizability, outcome of } \\
\text { interest, dropouts were taken care. } \\
\text { Though there is no mention of }\end{array}$ & $\begin{array}{l}\text { High due to use of } \\
\text { standard tools such as } \\
\text { standard mercury } \\
\text { sphygmomanometer, } \\
\text { automatic oscillometric } \\
\text { device, specialist } \\
\text { physicians, stadiometer }\end{array}$ & strong \\
\hline
\end{tabular}




\begin{tabular}{|c|c|c|c|c|}
\hline & $\begin{array}{l}\text { statistical analysis. But blinding was } \\
\text { not done. }\end{array}$ & $\begin{array}{l}\text { acceptability of intervention, } \\
\text { power analysis. }\end{array}$ & $\begin{array}{l}\text { for height, beam scale for } \\
\text { weight and auto analyser }\end{array}$ & \\
\hline $\begin{array}{l}\text { Liu S., Goodman J., } \\
\text { Nolan R., Shawn L.S. } \\
\text { and Scott G., } 2012 .\end{array}$ & $\begin{array}{l}\text { Low because there is no blinding, } \\
\text { random allocation, concealment of } \\
\text { allocation, intention to treat analysis. } \\
\text { The other things were taken into } \\
\text { consideration such as control of } \\
\text { variables, similarity of groups at } \\
\text { baseline, adequacy of follow ups, data } \\
\text { collection methods (questionnaires and } \\
\text { recording), and statistical analysis. }\end{array}$ & $\begin{array}{l}\text { High due to sample size } 17 \\
\text { participants using power } \\
\text { calculation, outcome of interest } \\
\text { was systolic and diastolic blood } \\
\text { pressure, follow ups adequate all } \\
\text { completed (no drop out) the study, } \\
\text { cluster eligibility, cluster was } \\
\text { done. The sampling method was } \\
\text { non-probability. There is no } \\
\text { mention on acceptability of } \\
\text { intervention. }\end{array}$ & $\begin{array}{l}\text { High due to use of } \\
\text { standard tools, such as } \\
\text { heart rate monitor watch, } \\
\text { automated oscillometric } \\
\text { brachial blood pressure } \\
\text { device, applanation } \\
\text { tonometry for arterial } \\
\text { stiffness and finometer } \\
\text { MIDI MODEL-2 for } \\
\text { blood pressure beats, } \\
\text { ANOVA was used for } \\
\text { evaluation and automated } \\
\text { sphygmomanometer for } \\
\text { brachial blood pressure. }\end{array}$ & Slightly weak \\
\hline $\begin{array}{l}\text { Gunjal S., Shinde N., } \\
\text { Kazi A. and Khatri S., } \\
2013\end{array}$ & $\begin{array}{l}\text { Low due to none blinding, no } \\
\text { concealment of allocation, no random } \\
\text { allocation, intention to treat analysis } \\
\text { not mentioned, statistical analysis not } \\
\text { done. Others were done such as } \\
\text { similarity of groups at baseline, } \\
\text { adequacy of follow ups, data collection } \\
\text { method and control of variables. }\end{array}$ & $\begin{array}{l}\text { Low due to sample size, sampling } \\
\text { method non-probability, cluster } \\
\text { generalizability not mentioned, } \\
\text { and acceptability of intervention } \\
\text { not mentioned, power analysis was } \\
\text { not done. Cluster eligibility was } \\
\text { done, outcome, exclusion and all } \\
\text { these were done. }\end{array}$ & $\begin{array}{l}\text { High due to use of } \\
\text { standard tools, such as } \\
\text { karvonen's formula for } \\
\text { exercise intensity, } \\
\text { sphygmomanometer for } \\
\text { blood pressure, pulse } \\
\text { oxymeter for heart rate, } \\
\text { modified biplane } \\
\text { Sampson's method for } \\
\text { ejection fraction and } \\
\text { echocardiography was } \\
\text { done by experienced }\end{array}$ & Slightly weak \\
\hline
\end{tabular}




\begin{tabular}{|c|c|c|c|c|}
\hline & & & $\begin{array}{l}\text { cardiologist using vivid } 7 \\
\text { scanner with m35 probe }\end{array}$ & \\
\hline $\begin{array}{l}\text { Martin J.E., Dubbert } \\
\text { P.M. and Cushman } \\
\text { W.C., 1990. }\end{array}$ & $\begin{array}{l}\text { High due to blinding, control of } \\
\text { variables, random allocation, } \\
\text { concealment of allocation, similarity of } \\
\text { groups at baseline, adequacy of follow } \\
\text { ups, data collection methods. These } \\
\text { others are not mentioned, statistical } \\
\text { analysis, and intention to treat analysis. }\end{array}$ & $\begin{array}{l}\text { High due to sample size, sampling } \\
\text { method inclusion (probability), } \\
\text { cluster eligibility, dropouts, } \\
\text { exclusion and inclusion criteria. } \\
\text { These others are not mentioned } \\
\text { cluster generalizability, } \\
\text { acceptability of intervention, } \\
\text { outcome, and power analysis. }\end{array}$ & $\begin{array}{l}\text { High due to use of } \\
\text { standard tools such as } \\
\text { random zero } \\
\text { sphygmomanometer, } \\
\text { specialist nurse assessed } \\
\text { the blood pressure, and } \\
\text { ANOVA was used to } \\
\text { analyse variance. }\end{array}$ & strong \\
\hline $\begin{array}{l}\text { Cononie C.C., Graves } \\
\text { J.E., Pollock M.L., } \\
\text { Philips M.I., Sumners } \\
\text { C., and Hagberg J.M. } \\
\text { 1991. }\end{array}$ & $\begin{array}{l}\text { High due to, control of variables, } \\
\text { random allocation, concealment of } \\
\text { allocation, similarity of groups at } \\
\text { baseline, though there is no mention of } \\
\text { intention to treat analysis, adequacy of } \\
\text { follow ups, data collection methods, } \\
\text { statistical analysis and blinding. }\end{array}$ & $\begin{array}{l}\text { High due to sample size } 56 \\
\text { participants, sampling method } \\
\text { (probability), cluster eligibility, } \\
\text { dropouts accounted, exclusion and } \\
\text { inclusion used. Cluster } \\
\text { generalizability, acceptability of } \\
\text { intervention, outcome, and power } \\
\text { analysis are not mentioned. }\end{array}$ & $\begin{array}{l}\text { High due to use of } \\
\text { standard tools such as } \\
\text { random zero } \\
\text { sphygmomanometer, and } \\
\text { computerised collier co2 } \\
\text { rebreathing technique for } \\
\text { cardiac output. }\end{array}$ & strong \\
\hline $\begin{array}{l}\text { Moreira W.D., Fuchs } \\
\text { F.D., Lawrence J., Iberia } \\
\text { J.P. and Appel, } 1999 \text {. }\end{array}$ & $\begin{array}{l}\text { High due to blinding, control of } \\
\text { variables, random allocation, } \\
\text { concealment of allocation, similarity of } \\
\text { groups at baseline, intention to treat } \\
\text { analysis, statistical analysis, though } \\
\text { adequacy of follow ups, data collection } \\
\text { methods are not mentioned. }\end{array}$ & $\begin{array}{l}\text { High due to sample size of } 28 \\
\text { participants, sampling method } \\
\text { (probability), cluster eligibility, } \\
\text { exclusion and inclusion. Cluster } \\
\text { generalizability, acceptability of } \\
\text { intervention, outcome, dropouts, } \\
\text { and power analysis are not } \\
\text { mentioned. }\end{array}$ & $\begin{array}{l}\text { High due to use of } \\
\text { standard tools such as } \\
\text { model PIV device for } \\
\text { blood pressure and } \\
\text { treadmill for physical } \\
\text { fitness. }\end{array}$ & strong \\
\hline
\end{tabular}




\section{Synthesis of the Main Findings from the Evidence}

All the studies have shown that lifestyle modifications such as diet and exercise lowered blood pressure in hypertensive patients.

Table $8 \mathrm{a}$ shows the reduction of blood pressure in different types of exercise. In Moreira et al. mean 24 hours systolic blood pressure fell from 137.2 plus or minus 14.9 to 135 plus or minus $12.7 \mathrm{~mm} \mathrm{Hg}$, and the mean diastolic blood pressure fell from 92.1 plus or minus 10.0 to 89.3 plus or minus $7.7 \mathrm{~mm} \mathrm{Hg}$. In Cononie et al. the reduction in blood pressure in the endurance training group initial systolic blood pressure was 139 plus or minus 16, diastolic 81 plus or minus $8 \mathrm{~mm} \mathrm{Hg}$ and after six- month blood pressure fell to systolic 135 plus or minus 17, diastolic 76 plus or minus $7 \mathrm{~mm} \mathrm{Hg}$. In martin et al., blood pressure was reduced from systolic $136.6 \mathrm{~mm} \mathrm{Hg}$ and diastolic $94.8 \mathrm{~mm} \mathrm{hg}$ to systolic $130.1 \mathrm{~mm} \mathrm{Hg}$ and diastolic $85.2 \mathrm{~mm}$ Hg. In Gunjal et al., blood pressure reduced from systolic 152 plus or minus $12 \mathrm{~mm} \mathrm{Hg}$ and diastolic 96 plus or minus $8 \mathrm{~mm} \mathrm{Hg}$ to systolic 140 plus or minus $12.5 \mathrm{~mm} \mathrm{Hg}$ and diastolic 84 plus or minus $8 \mathrm{~mm} \mathrm{Hg}$. In Lui et al. blood pressure reduced from systolic 126 plus or minus $1.8 \mathrm{~mm} \mathrm{Hg}$ and diastolic 81 plus or minus 1.1 $\mathrm{mm} \mathrm{Hg}$ to systolic 120 plus or minus $1.8 \mathrm{~mm} \mathrm{Hg}$ and diastolic 75 plus or minus $1 \mathrm{~mm} \mathrm{Hg}$. Overall, there is a trend of reduced blood pressure from high to lower levels.

Table 8a. Below Pre and Post Exercise Intervention Blood Pressure Levels of Each Study

\begin{tabular}{|l|l|l|l|l|l|}
\hline \multicolumn{2}{|l|}{} & \multicolumn{2}{l|}{ Before intervention } & \multicolumn{2}{l|}{ After intervention } \\
\hline Study by & intervention & systolic & diastolic & systolic & diastolic \\
\hline $\begin{array}{l}\text { Cononie et al } \\
1991 .\end{array}$ & $\begin{array}{l}\text { Endurance } \\
\text { exercise }\end{array}$ & $\begin{array}{l}139 \pm 16 \mathrm{~mm} \\
\mathrm{Hg}\end{array}$ & $\begin{array}{l}81 \pm 8 \mathrm{~mm} \\
\mathrm{Hg}\end{array}$ & $\begin{array}{l}135 \pm 17 \mathrm{~mm} \\
\mathrm{Hg}\end{array}$ & $76 \pm 7 \mathrm{~mm} \mathrm{hg}$ \\
\hline $\begin{array}{l}\text { Martin et al } \\
1990\end{array}$ & $\begin{array}{l}\text { Aerobic } \\
\text { exercise }\end{array}$ & $\begin{array}{l}136.6 \mathrm{~mm} \\
\mathrm{Hg}\end{array}$ & $\begin{array}{l}94.8 \mathrm{~mm} \\
\mathrm{Hg}\end{array}$ & $130.1 \mathrm{~mm} \mathrm{hg}$ & $85.2 \mathrm{~mm} \mathrm{Hg}$ \\
\hline $\begin{array}{l}\text { Moreira et al } \\
1999\end{array}$ & $\begin{array}{l}\text { Physical } \\
\text { training } \\
\text { exercise }\end{array}$ & $\begin{array}{l}137.2 \pm 14.9 \\
\mathrm{~mm} \mathrm{Hg}\end{array}$ & $\begin{array}{l}92.1 \pm 10 \\
\mathrm{~mm} \mathrm{Hg}\end{array}$ & $\begin{array}{l}135.2 \pm 12.7 \\
\mathrm{~mm} \mathrm{Hg}\end{array}$ & $\begin{array}{l}89.3 \pm 7.7 \mathrm{~mm} \\
\mathrm{Hg}\end{array}$ \\
\hline $\begin{array}{l}\text { Gunjal et al } \\
2013\end{array}$ & $\begin{array}{l}\text { Aerobic interval } \\
\text { training } \\
\text { exercise }\end{array}$ & $\begin{array}{l}152 \pm 12 \mathrm{~mm} \\
\mathrm{Hg}\end{array}$ & $\begin{array}{l}96 \pm 8 \mathrm{~mm} \\
\mathrm{Hg}\end{array}$ & $\begin{array}{l}140 \pm 12.5 \\
\mathrm{~mm} \mathrm{Hg}\end{array}$ & $84 \pm 8 \mathrm{~mm} \mathrm{Hg}$ \\
\hline $\begin{array}{l}\text { Liu et al } \\
2012\end{array}$ & $\begin{array}{l}\text { Acute and } \\
\text { chronic aerobic } \\
\text { exercises }\end{array}$ & $\begin{array}{l}126 \pm 1.8 \\
\mathrm{~mm} \mathrm{Hg}\end{array}$ & $\begin{array}{l}81 \pm 1.1 \\
\mathrm{~mm} \mathrm{Hg}\end{array}$ & $\begin{array}{l}120 \pm 1.8 \\
\mathrm{~mm} \mathrm{Hg}\end{array}$ & $75 \pm 1 \mathrm{~mm} \mathrm{Hg}$ \\
\hline
\end{tabular}

Table $8 \mathrm{~b}$ shows different types of diets and there lowering effect on blood pressure. In Svetkey et al. the DASH diet significantly lowered systolic and diastolic blood pressure by $11.4 \mathrm{~mm} \mathrm{Hg}$ in all subgroups $\mathrm{p}=0.03$. In Sacks et al. DASH and low sodium lowered blood pressure by $11.5 \mathrm{Hg}$ in hypertensive patients $\mathrm{p}<0.001$. In Margetts et al. the fall in blood pressure following a vegetarian diet was $5 \mathrm{~mm}$ Hg $\mathrm{p}<0.05$. 
Table 8b. Pre and Post Diet Intervention Blood Pressure Levels of Each Study

\begin{tabular}{|l|l|l|l|l|l|l|}
\hline \multicolumn{2}{|l|}{} & \multicolumn{2}{|l|}{ Before intervention } & \multicolumn{2}{l|}{ After intervention } & \\
\hline Study by & Intervention & Systolic & Diastolic & Systolic & Diastolic & P value \\
\hline $\begin{array}{l}\text { Svetkey et al } \\
1999\end{array}$ & DASH diet & $160 \mathrm{~mm} \mathrm{Hg}$ & $95 \mathrm{~mm} \mathrm{Hg}$ & $148.6 \mathrm{~mm} \mathrm{Hg}$ & $83 \mathrm{~mm} \mathrm{Hg}$ & $\mathrm{P}=0.03$ \\
\hline $\begin{array}{l}\text { Sacks et al } \\
2001\end{array}$ & $\begin{array}{l}\text { DASH plus } \\
\text { sodium diet }\end{array}$ & $134 \mathrm{~mm} \mathrm{Hg}$ & $86 \mathrm{~mm} \mathrm{Hg}$ & $122.5 \mathrm{~mm} \mathrm{Hg}$ & $\begin{array}{l}74.5 \mathrm{~mm} \\
\mathrm{Hg}\end{array}$ & $\mathrm{P}<0.001$ \\
\hline $\begin{array}{l}\text { Margetts et } \\
\text { al 1986 }\end{array}$ & $\begin{array}{l}\text { Ovolactovegetarian } \\
\text { diet }\end{array}$ & $\begin{array}{l}154.4 \mathrm{~mm} \\
\mathrm{Hg}\end{array}$ & $\begin{array}{l}98.5 \mathrm{~mm} \\
\mathrm{Hg}\end{array}$ & $149.4 \mathrm{~mm} \mathrm{Hg}$ & $\begin{array}{l}93.5 \mathrm{~mm} \\
\mathrm{Hg}\end{array}$ & $\mathrm{P}<0.05$ \\
\hline
\end{tabular}

\section{Discussion}

\section{Summary of Key Findings}

There is good evidence from all the identified articles. All the included studies have identified diet and exercise as a means to reduce or lower blood pressure. Though the articles included did not exclusively just discuss on exercise and diet, it was one of the areas of study interest. Nevertheless, all the articles touched on the condition of interest, which is hypertension. It has been noted that hypertension patients greatly benefit from diet and exercise, lowering the effect on blood pressure. The treatment effect of exercise and diet on hypertensive patients was substantial. These lifestyle modifications (diet and exercise) have been highly recommended in these included studies.

Although the included articles in this review seem to have been of short duration, they seem to have been intensive studies because most of these were relevant to issues of long-term sustainability, which is of prime importance in clinical practice and in determining the public health impact of the studies considered.

\section{Interpretation of Key Findings}

Most of the findings were in line with the main objective, which is 'to investigate the effect of diet and exercise interventions on blood pressure in hypertension patients. The problem of validity makes it difficult to make firm conclusions on the basis of the articles considered and makes it probable that the findings reported are overestimates of the effect that might be achieved in practice.

The randomized controlled trials evidence was good though there was no study that looked at the intervention of interest the way it appears in the research question. In this review, the intervention of interest is diet and exercise, but most articles retrieved looked at either diet or exercised singly. All the randomized controlled trial included in this review was relevant to the research question and were of good methodological quality. Randomized controlled trials were explicit, reproducible and up to date. They were conducted in an explicit and wellstructured methodology which minimized the possibility of bias. Some of these studies were not explicit and were not well structured methodologically, which brought in the possibility of bias. Despite these shortcomings these studies had important information relevant to the research question and objective.

\section{Finding on Objective One}

Objective number one was 'to synthesize evidence from research papers assessing the effectiveness of healthy diet and exercise in lowering high blood pressure in hypertension patients compared to exercise alone'. In relation to this objective, all the included studies have evidence to support the use of diet and exercise as a means of lowering high blood pressure. The evidence was found in all the eight included articles. In all these articles, reduction in blood pressure was significant. 


\section{Findings on Objective Two}

Objective two was 'to discuss how a healthy diet and exercise and can be developed in order to reduce raised blood pressure in hypertensive patients. This means of lowering blood pressure is reasonably priced, low risk, and easily implementable. DASH diet includes most of the readily available foods, which are well accepted in most populations. The estimate of cost places the DASH diet between low-cost and moderatebased foods. High and moderate exercise have been seen to have the same effect on blood pressure as such, it has been recommended as a safe and efficacious intervention.

\section{Findings on Objective Three}

The last objective was on the assessment of the relationship between exercise and a healthy diet with hypertension. In all the five articles on exercise as an intervention means of lowering blood pressure, the effect has been seen even in chronic and acute exercises. Whether high or low-intensity trainings, the blood pressurelowering effect was substantial. It also found that a vegetarian diet lowered blood pressure in untreated subjects with mild hypertension. Even when other factors were held constant, the DASH diet lowered blood pressure. Foodless in sodium significantly lowered blood pressure in both control and DASH diets.

\section{Limitations of the Study}

The major limitations of this review were that none of these included articles looked at diet and exercise combined as an intervention and then comparing it with exercise alone. This search may also have been limited by none usage of truncation and wildcat symbol. If this search was to be repeated, efforts would be made to find all variant spellings and also variant endings (plural or singular) in order to increase sensitivity. The other limitation was that the confounding factors in other studies were not taken care of; hence they may have altered the outcome of interest. The other limitation is that most of these studies were of short duration.

\section{Implications and Application to Practice of the Study}

All the included articles showed a lot of factors and results that can be applied since most important factors that are related to individual and policy were considered where it might contribute to change the policy and practice. There is an acknowledgement that conventional treatment has done little to reduce the number of patients with hypertension. The research has found an alternative to reducing high blood pressure, such as lifestyle modifications (diet and exercise). Emphasis is now being placed on efficient and cost-effective strategies for diagnosing and managing hypertensive patients. Recent evidence from most studies indicates that non-pharmacological therapy, which includes dietary potassium and calcium supplements, reduction of salt intake, regular exercise, a diet high in fibre and low in cholesterol and saturated fats, produces a significant reduction in blood pressure. In most of the studies, salt restriction and increased physical activity are generally accepted lifestyle measures in the management of hypertension. In the studies that involved physical activities, the reduction in blood pressure was not related to the intensity of the exercises. The dietary approaches to stop hypertension (DASH) diet is also highly recommended in most of the studies done, and it was very effective in reducing blood pressure in both hypertensive and non-hypertensive. In line with the objectives of this study, it has been seen that diet and exercise play a major role in high blood pressure reduction.

\section{Indication for Further Research}

One of the areas that need further consideration is the sample size (should be bigger to be able to generalize the findings); longer duration for the research, also there is a need to reduce confounding factors. There is a need to assess the long-term safety, use, and acceptability of the intervention by communities. Most of these researches were done at higher-level centers, and there is a need 
to go to lower-level communities who are not taped. There is also a need to look at how exercise and diet impact on the quality of life and mortality rates.

\section{Recommendations}

Recommendations such as to eat well and exercise are generally safe and inexpensive and likely to have desired benefits. Most of the articles have recommended the use of diet and exercise in lowering high blood pressure. Most research on dietary approaches to stop hypertension (DASH) combination diet, which contains large amounts of fruit, vegetables, fish and nuts, low-fat dairy products, and reduced levels of total and saturated fat, together with exercise, have been effective in lowering high blood pressure. First, all stakeholders, both in government and individuals, must put in more effort to tap knowledge on the issue of exercise and diet for the management of hypertensive patients. This, I believe, could be done by educating practitioners and teaching them how to document exercise and diet in their practice.

It is important that all medical practitioners are introduced to this new research development in order to have standard health care that cut across all board. It is worth noting that the differences between pharmacological and none pharmacological are not necessarily anything but the way they are used. In recognizing the scientific aspects of exercise and diet, one needs to be cautious of not relegating conventional aspects of the practice. Patients with elevated blood pressure should follow a weight-reducing diet and also take regular exercises and restrict salt intake.

Just as various measures have been put in place by the governments to enhance the services of conventional medicine, attention must be also be given to exercise and diet. Budgetary allocations must much match that of a conventional system. Government must enhance efforts by scaling up the use of exercise and diet. In so doing, the government must put ineffective regulatory bodies to periodically check the works of these health posts.

I'm absolutely in support of advocacy for the use of exercise and diet; I think such an idea will not be bad at all considering the fact that many people use exercise and diet in their daily lives. It is imperative for people to realize that exercise and diet have been in our daily practices. Therefore, it is crucial for one to separate diet and exercise from our daily lives.

Integrating exercise and diet into the national health care policy of Zambia would be an action in the right direction. There must therefore be a much stronger national policy and regulatory framework on issues pertaining to safety, efficacy, quality, access, and rational use of diet and exercise.

Diet and exercise may treat and cure diseases that are currently leading to humans' potential extinction. If actions are taken soon to study and protect this new means of treating hypertension, these lifestyle modifications may find themselves to be the best means of reducing hypertension.

\section{Conclusions}

For a long time, people have lived with the impression that only conventional medicines can treat hypertension; it is time we consider such viewpoints once more. These studies have shown that diet and exercise can holds a vibrant role in the dispensation of good health practices the world over. Most of these studies have acknowledged the potency and prospects of using exercise and diet even with the presence of conventional medicine. It is evident from these studies that diet and exercise can be an alternative, not just complementing conventional medicine.

From the studies, it is clear that exercise and diet will reach one $100 \%$ usage among hypertensive patient; as such, clinicians should come together and fashion ways of enhancing the use of exercise and diet to reduce high blood pressure. Again, since diet and exercise play a central role in the general life of many people, it 
is important for the health systems to embrace this in its practices since there is empirical evidence to support its relevance to indigenous healing. Therefore, if there would be a comprehensive medical system world over, exercise and diet must find its way into practice.

\section{Acknowledgement}

I would like to take this opportunity to thank Dr. Nyanzi Lawrence of Teesside University UK for the guidance he rendered during my writing

\section{References}

[1] Springhouse, PA: Springhouse Corporation, (Eds.) (1992). Diseases, Nursing. Pp. 538-542 Retrieved from https://archive.org/details/diseases00spri.

[2] Appel, L, J., (1999). Nonpharmacologic therapies that reduce blood pressure: a fresh perspective. Clin Cardiol. 1999 Jul; 22(7 Suppl): III1-5. DOI: 10.1002/clc.4960221502. PMID: 10410298 ; PMCID: PMC6655381.

[3] WHO, World Health Day, (2013). A global brief on hypertension: silent killer, global public health crisis: World Health Day, (2013) WHO Reference Number: WHO/DCO/WHD/2013.2

https://www.who.int/publications/i/item/a-globalbrief-on-hypertension-silent-killer-global-publichealth-crisis-world-health-day-2013.

[4] Goma, F. M., Nzala, S. H., Babaniyi, O., Songolo, P., Zyaambo, C., Rudatsikira, E., Siziya, S., \& Muula, A. S. (2011). Prevalence of hypertension and its correlates in Lusaka urban district of Zambia: a population-based survey. International archives of medicine, 4, 34. retrieved from https://doi.org/10.1186/1755-7682-4-34.

[5] Mweene, M., Banda, J., Andrews, B., Mweene, M., Lakhi, S. (2010). Factors Associated with Poor Medication Adherence in Hypertensive Patients in Lusaka, Zambia. Medical Journal of Zambia, 37(4), 252-261. Retrieved from https://www.mjz.co.zm/index.php/mjz/article/view/3 78.

[6] Soudarssanane, M. B., Karthigeyan, M., Stephen, S., Sahai, A. (2006). High Blood Pressure/ up this review. Finally, I would also like to thank my family for giving me space to complete my project and also for providing me with unfailing support and continuous encouragement throughout the process of researching and writing this review.

\section{Conflict of Interest}

Himwaaba Gift declares no conflict of interest.

Hypertension in Adolescents Key Predictors of High Blood Pressure and Hypertension among Adolescents: A Simple Prescription for Prevention. Indian Journal of Community Medicine Vol. 31, No. 3, July - September 2006 164. Retrieved from https://www.ijcm.org.in/temp/IndianJCommunityMe d313164-2472491_065204.pdf.

[7] Ministry of Health and Central Board of Health, (2002). Integrated Technical Guidelines for Frontline Health Workers. 2nd Edition, Ministry of Health and Central Board of Health, Lusaka. Pp. 198-199.

[8] World Health Organization. (2007). Prevention of cardiovascular disease: pocket guidelines for assessment and management of cardiovascular risk: (WHO/ISH cardiovascular risk prediction charts for the European Region). World Health Organization. Retrieved from https://apps.who.int/iris/handle/10665/43784.

[9] World Health Organization, (2011). WHO recommendations for prevention and treatment of pre-eclampsia and eclampsia. Retrieved from https://www.guidelinecentral.com/summaries/whorecommendations-for-prevention-and-treatment-ofpre-eclampsia-and-eclampsia/\#section-society.

[10] Chowa, P. E., Lin, C., Goma, F., South-Paul, J. (2011). Prevalence of Hypertension among Women of Child-Bearing Age in Zambia. Medical Journal of Zambia, 38(3), 3-8. Retrieved from https://www.mjz.co.zm/index.php/mjz/article/view/3 92.

[11] Siziya, S., Rudatsikira, E., Babaniyi, O., Songolo, P., Mulenga, D., et al. (2012) Prevalence and Correlates of Hypertension among Adults Aged 
25 Years or Older in a Mining Town of Kitwe, Zambia. J Hypertens 1:105. DOI: 10.4172/21671095.1000105.

[12] Suhrcke, M., Nugent, R. A., Stuckler, D., Rocco, L. (2006). Chronic Disease: An Economic Perspective London: Oxford Health Alliance 2006 ISBN 0-9554018-1-X. retrieved from www.oxha.org. Chronic-disease-an-economic-perspective.pdf (who.int).

[13] Ministry of Health Global Fund (GF), (2011). Annual Health Statistical Bulletin. Directorate of Policy \& Planning Monitoring \& Evaluation Unit Haile Sellaise Avenue Ndeke House P.O. Box 30205 Lusaka, Zambia. Retrieved from https://www.moh.gov.zm/docs/reports/2011_Annual _Health_Bulletin_\%20FINAL\%20VERSION.pdf.

[14] Georgiopoulou, V. V., Kalogeropoulos, A. P., Butler, J. (2012). Heart failure in hypertension: prevention and treatment. Drugs. $2012 \mathrm{Jul}$; 72(10):1373-1398. DOI: $\quad 10.2165 / 11631100$ 000000000-00000.

[15] Khosh, F., Khosh, M. (2001) Natural approach to hypertension. Altern Med Rev. 2001 Dec; 6 (6):590600. PMID: 11804549. Retrieved from https://pubmed.ncbi.nlm.nih.gov/11804549/.

[16]Wilcox, R. G., Bennett, T., Brown, A. M., Macdonald, I. A. (1982). Is exercise good for high blood pressure? British Medical Journal (Clinical Research ed.). 1982 Sep; 285(6344):767-769. DOI: 10.1136/bmj.285.6344.767.

[17] Bettany-Saltikov J., (2010). Learning how to undertake a systematic review: part 1 . Nurs Stand. 2010 Aug 18-24; 24(50):47-55; quiz 56. DOI: 10.7748/ns2010.08.24.50.47.c7939. PMID: 20865948.
[18] Higgins, J. P. T., Green, S. (2006). Cochrane Handbook for Systematic Reviews of Interventions. In: The Cochrane Library, Issue 4, 2006. Chichester, UK: John Wiley \& Sons, Ltd. Retrieved from https://training.cochrane.org/handbook/archive/v4.2. 6.

[19] Akobeng AK., (2005). Principles of evidencebased medicine. Arch Dis Child. 2005 Aug; 90(8):837-40. DOI: 10.1136/adc.2005.071761. PMID: 16040884; PMCID: PMC1720507.

[20] Abalos E, Carroli G, Mackey ME, Bergel E., (2001). Critical appraisal of systematic reviews: The WHO Reproductive Health Library, No 4, Geneva, The World Health Organization, (WHO/RHR/01.6). Retrieved from http://www.ijsr.ir/files/site1/files/4Critical_appraisal _of_systematic_reviews.pdf.

[21] Ramsay, J., Carter, Y., Davidson, L., Dunne, D., Eldridge, S., Feder, G., Hegarty, K., Rivas, C., Taft, A., Warburton, A. (2009). Advocacy interventions to reduce or eliminate violence and promote the physical and psychosocial wellbeing of women who experience intimate partner abuse. Cochrane Database Syst Rev. 2009 Jul 8; (3): CD005043. DOI: 10.1002/14651858.CD005043.pub2. Update in: Cochrane Database Syst Rev. 2015; 12:CD005043. PMID: 19588364.

[22] Young, J., Solomon, M. (2009). How to critically appraise an article. Nat Rev Gastroenterol Hepatol 6, 82-91 (2009). Retrieved from https://doi.org/10.1038/ncpgasthep1331.

[23]Public Health Resource Unit, England, (2006). Critical appraisal skill program (CASP). Retrieved from

http://cfkr.dk/images/file/CASP20instrumentet.pdf. 


\title{
Access to Healthcare and Health Seeking Behaviour among Female Head Porters in Kumasi, Ghana: The Impact on Public Health
}

\author{
Justice Ofori-Amoah ${ }^{1 *}$, Justice Thomas Sevugu ${ }^{2}$, Sheila Ofori-Addai ${ }^{3}$, Emmanuel Nakua ${ }^{4}$, \\ Michael Rockson Adjei ${ }^{5}$ \\ ${ }^{1}$ District Health Directorate Ghana Health Service Sekyere East Effiduase-Ashanti Ghana \\ ${ }^{2}$ Municipal Health Directorate Atwima Nwabiagya Nkawie Ashanti-Ghana \\ ${ }^{3}$ Municipal Health Directorate, Ghana Health Service Ejisu, Ashanti-Ghana \\ ${ }^{4}$ Kwame Nkrumah University of Science and Technology, School of public Health \\ Department of Epidemiology, Ghana \\ ${ }^{5}$ Regional Health Directorate, Ashanti-Ghana
}

\begin{abstract}
Given the nodality of Kumasi, the city attracts migrants from all parts of Ghana into its market space. Notable among such migrants are the female head porters popularly called "Kayayie". As a result of the expensive rents in urban space, female head porters live in kiosks, verandas, and squatters in any available space. This exposes the porters to a myriad of environmental and health risks amidst poor health-seeking behaviour. This study sought to examine access to health and healthseeking behaviour of female head porters in Kumasi. The study adopted quantitative methods in collecting and analyzing data. The primary units of the investigation were female head porters. The study used a sample size of 250 respondents who were interviewed through self-administered questionnaires. Findings show that only $25.2 \%$ of the respondents had access to healthcare, as about 74.8\% lacked access to basic healthcare. The majority of those who had access to healthcare (54\%) go to the health facility by foot, while about $42.9 \%$ access the facility by car. Though $71.4 \%$ of the head porters were subscribers of NHIS, only $25.2 \%$ resort to professional healthcare givers when they are sick. Generally, access to health and health-seeking was poor among the female head porters. The study recommended the expansion of health facilities, especially in poor urban communities, and education on health-seeking among head porters.
\end{abstract}

Keywords: Female head porters, Health seeking behaviour, Health conditions, Migration; Urban poor.

\section{Introduction}

Migration continues to characterize most urban areas, with the majority of people who are susceptible to migration being young adults [1]. Research has argued that one out of every eight migrants are young people within the ages of 15 and 24 years [2].

Young people are always on the move to find greener pastures elsewhere or to secure a livelihood opportunity. Estimates claim that about a quarter of young people desire to migrate to other countries to seek better opportunities [3]. Though external migration is always blamed for the woes of the youth, internal migrations are on the rise and pose threats to the sustainability of both the urban centers that receive these large numbers and the dwindling rural areas which lose these young people [4].

For example, [5] argues that the youth in Africa are always moving as they desire to migrate from rural areas to urban areas in search for better opportunities and greener 
pastures. In this regard, most rural dwellers in Africa, such as Morocco and Ghana, see ruralurban migration as a survival strategy to withstand harsh economic conditions in rural areas $[5 ; 6]$. Some scholars argue that lack of decent opportunities such as education and better livelihood options are responsible for this migration trend, though other factors may play [7; 8]. A myriad of reasons exists for the engagement of women and young girls in head porting [9].

According to [10], most girls who engage in head porting do so because they want to go into an apprenticeship, go back to school, raise capital for future business ventures, take care of their families, or to buy wares for marriage. However, it is worth noting that some head porters had multiple reasons for their involvement in porting. Similar results were also obtained by $[11,12,13]$. Other studies established that lack of education, poverty, and socio-cultural factors accounted for some of the reasons why young female adolescents migrate to the South to engage in head porting popularly called in Ghana 'kayayie' [6].

Research shows that open spaces, platforms at lorry stations, makeshift temporary wooden structures, and stalls serve as abodes for most head porters in Accra [14]. In a study conducted by [15] and [16], young girls engaging in head porting activities face problems such as poor health care, poor housing facilities, inadequate sanitation facilities, and harassment by men at their sleeping places [11]. These findings are supported by [17], who revealed that a decent place to sleep after a hard day's work, lack of safety and security of Kayayei and their belongings, harassment, and exploitation from clients were the problems confronting kayayei.

The poor conditions under which head porters live and work exposes them to health risks and complications [18]. Also, it is established that head porters in Southern Ghana are exposed to psychological problems, physical abuse, and health hazards [14]. [19] posit that poor eating habits and lack of accommodation, harsh working conditions, and lack of knowledge about health conditions exposes head porters to health problems such as skin rashes, cholera, neck pains, stomach ache and malaria.

As a result, [18] found that malaria was a common health challenge amongst female porters. Yet, lack of faith in the National Health Insurance Scheme, financial constraints, and long waiting periods at the health facilities militated against seeking appropriate health care at the hospitals and clinics by female head porters [19]. Access to and utilization of health services has been influenced by the use of the National Health Insurance Scheme. Inability to generate the needed funds to bear the high cost of healthcare service significantly affects the utilization of health [20].

Despite the fact that the health challenges faced by head porters who migrate to the Southern part of Ghana in search of livelihoods, the health-related impacts of their activities have been under-explored. For example, very little is known about health-related issues and the health-seeking behaviour of head porters. Also, the roles of stakeholders in ensuring access to good health and how socially supportive networks developed by porters are used in their health-seeking behaviour have been largely ignored.

Accordingly, this research explores access to health and health-seeking behaviour of female head porters in Kumasi. Rural-urban migration is old in Africa and greatly influences the urbanization pattern to a significant degree. While people migrate from the northern part of Ghana to the southern part in search of economic opportunities, they encounter many challenges [21].

One of these challenges is the poor healthseeking behaviour of head porters [8]. Due to the competitive nature of urban circumstances and the demanding monetary and other returns in professional healthcare services, head porters shirk professional healthcare for selfmedication, herbalists, and other traditional 
methods. Sometimes, some rely on the directions from their spiritual directors the expense of professional healthcare.

Though some of these head porters are aware of the impact of relying on unprofessional healthcare givers, poverty, expensive nature of professional healthcare, lack of available health infrastructure, socio-cultural factors, and or environmental conditions have influenced their health seeking negatively [21].

The impact of seeking unprofessional healthcare is great and has been estimated to be responsible for the death of about $50 \%$ of all patients from developing countries [22]. This raises concerns and makes the subject topic as increasing global concerns on health practices continue to gain center stage in all international and national discourses. This research aims to identify health challenges facing female head porters in Kumasi, identify the health-seeking behaviours and practices of female head porters, and determine the factors influencing head porters' access to health service in Kumasi.

\section{Research Methodology}

This study used a quantitative research design in understanding the access to healthcare and health-seeking behaviour among female head porters in Kumasi. Appropriately, a quantitative method was used in the collection and analysis of data.

The study first sought to understand the reasons for migration, the nature and trend of the migration, and the health-seeking behaviour of female head porters in Kumasi. With the estimated study population of 14,000 female head porters (kayayie people), the sample size of 250 respondents was determined to be surveyed. The sample size was determined through the use of Slovin's formula for the determination of samples. Pre-coded and selfadministered questionnaires were used to elicit data from the respondents. The nature of the questionnaire design included both open-ended and close-ended questions. The questions targeted the socio-economic and cultural characteristics and health-seeking behaviour of female head porters.

The author, therefore, sought administrative clearance from the various stakeholders before embarking on the study. This research was conducted in compliance with the ethical guidelines of the Kwame Nkrumah University of Science and Technology and Komfo Anokye Ethical Review Board. The researcher received positive feedback and was cleared to undertake the study based on the protocols and the data collection instruments presented for approval.

\section{Results of the Study}

\section{Demographic Characteristics of the Study Population}

The mean age of the respondents was 25.06 \pm 7.06 years, with those aged between 20-24 years forming the majority (33.6\%). About $49.6 \%$ of the respondents do not have formal education.

Again, only $0.8 \%$ of those who have formal education obtained WASSCE certificates (Table 1). The remaining respondents have education up to the basic school level. The majority of the respondents were single (50.4\%) with an average monthly income of GHC $253.71 \pm 102.37$. 
Table 1. Socio-demographic Characteristics of Respondents

\begin{tabular}{|c|c|c|}
\hline \multirow[t]{2}{*}{ Variable } & \multicolumn{2}{|l|}{ Head porters } \\
\hline & Frequency $(n=250)$ & Percent (\%) \\
\hline \multicolumn{3}{|c|}{ Age of porter (years) } \\
\hline Mean $( \pm \mathrm{SD})$ & $25.06 \pm 7.06$ & \\
\hline$<20$ & 68 & 27.2 \\
\hline $20-24$ & 84 & 33.6 \\
\hline $25-29$ & 40 & 16.0 \\
\hline $30-39$ & 37 & 14.8 \\
\hline $40-49$ & 21 & 8.4 \\
\hline $50-59$ & 0 & 0.0 \\
\hline $60+$ & 0 & 0.0 \\
\hline \multicolumn{3}{|l|}{ Marital status } \\
\hline Single & 126 & 50.4 \\
\hline Divorced & 89 & 35.6 \\
\hline Married & 35 & 14.0 \\
\hline \multicolumn{3}{|l|}{ Educational status } \\
\hline Not educated & 124 & 49.6 \\
\hline Primary & 86 & 34.4 \\
\hline JHS & 14 & 5.6 \\
\hline SHS & 2 & 0.8 \\
\hline Tertiary & 0 & 0.0 \\
\hline Informal & 24 & 9.6 \\
\hline \multicolumn{3}{|c|}{ Average monthly income } \\
\hline Mean $\pm \mathrm{SD}$ & $253.71+102.37$ & \\
\hline GHS $100-199$ & 63 & 25.2 \\
\hline GHS $200-299$ & 78 & 31.2 \\
\hline GHS $300-399$ & 81 & 32.4 \\
\hline GHS $400 \&$ above & 28 & 11.2 \\
\hline
\end{tabular}

Indicatively, findings show that health- access healthcare services. Car was the major seeking behaviour is still poor among means of transport to the healthcare facility by respondents as only $25.2 \%$ of the people almost $42.9 \%$ of the respondents. Therefore, the interviewed have access to healthcare when medical bills, transport costs, and the time spent they are not well (Table 2a). The majority of seeking healthcare services were revealed to be the respondents (74.8\%) indicated their the major reasons female head porters had low inability to access healthcare in their access to health facilities. Tables 2-4 show the threatening health conditions. Among those results of the study, which were further who accessed healthcare, a majority, 54\%, discussed to inform policy and practice.

walked for about 3-4 hours before they could 
Table 2. Access to Healthcare Services by Female Head Porters in Kumasi

\begin{tabular}{|c|c|c|}
\hline Variable & Frequency $(n=250)$ & Percent (\%) \\
\hline \multicolumn{3}{|l|}{ Access healthcare when need arises } \\
\hline No & 187 & 74.8 \\
\hline Yes & 63 & 25.2 \\
\hline \multicolumn{3}{|l|}{ Walking distance to health facility $(n=63)$} \\
\hline Mean $( \pm$ SD) & $178.33 \pm 66.17$ & \\
\hline$<1$ hour & 3 & 4.8 \\
\hline $1-2$ hours & 22 & 34.9 \\
\hline 2-3 hours & 4 & 6.3 \\
\hline 3-4 hours & 34 & 54.0 \\
\hline \multicolumn{3}{|c|}{ Means of transportation to health facility $(n=63)$} \\
\hline Car & 27 & 42.9 \\
\hline Bicycle & 3 & 4.8 \\
\hline Motor cycle & 24 & 38.1 \\
\hline By foot & 9 & 14.3 \\
\hline \multicolumn{3}{|c|}{ Mode of payment of health services $(n=63)$} \\
\hline National Health Insurance Scheme (NHIS) & 45 & 71.4 \\
\hline On credit (Pay later) & 8 & 12.7 \\
\hline Pay as you go & 10 & 15.9 \\
\hline \multicolumn{3}{|c|}{ Properly attended to the last time accessed healthcare services $(n=63)$} \\
\hline No & 13 & 20.6 \\
\hline Yes & 50 & 79.4 \\
\hline \multicolumn{3}{|l|}{ Reason for visiting health facility $(\mathrm{n}=63)$} \\
\hline Assured of being treated & 28 & 44.4 \\
\hline Best place for ill health treatment & 11 & 17.5 \\
\hline National health insurance & 24 & 38.1 \\
\hline \multicolumn{3}{|c|}{ Conditions for accessing healthcare $(n=63)$} \\
\hline Boils & 8 & 12.7 \\
\hline Gonorrhea & 9 & 14.3 \\
\hline Malaria & 23 & 36.5 \\
\hline Stomach pains & 15 & 23.8 \\
\hline Wounds & 8 & 12.7 \\
\hline
\end{tabular}

Table 3. Health Seeking Behaviours of Female Head Porters in Kumasi

\begin{tabular}{|l|l|l|}
\hline Variable & Frequency $(\mathbf{n = 2 5 0})$ & Percent (\%) \\
\hline \multicolumn{2}{|l|}{ Last time of feeling sick } \\
\hline 1 month & 62 & 24.8 \\
\hline 2 months & 74 & 29.6 \\
\hline $3-5$ months & 65 & 26.0 \\
\hline 6 months & 49 & 19.6 \\
\hline Place medical services was sought & \multicolumn{1}{l|}{} \\
\hline Hospital & 29 & 11.6 \\
\hline Herbalist & 91 & 36.4 \\
\hline Pharmacy & 76 & 30.4 \\
\hline
\end{tabular}




\begin{tabular}{|l|l|l|}
\hline Self-medication & 54 & 21.6 \\
\hline Practice of family planning & 99.2 \\
\hline No & 248 & 0.8 \\
\hline Yes & 2 & 11.2 \\
\hline Place of delivery & \multicolumn{2}{|l|}{} \\
\hline Home & 28 & 13.2 \\
\hline Hospital & 33 & 16.4 \\
\hline TBA & 41 & 59.2 \\
\hline Never given birth & 148 & \\
\hline Number of ANC visits (n=102) & 63.7 \\
\hline No ANC visits & 65 & 15.7 \\
\hline$<4$ visits & 16 & 20.6 \\
\hline $4+$ visits & 21 & \\
\hline Vaccination of child (n=102) & 91.2 \\
\hline No & 93 & 8.8 \\
\hline Yes & 9 & 98.0 \\
\hline Knowledge of first aid & 245 & 2.0 \\
\hline No & 5 & 98.4 \\
\hline Yes & 246 & 1.6 \\
\hline Availability of first aid at home & \\
\hline No & 4 & \\
\hline Yes & \\
\hline
\end{tabular}


Table 4. Factors Influencing Female Head Porters' Access to Health Services in Kumasi

\begin{tabular}{|c|c|c|c|c|c|c|c|}
\hline \multicolumn{8}{|c|}{ Access to healthcare } \\
\hline \multirow[t]{2}{*}{ Variables } & No & Yes & Total & \multirow[t]{2}{*}{$\chi^{2}$} & \multirow{2}{*}{$\begin{array}{l}p \text { - } \\
\text { value }\end{array}$} & \multirow[t]{2}{*}{ COR $[95 \%$ CI], p-value } & \multirow[t]{2}{*}{ AOR $[95 \%$ CI], p-value } \\
\hline & $n=187(\%)$ & $n=63(\%)$ & $\mathrm{N}=(\%)$ & & & & \\
\hline \multicolumn{8}{|l|}{ Age (years) } \\
\hline$<20$ & $58(31.0)$ & $10(15.9)$ & $68(27.2)$ & & & & \\
\hline $20-24$ & $64(34.2)$ & $20(31.7)$ & $84(33.6)$ & & & $1.81[0.78-4.19] 0.164$ & $1.22[0.29-5.22] 0.784$ \\
\hline $25-29$ & $29(15.5)$ & $11(17.5)$ & $40(16.0)$ & & & $2.20[0.83-5.78] 0.109$ & $1.16[0.19-7.01] 0.873$ \\
\hline $30-34$ & $29(10.2)$ & $8(12.7)$ & $27(10.8)$ & & & $2.44[0.84-7.08] 0.100$ & $1.54[0.16-14.63] 0.703$ \\
\hline $35+$ & $17(17.1)$ & $14(22.2)$ & $31(12.4)$ & 11.00 & 0.027 & $4.78[1.80-12.66] 0.002$ & $5.88[0.28-121.32] 0.252$ \\
\hline \multicolumn{8}{|l|}{ Native region } \\
\hline North East & $40(21.4)$ & $19(30.2)$ & $59(23.6)$ & & & & \\
\hline Northern & $70(37.4)$ & $24(38.1)$ & $94(37.6)$ & & & $0.72[0.35-1.48] 0.372$ & $1.63[0.45-5.88] 0.455$ \\
\hline Savanna & $14(7.5)$ & $9(14.3)$ & $23(9.2)$ & & & $1.35[0.50-3.68] 0.553$ & $2.60[0.40-16.95] 0.319$ \\
\hline Upper East & $31(16.6)$ & $6(9.5)$ & $37(14.8)$ & & & $0.41[0.14-1.14] 0.088$ & $0.07[0.01-0.97] 0.047$ \\
\hline Upper West & $32(17.1)$ & $5(7.9)$ & $37(14.8)$ & 8.17 & 0.085 & $0.32[0.11-0.98] 0.045$ & $0.30[0.05-1.90] 0.201$ \\
\hline \multicolumn{8}{|l|}{ Marital status } \\
\hline Single & $103(55.1)$ & $23(36.5)$ & $126(50.4)$ & & & & \\
\hline Divorced & $55(29.4)$ & $34(54.0)$ & $89(35.6)$ & & & $2.77[1.49-5.16] 0.001$ & $2.24[0.44-11.32] 0.328$ \\
\hline Married & $29(15.5)$ & $6(9.5)$ & $35(14.0)$ & 12.41 & 0.002 & $0.93[0.34-2.49] 0.880$ & $4.54[0.94-21.80] 0.058$ \\
\hline \multicolumn{8}{|l|}{ Educational status } \\
\hline Not educated & $93(49.7)$ & $31(49.2)$ & $124(49.6)$ & & & & \\
\hline Primary & $70(37.4)$ & $16(25.4)$ & $86(34.4)$ & & & $0.69[0.35-1.34] 0.287$ & \\
\hline JHS & $9(4.8)$ & $5(7.9)$ & $14(5.6)$ & & & $1.72[0.56-5.29] 0.346$ & \\
\hline SHS & $0(0.0)$ & $2(3.2)$ & $2(0.8)$ & & & $14.84[0.69-17.51] 0.084$ & \\
\hline Informal & $15(8.0)$ & $9(14.3)$ & $24(9.6)$ & 10.67 & 0.031 & $1.82[0.74-4.49] 0.194$ & \\
\hline \multicolumn{8}{|l|}{ Residence } \\
\hline Rented apartment & $11(5.9)$ & $13(20.6)$ & $24(9.6)$ & & & & \\
\hline
\end{tabular}




\begin{tabular}{|c|c|c|c|c|c|c|c|}
\hline Container/Kiosk & $123(65.8)$ & $38(60.3)$ & $161(64.4)$ & & & $0.26[0.11-0.63] 0.003$ & $0.43[0.06-2.99] 0.398$ \\
\hline Ghato & $53(28.3)$ & $12(19.1)$ & $65(26.0)$ & 12.47 & 0.002 & $0.19[0.07-0.53] 0.001$ & $0.28[0.03-2.88] 0.285$ \\
\hline \multicolumn{8}{|l|}{ Family size } \\
\hline$<10$ & $17(9.1)$ & $5(7.9)$ & $22(8.8)$ & & & & \\
\hline $10-14$ & $74(39.5)$ & $32(50.8)$ & $106(42.4)$ & & & $1.47[0.50-4.33] 0.484$ & \\
\hline $15-19$ & $48(25.7)$ & $9(14.3)$ & $57(22.8)$ & & & $0.64[0.19-2.17] 0.471$ & \\
\hline $20+$ & $48(25.7)$ & $17(27.0)$ & $65(26.0)$ & 4.18 & 0.243 & $1.20[0.38-3.77] 0.749$ & \\
\hline \multicolumn{8}{|c|}{ Sex of household head (home) } \\
\hline Female & $36(19.3)$ & $10(15.9)$ & $46(18.4)$ & & & & \\
\hline Male & $151(80.7)$ & $53(84.1)$ & $204(81.6)$ & 0.36 & 0.550 & $1.26[0.58-2.72] 0.550$ & \\
\hline \multicolumn{8}{|c|}{ Household head was a porter } \\
\hline No & $165(88.2)$ & $50(79.4)$ & $215(86.0)$ & & & & \\
\hline Yes & $22(11.8)$ & $13(20.6)$ & $35(14.0)$ & 3.08 & 0.079 & $1.95[0.92-4.15] 0.083$ & $3.78[0.87-16.32] 0.075$ \\
\hline \multicolumn{8}{|l|}{ Number of children } \\
\hline None & $122(65.2)$ & $26(41.2)$ & $148(59.2)$ & & & & \\
\hline One & $19(10.2)$ & $13(20.6)$ & $32(12.8)$ & & & $3.21[1.41-7.31] 0.005$ & $1.61[0.30-8.62] 0.580$ \\
\hline Two & $23(12.3)$ & $12(19.1)$ & $35(14.0)$ & & & $2.45[1.08-5.54] 0.032$ & $0.74[0.10-5.66] 0.775$ \\
\hline $3+$ & $23(12.3)$ & $12(19.1)$ & $35(14.0)$ & 11.68 & 0.009 & $2.45[1.08-5.54] 0.032$ & $0.14[0.01-2.88] 0.205$ \\
\hline \multicolumn{8}{|l|}{ Monthly income } \\
\hline GHS 100-199 & $54(28.9)$ & $9(14.3)$ & $63(25.2)$ & & & & \\
\hline GHS $200-299$ & $59(31.5)$ & $19(30.2)$ & $78(31.2)$ & & & $1.93[0.81-4.63] 0.140$ & $1.97[0.46-8.53] 0.362$ \\
\hline GHS $300-399$ & $58(31.0)$ & $23(36.5)$ & $81(32.4)$ & & & $2.38[1.01-5.59] 0.047$ & $0.91[0.23-3.56] 0.893$ \\
\hline GHS 400 and above & $16(8.6)$ & $12(19.0)$ & $28(11.2)$ & 9.08 & 0.028 & $4.50[1.61-12.59] 0.004$ & $1.06[0.19-5.93] 0.948$ \\
\hline \multicolumn{8}{|l|}{ Insurance status } \\
\hline No & $152(81.3)$ & $10(15.9)$ & $162(64.8)$ & & & & \\
\hline Yes & $35(18.7)$ & $53(84.1)$ & $88(35.2)$ & 88.39 & $<0.001$ & $23.02[10.67-49.67] 0.001$ & $4.62[1.51-14.16] 0.007$ \\
\hline \multicolumn{8}{|c|}{ Place of medical services } \\
\hline Hospital & $0(0.0)$ & $29(46.0)$ & $29(11.6)$ & & & & \\
\hline Herbalist & $91(48.7)$ & $0(0.0)$ & $91(36.4)$ & & & $0.01[0.00-0.01]<0.001$ & $0.01[0.00-0.04]<0.001$ \\
\hline
\end{tabular}




\begin{tabular}{|l|l|l|l|l|l|l|l|}
\hline Pharmacy & $48(25.7)$ & $28(44.4)$ & $76(30.4)$ & & & $0.01[0.00-0.17] 0.001$ & $\mathbf{0 . 0 3}[\mathbf{0 . 0 0}-\mathbf{0 . 4 7}] \mathbf{0 . 0 1 2}$ \\
\hline Self-medication & $48(25.7)$ & $6(9.5)$ & $54(21.6)$ & $\mathbf{1 2 7 . 8 9}$ & $<\mathbf{0 . 0 0 1}$ & $0.01[0.00-0.04]<0.001$ & $\mathbf{0 . 0 1}[\mathbf{0 . 0 0}-\mathbf{0 . 1 1}<<\mathbf{0 . 0 0 1}$ \\
\hline Source of drinking water \\
\hline Ghana Water Company & $60(32.1)$ & $32(50.8)$ & $92(36.8)$ & & & & \\
\hline Open Market & $47(25.1)$ & $15(23.8)$ & $62(24.8)$ & & & $0.60[0.29-1.23] 0.164$ & $2.45[0.67-8.89] 0.175$ \\
\hline Well & $80(42.8)$ & $16(25.4)$ & $96(38.4)$ & $\mathbf{8 . 2 2}$ & $\mathbf{0 . 0 1 6}$ & $0.38[0.19-0.75] 0.005$ & $1.02[0.30-3.44] 0.972$ \\
\hline Access to home first aid \\
\hline No & $487(100.0)$ & $59(93.6)$ & $246(98.4)$ & & & & \\
\hline Yes & $0(0.0)$ & $4(6.4)$ & $4(1.6)$ & $\mathbf{1 2 . 0 7}$ & $\mathbf{0 . 0 0 1}$ & $28.36[1.50-534.48] 0.026$ & $1.47[0.03-73.16] 0.845$ \\
\hline
\end{tabular}

Significant difference. $\alpha<0.0$ 


\section{Discussion of Findings}

Access to healthcare is fundamental for the development of any economy. The revealing findings of only $25.2 \%$ having access to healthcare among the respondents could be disastrous for the health and wellbeing of the female head porters. However, this finding corroborates an earlier study conducted in Accra by [23], who found that only $25 \%$ of the head porters have access to healthcare services from health facilities. The current study showed that $74.8 \%$ of the female head porters surveyed did not have access to healthcare services due to limited income and other socio-cultural circumstances. Our findings also corroborate studies by [24] and [21] that low income and socio-cultural barriers are a hindrance to healthseeking among female porters. The implication of this is that female head porters may end up complicating their health situations, thereby posing dangers to their health and wellbeing. Poor access to healthcare among female head porters amidst poor health-seeking behaviour suggests that there is the need for appropriate measures to help promote health-seeking and healthy living among the head porters.

The findings from the study also revealed that the majority of the female head porters in Kumasi $(74.8 \%)$ do not have access to health facilities when they are sick. Again, among those who had access to healthcare, some had to delay for about a year in order to raise the needed income to attend healthcare. This confirms similar findings from leprosy patients in Ethiopia, who had to wait for one year before accessing healthcare [25]. The implication is that the medical conditions of some of these people may be worse off before they get access to healthcare services. Others delayed in accessing medical care because they had to walk for long distances in order to access healthcare services. This study in that regard validates the findings by [18] that many poor female head porters had to walk for long distances before getting physical access to healthcare. This implies that some patients' conditions may be worsened as a result of the delay in reaching medical centres. This can result in a fatality or exacerbated complications with enormous for public health and wellbeing.

There is inadequate access to and utilization of healthcare services. As asserted by [20], the inability to generate the needed funds to pay the high cost of healthcare services significantly affects the health-seeking of the female head porters. This could have accounted for the low access to healthcare $(25.2 \%)$ in this study. [21] also found that the majority of the head porters are aware of the existence of a health facility around their residence, although most of them seek healthcare outside formal health facilities. Regarding the factors that influenced the head porter's access to healthcare, our findings revealed that female head porters from the Upper East region were 93\% less likely to access healthcare compared to those from the North East region (Table 4). Female head porters with NHIS subscriptions were also 4.62 times more likely to access healthcare as compared to those without NHIS. Clearly, NHIS makes a difference in access to healthcare provision and can influence healthseeking among female head porters.

Although NHIS is known to cut down the cost of medical expenses, some concerns raised were that the scheme could not offer good quality healthcare [26]. Similarly, [23] found that access to and utilization of healthcare services is significantly influenced by the use of NHIS. Though the majority of the female head porters $(71.4 \%)$ were subscribers of NHIS, only a few of them could renew and utilize their NHIS for healthcare services. This finding agrees with [26], who postulate that the Ministry of Gender, Children and Social Protection enrolled the vulnerable, including head porters, on the NHIS for free. However, due to their poor income status their preference for traditional medicine, most of these enrollees do not utilize the scheme when they are sick. 
Another factor that significantly influenced healthcare utilization was the seeking of herbalist and pharmacy services. Comparatively, healthcare utilization in professional medicine were lower as head porters who sought medical services from Herbalist, Pharmacy, and self-medication. About one-third of these head porters sought herbalists when they needed medical services, whiles quite a proportion also utilized pharmacy or practiced self-medication. This confirms findings of [27] that the popular means of seeking healthcare by head porters was purchasing drugs from pharmacies or drug peddlers instead of professional healthcare givers.

Health challenges facing head porters were also assessed in this current study. Malaria was a major health condition faced by most of the head porters. This confirms earlier studies conducted in Accra by [19], who found malaria as one of the health-related concerns among head porters. Similarly, [18] found out that malaria was a common health challenge amongst female porters. Other health conditions experienced by female head porters in Kumasi include general body pains, typhoid fever, boils, gonorrhea, and wounds. General body pains experienced by these head porters may be attributed to the heaviness of the loads they carry and the distance they cover carrying the loads. A study conducted by [18] found out that the goods carried by head porters were very heavy.

\section{Recommendations}

The research recommended the following for policy and practice based on the findings of the study.

First of all, there is the need for educational campaigns throughout the areas occupied by these head porters to educate them on the need for professional medical care and the importance of health-seeking. This educational campaign should extend to the general citizenry to educate and inform them on the need to maintain the health of the body and soul. In addition, the government should establish healthcare centers in and around slum areas usually occupied by these migrant women and children. Again, social interventions programs should not only register head porters and other urban poor free but make allowance for free premium renewal. This will encourage them to seek professional healthcare. More healthcare facilities should also be established to ensure that facilities are available for all. This will reduce the time and distance covered to access health needs. Lastly, as a behavioural trait, the head porters need cultural orientation on the need for professional medical attention irrespective of one's beliefs. These will help improve the health-seeking among female head porters and generally contribute to improved healthcare delivery.

\section{Conclusion}

Access to health and health-seeking behaviour among female head porters in Kumasi is low. Head porters continue to face a myriad of challenges, such as a poor living environment which worsens their health conditions. Again, due to prejudice and perceptual biases, most female head porters resort to traditional medical treatment to neglect of professional healthcare. As a result, the female head porters are not able to make good use of the National Health Insurance Scheme even upon free initial registration. This is because many of them could not get the needed funds to renew their subscription to the NHIS. Basic problems in healthcare provision continue to exist around migrant communities and Zongos, where most of the female head porters live. It is recommended that educational campaigns in addition to infrastructural provision, will help increase the health-seeking behaviour of female head porters. Also, intensification of social vulnerability interventions can help ameliorate the plight of some of these head porters. 


\section{Acknowledgement}

The author thanks the almighty God for the gift of wisdom, knowledge, and insight in completing this study. Secondly, the author is grateful to the anonymous supervisors who spent every effort to make sure this work was complete. Lastly, the author's thanks all anonymous reviewers for their valuable insights in enriching this work.

\section{References}

[1] Awumbila, M., Kofi Tehe, J., Litchfield, J., Boakye-Yiadom, L., Deshingkar, P. \& Quartey, P. (2015). Are migrant households better off than nonmigrant households? Evidence from Ghana. Migration Out of Poverty Working Paper No. 28.

[2] UNICEF (2007). The impact of international migration: children left behind in selected countries of Latin America and the Carribean, Division of policy and planning, working paper. University of Ghana http://ugspace.ug.edu.gh.

[3] Deshingkar, P. \& Grimm, S. (2005) Voluntary internal migration: An update. Overseas Development Institute.

[4] Owusu, L., \& Yeboah, T. (2018). Living conditions and social determinants of healthcare inequities affecting female migrants in Ghana. GeoJournal, 83(5), 1005-1017.

[5] Tufeiru, A. (2014). The Nexus of Female Capital and North-South Labor Migration in Ghana: A Potential Remedy from Microfinance. Journal of Developing Societies (Sage Publications Inc.), 30(1), 91-114. https://doi.org/10.1177/0169796X13504680.

[6] Awumbila, M., Manuh,T. Quartey, P., Bosiakoh, T.A and Tagoe, C.A. (2011a) Migration and Mobility in Ghana: Trends, Issues and Emerging Research Gaps. Woeli Publishing: Accra.

[7] Creswell, J.W. (2009). Research Design: A Qualitative, Quantitative, and Mixed Method Approaches. Los Angeles: SAGE Publication.

[8] Owusu, A. (2012). The Living Conditions of Female Head Porters in the Kumasi Metropolis, Ghana.

\section{Funding}

No external funding was received for this study. The researchers themselves covered all costs related to this research.

\section{Competing interests}

The authors declare that they have no competing interests.

https://www.researchgate.net/publication/256932927

[9] Otieku, E., Ackah, C. G., \& Forkuor, D. (2017). Motivations, income determinants and livelihood vulnerability of female teenage head porters in Kasoa, Ghana. International Journal of Social Economics, $\quad 44(12), \quad 2396-2408$. https://doi.org/10.1108/IJSE-10-2016-0286.

[10] Azumah, F. D. \& Onzaberrugu J. N. (2018). The Lifestle of female head porters: the single mother and her coping strategies at Aboabo, Kumasi. International Journal of Innovation Education and Research 6(2).

[11] ILO (2014). World of work report: Developing with jobs.

[12] Kwankye, S.O., Anarfi, J. K., Tagoe, (2011) Migration Impacts within the West African SubRegion. Unpublished paper prepared for the Research Programme Consortium (RPC) on Migrating out of poverty. Brighton: University of Sussex.

[13] Wilson, A. (2012). Resources for Thriving among Female porters in Accra. A Qualitative study of Migrants from Northern Ghana to Greater Accra Region. A Salutogenic Approach. Retrieved from https://bora.uib.no/handle/1956/5879.

[14] Shamsu-Deen, Z. (2013). Migration and Health Nexus: A Case of Female Porters (Kayayei) in Accra, Ghana. Research on Humanities and Social Sciences, 3(3), 103-109.

[15] Nyarko, S. H., \& Tahiru, A. M. (2018). Harsh Working Conditions and Poor Eating Habits: Health-Related Concerns of Female Head Porters (Kayayei) in the Mallam Atta Market, Accra, Ghana. 
BioMed Research International, 2018, 1-7. https://doi.org/10.1155/2018/6201837.

[16] Shamsu-Deen, Z., \& Adadow, Y. (2019). Health-seeking behaviour among migrant female head porters in the City of Accra, Ghana. Ghana Journal of Development Studies, 16(2), 138-156156. https://doi.org/10.4314/gjds.v16i2.7.

[17] Opare, J. A. (2003). Kayayei: The women head porters of southern Ghana. Journal of Social Development in Africa, 18(2). https://doi.org/10.4314/jsda.v18i2.23825.

[18] Awumbila, M. and Ardayfio-Schandorf, E (2008). Gendered poverty, migration and livelihood strategies of female porters in Accra, Ghana, Norwegian journal of Geography, 62(3):171-179.

[19] Montgomery, M., R. (2009). Urban poverty and health in developing Countries. Population Bulletins Vol. 64, No.2. Stony Brook University.

[20] Owusu, G., Agyei-Mensah, S. and Lund, R. (2008). Slums of hope and slums of despair: Mobility and livelihoods in Nima, Accra, Norsk Geografisk Tidsskrift, 62:180-190.

[21] Owusu-Ansah, J. K., \& Addai, M. (2016). Coping with life in a squatter settlement: The case of migrant women in Kumasi, Ghana. Journal of Science and Technology, 33(3).

[22] Awumbila, M., \& Ardayfio-Schandorf, E. (2008). Gendered poverty, migration and livelihood strategies of female porters in Accra, Ghana. Norwegian Journal of Geography, 62(3), 171-179. https://doi.org/10.1080/00291950802335772.

[23] Potts, D. (2008). Recent trends in rural-urban and urban-rural migration in sub-Saharan Africa: The empirical evidence and implications for understanding urban livelihood insecurity. Paper No. 6, Department of Geography, King's College London.

[24] Kwankye, S.O., Anarfi, J. K., Tagoe, C. A., and Castaldo, A. (2009) Independent North-South Child Migration in Ghana: The Decision-making Process. Migration DRC Working Paper T29.

[25] Assesfa A., Nash, J., Tefera Tamiru, \& Byass, P. (2000). Patterns of health seeking behavior amongst leprosy patients in the former Shao province. Ethiop. J. Health Dev.14(1):43- 47.

[26] Owusu, L. \& Yeboah, T. (2017). Living conditions and social determinants of healthcare inequalities affecting female migrants in Ghana. Geo Journal.

[27] Agarwal, S., Attah, M., Apt, N., Grieco, M., Kwakye, E. A., \& Turner, J. (1997). Bearing the weight: The kayayoo, Ghana's working girl child. International Social Work, 40(3), 245-263. https://doi.org/10.1177/002087289704000302. 


\title{
Strengthening Capacities of Ward Development Committees to Promote Health in Nigeria: A Case Study of Osun State
}

\author{
Helen U. Ekpo ${ }^{1 *}$, Nnodimele O. Atulomah ${ }^{2}$ \\ ${ }^{1}$ Department of Public Health, Texila American University, Guyana \\ ${ }^{2}$ Department of Public Health, Babcock University, Ogun State
}

\begin{abstract}
Unsatisfactory health indices characterize Osun State Nigeria Primary Health Care facilities and poor operational conditions. Residents patronize private health facilities with attendant payment of huge out-of-pocket medical bills. Implementation of the Basic Health Care Provision Fund (BHCPF), a mechanism to increase access to quality health care for all its citizens initiated by the state government, commenced in 2018. The study sought to determine the extent to which capacity building/training of Ward development committees (WDC) in BHCPF supported PHCs has contributed to the provision of quality health services in the BHCPF supported facilities. The study was qualitative in design and used three focus group discussions held in three BHCPF implementing LGAs with thirtyfive (27males, 8 females) consenting trained WDC members. Prior to the BHCPF training, the majority of the WDCs were not actively involved in the management of their PHCs, as political appointees and were unclear about their roles and responsibilities to the health facilities in their wards. After the training, most of the trained WDCs engaged with their PHC staff to debrief, review the quality improvement plans for their health facilities, identified immediate needs to address, approached influential people in the community, and mobilized local resources to address identified gaps. Electricity and water supply were restored in most of the facilities, hospital beds and basic equipment for were procured for PHCs, building, and equipping of the laboratory were completed. Building the capacity of the WDC on their roles and responsibilities strengthened them to contribute to the provision of quality health services in their communities.
\end{abstract}

Keywords: Access, capacity building, quality improvement, Universal Health Coverage, Ward development committees.

\section{Introduction}

Nigeria is considered to have one of the worst health indices in the world and contributes to 10 percent of the global maternal deaths. In Nigeria, the under-five mortality rate (U5MR) and the maternal mortality rate is reducing but not as expected considering all the various initiatives that have been implemented over the passing decades. With a U5MR of 132 per 1000 live births and maternal mortality rate of 512 deaths per 100,000 live births $[1,2,3]$, translated to mean that one Nigerian woman dies in childbirth every 10 minutes, and one Nigerian child under-
5 years of age die every minute. The Multiple Indicator Cluster Survey (MICS) conducted by the national bureau of statistics and UNICEF in 2016 to 2017 showed that the maternal mortality rate in Osun was 169/100,000 live birth and U5MR was 101/1000LB [4].

The commitment of Nigeria to the improvement of maternal and child health indices as well as Universal Health Coverage was symbolised by the enactment of the National Health Act of 2014, section 11, which mandated the establishment of a Basic Health Care Provision Fund (BHCPF) [5]. This large-scale health sector reform effort sought to expand the 
fiscal space by deploying financial resources to the frontlines for primary health care services. The BHCPF is designed to be a sustainable model for ensuring equity and financial risk protection for vulnerable populations by guaranteeing access to a basic minimum package of health services [6].

Under the BHCPF, pregnant women are to receive antenatal care, child delivery care (Including caesarian section), and immunization free of charge. Children of under 5 years of age are to receive immunization, treatment for malaria, measles, pneumonia, and dysentery free of charge. The funding of the BHCPF is financed by an annual grant from the Federal Government of Nigeria (FGN), stipulating a budget of not less than one percent of the Consolidated Revenue Fund (CRF), grants from international donor agencies, and states government counterpart funding. Expectations of strategic implementation of the BHCPF would result in improved national and states health indices and firmly place Nigeria on the path to achieving universal health coverage [6]. Despite the introduction of the scheme, many healthcare systems in various states have not been obliged to adopt the scheme [7].

The Osun state government in 2017 met the requirements for accessing National BHCPF financing and in 2018 took a bold step to commence the implementation of BHCPF in one focal PHC per ward (a total of 332 PHCs in 30 LGAs), beginning with the renovation and providing essential equipment of the focal PHCs, strengthening capacities (training, mentoring, coaching and supportive supervision) of health workers and ward development committee (WDC) members for efficient utilization of BHCPF to provide basic minimum health care services package to the people of Osun state as a means of achieving the universal health care coverage $[8,9]$. The Ward development committee exists at the community level as part of the implementation of the Ward Health System (WHS), to enable mobilisation and governance of community resources. In line with national policy, the WDCs are expected to be involved in joint management of the PHC facilities and service delivery, together with health workers [10, 11]. This study was undertaken in Osun State to document the extent to which training of WDCs, in BHCPF has contributed to the provision of quality services in the focal PHCs and increased access to healthcare for residents.

\section{Materials and Methods}

\section{Study Design, Subjects, and Settings}

This is a qualitative study to explore the place of capacity building and strengthening of WDCs in ensuring that quality healthcare services are provided at BHCPF supported facilities in Osun state. Osun State is in the southwestern geopolitical region of Nigeria and consists of 30 local government areas (LGAs), with a total landmass of about 9,251 square kilometers, and is home to an estimated population of 5.1 million people in 2019 (Osun SBS, 2019). Three (3) focus group discussions (FGD) were conducted with WDCs who were trained on the BHCPF program and were involved in the management of the PHC in their wards. The first FGD was conducted on the $18^{\text {th }}$ of April 2019, with 10 trained WDCs from Osogbo LGA in Osun Central senatorial district, the $2^{\text {nd }}$ FGD held on the $24^{\text {th }}$ of May 2019 with 10 BHCPF trained selected WDCs from Oriade LGA in Osun East senatorial district, and the $3^{\text {rd }}$ FGD occurred on the $19^{\text {th }}$ of June 2019 with 15 trained WDCs from Ejigbo LGA of the Osun West senatorial district. A total of 35 (27males, 8 females) trained WDC members consented and participated in the focus group discussions, which were held 2 weeks after their BHCPF training. The study protocol was submitted to the Ethical committee of the Osun State Ministry of Health, and approval for the study was obtained to conduct the study.

Each focus group discussion session was one hour with the lead investigator for the study as the moderator for the 3 FGDs assisted by 2 officers of the Osun State Ministry of health as note-takers. The FGD guide and checklist was 
predetermined, open-ended questions about the BHCPF training and elicited feedback on the accomplishment of the WDCs immediately after the training. The focus group discussions were structured to cover specific topics, including: (1) role of the WDCs prior to the training, (2) the training experience (3) Engagement of WDCs with community-level stakeholders in health. The principal investigator guided the discussion from one planned topic to another during the focus group discussions. Transcripts of the focus groups were independently coded based on key themes and emergent categories related to the roles of the WDC prior to the training, the training experience, and engagement with community stakeholders in health. The qualitative data was thematically analyzed to achieve research objectives by identifying common themes within each FGD response from the LGAs and identifying and recording commonalities and differences.

\section{Results}

\section{Focus Group Discussion Participants}

The participants were predominantly men, $83 \%$, while women constituted $17 \%$ of WDCs that participated in the focus group discussions from the selected 3 LGAs from each of senatorial districts in Osun State. The focus group discussion guide consisted of open-ended questions used to elicit a variety of participant's responses regarding the participants' perspectives regarding their experiences, and the qualitative analysis uncovered an assortment of main themes. These are outlined below, including memorable quotes from participants.

\section{Set up of WDC}

The focus group discussion revealed that the majority of the WDCs in Osun state were set up by the state primary health care development agency. However, the guidelines for constituting members of the WDCs have not been strictly followed, as there are very few women represented in most committees, and local government chairmen have used their offices to nominate political affiliates from the wards as part of members.

"In most wards prior to strict guidelines from the PHCDB, on the composition and structure of the committees, members were selected from each village /clan that makes up the community, these are few men and women who are committed and have interest in the wellbeing of their people. They are mostly elderly people, and not all the villages are represented in the WDC as sometimes people who build houses around the health facilities were selected to be part of the WDC, and as such, some communities/villages are not represented in the $W D C " \mathrm{OM}$.

\section{Focus Group Discussion participants}

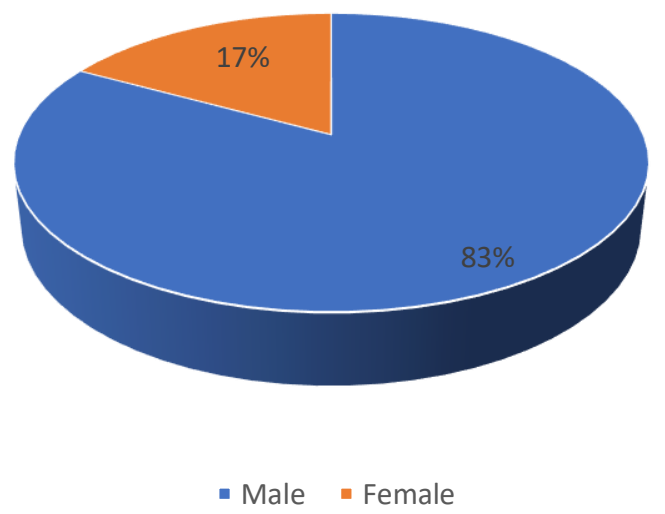

Figure 1. Percentage of Focus Group Discussion Participants by Sex 


\section{Constitution and Composition of Ward Development Committees in Osun State}

Most of the WDCs in Osun had few women representation, and in some, there are no women represented in the committees, hence considered an all-men affair. It was reported that this lack of women representation emerged from the observed lack of active participation of women in the local politics, only very few are women who are strong politically, and women in their wards are part of the committees.

"eeeh in my LGA-Oriade, there are very few women among us, it is not as if, they are not selected to join the fact is that they like money too much and whatsoever will take their time and not give money is not counted as important to them. So, when they are nominated to be part of the WDC, you find out that they won't come for meetings regularly complain ti poju. They might be part of the WDC but not active at all."

\section{Role of WDC in Health Management}

When participants were asked if they were familiar or aware of their roles and responsibilities as WDC members as it relates to the management of the PHCs prior to the BHCPF training, the majority stated that they were not informed clearly of their roles, but often the officer in charge of their facilities do approach them for specific assistance to address immediate needs at the PHCs. For instance, a complaint about a leaking roof, lack of or inadequate drugs supply, or lack of basic functional equipment and securing the PHCs. The WDCs reported addressing some of the issues by approaching community members for help or the LGA chairmen to support.

"In my ward, we never used to have meetings with the facilities staff just as my colleagues here said if there is any problem, the OIC will inform us, and we try to solve the problem. We did not take the issue of mobilizing the community to access services in the PHC as a priority as our people prefer the quacks and traditional medicine healers. But now it is very different oo" ANM.
"In my own ward, the WDCs were not aware of going to inform people about the services in the health facilities, in fact, I personally did not know that was part of my job, most of us see the position as part of our political benefits and were only concerned about what was in it for us, so we did not do much except for once in a while walking into the facilities to greet the staff and play with them then we also use to discuss current issues so did not contribute much to solving problems in the facilities" TM.

\section{Capacity Building on BHCPF for WDCs}

Most of the participants had diverse expectations of the training. According to the participants, the workshop enhanced their understanding regarding their roles and responsibilities as WDCs managing health facilities in their wards. Some of the misconceptions about the training by the WDCs, included thinking that they might be expected to provide some clinical services at the PHC, some felt they would gather skills to enable them to supervise the health workers at the facilities and hold them accountable, while others felt the training was part of dividend of democracy as an incentive for being loyal party members and the new health care program will be more accessible or affordable for the party members in the communities. However, their expectation and misconceptions concerning the training and BHCPF program in the wards changed from the 1 st day of participating in the workshop. As explained by WDC from Isale osolo ward in Ejigbo LGA.

"For me, I thought since the training was on health issues and you know they trained us with our OICs, so I thought the training will be on how to provide treatment for minor injuries and how to give injections in fact, I met with one of the facilitators to ask when will they start teaching that aspect. it was then the facilitator had to explain to me and the entire class the purpose of the workshop and why they had to be trained with the OICs so that we as WDCs can have an understanding of the task for the health 
care workers in ensuring the success of the $B H C P F$ program in the ward and the support needed from the WDCs to ensure all go as planned" YM.

Explaining further, a few of the WDC representatives said when they came on board, a lot of them thought it was a position that would come with a lot of incentives, but over time, their view started changing, and now they have a clear knowledge of their roles and responsibilities and the impact their work would make in their community.

"The workshop has really changed my perspective and mind toward WDC roles and responsibilities. I thought that the position comes with some form of money or incentives attached to it like I will now be paid a monthly allowance for working as a WDC, and this training is to prepare me for the kind of work I am to do, but now all that has changes as I have a better understanding of how WDCs are to operate with the PHC staff, and our responsibilities towards ensuring that problems at the facilities are resolved quickly for the benefit of our people especially the women and children. Now, and if possible, the WDC meeting with facility staff will now be conducted weekly or at least fortnightly" OM.

Participants were very enthusiastic about the relevance of the training and its benefits to their work. They agreed that the workshop exceeded their expectations as the content of the training was quite technical, but facilitation of the content was very simple with engaging exercises and participatory processes, which enabled them to learn easily. As stated by the WDC from Ipetu Ijesha ward, Oriade LGA,

"The training was very good for someone like me who doesn't understand so much English, the facilitators used local language sometimes they engaged some of us the participants to translate exactly what was taught in summary and it helped people like me, also I was sitting close to my OIC at the workshop so if I did not understand certain things, she explained to me. The drama on the roles and responsibilities of the WDC during the workshop was very useful. It made me to understand exactly what I'm to do and how to ensure that everybody, especially our women access the services and how to mobilize the community to support the facility" SM.

\section{Improved Quality of Service at the PHCs Following BHCPF Training}

Most of the participants agreed that a lot has changed very quickly in their wards and supported PHCs facilities since the end of the training. Some of the WDC has facilitated the reconnection of electricity in their facilities to the national power grid after several years without electricity, boreholes have started functioning, some of the WDCs have held town hall meetings in their community to raise awareness about the new BHCPF program, services available at the facilities and it benefits to every member of the community. Some of the WDCs have mobilized resources such as hospital furniture and equipment for their facilities, and all have held regular meetings with their facilities staff to review their scorecards, identify gaps, develop quality improvement plans and business plans to address the identified gaps, and have submitted same to the State PHCDB for necessary technical and financial support to address these issues. All of these have contributed immensely to the improved quality of services provided at the PHC facilities in their various wards. As stated by the Alekuwodo Ward WDC chair,

"Immediately after our training at IjebuIjesha, I met with the other WDCs to give them feedback on the training and the enormous tasks ahead of us, and then we also met with the PHC staff to look at the scorecards and identify immediate gaps we can address. One of the gaps was that the facility has been cut off from electricity supply for the past 4 years ago and because of this our staff cannot work late into the night, and the borehole is not working because no electricity our staff have to fetch water from neighbors house every day to use in the facility. Fortunately, the Electricity distribution agency 
(NEPA) official is also part of the committee, and his house is just down the street, so we complained to him about the situation, and he sent his boys from the NEPA office the following day to access the situation. By the very next day, they were here with their ladder to fix the problem, and now we have electricity in the facility our borehole is bringing water now even community members are coming to the facility to fetch water" OWC.

"I and my ward, we met with the facility staff and the major gap is the lack of bed and mattress for the PHC, we met our people and explained that pregnant women are not using the facility because of lack of bed and some other equipment. To my surprise, people started donating some gave us 500-naira others less and now we have 2 beds, mattress, and other furniture like tables, plastic chairs, and benches for our facility - WDC Ayegbogbo".

\section{Engagement with Community Level Stakeholders in Health:}

All the WDCs described the relationship between them and the PHC staff as very cordial and strong. The relationship was further strengthened after the training, which clarified the roles and responsibilities of the various stakeholders in health, especially the health facility staffs and the WDCs. They hold regular meetings, review quality improvement plans together, discuss strategies to address quality issues, work closely to ensure that all members of the community are benefiting from the program, and there is transparency in all that is done.

The Local government health authority supervises the work of the facilities staff and also provides support by participating in some of the meetings with the WDCs to discuss progress and challenges. This is especially important in the implementation of the BHCPF program, where WDCs are co-signatories to the official account of the facilities. As a result of this close collaboration between WDCs and PHC facilities staff, the quality of services rendered in the facilities has improved in facilities, staff are showing more commitment to their work to due improved conditions at the health facilities and the increase in client load to their facility has kept them busy, motivating them and giving them a sense of responsibility. As stated by the WDC from Oke Baale.

"The facility staff and we, the WDCs in my ward, work cordially together, we understand what needs to be done, and we are ensuring that we do the little we can as politicians to support our people. In my own ward, the chairman recently brought and donated essential medicines to all the facilities in the wards as a result of our visit to him. In fact, the focal centre got double the share of the drugs because of the clients that are now trooping in. Politicians don't joke with this type of thing as it projects them in a good light, and they use it to score political marks for next campaign, so we are using every means to get them to work four people now".

"Pregnant women and nursing mothers are now patronizing our PHC facility in the ward. In fact, the day before yesterday, my family benefitted from the free services because my pregnant wife delivered a bouncing baby boy safely at the ipetu ijesha PHC without us paying anything. We thank God, and we want the government to continue doing what they are doing now". Last week the OIC complained to me that work is too much now as women prefer to come to our centre they travel from very far to our place and it is because of the free services especially the drugs, the program is very good".

\section{Discussions}

The study sought to determine the extent to which capacity building/training of Ward development committees in BHCPF supported PHCs has contributed to the provision of quality services in the BHCPF supported facilities. The focus group discussion provided answers to the following research questions how did the capacity building of WDCs on BHCPF inform their roles in $\mathrm{PHC}$ management and inspire their 
involvement? How did the capacity building/training of the Ward development committee's members awaken their understanding of a relationship between the roles of WDCs and the quality of services at the PHCs?

The establishment of Ward Development Committees was facilitated by the state primary health care development agency as stipulated or recommended in national guidelines, and there are still gaps in the composition of the WDCs in the LGAs. Women's poor representation in the WDCs have an implication on the health outcomes, and indices in Osun state as women voices will not be heard, and quality improvement of health services may not take issues that affect women into consideration. This finding is consistent with other studies by Iyanda and Akinyemi, which found that in some wards, it was observed that female participation was very minimal [12]. The study also agrees with the findings of the Nigeria Health Watch that female leadership in the health sector is not only important to make a case for inclusiveness, gender equity, and representation in global health leadership, but a lack of this representation can also be said to have implications for the health outcomes and indices in Nigeria [13].

\section{Role of WDC in Health Management}

Prior to the BHCPF training, the WDCs in Osun state lacked understanding of their defined roles and responsibilities in the management of $\mathrm{PHC}$ as specified in the national guidelines and therefore could not perform most of their task/functions effectively. Creating awareness about the availability of services in the PHCs was not a priority for the WDCs. This resulted to low patronage and low utilization of services by the community members and women. This is consistent with findings by [14], Azuh, Agofure, and Sarki that the factors that affected the functionality of the WDCs include poor understanding of their functions by both the WDC and the community members, lack of incentives, the lopsided composition of the WDCs, absence of quality service in the health facilities (lack of skilled manpower, equipment, and drugs), lack of 24 hours service in most facilities, poor understanding by the health facility staff of the roles of the WDC in PHC programmes and their hostile attitude towards the WDC members $[14,15,16]$.

\section{Capacity Building on BHCPF for WDCs}

The commencement of the BHCPF program in Osun state-provided opportunity for the capacity building training of WDCs and Health workers on their roles and responsibilities in ensuring that success of the program in the state. The use of adult learning principles and teaching methods during the entire training promoted the learning of WDCs and health care workers. Misconceptions and non-clarity on roles, responsibilities of stakeholders in any program, and relationship lines expectations between the WDCs and health facility staff leads to mistrust, disharmony, unrealistic expectations, and nonachievement of the goals /objectives of the program.

This may lead to a hostile attitude of the WDCs to the health workers and vice versa and may disrupt the provision of quality health services to the clients in the community, resulting in poor maternal and child health indices in the community. This is consistent with the findings by $[17,18]$, that CDC/CDA members who took the lead in implementing health and developmental interventions had inadequate knowledge of the WHS, reflected the past, when community involvement in PHC implementation had been a kind of tokenism. Lessons from the past had not been effectively utilized, and the direct and/or indirect impacts of this neglect are probably responsible even for the country's current poor health development and unacceptable vital statistics (Infant, Under-five, and Maternal Mortality Rates). When communities have adequate knowledge and are fully mobilized, they participate actively in the running of their PHC services. Service 
utilization and coverage improve, and the indices for measuring the quality of health are better $[17,18]$.

\section{Improved Quality of Service at the PHCs following BHCPF Training}

Our finding revealed that there was a significant improvement of services rendered by WDCs following the BHCPF training. When stakeholders in PHC management are well informed about their roles and responsibilities and are motivated by capacity-building efforts such as training and mentoring, there is an increased likelihood of improved functionality of the stakeholders (WDCs) in response to the needs of the health facilities. WDCs are more likely to perform their specified roles and responsibilities once they have a clear understanding about them and are more likely to be effective in addressing identified needs of the facilities by mobilizing local resources to address them.

This agrees with the study findings [19] that health committees provide a mechanism that enables communities to be active and informed participants in the creation of a responsive health system that serves them efficiently and the results from the survey of PHC facilities by [20] also showed that community health committees were the major source of support for building maintenance in majority of the selected PHC facilities.

\section{Conclusion}

Findings from this qualitative research provide evidence that in communities where the BHCPF program commenced and is implemented according to the national guidelines with requisite training for the ward development committees, there is increased participation and commitment by the WDCs to ensure that PHCs are supported to provide quality services to the communities they serve. This is evident in the way trained WDCs mobilized community resources to support the PHCs; the improved relationship between the
WDCs and health workers which led to an improved understanding of the roles and responsibilities of the stakeholders in PHC management in the wards. The BHCPF program will guarantee improved access to quality health care to vulnerable groups, especially women of childbearing age and children. States and communities where the BHCPF scheme are being implemented stand a better chance of providing quality health care services to pregnant women, children, and vulnerable groups in the community, making equitable and accessible health care service and delivery possible in these communities. The communities also own the program as they see themselves as major stakeholders in the scheme ensuring the sustainability of the scheme in the communities where it is implemented.

\section{Recommendations}

There is a need for states governments in Nigeria to adopt the BHCPF program, a veritable scheme that will contribute tothe provision of equitable health care services to all Nigerians andultimately contribute to the achievement ofo universal health coverage to all Nigerians in the nearest future. The training and capacity development provided to health care workers and WDCs participating in the scheme are very beneficial.

It provides a road map for the provision of quality health care services to the most vulnerable in society. The BHCPF training provided an opportunity for PHCs staff and WDCs to jointly identify quality issues or gaps in their facilities, analyze data from their facilities to identify problems in terms of why community members were not accessing health care, work closely with the WDCs and their supervisors at the local government health council to implement strategies that will improve access to services for the population at the PHC. All these efforts are geared towards ensuring that quality health care services are provided to all Nigerians, especially the most vulnerable in the community. 


\section{Acknowledgement}

The authors express gratitude to members of the ward development committees and Primary Health Care (PHC) workers in Osun state for consenting to participate in the study. We acknowledge the support of all who in one way or the other has contributed to this study, especially Mrs. Janet Adedeji, Officer in Charge of Isale agbara $\mathrm{PHC}$ in organizing the discussion sessions and mobilization of resources and data gathering during the covid 19 lockdown in the

\section{References}

[1] National Population Commission (NPC) [Nigeria] and ICF. 2019. Nigeria Demographic and Health Survey 2018. Abuja, Nigeria, and Rockville, Maryland, USA: NPC and ICF.

[2] World Bank, 2017. https://data.worldbank.org/indicator/SH.DYN.MOR T?locations=NG.

[3] World Bank Group 2018: Country focus: Nigeria Biannual Economic Update Investing in Human Capital for Nigeria's Future http://documents.worldbank.org/curated/en/3467715 42864299850/pdf/132316-21-11-2018-17-31-9NigeriaBEUAMF.pdf.

[4] National Bureau of Statistics (NBS) and United Nations Children's Fund (UNICEF), 2017: Multiple Indicator Cluster Survey 2016-17, Survey Findings Report. Abuja, Nigeria: National Bureau of Statistics and United Nations Children's Fund.

[5] Nigeria Health Watch 2018, Official Gazette of the National Health Act- FGN 2014: https://nigeriahealthwatch.com/wpcontent/uploads/bsk-pdf-manager/2018/07/01_Official-Gazette-of-the-National-Health-ActFGN.pdf retrieved 12.09.2020.

[6] Federal Ministry of Health, 2020: Guideline for the Administration, Disbursement, and Monitoring of the Basic Health Care Provision Fund (BHCPF) retrieved

https://www.health.gov.ng/doc/BHCPF-2020-

Guidelines.pdf. state, including all staff of the State Ministry of Health DPRS unit.

\section{Conflict-of-interest Statement}

The authors received no funding for this study and have no conflicts of interest to declare. All co-authors have seen and agree with the contents of the manuscript, and there is no financial interest to report. We certify that the submission is original work and is not under review at any other publication.

[7] Awal, A., Ezenwa S., Atobatele S., Nzobiwu A., \& Uweiza H., 2020. Preliminary learnings from Nigeria's Basic Health Care Provision Fund, https://r4d.org/blog/preliminary-learnings-fromnigerias-basic-health-care-provision-fund/.

[8] Oginni A. S., 2019. Update on Basic Health Care Provision Fund (BHCPF) Implementation in Osun State: Report submitted to BHCPF State Steering Committee (Unpublished).

[9] Oyebode O., 2019. Update on Basic Health Care Provision Fund (BHCPF) Implementation in Osun State: Progress and Challenges. Report submitted to BHCPF State Steering Committee (Unpublished).

[10]National Primary Health Care Development Agency (NPHCDA) (2018): Ward Health System, 2nd Ed. August 2018.

[11]National Primary Health Care Development Agency, 2014. Minimum Standards for Primary Health Care in Nigeria 2014.

[12] Iyanda, O. F., \& Akinyemi, O. O., 2017. Our chairman is very efficient: community participation in delivering primary health care in Ibadan, Southwest Nigeria. The Pan African Medical Journal, $27, \quad 258$. https://doi.org/10.11604/pamj.2017.27.258.12892 https://www.ncbi.nlm.nih.gov/pmc/articles/PMC566 0304/ 235.2021.

[13]Nigeria Health Watch (2020): The need for women's leadership in global health - The Nigeria experience; https://nigeriahealthwatch.com/the-needfor-womens-leadership-in-global-health-the-nigeriaexperience/ retrieved 21.5.21. 
[14] Oyari F.O., Ogbonnaya L.U., Ota M.O., \& Azuogu B., 2017: How Ready are the Ward Development Committees to Facilitate Universal Health Coverage in Ebonyi State, Nigeria; Journal of Primary Health Care and General Practice 1 (1) 005 www.scientonline.org https://scientonline.org/openaccess/how-ready-are-the-ward-developmentcommittees-to-facilitate-universal-health-coveragein-ebonyi-state-nigeria.pdf retrieved 21.05.2021.

[15] Azuh D. E., 2017; The Role and Challenges of Ward Development Committees in Promoting Grassroots Health Awareness in Ogun State Nigeria; Journal of Business and Management 19 (7) 41-48 www.iosrjournals.org.

[16] Agofure, O., \& Sarki, E., 2017. Utilization of Primary Health Care Services in Jaba Local Government Area of Kaduna State Nigeria. Ethiopian Journal of health sciences, 27 (4), 339-350. https://doi.org/10.4314/ejhs.v27i4.5.

[17] Srivastava, A., Gope, R., Nair, N. et al. 2015, Are village health sanitation and nutrition committees fulfilling their roles for decentralised health planning and action? A mixed-methods study from rural eastern India. BMC Public Health 16, 59 https://doi.org/10.1186/s12889-016-2699-4.

[18] Abosede O.A, Campbell P.C., Olufunlayo T., Sholeye O.O., 2012 Establishing a Sustainable Ward Health System in Nigeria: Are Key Implementers Well Informed? J Community Med Health Educ 2:164. DOI: 10.4172/2161-0711.1000164.

[19] Mulumba, M., London, L., Nantaba, J., \& Ngwena, C. 2018. Using Health Committees to Promote Community Participation as a Social Determinant of the Right to Health: Lessons from Uganda and South Africa. Health and human rights, 20(2), 11-17.

[20]Gupta M.D, Gauri V., Khemani S., 2003, Decentralized Delivery of Primary Health Services in Nigeria. Africa Region Human Development Working Paper Series. Washington, DC: The World Bank; 2003. 


\title{
Factors Contributing to Community None Acceptance for Indoor Residual Spraying (IRS) for Malaria prevention in Chipushi Area of Mpika, Zambia
}

\author{
Tembo Elemiya \\ Master of Public Health, Texila American University, Zambia
}

\begin{abstract}
Indoor residual spraying (IRS) is one of the primary vector control interventions for reducing and interrupting malaria transmission. In recent years, however, it has received relatively little attention. Just like it is the case in the 17 villages of the Chipushi area of Mpika district in Muchinga province, Zambia. In community work, among the things that attracted my attention are the non-acceptance and perceived negative attitudes towards acceptance for indoor residual spraying. The purpose of this study was to analyze and establish the factors that contribute to none acceptance for Indoor Residual Spraying (IRS) in the Chipushi area of Mpika, Zambia. None acceptance, in this case, refers to a widespread negative response to having indoor residual spraying performed in people's homes at the community level. Simple random sampling was used to come up with the study population. And after executing the study through the questionnaire and semi-structured interviews on the 97 respondents, findings revealed that $12(12.4 \%)$ respondents believed that chemicals used in IRS increase mosquitoes and bed bugs instead of controlling them. Other $22(22.7 \%)$ never believed IRS could reduce the incidence of malaria. $18(18.6 \%)$ respondents avoided being in-convenience by the spray operators and health personnel. $10(10.3 \%)$ respondents don't want to be seen how wrecked their houses are or fear of being embarrassed due to lack of sanity in their homes. Similarly, 17 (17.5\%) respondents believed that by the culture, they could not allow strangers to expose their privacy in their homes. Surprisingly $26(26.8 \%)$ respondents never just wanted to participate in spray operations.
\end{abstract}

Keywords: Community, Households, Indoor Residual Spraying, Malaria elimination, Prevention.

\section{Introduction}

Malaria is one of the leading causes of mortality, particularly in Africa, with approximately $90 \%$ of the 528,000 malaria deaths estimated all over the world occurring in Africa. Another region of interest, while recognized internationally for its ambitious goal and plans of malaria elimination and having attained pre-elimination levels, the Southern Province of Zambia as a whole has surprisingly remained a highly endemic area for malaria. This is my major concern being a citizen of the country Zambia. For the past one year, we have seen that malaria still tops on the top ten diseases in the Mpika district of Muchinga Province, Zambia [1].
The national malaria profile in Zambia shows an increased risk for malaria, with almost 16 million people at risk. In 2015 alone, it was estimated that over 5 million malaria cases (about 98\% is due to plasmodium) were seen and recorded [1].

My objectives for this study are actually aimed at laying down the foundation for replicating new research.

\section{General Objectives}

1. What are the factors contributing to none acceptance for IRS in communities?

2. What strategies could be employed to promote acceptance for IRS? 


\section{Specific Objectives}

1. To ascertain the cause for none acceptance for indoor residual spraying in the Chipushi area of Mpika, Zambia.

2. What is the reason for none acceptance for IRS in the Chipushi area of Mpika?

The table below shows the malaria incidence in Zambia as for the 2015 fiscal year. The outpatient cases reported show that the high cases were reported in the copper belt province while lower cases were reported in the southern province. While high incidences per 1000 cases were recorded in Northwestern, Luapula, and Muchinga Provinces. My study area of Chipushi is actually in the Muchinga Province.

Table 1. Malaria incidence in Zambia

\begin{tabular}{|l|l|l|l|}
\hline Province & Population 2015 & $\begin{array}{l}\text { Total malaria OPD } \\
\text { cases reported }\end{array}$ & $\begin{array}{l}\text { Total reported malaria } \\
\text { incidence per 1000 }\end{array}$ \\
\hline Copper belt & $2,362,216$ & 815,988 & 345.4 \\
\hline Luapula & $1,102,625$ & 773,710 & 701.7 \\
\hline Northwestern & 843,156 & 680,375 & 806.9 \\
\hline Eastern & $1,813,450$ & 670,838 & 369.9 \\
\hline Northern & $1,304,434$ & 608,925 & 466.8 \\
\hline Western & 993,472 & 496,326 & 499.6 \\
\hline Muchinga & 449,445 & 449,445 & 502.1 \\
\hline Lusaka & $2,943,695$ & 92,185 & 31.3 \\
\hline Southern & $1,714,787$ & 45,794 & 26.7 \\
\hline
\end{tabular}

Source: HMIS 2015 OPD daily

Indoor Residual Spraying (IRS) is simply one of the very primary vector control measures or interventions intended for reducing and interrupting malaria transmission via a mosquito bite. Unfortunately, in recent years, however, it has received relatively little or sub-standard attention [2].

By definition Indoor Residual Spraying (IRS) is simply the application of somewhat a longacting chemical insecticide on the walls and roofs of all houses and domestic animal shelters in a given area in order to kill the adult mosquitoes that lands and rests on these surfaces of the walls [2].

The government of the Republic of Zambia (GRZ) resumed the IRS programs in 2003, and then in recent years, it has been increasing resource allocation towards malaria control in general, and IRS, in particular, is high on budget. PMI had supported IRS since 2009 and was preceded by three years of USAID- funded IRS. By 2015, PMI was supporting IRS operations in 25 PMI focus districts in Zambia. Since 2016,
Zambia has benefitted from the UNITAIDfunded NgenIRS project and subsidy also, and in 2017, the PMI- supported campaign targeted 648,800 structures in the same four high burden provinces and aimed to protect a population of $2,626,718$, which translates to almost $15 \%$ of the population. PMI plans to spray around 500,000 structures in the 2020 season alone, of which data is yet to be verified. District Health Offices (DHOs) provide overall planning, conclusion, and monitoring of malaria activities within their districts. Activities such as the implementation of IRS, ITN distribution, and malaria case management at level one hospitals, health centers, and in the community are implemented through DHOs. The National Malaria Elimination Center (NMEC), previously known as the National Malaria Control Center (NMCC), provides technical support but not operational assistance at these levels [3].

Under the district health office in my study area of Mpika in Zambia, malaria is still ranked the highest cause of morbidity and mortality. 
And Muchinga province, under which Mpika falls, is ranked among the top four most affected provinces in Zambia. Malaria disease caused by Plasmodium falciparum may result in death within hours or a few days of infection, especially in those with low immunity, such as children, pregnant women, people living with HIV/AIDS, and travelers [4].

Studies have shown and explored some factors hindering the acceptability and use of available malaria prevention measures to better inform area-specific strategies that can lead to the much-needed malaria elimination levels [5].

\section{Methods}

Understanding approach to research has a number of advantages which makes it suitable and more reliable to be used. Basically, it provides strengths that rule out or offset the weaknesses of both quantitative and qualitative research [6]. For instance, it is clear that quantitative research is very weak in understanding the context and setup in which people tend to behave, something that qualitative research resolves. On the other hand, qualitative research is seen as deficient because of the potential for biased interpretations made by the researcher and the difficulty in generalizing findings to a large group. Quantitative research does not have these weaknesses. Thus, by using the understanding approach to research, the strengths of each approach can make up for the weaknesses of the other.

Additionally, it was pointed out further that the understanding approach provides a more complete and comprehensive understanding of the research problem than either quantitative or qualitative approaches alone. Moreover, it provides an approach for developing better, more context-specific instruments. By the way, using qualitative research makes it possible to gather information about certain topics or the construct in order to develop an instrument with greater construct validity, that is, the measures the construct intends to measure after all. And above all, this, in turn, helps to explain findings or how the causal processes work [6].

However, it is stipulated that an understanding approach to research has as well a number of disadvantages or demerits [7]. For instance, the research design can sometimes be very complex. In addition to that, it takes much more time and resources to plan and implement this type of research and therefore requires added inputs from stakeholders. Moreover, it may be difficult to plan and implement one method by drawing on the findings of another. And also, it may be unclear how to resolve clear discrepancies that arise in the interpretation of the findings, and hence solutions are found.

Constraints are common in research especially doing in rural areas like in my place. By definition, constraints are obstacles or even barriers that prevent or hinders progress. Thus, when planning well-meaning research, it is important to take into consideration such constraints in research that could hinder progress. The first practical constraint is the lack of cooperation or insecurity attitudes by some respondents that the researcher targets. This may make it hard to collect enough and quality data.

In addition, accessing locally published literature may also be another challenge, especially in under privileged communities like my own study area. Moreover, time is another constraint because it could be insufficient to conduct the needed experiments, so that the duration may take much longer than the usual period of any research grant or resources (for instance, the project needs more than 5 years of support to be completed) [8].

According to verified reports, the other practical constraint is that the required research experiments may be deemed to be too dangerous to be conducted at a given institution or facility [9]. Lastly, the proposed experiment will necessitate the violation of some official prohibitions, restrictions, or public laws which are established by the national government agencies, for example, DNA cloning, stem-cell 
studies, chemical synthesis of some toxic materials, among others.

Therefore, planning the research approach should take this practical constraint into consideration in order to determine which approach could be suitable.

The research process takes a number of steps for it to be developed in its complete manner. The first step is to identify and develop your topic. The second step is to find background information. The practice is that one needs to look up for keywords in the indexes to the subject encyclopedia. Reading articles in this encyclopedia will set the context for the research. You need to take note of any relevant items in the bibliography right at the end of the encyclopedia articles. Additional background information may be found in your lecture notes, textbooks, and reserve readings [10].

Thirdly, use catalogs to find books and media. In the fourth step, you use indexes to find periodical articles that is use periodical indexes and abstracts to find citations to articles. The indexes and abstracts may mostly be in hardcopy print or softcopy computer-based formats or even both. One can easily find periodical articles by the article authors, title, or keywords by using the periodical indexes available in the library's home page part [11].

The fifth step is to find additional internet resources. Almost everyone now is aware of the uses of the Google platform and its accessories, Google Scholar, Google Books, Google News, YouTube, among others, to search and find information on the open Internet so fast (as opposed to the subscription-only resources you will encounter in steps 2 through 4 above).

The Sixth step involves evaluating what you find, See, and how to critically analyze the information sources to distinguish scholarly from Non-Scholarly Periodicals. If you have found too many or too few source materials, you may have to narrow or broaden your topic to suit the search.

The last step, as stated in other reports, it is cited that what you find using a standard format as prescribed by the faculty in which the study is directed. It is worth noting that knowingly presenting the work of other people or scholars as your own work is known as plagiarism [11].

\section{Study Area}

The study will focus on the seventeen villages in the Chipushi area of Mpika, Zambia, with a total catchment population of approximately 4494. These villages are based in the Chishibesonde ward of Mpika Central constituency. Villages covered include;

Kabuswe, Kabimbili, Mashinda, Kamfwa, Lupasha, File, ZNS, Matebe, Mama, Kansumba, chailo, Mungalaba, Mubanga, Mwiko, Kanungulila, Shipili and Namfunda. Much of the studies will involve focused group discussions and questionnaires to be administered to selected individuals in the sample group, with the majority of the inhabitants of chipushi living in extreme poverty.

\section{Study Population}

The study population will include the target population from the Chipushi area. The population of interest are derived from the sampled households out of the 926 households doted around the catchment area. All these are selected from all the 17 target villages in the Chipushi catchment area.

\section{Study Duration}

The study is expected to take approximately six to nine months. However, with the help of community involvement, it is possible to have the final report before the estimated time frame. I have made a very good personal relationship with the community structures in all the study areas of Chipushi hence the advantage of not pressurizing while collecting essential data. This co-existence with the community is very important in order to win the support of the sample population as well as the community leadership, who in turn give massive support to data collection needs. This collaboration helps to shorten and simplify the process of research. 


\section{Sampling Method}

In this study, a simple random sampling technique was used to select community respondents while judgmental, also called as purposive sampling, was deployed to select some respondents like the healthcare workers and 17 headmen. Simple random sampling was picked because of its advantage. Sample random sampling gives each participant in the population an equal chance to be part of the sample of the study. In other words, simple random sampling does not bias. On the other hand, judgmental sampling has been chosen because it produces a sample that is more representative of the population [12].

\section{Sample Size}

The study sample size will include 20 neighborhood health committee members, 20 household heads, 20 health care workers, 20 youths, and 17 headmen. The total sample of 97 respondents. All these are selected from all the 17 target villages in the Chipushi catchment area. The youths are involved because it's a very aggressive group in the community, and they have information concerning the happenings in the community. Omitting them may mean missing out on the vital voice's cardinal to the study.

Study tools various schedules, checklists, etc. to be used.

In obtaining information for the study, the following tools (instruments) were used: questionnaire, observation schedule, and semistructured interviews guide.

\section{Questionnaires}

The questionnaires were used because of the following advantages that they gave to the researcher: it was easy to collect data from a large sample, and because of this result can be dependable and reliable, confidentiality was upheld and saved time. Furthermore, the questionnaire made it possible to reach respondents in a more convenient way, and above all, it was free from the bias of the interviewer. However, it also had some disadvantages, and these include: it was likely to be the slowest of all because it allowed respondents to answer questions on the questionnaire at their own pace. It sometimes results in the low rate of return of the duly filled questionnaire.

\section{Focused Group Discussion Schedule}

The researchers chose this tool because it gave him first-hand information that he used to complement other methods. The respondents are put together in small groups and share the topic for discussion. A guided approach is the best in this type of data collection especially dealing with less literate people.

\section{Semi-Structured Interview}

A semi-structured interview was selected to be used in collecting data due to the following advantages; firstly, data collected in this manner are suitable for interpretative phenomenological analysis (IPA); the process is also very fast. However, it is not free from biasness. This was taken care of by avoiding bias.

\section{Results}

My critical discovery about this research is that most people in the study population are generally illiterate and poor. They are mostly guided by their social norms and traditions, which are perceived to protect their integrity. These traditions come from way back in ancient times or are sometimes wrongly oriented. Going down to dig the roots of these misconceptions may be the very solution to reducing the cases of malaria in the long run. The demographic characteristics of the respondents of this study are mostly community members who live together under similar conditions. 


\section{Questionnaire Respondents by gender}

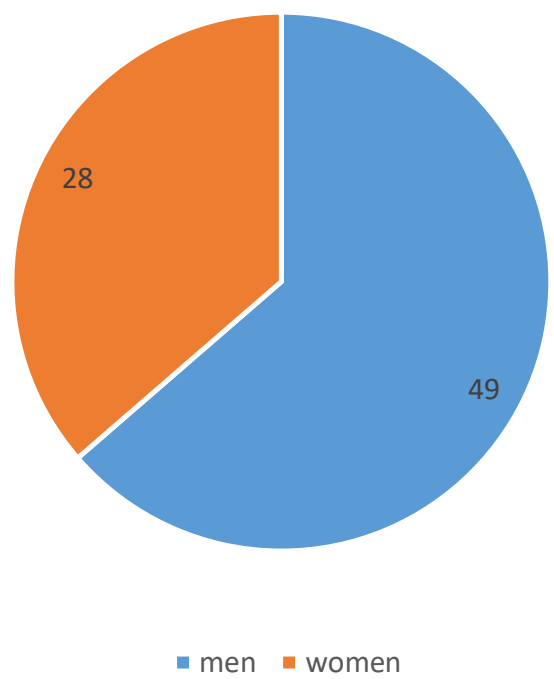

Figure 1. Demographic Characteristics of Respondents by Gender

It is one thing to say that research should be balanced on sexual grounds due to issues of gender balancing. However, the best practices on the selection of the sample size will mostly come out in a random way. After selection of my simple random selected sample, I found that men out-numbered women by double. However, it is manageable within the context of the study. This is because most homes are male-headed, unlike otherwise.

\section{Respondents by Status}

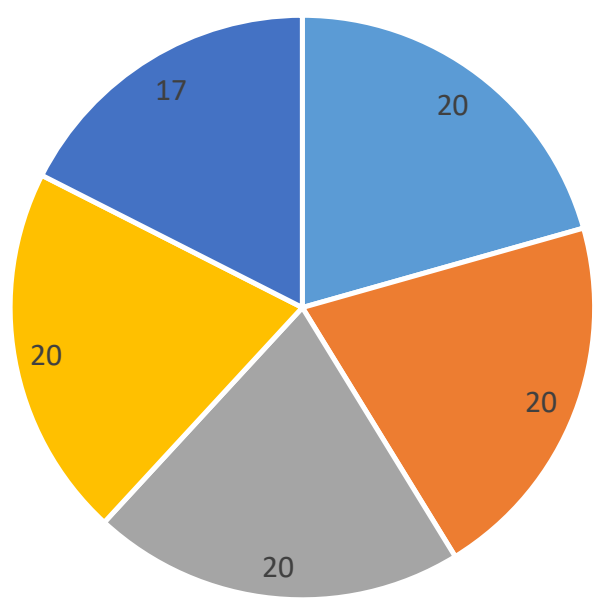

- Healthcare workers

- Household heads

$\because$ NHCs

- Youths

- village heads

Figure 2. Demographic Characteristics of Respondents by Status 


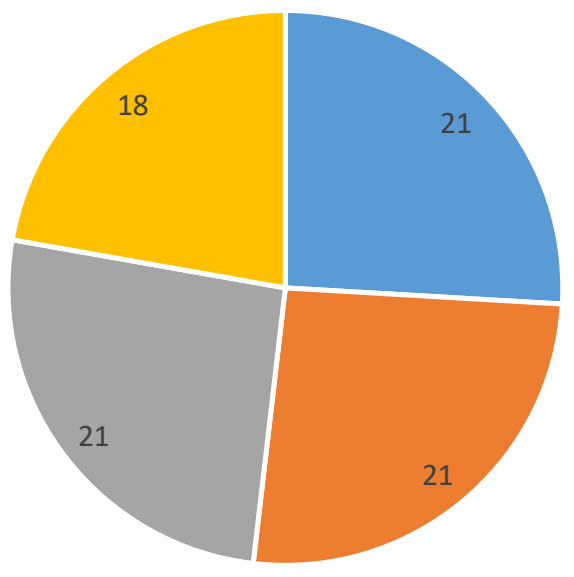

- HCWs $\square \mathrm{HHHS}=\mathrm{NHCs} \backsim$ Village Heads

Figure 3. Demographic Characteristics of Respondents by Percentage

The other findings concerning Indoor Residual Spraying in some areas of Mpika rural shows that the past three IRS operations did not achieve its intended targets. The entire district recorded almost $45 \%$ plus coverage. It is much less in my study population area of Chipushi. Being a primary health care provider working in a small clinic in Chipushi, Mpika, I have personally seen and experienced the apathy exhibited by the communities in accepting IRS. IRS is inherently challenging, and each year has brought its share of problems [13].

From my own observation, I saw how some people underplayed the process of IRS and ending up running away from the spray operators to the woods. Others leave children to report to the spray operators that they are not home when they actually are inside the house, hiding. Some villages preferred to go in their farms to work than waiting for their homes to be sprayed. Even after advertising and sensitization on the value of spraying, people never understood the importance thereof. The value of which is less received in the communities under this study. Probably future research should target to evaluate the effectiveness of IRS on malaria vectors, prevalence, and the community perception on IRS after spraying. Other studies believe that larval source management has several aspects that are significantly more sustainable than IRS and ITNs [14]. However, World Health Organization recommends the use of ITNs and IRS as part of a global framework for integrated vector management as the mainstay of vector control in sub- Saharan Africa [15].

\section{Discussion}

My research question, 'Factors Contributing to Community none acceptance for Indoor Residual Spraying (IRS) against mosquitoes as prevention for malaria in rural areas of Mpika, Zambia. I endeavor to find out why there is little acceptance in IRS in rural areas of Mpika, Zambia. From the primary survey I did in almost 17 villages, there are a number of concerns regarding IRS.

In the recent past, there has been poor coverage of indoor residual spraying in most rural parts of Mpika, Zambia. There is a need to do research in this area to ascertain why the acceptance levels for IRS are low in these rural communities. 
This study will help authorities and communities to adjust and understand the benefits of indoor residual spraying in the prevention of malaria. Without this, the battle for the elimination of malaria by 2021 will be farfetched. The control for malaria is a complex chain of measures that often complement one another [16].

As a public health professional, I am alive to the fact that the fight for the elimination of malaria in our communities, especially in subSaharan Africa and Zambia in particular, is supposed to receive the attention it deserves. I really want to understand the development of the effect of IRS in the prevention of escalating cases of plasmodium in the communities as a positive stride towards winning the fight against malaria.

The vital information worth knowing is that there are well above 16 million people who are at high risk of malaria infection in Zambia. And it was estimated in 2015 that there were over 5 million malaria cases. This is extremely high.

If knowledge of the effects and indeed the benefits of accepting IRS is optimized in rural communities, we would one day very soon defeat malaria. This work is targeting pulling out the misconceptions, negative social norms, beliefs, myths, and any other negative orientation surrounding the Indoor Residual Spraying programs.

In my work, there will be no clinical or chemical experiments involved to ascertain the efficacy and effect of the chemicals used during indoor residual spraying, as this will require high-level laboratory experiments and tests. However, necessary information concerning chemicals used will be collected in order to understand what other literature reports concerning these chemicals.

This will help us find out how these chemicals can affect individuals as well as the environment. Maybe the study could also make us learn how these chemicals could be a threat to health in another way. Or could this be the reason why communities have a negative response towards Indoor Residual Spraying? This is the question that begs to be answered if progress in the malaria fight is to be made in the area of prevention. As it is said, prevention is better than cure. In our local dialect, it is said that "the earliest person drinks cleaner water." Meaning whoever starts the race early will definitely find a winning foot. The earlier you act, the better. However, the target and sample population involved in the study is unfortunately comprised of mostly less learned people, although they have a wide range of perceived knowledge in their local beliefs and customs. Almost 90\% of the target population are peasant farmers depending mainly on seasonal crops like maize, pumpkins, and sweet potatoes, mostly planted in the rain season.

The recent call for malaria elimination is expected to result in changes in the selection of interventions, and additional research into uses of environmental management in varied settings is listed as necessary for improving vector control [17]. Our primary goal for this study is to get verified information why there is poor acceptance for indoor residual spraying in some rural areas of Mpika, Zambia. This research will be helpful to many more communities in our country, Zambia and beyond, to come up with measures that will promote acceptance. Information will also be shared with the concerned communities in the study and any other interest groups. Many communities involved are in under privileged settings of rural Mpika.

However, the main concern is that they are also vulnerable to various diseases, which include malaria. Finding lasting solutions to reducing malaria can greatly help in reducing morbidity and mortality from malaria. Moreover, malaria is the highest-ranked cause of morbidity and mortality in this area of study.

All avenues to eliminate malaria require the involvement of the communities where cases of malaria come from. Without considering inputs from the community can be a grave omission in the fight for a malaria free society. Hence the 
significance of such a study to be supported and be actualized. Indoor Residual Spraying, if well implemented, will be a major force in the elimination of malaria. I am passionate about this study because malaria is still our number one cause of morbidity and mortality in all ages in our country, Zambia.

Indoor Residual Spraying (IRS) with insecticides is a very powerful way to rapidly reduce malaria transmission by spraying inside homes. It involves mostly the spraying of the inside walls of housing structures with a certified chemical or insecticide. Typically, once or twice per year. To confer significant community protection, Indoor Residual Spraying (IRS) should be implemented at a high level of coverage in areas where the activity is being done. Globally, IRS effective protection declined from a high of 5\% in 2010 to about $3 \%$ in 2017, with decreases seen across all World Health Organization regions [18].

\section{Conclusion}

A number of malaria prevention strategies have been evaluated since the turn of the century. [19]. However, there are failed programs in malaria prevention in many communities of Mpika, Zambia, for a long time. The average coverage for the most recent two Indoor residual sprayings (IRS) in the Chipushi area of Mpika were very alarmingly low. Records for the past three years at the nearby catchment area health facility shows that in the first operation in 2017, the coverage for IRS was 122 (13.2\%), 199 (21.4\%) in 2018 out of the 926 households where sprayed. In the most recent campaign in 2019 , only 88 (9.5\%) households were sprayed out of the 926 households.

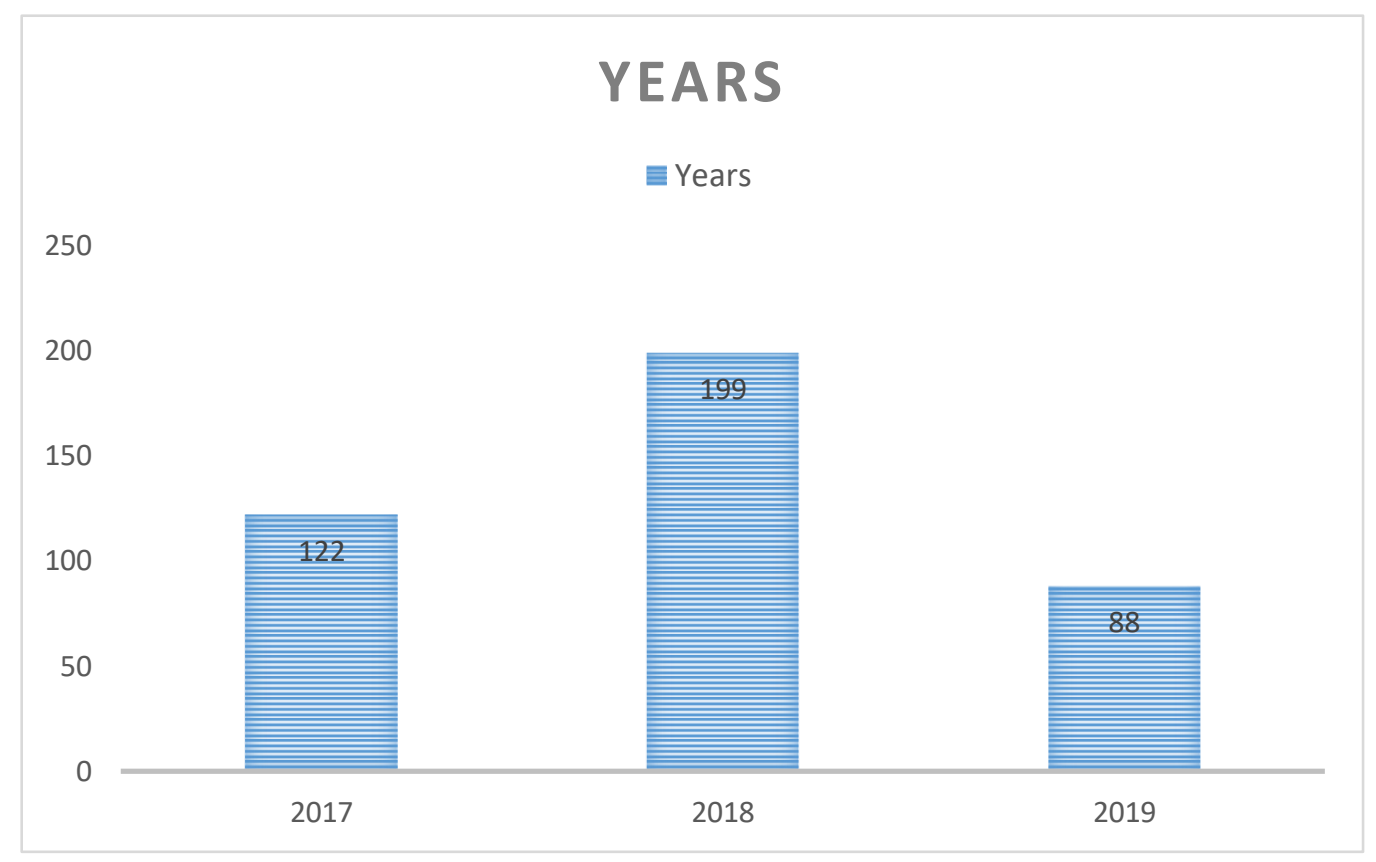

Source: HMIS, 2020 [1]

Figure 4. Health Facility Three Years' Trend Data for IRS- Chipushi Area

This trend in the Chipushi area of Mpika, Zambia, means that the acceptance levels for IRS fluctuate. This is not good for coverage and meeting the targets for the program of malaria prevention. If this trend is left unchecked, then the fight for a malaria-free society will be farfetched. This trend from 2017 to 2019 is worth being investigated and possible reasons established for the poor coverages recorded in achieving the full targets. The findings, recommendations, and conclusions thereof will most likely help to improve the intended targets.

The other findings concerning Indoor Residual Spraying in some areas of Mpika rural 
shows that the past three IRS operations did not achieve its intended targets. The entire district recorded almost $45 \%$ plus coverage. It is much less in my study population area of Chipushi. Being a primary health care provider working in a small clinic in Chipushi, Mpika, I have personally seen and experienced the apathy exhibited by the communities in accepting IRS. As a matter of fact, IRS is unfortunately challenging, and each year brings with it various problems.

From my own observation, I saw how some people demonized the process of IRS and ending up running away from the spray operators to the woods. Others leave children to report to the spray operators that they are not home when actually are inside the house, hiding. Some villages preferred to go in their farms to work than waiting for their homes to be sprayed. Even after advertising and sensitization on the value of spraying, people never understood the importance thereof. The value of which is less received in the communities under this study. Future research should probably target evaluating the effectiveness of IRS on malaria vectors, prevalence, and the community perception on IRS after spraying. On the other hand, other people never just accepted to have their houses sprayed.
After executing the study through the questionnaire and semi-structured interviews, findings of the research revealed that 12 of the respondents believed that the chemicals used in IRS increase mosquitoes and bugs instead of controlling them. Yet other 22 never believed IRS could reduce the incidence of malaria in the communities.

In this study, I also found that 18 respondents avoided being in-convenience by the spray operators and other health personnel. In the same vain, 10 respondents don't want to be seen how wrecked their houses are. For fear of being embarrassed due to lack of sanity in their homes. Yet again, it was found that 17 of the respondents believed that by the culture they could not allow strangers to expose their privacy in their homes. Others believed that it was embarrassing to see that the spray operators were too young to see their privacy.

One surprising finding was that 26 respondents never just wanted to participate in the spray operations. These did not give any reasons for not allowing spray operators to cover their homes. They participated in the enumeration process but never took part in the final spraying process.

The following table/figure shows how the distribution of respondents was recorded.

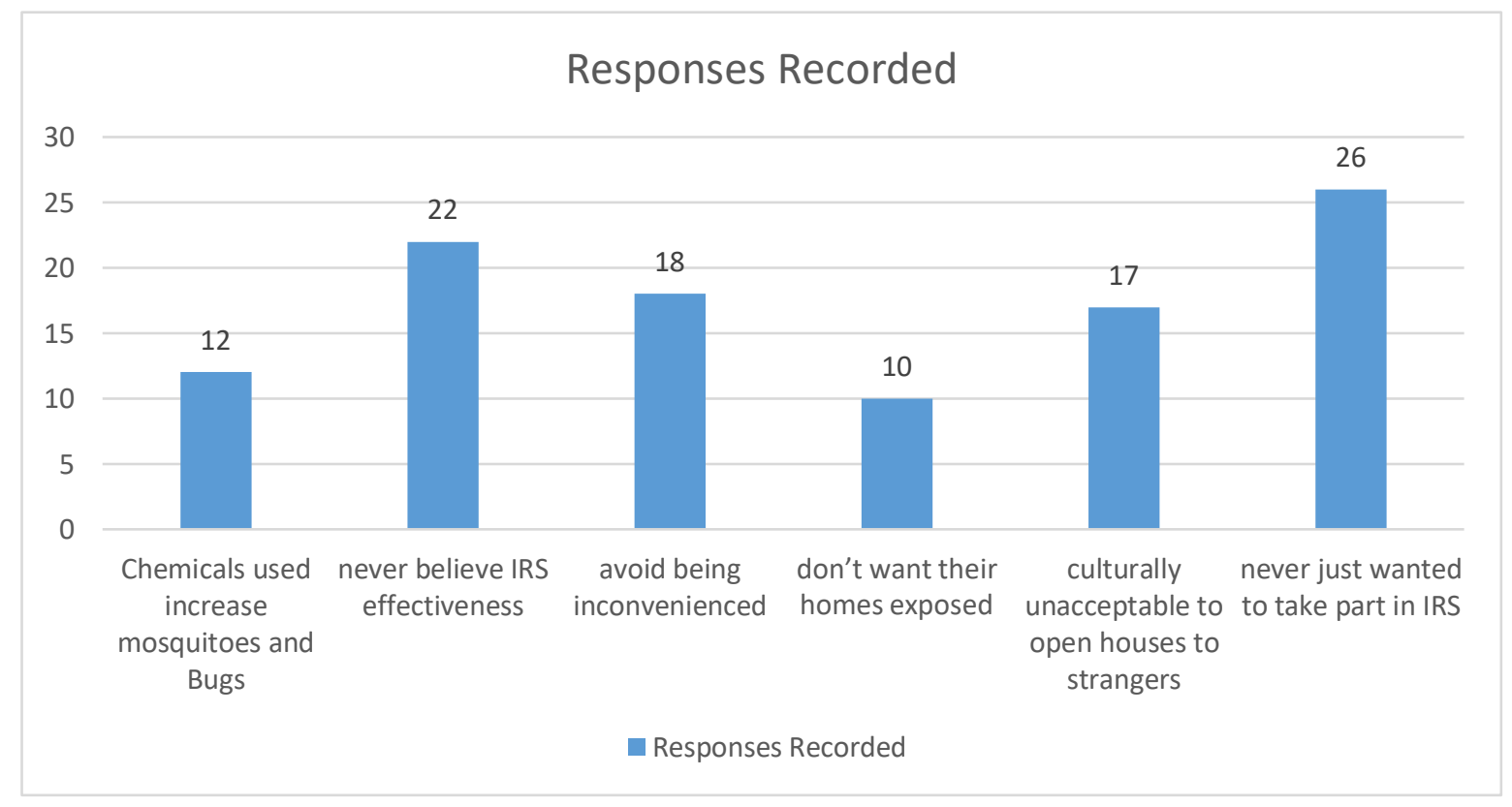

Figure 5. Respondents' Distribution of Responses 
This study will mainly focus on the factors behind none acceptance of the Indoor Residual Spraying in the rural chipushi area of Mpika, Zambia. And this will give insight into further research in the responses recorded thus far.

When enacting a large-scale new measure such as IRS to curb incidence of disease, Gamiccia suggests drawing up a health education plan that recognizes community priorities and has inputs from an epidemiologist, sociologist, and health educator working together [20]. Malaria eradication is a goal worth pursuing today more than ever before [21].

\section{Conflict of Interest}

After a thorough interaction with my guide concerning conflict of interest in this study, I was able to identify and mitigate potential or actual conflict of interest and are managed accordingly. Being a qualified health worker was easy to interview my fellow health workers using a questionnaire to eliminate cohesion and possible bias. Very interesting and challenging all together.

\section{References}

[1] Health Management Information System., 2020, Health statistics: Information office, 8(2), 36-42, https://www.zambiahmis.org/dhis.

[2] World Health Organization., 2006, Indoor Residual Spraying: Use of indoor residual spraying for scaling up global malaria control and elimination, 12(6), 1- 8,

https://apps.who.int/iris/handle/10665/69386.

[3] US President's malaria initiative., 2019, Zambia malaria operational plan FY 2020: USAIDS, Global malaria strategy, 12(4), 39-46, https://www.pmi.gov. [4] Zambia Malaria Elimination Centre., 2015, Malaria Overview: Malaria Elimination Strategy, https://www.nmec.org.zm/malaria-overview.

[5] Ingabire, C.M. et al., 2015, Factors impeding the acceptability and use of malaria preventive measures: implications for malaria elimination in eastern Rwanda, 14:136 $1-7$ https://www.researchgate.net/publication/274707254

\section{Acknowledgements}

First and foremost, I would like to thank my heavenly father, Jehovah, for his unfailing love and protection for my life. I would not be here if not for him. It has been a tough but an interesting journey at Texila. Many well-meaning academicians, faculties, and coordinators helped me to achieve my goal today. I am grateful for their immeasurable commitment and encouragement.

Furthermore, I thank my student mentors from year one to date for their resilient support. I cannot forget my employers for allowing me time offs to attend teachings, webinar sessions, conferences, and exams with no objection. I am highly indebted to them for their understanding. I cannot forget to acknowledge my district health office for their technical support and my guide, Prof. Gelson Tembo. Finally, I thank my family, who have been helpful throughout my studies. To all of these wonderful people am thankful and excited for being my family.

_Factors_impending_the_acceptability_and_use_of_ malaria_preventive_measure_implications_for_mala ria_elimination_in_eastern_Rwanda.

[6] Davis, B. G., 1993, The Understanding Approach to Research. San Francisco: Jossey-Bass.

[7] Altman, H. B., \& Cashin, W. E., 2003, The Research Methodology. London: McMillan Press.

[8] Eberly, M.B., 2001, Research practical obstacles: Journal of research, 50(1), 6- 7.

[9] Daniels, C.K., 1988, The research constraints: Bolton, MA, Anker.

[10] Woolcock, M.J., 2003, The research steps: Journal of research project, 12(2), 1- 9, https://www.iedunote.com/research-process.

[11] Grunert, J., 1997, The seven key Research steps: Bolton, MA, Anker, https://course.lumenlearning.com/ivytecheng111/chapter/the-seven-steps-of-the-researchprocess-revise-customize/. 
[12] N'gandu, S.K., 2013, writing a research proposal in educational research, Lusaka: The University of Zambia.

[13] US presidential malaria initiative., 2019, Zambia malaria operational plan FY 2020: US AID- Global malaria strategy, 51- 52, https://www.pmi.gov/where-we-work/zambia.

[14]Lindsay, S.W. \& Fillinger, U., 2011, Larval Source management for malaria control in Africa: myths \& reality. Malaria journal, 10:383, 5-6, https://www.malariajournal.com/content/10/1/353.

[15] Majambere, S. et al., 2010, Is mosquito larval source management appropriate for reducing malaria in areas of extensive flooding in the Gambia? A crossover intervention trial. American Journal for tropical medicine \& Hygiene, 82(2), 176-184.

[16] Steketee, R.W., 2009, Control of malaria: American journal of tropical medicine \& hygiene. 80(6), 879-880,

https://www.ajtmh.org/cgi/reprint/80/6/879.

[17] Castrol, M.C., et al., 2009, community based environmental management for malaria control: evidence from a small- scale interaction in Dar es Salaam, Tanzania. Bio-med central malaria journal, $8: 57$,

https://www.malariajournal.com/content/8/1/157.

[18] World Health Organization., 2015, malaria: WHO global technical strategy for malaria 20162030, https://reliefweb.int/report/world/who-globaltechnical-strategy-malaria-2016-2030.

[19] Seidlein, L.V., 2016, Malaria prevention strategies: $17^{\text {th }}$ international congress on infectious diseases. International journal of infectious diseases, $45 \mathrm{~S}$ $1-477$, http://dx.doi.org/10.1016/j.ijid.2016.02.069.

[20] Ganiccia, G., 1981, Health education in malaria control: Why has it failed, world health forum, 2, 385393.

[21]Hall, B.F. \& Fauci, A.S., 2009, Malaria control, elimination, \& eradication: The role of the evolving bio-medical research agenda. The journal of infectious diseases, 200:1639-43, https://academic.oup.com/jid/articleabstract/200/11/1639/831923. 


\title{
Factors Determining the Choice of Place of Delivery among Antenatal Attendees in Primary Health Care Centres in Lafia Nigeria
}

\author{
Ikrama Hassan ${ }^{1}$, Edna Philip ${ }^{2}$, Anazodo Michael ${ }^{1}$, Ann Joshua ${ }^{3}$, Lawal Abdulmumuni \\ Ahmed $^{4}$, Babatunde Joseph ${ }^{1}$, Bello Surajudeen Oyeleke ${ }^{5 *}$, Sasetu Stephen ${ }^{6}$ \\ ${ }^{1}$ Epidemiology and Community Health Department, Dalhatu Araf Specialist Hospital, \\ Lafia Nasarawa State, Nigeria \\ ${ }^{2}$ Nursing Department, Dalhatu Araf Specialist Hospital, Lafia Nasarawa State, Nigeria. \\ ${ }^{3}$ Planning, Research and Statistics Department, Ministry of Health, Lafia Nasarawa State, \\ Nigeria \\ ${ }^{4}$ Department of Anatomy, Federal University of Lafia, Lafia Nasarawa State, Nigeria \\ ${ }^{5}$ Paediatrics Department, Dalhatu Araf Specialist Hospital, Lafia Nasarawa State, Nigeria \\ ${ }^{6}$ Planning and Statistics Department, Nasarawa Primary Healthcare Development Agency, \\ Lafia Nasarawa State, Nigeria
}

\begin{abstract}
Unskilled home delivery is a threat to maternal and child health. In Northern Nigeria, many pregnant women attend antenatal care but opt to deliver at home. This study determined knowledge on pregnancy outcome, the burden of home delivery, and factors contributing to the choice of place of delivery. A cross-sectional study was done with the subjects selected by multi-stage sampling. The data was analyzed using SPSS. Results were presented in frequencies and percentages with chisquare used in determining the statistical significance between the socio-demographic characteristics and the choice of a planned place of delivery. The mean age of participants is 27.6 \pm 5.0 years. Of the 404 participants and $43.3 \%$ are from the lower social status. Most participants were delivered at home due to sudden labour (25.6\%), lack of transportation (20.5\%), high cost of hospital deliveries (13.7\%). Most understand that leg swelling may connote problems in Pregnancy, Hypertension can occur in Pregnancy, and a normal pregnancy may become complicated. Educational status, health worker's attitudes, previous experience, ease of transportation, and numbers of parity are all significant determinants of the choice of place of delivery ( $p<0.0001)$. Most participants delivered in the hospital, but a significant number still delivers at home despite knowing that Hypertension can occur in Pregnancy and that normal Pregnancy can become complicated. Reasons for their decision were lack of transportation means, an attitude of healthcare workers, and high cost of hospital deliveries. The major determinant of choice of delivery place is; educational status, previous experience, and attitude of healthcare workers.
\end{abstract}

Keywords: Choice, Determining, Delivery, Factors, Place, Pregnant.

\section{Introduction}

A great number of women and their unborn babies lost their lives in sub-Saharan Africa from Pregnancy-related complications [1]. Globally, approximately 830 women die every day from preventable and childbirth [1]. In our resource-poor settings, home delivery is usually the cheapest option but is associated with risks of infection and lack of available equipment in the event of complications [2]. Many women, especially in sub- Saharan countries, were not lucky enough to be cared for 
during Pregnancy and childbirth by qualified healthcare personnel [2]. Skilled care, before, during, and after childbirth, can save the lives of women and newborn babies [3]. The level of assistance that a woman receives during childbirth is a strong determinant of the overall outcome for her and her newborn [4]. The presence of a skilled attendant during birth is therefore imperative. The term 'skilled attendant' refers to caregivers with midwifery skills, such as physicians and other qualified healthcare workers $[4,5]$.

Nigeria has continued to witness a high death of women relating to Pregnancy with substantial variations across its regions [6]. Despite this, the use of reproductive health services remains low, and home delivery among childbearing age is more and widespread. Hence maternal morbidity and mortality remain a public health problem [2]. This may be influenced by a lot of factors, including demographic, socio-economic, cultural, Obstetric, and health system factors [7].

In Nigeria, most deliveries take place at home or with the Traditional Birth Attendants (TBAs). In Nigeria, $25 \%$ and $60 \%$ of pregnant women in rural and urban areas respectively uses delivery services at health care facilities [7]. In Kano, Northern Nigeria, the majority (74.1\%) of the women between the ages of 2535 years deliver at home, mainly due to health worker's attitudes and the presence of male healthcare workers during delivery [7].

Nasarawa State, which is located in North Central Nigeria, is reported to have the highest rates of maternal mortality ratio within the region, 700 women per 10,000 live births and 103 children per 1,000 live births annually, with an approximate population of over 200 million citizens [8]. Home delivery in Nasarawa State, Nigeria, is common and is one of the major causes of maternal and infant mortality in the state. In Nasarawa State, $80 \%$ of home deliveries are conducted by unskilled birth attendants (mostly family members) [9].
The poor organization has been a major challenge in Nigeria [10]. [11] asserted that maternity care in Nigeria is organized around three tiers the primary, secondary, and tertiary care levels. Pregnant women are to receive antenatal care, natal and post-delivery care at the primary health centers nearest to them [12]. In Nigeria, the maternal mortality rate is high, with maternal deaths the highest in the world after India [13].

The Nigerian health system as a whole has been plagued by problems of service quality, including unfriendly staff attitudes to patients, inadequate skills, decaying infrastructures, and chronic shortages of essential drugs. Approximately two-thirds (2/3) of all Nigerian women deliver outside the facilities and without a medically skilled attendant present.

\section{Rationale for the Study}

The maternal mortality rate is known to be higher in the Northern region. The exact burden has not been well delineated in Nasarawa State, North-Central Nigeria. Some women attend antenatal care but will end up delivering at home rather than in the hospital.

This motivates the researchers to carry out this study so as to determine the factors influencing the choice of delivery place among antenatal attendees in Lafia Nasarawa State, Nigeria.

\section{Specific Objectives}

1. To ascertain the choice of delivery place among ANC attendees in PHC clinics in the Lafia metropolis.

2. To assess the knowledge of ANC attendees on skilled birth delivery.

3. To determine factors that influence the choice of delivery place among these clients.

\section{Methodology}

The study was conducted in two PHCs situated in Lafia metropolis, the state capital. Hausa is the unofficial lingua franca of the 
people of the area, and the major occupations are farming, trading, and civil servants.

\section{Study Design}

This was a cross-sectional prospective study.

\section{Sample Size Estimation}

The sample size was calculated using the formula:

$$
\begin{aligned}
& n=\frac{Z^{2} p+q}{d^{2}} \\
& =\frac{Z^{2} p(1-p)}{d^{2}}
\end{aligned}
$$

$\mathrm{n}=$ is the initial sample size

$\mathrm{p}=$ Prevalence of pregnant women who prefer home delivery from a previous study $=39.3 \%$ [14].

$\mathrm{q}=1-\mathrm{p}$.

$\mathrm{Z}_{\mathrm{a} / 2}=1.96$ (alpha deviate confidence level)

$\mathrm{P}=39.3 \%[14]$

$\mathrm{q}=1-0.393=0.607$.

$\mathrm{d}=0.05$

$$
n=\frac{1.96 \times 0.393 \times 0.607}{0.05^{2}}
$$

$\mathrm{n}=366.56$.

$\mathrm{N}=$ is the final sample size.

$10 \%$ is added for Non-Response Rate (NRR)

$=10 \%$ of $366.56=36.656$.

$\mathrm{N}=366.56+36.656=404$.

Therefore, the minimum sample size calculated was 404 .

\section{Sampling Technique}

A multi-stage sampling technique was used to select one ward each from Lafia Township and another from the lafia environs using random sampling. One Primary Healthcare Centres (PHC) is then selected from each of the two wards earlier selected also using a simple random sampling method.

The pregnant women attending the selected PHC for Antenatal Clinic (ANC) were then approached; the study explained to them in detail and is recruited through a convenient sampling after obtaining an informed consent until the desired number (202 per PHC) is attained.

\section{Inclusion Criteria}

All pregnant women who have delivered once or more and attends antenatal care in those two PHCs were eligible to be chosen.

\section{Exclusion Criteria}

Pregnant women that are primigravida (first Pregnancy).

\section{Data Collection Procedure}

A questionnaire-based study. The first section seeks for socio-demographic background, while the second section seeks to evaluate the factors affecting the choice of delivery place among antenatal attendees in PHC clinics within the Lafia metropolis. The questions are closed-ended, with few requesting for an explanation on their responses.

\section{Statistical Analysis}

The data analysis was with SPSS version 23.0, and the result was presented in tables while chi-square was used to assess the statistical significance between the sociodemographic characteristics and choice of a planned place of delivery.

\section{Confidentiality of Data}

Data de-identifiers were used, stored in a mini-computer that is pass-worded, and kept in a safe locker where only the principal author had access to it. All data collected was protected against unlawful or unauthorized access, disclosure, or theft. All information was kept secret and confidential to prevent legal or reputational damage and other severe consequences.

\section{Results}

\section{Socio-demographic Characteristics}

There were 404 women of reproductive age in the study, giving a response rate of $100 \%$ with an average of 27.6 years \pm 5.0 years, most 
of which were aged $21-30$ years equivalent to $256(63.5 \%)$. More than two-thirds of the participants $(81.5 \%)$ had secondary or tertiary education, with half $(50.2 \%)$ of them engaged in petty businesses. Most are married (98.7\%) and from monogamous families ((73.9\%). Also, more than a third $(43.3 \%)$ belonged to the lower social class Table 1 .

Table 1. Socio-demographic Characteristics

\begin{tabular}{|c|c|}
\hline Variables & Frequencies n $(\%)$ \\
\hline \multicolumn{2}{|l|}{ Age group } \\
\hline$\leq 20$ & 49 (12.2) \\
\hline $21-30$ & $256(63.5)$ \\
\hline $31-40$ & $96(23.8)$ \\
\hline $41-50$ & $3(0.5)$ \\
\hline \multicolumn{2}{|l|}{ Marital status } \\
\hline Single & $2(0.5)$ \\
\hline Married & $398(98.7)$ \\
\hline Divorced & $4(0.7)$ \\
\hline \multicolumn{2}{|c|}{ Type of marriage } \\
\hline Monogamous & $290(73.9)$ \\
\hline Polygamous & $114(26.1)$ \\
\hline \multicolumn{2}{|l|}{ Religion } \\
\hline Christian & $145(35.7)$ \\
\hline Muslim & $259(64.3)$ \\
\hline \multicolumn{2}{|c|}{ Educational status } \\
\hline None & $19(4.5)$ \\
\hline Primary & $57(14.0)$ \\
\hline Secondary & $173(43.0)$ \\
\hline Tertiary & $155(38.5)$ \\
\hline \multicolumn{2}{|l|}{ Occupation } \\
\hline Housewife & $110(27.2)$ \\
\hline Farming & $24(5.9)$ \\
\hline Artisan & $28(6.9)$ \\
\hline Petty trading & $203(50.2)$ \\
\hline Civil servant & $39(9.8)$ \\
\hline \multicolumn{2}{|l|}{ Social status } \\
\hline Lower class & $175(43.3)$ \\
\hline Middle class & $137(33.9)$ \\
\hline Higher class & $92(22.8)$ \\
\hline
\end{tabular}

Mean age of the ANC attendee $27.60 \pm 4.98$

\section{Factors Determining Choice of Delivery Place}

Most $332(82.2 \%)$ chose to deliver in the hospital. Reasons for some participants (17.8\%) who still chose home delivery for delivery of their index pregnancies included; sudden labour
\& delivery (25.6\%), distance to the health facility and lack of transport means (20.5\%), and high cost of care associated with hospital deliveries $(13.7 \%)$.

Of the respondents, $(29.0 \%)$ confirmed that their last deliveries were at home. Close to a third (31.6\%) of those preferring home delivery 
will be delivered by the TBA. Of those that chose home deliveries with the TBAs, $(70.3 \%)$ are happy with the 'treatment' accorded them by the TBAs. The reasons for preferring TBAs are; Attention given to them (46.2\%) and lower cost $(23.1 \%)$ Table 2.

Table 2. Factors Determining Choice of Delivery Place

\begin{tabular}{|c|c|}
\hline \multicolumn{2}{|l|}{ Choice of place of delivery Frequencies n (\%) } \\
\hline \multicolumn{2}{|l|}{ Where do you choose to deliver your current Pregnancy } \\
\hline Home & $72(17.8)$ \\
\hline Hospital & $332(82.2)$ \\
\hline \multicolumn{2}{|l|}{ Place of the previous delivery } \\
\hline Hospital & $287(71.0)$ \\
\hline Home & $117(29.0)$ \\
\hline \multicolumn{2}{|l|}{ Reasons for delivering at home } \\
\hline Distance/lack of transportation means to the Hospital & $24(20.5)$ \\
\hline High cost of hospital delivery & $16(13.7)$ \\
\hline Attitude of HCW & $5(4.3)$ \\
\hline Sudden labour / delivery & $30(25.6)$ \\
\hline No reason & $5(4.3)$ \\
\hline My neighbour is a Nurse/Midwife & $6(5.1)$ \\
\hline No available bed space in Hospital & $4(3.4)$ \\
\hline My husband insisted I deliver at home & $8(6.8)$ \\
\hline Convenience & $7(6.0)$ \\
\hline Personal choice to deliver at home & $7(6.0)$ \\
\hline No sign of complication & $5(4.3)$ \\
\hline \multicolumn{2}{|l|}{ Who conducted the home delivery } \\
\hline Midwife & $32(27.4)$ \\
\hline CHEW & $34(29.0)$ \\
\hline TBA & $37(31.6)$ \\
\hline Unskilled birth attendant & $14(12.0)$ \\
\hline \multicolumn{2}{|c|}{ Do you like the way the TBA treat you during delivery } \\
\hline Yes & $26(70.3)$ \\
\hline No & $11(29.7)$ \\
\hline \multicolumn{2}{|l|}{ If yes to the above, why? } \\
\hline I felt relaxed and comfortable & $5(19.2)$ \\
\hline Low cost & $6(23.1)$ \\
\hline Given adequate attention & $12(46.2)$ \\
\hline Polite and caring & $3(11.5)$ \\
\hline
\end{tabular}

\section{Knowledge of ANC and Factors Influencing Choice of Delivery Place}

Most of the ANC attendees (55.4\%) believe that ANC should commence the moment they know they are pregnant. One-third (33.4\%) believe that the ANC tests are not necessary.
The majority of the participants, 309 $(80.1 \%)$, say swelling of legs can be a sign of a problem in Pregnancy, 307 (80.2\%) say Hypertension can occur during Pregnancy, 270 $(70.5 \%)$ say a normal pregnancy can have complications along the line while $14.9 \%$ believes that occasional bleeding in Pregnancy may be normal. More than a third (39.4\%) 
believe they can be delivered at home if their ANC is normal. Less than a quarter $(22.3 \%)$ believe that the cost of care during childbirth at the hospital is rather too high.
The following are reasons that can make one deliver outside the Hospital; Distance (62.1\%), Husband hindrance (53.2\%), Not buying delivery items $(55.9 \%)$, and those with fewer pregnancies $[1,2](76.7 \%)$.

Table 3. Knowledge of ANC and Factors Influencing Choice of Delivery Place

\begin{tabular}{|c|c|}
\hline Variables & Frequencies n $(\%)$ \\
\hline \multicolumn{2}{|l|}{ Knowledge of when ANC should start } \\
\hline ANC attendance begins the moment I know I am pregnant & $224(55.4)$ \\
\hline ANC should begin only when the Pregnancy is noticeable & $180(44.6)$ \\
\hline \multicolumn{2}{|l|}{ The tests done during ANC are not necessary } \\
\hline Yes & $135(33.4)$ \\
\hline No & $269(66.6)$ \\
\hline \multicolumn{2}{|l|}{ Swelling of legs can be a sign of a problem } \\
\hline Yes & $323(80.0)$ \\
\hline No & $81(20.0)$ \\
\hline \multicolumn{2}{|l|}{ Hypertension can occur during Pregnancy } \\
\hline Yes & $329(81.4)$ \\
\hline No & $75(18.6)$ \\
\hline \multicolumn{2}{|c|}{ A normal pregnancy can have complication along the line } \\
\hline Yes & $290(71.8)$ \\
\hline No & $114(28.2)$ \\
\hline \multicolumn{2}{|c|}{ Occasional bleeding is normal occurrence during Pregnancy } \\
\hline Yes & $60(14.9)$ \\
\hline No & $344(85.1)$ \\
\hline \multicolumn{2}{|l|}{ I can deliver at home if my ANC is uneventful } \\
\hline Yes & $159(39.4)$ \\
\hline No & $245(60.6)$ \\
\hline \multicolumn{2}{|l|}{ Is the cost of hospital delivery high? } \\
\hline Yes & $90(22.3)$ \\
\hline No & $314(77.7)$ \\
\hline \multicolumn{2}{|c|}{ Can distance to health care centre cause a woman to deliver at home } \\
\hline Yes & $251(62.1)$ \\
\hline No & $153(37.9)$ \\
\hline \multicolumn{2}{|c|}{ Can failure to book for ANC be a reason for home delivery } \\
\hline Yes & $72(17.8)$ \\
\hline No & $332(82.2)$ \\
\hline \multicolumn{2}{|l|}{ Can husband be hindrance to hospital delivery? } \\
\hline Yes & $215(53.2)$ \\
\hline No & $189(46.8)$ \\
\hline \multicolumn{2}{|c|}{ Can lack of buying delivery items cause a woman to deliver at home } \\
\hline Yes & $226(55.9)$ \\
\hline No & $178(44.1)$ \\
\hline Do you like the lithotomy of delivery in the hospital? & \\
\hline
\end{tabular}




\begin{tabular}{|l|l|}
\hline Yes & $282(69.8)$ \\
\hline No & $122(30.2)$ \\
\hline \multicolumn{2}{|l|}{ How many pregnancies have you had in the last 5 years } \\
\hline 1 & $179(44.3)$ \\
\hline 2 & $131(32.4)$ \\
\hline 3 & $58(14.4)$ \\
\hline 4 & $36(8.9)$ \\
\hline
\end{tabular}

Mean number of pregnancies $2.76 \pm 1.51$. The mean ANC visits in current Pregnancy $2.55 \pm 0.98$

\section{Relationship Between Place of Delivery and Some Demographic Factors}

Significant factors influencing the participants decision whether to deliver in the hospital or at home by this study participant includes; the level of educational, religion, means \& ease of transportation, satisfaction with the healthcare workers / last delivery experience, the position (lithotomy) used at delivery and the number of pregnancies where the multi-gravida mostly prefers home deliveries $(\mathrm{p}=<0.0001)$ Table 4 .

Table 4. Relationship Between Place of Delivery and Some Demographic Factors

\begin{tabular}{|c|c|c|}
\hline Variables & Chi-square & p-value \\
\hline \multicolumn{3}{|c|}{ Desire to deliver at the place of your last child birth? } \\
\hline Educational status & 22.531 & $<0.0001$ \\
\hline Previous experiences with home or hospital deliveries & 42.610 & $<0.0001$ \\
\hline Satisfaction with the behaviour of health workers & 27.593 & $<0.0001$ \\
\hline Ease of transportation during labour & 16.020 & 0.031 \\
\hline The lithotomy position of delivery & 30.617 & $<0.0001$ \\
\hline Religion & 19.172 & $<0.017$ \\
\hline Number of pregnancies in the last five years & 48.373 & $<0.0001$ \\
\hline
\end{tabular}

\section{Discussion}

Most respondents in the present study were in their third decade of life $(21-30$ years $)$ with a mean age of 27.6 \pm 5.0 . This is similar to an earlier report by [7] in Kano, Nigeria. In contrast, [6] found a higher mean age from Ekiti South-Western Nigeria.

This observation may be attributed to the geopolitical zoning (Northern vs. Southern Nigeria) with its similarity in culture and religion that influences the age of marriage and childbearing. More than two-thirds of the participants in this study had their last delivery in the hospital.

Our finding is similar to the Ekiti study, with the similarity in the educational status of our respondents being a possible explanation for the similarity. A significant number (29\%) had their last deliveries at home with approximately, one-sixth (17.8\%) of them still willing to be delivered at home in their next delivery. This is at sharp variance with the findings among Eritrean women in which almost three-quarter of them delivers at home [15]. The difference may be due to the variation in study sites and the rural nature of their study compared to ours.

The reasons for the preference of home delivery by some in this study were sudden onset of labour, lack of transportation means, and high hospital cost. Others are; a distance of the health facility, husband hindrance, and not having delivery items ready. This is not surprising as most of our study participants are from a lower social status. In addition, we found participants in this study preferring to be delivered at home by the unskilled TBAs because of unfettered attention (46.2\%) 
accorded them and the lower cost $(23.1 \%)$ of delivery when compared with delivery at the hospital. About one-quarter of the women believes that the cost of delivery at the hospital is high.

Similar findings have been reported by other authors $[6,15]$. The reason for this preference may also be due to habit, which will explain this irrational choice despite knowing the risk involved [16]. Home deliveries were conducted by the TBA in about a third of cases $(31.6 \%)$ among those that chose home deliveries. This may not be a true reflection as the responders believed that others that conducted their deliveries at home were Doctors and Nurses. This assertion may be wrong as many in this environment address every male that works in the hospital as a doctor and females as Nurses.

Although, most in this study understand that leg swelling in Pregnancy may be a signal to danger. A majority also know that Hypertension can occur in Pregnancy and that a hitherto normal pregnancy may get complicated [17]. Significant factors influencing the choice of where to be delivered include; educational status, previous experiences, satisfaction with the healthcare worker's attitude, religion, lower parity, and delivery positioning (lithotomy) at the Hospital [18-21].

A third was of the opinion that the ANC sets of investigations were not necessary; the relatively low level of education may justify this unhealthy belief. Some believe that once their antenatal care attendance period is uneventful, then they can be safely delivered at home. Probably due to their religion, healthcare worker's attitude, and or dislike for the lithotomy position by some respondents.

\section{References}

[1] World Health Organization, WHO maternal mortality fact sheet 2018 .

[2] Dahal RK. 2013. Factors influencing the choice of place of delivery among women in Eastern rural Nepal. International Journal of Maternal and Child

\section{Conclusions}

Most participants had their deliveries in the hospital, but a significant number (29\%) still delivers at home despite knowing that Hypertension can occur in Pregnancy and that normal Pregnancy can become complicated. Reasons for their decision were due to lack of transportation means, the attitude of healthcare workers, and high cost of hospital deliveries. The major determinant of choice of place of delivery are; educational status, religion, previous experience, the attitude of healthcare workers, and parity.

\section{Recommendations}

1. Efforts should be made to make universal health coverage through the inclusion of every woman of childbearing age in the scheme.

2. Training and retraining of healthcare workers on attitudinal change.

3. Education should be made compulsory up to the secondary school level.

\section{Acknowledgement}

Mr Caleb Eselema Odonye is acknowledged for his assistance in data entering and analysis. All the mothers that participated in this study are also appreciated.

\section{Conflict of Interest}

There is none to be declared.

\section{Funding}

The research was funded by the Dalhatu Araf Specialist Hospital Research Unit.

Health. $\quad 1 \quad$ (2): $\quad 20 \quad-\quad 37$. www.semanticscholar.org/paper/factors-influencingthe-choice-of-place-of-delivery-dahal.

[3] Adegoke A.A, Hofman J.J, Kongnyuy E.J, van den Broek N. 2011. Monitoring and evaluation of skilled Birth Attendance: A proposed new 
framework. Midwifery. 27 (1): 350 - 359 . www.academia.edu/24971185/Adegoke.

[4] Thomson A. The joint WHO/ICM/FIGO statement on skilled attendants at birth. Midwifery 2005; 21(1): 1 - 3 .

[5] Adegoke A.A, Mani S, Abubakar A, van den Broek N. 2013. Capacity building of skilled Birth Attendants: A review of pre-service education curricula. Midwifery. 29 (7): e64 - e72. www.pubmed.ncbi.nlm.nih.gov/23199532/.

[6] Oluwadare T, Adegbilero - Iwari O, Fasoro A.A, Oluwafemi F.S. 2021. Determinants of choice of place of delivery among women of childbearing age in Ido - Ekiti Nigeria. Annals of Romanian Society for Cell Biology. 25 (4): 4554 - 4565. www.researchgate.net/publication352017679.

[7] Abubakar S, Adamu D, Hamza R, Galadima J.B. 2017. Determinants of home delivery among women attending ante-natal care in Bagwai town Kano Nigeria. African Journal of Reproductive Health. 21 (4): 73 - 79. www.ajrh.info/index.php/ajrh/article.

[8] World Health Organization, WHO report on high-rate mortality fact sheet 2017.

[9] Ajayi A.I, Akpan W. 2020. Maternal health care services utilization in the context of 'Abiye' (safe motherhood) programme in Ondo State Nigeria. BMC Public Health. 20 (1): 362 - 370. www.pubmed.ncbi.nlm.nih.gov.

[10] Idris S.H, Gwarzo U.M.D, Shehu A.U. 2006. Determinants of place of delivery among women in a semi-urban settlement in Zaria, Northern Nigeria, Annals of African Medicine. 5 (2): 68 - 72 . www.bioline.org.br/pdf.

[11] Abe E, Omo-Aghoja L.O. 2008. Maternal mortality at the Central Hospital, Benin City, Nigeria: A ten-year review. African Journal of Reproductive Health. 12 (3): 17-26. www.scirp.org. [12] Ewa EE, Lasisi CJ, Maduka SO, Ita AE, Ibor UW and Anjorin OA. 2012. Perceived factors influencing the choice of antenatal care and delivery centers among childbearing women in Ibadan North South-Western, Nigeria. Ethiopian Journal of Environmental Studies and Management. 5 (4): 373 - 383. www.semanticscholar.org/paper.
[13] Reproductive Health resource survey at primary health care level of government facilities FMOH, Abuja; 2002.

[14]Envuladu E.A, Agbo H.A, Lassa S, Kigbu J.H, Zoakah A.I. 2013. Factors determining the choice of a place of delivery among pregnant women in Russia village of Jos North, Nigeria: achieving the MDG s 4 and 5. International Journal of Medicine and Biomedical Research. 2 (1): 23 - 27. www.researchgate.net/publication/269604857-.

[15] Kifle M.M, Kesete H.F, Gaim H.T, Angosom G.S, Araya M.B. 2018. A health facility or home delivery? Factors influencing the choice of delivery place among mothers living in rural communities of Eritrea. Journal of Health, Population, and Nutrition. $37 \quad$ (1): $\quad 22 \quad$ - 36. www.researchgate.net/publication/328431657-.

[16] Broda A, Kruger J, Schinke S, Weber A. 2018. Determinants of choice of delivery place: Testing rational choice theory and habitus theory. $\begin{array}{lllll}\text { Midwifery. } & 63(4): & 33 & - & 38 .\end{array}$ www.daneshyari.com/article/preview.

[17] Kumari B.S, Thompson S. 2016. Choice of Place of Delivery - Home or Hospitals, among mothers of Urban slums of Nalgonda district. Indian Journal of Applied Research. 6 (1): 336 - 338. www.worldwidejournals.com/indian-journal-ofapplied-research(IJAR)/fileview.

[18] Uwiduhaye M, Mung'atu J.K. 2016. Modelling factors influencing the choice of Delivery place at birth among pregnant women in Rwanda using Multinomial logistic method. International Journal of Science and Research. 7 (11): 124 - 129. www.ijsr.net/archive.

[19] Okang C.A, Kaseje D. 2015. The Pull and Push factors influencing of place and delivery attendant in Urban slums of Nyalenda, Kisumu East District, Kenya. International Journal of Humanities and Social Science. 5 (1): 133 - 140. www.ijhssnet.com/journals.

[20] Gebregziabher N.K, Zeray A.Y, Abtew Y.T, Kinfe T.D, Abrha D.T. 2019. Factors determining the choice of place of delivery: an analytical crosssectional study of mothers in Akordet town Eritrea. BMC Public Health. 19 (1): 924 - 934. www.bmcpublichealth.biomedcentral.com/track. 
[21] Nwankwo O.N.O, Ani O.E, Akpoke M, Ugwa E.A. 2019. Determinants of choice of place of delivery among women attending two referrals
Hospitals in Kano North-West Nigeria. Nigeria Medical Journal. 60 (2): 68 - 75 . www.nigeriamedj.com/article. 


\title{
Partner Notification Services (PNS) Among HIV Positive Key Populations: An Important Strategy Towards Achieving UNAIDS 95.95.95 Goals by the Year 2030
}

\author{
Ugbena, Eneojo Richard $^{1 *}$, Egbe, Aneaton ${ }^{1}$, Ikani, Samuel ${ }^{1}$, Okekearu, Ifeanyi ${ }^{1}$ \\ ${ }^{1}$ Society for Family Health, Nigeria
}

\begin{abstract}
Key Populations are the major drivers of the HIV epidemic in most settings; thus, identifying positive KPs and their sexual partners becomes a strong strategy in the effort to achieve the first UNAID 95 goal. This study describes the level of acceptability and outcome of PNS among HIV-positive KPs using the various approaches for PNS. A descriptive study of all HIV positives KPs initiating ART in 7 OneStop-Shop facilities that accepted PNS was conducted over 3 months. With the consent of patients who accepted PNS, their partners were reached using any of the PNS approaches. Partners who consented for HTS were tested, and positives partners were linked to ART services. Data were analyzed to describe the acceptability and outcome of PNS among KPs. Only 846/2,486 (34\%) positive KPs accepted PNS. The 846 KPs elicited 941 partners, out of which 938 (99.6\%) accepted HTS. 421/938 (45\%) of the partners tested positive compared to PWIDF (15\%), MSM (7\%), FSW (4\%) and PWIDM (4\%). 129/421 (31\%) of the positive partners were already known positives, with $61 \%$ already on ART. The commonest method of PNS accepted among KPs was the passive method (54\%), followed by the contract method (22\%), provider-initiated (19\%), and dual method (5\%). There was poor acceptance of PNS among KPs and, the HIV positivity rate was much higher among their partners than any of the KPs sub-groups. The passive approach was the most preferred method of PNS among KPs. This should be considered strongly as we scale up PNS in Nigeria.
\end{abstract}

Keywords: HIV/AIDS, Key Populations in Nigeria, Partner notification services, UNAIDS 95-95-95 targets.

\section{Introduction}

It was estimated that, as at the end of 2015, over 36 million people worldwide had HIV, and of these, $40 \%$ remained undiagnosed [1]. This figure increased to approximately 38 million people in 2019 across the globe, of which only $81 \%$ knew their HIV status [2]. In Nigeria, only $34 \%$ of the adult population knew their HIV status as of 2016 [3]. The majority of the world's new HIV infections occur in resource-poor countries, with two-thirds of the world's HIVinfected population living in Africa [4]. Nigeria has the second-largest HIV epidemic burden in the world, second to South Africa [5]. Although Nigeria HIV prevalence among adults is $1.5 \%$ compared to other sub-Saharan African countries such as South Africa (19\%) and Zambia (11.5\%), the size of Nigeria's population means that about 1.9 million people were living with HIV in 2019 [5]. The country has a mixed epidemic, meaning that while HIV prevalence among the general population is high, certain groups still carry a far greater HIV burden compared to the rest of the population [5]. Also, from previous sentinel surveys, the distribution of HIV across all states is not uniform. While some states have a very high prevalence above the national average, others have very low prevalence compared to the national average [6]. In most countries and settings, Key Populations (KPs) are disproportionately affected by HIV 
infection. KPs are groups that have a high risk and disproportionate burden of HIV in all epidemic settings due to their behavioral patterns and specific legal and social challenges that increase their vulnerability to HIV, including barriers to accessing HIV prevention, treatment, and other health and social services [7]. Key populations include Men who have Sex with Men (MSM), People Who Inject Drugs (PWID), and Brothel Based Female Sex Workers (BBFSW), None Brothel Based Female Sex Workers (NBBFSW), people in prisons and closed settings, and transgender people. In Nigeria, the prevalence of HIV among MSM, BBFSW, NBBFSW and PWID were 23\%, $19.4 \%, 8.6 \%$ and $3.4 \%$ respectively. [8] compared to the national prevalence of 3.0 as at 2014 [6]. These sub-populations; Sex workers, men who have sex with men, and people who inject drugs, make up only $3.4 \%$ of the population, yet account for around $32 \%$ of new HIV infections [5]. The implication is that these sub-populations will continue to drive the epidemic within the country even though there has been a general decline in prevalence among KPs from 2010 to 2014 except for MSM who have shown a consistent increase from $14 \%$ in 2007, $17.2 \%$ in 2010 and $22.9 \%$ in 2014 [9]. Because of stigma and discrimination and the law criminalizing high-risk behaviors among KPs in Nigeria, most KPs do not identify as KPs thus, endangering the general public. KPs continue to drive the HIV epidemic because sexual transmission by KPs is not limited within the groups. Program experience has shown that an MSM may be married to a female partner without the wife knowing that her husband is an MSM. The clients of FSW are from the general population some who are regarded as special boyfriends and usually does not use a condom to prevent HIV transmission.

Similarly, some of the PWID usually get married or are engaged in sex works thus, and they have the dual risk of the method of infection. Besides, because of their sexual orientation, KPs generally have poor health- seeking behavior due to stigma and discrimination at health facilities and in the general public. These practices obviously, fuels the continuous spread of HIV infection among KPs and the general population.

The World has continued to make an effort on the control and elimination of HIV/AIDS. The Joint United Nations Program on HIV and AIDS (UNAIDS) has been the main advocate for accelerated, comprehensive, and coordinated global action on the HIV/AIDS pandemic since 2001 [10]. In 2011, based on achievements made at the time, UNAIDS set a global target of putting 15 million HIV/AIDS patients on treatment by 2015 . The " 15 by 15 " target was adopted at the United Nations High-Level Meeting in 2011, as part of the political declaration on HIV/AIDS: "Intensifying Our Efforts to Eliminate HIV and AIDS" [11]. The target of 15 million people receiving HIV treatment by 2015 was reached nine months early-proof of the global desire and commitment to eliminating the HIV/AIDS epidemic.

The lessons learned in the successful global push to provide antiretroviral therapy to 15 million people by 2015 provided a roadmap for ending the AIDS epidemic as a public health threat. As a central component of the effort to end the epidemic, UNAIDS came up with a new target called UNAIDS 90-90-90 for antiretroviral therapy to be achieved by 2020 [11]. This target is an intermediate goal towards achieving an ambitious goal of reaching 95-9595 by the year 2030 to end the HIV/AIDS epidemic. The 90-90-90 targets imply that by $2020,90 \%$ of all people living with HIV will know their HIV status, $90 \%$ of all people with an HIV diagnosis will receive sustained antiretroviral therapy, and $90 \%$ of all people receiving antiretroviral therapy will achieve viral suppression [11]. These new developments were described as "game changers," adding new tools to a long-established mix of behavioral, biomedical, and structural HIV prevention interventions [12]. According to UNAIDS, if the 
new target could be achieved, the number of new HIV infections will be reduced to under 500000 in 2020 and under 200000 in 2030, thus effectively ending the AIDS epidemic as a public health threat. Compared with a 2010 baseline, these numbers would constitute a $75 \%$ reduction in new HIV infections by 2020 and a $90 \%$ reduction by 2030 [13]. Since they were launched at the 20th International AIDS Conference in Melbourne, Australia, in 2014, the 90-90-90 targets became a central pillar of the global quest to end the AIDS epidemic. The targets reflect a fundamental shift in the world's approach to HIV treatment, moving it away from a focus on the number of people accessing antiretroviral therapy and towards the importance of maximizing viral suppression among people living with HIV [14].

Four years after the launching of UNAIDS 90-90-90, global leaders from civil society, governments, the private sector, and academia came together for a two-day workshop on 21 and 22 July in Amsterdam, Netherlands, to highlight the successes, identify gaps and share best practices in order to reach 90-90-90 [15]. By the end of 2017, the world had achieved 75-79-81, meaning that globally, $75 \%$ of people living with HIV knew their status, $79 \%$ of people living with HIV who knew their status were accessing antiretroviral therapy, and $81 \%$ of people accessing treatment had suppressed viral loads [15].

According to UNAIDS estimates, there were around 36.9 million people living with HIV worldwide in 2017, with around 21.7 million people accessing life-saving medicines that keep people alive and well and stop the transmission of the virus, about 1.8 million new HIV infections occurred while 940000 people died from AIDS-related illness worldwide, compared to 1.9 million in 2004 [16]. However, UNAIDS also estimates that AIDS-related deaths have been reduced by more than $51 \%$ since the peak in 2004, but around one in four people worldwide continue to be unaware that they are living with HIV [16].
Despite the global successes, the evidence presented at a workshop in Amsterdam showed that entire regions and populations are still being left behind. Progress in eastern Europe and central Asia, western and central Africa, and the Middle East and North Africa were falling behind [15]. Data from a variety of sources showed that gaps in the 90-90-90 continuum are greater for key populations, men and young people, [14] because they were not being reached by traditional health facility-based HIV testing services. Lack of political commitment, user fees, and stigma and discrimination were some of the identified barriers to progress [15]. Other barriers are [14]: harmful masculine gender norms which contributed to greater risktaking and poorer uptake of health services among men; consent laws and insufficient access to comprehensive sexuality education which denied young people the services and knowledge they need; Key populations often face criminalization and high levels of stigma and discrimination. Thus, closing gaps in service coverage requires intensified efforts to convince men to reject harmful versions of masculinity and to reach and empower women and girls, young people, and key populations, to enhance their agency and to ensure their human rights are respected and protected. Also, addressing stigma, discrimination, and human rights violations at all levels through the creation of a protective and empowering legal environment and the strong rule of law is imperative for both the AIDS response and the wider 2030 Agenda for Sustainable Development [14].

As of 2019, a review of the progress made on achieving the UNAIDS 90-90-90 goal showed that 14 countries had met the targets [17]. However, in June 2020, the UNAIDS report on the global AIDS epidemic showed that 2020 targets could not be met because of deeply unequal success within and between countries with COVID-19 risks blowing HIV progress way off course [17]. With the 90-90-90 targets unachievable in 2020, the new effort is geared towards doubling our effort towards the 
attainment of the UNAIDS 95-95-95 targets in 2030 using the fast-track approach [18]. The Fast-Track approach is an agenda for quickening the pace of implementation, focus, and change at the global, regional, country, province, district, and city levels. It involves setting ambitious targets and accelerating the delivery of highimpact HIV prevention and treatment services. It means using innovation to expand services, to better address people's needs and perspectives, and focus on the locations and populations with the highest HIV burden. It addresses social and legal barriers and advances human rights and gender equality.

To be able to address the gap in knowledge of HIV status, which is the first target in UNAIDS 95-95-95 goals, will require a new approach that will enhance the efficiency and coverage of HIV testing both in the general population and among KPs. HIV partner notification is an approach that has the potential to improve coverage while also identifying people with undiagnosed HIV infection [1] and one of the most important ways to prevent the spread of HIV [19]. HIV partner notification is a voluntary process where trained health workers, including lay providers, ask people diagnosed with HIV about their sexual partners or drug-injecting partners, and with the consent of the HIV-positive client, offer these partners voluntary HIV testing [1][20]. Usually, the person diagnosed with HIV is encouraged to voluntarily disclose their status and notify their partner(s). Their partner(s) can then be confidentially contacted and offered voluntary HIV testing services, prevention, treatment and care if they test positive [21]. These services will ensure that persons in a sexual network are identified to access HIV services as early as possible, even before the manifestation of the disease. PNS can be offered either actively or passively. While passive notification means that the person diagnosed with the infection voluntarily notify their partner, but in an active notification, the positive patient gives consent to the health care worker to assist in whichever way possible to notify their partner. Once an index case has identified a partner, they should be notified as soon as possible. This will give the partner an opportunity to protect themselves from infection if they don't have HIV or, if they are having sex or sharing needles with others, to take steps to protect or notify those partners [19].

Active or assisted partner notification has been an important public health approach in infectious disease management for decades, including programs targeting sexually transmitted infections (STIs) and tuberculosis (TB) [1]. STI partner notification approaches have been shown to be effective in diagnosing and treating STIs and preventing recurrent infection.

Likewise, active tracing of contacts and the voluntary screening of household members of people with active TB is an effective and standard approach that has been used successfully in communities with high HIV and TB prevalence. In 2012 WHO developed guidance recommending couples and partner HTS, including support for a mutual disclosure, with a special focus on testing the partners of people diagnosed with HIV infection in all epidemiological settings [1]. The benefits of partner and couples HTS have been well documented, including mutual support to access prevention, treatment, and care services, as well as improved adherence and retention in treatment and prevention of mother-to-child transmission programs. Partner testing also allows those in serodiscordant partnerships to prioritize effective HIV prevention, such as the use of condoms, immediate antiretroviral therapy (ART), medication adherence by HIVpositive partners, and pre-exposure prophylaxis (PrEP) for HIV-negative partners.

Because the sexual partners of HIV positive individuals have an increased probability of also being HIV positive if they continue to have sex without taking any of the prevention measures, it, therefore, become a very important for partners of positive KPs to know their HIV status and take appropriate measures depending on whether they turn out positive or negative. This 
implies that at the point of diagnoses or when the KP knows their HIV-positive status, they must have the opportunity to identify their partners who are likely to be at risk of contracting the infection from them. However, partner testing services, including partner notification, for people diagnosed with HIV have not been routinely offered or implemented; therefore, uptake and coverage remain low [1]. For KPs who are drivers of the epidemics in all settings, it is important to offer PNS to all positives KPs in order to elicit all their sexual partners who are at risk of contracting HIV infection.

This process will help to identify HIV positives cases among persons in the sexual network early enough and put them on treatment. Previous studies [22, 23, 24] have shown that the early HIV-positive persons are identified, linked to treatment, and retained on treatment, the earlier they will achieve viral load suppression and, thus, reduced rate of transmission to uninfected persons. This is the idea behind the UNAIDS 95-95-95 goals that if $95 \%$ of persons who are infected know their HIV status, 95\% of those who know their HIV status are linked and retained on treatment and, if $95 \%$ of those retained on treatment achieve viral load suppression by 2030 then, HIV/AIDs epidemic would have been controlled. The PNS among KPs remains very relevant as a recent report by UNAIDS in 2020 showed that there is unequal progress in the fight against HIV/AIDS, with too many vulnerable people and sub-populations as KPs are left behind.

A study has described that about $62 \%$ of new HIV infections occurred among key populations and their sexual partners, including gay men and other men who have sex with men, sex workers, people who inject drugs, and people in prison, despite them constituting a very small proportion of the general population [17]. Therefore, it is very important to implore any strategy like PNS among HIV positives KPs to be able to identify their partners who are positive and link them to treat to be able to achieve viral suppression and limit further transmission.
The object of this study was to describe the level of acceptability and outcome of PNS among HIV positive KPs using the various approaches for PNS services and to describe the proportion of HIV positive KPs who accepted partner notification services after diagnosis. This work also defines the various methods of partner notification services used to reach the partners of Key Population and describe the proportion of KPs partners who accepted HIV testing after notification. This study is to determine the HIV prevalence among partners of KPs who consented and tested for HIV.

\section{Methodology}

\section{Study Area}

This study was carried out across 7 states supported by SHiPS for the MARPS project in Nigeria.

In each of the states, the project established a One-Stop-Shop facility to provide HIV prevention, treatment, and care services for Key Populations and their partners. Other services provided at the sites include partners notification services, syndromic management of STIs, and cervical cancer screening.

\section{Study Design}

This was a descriptive study using routine program data. All HIV-positive KPs accessing services in the 7 One-Stop-Shop facilities were offered PNS during enrollment into a treatment program.

Those who consented chose one of the approaches of partner notification services, and effort was made by the project to reach their partners. Consent was obtained from the partners who were not previously known positives to take HIV screening, and all partners who tested positives were linked to treatment services.

\section{Sampling Technique}

There was no sampling of participants, but all HIV positives KPs identified at the 7 OSS across the 7 states during the period of study were offered PNS. KPs who consented for PNS were 
enrolled and were asked to provide the list of their partners to be notified. The participants also agreed with the health care providers on the best approach to reach their partners. Voluntary counselling and testing for HIV was provided to partners who were notified and accepted HIV testing.

\section{Data Collection Methods}

A partner notification services register (a PEPPFAR tool) was used to capture data on participants, their partners, and the outcome of HIV testing among partners as part of routine program services. Data was abstracted from the routine service register by the facility record clerk who was trained on data abstraction for the study.

\section{Ethical Consideration}

Only participants who accepted PNS were enrolled for the study, and participant's records were identified using PNS unique identification number. The researcher did not meet the participants in person neither was their names or location included in the data abstracted. Only partners who consented for HIV testing after notification were provided voluntary counselling and testing and provided results. There was no disclosure of the participant who enlisted a partner and verse versa, and neither was there a disclosure of the outcome of the testing result of the partner to the participants who enlisted them except if there was consent to do so.

\section{Study Limitation}

The study did not elicit reasons why clients declined PNS. With the low acceptance rate of PNS, it is important to know various reasons why clients did not accept PNS. This is important for the program to be able to strategize on improving the acceptance rate. Also, there was no data to show which of the KP sub-group has the highest PNS acceptance rate, what method of PNS was mostly preferred by subpopulations of KP, and the group that has the highest positivity rate among their partners. Further study should include these finer analyses to provide more information to guide programming.

\section{Results}

Table 1. PNS Cascade Among Participants

\begin{tabular}{|l|l|l|}
\hline PNS cascade & Number & Percent \\
\hline Number of KPs enrolled into the program during the period & 47668 & \\
\hline Number of KPs who received HIV counselling and testing & 47668 & $100 \%$ \\
\hline Number of KP who tested positive & 2486 & $5 \%$ \\
\hline Number of HIV positive KPs who accepted PNS & 846 & $34 \%$ \\
\hline Number of Partners elicited by HIV positive KPs & 941 & \\
\hline Number of partners notified and tested for HIV & 938 & $99.60 \%$ \\
\hline Number of KPs partners who tested HIV positive & 421 & $45 \%$ \\
\hline
\end{tabular}

Out of 47,668 KPs tested during the period, 2,486 (5\%) tested HIV positive, with only 846 (34\%) accepting PNS. The 846 positive KPs elicited 941 partners, out of which 938 (99.6\%) were notified and accepted HIV counselling and testing. Four hundred and twenty-one (45\%) of the partners who tested for HIV were positive for the virus. 
Table 2. Sex and HIV Prevalence among Participants

\begin{tabular}{|l|l|l|l|l|}
\hline Sex & Number tested & $\boldsymbol{\%}$ & Number pos & Prevalence \\
\hline Male & 9534 & 20 & 895 & $9.3 \%$ \\
\hline Female & 38134 & 80 & 1591 & $4.1 \%$ \\
\hline Total & 47668 & 100 & 2486 & \\
\hline
\end{tabular}

Twenty percent of the participants were male, which included MSM, PWIDM, and male partners, while the remaining $80 \%$ were female, made up of FSW, PWIDF, and female partners. HIV positivity rate was higher among males 9.3\% than among females $4.1 \%$.

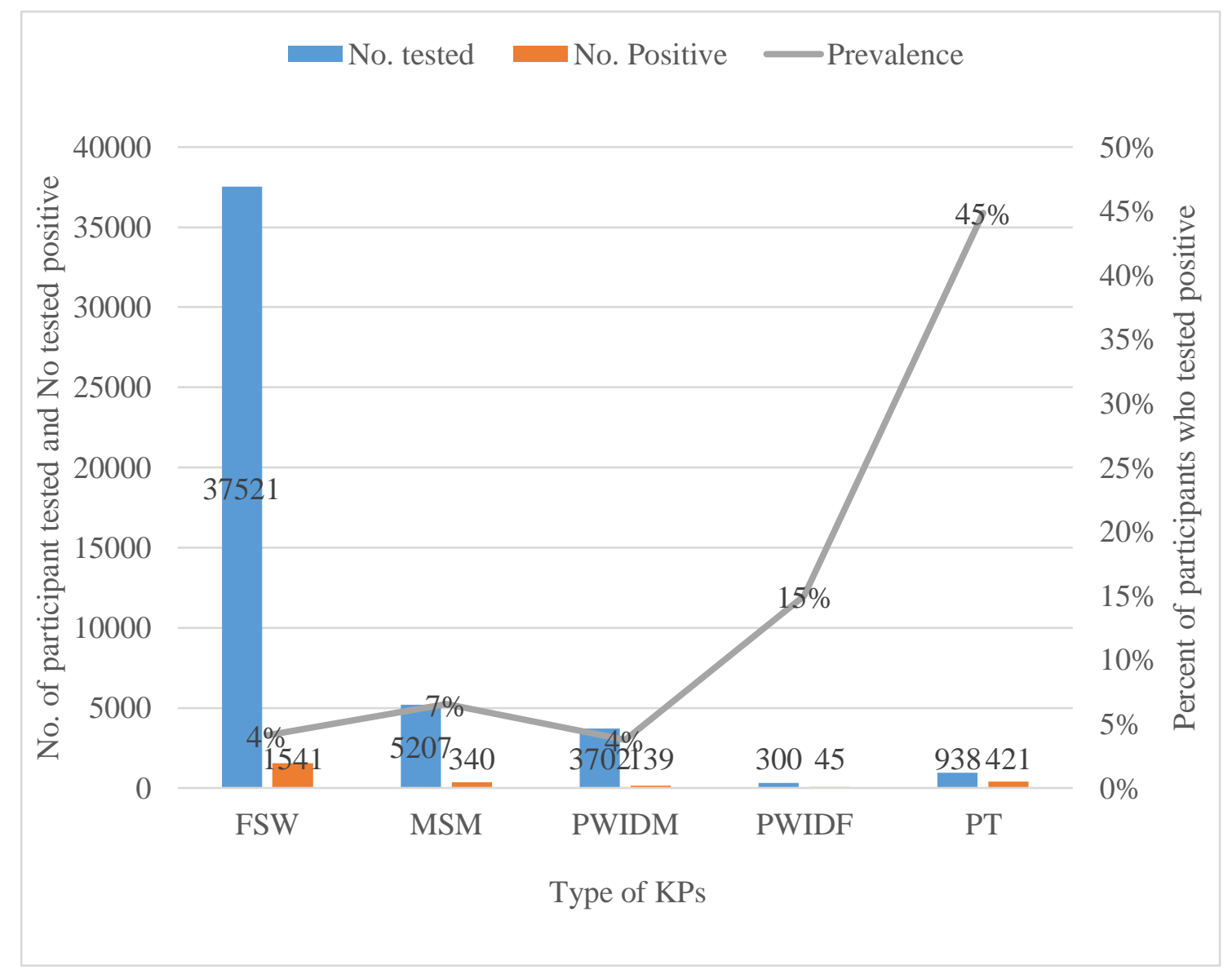

Figure 1. HIV Prevalence among KPs and their Partners 


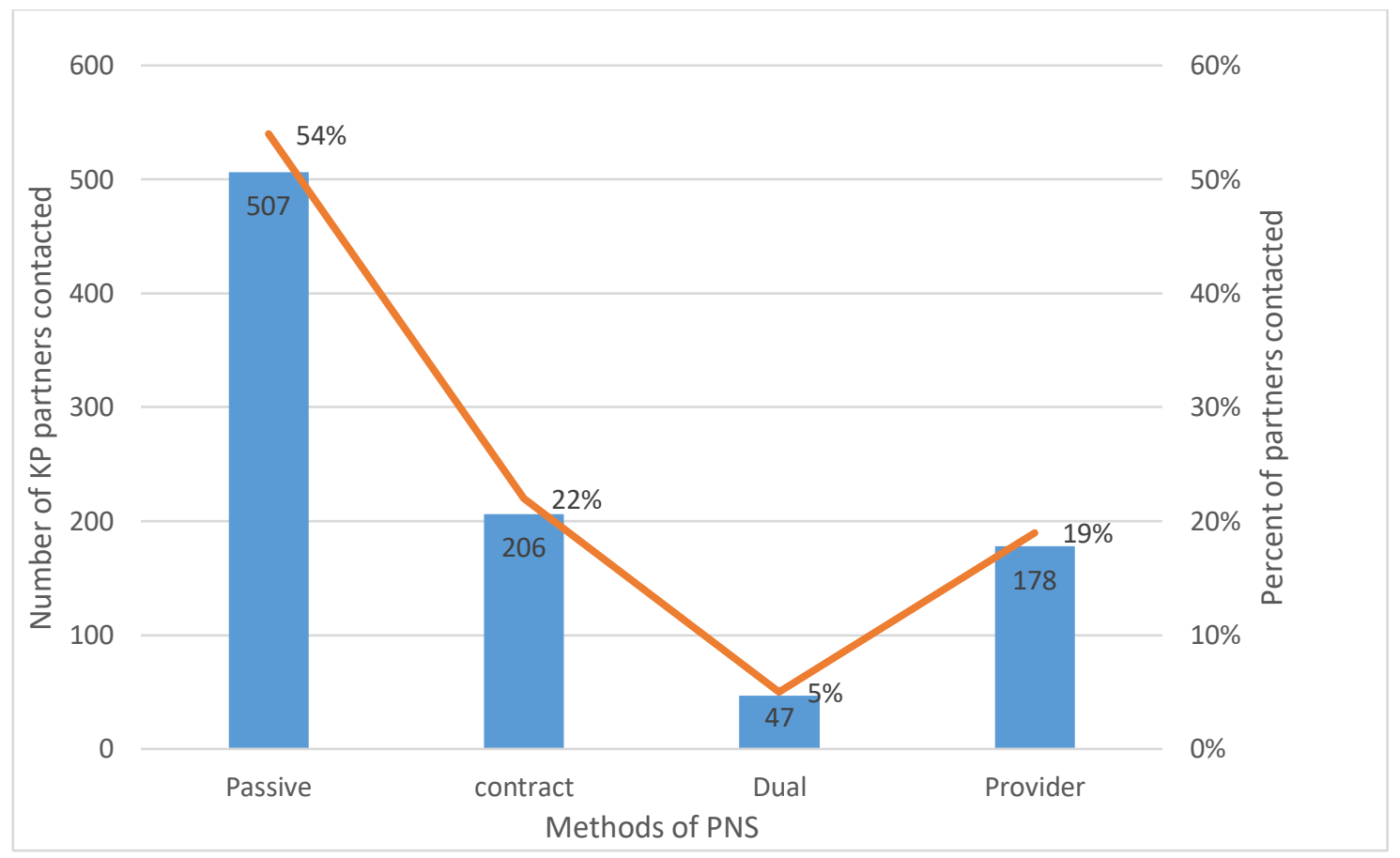

Figure 2. Methods of Partner Notification Services

The commonest method of partner followed by contract method (22\%), providernotification accepted by KPs was a passive initiated (19\%), and dual method was the least method which accounted for $54 \%$ of cases, method (5\%).

Table 3. HIV Positive Partners of KPs and Status of ART Services at the Time of Partner Notification and Testing

\begin{tabular}{|l|l|l|l|}
\hline \multicolumn{4}{|l|}{ ART status } \\
\hline HIV status & On ART (\%) & Not on ART (\%) & Total (\%) \\
\hline Known Positive & $77(61 \%)$ & $52(39 \%)$ & $129(31 \%)$ \\
\hline New positive & $0(0 \%)$ & $292(100 \%)$ & $292(69 \%)$ \\
\hline Total & $77(18 \%)$ & $344(82 \%)$ & $421(100 \%)$ \\
\hline
\end{tabular}

Out of the 421 partners who tested positive, $129(31 \%)$ were previously known positive, while 292 (69\%) were new positive cases identified. Of the 129 who were already known positives, $61 \%$ were already on ART, while the remaining $39 \%$ are ART naïve and were linked to ART services. Overall, $82 \%$ of HIV positive clients identified needed to be linked to HIV care and treatment services.

\section{Discussion}

The acceptance of HIV testing among the general population in Nigeria was $76 \%$ [25], while it varies among KPs: PWID 54\%, MSM
65\%, and FSW 88\% [8]. However, in an organized program such as provider-initiated counselling and testing, previous studies have demonstrated a higher acceptance rate of $94 \%$ [26] and $98.7 \%$ in Nigeria [27]. Similarly, on this project, "strengthening HIV prevention services for Most at Risk Populations where HIV counselling and testing is part of the intervention, $100 \%$ of the participants accepted testing, and those who tested positive were linked to treatment services.

Although Nigeria has a generalized HIV epidemic, the spread is not the same across all 
the regions, states, and even within the same state. The NAIIS survey reported a national prevalence of $1.4 \%$, with the prevalence generally higher among females than males and more among the youth than older adults [28]. This new report shows a lower burden of HIV infection in the country compared to previous surveys that reported prevalence of 3\% [6]. Also, previous surveys among Key Populations have shown varied burdens with MSM having the highest prevalence of $23 \%$, BBFSW $19.4 \%$, NBBFSW 8.6\%, and PWID 3.4\% [8] compared to the finding in this study which shows a prevalence of $7 \%$ for MSM, $4 \%$ for FSW, PWID male $4 \%$, and PIWD female $15 \%$. The higher prevalence reported by the survey may be related to the methodology for recruiting participants, which used snow-ball sampling and financial inducement for the index case based on the number of participants recruited by an index case. The snow-ball method and financial benefit to index case have the tendency for a positive KP to recruit another positive $\mathrm{KP}$ compared to the project intervention, which enrolled participants by visiting the location of KPs and testing all who consented. Besides, the project also delivered HIV prevention services for cohorts of KPs within the communities as part of the intervention strategy, which raised awareness on HIV prevention among the KPs, resulting in lower prevalence among the intervention group. The higher prevalence among PWID females than PWID males may be due to the dual risk of infection among PWID females who are mainly FSW with multiple sexual partners and sharing unsterilized needles with fellow drug users. Also, since most of the PWID females are FSW, the effect of drug use increased their vulnerability to high sexual risk behavior. The overall prevalence of 5\% among KPs in this study compared to $1.4 \%$ [28] among the general population implies that Key Populations will continue to drive the epidemic since their sexual network cut across both Key Populations and the general populations. For the world to meet up with the UNAIDS 95-95-95 goals requires that most infected persons must be identified, linked, and retained on treatment to be able to achieve viral suppression and the ultimate benefit of a reduced new infection. A very significant finding in this study is the 421/938 (45\%) HIV prevalence among partners of KPs who consented, tested for HIV, and received their test results. Similar intervention among the general population in Nigeria. [29] reported a prevalence of $51 \%$. Various rates have also been reported for other countries, demonstrating a very high positive yield from PNS. Out of the 421 positives identified, $77(18 \%)$ were known positives already on ART, while the remaining $82 \%$ were either newly identified cases or old cases that were not linked to ART services. The finding from this study has demonstrated that HIV-positive case finding using PNS services among KPs is very effective in reaching sexual networks of the drivers of the epidemic in a country where sexual transmission is the major mode of spreading the disease. Without PNS services, the 344/421 (82\%) new positives cases will be left in the community and may continue to spread the infection. Overall, PNS is a necessary strategy that we must use for both the general population and Key Populations if we must achieve UNAIDS first "95" of the 9595-95 goals.

An important concern found in the study is the PNS acceptance rate by HIV-positive KPs. Only $34 \%$ of the positive cases accepted that their partners should be notified of their risk for acquiring HIV through them. This is one of the challenges earlier described by a study [30] amongst KPs who were less able or willing to identify partners. Although this also occurred among the general population, particularly among people with casual partners, recall of and contact information for partners was better among heterosexual women than among men who have sex with men or people who inject drugs [30]. Such a low acceptance rate will translate to a missed opportunity for a high 
positive yield that has been described for PNS. It is imperative that programs will need to do more to be able to overcome such challenges in order to reap the benefit of PNS. However, it was quite impressive to see that almost all partners (99.6\%) who were notified consented for HIV testing and were tested and received their test result with a $45 \%$ positivity rate. A much higher $72 \%$ positivity rate has been reported among partners of HIV-positive pregnant women, while among PWID and MSM, the rates vary from 5$80 \%$ [30]. This high positivity rate among sexual partners implies that transmission is largely through sexual networking.

In this study, the HIV prevalence among male participants is $9.3 \%$ higher than $4.1 \%$ among females, even though in the general population, the prevalence is higher among females than males. This may be due to the high prevalence among MSM partners, and besides, most partners of FSW are male, resulting to a larger pool of males tested among the partners of KPs. Particularly at a point when an effort is being made to get more men for testing, PNS has shown how testing and positivity yield can be improved among men.

The most acceptable method of partner notification services in this study is the passive method, where the positive index cases are expected to notify their partner themselves of their HIV positive status and to encourage their partners to take HIV tests to determine their own status. This is contrary to most studies in [30], where assisted/provider-initiated method is preferred. However, a study in Tanzania [30] has reported a high rate $(93 \%)$ of acceptance of passive notification among participants overassisted methods. Similarly, in a study among FSW in Guatemala, $85 \%$ of the women preferred passive notification over letter or phone call by a health provider [30]. In a study in the US among MSM, assisted PNS was preferred because they believe that it protected against blame, violence, and stigma. In Singapore, men who have sex with men preferred email for partner notification significantly more than did heterosexual respondents. The choice of passive method over the contract and provider-initiated methods may be related to the fear that their partner may not be comfortable with the presence of the third party during the notification process. Although more success rate has been reported through the provider-initiated method in other settings, the higher acceptance rate of 54\% among partners using the passive method in this study has also demonstrated that the passive method may be preferred by the KP subpopulations perhaps due to high level of stigmatization, discrimination, and criminalization of KPs in the country. Also, the higher acceptance rate of $46 \%$ for assisted PNS implies that no one method is preferred. Thus, various options of PNS should be provided to any client in order to improve the acceptance rate among index cases.

\section{Conclusion}

Acceptance of PNS among KPs is very low, but the prevalence of HIV is much higher among partners who were identified and tested than the KPs sub-groups.

Most KPs preferred a passive approach to notify their partners of their HIV positive status and then encourage them to determine their own status.

For an effective HIV control in 2030 as recommended by UNAIDS, targeted testing through PNS is key to identifying a lot of HIV positives individual who will be missed if HIV interventions target only people who identifies as KPs. The low acceptance of PNS among KPs is a challenge for HIV intervention. More evidence is required to identify an innovative way to reach partners of HIV positives KPs, encourage them to determine their HIV status, and take necessary steps for HIV prevention, treatment, or care services as may be necessary.

\section{Recommendation}

1. As we scale up PNS in Nigeria, this study has shown that passive referral is the most 
acceptable approach among KPs, and this should be considered strongly in programming PNS among KPs.

2. Only $34 \%$ of the KPs accepted PNS. There is the need for strong counselling at the point when PNS is offered to stress the benefit of PNS. This is likely to improve PNS uptake among KPs.

3. There is a need for policy formulation that will create enable environment for PNS activities. Law enforcement agents and legal practitioners should not treat issues of PNS as a crime.

4. Because both passive and assisted methods of PNS are highly rated in this study, any index case should be allowed to choose any of the methods he or she deem appropriate for each partner.

5. One limitation of this study is that there is no data to show which of the KP sub-group has the highest acceptance of PNS and the subgroup that has the highest positivity rate

\section{References}

[1] World Health Organization Geneva (2016). Guidelines on HIV Self-Testing and Partner Notification: Supplement to Consolidated Guidelines on HIV Testing Services: World Health Organization; 2016 Dec. 3, Available from: https://www.ncbi.nlm.nih.gov/books/NBK401676/.

[2] The Global HIV epidemics (2019). Available at https://www.hiv.gov/hiv-basics/overview/data-andtrends/global-statistics.

[3] Averts (2020). HIV and AIDS in Nigeria. Available at https://www.avert.org/professionals/hivaround-world/sub-saharan-africa/nigeria.

[4] Jennifer L. Weinberg and Carrie L. Kovarik MD. (2010). The WHO Clinical Staging System for HIV/AIDS, American Medical Association Journal Ethics, Volume 12, Number 3: 202-206.

[5] Averts (2020). HIV and AIDS in Nigeria. Available at https://www.avert.org/professionals/hivaround-world/sub-saharan-africa/nigeria. among their partners. Further study should include this finer analysis to guide programing.

\section{Acknowledgement}

The authors acknowledge the Key Populations members who participated in the study and the OSS staff for the incredible work and dedication to duty that ensured accurate data was abstracted for the study. None of the authors has any conflict of interest to declare.

\section{Funding}

The SHIPS for MARPS project were funded by USAID through President's Emergency Funds for AIDS Relief (PEPFAR) and implemented by Society for Family Health, Nigeria.

\section{Conflict of interest}

There authors have declared that there is no conflict of interest in carrying out this study.

[6] Federal Ministry of Health Nigeria (2015). HIV Sero-prevalence among pregnant women in sentinel antenatal clinics by states: Available at http://www.sfhnigeria.org/wpcontent/uploads/2018/05/National-Strategic-framework-Final-28th-May-2018.pdf.

[7] World Health Organization (2014); Consolidated guidelines on HIV prevention, diagnosis, treatment, and care for key populations. Available at http://apps.who.int/iris/bitstream/10665/128048/1/97 89241507431_eng.pdf?ua=1\&ua=1.

[8] Federal Ministry of Health Nigeria (2015). Integrated Biological and Behavioural Sentinel Survey (IBBSS 2014). Available at https://naca.gov.ng/wpcontent/uploads/2016/11/Final-Nigeria-IBBSS-

2014-report.pdf.

[9] Eluwa, G.I., Adebajo, S.B., Eluwa, T. et al. (2019). Rising HIV prevalence among men who have sex with men in Nigeria: a trend analysis. $B M C$ 
Public Health 19, $1201 \quad$ (2019). https://doi.org/10.1186/s12889-019-7540-4.

[10] UNAIDS (2012). UNAIDS report on the global AIDS epidemic. Available at http://www.unaids.org/sites/default/files/media_asse t/20121120_UNAIDS_Global_Report_2012_with_a nnexes_en_1.pdf.

[11]UNAIDS press release (2015). Success in reaching 15 by 15 shows that we can end the AIDS epidemic available at http://www.unaids.org/en/resources/pressce ntre/pressreleaseandstatementarchive/2015/ july/20150719_15x15_PR.

[12] Graham B, Daniel R, Gary WD, Jeanne E, Marina C, Natalie H, Jack W (2015). Investigating combination HIV prevention: isolated interventions or complex system JIAS open access. https://doi.org/10.7448/IAS.18.1.20499.

[13] UNAIDS (2015). Fast-tracking combination prevention towards reducing new HIV infection to fewer than 500,000 by 2020. http://www.unaids.org/sites/default/files/media_asse t/20151019_JC2766_Fasttracking_combination_prevention.pdf.

[14] UNAIDS (2017). Ending AIDS, progress towards the 90-90-90 targets. Available at http://www.unaids.org/sites/default/files/media_asse t/Global_AIDS_update_2017_en.pdf.

[15] UNAIDS (2018). Accelerating towards 90-9090. Available

at

http://www.unaids.org/en/resources/presscentre/feat urestories/2018/july/90-90-90-targets-workshop.

[16] UNAIDS (2018). 90-90-90 treatment target. Available at http://www.unaids.org/en/90-90-90.

[17] UNAIDS (2020): Press Release. Available at https://www.unaids.org/en/resources/presscentre/pre ssreleaseandstatementarchive/2020/july/20200706_g lobal-aids-report.

[18] UNAIDS (2015). Understanding fast-track, accelerating action to ends AIDS epidemic by 2030 . https://www.unaids.org/sites/default/files/media_ass et/201506_JC2743_Understanding_FastTrack_en.pd f.

[19] Sexual Partners, Partner Counseling and Referral Services (PCRS). Available at https://www.aids.gov/hiv-aids-basics/justdiagnosed-with-hiv-aids/talking-about-yourstatus/sexual-partners/.

[20] WHO; Call for case studies of HIV partner notification programmes. Available at http://www.who.int/hiv/mediacentre/news/hivpartner-notification/en/.

[21] WHO; Call for case studies of HIV partner notification programmes, http://www.who.int/hiv/mediacentre/news/hivpartner-notification/en/.

[22] Schneider G, Juday T, Wentworth C 3rd, Lanes S, Hebden T, Seekins D.(2013); Impact of health care payer type on HIV stage of illness at the time of initiation of antiretroviral therapy in the USA. AIDS Care. 2013;25(11):1470-6. DOI: 10.1080/09540121.2013.774316.

[23] Siegfried N, Uthman OA, Rutherford GW. (2017); Optimal time for initiation of antiretroviral therapy in asymptomatic, HIV-infected, treatmentnaive adults. Cochrane Database Syst Rev. 2010 March 17;(3): $\quad$ CD008272. DOI: 10.1002/14651858.CD008272.pub2, https://www.ncbi.nlms.nih.gov/pubmed/20238364. [24] Jennifer L. Weinberg and Carrie L. Kovarik, MD (2010); The WHO Clinical Staging System for HIV/AIDS, American Medical Association Journal Ethics, Volume 12, Number 3: 202-206.

[25]Federal Ministry of Health Abuja (2013). National HIV\&AIDS and Reproductive Health Survey (NARHS plus 2012). Available at https://naca.gov.ng/narhs-plus-2012-final/.

[26] Felix A. Ogbo, Andrew Mogaji, Pascal Ogeleka, Kingsley E. Agho, John Idoko, Terver Zua Tule, and Andrew (2017) Assessment of provider-initiated HIV screening in Nigeria with sub-Saharan African comparison. BMC Health Serv Res. 2017; 17: 188. DOI: 10.1186/s12913-017-2132-4.

[27] Adaora Adeline Okechukwu, Eno Ekop, Chinwendu Daniel Ndukwe, Kudirat Eyinade Olateju (2016). Acceptance of provider-initiated testing and counseling for HIV infection by caregivers in a tertiary health institution in Abuja, Nigeria: a crosssectional study. The Pan African Medical Journal. 2016;24:245. Doi:10.11604/pamj.2016.24.245.9057. 
[28] Nigerian HIV/AIDS Indicator and Impact Survey (2018); Technical Report.

[29] Moses Katbi, Adeoye Adegboye, Adefisayo Adedoyin, Fadimatu Yunusa, Gbenga Kayode, Maryam Bello, Patrick Dakum (2018). Effect of clients Strategic Index Case Testing on communitybased detection of HIV infections (STRICT study). International Journal of Infectious Diseases 74 (2018)
54-60.

DOI: https://doi.org/10.1016/j.ijid.2018.06.018.

[30] World Health Organization (2016): Guidelines on HIV Self-Testing and Partner Notification: Supplement to Consolidated Guidelines on HIV Testing Services. Accessed on October 2020 https://www.ncbi.nlm.nih.gov/books/NBK401684/. 


\title{
Health Seeking Behaviour among Past and Current Tuberculosis Patients in a Low-Income Country
}

\author{
Gokul Mishra ${ }^{1}$, Tom Wingfield ${ }^{2}$, Sharad Kumar Sharma ${ }^{3}$ \\ ${ }^{1}$ PhD in Public Health Student, Texila American University, Guyana \\ ${ }^{2}$ Social Medicine, Infectious Diseases, and Migration (SIM) Group, Department of Global \\ Public Health Sciences, Karolinska Institutet, Stockholm, Sweden, Tropical and Infectious \\ Disease Unit, Liverpool University Hospitals NHS Foundation Trust, Liverpool, UK \\ ${ }^{3}$ National Tuberculosis Control Centre, Nayathimi, Bhaktapur Nepal
}

\begin{abstract}
In Nepal, the estimated incident cases are 0.07 million, of them, 0.03 million people are diagnosed and enrolled in the treatment annually, and numbers of undiagnosed people living with tuberculosis (TB) might be a threat to achieving END TB strategy targets. Understanding health-seeking behaviour and care pathways is crucial to reducing missed cases and decreasing TB transmission. The objective of the study was to identify the health-seeking behavior of TB patients and understand the reasons behind TB diagnostic and treatment delays in Nepal. This was a cross-sectional, population-based survey carried out in 99 clusters of 55 districts (total of 77) of Nepal. Primary Sampling Units were Village Development Committees or Municipalities and wards selected using systematic proportional to population size method. Of the total 54,200 people who attended in the survey, 1,825 had a history of TB and asked their health-seeking practice. $62 \%$ and $72 \%$ of the TB patients utilised the government health facilities for diagnosis and treatment. $18 \%$ of the TB patients said that they received diagnosis services, and $16 \%$ of patients took their treatment from outside of the country, especially India, due to fear of stigma and easy access to the services. The majority of the TB patients utilised government health facilities to receive diagnosis and treatment services. Some of the participants sought TB services from private health care providers, and a significant proportion of participants received them from India due to difficulty in accessing local services and fear of stigma and discrimination.
\end{abstract}

Keywords: Community Based Directly Observed Treatment, Health Seeking Behaviour, Prevalence Survey, Tuberculosis.

\section{Introduction}

Tuberculosis (TB) is the leading infectious diseases killer and a significant public health challenge worldwide. Globally, an estimated 10 million people developed TB disease in 2019, of whom approximately 3 million were not diagnosed, treated, or notified to national tuberculosis programs (NTPs). Of the remaining 7 million, many experienced substantial delays in accessing and receiving appropriate diagnosis and care. This unacceptable situation leads to unnecessary disability and loss of life and impedes tuberculosis control because of the onward transmission of TB at both household and community levels. To rectify these shortcomings and eliminate tuberculosis, new strategies are urgently required to find the missing cases, enhance tuberculosis case notification rates, and support people with TB to access quality care and become cured [1].

Tuberculosis (TB) remains a public health threat in Nepal and is responsible for the illhealth of thousands of people annually. In 2019, the estimated TB prevalence of Nepal was 215 TB cases per 100,000 population and incidence 
of $151 / 100,000$. These estimations are based on calculations by the World Health Organisation (WHO), which are informed by expert opinions, tuberculin skin test surveys, and trends in TB case notification imply that rates of $\mathrm{TB}$ have been static in Nepal since 2015. TB also ranks as the leading cause of death $(20 / 100,000$ population) in the country in 2019 as well.

There were 32,043 TB cases (all forms of TB) registered with the National TB Program of Nepal (NTP) in 2018/19, which includes 31,397 were incident $\mathrm{TB}$ cases (new and relapse). Among the NTP-registered cases at NTP, 37\% were female and $63 \%$ male. The national case notification rate (all forms of TB) was $109 /$ 100,000 population in 2019 [2].

There are multiple interlinked risk factors associated with TB exposure, infection, and progression to TB disease, which may explain the reasons behind this trend. First, exposure to TB (e.g., the number of viable TB bacilli to which an individual is exposed) and transmission rates are influenced by proximity to and duration of exposure to asymptomatic individuals with pulmonary TB and the amount of TB that individual is producing. Thus, transmission can be affected by the extent of pulmonary TB disease, duration, and frequency of cough, poor cough hygiene or self-isolation measures, overcrowded living circumstances (e.g., due to poverty, incarceration, shared accommodation), occupation (e.g., high-risk jobs such as mining and healthcare), or belonging to an underserved group (e.g., indigenous or homeless populations). Second, many other individual-level risk factors influence the likelihood of acquiring $\mathrm{TB}$ infection and the development of TB disease. Such risk factors include human immunodeficiency virus (HIV), poverty, malnutrition, chronic renal impairment, and diabetes, extremes of age, excess alcohol consumption, and smoking, and indoor air pollution. Barriers to accessing TB diagnostic and care services can influence $\mathrm{TB}$ rates by leading to more severe clinical disease, which in turn increases the likelihood of onward transmission of TB disease in the community [3]. Moreover, stigma and discrimination related to TB illness, especially in areas with high HIV and/or poverty prevalence, can lead to a reluctance to disclose $\mathrm{TB}$ status and seek TB diagnosis and care [4]. Without understanding and addressing these individual, household, and health systems-level risk factors for TB disease, TB control strategies, whether at a national or international level it will be difficult to eliminate TB.

The objective of the study was to identify the health-seeking behavior of TB patients to better understand the reasons behind TB diagnostic and treatment delay in Nepal and thereby inform national policy and contribute to the National Strategic Plan to eliminate TB in Nepal. It is expected that outputs from the study will include the development of a plan to reduce diagnosis and treatment delays through improved access to care, education to the patients, engagement of informal care providers (like traditional healers), strengthening private health care providers in TB program, and potentially contributing to design of socio-economic interventions to address the biosocial aspects of TB.

\section{Methods and Material}

National Tuberculosis Programme adopted the Tuberculosis Prevalence Survey-A handbook published by WHO to design the survey in Nepal [5]. This was a cross-sectional, population-based survey carried out in 99 clusters of 55 districts (total of 77) of Nepal. Primary Sampling Units (PSUs) were village development committees (VDC) or municipalities and wards (smallest administrative unit of the country) selected using the systematic PPS (proportional to population size) method, and within the wards, a social map was drawn of all block and households in the study sites, and 200 households were selected randomly and ensured in average 600 family members above the age 15 years in each cluster. Before organising the TB screening camps, the 
census was done at the selected households. There were 93,085 people enumerated, of whom $58,956(63 \%)$ were eligible, and they were invited to participate in the survey. Out of them, $54,200(92 \%)$ took part in the survey. Of them, 53,622 (onsite) participants were screened by both Xray and symptom screening questionnaire and 578 off-site participants were screened by only symptom screening questionnaire; out of them, 15,212 (28\%) screened participants had symptoms and radiological abnormalities and were recommended for sputum examination, of them, 1,934 (13\%) had cough 2 weeks or more, 414 (3\%) had hemoptysis, and 2,882 (19\%) had less than two weeks cough reported symptoms and 9,780 (65\%) had radiological abnormalities compatible with TB. Out of eligible participants for the sputum test, 15,011 participants submitted their sputum samples for Xpert MTB/RIF and smear testing through fluorescence microscope, and half of them submitted one more morning sample for molecular testing (Culture). Selected socioeconomic and demographic characteristics were examined using multiple logistic regression analysis because all the four outcome measures were dichotomous, and other relevant indicators were analyzed in frequency and percentage distribution.

\section{Results}

Out of the total participants who attended the survey, 1,825 (3\%) people had a history of tuberculosis. Table 1 gives a detailed overview of the prevalent TB disease seen in all the age groups, sex, terrain, ethnicity, education level, occupation, and wealth groups, indicating that tuberculosis is all over the country and any social dimensions. Age category wise, the participant's age over 65 years and above had a TB 6 times higher than the age group of 15-24 years, followed by nearly 3 times higher among the male participants, $4 \%$ in Kathmandu valley, $4 \%$ in Muslim around 5\%, education-wise, participants who had no education, suffered from the disease more, followed by unskilled manual workers and 3.5\% reach people got tuberculosis. The likelihood test results also show that TB is likely to be common in every social characteristic and all over the country.

Table 1. Socio-demographic Characteristics of the Participants, Percentage of Disease Presented, and the Likelihood of TB History and Adjusted Odd Ratio (aOR) of the People Living with the Disease

\begin{tabular}{|c|c|c|c|c|c|}
\hline \multirow[t]{2}{*}{ Variable } & \multicolumn{2}{|c|}{ Tuberculosis } & \multirow[t]{2}{*}{$\%$ Of Yes } & \multicolumn{2}{|c|}{ Logistic Regression } \\
\hline & No & Yes & & OR & $95 \% \mathrm{CI}$ \\
\hline \multicolumn{6}{|l|}{ Age $(\mathrm{N}=54,200)$} \\
\hline $15-24$ & 14147 & 172 & 1.2 & & \\
\hline $25-34$ & 10795 & 220 & 2.0 & 1.597 & $(1.265-2.015)$ \\
\hline $35-44$ & 9132 & 321 & 3.4 & 2.594 & $(2.068-3.252)$ \\
\hline $45-54$ & 7360 & 339 & 4.4 & 3.247 & $(2.582-4.084)$ \\
\hline $55-64$ & 5567 & 355 & 6.0 & 4.601 & $(3.645-5.807)$ \\
\hline $65+$ & 5381 & 411 & 7.1 & 5.466 & $(4.312-6.928)$ \\
\hline \multicolumn{6}{|l|}{ Gender $(N=54,200)$} \\
\hline Male & 21851 & 1126 & 4.9 & & \\
\hline Female & 30536 & 687 & 2.2 & 0.517 & $(0.453-0.590)$ \\
\hline \multicolumn{6}{|l|}{ Terrain $(\mathrm{N}=54,200)$} \\
\hline Mountain & 4605 & 108 & 2.3 & & \\
\hline Hill & 17309 & 499 & 2.8 & 1.317 & $(1.065-1.628)$ \\
\hline Terai & 25250 & 997 & 3.8 & 1.864 & $(1.512-2.298)$ \\
\hline Kathmandu Valley & 5209 & 223 & 4.1 & 2.190 & $(1.708-2.809)$ \\
\hline
\end{tabular}




\begin{tabular}{|l|l|l|l|l|l|}
\hline Dalit & 7444 & 246 & 3.2 & & \\
\hline Janjati & 16734 & 625 & 3.6 & 1.056 & $(0.906-1.232)$ \\
\hline Madhesi & 7682 & 295 & 3.7 & 0.953 & $(0.796-1.140)$ \\
\hline Muslim & 2531 & 114 & 4.3 & 1.256 & $(0.993-1.588)$ \\
\hline Brahmin/Kshetri & 17087 & 510 & 2.9 & 0.863 & $(0.735-1.013)$ \\
\hline Other & 897 & 35 & 3.8 & 1.285 & $(0.891-1.853)$ \\
\hline Education (N=54,200) & \multicolumn{5}{|l|}{} \\
\hline No education & 16451 & 757 & 4.4 & & \\
\hline Incomplete primary & 12710 & 488 & 3.7 & 1.043 & $(0.920-1.184)$ \\
\hline Completed primary & 5922 & 164 & 2.7 & 0.975 & $(0.808-1.177)$ \\
\hline Incomplete secondary & 7918 & 195 & 2.4 & 0.975 & $(0.808-1.177)$ \\
\hline Completed secondary & 4506 & 111 & 2.4 & 0.931 & $(0.739-1.172)$ \\
\hline Above secondary & 4868 & 110 & 2.2 & 0.799 & $(0.617-1.034)$ \\
\hline Occupation (N=54,200) & \multicolumn{5}{|l|l|l|}{} \\
\hline Professional/technical/managerial & 1513 & 50 & 3.2 & & \\
\hline Clerical & 1207 & 37 & 3.0 & 0.900 & $(0.579-1.398)$ \\
\hline Sales and services & 2747 & 123 & 4.3 & 1.164 & $(0.817-1.659)$ \\
\hline Skilled manual & 2328 & 112 & 4.6 & 1.282 & $(0.887-1.851)$ \\
\hline Unskilled manual & 1423 & 70 & 4.7 & 1.294 & $(0.867-1.932)$ \\
\hline Agriculture & 14107 & 680 & 4.6 & 1.121 & $(0.805-1.562)$ \\
\hline Student & 6851 & 76 & 1.1 & 0.862 & $(0.569-1.305)$ \\
\hline Housewife & 16802 & 396 & 2.3 & 0.993 & $(0.701-1.407)$ \\
\hline Other/no occupation & 5400 & 278 & 4.9 & 1.068 & $(0.759-1.501)$ \\
\hline Wealth Index (N=54,200) & 21782 & 790 & 3.5 & & \\
\hline Rich & 10382 & 343 & 3.2 & 0.923 & $(0.803-1.061)$ \\
\hline Middle & 20213 & 690 & 3.3 & 0.981 & $(0.866-1.113)$ \\
\hline Poor & & & & \\
\hline
\end{tabular}

Data source: Nepal National Tuberculosis Prevalence Survey- 2018/19, Note: Variables that showed significant association during bivariate analysis at $* * * \mathrm{p}<0.001, * * \mathrm{p}<0.01$, and $*_{\mathrm{p}}<0.05 \quad(\mathrm{OR}=$ Odds Ratio, CI=Confidence Interval).

\section{Diagnostic Practice by Current and Past TB Patients}

Figure 1 gives an overview of the healthseeking practices of current and past TB patients for diagnosis. 1064/1767 (66\%) of the current and $38 / 58(60 \%)$ of the past tuberculosis patients visited government health facilities for the diagnosis. Similarly, 273/1767 (22\%) of the current and 13/58 (16\%) of the past TB patients were diagnosed by the private health facilities, $330 / 1767(19 \%)$ of the past and 6/58 (10\%) of the current TB patients had taken diagnostic services from abroad. The below- outlined graph presents health-seeking practices by current and past tuberculosis patients. 


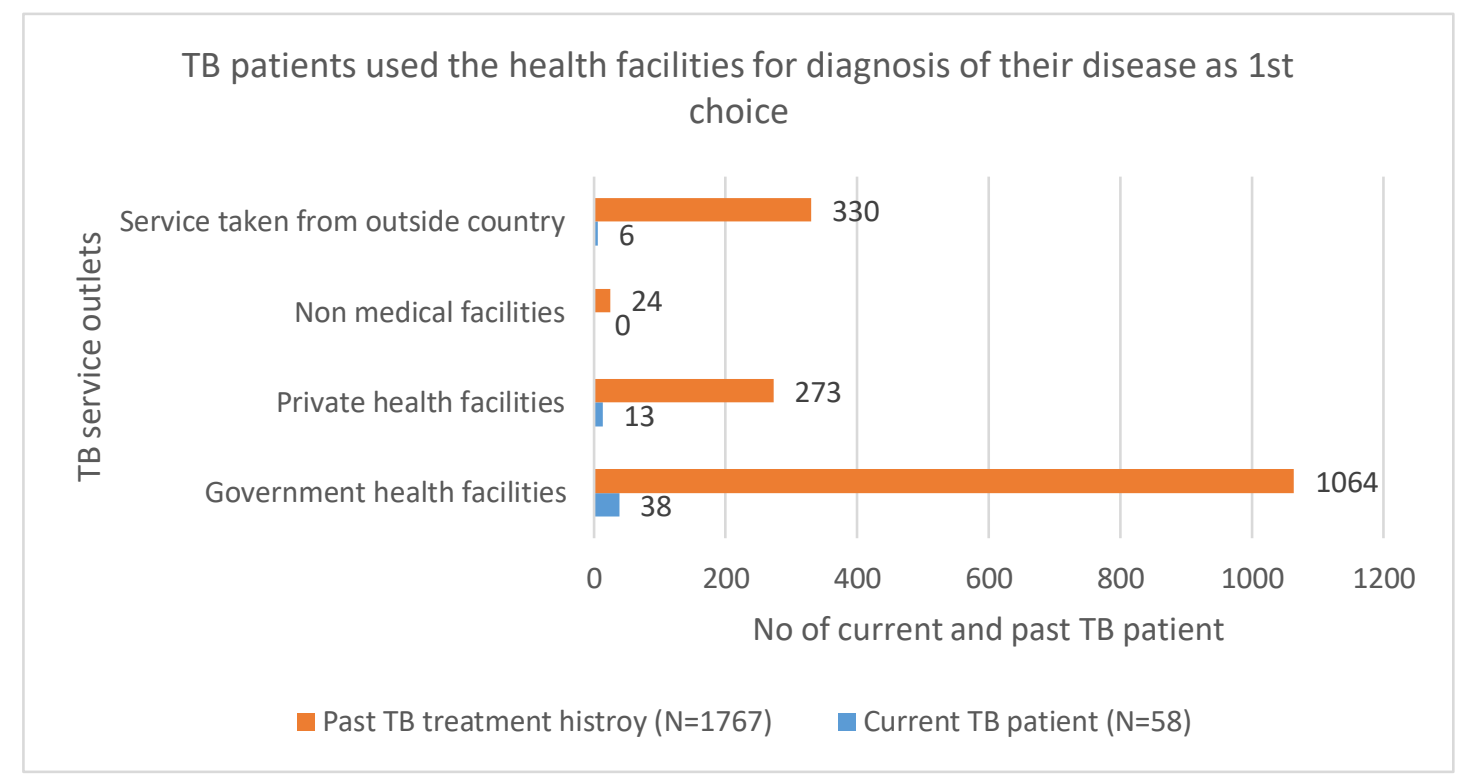

Figure 1. TB Patients used the Health Facilities for Diagnosis of their Disease as 1st Choice

Note: Government health facilities: Own and run by the government, private health facilities: own and run by the private sector supervised by the government, non-medical facilities: pharmacy, self-medication, and traditional healers, service is taken from outside country: patients who took medicine from India.

Figure 2 describes the current and past TB patient's first choice of place for TB treatment. $48 / 58(83 \%)$ of the current and 1237/ 1767 (70\%) of the past people living with tuberculosis took the treatment services from government health facilities. Similarly, some proportion $(5 / 58(9 \%), 187 / 1767(11 \%)$ of the patients (current, past) received the services from the private health facilities, very few patients (36 persons) took their treatment from the nonmedical facility (pharmacy) and 5/58 (9\%) of the past and 307/1767 (7\%) of the current patients were took anti TB treatment services from the abroad (majority from the India).

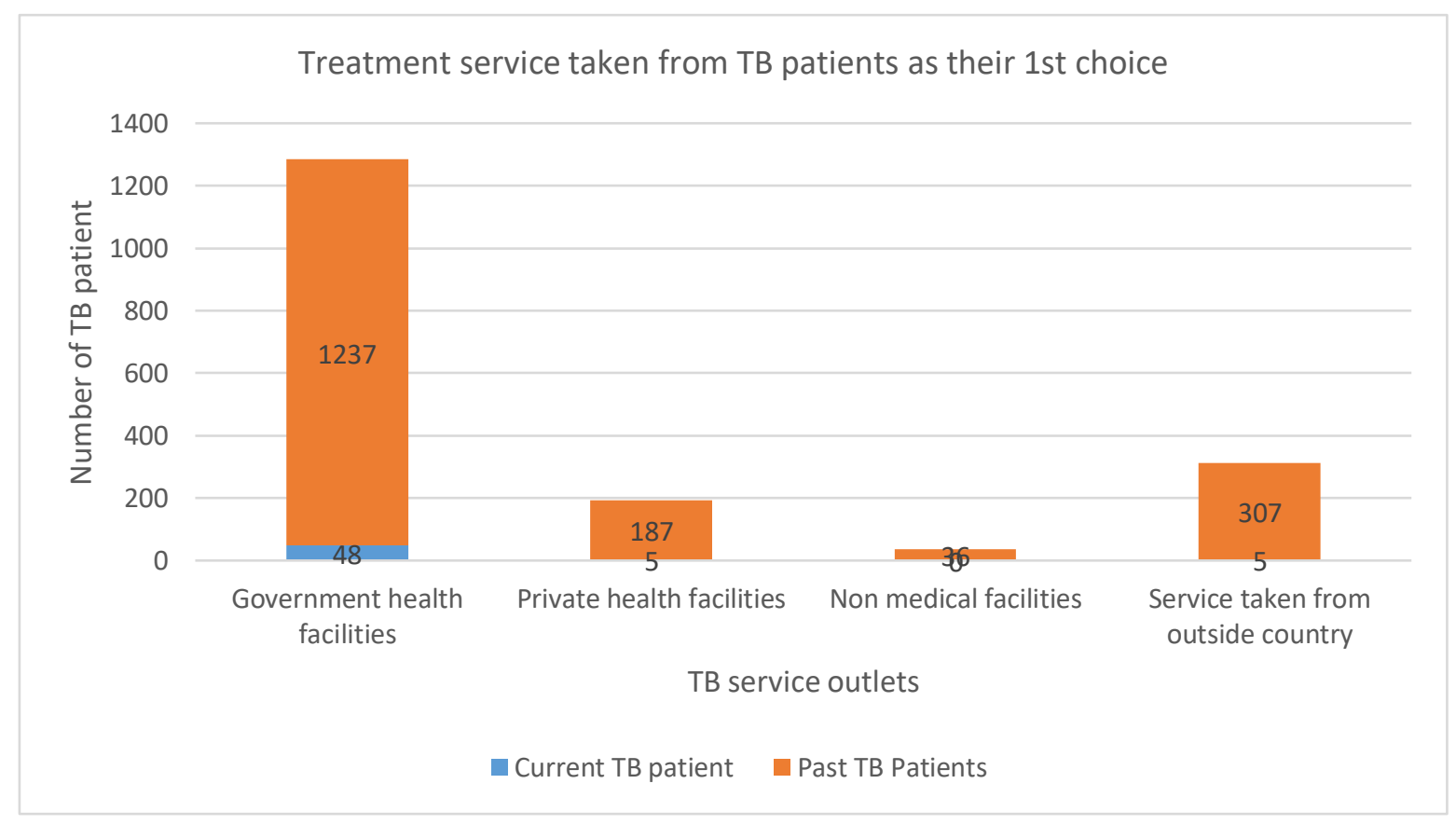

Figure 2. Treatment Service taken from TB Patients as their 1st Choice 
Note: Government health facilities: Own and run by the government, private health facilities: own and run by the private sector supervised by the government, non-medical facilities: pharmacy, self-medication, and traditional healers, service is taken from outside country: patients who took medicine from India.

Globally, there are two types of TB treatment commonly in practice which include health facility-based and community-based medication for the patients. The same therapy is practiced in Nepal. The graph outline below (Figure 3) provides the scenario of the current medication practices of the patients. $62 \%$ of the current people living with TB and $56 \%$ of the past TB patients had their medication at home and $28 \%$ and $26 \%$ current and past TB patients took treatment services from the government health facility. Similarly, 7\% and 9\% of the current and past TB patients managed their treatment without any observation. None of the patients reported community-based TB program, which is very crucial for the TB services to be people friendly. Figure3 provides the picture of utilisation practice of treatment services.

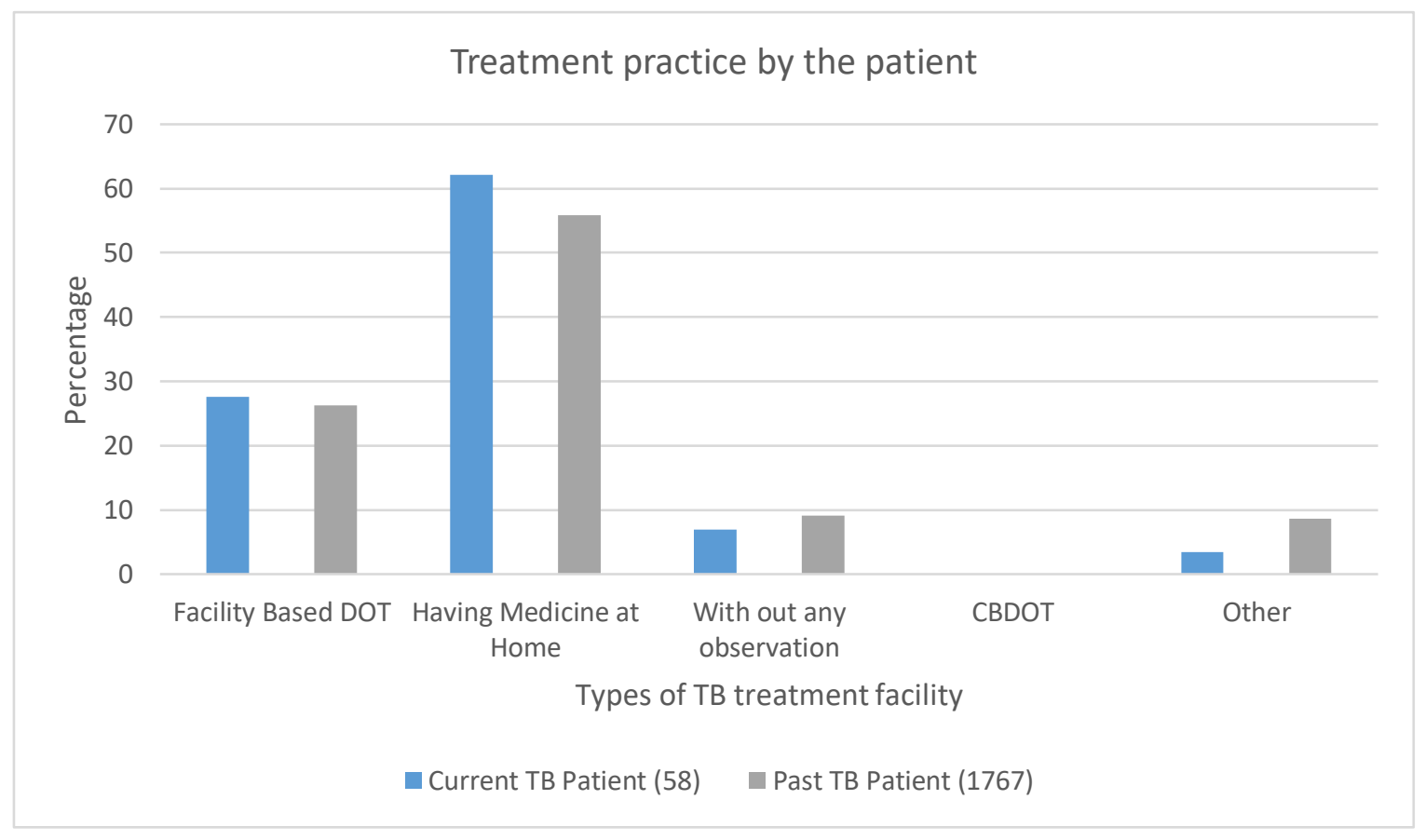

Figure 3. TB Treatment Practice by Current and Past TB Patients

Note: Facility-based DOT- patient visits at the health facility having medication, Having Medicine at Home: patient take medicine from the treatment center for a week or more and having medicine at home with the supervision of the family members, without any observation: patient take medicine from the treatment centre for a week or more and having medicine at home without the supervision of the family members, CBDOT: community-based DOT-trained volunteer provides the medicine to the $\mathrm{TB}$ patients in the community, and Other: Participants who had a history of TB, they were taken anti-TB medicine from outside of the country (majority from India).

\section{Discussion}

Tuberculosis is common and prevails in all age groups, sex, terrain, ethnicity, education status, occupation, and wealth index groups. The majority of cases are seen in the age of 65 and above, in the male population (survey participants from the Kathmandu valley), Muslim caste are mostly affected by tuberculosis compared to ethnic groups, uneducated person, engaged in unskilled profession participants and people from reach groups. 
According to Anderson's health care utilization model, there are predisposing factors, enabling factors, and need issues. Those aspects determine the utilization of the health care system [6]. The majority of the respondents who had a history of tuberculosis choose government health facilities as their first choice for diagnosis. Likewise, some proportion of the respondents reported that they visited private health facilities to take the diagnosis services as $1^{\text {st }}$ choice for identifying their disease and substantial numbers of participants visited outside of the country (majority in India) to diagnose their tuberculosis disease.

The choice of health facilities for TB treatment also demonstrates a similar portion of health service utilization for diagnosis. The majority of participants selected government facilities similar to the finding in the same survey of the Philippines [7], and almost $82 \%$ of TB patients sought tuberculosis treatment from the public health system in Gambia [8]. The reason for selecting government health facilities as the first choice could be due to free TB diagnosis and treatment services, accessibility and reliability, and faith on government services. An interesting fact is that some of the past TB patients and current TB patients also received the treatment from the outside of the country (most of them in India) due to fear of stigma and discrimination, lack of patient-friendly services, inaccessibility of the TB services and time limitation could be potential reasons. A similar study carried out in Indonesia demonstrates that most of the TB patients initially visited a nonformal health service providers (HSP) to seek the solution for their symptoms [9], but the majority of the TB patients from Gabon used combined treatment at the hospital with (herbal) self-medication and traditional/spiritual healing [10]. The study carried out in Kerala, India, highlighted the illiterate and people living in below the poverty line preferred to visit a public health facility to receive the diagnosis and treatment services [11]. The study done in Myanmar showed that the general practitioners were the first point of contact to address all kinds of tuberculosis issues [12].

The increasing private health providers that provide TB care and treatment are considerable facts in South East Asia [13], who provide easy access. On the other hand, the monitoring of diagnosis and treatment quality has become more challenging. The systematic review and meta-analysis in factors associated with the patient and diagnostic delays in Chinese TB patients indicated crucial reasons: availability of resources to perform prompt diagnosis and treatment, lack of trained health human resources, and geographical barriers [14]. The prevalence survey in Indonesia, as well as patient pathway analysis, found an important proportion of TB patients treated in private sectors $[15,16]$. The TB prevalence survey in Ghana demonstrates that two-third of the TB symptomatic person less preferred to visit a public health facility to test their sputum and treatment due to long-distance, lack of training on guidelines, and fear of infection, leading to low motivation among health staff for TB work [17]. The research related to engaging Informal Private Health Care Providers for TB Case Detection done in India, demonstrates that engaging informal health care providers is feasible and possible a large number of Person with Presumptive TB and TB patients can be identified through this effort [18]. The study done in Nigeria described that more robust engagement of pharmacy in TB programme with clear terms of reference (ToR) through effective orientation, provision of pay for performance are recommended as a policy approach to improve linkage of the client to TB diagnosis and treatment centres [19]. The assessment done in improving pathways to care through interventions co-created with communities in Malawi showed that clear pathways to care involve interventions that need to consider in contextual concerns by resolving personal level of socio-economic aspects and also boarder level of structural factors of gendered social dynamics and health system environment [20], the socio- 
economic and traditional factors are also substantial 'bottleneck' to hastening the uptake and utilisation of diagnostic and treatment tools for TB services [21], and adequate knowledge and positive health behaviour supports the TB patients in taking timely help from appropriate diagnosis and treatment health care outlets [22]. A quarter of the TB patients preferred for seeking care from the private health care service providers in Uganda [23]. However, more than seventy percent of people in Nepal still use and intend to visit the government health facilities to take TB diagnosis and treatment services.

The majority of men who participated in the survey shared their experience regarding the treatment they received from outside the country, and most of them were from the productive age categories. These findings, in some way, supported the prediction that a high proportion of migrant workers with $\mathrm{TB}$ treatment history took the health services. As many young populations migrant abroad as seasonal and regular workers, TB might have been identified and treated while they were there. Few papers mentioned the high prevalence of TB among migrants from Nepal. For example, in Western Sydney, among people born in Nepal, TB incidence was as high as 223 per 100 000 [24].

More than half of the participants with TB treatment history explained that the treatment was taken at home without supervision, but the patient themselves or their family members visited the health facility to collect the medicine once a week or more. More than a quarter of TB patients visited the treatment centre to have their

\section{Reference}

[1] World Health Organisation, (2019), Global Tuberculosis Report.

[2] Ministry of Health and Population, National Tuberculosis Control Centre, (2020), Annual Progress Report. medication under the direct supervision of health workers. Few numbers of patients took treatment themselves without observation. Nearly a quarter of TB patients did not take Directly Observed Treatment (DOT) of from the designated treatment centre in Nepal [25]. None of the patients received their medication from the Community DOT providers, which is a crucial and interesting finding from this study. This indicated that the quality of the DOT approach should be scrutinized for the future, and quality could be another issue for the patients.

\section{Conclusion}

The prevalence of TB is common in Nepali society. The majority of the participants explained that they wanted to receive the diagnosis and treatment services from the government health facilities. Some participants said that they received services from both private health institutions and outside of the country due to easy access, convenient times, and fear of stigma and discrimination.

\section{Acknowledgments}

The author would like to thank the Director of the National Tuberculosis Centre (NTCC) for his approval, guidance, and supports to complete this article. Finally, I would also like to thank all the contributors and supporters for completing this work successfully.

\section{Conflict of Interest}

The authors declare that there is no conflict of interest.

[3] Onuka O, et al., 2018, Effectiveness of Contact Tracing of Index Tuberculosis Cases in Nigeria. Adv Infect Dis. 2018;08(04):173-99.

[4] Amo-Adjei J, 2016., Individual, household and community-level factors associated with keeping tuberculosis status secret in Ghana. BMC Public

Health [Internet]. 2016;16(1):1-9 http://dx.doi.org/10.1186/s12889-016-3842. 
[5] World Health Organisation (2011), Tuberculosis Prevalence Surveys: a handbook-the lime book, WHO/HTM/TB/2010.17.

[6] Andersen RM, (1995), Andersen and Newman Framework of Health Services Utilization. J Health Soc Behav [Internet]. 1995;36 (December):1-10. Available from:

http://www.ncbi.nlm.nih.gov/pubmed/7738325.

[7] Department of Health Republic of Philippines (2016), National TB Prevalence Survey, Philippines. Manila; 2017.

[8] Kasse et al.; (2006), Health seeking behaviour, health system experience and tuberculosis case finding in Gambians with cough, BMC Public Health 2006, 6:143 doi:10.1186/1471-2458-6-143.

[9] Nurul Islamy, (2012), Health Care Seeking Behaviour of Community and TB patients and capability of the nonformal health service provider in Tanjung Bentang Subdistrict, Indonesia, Journal Kedokteran dan Keschatan Universitas Lampung, Volume 2, Nomor 2, page 59-63.

[10] A. L. Cremers, et al., (2013), Perceptions, health care seeking behaviour and implementation of a tuberculosis control programme in Lambaréné, Gabon, Public Health Action, VOL 3, NO 4, http://dx.doi.org/10.5588/pha.13.0038.

[11] Paramasivam S et al., (2016), Knowledge and health-seeking behaviour of tuberculosis patients in Kerala, India, Int J Community Med Public Health. 2016 Sep;3(9):2464-2471 http://www.ijcmph.com.

[12] Saw et al.; (2009), Public and/or private health care: Tuberculosis patients' perspectives in Myanmar, Health Research Policy and Systems 2009, 7:19 DOI:10.1186/1478-4505-7-19.

[13] Basnyat B, et al., (2018), Tuberculosis in South Asia: A tide in the affairs of men. Vol. 13, Multidisciplinary Respiratory Medicine. BioMed Central Ltd.

[14] Li et al., (2013), Factors associated with patient, and diagnostic delays in Chinese TB patients: a systematic review and meta-analysis, BMC Medicine, http://www.biomedcentral.com/17417015/11/156.

[15] Surya A, et al. (2017), Quality Tuberculosis Care in Indonesia: Using Patient Pathway Analysis to
Optimize Public-Private Collaboration. J Infect Dis. 2017;216: S724-32.

[16] Ministry of Health Republic of Indonesia (2015), National Tuberculosis Prevalence Survey 2013-2014. [17]Der, JB; (2021) Pathways to tuberculosis diagnosis and treatment in Ghana: identifying the gaps and seeking solutions. $\mathrm{PhD}$ (research paper style) thesis, London School of Hygiene \& Tropical Medicine.

DOI: https://doi.org/10.17037/PUBS.04660749.

[18] Santosha Kelamane et al., (2021), Engaging Informal Private Health Care Providers for TB Case Detection: Experiences from RIPEND Project in India, Hindawi Tuberculosis Research and Treatment Volume 2021, Article ID 9579167, 10 pages https://doi.org/10.1155/2021/9579167.

[19] Cosmas Kenan Onah et al., (2021), Addressing Constraints to Informal Health Service Providers' Involvement in Tuberculosis Control: A Qualitative Study of Patent Medicine Dealers and Tuberculosis Programme Managers in Ebonyi State Nigeria, DOI: https://doi.org/10.21203/rs.3.rs-632368/v1.

[20]Phiri MM, Makepeace E, Nyali M, et al. (2020), Improving pathways to care through interventions cocreated with communities: a qualitative investigation of men's barriers to tuberculosis care-seeking in an informal settlement in Blantyre, Malawi. BMJ Open 2021;11: e044944. doi:10.1136/ BMJ open-2020044944.

[21] Msoka EF et al. (2021), Qualitative assessment of the impact of socio-economic and cultural barriers on uptake and utilisation of tuberculosis diagnostic and treatment tools in East Africa: a cross-sectional study. BMJ Open 2021;11: e050911. doi:10.1136/ BMJ open-2021-050911.

[22] Janmejaya Samal, (2016), Health Seeking Behaviour among Tuberculosis Patients in India: A Systematic Review, Journal of Clinical and Diagnostic Research. 2016 Oct, Vol-10(10): LE01LE06, DOI: 10.7860/JCDR/2016/19678.8598.

[23] Muttamba W, et al. (2019), Health seeking behavior among individuals presenting with chronic cough at referral hospitals in Uganda; Missed opportunity for early tuberculosis diagnosis. PLoS ONE 14(6): e0217900. https://doi.org/10.1371/journal. pone.0217900. 
[24] Norton S, et al (2019), Detailed characterisation of the tuberculosis epidemic in Western Sydney: a descriptive epidemiological study. ERJ Open Res. 2019;5(3):00211-2018.

[25] Gautam N, et al, (2021), Knowledge on tuberculosis and utilization of DOTS service by tuberculosis patients in Lalitpur District, Nepal. PLoS ONE $\quad 16(1): \quad$ e0245686. https://doi.org/10.1371/journal.pone.0245686. 


\title{
Analyzing the Magnitude of Global Epidemiological Transition in Sub- Saharan Africa: A Need to Review the Current Healthcare Management Approach
}

\author{
Abiodun Bamidele Adelowo \\ Department of Public health, Texila American University, Guyana
}

\begin{abstract}
Since after World War II, the world has been grappling with the grumbling rising prevalence and economic burden of non-communicable diseases (NCDs). The rise of these chronic diseases has reached an epidemic proportion and a melting point in many communities of the world. This has been made worse by the recent COVID-19 pandemic. While the world is still battling this debilitating reality, a more gruesome scenario is evolving in low-income and Middle-Income Countries (LMICs). Although these countries account for the highest poverty index in the world, they also account for a disproportionately higher burden of NCDs. More than $80 \%$ of NCD-related deaths are presently recorded among the LMICs. Ironically, although most sub-Saharan Africa (SSA) countries can be categorized as LMICs, yet communicable diseases (CDs) still constitute the highest disease burden in this region. However, based on global projections, SSA may soon lose this 'advantage' and may become the region with the highest burden of NCDs by the year 2030. If the present trajectory is left unshattered, the resulting heavy double burden of CDs and NCDs will likely crumble the already fragile economy of most SSA countries and tilt the region into an unprecedented recession. A critical review of the present disease-centered healthcare management approach and adoption of a more evidence-based health promotion-centered management approach may be vital in salvaging the situation. This article briefly reviewed the global epidemiologic transition, compared the disease- and health promotion-centered healthcare models, and made a case for a change in health management strategy in SSA.
\end{abstract}

Keywords: Disease-centered approach, Epidemiological transition, Health promotion-centered approach, lifestyle modification, Non-communicable Diseases Risk factors, sub-Saharan Africa.

\section{Introduction}

For many centuries, communicable diseases (CDs) accounted for the highest global causes of morbidity and mortality. A turning point was, however, noticed during the first half of the $20^{\text {th }}$ century. Precisely after the Second World War, the high-income industrialized countries of the world made major breakthroughs against infectious and childhood diseases, primarily through advances in pharmacotherapy, public health vaccination, and sanitation. These measures led to a drastic and considerable decrease in the prevalence of CDs and maternal and infant mortalities, with the consequential increase in life expectancy to middle and late adult life, a process which medical science significantly perfected over the next 100 years [1-3].

As however noticed, the relative healthcare stability that was achieved through the effective fight against communicable and nutrition-related diseases seems to have created a vacuum, which had been filled up with a rather more challenging group of chronic diseases - the noncommunicable diseases (NCDs). The global epidemiological transition from CDs to NCDs started in the middle of the $20^{\text {th }}$ century, with heart diseases (and many other NCDs) virtually unknown until the 1920s, when the cases of 
atherosclerotic heart diseases were first comprehensively documented [1-3]. However, in just a few decades after that, the burden of NCDs has risen significantly, spreading very fast from America to Europe, Asia, and to the rest of the world $[1,4]$. For example, atherosclerosisrelated diseases were so rare in Japan in the 1950s and 70s that the University of Tokyo had to be importing atherosclerotic coronary artery specimens from John Hopkins University in Baltimore for practical demonstration during medical training. A few decades later, due to the epidemiological transition in Asia, Japan soon had enough local cases of coronary artery diseases [1].

By the $21^{\text {st }}$ century, NCDs had clearly become the leading global causes of morbidity and mortality. $70 \%$ of all yearly deaths worldwide are now attributed to NCDs [6]. Out of the 57 million deaths recorded globally in 2016, 41 million or $73 \%$, were due to NCDs, mainly from cardiovascular diseases - CVDs (17.9 million deaths, accounting for $44 \%$ of all NCD deaths and $31 \%$ of all global deaths); cancers ( 9 million deaths, $22 \%$ of all NCD deaths and $16 \%$ of all global deaths); chronic obstructive respiratory diseases - COPD (3.8 million deaths, $9 \%$ of all NCD deaths, and $7 \%$ of all global deaths); and diabetes mellitus - DM (1.6 million deaths, 4\% of all NCD deaths and $3 \%$ of all global deaths) [7], which means that in the same year, the mortality rate from NCDs more than doubled the mortality rates from all other causes combined (including deaths from HIV/AIDS, maternal mortality, malaria, terrorism, war, and natural disasters).

NCDs are also the leading cause of global premature adult death (deaths occurring in those aged 30-69 years), the most productive age group in the world. It accounts for about $75 \%$ of annual global premature adult death [7]. The prevalence of NCDs and related mortality will likely continue to increase globally, with the greatest rise and impact expected to be seen and felt in the low- and middle-income countries (LMICs) [7]. The recent COVID-19 pandemic has added another dimension to the epidemiology and pathophysiology of NCDs. The incidence, progression, hospitalization, and case-fatality rates of COVID-19 cases have been noticed to increase in the presence of underlying NCDs (mainly CVDs, DM, COPD, and some cancers) [8]. Furthermore, the development of COVID-19 has also been associated with rapid clinical progression of most NCDs, with increased mortality from NCD-related complications [9]. By implication, any COVID19 preventive and treatment effort, without due consideration for the prevention and control of NCDs, will likely be inadequate in controlling the COVID-19 pandemic.

\section{The Disproportionate Burden of Non- Communicable Diseases in the LMICs and SSA}

A rather worrisome development is the disproportionate impact of NCDs on the Lowand Middle-Income Countries (LMIC) of the world. Although this group of countries constitutes the poorest nations in the world, NCDs presently strike the hardest on these nations [2]. What were once viewed as "diseases of affluence" have now encroached deep into the fabrics of the LMICs, up to an epidemic proportion in most of these nations [10-12]. More than two-thirds of all cancer deaths and nearly $80 \%$ of all NCD-related deaths now occur annually in the LMICs $[7,13]$. Specifically, in the year 2016, $78 \%$ of all NCD deaths, and $85 \%$ of premature adult NCD deaths, were reported in the LMICs [7]. Adults living in the LMICs presently face the highest comparable risk of dying from NCDs (Low-income - 21\% and Middle-income $-23 \%$ ), which almost doubled the risk for adults in high-income countries (12\%) [7]. Likewise, in the high-income countries, the proportion of all premature adult mortality from NCDs $(25 \%)$ is almost half of that of low-income $(43 \%)$ and lower-middleincome countries (47\%) [7]. These statistics meant more than four out of every five NCDrelated deaths presently occur among the poorest 
communities of the world - an unsustainable situation that has been projected to worsen in the next few decades [13].

It has also been projected that the estimated percentage increase in global cancer incidence by the year 2030, compared with the year 2008, is expected to be greater in low- $(82 \%)$ and lower-middle-income countries (70\%) compared with the upper-middle (58\%) and high-income countries (40\%) [13]. As noticed by the World Health Organization (WHO), NCDs have now created a form of vicious cycle among the LMICs: poverty exposes the people living in LMICs to behavioral and environmental risk factors that increase their chances of developing NCDs; while in return, the costs of managing NCDs often become an important driver to the downward poverty trend in many families [13]. Consequently, NCDs presently deliver a two-punch blow to the socioeconomic growth of most LMICs. On a Macroeconomic level, the direct and indirect costs of managing NCDs cause billions of dollars in losses of national income and then shove millions of people in the microeconomy below the poverty line each and every year [13].

Paradoxically, although most countries in Sub-Saharan Africa (SSA) fall in the LMICs category, yet the present morbidity and mortality profiles in most of these countries are not exactly similar to the rest of the LMICs. Most countries that are geographically located in the south of the Sahara still have more morbidity and mortality profiles from communicable, maternal, perinatal, and nutritional conditions compared to NCDs [13]. For instance, as of the year 2016, the NCD attributable mortality rate in Nigeria (the country with the largest population in the SSA) was only $29 \%$, out of which CVDs and diabetes mellitus accounted for only $11 \%$ and $1 \%$ of the proportional mortality rate respectively [7]. Similarly, in the same year, 2016, the NCD attributable death rates in Kenya, Congo Democratic Republic, and Mali was only 37\%, $38 \%$, and 39\%, respectively, while communicable and related diseases are responsible for the larger percentage of death in each of these countries [7]. The different morbidity and mortality profiles in most SSA countries compared to the rest of LMICs and the rest of the world can be attributed to multiple factors. Some of which may include peculiar environmental, demographic, socio-economic, and healthcare system factors of the region compared to the rest of the world [14].

Table 1. Comparison of 2016 Mortality Rates from Different Countries

\begin{tabular}{|l|l|l|l|l|l|l|}
\hline & \multicolumn{2}{|l|}{$\begin{array}{l}\text { High-Income } \\
\text { Countries }\end{array}$} & \multicolumn{2}{l|}{$\begin{array}{l}\text { Low- and Middle- } \\
\text { Income Countries }\end{array}$} & $\begin{array}{l}\text { Sub-Saharan } \\
\text { African Countries }\end{array}$ \\
\hline Diseases & USA & France & India & Brazil & Nigeria & Zambia \\
\hline $\begin{array}{l}\text { All communicable, maternal, } \\
\text { perinatal, and nutritional }\end{array}$ & $5 \%$ & $6 \%$ & $26 \%$ & $14 \%$ & $63 \%$ & $61 \%$ \\
\hline All non-communicable & $88 \%$ & $88 \%$ & $63 \%$ & $74 \%$ & $29 \%$ & $29 \%$ \\
\hline - Cardiovascular & $30 \%$ & $26 \%$ & $27 \%$ & $28 \%$ & $11 \%$ & $10 \%$ \\
\hline - Cancers & $22 \%$ & $31 \%$ & $9 \%$ & $18 \%$ & $4 \%$ & $6 \%$ \\
\hline - Chronic respiratory & $9 \%$ & $6 \%$ & $11 \%$ & $6 \%$ & $2 \%$ & $2 \%$ \\
\hline - Diabetes mellitus & $3 \%$ & $2 \%$ & $3 \%$ & $5 \%$ & $1 \%$ & $1 \%$ \\
\hline
\end{tabular}

Table 1 illustrated relatively high noncommunicable disease attributable mortality rates in the selected high-income and lowmiddle-income countries (LMICs), compared to communicable, maternal, perinatal, and nutritional conditions. However, in most counties in sub-Saharan Africa, as seen in the selected countries, communicable diseases are still responsible for more deaths in this region [7]. 
The prevalence of NCDs (like CVDs, hypertension, dyslipidemia, diabetes mellitus, obesity, osteoporosis, and some types of cancer) is fast rising in the SSA region, and at its present rate, these chronic diseases may likely outpace the infectious diseases in all the SSA countries in no distant future and may cause almost threequarters as many deaths as communicable, maternal, perinatal, and nutritional conditions, and far exceed them as the most common causes of death by as early as the year $2030[13,15]$. If this happened, most countries in SSA would have lost the golden and rare opportunity to prevent or at least delay the heavy disease and economic burdens that NCDs presently pulls on most high-income countries of the world. Also, the present burden of the high prevalence of CDs would not likely have considerably abated by the year 2030 in SSA. This is especially true with the emergence and the reemergence of different communicable diseases, as seen with the COVID-19 pandemic. A double disease burden of CDs and NCDs may crumble the fragile and unstable economic system of most countries in SSA, a situation that may usher in an unprecedented economic recession on some if not all of these poorest nations of the world. Furthermore, the SSA region may not be the only region to suffer from the missed opportunity. The ripple effect of the double disease burden on SSA may likely be felt not only by other African communities but indeed by the entire interconnected global economy [13, 16].

The present infectious diseases-dominant disease profile in most SSA countries provides a rare window of opportunity for the global and regional political and health authorities to enact series of policies and programs to prevent and control the anticipated rise of NCDs among the SSA nations, and by so doing prevent, delay, or at least mitigate the health and economic catastrophes that a possible high burden of NCDs and CDs might have on some of these poorest countries of the world. Unfortunately, the present pace of actions and enthusiasm might not be enough to cause any significant impact in the changing disease profile in SSA. The political and health authorities in the SSA, the World Health Organisation, and other global stakeholders must do more to save Africa from the possible consequences of the rising burden of NCDs in the continent.

\section{The Root and Underlying Causes of the Evolving Epidemiological Transition in Sub-Saharan Africa}

The increasing globalization, urbanization, and industrialization have made most of the people in SSA change from their traditional agrarian lifestyle to the western style of living [17]. The traditional lifestyle and culture in most SSA are characterized by regular and often vigorous physical activity in the form of subsistence farming, hunting, traveling long distances on foot, etc. These are accompanied by sustenance on a high fiber, whole plant-based diet that is rich in vegetables, fruits, and legumes [17]. These traditional forms of lifestyle have gradually been eroded and substituted by the urban or "western lifestyles" characterized by the fast-paced, wage-earning economy and sedentary lifestyle. A situation that has resulted in an overreliance on the motorized transportation system and frequent consumption of unhealthy diets rich in refined carbohydrates, fats, and salts [17]. The economic transition in SSA has also resulted in a significant reduction in general physical activity levels, decreased hours of rest and relaxation, reduced quality and duration of sleep, and increased stress levels [17]. These conditions, in association with the rising unplanned or poorly planned and polluted urban settlements, overpopulation, aging population, and poor healthcare system, presently constitute the major root and underlying causes or determinants that are driving the environmental, socio-economic, cultural, and consequently, epidemiological changes in most countries in the south of the Sahara [12, 17, 18]. Policies and programs that target these root and underlying causes will be 
critical in slowing down the epidemiological transition in SSA.

Definitive actions must be taken now as the window of opportunity is fast closing. This is so because the prevalence of the primary and intermediate underlying risk or determinant factors for NCDs is fast rising in SSA. They are taking Nigeria (the country with the largest population in SSA) as a case study. Presently, the prevalence of hypertension, a major intermediate risk factor for most of the other NCDs, is significantly high in Nigeria and most countries in SSA. About $46.4 \%$ to $47.2 \%$ of Nigerian adults are presently hypertensive [19, 20]. Also, about $6 \%$ of Nigerians ( $\geq 15$ years) smoke tobacco daily [16]; while about $17.3 \%$, $6.6 \%$, and $29.3 \%$ of Nigerian adults usually get secondhand exposure to tobacco smoke at the workplace home, and restaurants, respectively [21]. The per capita consumption of pure alcohol in Nigeria is about 13 liters (22\% in males and $5 \%$ in females) [16], the prevalence of insufficient physical activity among Nigerians is $25 \%$ ( $22 \%$ male and $27 \%$ female), while about $80 \%$ of working-class Nigerian adults are classified as physically inactive [16, 21]. Furthermore, the Federal Ministry of Health of Nigeria opined that the consumption of fruits and vegetables is inadequate in most regions of the country, while excessive intake of salt and refined sugars is common [21].

The mean population salt intake in Nigerian adults (aged $\geq 20$ years) of $7 \mathrm{~g} /$ day is significantly high compared to other countries [16]. The prevalence of overweight and obesity among Nigerians (aged $\geq 20$ years) is $26.8 \%$ ( $24.2 \%$ in males and $29.3 \%$ in females); while the prevalence of raised total blood cholesterol $(\geq 5.0 \mathrm{mmol} / \mathrm{L}$ ) in people age $\geq 25$ years in Nigeria is $16.1 \%$ (13.6\% in males and $18.5 \%$ in females) [13]. These statistics of a high prevalence of the NCD-related risk factors in Nigeria are similar and sometimes higher in most other SSA [16]. In fact, the prevalence of hypertension in SSA can be as high as $48 \%$, obesity as high as $43 \%$, while current smoking of tobacco can be as high as 71\% [22]. These risk factors constitute a vital link in the pathophysiology of most NCDs, and their prolonged presence, either singly or combined, usually ignites a cascade of pathologic events that eventually culminate in the development of NCDs among the affected people [18]. Consequently, the present high prevalence of NCD-related risk factors among people living in SSA will likely translate to a high burden of NCDs in a few decades from now. The countries in SSA must urgently adopt a healthcare system that deliberately identifies and modify these risk factors among the people.

\section{The Need for Transition from Disease- centered to Health Promotion-centered Health Management Model}

The traditional biomedical healthcare model that constitutes the core of the medical management of diseases in Nigeria and most other SSA is a disease-centered or oriented model and seems to be inefficient in curbing the rising prevalence of chronic NCDs in the subregion. In this 'paternalistic' standard treatment model, the health professional primarily decides the appropriate course of treatment, and basically, intervene in the management of chronic NCDs at the secondary and tertiary prevention levels, with less emphasis on the patient's involvement in the primordial and primary prevention of diseases [23, 24]. The primary focus of the disease-centered traditional biomedical healthcare approach in chronic disease management is to rely on data from health screening and early diagnosis of specific diseases (like hypertension, diabetes mellitus, and cancer), to commence treatment in order to prevent or delay the clinical progression of the identified chronic diseases [25]. Except in few occasions (like cervical cancer when detected early), the biomedical model does not cure chronic NCDs, rather prevent, delay, or mitigate the clinical progression of the diseases and possible associated complications through the 
prescription of medications, surgery, radiotherapy, and the rest.

Although NCDs still constitute the highest disease burden in the developed world, some of these high-income countries have made some progress in controlling the rising trend of NCDs in their nations $[16,26]$. In fact, due to some definite interventions from some countries, the risk of dying from the four major NCDs in people aged 30 to 70 years has slightly dropped globally, from $22 \%$ in 2000 to $18 \%$ in 2016 [27]. The most important measures that explain the slight downward spiral in the prevalence of chronic diseases in some of these developed nations is not necessarily their advanced medical care or technology, rather their change of management approach from the 'diseasecentered' to the 'health promotion-centered' approach [26-30]. The health promotioncentered approach to healthcare is fast gaining traction in most regions of the world [4]. It is the process in the public health physicians, and clinicians collaborate with the people or patients to increase control over and to improve their health by focusing on a healthy lifestyle among the general population and the early risk identification and modification among the atrisk population [31]. This health promotion- centered approach, a form of a patient-centered approach, diverts the attention of clinical care from the screening and diagnosis of chronic NCDs to primarily the promotion of the wellbeing of the people while preventing or delaying the onset of the chronic diseases through comprehensive risk identification and lifestyle modification [23].

\section{Health Promotion Approach: A more Evidence-based Solution to the Rising Burden of Chronic Diseases}

Despite the gloomy future painted by the rising prevalence of NCDs, all hopes are not lost. The projected future gory disease burden and economic woos, especially on SSA nations, does not have to happen. Although in recent years, the burden of NCDs has been rising globally, so also is the knowledge and understanding of its prevention and control [17]. According to the Commonwealth Business Council, up to $80 \%$ of CVDs and type 2 diabetes mellitus (T2DM), and over a third of cancers could be prevented, and countries can reverse the advances of these diseases and achieve quick gains if the appropriate intervention approach is adopted, in which preventive and promotive measures are prioritized [18].

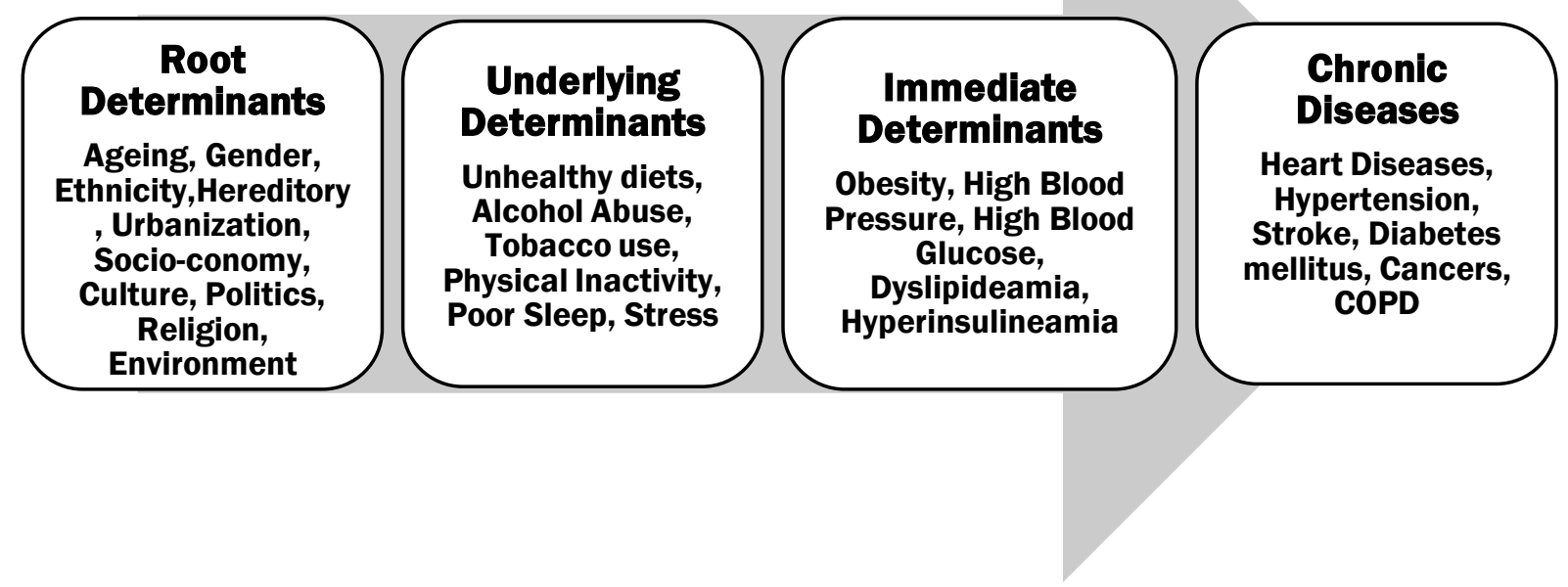

Figure 1. Causation Pathway of Most Chronic Non-Communicable Diseases 
Any intervention that effectively disrupts the pathway in Figure 1 will likely lead to a reduction in the prevalence of most chronic noncommunicable diseases.

Effective public health and clinical intervention policies, programs, or guidelines anywhere along with the disease evolution of NCDs, most importantly in the early phases, could disrupt the common pathophysiological process that characterizes most chronic NCDs and thus confer cardiovascular and metabolic protection on the affected individuals [19]. A role that health promotion-centered healthcare can effectively play. According to the $\mathrm{WHO}$ and United Nations, the adoption of a comprehensive preventive or health promotion-centered management approach that identifies and mitigates the implicated risk factors or determinants as earliest as possible can effectively disrupt the causative or pathophysiologic pathway of most NCDs $[4,14]$ Systematic and comprehensive control of these risk factors through evidence-based healthpromoting interventions that focus on healthy lifestyle and behavioral change among the general and at-risk population is essential and a fundamental strategy in the prevention and control of NCDs [31].

Particularly, modification of the unhealthy lifestyle-related risk factors of the at-risk population - by deliberately and effectively controlling the intermediate biological risk factors or immediate determinants like high blood lipids, high blood pressure, high blood glucose, and overweight/obesity (especially central obesity), through the effective control of the primary behavioral risk factors or underlying determinants like unhealthy/atherogenic diets, alcohol abuse, physical inactivity, tobacco use, high-stress level, and poor sleep - can have a profound and favorable impact on decreasing the incidence of initial and recurrent pathologic cardiovascular and metabolic events that are essential to the eventual development of most NCDs [20]. On a long-term basis, health promotional efforts that control the political, environmental, healthcare system, and socioeconomic root determinants of NCDs is essential in the management of the rising surge of these diseases.

Reduced morbidity and mortality rates of chronic NCDs will likely play a significant role not only in ensuring a stronger healthcare system and an improved economy among the SSA nations but may also likely significantly assist in reducing the susceptibility, severity, and casefatality rates of some infectious diseases, like COVID-19, among these nations.

\section{Conclusion}

Despite the stacking odds, winning the battle against NCDs in the SSA and the rest of the world is visible, and reversal of the trend is highly achievable, provided the healthcare management approach is comprehensive and multi-sectorial, centering on health promotion and lifestyle modification, in which there exist appropriate and adequate collaboration between government agencies, civil societies, and private sectors [18]. However, the increasing prevalence of NCD-related risk factors in SSA means the window of opportunity to strike when the iron is hottest is closing fast in this region. All hands must be on deck now; if not, a gloomy future of high disease and economic burdens await the SSA as earliest as the year 2030.

The responsibility rest on all related clinicians, public health physicians, and policymakers - government, non-governmental organizations, and politicians - to review the present healthcare management strategies and incorporate appropriate promotive healthcare management approach both in the prevention and treatment of chronic NCDs. They are also meant to sensitize and train the primary healthcare physicians and other healthcare professionals on the knowledge and skills of conducting a chronic disease risk assessment on their patients and instituting evidence-based lifestyle modification measures to reduce the identified risk factors. Accordingly, everybody must play a role and adopt adequate measures to 
tackle the rising NCD epidemics in their space of influence, with all making meaningful changes and investing adequate resources [18].

\section{Conflict of Interest}

The author declares no conflict of interest.

\section{References}

[1] Diehl H., 2011, Modern Medicine: Miracles, Medicines, Money \& Mirages, Lifestyle Medicine Institute of Loma Linda California Press, pp 1 - 14. [2] McKeown R.E., 2009, The Epidemiologic Transition: Changing Patterns of Mortality and Population Dynamics, Am J Lifestyle Med., 3(1 Suppl), 19S-26S.

https://doi:10.1177/1559827609335350.

[3] Sarukhan A., 2018, The Epidemiological Transition (or What We Died, Die and Will Die From). Barcelona Institute for Global Health (ISGlobal), Date of access: 3/2/2021. https://www.isglobal.org/en/healthisglobal/-/customblog-portlet/la-transicion-epidemiologica-o-de-quemoriamos-morimos-y-moriremos-/3098670/0.

[4] Ipsum L., 2021, The epidemiological transition. London School of Hygiene \& Tropical Medicine, Date of access: 3/2/21. https://www.futurelearn.com/info/courses/publichealth-history/0/steps/30337.

[5] Schettler G., 1983, Atherosclerosis during periods of food deprivation following world wars I and II, Preventive Medicine, 12 (1), 75 - 83. https://doi.org/10.1016/0091-7435(83)90174-3.

[6] World Health Organization, 2020, Noncommunicable diseases progress monitor 2020, World Health Organization, Date of access: 7/3/2021. https://apps.who.int/iris/handle/10665/330805.

[7] World Health Organization, 2018, Noncommunicable Diseases Country profiles 2018, World Health Organization, Date of access: 5/2/2019. https://www.who.int/nmh/publications/ncd-profiles2018/en/.

[8] Ambrosino I., Barbagelata E., Ortona E., Ruggieri A., Massiah G., Giannico O.V., et al., 2020, Gender differences in patients with COVID-19: a narrative

\section{Acknowledgement}

The author appreciates the entire faculties and staff of the Department of Human Kinetics and Health Education, University of Lagos, for their training and supports over the years.

review. Monaldi Archives for Chest Disease, 90 (1389), 318-24.

[9] Bonyan F.A., Shareef L.G., Al-waily A., Abdulrazaq A.A., and Al-Rubayee W.A., 2020, COVID-19 clinical characteristics and outcomes in 60 hospitalized Iraqi patients - Case series. Medical Science, 24(104), 2251-58.

[10] Ezzati M., Hoorn S.V., Lawes C.M.M., Leach R, James W.P.T., Lopez A.D., et al., 2005, Rethinking the "Diseases of Affluence" Paradigm: Global Patterns of Nutritional Risks in Relation to Economic Development. PLoS Medicine, 2 (5), 404-12. [11] World Health Organization, 2005, Rethinking "diseases of affluence" the economic impact of chronic diseases. World Health Organization, Date of access: 12/3/2021

https://www.who.int/chp/chronic_disease_report/me dia/Factsheet4.pdf?ua $=1$.

[12]Bloom D.E., Cafiero E.T., and Jané-Llopis E., Abrahams-Gessel S., Bloom L.R., Fathima S., et al., 2011, The Global Economic Burden of Noncommunicable Diseases. World Economic Forum, Date of access: 5/7/2018. http://www3.weforum.org/docs/WEF_Harvard_HE_ GlobalEconomicBurdenNonCommunicableDiseases _2011.pdf.

[13] World Health Organization, 2011, Global Status Report on Non-Communicable Diseases 2010. World Health Organization. Date of access: 5/7/2018. https://www.who.int/nmh/publications/ncd_report_f ull_en.pdf.

[14]Boutayeb A., 2010, The Burden of Communicable and Non-Communicable Diseases in Developing Countries. In: Preedy V.R., Watson R.R. (eds) Handbook of Disease Burdens and Quality of Life Measures, Springer, New York, NY. https://doi.org/10.1007/978-0-387-78665-0_32. 
[15] Sibai A., Tohme R.A., Mahfoud Z., Chaaya M., and Hwalla N., 2009, Non-communicable Diseases and Behavioral Risk Factor Survey: Comparison of estimates based on cell phone interviews with faceto-face interviews, World Health OrganizationLebanon office.

[16] World Health Organization, 2008, Executive summary: 2008-2013 Action Plan for the Global Strategy for the Prevention and Control of Non communicable Diseases Report 2008, World Health Organization, Date of access: 30/4/2021. https://www.who.int/nmh/publications/ncd_action_p lan_en.pdf.

[17] Cooper R.S., Amoah A.G., and Mensah G.A., 2003, High blood pressure: the foundation for epidemic cardiovascular disease in African populations, Ethn Dis., 13, 48 - 52.

[18]Bonita R., Beaglehole R., and Kjellström T., 2006, Basic epidemiology, $2^{\text {nd }}$ edition, World Health Organization, Date of access: 3/4/2020. https://apps.who.int/iris/bitstream/handle/10665/435 41/9241547073_eng.pdf?sequence=1\&isAllowed=y. [19] Akinlua J.T., Meakin R., Umar A.M, and Freemantle N., 2015, Current Prevalence Pattern of Hypertension in Nigeria: A Systematic Review, PLoS ONE, 10, 0140021.

[20] Ogah O. S., and Rayner B.L., 2013, Recent advances in hypertension in sub-Saharan Africa. Heart, 0, 1 - 8. https://Doi:10.1136/heartjnl-2012303227.

[21]Federal Ministry of Health of Nigeria, 2015, National Strategic Plan of Action on Prevention and Control of Non-Communicable Diseases, Federal Ministry of Health - Nigeria, Date of access: $12 / 6 / 2018$.

www.medbox.org/Nigeria-national...prevention-andcontrol...noncommunicablediseases.pdf.

[22] Dalal S., Beunza J.J., Volmink J., Adebamowo C., Bajunirwe F., Njelekela M., et al., 2011, noncommunicable diseases in sub-Saharan Africa: what we know now. Int J Epidemiol., 40: 885-901.

[23] Groves J., 2010, International Alliance of Patients' Organizations perspectives on personcentered medicine. International Journal of Integrated Care, 10, 27-29. ISSN 1568-4156. URL: http://www.ijic.org.
[24] Roy M., Levasseur M., Couturier Y., Lindströme B., and Généreux M., 2015, The relevance of positive approaches to health for patient-centered care medicine. Preventive Medicine Reports, 2, 10 - 12 . http://dx.doi.org/10.1016/j.pmedr.2014.11.005.

[25]Chawla N.V., and Davis D.A., 2013, Bringing Big Data to Personalized Healthcare: A PatientCentered Framework. J Gen Intern Med, 28(Suppl 3): S660-5. http://DOI:10.1007/s11606-013-2455-8.

[26] Wu F., Narimatsu H., Li X., Nakamura S., Sho R., Zhao G, et al., 2017, non-communicable diseases control in China and Japan. Globalization and Health, 13, 91. http://DOI:10.1186/s12992-0170315-8.

[27] World Health Organization, 2020, Assessing national capacity for the prevention and control of non-communicable diseases: report of the 2019 global survey, World Health Organization, Date of access:

14/3/2021.https://www.who.int/publications/i/item/n cd-ccs-2019.

[28] United Nations, 2011, Draft Resolution Submitted by the President of the General Assembly: Political declaration of the High-level Meeting of the General Assembly on the Prevention and Control of Non-Communicable Diseases, United Nations, Date of access: 30/4/2021.

https://www.who.int/nmh/events/un_ncd_summit20 11/political_declaration_en.pdf.

[29] World Health Organization, 2009, Milestones in Health Promotion: Statements from Global Conferences, World Health Organization, Date of access: 30/4/2021.

https://www.who.int/healthpromotion/Milestones_H ealth_Promotion_05022010.pdf.

[30] World Health Organization, 2004, National Action Plan for Prevention and Control of NonCommunicable Diseases and Health Promotion in Pakistan: A Public-Private Partnership in Health, World Health Organization, - WHO Report 2004; 1 -141 .

[31] Okafor C.N., Young E.E., Nwobi A.E., 2016, Health promotion strategies for the prevention and control of non-communicable diseases in Nigeria. South American Journal of Public Health, 4(1), 1 10 . 


\title{
Determinants of Hesitancy to Childhood Immunizations in a Peri -Urban Settlement; A Case Study of Nansana Municipality, Uganda
}

\author{
Amos Kijjambu ${ }^{1 *}$, Edgar Mugema Mulogo 2 \\ ${ }^{1} \mathrm{MPH}, \mathrm{PhD}$ Candidate, Public Health, Texila American University, Guyana \\ ${ }^{2}$ Professor, Department of Community Health, Mbarara University of Science and \\ Technology, Mbarara, Uganda
}

\begin{abstract}
Vaccine hesitancy to immunization against the childhood vaccine-preventable diseases is increasingly becoming a concern worldwide, which negatively impacts the parents' willingness to vaccinate their children. The objective of this study was to establish the current prevalence of vaccine hesitancy and the factors that determine parent's hesitancy to childhood immunizations in Nansana Municipality, Wakiso District, Uganda. This was a cross-sectional mixed methods study, utilizing both qualitative and quantitative approaches. Evaluation of the determinants of vaccine hesitancy was carried out on 344 parents of children under 24 months, using simple random sampling on pre-tested structured questionnaires. Data was analyzed using SPSS 20.0 software. Additionally, 2 focus group discussions with parents were also conducted. Vaccine hesitancy was found to be 27.6\%. Education level (AOR=4.9, 95\% CI, $2.6-29.5, p=0.01)$, belief in vaccine effectiveness (AOR=0.47, 95\% CI, $0.17-0.97, p=0.01)$, health workers attitude (AOR=0.22, 95\% CI, $0.06-0.86, p=0.03)$, timing of immunization service clinic $(A O R=3.4,95 \% C I, 1.8-6.4, p=0.01)$ and adequate information provision $(A O R=0.64,95 \% C I, 0.16-0.99, p=0.04)$, were the factors that were independently determining vaccine hesitancy. The vaccine hesitancy prevalence rate is comparatively similar to previous urban area studies. Despite parents overwhelmingly believing in vaccines protecting their children from vaccine-preventable disease, these same parents, express concerns regarding timing of the clinic and the side effects of vaccines. There is a need to improve on communication and information flow to address the many vaccine safety concerns, such as side effects.
\end{abstract}

Keywords: Childhood, Determinants, Hesitancy, Immunization, Urban.

\section{Introduction}

Worldwide, the parental vaccine hesitancy to childhood immunizations is a growing problem with a significant public health impact [1], which reflects concerns about the decision to vaccinate their children against the childhood Vaccine-Preventable Diseases (VPDS) [2], yet childhood immunization is a key intervention towards attaining Sustainable Development Goal (SDG) number 3 that aims at reduction of under-five mortality to less than $25 / 1000$ live births by 2030 [3], as immunizations are protective measures against childhood vaccine- preventable infectious diseases [4], and is one of the most cost-effective health investments, with proven strategies that make it accessible to even the most hard-to-reach and vulnerable populations [5], therefore making immunization a reliable child survival strategy, that prevents more than 2.5 million child deaths each year globally [6]. However, worldwide, the VaccinePreventable Diseases (VPDs) burden has remained high, and the immunization coverage rates have plateaued for the last decade, with an estimated 19.7 million children under 1 year not receiving the basic vaccines in 2019 [7]. Approximately 10 million under-five deaths 
occur in low-income countries annually, most of which are from VPDs [8].

Vaccine hesitancy can take different forms, including parents refusing all recommended vaccines or delaying in taking the vaccines due to different reasons $[9,10,11]$. The World Health Organization defines vaccine hesitancy as a "delay in acceptance or refusal of vaccines despite availability of vaccination services [1]. Indeed, the majority of parents agree to vaccinate their children amid concerns [2].

For instance, in a Canadian survey, $70 \%$ of parents were concerned about potential side effects of vaccines, and $38 \%$ believed that a vaccine could cause the disease that it was supposed to prevent [12], while in another study, parents whose children were not immunized cited the lack of perceived necessity of vaccines $(28 \%)$, concerns regarding vaccine safety (17\%), and the perceived number of side effects (12\%) as top reasons for not immunizing [13]. In a prevalence study for vaccine hesitancy among parents in the urban area of Western Bengal, India, indicated vaccine hesitancy prevalence of $29 \%$ [14], a result which was comparatively similar in a national study performed by Gust in Nigeria, where $28 \%$ of parents reported vaccine hesitancy, of which approximately two-thirds delayed or refused only certain vaccines [11].

According to the Strategic Advisory Group of Expert (SAGE) on immunization, the reasons for vaccine hesitancy fit into 3 categories: lack of confidence in effectiveness, safety, the system, or policy makers, complacency with perceived low risk of acquiring VPDs, and lack of convenience in the availability, accessibility, and appeal of immunization services, including time, place, language, and cultural contexts [1]. Consequently, challenges to maintaining adequate vaccine coverage include overcoming negative vaccine- and individual-specific attitudes and beliefs amidst a continual barrage of external factors such as vaccine controversies and evolving vaccination schedules that can also affect vaccination acceptance [15].

However, some parents are concerned about the cumulative pain and discomfort experienced by children who receive multiple shots at once, yet others worry about the potential health risks of receiving multiple vaccinations during one clinic visit, wondering whether the body can handle so many different antigens at once. In addition to that, parents' question whether the immune system may become overloaded by receipt of all the recommended vaccines during early childhood [16]. In some recent qualitative studies, it has been shown that mothers of infants who are afraid of vaccine adverse effects either decline or delay subsequent immunizations [17], yet results from earlier Qualitative studies have also suggested that vaccine-hesitant parents are significantly concerned about the immediate side effects of vaccines, such as redness, swelling or pain at the injection site [18]. The discomfort associated with vaccinations remains a significant barrier to vaccination, even as children age [15]. Although vaccines are well tolerated, no vaccine is entirely without risk, but due to lack of awareness, when children experience mild side effects, their mothers may refuse further immunizations [19, 20]. This vaccine refusal has been associated with outbreaks of invasive Haemophilus influenzae type $b$ disease, varicella, pneumococcal disease, measles, and pertussis, resulting in the unnecessary suffering of young children and waste of limited public health resources. Vaccine hesitancy is an extremely important issue that needs to be addressed because effective control of vaccine-preventable diseases generally requires indefinite maintenance of extremely high rates of timely vaccination $[2,15,20]$. This, therefore, calls for much-needed information about vaccines and safety. Although childhood immunizations are free in Uganda and many strategies like radio talk shows are done in a bid to change socio-cultural, religious beliefs and attitudes 
towards immunization and address vaccine hesitancy issues, and improve immunization coverage, there is little success [8, 21, 22], but only $55 \%$ of children aged $12-23$ months are fully vaccinated [23], yet the immunization agenda sets out seven priority areas and four core principles in, a world where everyone, everywhere, at every age, fully benefits from vaccines for good health and well-being [24].

Nansana Municipality is located in the Wakiso District of Central Uganda, in close proximity to Kampala City. It has a population of 532,800 people, with urban and peri-urban settlements. The municipality has persistently performed poorly with low routine immunization coverage and continues to frequently report outbreaks of vaccinepreventable diseases, especially measles. In the financial year 2018/19, the Municipality reported $41 \%$ and $42 \%$ coverage of Penta 3 and Measles vaccinations, respectively [25], which were far below the district performance at $82 \%$ and $87 \%$, respectively [26] and the national target of $>90 \%$ and $95 \%$ respectively [23], which could be due to increasing vaccine hesitancy.

In response to this, the current study explored the determinants of hesitancy to childhood immunizations of vaccinepreventable diseases in an urban setting like Nansana Municipality. The results of this study add to existing knowledge and guide policy makers to address the vaccine hesitancy issues to improve immunization programs in Uganda urban areas and sub-Saharan Africa and provide useful information for further research on these issues.

\section{Materials and Methods}

This was a cross-sectional mixed methods study using both quantitative and qualitative data collection methods, which was conducted between June and August 2021 in Nansana Municipality. The area is made up of four administrative divisions, namely, Nansana, Nabweru, Gombe, and Busukuma, and 29 parishes. It has 54 health facilities, with only $39 \%$ (21/54) of the health facilities having EPI services, while some of the remaining health facilities are used as outreach posts for EPI services [25].

The evaluation of the determinants of hesitancy to childhood immunization for vaccine-preventable diseases was carried out using researcher-administered questionnaires of 344 parents/guardians of children under 24 months. The sample size for quantitative data was estimated using the Kish Leslie formulae, 1965 of unknown population, [27] with vaccine hesitancy is estimated to be $29 \%$ [14]. Additionally, 2 focus group discussions of parents/guardians of children under 24 months from 2 randomly selected villages were all also conducted. The study employed simple random sampling strategies to identify respondents for the interviews. However, probability proportionate to size (PPS) was used for allocating the household according to the population of the divisions of Nansana Municipality, as shown in Table 1.

Table 1. Sample Size and Distribution among the Divisions of Nansana Municipality 2021

\begin{tabular}{|l|l|l|l|}
\hline Division & Number of Households & Percentage (\%) of HH & Sample Size \\
\hline Nansana & 52,725 & $39 \%$ & 134 \\
\hline Nabweru & 38,775 & $29 \%$ & 100 \\
\hline Gombe & 28,667 & $21 \%$ & 72 \\
\hline Busukuma & 14,444 & $11 \%$ & 38 \\
\hline Municipality & $\mathbf{1 3 3 , 2 0 0}$ & $\mathbf{1 0 0 \%}$ & $\mathbf{3 4 4}$ \\
\hline
\end{tabular}

A total of 2 focus group discussions from 2 randomly selected villages were conducted for parents/guardians of children $<24$ months. Each focus group had 8 participants (socially 
distanced, following the COVID-19 protocols to avoid it transmission), with each session taking 45 to 60 minutes.

\section{Participant Consent and Ethical Approvals}

Ethical approval was obtained from Mbarara University of Science and Technology, Research and Ethics Committee (MUST -REC, REF MUST-2021-68), and the Uganda National Council for Science and Technology (UNCST-REF HS1507ES). The clearance for conducting the research study in Nansana Municipality was sought and granted from Wakiso District Health Officer's office and the Nansana Municipal Council Town Clerk's office. All the participants were subjected to informed consent.

\section{Data Collection, Management, and Analysis}

Before data collection, the research instruments were pre-tested through the pilot study to determine suitability and appropriateness to ensure clarity and relevancy of data collection instruments. The structured questionnaire was adopted from the world health organization (WHO)-SAGE on vaccine hesitancy [28].

The content of the questionnaire included: socio-demographic variables, questions related to health services delivery in immunization context. Trained research assistants collected data under the guidance of the principal investigator.

Data was collected, cleaned, edited, and entered in SPSS version 20. Descriptive statistics were expressed as means/medians, frequencies, and percentages, whereas inferential statistics were analyzed using the Chi-square $\left(\chi^{2}\right)$ technique, where bivariate analysis was conducted to examine the association between the socio-demographics of parents, the health care system factors, and vaccine hesitancy. Crude Odds Ratios (COR) and corresponding 95\% Confidence Intervals
(CI) were reported. Significant variables (with a p-value $<0.05$ ) from the bivariate analysis were included in the models, the multivariate logistic regression to determine variables independently associated with vaccine hesitancy. Adjusted Odds Ratios (AOR) with corresponding 95\% CI were reported, and significance levels of $\mathrm{p}$ value $<0.05$ were used for hypothesis testing.

Qualitative data from the focus group discussions were captured as stated from the focus groups and key informants, transcribed and uploaded into the qualitative analysis software MAXQDA version 12. Data was analyzed following the six steps of the thematic approach developed by Braun and Clarke [29]. The data from the quantitative and qualitative analysis was triangulated. Data and information collected during the course of the study have been safely stored.

\section{Operational Definitions}

The following operational definitions were used:

\section{Hesitancy}

If the parent/guardian has ever been reluctant or hesitant to take the child for vaccination against the childhood vaccine-preventable diseases, he/she was considered having hesitancy.

\section{Refusal}

If the parents/guardian ever refused to take her or his child for immunization against the childhood vaccine-preventable diseases, he/she was considered a refusal.

\section{Results}

From the total of 344 sampled parents/guardians, the majority (72\%) had reached a secondary level of education or above, and more than $86 \%$ of the respondents were married or cohabiting. Most of the respondents $(81 \%)$ believed that immunization was beneficial for their children in preventing the occurrence and spread of diseases, and equally as many as $80 \%$ had some knowledge 
about childhood immunized diseases. The majority of the parents, $71 \%$, had a positive view of the health workers attitude, about $60 \%$ of them living within 2 kilometers from the health facility providing immunization services, and as many as $65 \%$ of the parents having had an experience with side effects from childhood immunization, though still a slight majority $58 \%$ appreciated that they had received adequate information about immunization for their children. The prevalence of vaccine hesitancy for childhood immunization among parents/guardians was found to be $27.6 \%$, while about $3 \%$ ever had a history of refusal to take their children for immunizations.

\section{Socio-Demographic Characteristics Determining Hesitancy to Childhood Immunizations}

Of the socio-demographic characteristics of the respondents, only the education level and the parent's belief in vaccine importance were found to be significantly associated with parental hesitancy to childhood immunizations, as shown in Table 2.

Table 2. Association between Socio-Demographic Factors and Vaccine Hesitancy in Bivariate Analysis, 2021

\begin{tabular}{|c|c|c|c|c|c|c|}
\hline \multirow[t]{3}{*}{ Variables } & \multicolumn{2}{|c|}{ Hesitancy to vaccinations } & \multirow[t]{3}{*}{$\chi^{2}$} & \multirow[t]{3}{*}{ df } & \multirow[t]{3}{*}{ p-value } & \multirow[t]{3}{*}{ COR; $(95 \% \mathrm{CI})$} \\
\hline & Yes & No & & & & \\
\hline & Freq $(\%)$ & Freq $(\%)$ & & & & \\
\hline \multicolumn{7}{|c|}{ Age of parent/guardian } \\
\hline$<25$ years & $38(27.1)$ & $108(72.9)$ & \multirow[t]{3}{*}{0.082} & \multirow[t]{3}{*}{2} & \multirow[t]{3}{*}{0.960} & \\
\hline $25-45$ years & $54(28.1)$ & $138(71.9)$ & & & & \\
\hline$>45$ years & $3(25.0)$ & $9(75.0)$ & & & & \\
\hline \multicolumn{7}{|c|}{ Gender of the parent/guardian } \\
\hline Male & $16(33.3)$ & $32(66.7)$ & \multirow[t]{2}{*}{0.912} & \multirow[t]{2}{*}{1} & \multirow[t]{2}{*}{0.340} & \\
\hline Female & $79(26.7)$ & $217(73.3)$ & & & & \\
\hline \multicolumn{7}{|l|}{ Education level } \\
\hline Never been to school & $6(85.7)$ & $1(14.3)$ & \multirow[t]{4}{*}{15.616} & \multirow[t]{4}{*}{3} & \multirow[t]{4}{*}{0.01} & \multirow[t]{4}{*}{$3.73(1.24-18.7)$} \\
\hline Primary $(\mathrm{P} 1-\mathrm{P} 7)$ & $22(24.4)$ & $68(75.6)$ & & & & \\
\hline Secondary (S1 - S6) & $54(28.4)$ & $136(71.6)$ & & & & \\
\hline Post-secondary & $15(26.3)$ & $42(73.7)$ & & & & \\
\hline \multicolumn{7}{|l|}{ Marital status } \\
\hline Never married & $4(16.0)$ & $21(84.0)$ & \multirow[t]{4}{*}{4.326} & \multirow[t]{4}{*}{3} & \multirow[t]{4}{*}{0.228} & \\
\hline Married/cohabiting & $86(29.1)$ & $210(70.1)$ & & & & \\
\hline Divorced/separated & $3(15.8)$ & $16(84.2)$ & & & & \\
\hline Widowed & $2(50.0)$ & $2(50.0)$ & & & & \\
\hline \multicolumn{7}{|l|}{ Religious affiliation } \\
\hline Catholic & $31(28.2)$ & $79(71.8)$ & \multirow[t]{6}{*}{4.458} & \multirow[t]{6}{*}{5} & \multirow[t]{6}{*}{0.486} & \\
\hline Protestant (Anglican) & $20(24.1)$ & $63(75.9)$ & & & & \\
\hline Muslim & $28(35.0)$ & $52(65.0)$ & & & & \\
\hline $\begin{array}{l}\text { Seventh Day } \\
\text { Adventist (SDA) }\end{array}$ & $4(16.0)$ & $21(84.0)$ & & & & \\
\hline Pentecostal & $11(26.2)$ & $31(73.8)$ & & & & \\
\hline Other religions & $1(25.0)$ & $3(75.0)$ & & & & \\
\hline \multicolumn{7}{|l|}{ Monthly Income } \\
\hline$<48$ USD & $21(32.3)$ & $44(67.7)$ & 1.222 & 2 & 0.543 & \\
\hline
\end{tabular}




\begin{tabular}{|c|c|c|c|c|c|c|}
\hline $49-143$ USD & $53(25.6)$ & $154(74.4)$ & & & & \\
\hline$>144$ USD & $21(29.2)$ & $51(70.8)$ & & & & \\
\hline \multicolumn{7}{|c|}{ Belief in vaccine importance } \\
\hline Yes & $54(19.4)$ & $225(80.6)$ & \multirow[t]{2}{*}{34.264} & \multirow[t]{2}{*}{1} & \multirow[t]{2}{*}{0.004} & \\
\hline No & $36(55.3)$ & $29(44.7)$ & & & & \\
\hline \multicolumn{7}{|c|}{ Knowledge of diseases } \\
\hline Yes & $71(25.8)$ & $204(74.2)$ & \multirow[t]{2}{*}{2.217} & \multirow[t]{2}{*}{1} & \multirow[t]{2}{*}{0.136} & \\
\hline No & $24(34.8)$ & $45(65.2)$ & & & & \\
\hline
\end{tabular}

The other socio-demographic variables, such as the age of the parent/guardian, gender of the parent/guardian, marital status, religion, monthly income, and knowledge of childhood immunized diseases, were found not to be determinants of hesitancy to childhood vaccinations against vaccine-preventable diseases.

Parents who had never received any formal education were about 4 times more likely to hesitate to take their children for immunization $(\mathrm{COR}=3.7,95 \%$ confidence interval, CI: 1.2 18.6), compared to those who had any formal education. On the other hand, parents who believed in vaccines protecting their children from the vaccine-preventable diseases were 3 times less likely to hesitate to take their children for immunization $(\mathrm{COR}=0.3,95 \% \mathrm{CI}$ : 0.1 - 0.7), compared to those who did not believe in vaccine importance, see Table 2 . Both factors retained their significance of determinants of hesitancy to childhood immunization after adjusting all other characteristics, as shown in Table 4.

\section{Health Care Delivery System Determinants of Parental Hesitancy to Childhood Immunizations}

There was significant association (p-value $<\mathbf{0 . 0 5})$ between some health service deliveryrelated factors to the parent's hesitancy to taking their children for immunization. These included health workers attitude $(\mathrm{COR}=0.16$, 95\% CI: $0.03-0.39$ ), availability of vaccines $(\mathrm{COR}=0.12, \quad 95 \% \quad \mathrm{CI}: \quad 0.04-0.42)$, accessibility to immunization services $(\mathrm{COR}=$ 0.22 , 95\% CI: $0.07-0.70)$, timing of the immunization clinic (COR $=5.2$, 95\% CI: $3.2-$ $8.7)$, side effects to vaccinations $(0.25,95 \% \mathrm{CI}$ : $0.08-0.79$ ), and information provision on immunization $\quad(\mathrm{COR}=0.24,95 \%$ CI: $0.08-$ 0.69), were all significantly associated with hesitancy to childhood immunization, see Table 3.

Table 3. Association between Health Care System Factors and Vaccine Hesitancy in Bivariate Analysis, 2021

\begin{tabular}{|c|c|c|c|c|c|c|}
\hline \multirow[t]{3}{*}{ Variables } & \multicolumn{2}{|c|}{ Hesitant to vaccination } & \multirow[t]{3}{*}{$\chi^{2}$} & \multirow[t]{3}{*}{ df } & \multirow[t]{3}{*}{ p-value } & \multirow[t]{3}{*}{$\operatorname{COR}(95 \% \mathrm{CI})$} \\
\hline & Yes & No & & & & \\
\hline & Freq $(\%)$ & Freq $(\%)$ & & & & \\
\hline \multicolumn{7}{|l|}{ Attitude of health workers } \\
\hline Positive (Friendly) & $52(21.4)$ & $193(78.6)$ & \multirow[t]{2}{*}{20.856} & \multirow[t]{2}{*}{1} & \multirow[t]{2}{*}{0.000} & \multirow[t]{2}{*}{$0.16(0.06-0.39$} \\
\hline Negative (Rude) & $34(34.4)$ & $65(65.6)$ & & & & \\
\hline \multicolumn{7}{|c|}{ Distance from the health facility } \\
\hline$<2$ kilometers & $47(22.8)$ & $159(77.2)$ & \multirow[t]{3}{*}{5.922} & \multirow[t]{3}{*}{2} & \multirow[t]{3}{*}{0.152} & \\
\hline $3-5$ kilometers & $38(34.9)$ & $71(65.1)$ & & & & \\
\hline$>5$ kilometers & $10(34.5)$ & $19(65.5)$ & & & & \\
\hline \multicolumn{7}{|l|}{ Availability of vaccines } \\
\hline Always available & $63(21.7)$ & $224(78.3)$ & \multirow[t]{2}{*}{26.740} & \multirow[t]{2}{*}{2} & \multirow[t]{2}{*}{0.012} & \multirow[t]{2}{*}{$0.12(0.04-0.42)$} \\
\hline Sometimes not all available & $24(47.9)$ & $26(52.1)$ & & & & \\
\hline
\end{tabular}




\begin{tabular}{|c|c|c|c|c|c|c|}
\hline Most times not any available & $3(42.9)$ & $4(57.1)$ & & & & \\
\hline \multicolumn{7}{|c|}{ Accessibility to immunization services } \\
\hline Yes & $70(23.1)$ & $235(76.9)$ & \multirow[t]{2}{*}{20.521} & \multirow[t]{2}{*}{1} & \multirow[t]{2}{*}{0.013} & \multirow[t]{2}{*}{$0.22(0.07-0.70)$} \\
\hline No & $21(52.6)$ & $18(47.4)$ & & & & \\
\hline \multicolumn{7}{|c|}{ Poor timing of immunization clinic } \\
\hline Yes & $58(53.7)$ & $50(46.2)$ & \multirow[t]{2}{*}{44.998} & \multirow[t]{2}{*}{1} & \multirow[t]{2}{*}{0.000} & \multirow[t]{2}{*}{$5.23(3.18-8.77)$} \\
\hline No & $44(18.6)$ & $192(81.4)$ & & & & \\
\hline \multicolumn{7}{|l|}{ Waiting time } \\
\hline$<3$ hours & $28(25.2)$ & $83(74.8)$ & \multirow[t]{3}{*}{1.459} & \multirow[t]{3}{*}{2} & \multirow[t]{3}{*}{0.482} & \\
\hline $4-5$ hours & $52(27.4)$ & $138(72.6)$ & & & & \\
\hline$>6$ hours & $15(34.9)$ & $28(65.1)$ & & & & \\
\hline \multicolumn{7}{|c|}{ Side effects after vaccinations } \\
\hline Yes & $72(32.3)$ & $151(67.7)$ & \multirow[t]{2}{*}{10.56} & \multirow[t]{2}{*}{1} & \multirow[t]{2}{*}{0.027} & \multirow[t]{2}{*}{$0.25(0.08-0.79)$} \\
\hline No & $28(22.9)$ & $93(77.1)$ & & & & \\
\hline \multicolumn{7}{|c|}{ Adequate information provision } \\
\hline Yes & $43(21.6)$ & $158(78.4)$ & \multirow[t]{2}{*}{16.301} & \multirow[t]{2}{*}{1} & \multirow[t]{2}{*}{0.018} & \multirow[t]{2}{*}{$0.24(0.08-0.69)$} \\
\hline No & $58(40.5)$ & $85(59.5)$ & & & & \\
\hline
\end{tabular}

Health worker's attitude, the timing of the immunization clinic, and adequate information provision all retained their significance of determinants of hesitancy to childhood immunization after adjusting all other characteristics as shown in Table 4. However, Other factors like distance from the health facility and waiting time were not significantly associated with vaccine hesitancy.

\section{Independent Determinants of Parental Vaccine Hesitancy to Childhood Immunizations}

In the final logistic regression model, education level, belief in vaccine importance, health workers attitude, the timing of immunization clinic, availability of vaccines, and adequate information provision were found to be independent determinants of hesitancy to childhood immunizations of vaccinepreventable diseases. Parents/guardians who had no formal education were 5 times more likely to hesitate to take their children for immunization (adjusted OR=4.9, 95\%CI: 2.6 29.5, $p=0.01$ ), compared to those who had attained a post-secondary level of education. Similarly, parents who viewed the timing of immunization services as poor were 3 times more likely to hesitate to take their children for immunization than those who did have a negative view of the immunization service's timing $(\mathrm{AOR}=3.4,95 \% \mathrm{CI}: 1.8-6.4, \mathrm{p}=0.01)$. On the other hand, parents/guardians who believed in vaccines protecting their children against the vaccine-preventable diseases were 2 times less likely to hesitate to take their children for vaccination $(\mathrm{AOR}=0.47,95 \% \mathrm{CI}$ : $0.17-0.97, \mathrm{p}=0.01$ ) compared to those who did not believe in vaccine importance, as well as those parents/guardians who had a positive view of health workers attitude being 5 times less likely to hesitate to take their children for vaccination compared to those who had a negative view of health workers attitude (AOR $=0.22$, 95\% CI: 0.06- 0.86, $\mathrm{p}=0.03)$. In the same vein, parents who thought they were provided with adequate information on immunization were about 2 times less likely to hesitate to take their children for vaccination (AOR $=0.64,95 \%$ CI: $0.06-0.99, p=0.04$ ) compared to those who believed were not provided with adequate information concerning immunization as shown in Table 4. 
Table 4. Multivariate Logistic Regression showing the Association between Socio-Demographic and Health Care System Factors and Parental Vaccine Hesitancy, 2021

\begin{tabular}{|l|l|l|l|l|l|}
\hline \multirow{2}{*}{ Variable } & \multirow{2}{*}{ Response } & \multicolumn{2}{|l|}{ Hesitant to vaccination } & \multirow{2}{*}{ AOR $($ CI; 95\%) } & p=value \\
\cline { 3 - 4 } & & Yes & No & & \\
\cline { 3 - 4 } & & Freq (\%) & Freq (\%) & & \\
\hline Education level & Informal & $6(85.7)$ & $1(14.3)$ & $\mathbf{4 . 9 1}(\mathbf{2 . 6}-\mathbf{2 9 . 5})$ & $\mathbf{0 . 0 1 2}$ \\
\hline Belief in vaccine importance & Yes & $54(19.4)$ & $225(80.6)$ & $\mathbf{0 . 4 7}(\mathbf{0 . 1 7}-\mathbf{0 . 9 7})$ & $\mathbf{0 . 0 1 4}$ \\
\hline Attitude of health workers & Friendly & $52(21.4)$ & $193(78.6)$ & $\mathbf{0 . 2 2}(\mathbf{0 . 0 6}-\mathbf{0 . 8 6})$ & $\mathbf{0 . 0 3 1}$ \\
\hline Availability of vaccine's & Always & $63(21.7)$ & $224(78.3)$ & $1.09(0.23-5.22)$ & 0.912 \\
\hline Easy accessibility to services & Yes & $70(23.1)$ & $235(76.9)$ & $2.74(0.62-12.1)$ & 0.184 \\
\hline Poor timing of clinic & Yes & $58(53.7)$ & $50(46.2)$ & $\mathbf{3 . 4 0}(\mathbf{1 . 8 1}-\mathbf{6 . 3 5})$ & $\mathbf{0 . 0 1 0}$ \\
\hline Side effects from vaccinations & No & $28(22.9)$ & $93(77.1)$ & $1.01(0.17-6.06)$ & 0.99 \\
\hline Adequate information & Yes & $43(21.6)$ & $158(78.4)$ & $\mathbf{0 . 6 4 ( 0 . 1 6 - \mathbf { 0 . 9 9 } )}$ & $\mathbf{0 . 0 4 3}$ \\
\hline
\end{tabular}

\section{Key Findings from the Focus Groups}

About $94 \%$ of the focus group discussion participants were females of median age 29 years. The focus area for the group discussions included (but was not limited to) the following questions: Do you believe that vaccines can protect children from serious diseases? Do you think that most parents like you have their children vaccinated with all the recommended vaccines?

Have you ever been reluctant or hesitated to get a vaccination for your child? Have you ever refused vaccination for your child? Why do you think children are given vaccines/immunization; are there situations when you failed to bring your child for immunization and what were the reasons? Has distance, the timing of clinic, the time needed to get to a clinic or wait at the clinic and/or costs in getting to the clinic prevented you from getting your child immunized? Are there other pressures in your life that prevent you from getting your child immunized on time?

Parents/guardians expressed their concerns about the long waiting time, inadequate health worker staffing numbers, and sometimes missing vaccines due to stock-outs as significant gaps affecting immunization service delivery.
"Generally, the health workers are good, and I have no problem with them, only that they are few yet we are many mothers" "I have no issues with the nurses. They try their best, but they get tired because we many on that day. We get tired when we go as we wait for a very long time" FGD1.

"Sometimes we go, and they tell us the "drugs" are not available, that we should come back another time, the "drugs" for babies. Sometimes the nurse immunizing is not there. "Even me mine of 11months has just received it that of 9 months because when I went there the last time, I could not get. Then I had to first be sure before going back" "You can walk or get a motorcycle, yet when you reach there, they send you back" FGD2.

Respondents were asked about the side effects to childhood vaccinations, how often this happens?

"They usually have pain and fever. The injections are very painful. My child's thigh got swollen after the injection, I came to the nurse, and she told me that all will be well", (FGD1).

"We really need more information about side effects of vaccines to convince our husbands, because, if the child gets fever and cries, they refuse us to come back for another "dose" (FGD1)"We need more information from the health workers and VHTs why they our children all those injections", (FGD2). 
The religious issues concerning vaccines were also noted;

"Some of the parents refuse to take their children for vaccination because of their religious beliefs. "Some believe in no need of vaccines as God protects them".

The effect of Covid-19 have also been felt, leading to fear of mothers taking their children for immunization, compounded by travel restriction and increased transport cost as noted by some mothers;

"We fear this Covid disease which is killing many people, we shall wait till it safe to take our children for immunization" (FGD1). "The transport cost for the "boda boda" has doubled. I can't afford that now" (FGD2).

\section{Discussion}

The findings show that the major determinants of parental vaccine hesitancy to childhood immunizations against vaccinepreventable diseases in this urban context were; education level, belief in vaccine importance in protective the child against the preventable killer diseases, health workers attitude, the timing of clinic for immunization services and adequate information provision.

Parent's level of education impacts on understanding of issues and greatly influences their decisions to vaccinate their children or not. Consistent with several studies conducted elsewhere, parents with less or no formal education have greater distrust in the medical community, express more concerns about vaccine safety, and have less belief in the necessity and efficacy of vaccines [30-33]. However, in contrast to finding in this study, Opel et al. found that parents with higher levels of education were nearly four times as likely to be concerned about the safety of vaccines than those from lower education levels [30], giving mixed results on the level of education and it impacts on parental vaccine acceptance and uptake. In a SAGE group systematic reviews, having attained higher education status in India and Nigeria promoted parental vaccine acceptance, while in the USA, China, and Lebanon, parents with a higher level of education persistently had more doubts on vaccines compared to those with lower education levels [34].

Parent's belief in vaccines' effectiveness and safety promotes trust, improves individual attitude, and reduces vaccine hesitancy. Consistent with studies conducted elsewhere, parents who have faith in vaccines protecting their children against the VPDs are more likely to have immunization acceptance and uptake of immunization [1, 13, 15]. A study done in Nigeria reported that parents who individually believe in vaccine effectiveness and safety take their children for vaccination more consistently and complete their immunization schedules [20]. In the current study, the variation in believing in different types of vaccines' effectiveness in protecting the children might have impacted the results. However, information on the belief in different vaccine antigen effectiveness was not collected and is an area for further investigation.

When the health worker's attitude is deemed as friendly by the parents/guardians positively impacts on parent's acceptance of immunization programs and therefore reduces on vaccine hesitancy. This consequently promotes a healthy parent-to-health worker relationship, resulting in addressing issues like the importance of completing the immunization schedule and the safety of vaccines [1, 28, 35]. According to [36], the study showed that parents who reported that their vaccination decisions were positively influenced by healthcare providers were also more likely to believe that vaccines were safe. In fact, parents with lower levels of trust in their child's doctor also have lower confidence in the safety of vaccines and therefore hesitate to vaccinate their children [32].

The convenience of the immunization services clinic also impacts on parents' access to immunization services, which, when is good, greatly reduces on hesitancy of parents to take 
their children vaccination which improves childhood immunization uptake and completion of the immunization schedule $[15,17]$. On the other hand, lack of convenience by parents and poor accessibility to immunization services greatly increases parental hesitancy to their children immunization $[1,28]$. The frustration from parents because of the long waiting time negatively impacts their decisions to take their children to the health facility for immunization [19]. They would rather stay home or attend to the immediate financial needs, rather than endure the long waiting time of 4-7 hours, including the travel to and from the health facility, yet they have their businesses and other competing needs to attend to Abdulraheem 2011 [20]. This would indirectly contribute to a delay in the schedule for the affected children because these parents/guardians may hesitate to return on the next rescheduled date. This calls for appropriate area-specific planning and local research within the division to find the ways to reach to these vulnerable children for protection against these vaccine preventable diseases in order to achieve the IA2030 [24].

Good communication leads to understanding and sharing of information. Adequate information provision, therefore, promotes vaccine acceptance and greatly reduces on vaccine hesitancy. In a study by Smith et al., effective communication and vital information sharing to parents reduce parental concerns about vaccine safety and side effects [36] and negative rumors about the vaccines [37]. When the parents are not given adequate information are more likely to hesitate to take their children for vaccination, despite overwhelmingly believing in vaccines protecting their children against the diseases [9]. Well-informed parents are likely to understand the importance of honoring the return dates and completing the immunization schedule [21]. As indicated in the focus group discussions, the parents need more adequate information on how to address the side effects.
The prevalence of $27.6 \%$ for parental hesitancy towards childhood immunization found in this study, does explain in part why immunization uptake is low in Nansana Municipality [25] and frequent outbreaks of measles in the area. A comparable study done in India from an urban of West Bangal had hesitancy marginally higher at 29\% Sikder2020 [14], while from another study from Nigeria it was $28 \%$ [11]. The refusal parents prevalence of $3 \%$ was slightly higher than a previous study result of $1-2 \%$ from the USA, $[9,15]$.

In contrast to the findings of a review of studies conducted elsewhere, parents age, gender, religion, income, marital status, knowledge of vaccines, distance to the immunization center, and waiting time were not found to be associated with vaccine hesitancy $[34,37,38]$. In other studies, Parents of lowerincome brackets have greater levels of concern about the safety and necessity of vaccines as compared with those of higher income [30-32, 39]. However, socioeconomic factors appear to have conflicting associations with parental immunization acceptance, which could reflect differences in underlying beliefs about vaccines that differ by socioeconomic strata [15].

Availability of vaccines and side effects of vaccines were not independently associated with parental vaccine hesitancy. The availability of vaccine issues could be attributed to easy accessibility to other immunization centers since over $90 \%$ of parents live within a 5-kilometer distance from the health facility offering EPI services. On the other hand, the issue of side effects not being independently associated with vaccine hesitancy could probably be because, although some parents/guardians may get side effects or reactions to vaccines, they might have been given information about expected reactions to vaccinations like fever and pain at the site and therefore cannot hinder them taking their children for vaccination, which makes it of less importance. In contrast to studies elsewhere, the side effects of vaccines frequently and 
consistently were the major independent determinants to parental vaccine hesitancy [20, 34, 37, 40]. Side effects from vaccinations negatively affect parents decisions to delay or stop the immunization of their children $[16,17$, 20].

Admittedly, however, as reported by SAGE, very few studies on vaccine hesitancy have been conducted in African compared to the Americas and Europe, yet the burden of unimmunized children as high as over $80 \%$ are from Africa [34]. In fact, little is known about the nature and causes of vaccine hesitancy in Africa, with most research in this area conducted in high-income countries [41]. A few of the studies conducted in Kenya, Malawi, and Ethiopia [37], and Nigeria [34], mostly use models developed in Western countries, which may not be suitable for African populations.

The impact of misinformation about childhood immunization on social media platforms and how they can affect parental vaccine hesitancy in an urban settlement have not been explored by this study and therefore recommended for further research.

\section{Study Limitations}

Although the study was confined to one municipality, this study area is typical of other urban settings in terms of health infrastructure and in Uganda. The study findings are therefore comparable across similar settings. We also note that this was a cross-sectional study and therefore, we cannot define the temporal relationship between the independent variables and outcome.

The direction of causality can therefore only be regarded as suggestive. The data collected on a number of independent variables were based on self-reports that are likely to be subject to social desirability bias. As a result, there is a limit to which such responses can be considered accurate by foreknowledge of what, in the view of the respondent, would be a suitable response. However, the current findings do carry implications for health service managers, decision-makers, and health care providers in their consideration of designing the measures to address parental hesitancy to childhood vaccinations against vaccinepreventable diseases.

\section{Conclusion}

The parental vaccine hesitancy prevalence rate is comparatively similar to previous urban area studies.

Although parents overwhelmingly share the belief that vaccines are a good way to protect their children from vaccine-preventable disease, these same parents express concerns regarding the convenience of the immunization clinic services and side effects of vaccines. Even though the information is available to address the many vaccine safety concerns, such information is not reaching many parents in an effective manner.

\section{Appendices}

\section{Abbreviations}

$\begin{array}{lll}\text { AOR } & : \text { Adjusted Odds Ratio } \\ \text { COR } & : \text { Crude Odds Ratio } \\ \text { COVID-19 } & : \text { Corana Virus Disease -2019 } \\ \text { CI } & : \text { confidence interval } \\ \text { FGD } & : \text { Focus Group Discussion } \\ \text { IA2030 } & : \text { Immunization Agenda 2030 } \\ \text { SPSS } & : \text { Statistical Package for Social Sciences } \\ \text { WHO } & : \text { World Health Organization }\end{array}$

\section{Consent for publication}

Not applicable.

\section{Availability of Data and Materials}

All data supporting our findings are contained in the paper. There are no restrictions to data sources.

\section{Competing interests}

The authors declare that there are no competing interests.

\section{Funding}

The study was self-sponsored. 


\section{Acknowledgements}

All participants in this study

\section{References}

[1] MacDonald, N. E, 2015 "Vaccine hesitancy: Definition, scope, and determinants," Vaccine, 33(34), 4161-4164, https://doi.org/10.1016/j.vaccine.2015.04.036.

[2] Salmon, D. A., Dudley, M. Z., Glanz, J. M, and S. B. Omer, S. B, 2015 "Vaccine hesitancy: Causes, consequences, and a call to action," Vaccine, vol. 33, D66-D71.

https://doi.org/10.1016/j.vaccine.2015.09.035.

[3] World Health Organization, 2018 "World health statistics 2018: monitoring health for the SDGs, sustainable development goals: World Health Organization," Geneva, Switzerland, https://creativecommons.org/licenses/by-ncsa/3.0/igo.

[4] Tadesse, H., Deribew, A and Woldie, M, 2009 "Predictors of defaulting from completion of child immunization in south Ethiopia, May 2008 A case control study," BMC Public Health, vol. 9, 4-9, https://doi.org/10.1186/1471-2458-9-150.

[5] World Health Organization, 2009 "World Health Statistics," WHO Library Cataloguing-inPublication Data Geneva, World Health Organization, Geneva, Switzerland.

[6] Wolfson et al., 2008 "Estimating the costs of achieving the WHO - UNICEF Global Immunization Vision and Strategy, 2006 - 2015," https://doi.org/10.2471/BLT.07.045096.

[7] World Health Organization, 2021"World Health Statistics," World Health Organization, Geneva, Switzerland,

https://creativecommons.org/licenses/by-ncsa/3.0/igo.

[8] Rutherford, M. E., Mulholland, K and Hill, P. C, 2010 "How access to health care relates to underfive mortality in sub-Saharan Africa: systematic review," Trop. Med. Int. Heal., 15(5), 508-519, https://doi.org/10.1111/j.1365-3156.2010.02497.x.

[9] Freed, G. L., Clark, S. J., Butchart, A. T., Singer, D. C, and Matthew, M, 2010 "Parental Vaccine (parents/guardians, Nansana Municipal Council health team, and the Research assistants).

Safety Concerns in 2009 Parental Vaccine Safety Concerns" Off. J. Am. Acad. Pediatr, DOI: 10.1542/peds.2009-1962.

[10] Schaffer, S. E., Singer, D., Butchart, A. T and M. Davis, M, 2011 "Alternative Vaccination Schedule Preferences Among Parents of Young Children," Vaccines, https://doi.org/10.1542/peds.2011-0400.

[11]Gust, D. A., Darling, N., Kennedy, A and Schwartz, B, 2021 "Parents with Doubts About Vaccines: Which Vaccines," vol 3, https://doi.org/10.1542/peds.2007-0538.

[12]Dubé et al., 2013 "Vaccine hesitancy an overview," Hum. Vaccine. Immunother., vol. 5515, https://doi.org/10.4161/hv.24657.

[13] Guay, M., Dubé, E and Laberge, C, 2018 "A Portrait of Vaccine-Hesitant Canadians," in Public Health in the Age of Anxiety, University of Toronto Press, pp. 165-194. https://doi.org/10.3138/9781487510404-008.

[14]Sikder et al., 2020 "Prevalence of vaccine hesitancy and its associated factors in an urban area of West Bengal, India," Int. J. Community Med. Public $\quad H e a l ., \quad 7 \quad$ (9), 43-49, http://dx.doi.org/10.18203/2394-

6040.ijcmph20203905.

[15] Gowda, C, and Dempsey, A. F, 2013 "The rise (and fall?) of parental vaccine hesitancy," Hum. Vaccine. Immunother., vol. 5515, https://doi.org/10.4161/hv.25085.

[16] Williams, S. E, 2014 "What are the factors that contribute to parental vaccine-hesitancy and what can we do about it?" Hum. Vaccine. Immunother., vol. 5515, https://doi.org/10.4161/hv.28596.

[17] McClure, C. C., Cataldi, J. R and S. T. O'Leary, S. T. O, 2017 "Vaccine Hesitancy: Where We Are and Where We Are Going," Clin. Ther., 39 (8), 1550-1562,

https://doi.org/10.1016/j.clinthera.2017.07.003.

[18] Shui, I., Kennedy, A., Wooten, K and Schwartz, B, 2005 "Factors Influencing African-American Mothers' Concerns about Immunization Safety: A 
Summary of Focus Group Findings," Atlanta Georgia, PMID: 15926642.

[19] Al-moukhtar, O and Al-, O, 2011 "Knowledge, attitude and practices of mothers regarding immunization of infants and preschool children at Al-Beida City, Libya 2008,” Egypt J Pediatr Allergy Immunol, 9 (1), 29-34.

[20] Abdulraheem, L. S., Onajole, A. T., Jimoh, A. A. G and Oladipo, A. R, 2011 "Reasons for incomplete vaccination and factors for missed opportunities among rural Nigerian children," J. Public Heal. Epidemiol., vol. 3, April 194-203, http://www.academicjournals.org/jphe.

[21]Malande et al., 2019 "Barriers to effective uptake and provision of immunization in a rural district in Uganda," PLoS One, 14 (2), e0212270, 14 (2), p. e0212270, https://doi.org/10.1371/journal.pone.0212270.

[22] Maina, J., Karanja, L. C \& Kombich, S, 2013 "Immunization coverage and its determinants among children aged 12 - 23 months in a peri-urban area of Kenya.," vol. 8688, 1-7, https://doi.org/10.11604/pamj.2013.14.3.2181.

[23] Ministry of Health, "Health Annual health Sector Performance Report," 2019. Ministry of Health: Kampala, Uganda.

[24] O'Brien, K., Lindstrand, A and Nandy, R, 2021 "The Immunization Agenda 2030: a vision of global impact, reaching all, grounded in the realities of a changing world,"

http://dx.doi.org/10.2139/ssrn.3830709.

[25]Nansana Municipal Council, HMIS Report 2019 "Nansana Municipality Health Records." Municipal Health Office, Nansana, Uganda.

[26] Wakiso District Local Government, HMIS Report 2019 "Wakiso District Health Records." District Health Officer, Wakiso, Uganda.

[27] Pourhoseingholi, M.A., M. Vahedi, M and M. Rahimzadeh, M, 2013 "Sample size calculation in medical studies," 6 (1), 14-17, PMID: 24834239.

[28] World Health Organization, 2014 "Report of the Sage Working Group on Vaccine Hesitancy," http://www.who.int/immunization/sage/sage_wg_va ccine_hesitancy_apr12/en/.

[29] Braun, V, 2014 "What can " thematic analysis", offer health and well-being researchers?" Int J
Qualitative Stud Health Well-being, 1, 9-10, http://dx.doi.org/10.3402/qhw.v9.26152.

[30] Opel et al., 2011 "Validity, and reliability of a survey to identify vaccine-hesitant parents," Vaccine, $29 \quad$ (38), 6598-6605, https://doi.org/10.1016/j.vaccine.2011.06.115.

[31] Shui, I. M., Weintraub, E. S and Gust, D. A, 2006 "Parents concerned about vaccine safety: differences in race/ethnicity and attitudes," Am. J. Prev. Med., 31 (3), 244-251, https://doi.org/10.1016/j.amepre.2006.04.006.

[32] Gust, D. A., Woodruff, R., Kennedy, A., Brown, C., Sheedy, K and Hibbs, B, 2003 "Parental perceptions surrounding risks and benefits of immunization," in Seminars in pediatric infectious diseases, 2003, $14 \quad$ (3), 207-212, https://doi.org/10.1016/S1045-1870(03)00035-9.

[33] Gust, D. A., A. Kennedy, A., Shui, I., Smith, P. J., Nowak, G and Pickering, L. K, 2005 "Parent attitudes toward immunizations and healthcare providers: the role of information," Am. J. Prev. Med., $29 \quad$ (2), 105-112, https://doi.org/10.1016/j.amepre.2005.04.010\.

[34] Sadaf, A., Richards, J. L., Glanz, J., Salmon, D. A, and S. B. Omer, S. B, 2013 “A systematic review of interventions for reducing parental vaccine refusal and vaccine hesitancy," Vaccine, 31 (40), 42934304, https://doi.org/10.1016/j.vaccine.2013.07.013. [35]Olson, O, and Berry, C, 2020 "Addressing Parental Vaccine Hesitancy towards Childhood Vaccines in the United States: A Systematic Literature Review of Communication Interventions and Strategies," $\quad$ Vaccine, 2020, https://doi.org/10.3390/vaccines8040590.

[36] Smith, P. J., Kennedy, A. M., Wooten, K., Gust, D. A and Pickering, L. K, 2006 "Association between health care providers' influence on parents who have concerns about vaccine safety and vaccination coverage," Pediatrics, 118 (5), e1287e1292, https://doi.org/10.1542/peds.2006-0923.

[37]Adamu et al., 2021 "Drivers of hesitancy towards recommended childhood vaccines in African settings: a scoping review of literature from Kenya, Malawi, and Ethiopia," Expert Rev. Vaccines, $20 \quad$ (5), 611-621, https://.doi.org/10.1080/14760584.2021.1899819. 
[38] Azizi, F. S. M., Kew, Y and Moy, F. M, 2017 "Vaccine hesitancy among parents in a multi-ethnic country, Malaysia,” Vaccine, 35 (22), 2955-2961, https://doi.org/10.1016/j.vaccine.2017.04.010.

[39] Kennedy, A. M., Brown, C. J and D. A. Gust, D. A, 2005 "Vaccine beliefs of parents who oppose compulsory vaccination," Public Health Rep., 120 (3), 252-258, https://doi.org/10.1177/003335490512000306.

[40] Giambi et al., 2018 "Parental vaccine hesitancy in Italy - Results from a national survey," Vaccine,
36 (6), 779-787, https://doi.org/10.1016/j.vaccine.2017.12.074. [41] Cooper, S., Betsch, C., Sambala, E Z., Mchiza, $\mathrm{N}$ and Wiysonge, C. S, 2018 "Vaccine hesitancy-a potential threat to the achievements of vaccination programmes in Africa," Hum. Vaccine. Immunother, $14 \quad$ (10), 2355-2357, https://doi.org/10.1080/21645515.2018.1460987.w. 


\title{
Financial Health Affects Medical Outcomes; the Case of Some Mission Hospitals in Ghana
}

\author{
Ebenezer Kenneth Abban \\ Healthcare Administration, Texila American University, Akwatia, Ghana
}

\begin{abstract}
Health financing is a major pillar in the delivery system. Health care services are financed by governments and non-governmental organizations, all for the ultimate objective of ensuring the delivery of care. Health facilities have the onus to create the enabling environment to ensure that care is in continuum and at least efforts are made at the provision of quality care. The financial healthiness of hospitals certainly affects medical outcomes since it takes money to render every service in the healthcare industry. This study worked on the assumption that financial health affects medical outcomes, and the data has proven to be true that there was a positive/significant correlation $(p<0.0001 *)$ of the topic.
\end{abstract}

Keywords: Clinical Indicators, Financial Health, Health Financing, Hospitals, Healthcare, Medical Outcomes.

\section{Introduction}

Financial management is arguably one major component in the delivery of all services [1], especially in health services delivery to meet the expectations of patients. The exercise of power plays a crucial role in the management of healthcare organizations [2]. Given that power influences the administration of health service delivery, it is the opinion of the researcher that strong leadership towards the right objectives in the delivery of quality health services can significantly position the financial health of hospitals to positively affect medical outcomes.

"According to the 2009 World Health Organization (WHO) National Health Accounts, 47 percent of total health spending in Ghana is private (37 percent paid out of pocket and 10 percent paid by private insurance and other private risk-pooling mechanisms). Of the 53 percent public spending share, the NHIS accounts for some 30 percent of public spending on health and 16 percent of total health spending. Depending on how it is measured, public spending on health in Ghana is either slightly above or about the same as global income comparators. Depending on how it is measured, out-of-pocket spending (a gross measure of financial protection) in Ghana is higher than or about the same as global income comparators but twice the threshold recommended by the WHO" [3].

Medical outcomes are largely dependent on the availability of adequate funds. Availability of funds in healthcare delivery is very essential at all times. Therefore, health financing on the back of good leadership [4] could be described as the lifeline to the very survival of the healthcare industry, especially, in an era where a study by John Hopkins found that disruption to the health systems caused by Covid-19 could result in an additional 1.1 million child deaths and 56,700 maternal deaths in low- and middleincome countries [5]. Concerns such as the ability to raise funds for health; reducing financial barriers to access healthcare through prepayment and subsequent pooling of funds in preference to direct out-of-pocket payments by patients and allocating or using funds in a way that promotes efficiency and equity in health 
financing determine the very existence of healthcare service delivery in any country [6]. Health financing, and the subsequent medical outcomes, have even become more relevant and crucial today in the world more than ever before because governments across the globe are making and require every effort, on a continuous basis, towards the achievement of the Sustainable Development Goals (SDGs) of 2030, and in particular SDG 3 - "To ensure healthy lives and promote well-being for all at all ages."[7]. Health financing invariably is basic to the very survival of the operations of healthcare delivery systems [8].

It refers to the "function of a health system concerned with the mobilization, accumulation, and allocation of money to cover the health needs of the people, individually and collectively, in the health system the purpose of health financing is to make funding available, as well as to set the right financial incentives to providers, to ensure that all individuals have access to effective public health and personal health care" [9].

Funding for the delivery of healthcare ultimately aims at yielding better medical outcomes. In the estimation of the World Health Organization [10], measuring progress towards universal health coverage for example, shall require strong country health financing systems that can provide equitable access to quality health services. Thus, many healthcare providers often present quarterly, semi-annually, and annual performance reviews on their performances. Invariably, the objective of health financing, as generally expressed by scholars of the industry, is not only to put systems to raise adequate funding for healthcare delivery but more importantly, to create an equitable system of payment where patients are able to access unimpeded health services without the risk of not having access to healthcare due to financial difficulties. Therefore, health financing could largely imply systems to raise sufficient funds for the delivery of healthcare and to dispense financial risk defense for the general population.
These objectives will be easier to obtain if the available funds are used efficiently - so efficiency in a resource is usually taken as a third objective. As a result, according to World Health Organization, the financing system is often divided conceptually into three inter-related functions - revenue collection, fund pooling, and purchasing/provision of services. Before focusing on measurement strategies and indicators for these functions, it is important to understand the key components of each of them. In the World Health Organization's assessments of member country's health financing regime for 2015, this assertion was made.

"Most low-income and many middle-income countries, revenue collection derives from a mix of domestic and external sources. Despite the substantial increases in external assistance for health since 2000, the resources available are still insufficient in most low-income settings to assure universal coverage with even a very basic set of needed interventions. This is not the place to debate exactly how much is needed, but adjustment of Commission on Macroeconomics and Health estimates of the cost of a core package to current prices reveals a need for around US\$40 per person per year. This is an underestimate for many reasons, but even then, almost a third of the 193 member countries of WHO did not yet have access to even this level of funding in 2005, while 33 spend less than $\$ 25$ per person each year despite increased external inflows. An ideal indicator of this part of the financing system would need to capture the amount and the adequacy of the funds that are raised."

Ghana is a member of the World Health Organization, and like other sub-Saharan African countries, such as Kenya, Nigeria, Tanzania, and Uganda, different forms of health insurance were observed. These health insurances are primarily community-based. No doubt, the NHIS has made care accessible and affordable in Ghana, and some groups of people such as the aged, children, and pregnant women are given immunity against premium payment. 
This has assisted to remove some amount of financing barriers to healthcare. People who are registered in the scheme use healthcare services more than those who are not insured. Though the NHIS increased access to healthcare, this access is far from universal, as it demands premium payment before one can access healthcare thus, still impeding unimpeded access to care. Many studies reported varying proportions of the population who are not covered by the scheme; a World Bank study, for example, reported that only $40 \%$ of the Ghanaian population were enrolled in the scheme by 2013 [11]. A health financing regime that totally insolates the population from financial difficulty in accessing an equitable healthcare delivery system may still be far from achievable in Ghana.

This requires resilient and well-managed financial systems at the facility level so that patient's need, at least those who can access care, are met on a visit. Purchasing of medical consumables, payment of salaries of staff, and indeed maintenance of general operation systems of the hospital all require the use of money. Health financial eventually aims at a healthy financial base for quality delivery of health services. Thus, the financial health of hospitals is largely related to medical outcomes because service delivery is closely knit to funding capacity. Consequently, the researcher sought to test this hypothesis:

Ho (null): $\mu \mathrm{A}-\mu \mathrm{c}=\mathrm{O}$ Financial health does not influence medical outcomes of hospital.

Ha (alter): $\mu \mathrm{A}-\mu \mathrm{c}=\varnothing$ Financial health does influence medical outcomes of hospital.

\section{Methodology}

All the seven mission hospitals in that part of Ghana were selected. A targeted group of three each of health information officers and senior accountants were engaged in structured interviews. This was based on the last three year's (2018 - 2020) financial position statements and ten year's of clinical indicators on specific medical outcomes. While simple random sampling was employed for the other selected health workers based on the number of respondents for each facility. Each hospital had a total of the designated number as shown in the sample size table (Refer Table 1).

These people were engaged through field agents at the 7 hospitals to ensure that the responses would be true and objective reflections of the real situations on the ground. Thus, to avoid unnecessary biases in the responses so that the ultimate result of the study could ignite the enabling discussions needed to open new avenues and add to the stock of knowledge. Following from Bryman and Bell (2007), the researcher solemnly declared adherence to the standards as required under ethical considerations of research work. And ethical clearance was sought from the Institutional Review Board of the Christian Health Association of Ghana PIN: (CHAGIRB02022021).

\section{Study Type}

A cross sectional study research design. It employed trend analysis of data available and which were collected on the field.

\section{Population and Sample Size}

The total population of the study was 2853 . And the formula below was used to select a total of 1350 as the sample size $(n)=N /\left[1+N\left(e^{2}\right)\right]$. Where; $\mathrm{n}=$ Sample Size, $\mathrm{N}=$ Total population, $\mathrm{e}=$ margin of error $(5 \%$ or 0.05$)$ with confidence level of $95 \%$. Refer Table 1. 
Table 1. Sample size

\begin{tabular}{|l|l|l|}
\hline Facilities & Population & Sample size (n) \\
\hline 1 & 687 & 253 \\
\hline 2 & 484 & 219 \\
\hline 3 & 620 & 243 \\
\hline 4 & 286 & 167 \\
\hline 5 & 218 & 141 \\
\hline 6 & 238 & 149 \\
\hline 7 & 320 & 178 \\
\hline Total & 2853 & 1350 \\
\hline
\end{tabular}

Source: Ryan, (2013)

\section{Data Collection and Tools}

The investigator utilized structured interviews and administration of questionnaires in a survey to collect and gathered the required data. Data were entered into open-source software - Epidata. The data were later exported to 'Stata 15' software for analysis. In the interviews, participants of the study were asked questions bothered on the financial health and medical outcomes of the hospitals over a period of three years and ten years. Questions on the financial health of the hospitals based on the financial position statements of the hospitals for the previous three years $(2018$ - 2020) were asked, and financial ratios were calculated in a word document table. The data on annual clinical indicators for ten years $(2011-2020)$ were entered onto a simple excel spreadsheet to determine the averages of the medical outcomes. Additionally, respondents of the questionnaire were made to answer 5-point Likert scale questions on the financial performance and medical outcomes of the hospitals.

\section{Data Analysis}

Financial ratios were used, and averages were applied in each of the parameters in assessing the financial health of the facilities. Particular reference was made to profitability, liquidity, and operating efficiency. This was based on the assessment of the audited financial position statements of the mission hospitals for a threeyear period (2018-2020). Again, utilizing the remits set by Alanna-Moriarty [12], trend analysis, for ten years, was performed on the rate of admissions, rate of OPD attendance, and percentage of OPD insured using a simple excel spreadsheet. Emphasis was laid on the previous three years $(2018-2020)$ at the results column to correspond with the effect of financial health on medical outcomes as indicated by the topic. Additionally, 'Stata 15' was used in the analysis of the data gathered from the responses to the questionnaire. The data was analyzed in descriptive, regression, correlation, and hypothesis testing to establish the veracity or otherwise of the influence of the independent variable on the medical outcomes of mission hospitals.

\section{Variables Measurement}

Refer Table 2.

Table 2. Variables Measurement

\begin{tabular}{|l|l|}
\hline Table of Variables Measurement \\
\hline Dependent variable & Medical outcomes of hospital \\
\hline Independent variables & Financial health \\
\hline
\end{tabular}

Source: Field work, 2021 


\section{Results and Discussions}

Table 3 below shows an unadjusted linear regression analysis. The analysis revealed that there is strong evidence of a statistically significant relationship between financial health and medical outcomes of the 7 mission hospitals. The outcome of the analysis indicated that a unit change in the perceived mean score of the financial health of mission hospitals will increase the perceived mean score of medical outcomes by 0.49 times with $p$-value $<0.0001$; 95\%CI [0.45-0.54].

The R-squared of $25.3 \%$ shows that financial health accounts for $25.3 \%$ of the variations in the model. The outcome of the analysis proves my hypothesis that financial health influences medical outcomes in mission hospitals was true. The financial health of mission hospitals has a positive effect on medical outcomes.

Table 3. Simple Linear Regression showing the Impact of Financial Health on Medical Outcomes of Mission Hospitals

\begin{tabular}{|l|l|l|l|l|}
\hline Covariate & Coefficient & Standard Error & $\boldsymbol{p}$-value & 95\% CI \\
\hline Financial health & 0.49 & 0.02 & $<0.0001 *$ & {$[0.45-0.54]$} \\
\hline
\end{tabular}

Statistically significant at $\mathrm{p}<0.0001 *$

CI - Confidence Interval

Adjusted R-squared $=0.2530$

Hypothesis

Reject $\mathrm{H}_{0}$ and conclude on $\mathrm{H}_{1}$

The investigator relied on the averages gathered on the year to year ending financial statements of the selected facilities in calculating the profitability of the hospitals. Financial ratios, i.e., return on capital; net profit margin, and asset turnover ratios, were utilized. Generally, return on capital employed measures the extent of a company's profitability. If the ratio was rising, it meant that the capital employed of the company was generating enough profits. From table 3, the average of this ratio increased from $2.79 \%$ in 2018 to $7.32 \%$ in 2019 . It, however reduced by $5.25 \%$ in 2020 .

Although in 2020 it decreased, it was still better than that of 2018. And this meant that the hospitals were profitable under the period of review. For every Cedi of Capital Employed by the Hospitals in 2020, 5.25\% of it was generated into operating profit or surplus. Thus, to earn every Cedi, the hospital needed to employ GH $\varnothing 19.05$ worth of Capital. Net Profit margin shows the net profit expressed as a percentage of sales /turnover/revenue. When this ratio is rising, it is an indication that operating expenses are effectively controlled and that the company earns a meaningful profit from its sales. The Net
Profit Margin increased from $1.72 \%$ in 2018 to $4.59 \%$ in 2019 but decreased to $3.10 \%$ in 2020 . A $3.10 \%$ Margin is an indication that the Hospitals earn, on average, 3.10 pesewas for every Cedi it collected. Asset Turnover measures how well the assets of a business are being used to generate sales. This explains more about the efficiency of the assets. The assets turnover ratio, however decreased from 1.62 times in 2018 to 1.59 times in 2019 before rising to 1.69 times in 2020.

The Liquidity position of the hospitals was determined by assessing the current and quick or acid test ratios. The current ratio shows the hospitals' ability to pay short-term obligations or those due within one year. It is generally asserted that the best relationship between current assets and current liabilities should be 2:1.

The current ratio has been rising over the years. For every GH $₫ 1.00$, the hospitals' owed in current liabilities, they had on average $\mathrm{GH} ф 2.35$ to pay in 2018; $\mathrm{GH} ф 2.48$ to pay in 2019 , and $\mathrm{GH} \phi 3.41$ to pay in 2020. Quick ratio or the acid test ratio compares the Hospitals' most short-term assets to its most short-term 
liabilities to see if it has enough cash to buy off the immediate liabilities.

This ratio shows the relationship between liquid assets and current liabilities. Generally, a ratio of $1: 1$ is acceptable. The quick ratio has been increasing over the period 1.73:1 in 2018, 1.98:1 in 2019, and 2.66:1 in 2020. In calculating the operation efficiency of the hospitals, the receivables days ratio which focuses on the time it takes for debtors to settle their bills and shows whether debtors are allowed excessive credit period, which was 83.56 days in 2018, 87.09 days in 2019, and 74.62 days in 2020; payables days ratio which gives insight into whether a business is taking full advantage of trade credit available to it or not stood at 237.98 day in 2018 , 242.81 days in 2019, and 152.45 days in 2020; the average inventory turnover period which depicts the rate at which the hospitals sold and replaced their stock of goods during a particular period which was 176.09 days in $2018,128.26$ days in 2019 and 115.18 days in 2020; and the rate of inventory turnover, a measurement of the number of times inventory was sold or used in a given time period, usually per year - the rate rising shows how well the hospitals had been converting their inventory into sales, the rate of inventory turnover for 2018 was 2.07 times then increased to 2.85times in 2019 and in 2020 the rate was 3.17 times, were all analyzed. The ratios, when put together, helped to determine the cash conversion cycle, which measures how much time the hospitals took to sell their inventory, how much time they took to collect receivables, and how much time they took to pay their bills. The cash conversion cycle of the hospitals had been reducing from 21.46 in 2018 to -27.46 in 2019 , then to -4.23 in 2020 . The negative cash conversion cycle meant that it took the hospitals a longer time to pay suppliers/creditors than it took them to sell their inventory and get reimbursed by their debtors. This implies that the operations of the hospitals were financed by suppliers. Therefore, the hospitals did not need operating cash to grow.

These financial metrics reflected on the medical outcomes of the hospitals over the period under discussion. Utilizing clinical indicators on a trend analysis basis, over a period of ten years and five years, in some cases, i.e., a trend of admissions, a trend of OPD attendance, and trend of percentage of OPD insured, the data spoke to the hypothesis as true.

The trend of admissions, generally, is a measure of hospital revenue mobilization. Inpatient services pay better [13] than outpatient service. Although in recent times, however, the trend is changing. All things being equal, when admissions grow in percentages or numbers, it also means that revenue could rise. Bed occupancy rate reels on inpatients services. The latter, just like the former, is also acutely observed as a measure of the medical outcome. Globally, it is evident from available data that, due to the novel COVID-19, total hospital admissions dropped by $8.5 \%$ of the total expected admission in 2020.

Thus, "total admissions dropped to $69.2 \%$ of predicted admissions during the week ending April 4, 2020 - the lowest point in the year before rising again and staying at or above $90 \%$ since June 2020" [14].

This was not different from the trend in Ghana as hospitalization generally went down in 2020 [15]. Among other reasons, people simply refused to visit hospitals for fear of contracting the virus. Nevertheless, even though from figure 1 , it is observed that total admissions went down in the mission hospitals by 4 percentage points from the previous year, the figure was better comparing with $8.5 \%$ as was reported elsewhere, and extremely ahead of the years 2017 and 2018. 

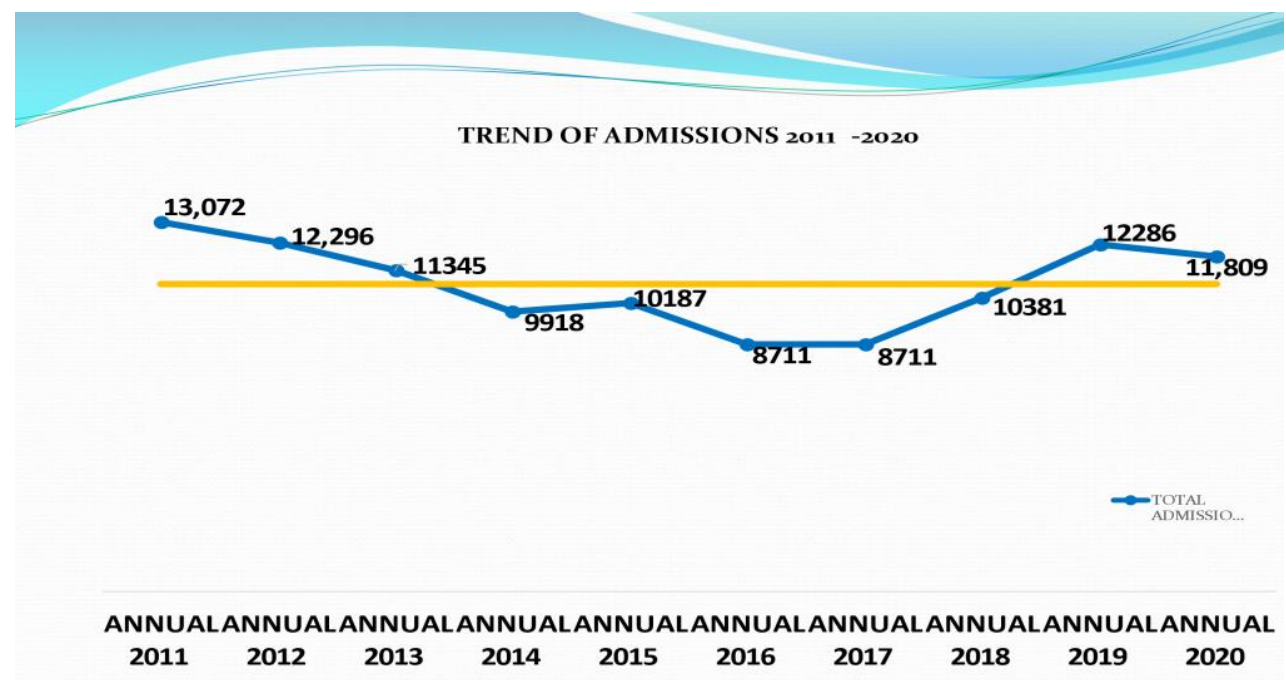

Source: Fieldwork, 2021

Figure 1. Trend of Admissions

OPD attendance as a measure of medical outcomes was good. Wendy Gerhardt \& Ankit Arora share the view that, unlike previous times when patients would spend more days in the hospital after, for example, surgical procedure, today, many patients have procedures in ambulatory centers and go home the same day. The shift lays focus now, more than ever, on outpatient care, and this largely is made possible by the advances in clinical technology. There is no doubt that the rise in OPD attendance is a measure of revenue increases. Although, according to Akudjedy, hospital's out-patient attendance reduced by almost $50 \%$ with attendant loss of revenue in 2020, the story was different albeit marginally. The OPD attendance at the mission hospitals saw an increase of 0.33 percent on the contrary. Clearly, this was a measure of good medical outcome (Figure 2).
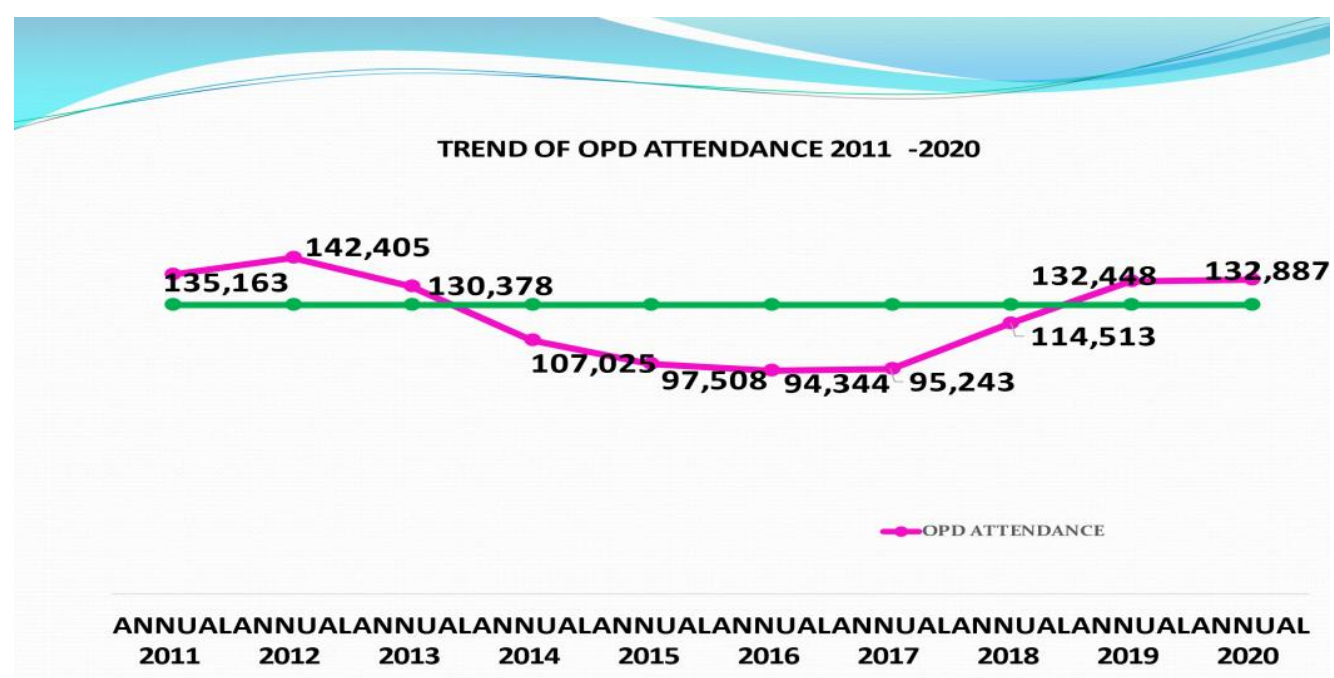

Source: Fieldwork, 2021

Figure 2. Trend of OPD Attendance 
Advance healthcare revenue practice Ultimately, the percentage of OPD insured management services write on its website that, among other things, it specializes in hospitalwide revenue mobilization, which enables hospitals to collect maximum reimbursements for the services rendered to their patients. It is when people visit the hospital with an insurance membership cards that reimbursement can be made. Health insurance reimbursement obviously is a measure of revenue mobilization. (figure 3) measures good medical outcomes since ordinarily, people will not visit the hospital where they were not sure of receiving quality care. Patients visit hospitals where they feel comfortable and were sure of receiving the best of care. This as a measure of medical outcomes was progressively on the rise during the year under review, about $89 \%$ of those who visited the mission hospitals were NHIS card bearers.

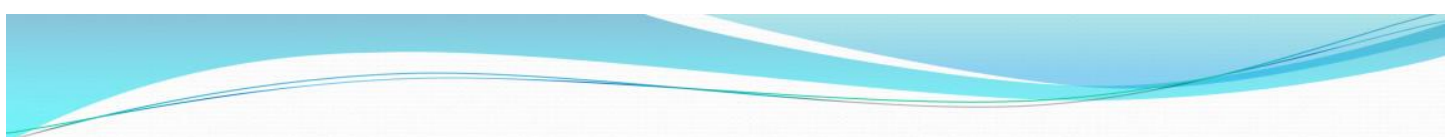

PERCENTAGE OPD INSURED 20112020

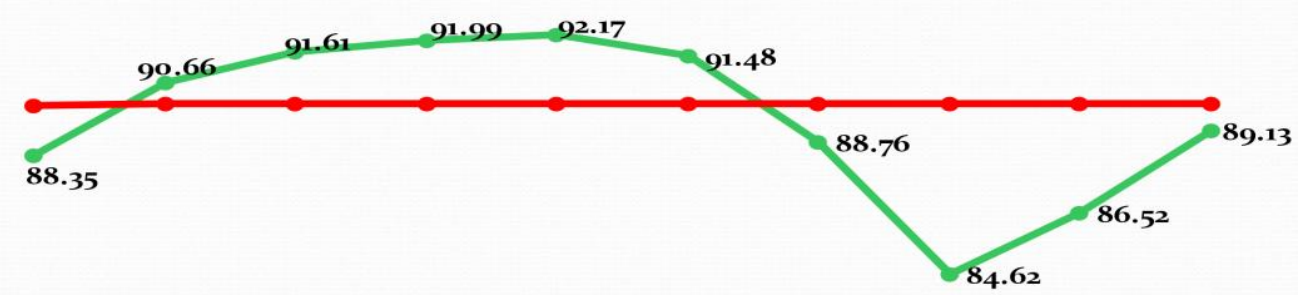

ANNUAL ANNUAL ANNUAL ANNUAL ANNUAL ANNUAL ANNUAL ANNUAL ANNUAL ANNUAL

$\begin{array}{llllllllll}2011 & 2012 & 2013 & 2014 & 2015 & 2016 & 2017 & 2018 & 2019 & 2020\end{array}$

Source: Fieldwork, 2021

\section{Conclusion}

The investigator was right by his assumption that financial health affects the medical outcomes of the hospital. From the above data and subsequent discussions, it came out clearly that the financial health of the hospitals had

Figure 3. Trend of Percentage OPD Insured

Table 4. Financial Health Indicators

\begin{tabular}{|l|l|l|l|}
\hline Parameters/Ratios & $\mathbf{2 0 1 8}$ & $\mathbf{2 0 1 9}$ & $\mathbf{2 0 2 0}$ \\
\hline Profitability Ratios & 2.79 & 7.32 & 5.25 \\
\hline Return on Capital Employed (ROCE) & 1.72 & 4.59 & 3.10 \\
\hline Net Profit Margin & 1.62 & 1.59 & 1.69 \\
\hline Asset Turnover Ratio & 2.35 & 2.48 & 3.41 \\
\hline Liquidity Ratios & 1.73 & 1.98 & 2.66 \\
\hline Current Ratio & &
\end{tabular}




\begin{tabular}{|l|l|l|l|} 
Working Capital Management Ratios \\
\hline Receivables Days Ratio (Average Receivables Collection Period) & 83.56 & 87.09 & 74.62 \\
\hline Payables Days Ratio (Average payables payment period) & 237.98 & 242.81 & 194.03 \\
\hline Average Inventory Turnover Period & 176.09 & 128.26 & 115.18 \\
\hline Rate of Inventory Turnover & 2.07 & 2.85 & 3.17 \\
\hline Cash Conversion Cycle & 21.67 & $(27.46)$ & $(4.23)$ \\
\hline
\end{tabular}

\section{Acknowledgment}

I would like to sincerely thank Professor Peter Agyei-Baffour for his guidance in this investigation. Also, I wish to thank Godwin Adzakpah and Richard Ahorlu, CA, for their inputs in this study.

\section{References}

[1] Henry Frimpong, (2017). An Anatomy of the Business and Financial Performance of State-Owned Financial Institutions in Ghana (2012-2015). Available at

https://www.texilajournal.com/management/article/1 569-an-anatomy-of and retrieved on 3/06/2021.

[2] Aberese-Ako \& co, 2018. Leadership style on two Ghanaian hospitals in a challenging environment. Health Policy and Planning, Volume 33, Issue suppl_2, July 2018, Pages ii16-ii26, https://doi.org/10.1093/heapol/czy038. Retrieved on 29/06/2021.

[3] George Schieber et al, (2012). World Bank Report: Health Financing in Ghana at Crossroads. Available at

https://openknowledge.worldbank.org/handle/10986/ 2729 and retrieved on 17/07/2021.

[4] John Kweku Asamoah, (2018). The Impact of Effective Leadership Practice on Organizational Performance and Growth of state-owned banks in Ghana: The Case of National Investment Bank, Ghana.

[5] Stella Cherono (2021). Kenyan Doctor wins WHO Director-General Award. Available at https://nation.africa/kenya/gender/kenyan-doctorwins-who-director-general-s-award--3414122 and retrieved on 09/06/21.

[6] World Health Report (2010). Health systems financing: the path to universal coverage. Geneva:

\section{Conflict of Interest}

The principal investigator declares that there is no conflict of interest.

World Health Organization; 2010. Available on https://www.who.int/bulletin/volumes/91/8/12-

113985/en/, and retrieved on 13/05/2021.

[7] World Health Report (2000). Health systems: improving performance. World Health Organization, Geneva, 2000 available at https://www.who.int/healthinfo/statistics/toolkit_hss/ EN_PDF_Toolkit_HSS_Financing.pdf and retrieved on $25 / 05 / 2021$.

[8] George Schieber et al, (2012). World Bank Report: Health Financing in Ghana at Crossroads. Available

at https://openknowledge.worldbank.org/handle/10986/ 2729 and retrieved on 17/07/2021.

[9] World Health Organization, (June 2008). Health Systems Financing. Available and retrieved on 20/05/2021

https://www.who.int/healthinfo/statistics/toolkit_hss/ EN_PDF_Toolkit_HSS_Financing.pdf.

[10] World Health Organization, (2021). Overview health financing. Available at https://www.who.int/health-topics/health-

financing\#tab=tab_1 and retrieved on 17/07/2021.

[11]Christmals CD, Aidam K, (2020). Implementation of the National Health Insurance Scheme (NHIS) in Ghana: Lessons for South Africa and Low- and Middle-Income Countries. Available at https://www.dovepress.com/implementation-of-thenational-health-insurance-scheme-nhis-in-ghana-1- 
peer-reviewed-fulltext-article-RMHP and retrieved on $22 / 05 / 2021$.

[12] Alanna-Moriarty (2011). Definitive healthcare Interactive dashboard with rich customization and self-service.

Available

at

https://www.datanyze.com/people/Alanna-

Moriarty/-1049632075.

[13] Wendy Gerhardt \& Ankit Arora (2020). Hospital revenue trends Outpatient, home, virtual, and other care settings are becoming more common. Retrieved on $10 / 08 / 2021$ and available at https://www2.deloitte.com/us/en/insights/industry/he alth-care/outpatient-virtual-health-care-trends.html. [14] Tyler Heist et at, (2021). Trends in overall and non-covid-19 hospital admissions. Retrieved on $12 / 08 / 2021$ and available at https://www.kff.org/health-costs/issue-brief/trendsin-overall-and-non-covid-19-hospital-admissions/.

[15]Nana Kwame Ayisi-Boateng et al (2020). Fighting the covid-19 pandemic in Ghana: a report from the Kwame Nkrumah University of Science and Technology, Kumasi. Retrieved on 20/07/2021 at Doi: 10.11604/pamj.supp.2020.37.43.25749.

[16] George Schieber, Cheryl Cashin, Karima Saleh, Rouselle Lavado (2012). Health financing in Ghana. World Bank Publications.

[17] NHIS, (2021). NHIS Review. Terms of reference for defining options for national health insurance scheme reforms. Retrieved on 02/07/2021 and available at http://www.nhis.gov.gh/nhisreview.aspx. [18] World Health Organization, World Bank, (2015). Tracking universal health coverage: first global monitoring report. Retrieved on 17/07/2021 and available

at www.who.int/healthinfo/universal_health_coverage/ report/2015/en.

[19]Helleiner, G. K., (1983). “Accelerated development in sub-Saharan Africa, an agenda for action: The World Bank, (Washington, 1981) viii + 198 pp," Journal of Development Economics, Elsevier, vol. 13(1-2), pages 259-264.

[20]Fallon E. Chipidza et al, (2015). Impact of the doctor-patient relationship. Retrieved on 22/07/2021. Published online 2015 Oct 22. Doi: 10.4088/PCC.15f01840.
[21]Ezat Wan Puteh S, Almualm Y. (2017). Catastrophic health expenditure among developing countries. Health Syst Policy Res. 2017;4. DOI:10.21767/2254-9137.100069.

[22] Tod Beasley (2020). How to gauge your hospital's financial health. Available at https://www.beckershospitalreview.com/how-togauge-your-hospital-s-financial-health.html and retrieved on 20/07/2021.

[23] Paul D. Cleary (1990). Using patient reports of outcomes to assess the effectiveness of medical care. Available at https://www.ncbi.nlm.nih.gov/books/NBK233993/ and retrieved on 21/07/2021.

[24] Sara Heath, 2020, How Will COVID-19 Change Patient Experience, Healthcare Delivery? at https://patientengagementhit.com/news/how-willcovid-19-change-patient-experience-healthcaredelivery, retrieved on 10/07/2021.

[25] Osondu Ogbuoji et all (2019). Closing Africa's health financing gap available at https://www.brookings.edu/blog/futuredevelopment/2019/03/01/closing-africas-healthfinancing-gap/ and retrieved on 09/07/2021.

[26]IBM health forum (2021). Healthcare performance measurements. Retrieved on 20/07/2021 and available at https://www.ibm.com/watsonhealth/learn/healthcare-performance-measurements.

[27] Ryan, T. P. (2013). Sample size determination and power, John Wiley \& Sons.

[28]Bryman, A, \& Bell, Emma, (2007). Business Research Methods. Oxford University Press.

[29] Amitava Dasgupta Jorge Sepulveda, (2013). Accurate results in the clinical laboratory. A guide to error detection and correction. Elsevier, Waltham, MA, USA.

[30] Audited Financial Statements (2018, 2019 \& 2020).

[31] Advance healthcare revenue practice management services (2021). Revenue management services. Retrieved on 15/08/2021 and available at https://www.ahrevenue.com/?gclid=CjwKCAjwx8iI BhBwEiwA2quaq6Lod8PMLtqYO8jHS1NFWGeru E9SVUC3smnG5mmNuwtubgk2aMJ9rhoCUpYQA vD_BwE. 
[32]T. N. Akudjedu et al. (2021). Impact of the Covid-19 pandemic on clinical radiography practice in low resource settings: The Ghanaian radiographers' perspective. Retrieved on 20/07/2021 at PMID: 33168371. DOI:

10.1016/j.radi.2020.10.013. 


\title{
Route of Administration of Corticosteroids and Asthma Relapse after Acute Care; Appraisal of Evidence on Effectiveness and Safety
}

\author{
Sogunle P.T ${ }^{1 *}$, Sogunle E.O ${ }^{2}$ \\ ${ }^{1}$ Department of Family Medicine, Federal Medical Centre, Abeokuta \\ ${ }^{2}$ Department of Public Health, Witwaterstrand University, South Africa
}

\begin{abstract}
Patients managed for acute exacerbation of asthma in acute settings respond to standard management protocol involving systemic and oral steroids. However, relapses are common due to poor adherence to tapering doses of oral steroids. Intramuscular (IM) administration of corticosteroids has been shown to be equipotent to oral steroids with the added advantage of convenient dosing and improved adherence. However, the role of the route of administration of corticosteroids related to relapse of asthma attacks after acute care has not been fully explored. To find and appraise up-to-date evidence in the literature that compares the effectiveness and safety of IM corticosteroids o a shortcourse oral corticosteroid in the treatment of asthma patients in acute care settings. The principles of evidence-based medicine (EBM) were used. Suitable articles were identified using MEDLINE, Cochrane library, and Google scholar. Titles and summary texts were reviewed. The full article of the relevant article was downloaded for critical appraisal of methodological quality using a measurement tool to assess systematic review 2 (AMSTAR 2). In applying AMSTAR 2 to the selected systematic review article, it was noted that the investigators followed most of the requirements. However, adequate investigation of publication bias and discussion of its likely impact on the review's result was not done by the researchers. No significant differences in effectiveness and safety were observed between IM corticosteroids and oral corticosteroids among this category of patients. Additional studies are required to compare different IM and oral corticosteroid preparations.
\end{abstract}

Keywords: Acute exacerbation of Asthma, AMSTER 2, Evidence-based medicine, Route of administration of corticosteroids.

\section{Introduction}

The clinical features of asthma resulting from reversible airway inflammation include chest tightness, worsening cough, shortness of breath, and wheezing [1]. In our context, most patients managed for acute exacerbation of asthma respond favourably to treatment with standard management protocol [2]. Systemic and oral steroids are administered, followed by gradual resolution of symptoms. Parenteral corticosteroids are ideally converted into oral steroids. Upon discharge, most patients have prescribed a tapering regimen of oral steroids in addition to inhaled steroid preparations using metered-dose inhalers. However, the rate of relapse requiring admission for further treatment is common. In literature, reports of relapse of acute asthma after the patient has been discharged from acute care settings ranges between 10 and 31\% [3-5]. This situation in this category of patients constitutes a need for a review of asthma management protocol in acute care settings.

In the reduction of the relapse rate of asthma following acute care, sufficient evidence has not been provided to support the role of the route of administering corticosteroids. Suggested associations have been reported with corticosteroids (particularly those with a depot- 
repository release) given to asthmatic patients before discharge from an emergency department via the intramuscular (IM) route [6-10] Intramuscular repository corticosteroids were found to be as equally useful as oral corticosteroids in these studies. It has been observed that the main challenge with asthma patients taking oral steroids in tapering dose is adherence. As a result of the high number of drugs and regular dosage changes, dosage tapering of oral steroids has been found to be complicated. As such, there is a lack of adherence after discharge in about $12 \%-22 \%$ of these patient $[11,12]$. This situation may be contributory to the relapse of acute exacerbation of asthma after acute care.

We, therefore, sought to find and appraise current research on asthma patients in acute care settings (emergency department or equivalent) that compares the effectiveness and safety of IM corticosteroids to oral corticosteroids before and after discharge, respectively. We made use of the principles of evidence-based medicine (EBM) for this purpose. We planned to search for up-todate evidence and critically appraise the evidence with an appropriate tool to determine the validity and utility of this evidence in this context. This review involves the first three steps in the recommended five general steps of EBM. We hope this paper will generate the needed evidence to carry out the remaining two steps in EBM.

\section{Methods}

\section{Evidence-Based Medicine}

The 5 steps in the EBM model are [13];

1. Identification of clinical question.

2. Best or suitable evidence.

3. Evidence critical appraisal for usefulness and validity.

4. Evidence results in application in clinical practice.

5. Evaluation of skill, information, and EBM procedures.

Evidence-based medicine can be defined as a systematic approach to solving clinical problems by integrating superlative research evidence with patient values and clinical expertise. It refers to judicious, conscientious, and explicit use of up-to-date superlative evidence in making appropriate clinical decisions [14-16]. The EBM tools include; identifying, critically appraising, and incorporation of evidence results into daily clinical practice. Searching for current best evidence is vital, and randomized controlled trials (RCTs) are mostly preferred for interventions [16]. Systematic reviews of RCTs in applied health research have become the standard method used in assessment and summarization $[17,18]$. The results obtained are of the highest level when compared to other research designs [19].

\section{Step 1: Generation of an Answerable Clinical Question}

This is the first and most important step in EBM. An important challenge in this step is to formulate an unanswerable clinical question [20]. A good question should be relevant and specific; communicated distinctly; With a clear objective and of necessity; and time-bound [19].

With regards to the interest of our article, using the PICO format, 4 or 3 of the items listed below must be included in a good clinical question:

1. Problem or patient: Patients with frequent relapse in attacks of asthma following discharge from emergency departments or acute care settings.

2. Intervention: IM corticosteroids.

3. Comparison: Oral Steroids.

4. Outcomes: Effectiveness and safety in the reduction in the incidence of relapse of asthma attacks after patients have been discharged from the acute care setting or its equivalent.

\section{A Four-Part Clinical Question}

In patients with recurrent relapses in attacks of asthma following discharge from acute care, are IM corticosteroids more effective and safer in the reduction of the incidence of relapse of 
asthma attacks when compared with oral steroids?

\section{Step 2: Finding the Evidence}

To identify previously published information to answer the research question, online electronic bibliographic databases were searched. It is important in EBM to use these databases effectively. MEDLINE, Cochrane library, and Google scholar were selected for use in this present article. The search terms used in the selected databases were: asthma, relapse, recurrence, emergency, acute care (problem P), IM corticosteroids, triamcinolone, depo repository steroid, dexamethasone, prednisolone (intervention I), oral steroid, oral steroid administration, (comparison $\mathrm{C}$ ), effectiveness, safety (outcome $\mathrm{O}$ ), randomized controlled trials, clinical trials, systematic review, metaanalysis (study design SD). We searched for a systematic review of randomized controlled studies or randomized controlled study, to provide information to answer the clinical question.

\section{Conducting the Search}

We commenced the search in PUBMED (MEDLINE) using certain keywords and generated terms on 20 July 2020 . We made use of the Boolean operators "AND" and "OR" to combine individual words or terms [21]. We used AND to retrieve articles containing all terms, while OR was used to retrieve articles containing either term. Five different search terms were used in MEDLINE resulted in 14 articles been highlighted (See supplementary list 1). The last $\left(6^{\text {th }}\right)$ search term combined the previous five searches with the AND Boolean operator, and 14 articles were retrieved. After reviewing the titles and summary texts of these fourteen articles, one article was found to be relevant. We did not search the Cochrane library because this article came from the Cochrane Database of Systematic Reviews. The full article of the only relevant article [22] was downloaded for critical appraisal of the quality of methodology. The AMSTAR 2 (A Measurement Tool to Assess Systematic Reviews 2) tool was used [23].

\section{Results}

\section{Article Selected}

Intramuscular versus oral corticosteroids to reduce relapses following discharge from the emergency department for acute asthma Kirkland SW, Cross E, Campbell S, Villa-Roel C, Rowe BH.

\section{Discussion}

\section{Step 3: AMSTAR Tool - Appraising the Evidence}

The quality of the methodology of systematic reviews can be assessed using the first AMSTAR, a measurement tool [24]. AMSTAR, an 11 - item widely used assessment tool developed for the evaluation of systematic review researches conducted for randomized trials. There is currently an increase in its use by authors, editors of journals, healthcare policymakers, as well as for assessments of agencies for health technology [24]. Multiple critiques of this tool have been published [22]. An updated version has recently been developed - AMSTAR 2 [23]. This version is believed to make decisions based on observational evidence in the real world, thereby assisting those making decisions in selecting systematic reviews of high quality.

The revised instrument (AMSTAR 2) has the following characteristics;

1. Overall - 16 items (10 items from the previous version).

2. The response categories are easier to follow than the first AMSTAR.

3. A comprehensible user manual is present.

4. Overall rating is present.

There are risks associated with accommodating the results obtained from one systematic review without a critical review of the quality of its methodology. Prior to AMSTAR, certain assessment tools have been developed i.e., Preferred Reporting Items for 
Systematic Reviews and Meta-Analyses (PRISMA) statement [24, 25] and Meta-analysis of Observational Studies in Epidemiology (MOOSE) [26, 27]. However, these tools do not focus on the way the authors conducted their review but rather how good the authors write in a comprehensible manner. Therefore, AMSTAR 2 as a measurement tool evaluates the methods used in planning and conducting a review [25]. The comprehensive AMSTAR 2 tool can be seen in supplementary list 2 [23].

\section{Application of AMSTAR 2 to the Systematic Review Article Selected.}

As strongly recommended by the developers, the combination of individual item ratings to add up to the total score was not done [23]. Instead, the effect of the possible inadequate rating for individual items were considered.

\section{On the Use of PICO for Research Questions and Inclusion Criteria for the Review}

PICO was used by the authors appropriately. Hence the research question reads, "To examine the effectiveness and safety of a single dose of intramuscular (IM) corticosteroids provided prior to discharge compared to a short course of oral corticosteroids in the treatment of acute asthma patients discharged from an ED or equivalent acute care setting."

\section{Presence of Explicit Statement from Review Protocol or Significant Deviation}

Yes - The review was conducted in line with the published protocol, and differences between the protocol and the review was discussed in a related section [22]. In this section, the authors highlighted the differences between the review and protocol. In response to peer review, the authors added an additional sensitivity analysis, in which studies that provided patients with additional corticosteroids as a co-intervention were excluded from the analysis. Risk of bias assessment was carried out on each included study.

\section{Selection of the Study Designs for Inclusion in the Review}

Yes - They selected RCTs or controlled trials conducted on paediatric or adult patients with acute asthma in an acute setting or equivalent. The studies compared the effectiveness of treatments with intramuscular or oral corticosteroids.

\section{Comprehensive Literature Search Strategy}

Yes - Most recently, on the 14th March 2018, searches were done on the Cochrane Airways Group Register of Trials. An extensive search was previously done in April 2017 - nine electronic databases were searched. They include Proquest Dissertations, Global Health, Embase, SCOPUS, Medline, LILACS, International Pharmaceutical Abstracts, EBMALL, CINAHL, and Theses Global. Grey literatures were searched. The list of references of review articles and primary studies and relevant manufacturers' websites were also searched. There was no restrictions on publication or language status. Twenty-four months or less was the time limit for the completion of the review of included literature.

\section{Duplication of Selected Study}

There was an independent screening of studies by two review authors (SWK and EC). Inclusion and exclusion criteria were identified. A third review author (CVR or BHR) was sometimes used during some disagreements. Duplicates were identified and excluded. The selection process was recorded in detail, and the PRISMA flow diagram was completed.

\section{Duplication of Data Extraction}

The authors used a data collection form for study characteristics and outcome data, which was piloted on at least one included study in the review. Two review authors (SWK and EC) independently extracted the following study characteristics into data collection forms from the included studies - Methods, Participants, Interventions, Outcomes Funding and notable 
conflict of interest of study authors shown in the 'Characteristics of included studies' table. Disagreements were resolved by reaching a consensus or through the involvement of a third review author (CVR or BHR). One of the review authors, SWK, used the Review Manager 5 (RevMan 5) file. To ensure adequate data entering, a second review author (EC) verified the extracted data for accuracy against the study report.

\section{List of Excluded Studies and Justification for Exclusions}

Yes - The full - text of twenty studies were downloaded by the authors for review. After this, eleven studies were excluded due to inappropriate design. The reasons for exclusion are presented in the table of characteristics for studies that were excluded in the article.

\section{Description of the Studies Included in Detail}

Yes - a total of nine studies were included. This was adequately shown on a table showing study designs, participants, intervention, comparators, outcome, and risk of bias.

\section{Usage of Satisfactory Technique to Assess the Risk of Bias (RoB) in Included Studies}

The risk of bias for each included study was examined using Cochrane's risk of bias tool. The domains examined were directed towards: (a) selection bias - allocation concealment \& random sequence generation; (b) Reporting bias - selective reporting; (c) Data attrition bias incomplete outcome; (d) Detection bias blinding of outcome assessment and other bias like a source of funding.

\section{Reported Sources of Funding for the Studies Included in the Review}

Yes - sources of funding for the review was reported by the authors. They include National Institute for Health Research (NIHR), via Cochrane Infrastructure funding to the Cochrane Airways Group; in-kind resources by the Emergency Medicine Research Group (EMeRG) affiliated with the Department of Emergency
Medicine University of Alberta; Canadian Institutes of Health Research (CIHR); CIHR in partnership with the Knowledge Translation branch, tier I Canada Research Chair in Evidence-based Emergency Medicine from CIHR through the Government of Canada (Ottawa, Ontario); Alberta Innovates Health Solutions (AIHS) Summer Studentship Award (Edmonton, Alberta).

\section{For Meta-analysis - Use of Appropriate Methods}

Yes, Meta-analysis was performed. Relative risk values, standardized mean difference or mean difference, were presented where appropriate.

For Meta-analysis - Assessment of the Potential Impact of RoB in Individual Studies on the Results

Yes, Meta-analysis was performed. In the summary of the findings' table, outcomes included all relapse i.e., relapse within or after ten days of discharge, adverse events, PEF/FEV, symptom scores, and beta-agonist use in a 24hour period. The five GRADE considerations (i.e. indirectness, risk of bias, publication bias, consistency of effect, and imprecision) were used to assess the quality of research for the outcome in question. The authors used the methods and recommendations described in Section 8.5 and Chapter 12 of the Cochrane Handbook for Systematic Reviews of Interventions [28, 29]. They used Grading of Recommendations Assessment, Development and Evaluation (GRADE) pro software. Footnotes were used to explain changes made to reduce the quality if studies were included. The risk of bias for the included studies was noted.

\section{Risk of Bias in Primary Studies during Discussion of the Results}

Yes. The authors included RCTs with a moderate or high risk of bias $(\mathrm{RoB})$. The total RoB ranged from unclear to high. None had a bias of low risk. Those (four) with a bias of high risk were not placebo-controlled trials. The other 
five studies had bias with unclear risk. In addition, the majority of studies did not adequately describe their method of randomization. Using GRADE, the total quality of the outcomes ranged from low to moderate. They were reduced to low quality, the primary outcomes of relapse as well as relapse after 10 days due to overall unclear to high risk of bias of the studies, and imprecision due to wide confidence intervals including both benefit, harm, and no effect.

The quality of the outcome adverse events was judged to be low quality due to the overall unclear to high risk of bias of the included studies and imprecision due to few events. They considered both 'symptom persistence' and '24hour beta-agonists use' to be low quality due the overall unclear to high risk of bias of the included studies, as well as few events. They assessed the 'outcome of relapse within 10 days' to be of moderate quality due to the overall unclear to high risk of bias of the studies. They reduced 'peak expiratory flow' to moderate quality due to imprecision of the results.

\section{Provision of Satisfactory Explanation for any Heterogeneity Observed}

Yes - The authors measured heterogeneity between the studies in the respective analysis. Significant heterogeneity was reported associated factors were examined using subgroup analysis. To examine sources of heterogeneity, the following analysis were conducted:

1. Children (zero to 18 years) versus adults (18 years \& older) to examine any potential agespecific treatment effects of IM or oral corticosteroids.

2. Relapse occurring within 10 days and over 10 days post-discharge.

3. Low versus moderate versus high exacerbation severity based on the pulmonary function obtained when a participants presented in the acute care setting or its equivalent prior to treatment with a bronchodilator.
4. Co-interventions received (ICS versus ICS corticosteroids/ Long-acting beta-agonists (LABA)). Subgroup analysis was restricted to relapse.

Sensitivity analysis was also carried out by removing the following types of studies from the primary outcome analyses.

1. Studies that were considered to be at high risk of bias based on the criteria outlined in the Cochrane Handbook for Systematic Reviews of Interventions [28].

2. Studies in which the duration of oral corticosteroid treatment was less than five days.

3. The results from fixed-effect models were compared with the random-effects models for the main outcome.

4. Studies in which supplemental corticosteroids were provided to the patients in the ED as a co-intervention.

\section{For Quantitative Synthesis - Adequate Investigation of Publication Bias and Discussion of the Likely Impact on the Results of the Review}

No - the authors did not perform graphical or statistical tests for publication bias and discussed the likelihood and magnitude of the impact of publication bias. The authors recognized that some studies could have been missed. They added that due to an insufficient number of included studies, publication bias could not be assessed as planned. As such, the risk of publication bias was considered unclear.

\section{Did the Review Authors Report any Potential Sources of Conflict of Interest and Funding for Review}

Yes. All internal and external sources of support, as well as funding, how any conflicts of interest were handled were discussed. These sources of funding and support were not involved in the preparation of this protocol and in any aspect of the conduct and reporting of the review. 


\section{AMSTAR 2 Critical Domains}

Seven domains were identified by the developers of AMSTAR 2. A review validity, as well as its conclusions, can be affected by these domains. However, the developers acknowledged that all steps are important.

Applying AMSTAR 2 Critical Domains to Systematic Review Article Selected

1. Protocol registered before the commencement of the review (item 2) - yes.

2. Adequacy of the literature search (item 4) yes.

3. Justification for excluding individual studies (item 7) - yes.

4. Risk of bias from individual studies being included in the review (item 9) - yes.

5. Appropriateness of meta-analytical methods (item 11) - yes.

6. Consideration of risk of bias when interpreting the results of the review (item 13) - yes.

7. Assessment of presence and likely impact of publication bias (item 15) - yes. [23].

\section{Rating the Overall Confidence in the Results of the Review}

There is a proposed method for the interpretation of detected weaknesses in both the non-critical and critical items. The ratings are described as either high/moderate/low/critically low. The full description of the proposed rating scale can be found in supplementary list 3 .

\section{Conclusions}

\section{Article Appraisal Conclusions}

According to the authors, the conclusions are itemized as follows;

1. In determining if IM corticosteroids are more effective in reducing relapse compared to oral corticosteroids among children or adults discharged from an ED or equivalent acute care setting for acute asthma, insufficient evidence was found.

2. Fewer adverse events were observed in patients that received IM corticosteroids. This was, however, not statistically significant.

3. It was suggested that additional studies comparing the effectiveness of IM versus oral corticosteroids could provide further evidence clarity.

4. It was also suggested that further studies should be conducted to compare the different types of IM corticosteroids (i.e., IM triamcinolone, methylprednisone, and dexamethasone), as well as other oral corticosteroids (i.e., oral prednisone and dexamethasone). The dosage and pharmacokinetics of these drugs should also be considered.

5. The preference of patients, as it relates to adherence, should also be considered.

The overall confidence in the above conclusions from this appraisal is rated as high because there was no non - critical weakness in the evaluation of the critical domains of the review. In view of the above, it is not advisable to proceed to EBM steps 4 and 5. The appraisal of results of further studies as enumerated above may engender the full implementation of 5 - step EBM as appropriate.

\section{Conflict of Interest}

The author declares that there is no conflict of interest.

\section{Acknowledgement}

Both SPT and SEO formulated the review question, the review topic, literature search, article selection, article critical appraisal, and the write-up of this evidence-based medicine review. 


\section{References}

[1] Croisant S. 2014 Epidemiology of Asthma: Prevalence and Burden of Disease. In: Brasier A. (eds) Heterogeneity in Asthma. Advances in Experimental Medicine and Biology, vol 795:17-29 Humana Press, Boston, MA. https://doi.org/10.1007/978-1-4614-8603-9_2.

[2] Rowe BH, Kirkland SW, Vandermeer B, et al. 2017. Prioritizing Systemic Corticosteroid Treatments to Mitigate Relapse in Adults With Acute Asthma: A Systematic Review and Network Metaanalysis. Academic Emergency Medicine: Official Journal of the Society for Academic Emergency Medicine. Mar;24(3):371-381. DOI: 10.1111/acem.13107. PMID: 27664401.

[3] Services UD of $H$ and $H$. National asthma education program: executive summary. Guidelines for the diagnosis and management of asthma Publication NO. 1991.

[4] Topal E, Gücenmez OA, Harmancı K, Arga M, Derinoz O, Turktas I, 2014. Potential predictors of relapse after treatment of asthma exacerbations in children, Annals of Allergy, Asthma \& Immunology, Volume 112 (4), 361-364, ISSN 1081-1206, https://doi.org/10.1016/j.anai.2014.01.025.

[5] Ducharme FM, Zemek RL, Chalut D, McGillivray D, Noya FJ, Resendes S, Khomenko L, Rouleau R, Zhang X. 2011. Written action plan in pediatric emergency room improves asthma prescribing, adherence, and control. Am J Respir Crit Care Med. 15;183(2):195-203. DOI: 10.1164/rccm.2010010115OC. Epub 2010 Aug 27. PMID: 20802165.

[6] McNamara RM, Rubin JM. 1993. Intramuscular methylprednisolone acetate for the prevention of relapse in acute asthma. Ann Emerg Med. 22(12):1829-35. DOI: $\quad$ 10.1016/s01960644(05)80409-3. PMID: 8239103.

[7] Hoffman IB, Fiel SB. 1988. Oral vs. repository corticosteroid therapy in acute asthma. Chest. 93(1):11-3. DOI: 10.1378/chest.93.1.11. PMID: 3275525.

[8] Lee CH, Lee CJ, Lan RS, Tsai YH, Chiang YC, Wang WJ, Tsao TC. 1993. Repository dexamethasone in the treatment of acute bronchial asthma. Changgeng Yi Xue Za Zhi. 16(1):25-9. PMID: 8490772.
[9] Schuckman H, DeJulius DP, Blanda M, Gerson LW, DeJulius AJ, Rajaratnam M. 1998. Comparison of intramuscular triamcinolone and oral prednisone in the outpatient treatment of acute asthma: a randomized controlled trial. Ann Emerg Med. 31(3):333-338. DOI: 10.1016/s0196-0644(98)703439. Erratum in: Ann Emerg Med 1998 Jun;31(6):795. PMID: 9506490.

[10]Chan JS, Cowie RL, Lazarenko GC, Little C, Scott S, Ford GT. 2001. Comparison of intramuscular betamethasone and oral prednisone in the prevention of relapse of acute asthma. Can Respir J. 8(3):147-52. DOI: 10.1155/2001/613426. PMID: 11420590.

[11] Saunders CE. 1987. Patient compliance in filling prescriptions after discharge from the emergency department. Am J Emerg Med.;5(4):283-6. DOI: 10.1016/0735-6757(87)90351-2. PMID: 3297080.

[12] Thomas EJ, Burstin HR, O’Neil AC, Orav EJ, Brennan TA. 1996. Patient noncompliance with medical advice after the emergency department visit. Ann Emerg Med. 27(1):49-55. DOI: 10.1016/s01960644(96)70296-2. PMID: 8572448.

[13]Titler M. Developing an evidence-based practice. 2006.

[14] Sackett DL. Evidence-based medicine: how to practice and teach. EBM. 2000.

[15] Sackett DL, Rosenberg WM, Gray JM, Haynes RB, Richardson WS. 1996. Evidence-based medicine. BMJ: British Medical Journal. 313: 170. DOI: https://doi.org/10.1136/bmj.312.7023.71.

[16]Akobeng AK. Principles of evidence-based medicine. Arch Dis Child. 2005 Aug;90(8):837-40. DOI: 10.1136/adc.2005.071761. PMID: 16040884; PMCID: PMC1720507.

[17] Antman EM, Lau J, Kupelnick B, Mosteller F, Chalmers TC. 1992. A comparison of results of metaanalyses of randomized control trials and recommendations of clinical experts. Treatments for myocardial infarction. JAMA. 1992 8;268(2):240-8. PMID: 1535110.

[18] Oxman AD, Guyatt GH. The science of reviewing research. Ann N Y Acad Sci. 1993 Dec 31;703:125-33; discussion 133-4. DOI: 10.1111/j.1749-6632.1993.tb26342.x. PMID: 8192290. 
[19]Liberati A, Altman DG, Tetzlaff J, Mulrow C, Gøtzsche PC, Ioannidis JP, Clarke M, Devereaux PJ, Kleijnen J, Moher D. 2009. The PRISMA statement for reporting systematic reviews and meta-analyses of studies that evaluate health care interventions: explanation and elaboration. $\mathbf{J}$ Clin Epidemiol. ;62(10):e1-34. DOI: 10.1016/j.jclinepi.PMID: 19631507.

[20] Akobeng AK. 2005. Understanding randomised controlled trials. Arch Dis Child. 90(8):840-4. DOI: 10.1136/adc.2004.058222. PMID: 16040885; PMCID: PMC1720509.

[21] Kang H. 2016. How to understand and conduct evidence-based medicine. Korean J Anesthesiol. 2016 Oct;69(5):435-445.

DOI: 10.4097/kjae.2016.69.5.435. Epub 2016 Sep 8. PMID: 27703623; PMCID: PMC5047978.

[22] Kirkland S, Cross E, Campbell S, Villa-Roel C, Rowe B. 2018. Intramuscular versus oral corticosteroids to reduce relapses following discharge from the emergency department for acute asthma. Cochrane Database of Systematic Reviews.. doi:10.1002/14651858.CD012629.pub2.

[23] Shea BJ, Reeves BC, Wells G, Thuku M, Hamel C, Moran J, et al. AMSTAR 2: a critical appraisal tool for systematic reviews that include randomised or non-randomised studies of healthcare interventions, or both. BMJ. 2017;358: j4008. doi:10.1136/bmj.j4008.

[24] Shea BJ, Grimshaw JM, Wells GA, Boers M, Andersson N, Hamel C, et al. Development of
AMSTAR: a measurement tool to assess the methodological quality of systematic reviews. BMC Medical Research Methodology. 2007;7: 10. doi:10.1186/1471-2288-7-10.

[25] Moher D, Liberati A, Tetzlaff J, Altman DG. Preferred reporting items for systematic reviews and meta-analyses: the PRISMA statement. BMJ. 2009;339: b2535. doi:10.1136/bmj.b2535.

[26] Shea BJ, Hamel C, Wells GA, Bouter LM, Kristjansson E, Grimshaw $\mathbf{J}$, et al. AMSTAR is a reliable and valid measurement tool to assess the methodological quality of systematic reviews. Journal of Clinical Epidemiology. 2009;62: 10131020. doi:10.1016/j.jclinepi.2008.10.009.

[27] Stroup DF, Berlin JA, Morton SC, Olkin I, Williamson GD, Rennie D, et al. Meta-analysis of Observational Studies in EpidemiologyA Proposal for Reporting. JAMA. 2000;283: 2008-2012. doi:10.1001/jama.283.15.2008.

[28]Higgins J, Altman D, Sterne J. Chapter 12: Assessing the risk of bias in included studies. In: Cochrane Handbook for Systematic Reviews of Interventions: The Cochrane Collaboration. 2011. Available: http://handbook.cochrane.org.

[29] Higgins J, Altman D, Sterne J. Chapter 8: Assessing the risk of bias in included studies. In: Cochrane Handbook for Systematic Reviews of Interventions: The Cochrane Collaboration. 2011. Available: http://handbook.cochrane.org. 


\title{
The Impact of COVID-19 Pandemic on Pharmacy Practices in the Tropics: Nigeria as a Case Study
}

\author{
Nnenna Genevieve Ekechukwu ${ }^{1 *}$, Kenneth Anele $\mathrm{Agu}^{2}$ \\ ${ }^{1}$ Bristol Pharmacy, Gwarimpa, Abuja, Nigeria \\ ${ }^{2}$ Associate Director, Howard University Global Initiative Nigeria, Abuja, Nigeria
}

\begin{abstract}
As the pandemic was sudden and no time was given to prepare for the lockdown measure, pharmaceutical practices were significantly disrupted in the aspects of manufacturing and supplying drugs, sales, and profit-making. Therefore, this study assessed the impacts of COVID-19 crisis on pharmaceutical practices in Nigeria. A descriptive cross-sectional design survey was adopted to draw information from the pharmacists (respondents) among the targeted population. 1,200 professional and practice pharmacists were systematically and randomly selected across the six geopolitical zones in Nigeria, while 1,118 copies of the administered questionnaire were retrieved, coded, and analyzed using descriptive and inferential statistics aided by the Statistical Package for Social Sciences (SPSS) software version 23 to run the analyses. The findings showed that COVID-19 had negative impacts on pharmaceutical practices, especially in hospital and community practices. A 25\%-49\% decrease was highly indicated in sales, purchase orders, and profits, while the majority, 347 (31.04\%) of the respondents, indicated that they had a 1\%-24\% decrease in their workforce. Also, total lockdown as a COVID-19 measure increased the level of insecurity and inflation during the pandemic. $75.13 \%$ of the pharmacists who represent the targeted population indicated that their place of work largely enforced COVID-19 basic preventive measures during the pandemic. This study concludes that necessary efforts should be put in place to ease the affairs of the pharmaceutical practices before, during, and after the pandemic.
\end{abstract}

Keywords: COVID-19, Impact, Lockdown, Pharmaceutical Care, Practices, Nigeria.

\section{Introduction}

The outbreak of the emerging infectious disease, named novel coronavirus (COVID-19), began in December 2019 and spread worldwide [1]. In April 2020, 213 countries, areas, or territories were greatly affected [2]. Globally, COVID-19 spreads to over 220 countries and territories with $172,946,180$ confirmed cases and 3,718,601 deaths, based on the report of June 4, 2021 [3]. Respiratory syndrome coronavirus (MERS-CoV) [4] and Severe Acute Respiratory Syndrome (SARS) are mainly caused by coronaviruses [5]. The pandemic has caused great havoc in the world, which includes but is not limited to human deaths, extraordinary health, and socioeconomic anguish. Similarly, studies have shown that health care workers were at a very high risk of infection during the COVID-19 pandemic [6, 7]. The COVID-19 pandemic affected many sectors, including the pharmaceutical sector and/or practices. All over the world, this pandemic brought unprecedented challenges and changes to all nations, including Nigeria $[8,9,10,11]$. Because of its impacts, basic precautions were recommended for individuals, countries, and regions to stop and/or mitigate the spread of the virus. A commendable method termed lockdown was made as to the directives from governments in different countries (including 
Nigeria) purposely to curb the spread of coronavirus [11].

The lockdown measure is highly restrictive on social freedoms and caused damage to the economy, more importantly in the pharmaceutical industry, care, and/or practices. The concept of 'lockdown' is the restriction of travel, closing of schools and nonessential businesses, banning social gatherings, and asking citizens to shelter in place [12]. Granting these measures have shown to be operational and effective in decreasing social contact, their economic costs are probable to be high.

Nigeria, which chiefly rests on importation to meet its demands, suffered a huge blow to several sectors, including the pharmaceutical industry. Even though the local industry in Nigeria fairs better when compared to its counterparts in other developing countries in Sub-Saharan African [13]. Previous studies showed that Nigeria is only being able to meet $25 \%$ of its local demand. The pharmaceutical market principally relies on the importation of machinery, pharmaceutical ingredients, and quality equipment from abroad [13].

Nigeria that predominantly banks on importation to attain its demands, underwent a massive setback to numerous sectors, including the pharmaceutical industry. Even though the local industry in Nigeria fairs better when compared to its counterparts in other developing countries in Sub-Saharan African [13]. Previous studies showed that Nigeria is only being able to meet $25 \%$ of its local demand. The pharmaceutical market principally relies on the importation of machinery, pharmaceutical ingredients, and quality equipment from abroad [13].

No matter how wealthy a nation or country is regarding the containment and mitigations of the COVID-19 pandemic, it will eventually have a profound influence on the economy in all countries and regions, especially in low- and middle-income nations. Since the COVID-19 outbreak was unexpected and there was no time to get ready for the lockdown style, as well as in the production and distributing of drugs, pharmaceutical practices were significantly disrupted at the local, regional and global levels. COVID-19 also affected pharmaceutical practices in Nigeria, especially in hospital and community pharmacies [14].

Studies have been conducted in different parts of the world on the COVID-19 pandemic related to the impacts and its associated factors $[11,15]$. Many studies had shown the positive impact of pharmaceutical care (PC) in improving patients' clinical, economic, and humanistic outcomes in America, Europe, and Asia [15, 16, 17, 18]. Several studies have been conducted in Africa related to the impact of pharmaceutical care on patients' outcomes, especially [19]. The type of research, such as experimental and non-experimental, recorded the activities and the impact of Pharmaceutical Practices (PC) in disease states [20, 21]. Studies proliferate in Nigeria on the activities of pharmaceutical practice [22, 23]. However, no or few studies have been conducted in assessing the impact of COVID-19 on pharmaceutical practices in Nigeria. Therefore, the impacts of the COVID-19 on pharmaceutical practices in Nigeria were assessed. Specifically, the impact of the pandemic on pharmaceutical care and practices and the strategic measures taken and practiced in the study area were assessed.

\section{Materials and Methods}

The study was confined to the entire Nigeria by selecting few States from each of the six geopolitical zones. Nigeria is located at the extreme inner corner of the Gulf of Guinea on the west coast of Africa and lies between latitudes $4 \mathrm{o}$ and $14 \mathrm{o}$ North of the equator and longitudes 20 42' and $15^{\circ} 00^{\prime}$ 'East of the Greenwich Meridian (Figure 1) [24, 25]. The National Population Commission estimated the population of Nigeria in 2006 at 140,431,790, which placed it among the most populous countries in the world and the most populated country in Africa. The 2016 projected population was 193,392,517 [26], and 2018 
population was put at 197 million [14]. The study area encompasses Abuja and 36 States that are further sectioned into 774 Local Government Areas (LGAs) [27]. The States and FCT are also further grouped into six geopolitical regions: North East, North West, North Central, South East, South West, and South-South regions (Figure 1). The grouping of the zones is based on geographical location, culture, and the historical origin of the regions, to mention but a few [27]. The study area (Nigeria) is classified as low-mid with a growth rate of $2.6 \%$ per year [28].

The method adopted for the study involved a cross-sectional descriptive design which was carried out among the professional and registered pharmacists at different pharmaceutical practices, especially in hospital practice, community practice, and industrial practice in the study area for a specific period. Of the total 21,892 registered pharmacists in the country [29], a total of 1,200 copies of a wellstructured self-made questionnaire were used to collect information from the respondents (registered pharmacists) who served as the sample population. The copies of the questionnaire were administered and/or mailed using a systematic random sampling technique in all the six geopolitical zones of Nigeria. The questionnaire that served as an instrument in this research was tested to ascertain its validity and reliability. The researcher consulted experts and renowned public health researchers by giving them the instrument to review the relevance of the questions on the subject matter to know whether it would test what it was designed for. The data collection tool was also pretested before they were administered. Of the total copies of the questionnaire administered in the study area, 1,118 copies were retrieved, coded in an excel Microsoft Package, and analyzed using SPSS version 23.

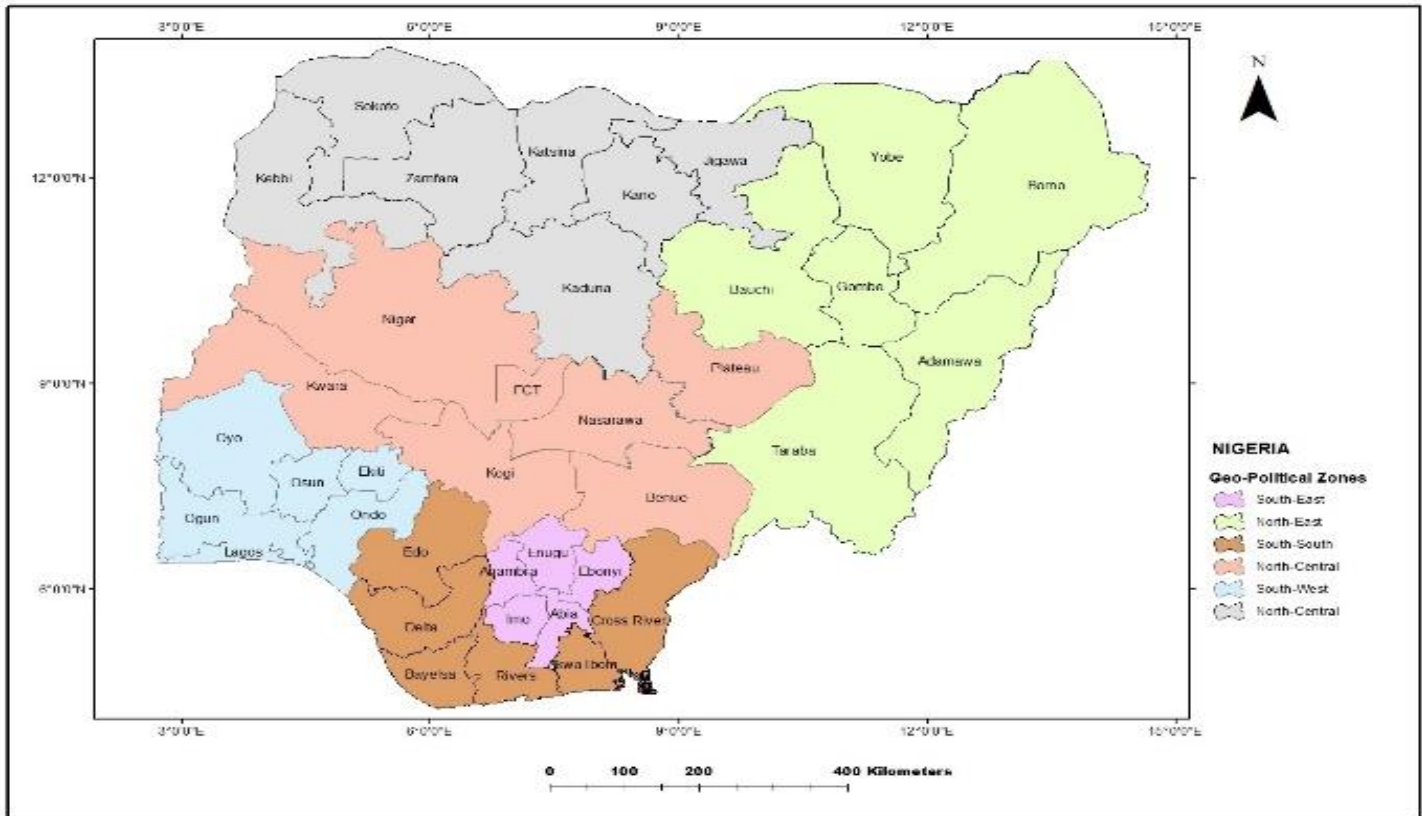

Figure.1. Map of the Study Area, Nigeria

\section{Results}

\section{Demographic Characteristics of the Pharmacists (Respondents)}

Table 1 presents the socio-demographic characteristics of the respondents in the studied area. The result showed that large proportions of the sampled population were male (51.4\%), while only $2.7 \%$ preferred not to indicate their gender. The majority, 939 (84\%) of the targeted population which represents the respondents, were between the ages of 30 and 59. In all the respondents in the study area, $908(81.2 \%)$ were married, $17.9 \%$ were single, and the least 
percentage $(0.9 \%)$ of the respondents constituted those who were separated. In the study area, all the respondents were professional pharmacists with university educational qualifications; $42.5 \%$ with Bachelor of Pharmacy, 25.8\% with Master degree, and 6.3\% with Ph.D. degrees.

Considering the respondents' areas or fields of practice, hospital practice, community practice, and industrial practice constituted larger percentages with $51.2 \%, 1.9 \%$, and $7.2 \%$, respectively (Table 1). Some of the respondents (Pharmacists) also practiced in the areas of health insurance, marketing/production, administrative, political, and NonGovernmental Organizations. A very small number of respondents, which represents $7.1 \%$, have spent 5-9 years in the pharmaceutical practices, while 268 (24.0\%) have spent between 10 and 14 years. Those pharmacists (respondents) who had spent between 20 and 24 years constituted $21.3 \%$, while the respondents who have spent more than 30 years in the practice of pharmacies constituted $8.0 \%$ (Table $1)$.

In terms of the hours spent at work, during the period of COVID-19, the majority, 722 (64.6\%), of the Pharmacists worked for 6-8 hours per day. Regarding the respondents in the selected geopolitical zones, the respondents were equally sampled across of the six zones in the country where South-West, North-Central, and South-East largely participated with larger percentages of $22.3 \%, 21.3 \%$ and 18.5 , respectively.

Table 1. Demographic Characteristics of the Respondents

\begin{tabular}{|l|l|l|l|}
\hline Variables & Frequency & Percent (\%) \\
\hline \multirow{5}{*}{ Gender } & Male & 575 & 51.4 \\
\cline { 2 - 4 } & Female & 513 & 45.9 \\
\cline { 2 - 4 } & Prefer not to say & 30 & 2.7 \\
\cline { 2 - 4 } & Total & $\mathbf{1 1 1 8}$ & $\mathbf{1 0 0 . 0}$ \\
\hline \multirow{5}{*}{ Age Bracket } & $18-29$ & 130 & 11.6 \\
\cline { 2 - 4 } & $30-39$ & 256 & 22.9 \\
\cline { 2 - 4 } & $40-49$ & 357 & 31.9 \\
\cline { 2 - 4 } & $50-59$ & 326 & 29.2 \\
\cline { 2 - 4 } & $60-69$ & 49 & 4.4 \\
\cline { 2 - 4 } & Total & $\mathbf{1 1 1 8}$ & $\mathbf{1 0 0 . 0}$ \\
\hline Earital Status & Single & 200 & 17.9 \\
\cline { 2 - 4 } & Married & 908 & 81.2 \\
\cline { 2 - 4 } & Separated & 10 & 0.9 \\
\cline { 2 - 4 } & Total & $\mathbf{1 1 1 8}$ & $\mathbf{1 0 0 . 0}$ \\
\hline \multirow{5}{*}{ Educational Level } & B. Pharm & 475 & 42.5 \\
\cline { 2 - 4 } & Masters & 288 & 25.8 \\
\cline { 2 - 4 } & Postgraduate Fellowship & 255 & 22.8 \\
\cline { 2 - 4 } & PhD. & 70 & 6.3 \\
\cline { 2 - 4 } & Others & 30 & 2.7 \\
\cline { 2 - 4 } & Total & $\mathbf{1 1 1 8}$ & $\mathbf{1 0 0 . 0}$ \\
\hline \multirow{5}{*}{ Area of Practice } & Academia & 10 & 0.9 \\
\cline { 2 - 4 } & Hospital & 572 & 51.2 \\
\cline { 2 - 4 } & Community & 31.9 \\
\cline { 2 - 4 } & Industrial & & \\
\hline
\end{tabular}




\begin{tabular}{|c|c|c|c|}
\hline & Public Health & 69 & 6.2 \\
\hline & Others & 30 & 2.7 \\
\hline & Total & 1118 & 100.0 \\
\hline \multirow{8}{*}{$\begin{array}{l}\text { Other Areas of } \\
\text { Practice }\end{array}$} & Do not practice in any other area & 1008 & 90.2 \\
\hline & NGO & 10 & 0.9 \\
\hline & Health Insurance & 40 & 3.6 \\
\hline & Marketing/Production & 20 & 1.8 \\
\hline & Academia & 20 & 1.8 \\
\hline & Administrative & 10 & 0.9 \\
\hline & Politics & 10 & 0.9 \\
\hline & Total & 1118 & 100.0 \\
\hline \multirow[t]{8}{*}{ Years of Practice } & $<5$ Years & 179 & 16.0 \\
\hline & $5-9$ Years & 79 & 7.1 \\
\hline & $10-14$ Years & 268 & 24.0 \\
\hline & $15-19$ Years & 108 & 9.7 \\
\hline & $20-24$ Years & 238 & 21.3 \\
\hline & $25-29$ Years & 157 & 14.0 \\
\hline & $\geq 30$ Years & 89 & 8.0 \\
\hline & Total & 1118 & 100.0 \\
\hline \multirow{5}{*}{$\begin{array}{l}\text { Ave. number of daily } \\
\text { hours of work }\end{array}$} & $3-5$ Hours & 20 & 1.8 \\
\hline & $6-8$ Hours & 722 & 64.6 \\
\hline & $9-11$ Hours & 277 & 24.8 \\
\hline & 12 Hours and Above & 99 & 8.9 \\
\hline & Total & 1118 & 100.0 \\
\hline \multirow{7}{*}{$\begin{array}{l}\text { Geo-Political Zone of } \\
\text { Practice }\end{array}$} & South-West & 249 & 22.3 \\
\hline & South-South & 169 & 15.1 \\
\hline & South-East & 207 & 18.5 \\
\hline & North-Central & 238 & 21.3 \\
\hline & North-East & 117 & 10.5 \\
\hline & North-West & 138 & 12.3 \\
\hline & Total & 1118 & 100.0 \\
\hline
\end{tabular}

\section{Impact of COVID-19 on Pharmaceutical Practices}

The impacts of the COVID-19 pandemic on all aspects of pharmaceutical work and/or enterprise are presented in Figure 2. The results showed that larger percentages of the pharmacists experienced a decline in their work/enterprise. $25 \%-49 \%$ decrease was highly indicated in sales, purchase orders, and profits. The majority, 347 (31.04\%), indicated that they had a $1 \%-24 \%$ decrease in their workforce, while 337 (30.14\%) of the pharmacists (respondents) indicated that COVID-19 had no impact on production. Also, the majority 374 $(33.45 \%)$ and 326 (29.16) of the sampled population revealed that COVID-19 affected sales, accounting for a $25 \%-49 \%$ decrease and $1 \%-24 \%$ decrease, respectively.

Table 2 presents the results of how COIVID19 impacted on work/enterprise of different areas of pharmaceutical practices. Hospital and community practices were greatly affected in sales with $51.16 \%$ and $31.93 \%$, respectively. The sales had a percentage decrease of $1 \%-24 \%$ and $25 \%-49 \%$, while the purchasing orders of the work/enterprise had a decrease of 1\%-24\% and $25 \%-49 \%$, which accounted for 37.84 and 
$31.34 \%$, respectively, as shown by the respondents. However, the impacts were greatly felt on Hospital practice and community practice with $51.16 \%$ and $31.93 \%$. In addition, $23.79 \%$, which represents 266 respondents, had shown that they experienced a $25-49 \%$ drop in the profit of the hospital pharmaceutical practice and $9.66 \%$ of the community practice because of the COVID-19 pandemic. Only 10 $(0.89 \%)$ respondents showed that COVID-19 had a 50-100\% profit increase in both hospital and community practices. Because of the impacts of the COVID-19 crisis and/or pandemic in the study area, $369(33.01 \%)$ of the pharmacists temporarily stopped working (Figure 3). This has profound effects on customers and the populace to provide treatment for illnesses and other infectious diseases. Among the $33.01 \%$ of the respondents who had temporarily stopped working because of the impact of the COVID-19, larger percentages of the respondents were in the hospital pharmacies, community pharmacies, and industrial, pharmaceutical practice with $20.48 \%, 7.16 \%$, and $3.58 \%$, respectively (Figure 4).

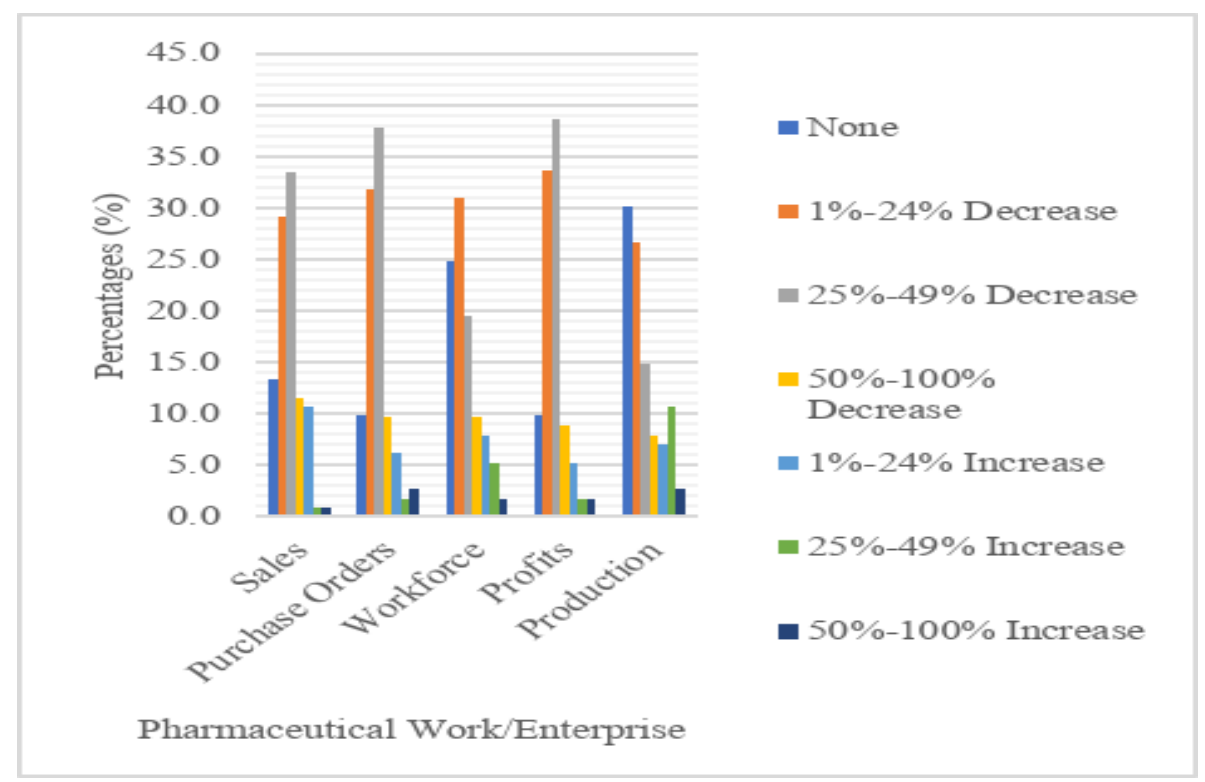

Figure. 2. Impact of COVID-19 Pandemic on Pharmaceutical Practices in the Study Area

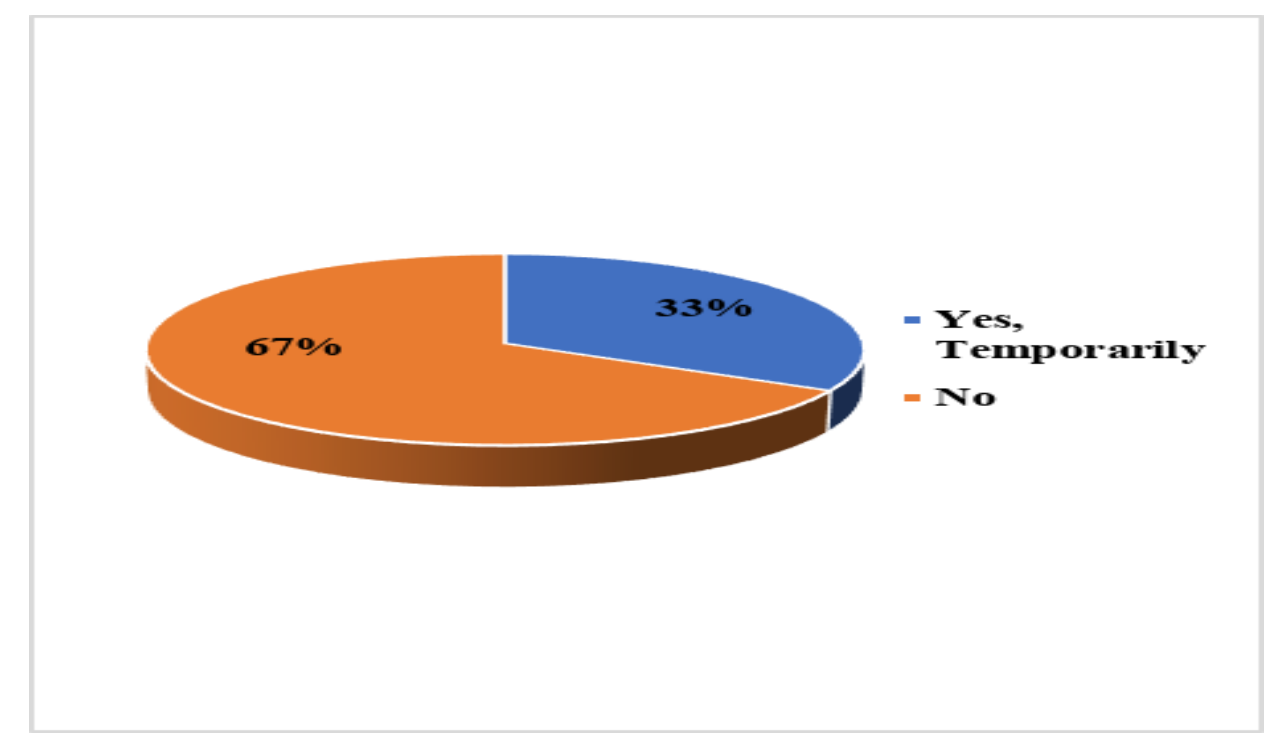

Figure 3. Rate at which Workers stopped Working because of COVID-19 Crisis 
Table 2. Cross Tabulation of the Impacts of COVID-19 and Pharmaceutical Practices

\begin{tabular}{|c|c|c|c|c|c|c|c|c|}
\hline \multirow[t]{2}{*}{ Work/Enterprise } & \multirow[t]{2}{*}{ Percentages of the Impact } & \multicolumn{6}{|c|}{ Area of Practice } & \multirow[t]{2}{*}{ Total } \\
\hline & & Academia & Hospital & Community & Industrial & Public Health & Others & \\
\hline \multirow[t]{8}{*}{ Sales } & None & $10(0.89)$ & $70(6.26)$ & $40(3.58)$ & $10(0.89)$ & $10(0.89)$ & $10(0.89)$ & $150(13.42)$ \\
\hline & $1 \%-24 \%$ Decrease & 0.0 & $178(15.92)$ & $99(8.86)$ & $20(1.79)$ & $9(0.81)$ & $20(1.79)$ & $326(29.16)$ \\
\hline & $25 \%-49 \%$ Decrease & 0.0 & $206(18.43)$ & $118(10.55)$ & 0.0 & $50(4.47)$ & 0.0 & $374(33.45)$ \\
\hline & $50 \%-100 \%$ Decrease & 0.0 & $89(7.96)$ & 0.0 & $40(3.58)$ & 0.0 & 0.0 & $129(11.54)$ \\
\hline & $1 \%-24 \%$ Increase & 0.0 & $29(2.59)$ & $80(7.16)$ & $10(0.89)$ & 0.0 & 0.0 & $119(10.64)$ \\
\hline & $25 \%-49 \%$ Increase & 0.0 & 0.0 & $10(0.89)$ & 0.0 & 0.0 & 0.0 & $10(0.89)$ \\
\hline & $50 \%-100 \%$ Increase & 0.0 & 0.0 & $10(0.89)$ & 0.0 & 0.0 & 0.0 & $10(0.89)$ \\
\hline & Total & $10(0.89)$ & $572(51.16)$ & 357(31.93) & $80(7.16)$ & $69(6.17)$ & $30(2.68)$ & $1118(100)$ \\
\hline \multirow[t]{8}{*}{ Purchase Orders } & None & $10(0.89)$ & $30(2.68)$ & $30(2.68)$ & $10(0.89)$ & $10(0.89)$ & $20(1.79)$ & $110(9.84)$ \\
\hline & $1 \%-24 \%$ Decrease & 0.0 & $178(15.92)$ & $109(9.75)$ & $20(1.79)$ & $39(3.49)$ & $10(0.89)$ & $356(31.84)$ \\
\hline & $25 \%-49 \%$ Decrease & 0.0 & $275(24.60)$ & $128(11.45)$ & 0.0 & $20(1.79)$ & 0.0 & $423(37.84)$ \\
\hline & $50 \%-100 \%$ Decrease & 0.0 & $59(5.28)$ & $10(0.89)$ & $40(3.58)$ & 0.0 & 0.0 & $109(9.75)$ \\
\hline & $1 \%-24 \%$ Increase & 0.0 & 0.0 & $60(5.37)$ & $10(0.89)$ & 0.0 & 0.0 & $70(6.26)$ \\
\hline & $25 \%-49 \%$ Increase & 0.0 & $10(0.89)$ & $10(0.89)$ & 0.0 & 0.0 & 0.0 & $20(1.79)$ \\
\hline & $50 \%-100 \%$ Increase & 0.0 & $20(1.79)$ & $10(0.89)$ & 0.0 & 0.0 & 0.0 & $30(2.68)$ \\
\hline & Total & $10(0.89)$ & $572(51.16)$ & 357(31.93) & $80(7.16)$ & $69(6.17)$ & $30(2.68)$ & 1118(100) \\
\hline \multirow[t]{8}{*}{ Workforce } & None & $10(0.89)$ & $109(9.75)$ & $60(5.37)$ & $60(5.37)$ & $29(2.59)$ & $10(0.89)$ & $278(24.87)$ \\
\hline & $1 \%-24 \%$ Decrease & 0.0 & $159(14.22)$ & $158(14.13)$ & $10(0.89)$ & 0.0 & $20(1.79)$ & $347(31.04)$ \\
\hline & $25 \%-49 \%$ Decrease & 0.0 & $159(14.22)$ & $39(3.49)$ & 0.0 & $20(1.79)$ & 0.0 & $218(19.50)$ \\
\hline & $50 \%-100 \%$ Decrease & 0.0 & $68(6.08)$ & $30(2.68)$ & $10(0.89)$ & 0.0 & 0.0 & $108(9.66)$ \\
\hline & $1 \%-24 \%$ Increase & 0.0 & $38(3.40)$ & $50(4.47)$ & 0.0 & 0.0 & 0.0 & $88(7.87)$ \\
\hline & $25 \%-49 \%$ Increase & 0.0 & $39(3.49)$ & $20(1.79)$ & 0.0 & 0.0 & 0.0 & $59(5.28)$ \\
\hline & $50 \%-100 \%$ Increase & 0.0 & 0.0 & 0.0 & 0.0 & $20(1.79)$ & 0.0 & $20(1.79)$ \\
\hline & Total & $10(0.89)$ & $572(51.16)$ & $357(31.93)$ & $80(7.16)$ & $69(6.17)$ & $30(2.68)$ & 1118(100) \\
\hline Profits & None & $10(0.89)$ & $30(2.68)$ & $30(2.68)$ & $10(0.89)$ & $10(0.89)$ & $20(1.79)$ & $110(9.84)$ \\
\hline
\end{tabular}




\begin{tabular}{|c|c|c|c|c|c|c|c|c|}
\hline & $1 \%-24 \%$ Decrease & 0.0 & $168(15.03)$ & $139(12.43)$ & $50(4.47)$ & $20(1.79)$ & 0.0 & $377(33.72)$ \\
\hline & $25 \%-49 \%$ Decrease & 0.0 & $266(23.79)$ & $108(9.66)$ & $10(0.89)$ & $39(3.49)$ & $10(0.89)$ & $433(38.73)$ \\
\hline & $50 \%-100 \%$ Decrease & 0.0 & $79(7.07)$ & $10(0.89)$ & $10(0.89)$ & 0.0 & 0.0 & $99(8.86)$ \\
\hline & $1 \%-24 \%$ Increase & 0.0 & $19(1.70)$ & $40(3.58)$ & 0.0 & 0.0 & 0.0 & $59(5.28)$ \\
\hline & $25 \%-49 \%$ Increase & 0.0 & 0.0 & $20(1.79)$ & 0.0 & 0.0 & 0.0 & $20(1.79)$ \\
\hline & $50 \%-100 \%$ Increase & 0.0 & $10(0.89)$ & $10(0.89)$ & 0.0 & 0.0 & 0.0 & $20(1.79)$ \\
\hline & Total & $10(0.89)$ & $572(51.16)$ & 357(31.93) & $80(7.16)$ & $69(6.17)$ & $30(2.68)$ & $1118(100)$ \\
\hline \multirow[t]{8}{*}{ Production } & None & $10(0.89)$ & $208(18.60)$ & $50(4.47)$ & $20(1.79)$ & $19(1.70)$ & $30(2.68)$ & $337(30.14)$ \\
\hline & $1 \%-24 \%$ Decrease & 0.0 & $118(10.55)$ & $120(10.73)$ & $50(4.47)$ & $10(0.89)$ & 0.0 & $298(26.65)$ \\
\hline & $25 \%-49 \%$ Decrease & 0.0 & $68(6.08)$ & $78(6.98)$ & 0.0 & $20(1.79)$ & 0.0 & $166(14.85)$ \\
\hline & $50 \%-100 \%$ Decrease & 0.0 & $69(6.17)$ & $20(1.79)$ & 0.0 & 0.0 & 0.0 & $89(7.96)$ \\
\hline & $1 \%-24 \%$ Increase & 0.0 & $29(2.59)$ & $40(3.58)$ & $10(0.89)$ & 0.0 & 0.0 & $79(7.07)$ \\
\hline & $25 \%-49 \%$ Increase & 0.0 & $70(6.26)$ & $39(3.49)$ & 0.0 & $10(0.89)$ & 0.0 & $119(10.64)$ \\
\hline & $50 \%-100 \%$ Increase & 0.0 & $10(0.89)$ & $10(0.89)$ & 0.0 & $10(0.89)$ & 0.0 & $30(2.68)$ \\
\hline & Total & $10(0.89)$ & $572(51.16)$ & 357(31.93) & $80(7.16)$ & 69(6.17) & $30(2.68)$ & 1118(100.0) \\
\hline
\end{tabular}




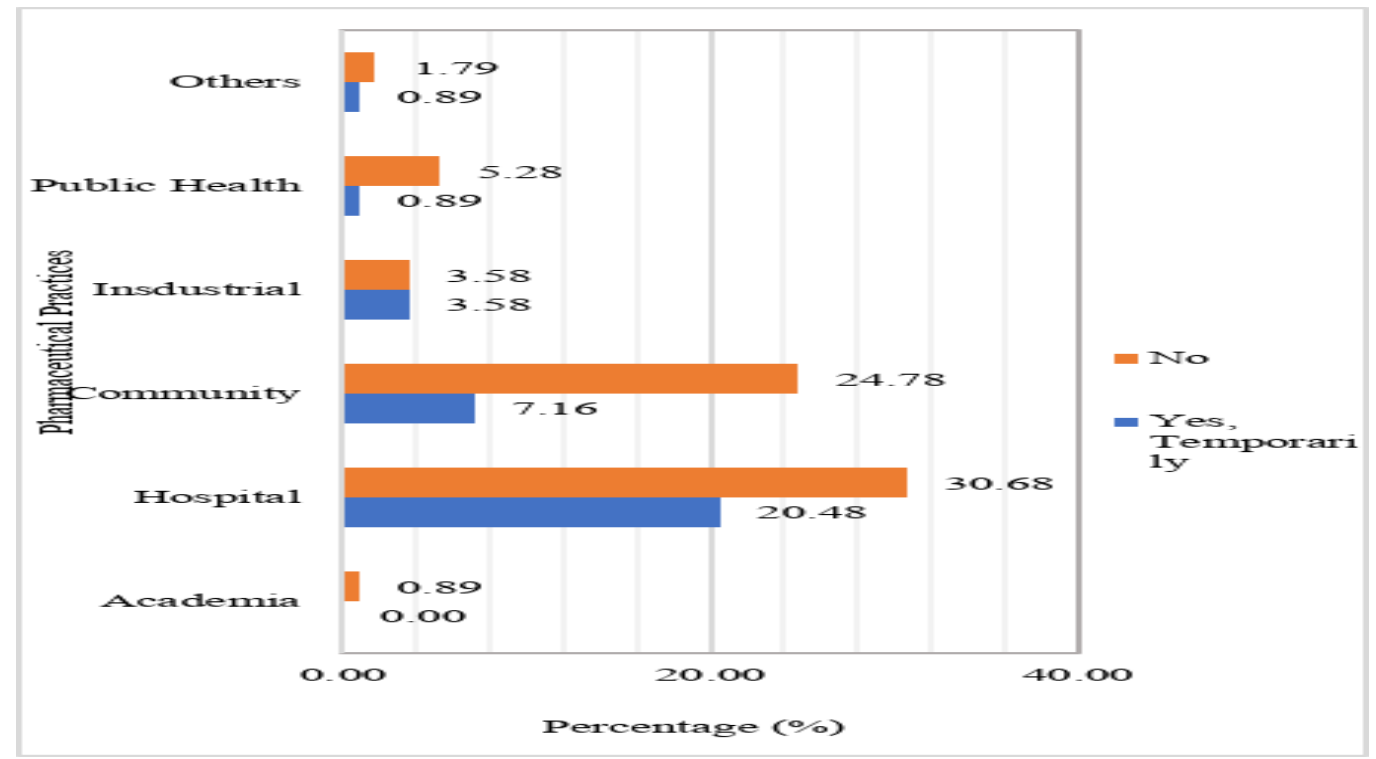

Figure 4. Rate at which Workers Stopped Working in the Pharmaceutical Practices because of COVID-19

Crisis

Figure 5 shows the extent to which the COVID-19 pandemic affected pharmaceutical work and/or business in Nigeria. The results of the study revealed that the pharmaceutical work and/or business was greatly affected by the COVID-19 pandemic, as indicated by the majority $506(45.26 \%)$ of the pharmacists (respondents), while 404 (36.14\%) indicated that their business was somewhat affected. This justifies that $81.40 \%$ of them indicated that the COVID-19 crisis affected their work and business.

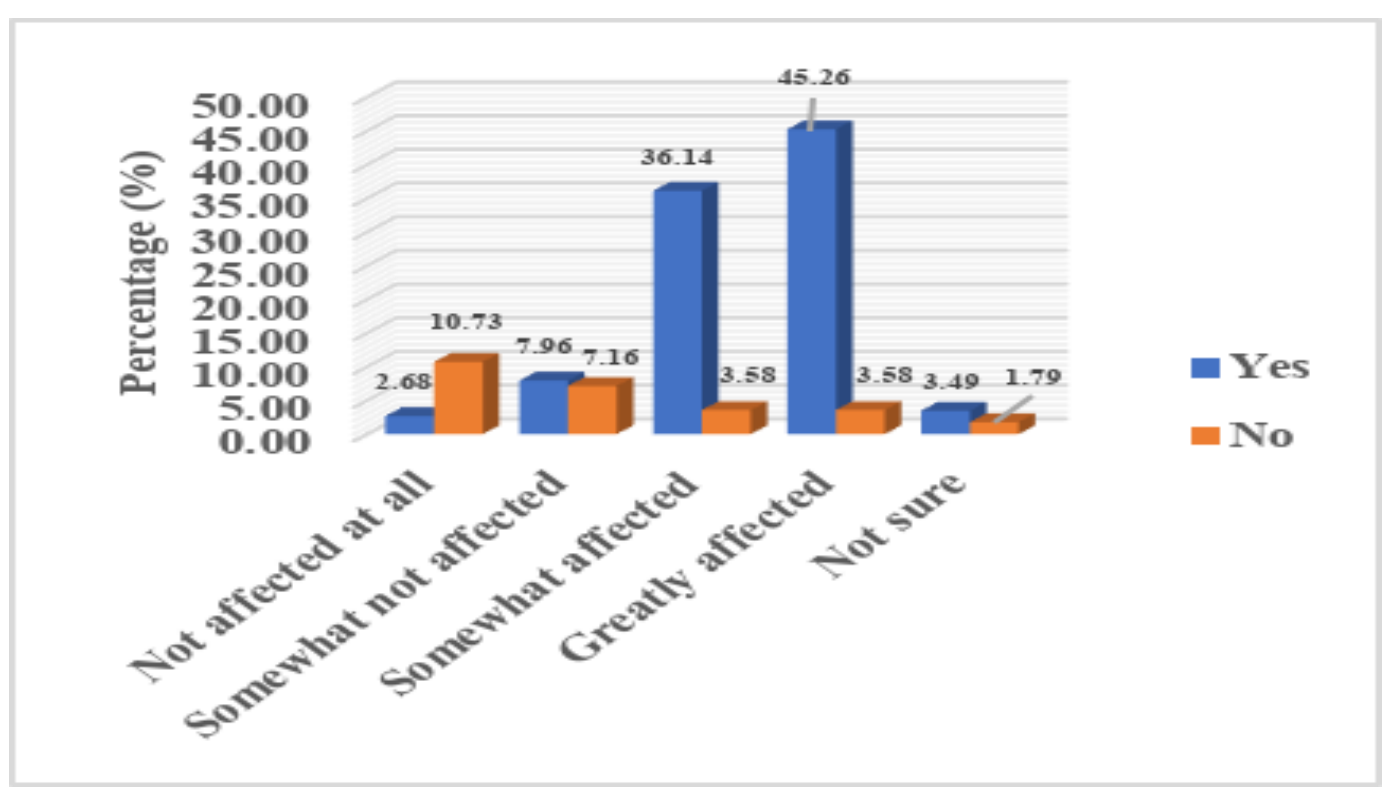

Figure 5. The Extent at which COVID-19 Pandemic affected Pharmaceutical Work and/or Business 
Strategic Measures Taken and Practiced as Responses to COVID-19 Crisis by Respondents in the Study Area

The outcomes of this study found out that the lockdown method, as a universal strategic measure of reducing the spread and extent of COVID-19, was associated with the level of spreading COVDI-19 and insecurity and inflation (Figure. 6). 49.82\% of the respondents (Pharmacists) agreed that total lockdown measure taken and practiced during COVID-19 reduced the spread of 2019 coronavirus disease (COVID-19) in the study area, while $40.70 \%$ of the respondents also agreed that total lockdown increased the level of insecurity and inflation in the course of the COVID-19 pandemic.

Table 3 shows that Pharmacists have taken and practiced some measures to mitigate and/or control the impacts of COVID-19 on the pharmaceutical practices in the study area.

'Diversifying sales channels through online marketing and free delivery (19.41\%)' was highly indicated by the pharmacists in the study area, followed by 'increased production due to increased demand (17.71\%)' and 'negotiating pays with staff $(16.82 \%)$. Hospital pharmacy and community pharmacy greatly responded to the impact caused by the COVID-19 pandemic with percentages of $51.16 \%$ and $31.93 \%$, respectively. Academia pharmaceutical practice was not involved in mitigating the impact of the COVID-19 pandemic in Nigeria as most of the schools and institutions were closed down during the pandemic.

Industrial, pharmaceutical practice responded to the COVID-19 pandemic by 'reducing the production of goods and services $(3.58 \%)$ '. Besides the available measures recommended and practiced by the organization/enterprise (Table 3), a small proportion of 158 (14.13\%) of the respondents indicated that they put some other strategic measures in place in response to the COVID-19 pandemic. Some other measures practiced by the pharmacists in the study area include working from home; teaching and carrying out examination online; use of virtual work tools, reducing the purchase of commodities due to paucity of funds; ensuring the use of face masks always; and providing the needed materials and equipment to end the virus.

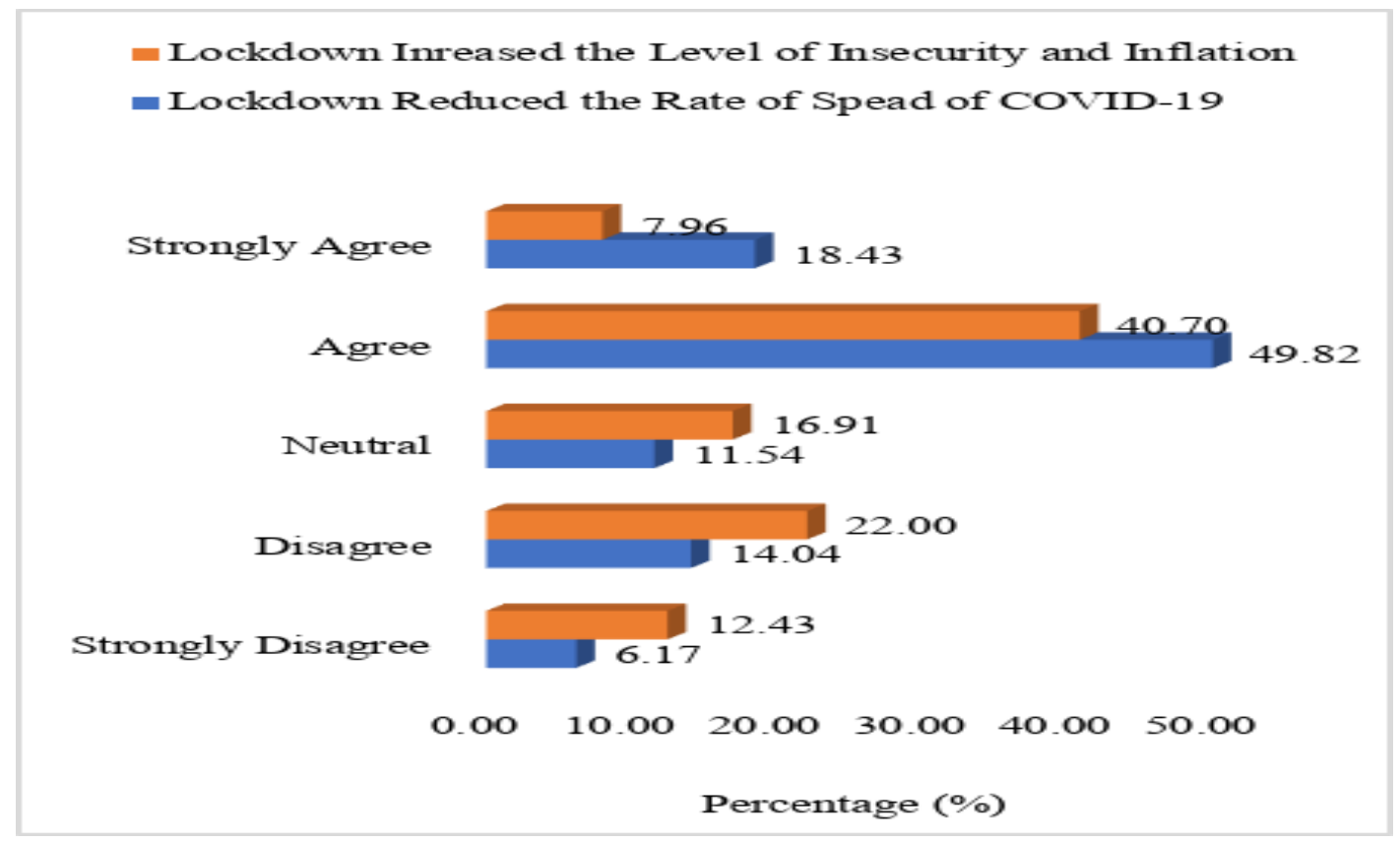

Figure. 6: Lockdown Measure with the Spread of COVID-19 and Level of Insecurity in the Study Area 
Table 3. How Pharmaceutical Organization/Enterprise responded to COVID-19

\begin{tabular}{|l|l|l|l|l|l|l|l|}
\hline \multirow{2}{*}{$\begin{array}{l}\text { How is your } \\
\text { organization/enterprise } \\
\text { responding to the pandemic? }\end{array}$} & Area of Practice & \multicolumn{3}{l|}{ Total } \\
\cline { 2 - 8 } & Academia & Hospital & Community & Industrial & $\begin{array}{l}\text { Public } \\
\text { Health }\end{array}$ & Others & \\
\hline $\begin{array}{l}\text { Regotiating pays with staff } \\
\text { staff }\end{array}$ & 0.0 & $78(6.98)$ & $80(7.16)$ & $20(1.79)$ & $10(0.89)$ & 0.0 & $188(16.82)$ \\
\hline $\begin{array}{l}\text { Reducing the numbers of } \\
\text { staff }\end{array}$ & 0.0 & $110(9.84)$ & $19(1.70)$ & 0.0 & $30(2.68)$ & 0.0 & $159(14.22)$ \\
\hline $\begin{array}{l}\text { Diversifying sales channels } \\
\text { through online marketing } \\
\text { and free delivery }\end{array}$ & 0.0 & $78(6.98)$ & $129(11.54)$ & $10(0.89)$ & 0.0 & 0.0 & $217(19.41)$ \\
\hline $\begin{array}{l}\text { Negotiating payment terms } \\
\text { with banks and suppliers }\end{array}$ & 0.0 & $30(2.68)$ & $69(6.17)$ & $10(0.89)$ & 0.0 & 0.0 & $109(9.75)$ \\
\hline $\begin{array}{l}\text { Reducing the production of } \\
\text { goods and services }\end{array}$ & 0.0 & $19(1.70)$ & $10(0.89)$ & $40(3.58)$ & 0.0 & 0.0 & $69(6.17)$ \\
\hline $\begin{array}{l}\text { Increased production due to } \\
\text { increased demand }\end{array}$ & 0.0 & $168(15.03)$ & $20(1.79)$ & 0.0 & 0.0 & $10(0.89)$ & $198(17.71)$ \\
\hline Others & $10(0.89)$ & $79(7.07)$ & $20(1.79)$ & 0.0 & $29(2.59)$ & $20(1.79)$ & $158(14.13)$ \\
\hline Total & $10(0.89)$ & $572(51.16)$ & $357(31.93)$ & $80(7.16)$ & $69(6.17)$ & $30(2.68)$ & $1118(100)$ \\
\hline
\end{tabular}

Considering the enforcement of COVID-19 basic preventive measures and practices recommended by the World Health Organisation (WHO) and Nigerian Centre for $(75.13 \%)$ of the respondents indicated that their place of work enforced COVID-19 basic preventive measures and to a great extent during the period of the pandemic (Figure 7).

Disease and Control (NCDC), the majority

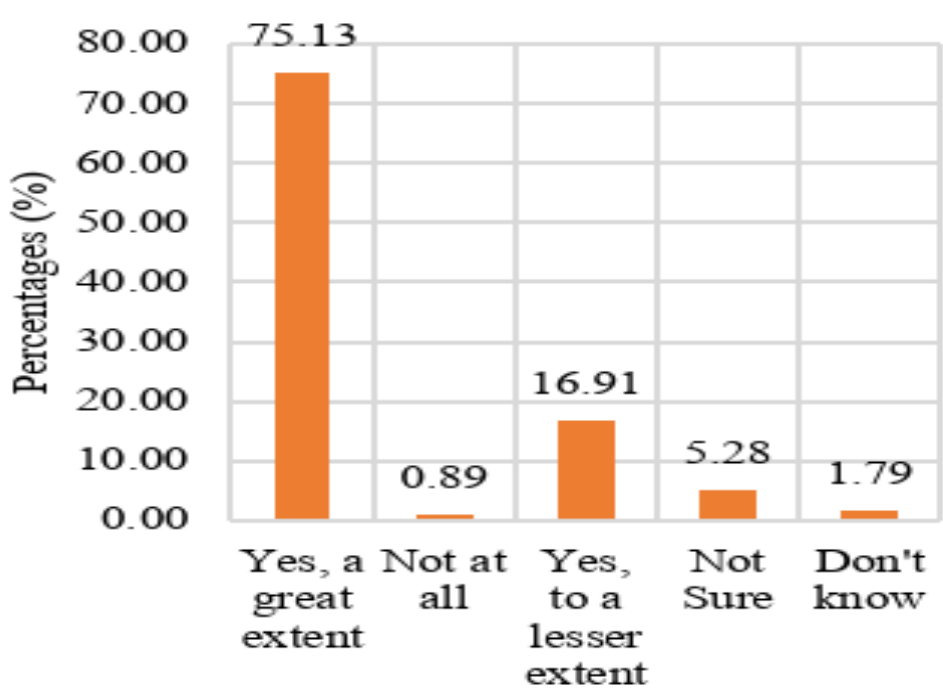

- Percent

Basic Measures and Practices

Figure 7. Enforcement of COVID-19 Basic Preventive Measures and Practices

Larger proportions of the respondents which constituted $209(18.69 \%)$ and $199(17.80 \%)$, had shown that their places of work enforced COVID-19 basic preventive measures and 
practices in North-central and South-west of enforced COVID-19 basic preventive measures Nigeria (Figure 8 ). Only $1.70 \%$ of the targeted in the northwest of the country. respondents were not sure if their place of work

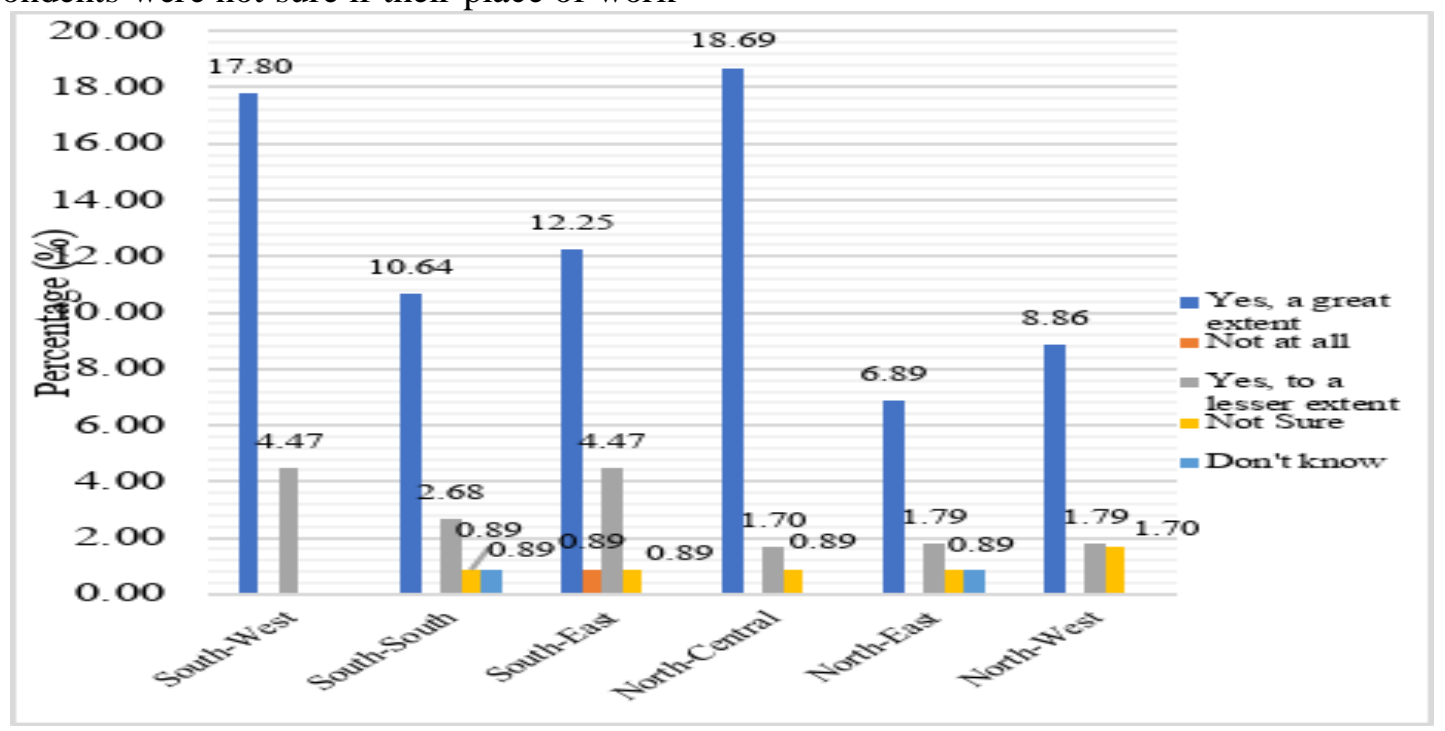

Figure. 8. Enforcement of COVID-19 Basic Preventive Measures and Practices in Geo-Political Zones

Among the working places that enforced COVID-19 basic preventive measures and practices, a large proportion $860(76.92 \%)$ of the respondents practiced 'social and physical distancing at work,' $75.31 \%$ of respondents practiced the 'use of PPEs and temperature checks', while only 40 (3.58\%) practiced other basic procedures which include the use of only face mask, face mask, and shield, face mask and gloves, regular handwashing with water and soap and, and the use of hand sanitizers (Figure 9).

\section{Discussion}

Pharmacists and pharmaceutical practices play significant roles in upholding and improving the health status of Nigerians. Because of the sudden emergence of COVID19 and no time to prepare for the lockdown measure concerning the manufacturing and supplying of drugs, pharmaceutical practices were significantly disrupted. Findings obtained in this study revealed the percentages of males and females varied as the ratio of males and females were 0.51 and 0.46. A decline in the percentage of aged people sampled in the study area could be a result of the population pyramid in Nigeria, which tends to be a less aged group at the apex. Because of the nature of the profession and/or work, all the respondents were professional pharmacists with a minimum of university educational qualifications, while some respondents also had other professional qualifications. Large proportions of the community, hospital and industrial practices justified the fact that the three pharmaceutical practices were immensely contributed to their quota during the COVID-19 pandemic. This is similar to the report of the previous studies such as [30].

Findings from this study also revealed that pharmaceutical practices were negatively affected in areas or aspects of sales, purchase orders, and profit-making, especially in hospital and community pharmaceutical practices in Nigeria, the study area. Based on the results of this study, the decrease in all areas/aspects of the pharmaceutical practices could be ascribed to the lockdown approach, and other factors such as low supplying of drugs, low production or manufacturing of drugs, low income, to mention but a few. The decrease in the workforce could be attributed to the fear of getting contracted with the virus in the study area. It is believed that the team of pharmacy teams are considered as important members of 
the healthcare workforce and also as the crucial frontline of healthcare workers [30]. Because they (pharmacy workforce) provide and/or offers an extensive array of healthcare services in pharmaceutical practices, especially community pharmacies [31].

The reason for the $25-49 \%$ decrease in the profit of the hospital and community pharmaceutical practices was due to the fact of low patronage and the fear of COVID-19 among the populace. Furthermore, several factors caused a temporary stoppage of working in the hospital, community, and industrial practices during COVID-19 by the respondents. The findings of this study corroborate the findings of [14]. Short-term impacts of the COVID-19 pandemic involve demand changes, regulation and revision, development process and research, and the shift towards telecommunications and telemedicine [32]. Many studies showed the adverse psychological health effects following quarantine which include emotional disturbance, depression, stress, low mood, irritability, insomnia, posttraumatic stress symptoms, anger, and emotional exhaustion [33 - 36]. Additionally, it has been stated that confusion, anger, and posttraumatic stress indicators caused by being quarantined for a long period, the panic of getting the virus, distress, boredom, insufficient supplies, poor information, monetary loss, and stigma are adverse psychological effects following quarantine [37].

The adoption of mitigation strategies of COVID-19 was practiced by a large number of respondents. This might be the result of the awareness and education level of the pharmacists (respondents). The consequent effect of lockdown brought about a high level of insecurity and inflation. An upsurge in the level of insecurity could be a result of difficulties people faced to feed themselves and other things during the lockdown period. Low supplies caused a persistent rise in the prices of goods and services during COVID-19. Previous studies have identified the psycho-social impact caused by lockdown measures [38]. The evidence has been reported the sufferings of psychological distress, insomnia, anxiety, and depression among the healthcare providers [39, 40].

The actions taken by the pharmacists during COVID-19 were because of the impact of COVID-19 on several aspects/areas of pharmaceutical practices in Nigeria, the study area. Studies reported many factors are associated with the impact of COVID-19. Also, the occurrence of anxiety was $60 \%$, and depression was $53 \%$, mostly mild and moderate levels, for the time being, just one out of four respondents testified the accessibility of mental health support team at the workplace among 2097 healthcare workers from 31 countries [15]. Due to the impact of the COVID-19 pandemic, actions were mostly taken by the hospital and community pharmaceutical practices. In the earlier studies, it has been established that respondents (pharmacists) are in a crucial position to provide an effective response to the COVID-19 pandemic, yet their expertise is not often recognized and underutilized [41]. In countries like Northern Ireland and New Zealand, the government acknowledged pharmacists' contributions by providing extra remuneration during the pandemic [42].

Findings obtained from this study further showed that the respondents' working place enforced and practiced basic preventive measures meant for COVID-19. It has been reported and recommended in the previous studies that healthcare systems should address the psychological burden among healthcare workers during the COVID-19 pandemic [15]. In spite of the fact that the government took actions towards the impacts of COVID-19, individuals also took proactive measures to curb the symptoms of COVID-19 [43]. In a similar study conducted in India, it was reported that there was a frequent visitation to hospitals for the actions to be taken regarding 
the emergence of COVID-19 by individuals [44].

The major basic COVID-19 preventive measures practiced by the pharmacists which constituted the respondents included 'social and physical distancing at work', 'use of PPEs and temperature checks', 'the use of only face mask, face mask and shield, face mask and gloves, frequent handwashing with water and soap, and the hand sanitizers'. The findings of this study correspond to the study of which reported social distancing, and the use of face masks was the most often reported by the pharmacists for prevention [45]. An online and/or conducted in Nigeria showed that wearing face masks, covering of mouth while sneezing, and avoiding crowded places are selfreported as practices among respondents [46].

Furthermore, the chance of positive mitigation strategies and/or practices towards COVID-19 was associated with a positive perception of the risk involved [47]. In Nigeria, previous studies also substantiate the pivotal role of positive risk perception on imbibing COVID-19 mitigating strategies and/or protective measures and attitudes [48]. The results obtained in this study are similar to the Knowledge concerning the practice of face masks in Saudi Arabia [49]. Because of the deadly nature of COVID-19, it has presented anxiety and/or fear in every individual with similar symptoms of illness [47]. Previous studies had shown that fear could prompt

\section{References}

[1] Lai, J., Ma, S., Wang, Y., Cai, Z., Hu, J., Wei, N., et al. 2020, Factors associated with mental health outcomes among health care workers exposed to coronavirus disease 2019. JAMA Netw Open, 3:e203976.

Doi:10.1001/ jamanetworkopen.2020.3976.

[2] World Health Organization, 2020, Coronavirus disease (COVID-19) Pandemic 2020. Available: https://www.who.int/emergencies/diseases/novelcoronavirus-2019. Accessed: 8 September 2021. healthy behavior among people or individuals, most importantly the period of a pandemic, but such behavior cannot be viable [50, 51, 52].

\section{Conclusion and Recommendation}

Pharmacists play significant roles to uphold and improving the health status of Nigerians. In this respect, the impact of COVID-19 on pharmaceutical practices has been assessed because of its unprecedented impacts on the pharmaceutical practices and the lives of healthcare professionals in the country. This study showed that COVID-19 had negative impacts on pharmaceutical practices, especially in hospital practices and community practices in the study area. Basic precautionary measures and actions towards the impact of COVID-19 in the study area were also enforced and practiced. Supports and assistance from government and non-governmental organizations are needed to better improve pharmaceutical care and services in Nigeria.

\section{Conflicts of Interest}

There is no conflict of interest between the authors.

\section{Acknowledgements}

The author expresses her appreciation and gratitude to all pharmacists and/or pharmaceutical practices and Afeez Alabi Salami for their willingness, assistance, and cooperation to participate in this study.

[3] World Health Organisation, 2021, COVID-19 report cases.

http://www.who.int/gho/countries/nga.pdf?ua=1.

[4] WHO, 2020, Middle East respiratory syndrome coronavirus (MERS-CoV). Available: https://www.who.int/emergencies/mers-cov/en/ Accessed: 8 September 2021.

[5] WHO, 2020, Severe Acute Respiratory Syndrome (SARS). Available: https://www.who.int/csr/sars/en/ Accessed: 7 September 2021. 
[6] The Lancet, 2020, COVID-19: protecting healthcare workers. $\quad$ Lancet. 395:922. doi:10.1016/S01406736(20)30644-9.

[7] Fatjona et aL. 2021, Impact of COVID-19 pandemic on mental health, risk perception and coping strategies among health care workers in Albania - evidence that needs attention. Clinical Epidemiology and Global Health, 12(2021)100824, 1-7. https://doi.org/10.1016/j.cegh.2021.100824.

[8] Lucero-Prisno, D.E., Adebisi, Y.A., and Lin, X., 2020, Current efforts and challenges facing responses to 2019-nCoV in Africa. Glob Health Res Policy, 5, 21. https://doi.org/10.1186/s41256-02000148-1.

[9] WHO, 2020, Mental health and psychosocial considerations during the COVID-19 outbreak. https://www.who.int/docs/default-

source/coronaviruse/mental-health-

considerations.pdf?sfvrsn=6d3578af_2;2020.

[10]Zhu, N., Zhang, D., Wang, W., et al., 2020, A novel coronavirus from patients with pneumonia in China, 2019. N Engl J Med. 382(8), 727-733. https://doi.org/10.1056/NEJMoa2001017.

[11]Roy, R.M. et al. 2021, Psychological distress during pandemic Covid-19 among adult general population: Result across 13 countries. Clinical Epidemiology and Global Health, 10 (2021), 100708, 1-6.

https://doi.org/10.1016/j.cegh.2021.100708.

[12] Scherbina, B., 2020, Determining the optimal duration of the COVID-19 suppression policy: A cost-benefit analysis. AEI Economics Working Paper 2020-03. American Enterprise Institute, 1-28.

[13] Akande-Sholabi, W., Adebisi, Y.A., Bello, A., and Ilesanmi, O.S., 2020, COVID-19 in Nigeria: Is the pharmaceutical sector spared? Public Health in Practice, $1, \quad 100044$ https://doi.org/10.1016/j.puhip.2020.100044.

[14] David, K.B., and Adebisi, Y.A., 2020, Proposed model for hospital and community pharmacy services during COVID-19 pandemic in Nigeria. Int J Pharm Pract, 28, 544-545.

[15] Mila, N.N.H., Roy, R.M., Ayesha, A., Fatjona, K., Radwa, A.E., Jeldah, M.N., and Adinegara, L.A., 2020, Immediate impact of COVID-19 on mental health and its associated factors among healthcare workers: A global perspective across 31 countries. Viewpoints, 10(2), 020381, 1-6. doi: 10.7189/jogh.10.020381.

[16] Wagner, E.H., 1998, Chronic disease management: What will it take to improve care for chronic illness? Efficient Clinical Practice, 1(1), 2-4. [17] Thomson, L.A., et al., 2007, Systematic review of the incidence and characteristics of preventable adverse drug events in ambulatory care. Annals of Pharmacotherapy, 41(9), 1411-1426.

[18] Shanmugam, S., et al., 2011, Impact of pharmaceutical care on quality of life in patients with type 2 diabetes mellitus. Journal of Royal Medical Society, 16(1), 412-418.

[19] Anyama, N., and Adome, R.O., 2003, Community pharmaceutical care: An 8-month critical review of two pharmacies in Kampala. African Health Sciences, 3(2), 87-93.

[20] Dunlop, J.A., and Shas, J.P., 2002, Pharmacist's perspective on pharmaceutical care implementation in New Zealand. Pharmacy World and Science, 24(6), 224-30.

[21] Gloria, N., and Sylvie, P., 2000, Optimizing adherence to pharmaceutical care plan. Journal of American Pharmaceutical Association, 40(4), 475482.

[22]Erah, P.O., and Nwazuoke, J.C., 2002, Identification of standards for pharmaceutical care in Benin City. Tropical Journal of Pharmaceutical Research, 1(2), 55-66.

[23] Oparah, C.A., and Eferakeya, A.E, 2005, Attitude of Nigerian pharmacists towards pharmaceutical care. Pharmacy World and Science, 27(3), 208-214.

[24] Salami, A.A., 2018, Assessment of remote sensing in deriving meteorological data for agricultural purposes in Nigeria. A Ph.D. proposal presented at the department of Geography and Environmental Management, University of Ilorin, Nigeria.

[25] Salami, A.A., Olorunfemi, J.F., and Olanrewaju, R.M., 2020, Geo-spatial analysis of rainfall amounts and rainy days using satellites and ground-based data in Nigeria. Journal of Meteorology and Climate Science, 18 (1). 
[26] National Population Commission, 2016, 2016 Projected population of Federal Republic of Nigeria 2006 Population and Housing Census, Priority Tables, Vol. VII Abuja, Nigeria.

[27]Eze, T.C., Okpala, C.S., and Ogbodo, J.C., 2014, Patterns of inequality in human development across Nigeria's six geopolitical zones. J Dev Ctries Stud., 4(8), 97-101.

[28] World Health Organization, 2015, Nigeria: World Health Organisation statistical profile 2015. Available from: http://www.who.int/gho/countries/nga.pdf?ua=1.

[29]Ekpenyong, A., Udoh, A., Kpokiri, E., and Bates, I., 2018, An analysis of pharmacy workforce capacity in Nigeria. Journal of Pharmaceutical Policy and Practice, 11:20. https://doi.org/10.1186/s40545-018-0147-9.

[30] Ashiru-Oredope, D., Chan, A.H.Y., Olaoye, O., Rutter, V., Babar, Z. and the C.P.A. COVID-19 Action Team, 2020, Needs assessment and impact of COVID-19 on pharmaceutical professionals in 31 commonwealth countries. $\mathrm{J}$ of Pharm Policy and Pract 13, 72, 1-11. https://doi.org/10.1186/s40545020-00275-7.

[31] Smith, A.J., Scahill, L.S., Harrison, J., Carroll, T., and Medlicott, J.N., 2018, Service provision in the wake of a new funding model for community pharmacy. BMC Health Services Research, 18, 2-10. https://doi.org/10.1186/s12913-018-3120-z.

[32] Ayati, N., Saiyarsarai, P., Nikfar, S., 2020-, Short- and long-term impacts of COVID-19 on the pharmaceutical sector. DARU Journal of Pharmaceutical Sciences, 28, 799-805. https://doi.org/10.1007/s40199-020-00358-5.

[33] Miles, S.H., Kaci, H., 2015, Public health and the politics of fear. Am J Bioeth. 15(4), 17-19. https://doi.org/10.1080/15265161.2015.1010994.

[34] Yoon, M.K., Kim, S.Y., Ko, H.S., Lee, M.S., 2016, System effectiveness of detection, brief intervention and refer to treatment for the people with post-traumatic emotional distress by MERS: A case report of community-based proactive intervention in South Korea. Int J Ment Health Syst. 10:51. https://doi.org/10.1186/s13033-016- 0083-5.

[35] Marzo, R.R., Singh, A., Mukti, R.F., 2021, A survey of psychological distress among Bangladeshi people during the COVID-19 pandemic. Clinical Epidemiology and Global Health. 10:1016. https://doi.org/10.1016/j.cegh.2020.100693.

[36] Htay, M.N.N., Marzo, R.R., AlRifai, A. et al., 2020, Immediate impact of COVID-19 on mental health and its associated factors among healthcare workers: a global perspective across 31 countries. J Glob Health. 2020;10, 020382. https://doi.org/10.7189/jogh.10.020381.

[37] Brooks, S.K., Webster, R.K., Smith, L.E., et al., 2020, The psychological impact of quarantine and how to reduce it: rapid review of the evidence. Lancet., 395(10227), 912-920. https://doi.org/10.1016/S0140-6736(20)30460-8.

[38] Nilima, N., Kaushik, S., Tiwary, B., Pandey, P.K., 2021, Psycho-social factors associated with the nationwide lockdown in India during COVID- 19 pandemic. Clin Epidemiol Glob Health, 9, 47-52.

[39]Lai, J., Ma, S., Wang, Y., Cai, Z., Hu, J., Wei, N., et al. 2020, Factors associated with mental health outcomes among health care workers exposed to coronavirus disease 2019. JAMA Netw Open. 3(3), e203976.

[40]Bohlken, J., Schömig, F., Lemke, M.R., Pumberger, M., Riedel-Heller, S.G., 2020, COVID19 Pandemic: Stress Experience of Healthcare Workers - A Short Current Review. Psychiatr Prax., 47(4), 190-7.

[41] Watson, M.C., Silver, K., and Watkins, R., 2019, How does the public conceptualise the quality of care and its measurement in community pharmacies in the UK: A qualitative interview study. BMJ Open, 9e027198, 1-7. Doi: 10.1136/bmjopen2018-027198.

[42] Bukhari, N., Rasheed, H., Nayyer, B., and Babar, Z., 2020, Pharmacists at the frontline beating the COVID-19 pandemic. Journal of Pharmaceutical Policy and Practice, 13, (8), 1-4. https://doi.org/10.1186/s40545-020-00210-w.

[43] Chukwuorji J.C., and Iorfa, S.K., 2020, Commentary on the coronavirus pandemic: Nigeria. Psychological Trauma: Theory, Research, Practice, and Policy, 12(S1), S188- S190. DOI $10.1037 /$ tra0000786.

[44]Dkhar, S.A., Quansar, R., Saleem, S.M. and Khan, S.M., 2020, Knowledge, attitude, and 
practices related to COVID-19 pandemic among social media users in $\mathrm{J} \& \mathrm{~K}$, India. Indian Journal of Public Health, 64(6), 205-210 DOI 10.4103/ijph.IJPH_469_20.

[45]Ilesanmi, O., and Afolabi, A., 2020, Perception and practices during the COVID-19 pandemic in an urban community in Nigeria: A cross-sectional study. PeerJ8:e10038. DOI 10.7717/peerj.10038.

[46]Iorfa, S.K., Ottu, I.F.A., Oguntayo, R., Ayandele, O., Kolawole, S.O., Gandi, G.C., Dangiwa, A.L., and Olapegba, P.O., 2020, COVID19 knowledge, risk perception and precautionary behavior among Nigerians: A moderated mediation approach. medRxiv

DOI 10.1101/2020.05.20.20104786.

[47]Zhong, B-L, Luo, W., Li, H-M., Zhang, Q-Q., Liu, X-G., Li, W-T., and Li, Y., 2020, Knowledge, attitudes and practices towards COVID19 among Chinese residents during the rapid rise period of the COVID-19 outbreak: A quick online cross-sectional survey. International Journal of Biological Sciences, 16(10), 1745-1752 DOI 10.7150/ijbs.45221.

[48] WHO, 2020b, Coronavirus disease (COVID-19) situation report-149 Geneva: World Health Organization. Accessed: 26 August 2020. https:/www.who.int/docs/defaultsource/coronaviruse/situationreports/20200623covid-19-sitrep-155.pdf?sfvrsn=ca01ebe_2.
[49] Al-Hanawi, M.K., Angawi, K., Aishareel, N., Qattan, A.M.N., Helmy, H.Z. ... Aisharqi, O., 2020, Knowledge, attitude and practice toward COVID-19 among the public in the Kingdom of Saudi Arabia: A cross-sectional study. Front. Public Health, 8, 217, 1-10. Doi:10.3389/fpubh.2020.00217.

[50]Witte, K., 1998, Fear as motivator, fear as inhibitor: using the extended parallel process model to explain fear appeal successes and failures. In Andersen, P.A. and Guerrero L.K., (Eds), The Handbook of Communication and Emotion: Research, Theory, Applications, and Contexts (pp. 423-450), San Diego: Academic.

[51] Nabi, R.L., 1999, A cognitive-functional model for the effects of discrete negative emotions on information processing, attitude change, and recall. Communication Theory, 9(3), 292-320. DOI 10.1111/j.1468-2885. 1999. Tb00172. x.

[52]Ufuwa, I.S., Akpa, C.O., Umeokonkwo, C.D., Umoke, M., Oguanuo, C.S., Olorukooba, A.A., Bamgboye, E., and Balogun, M.S., 2020, Knowledge and risk perception towards Lassa fever infection among residents of affected communities in Ebonyi State, Nigeria: Implications for risk communication. BMC Public Health, 20(1), 1-10. DOI 10.1186/s12889-020-8299-3. 


\title{
The Influence of Social Support on the Academic Performance/Self- Efficacy of Students in Methodist University College Students, Ghana
}

\author{
Peter Worlanyo Abomah \\ Methodist University College Ghana, Department of Social Sciences, Dansoman Accra \\ Ghana
}

\begin{abstract}
The study examined the influence of social support on the academic performance/self-efficacy of students at Methodist University College, Ghana. The purpose is to examine whether social support influence academic performance, examine whether gender differences exist in social support students receives and their academic performance, explore how high resilience self-will predict academic performance. The research design employed was a survey. One hundred and twenty students were selected for the study from four faculties of the University using stratified proportional and simple random sampling methods. The standardized instrument of medical outcome social support survey scale, the academic self-efficacy scale, and the resilience scale were used. Four hypotheses were analyzed. The results indicate that a positive relationship between social support leads to good academic performance. There was no difference in terms of social support and academic performance by female and male students. Students with high resilience had high academic attainments. Social assistance does not influence the academic self-efficacy of students. It is recommended that Universities and higher institutions of learning should have well-functioning counselling centres.
\end{abstract}

Keywords: Academic self-efficacy, Depression, Emotional Support, Psychological distress, Stress, Social Support.

\section{Introduction}

According to [1], going through university education is stressful. There realization that this stressful nature of the university education may take a toll on the mental health of the students, which may have an effect on their academic performance/self-efficacy. Social support serves as an important role when it comes to academic performance. It is very important to review the role of social support serves as a cushion against the stresses of life, which in the long run serves to promote good mental health [2].

The transition to university education and environment could result in all forms of stress and shock to students due to the difference in secondary education and university education [3]. It is not clear whether most students in tertiary institutions who experience stress and minor psychological distresses have access to or take advantage of the right type of social support as well as help-seeking environments such as the counseling centers in their various institutions or from their peers and family. As such, this study also aims at finding out whether the students take advantage of the social support from the counseling centers in their various institutions or from their peers and family when they experience minor psychological distress.

The study aims to examine the influence of this social support, psychological distress, on academic performance. It is assumed that the constant struggle by some students to excel academically may be due to lower social encouragement from family and friends and psychological distress. Recognized 
internationally as an important public health issue is the mental health of university students. It was found that psychological distress was linked to mental disability and lower academic achievement [4], [1]. There is a special pattern of distress that adolescents experience [5]. It may also go unnoticed if the lack of social encouragement from family relations, friends, and psychological distress is a contributing factor to low academic performance. According to [6], parental support has a positive influence on the academic performance and self consept of students. According to [7], Low self-esteem is a behavioural disorder which tends to effect the learning and performance of children in schools. There is a need to conduct studies to understand the burden of mental health issues among university students in this part of our world. This will guide interventions that decrease the risk and improve psychological well-being and promote the desire for adequate social encouragement from family and friends. This may result in improved academic performance. According to [8] academic anxiety correlates with academic performance. The study supports the finding of Abomah [9] academic anxiety leads to examination malpractices.

The results of [10] states that university engagement measures were positively related to students' learning achievement indicators The results of [11] indicates that depressive symptom increases the risk for academic problems It also support the findings of [12] that economic effects, and the effects on daily life, as well as delays in academic activities, were positively associated with anxiety symptoms

This happens if the basic gaols of humans as outlined by [13] are not met. The findings of [14] indicates that encouragement to achieve, the provision of care and support to deal with problems in a proactive manner and enabling relationship with significant others facilitated academic achievement dispute exposure to violence.
Even though some literature exists on the intervening variables between informal social support, psychological well-being, and academic performance, more extensive research should be conducted to get a broader idea of the ways in which social support from informal social networking between family and friends and how psychological distress relates to academic performance among university students. Therefore, the purpose of this study is to find out the kind of effect that social support from family and friends and psychological distress/resilience has on university students' academic performance. The objectives include to explore whether university students experience psychological distress, to examine gender differences that exist in the social encouragement students receive, to examine differences that exist in psychological distress There should be continuous research to improve tertiary education for knowledge society [15]. Hence the study indicates that students face, and to explore how psychological distress and social support influence academic performance/self-efficacy of students. The following hypotheses were tested. A significant correlation exists between social encouragement and academic self-efficacy. Females will report higher levels of social encouragement than their male counterparts. There will be a significant influence of social assistance and psychological distress on academic performance.

\section{Methods}

The survey was the research design used because the research provided information about the distribution of a wide range of the characteristics that are being looked for in this study. The population of interest for the study was the undergraduate students from all the faculties at Methodist University College. These were students pursuing degree courses from level 200 to level 300 of the University. The sample frame involves the level 200 and 300 students because they were the stable 
groups whilst the level 100 students were settling into the school, and the level 400 students were preparing to leave.

The sampling technique employed was simple random and stratified proportional method. Using the sampling technique, 120 undergraduate students were sampled for the study. There were four faculties at MUCG, which were the Business Administration faculty, the Informatics and Mathematical Sciences faculty, the Social Studies faculty, and the Arts and General Study's faculty. Thirty (30) students were selected from each faculty to reflect the numerical composition of four faculties within MUCG. This gave a total sample of one hundred and twenty (120) students.

The instrument was developed by [16]. A self-report tool made up of 19 items on a fivepoint Likert scale, thus how frequently they rely on others for support in various circumstances, was used. This survey used four distinct subscales of social assistance and a general functional social support index. The survey has Cronbach alphas greater than .91 for all factors and is fairly stable over time. An individual scale with the highest score or the overall support index indicates more social support. The academic self-efficacy scale was developed by [17] for measuring academic self-efficacy. This instrument is made up of 8 items on a 7point Likert scale that ranged. The scale has a Cronbach alpha reliability coefficient of 0.81 used for undergraduates. It also has high reliability. The item includes scores on the academic self-efficacy scale range from seven (7) to forty-nine. The RS measured psychological resilience and was created by
[18]. It consists of 25-items. This scale also comes in a short form which is termed (RS-14). Both the RS and RS-14 have Cronbach's $\alpha$ range of 0.72-0.94. The instruments (RS and RS-14) have their scoring done on a Likert scale of 1-7.

The scores group the partakers into low, moderate, and high resilience scores. Scoring for Medical Outcomes Study Social Support Survey (MOS-SSS) was used. Scoring for each scale was done by finding the average of the scores for each and every item on that subscale. For the overall support index, one has to calculate the average of first the scores of 18 items in the four subscales and the score for the extra additional item. In scoring for the Academic Self-Efficacy, the higher the score is indicative of a higher level of academic selfefficacy, the lower the scores respectively. There was scoring for the Resilience Scale (RS).

The total score ranges between 25 and 175 points. Scores exceeding 161 indicate a very high degree of resilience, among 146-160 a high, 131-145 a moderate, 116-130 low, and scores below 100 indicate a very low degree of resilience capacity [19]. Students' data such as age, religion, gender, marital status, level of study, and live on campus or not were collected. In demographics data, the students were asked to state their CGPA (which was their Cumulative Grade Point Average at the time of collecting data).

\section{Result}

Four hypotheses were analyzed, each with their appropriate statistical test.

Table 1. Representation of Respondents Gender, Age, Religion, Marital Status, Year/Level, Residential Status, and CGPA

\begin{tabular}{|l|l|l|l|l|}
\hline Groups & Frequency & Percent & Mean & Std. Deviation \\
\hline Gender & 3 & 2.5 & & \\
\hline Missing Data & 50 & 41.7 & & \\
\hline Male & 67 & 55.8 & & \\
\hline Female & \multicolumn{5}{|l}{} & & \\
\hline
\end{tabular}




\begin{tabular}{|l|l|l|l|l|}
\hline Total & 120 & 100 & & \\
\hline Age (Mean, SD) & 24.63 & 7.08 & & \\
\hline Religion & 2 & 1.7 & & \\
\hline Missing Data & 115 & 95.8 & & \\
\hline Christianity & 2 & 1.7 & & \\
\hline Islam & 1 & 0.8 & & \\
\hline Other & 120 & 100 & & \\
\hline Total & 1 & 0.8 & & \\
\hline Marital Status & 105 & 87.5 & & \\
\hline Missing Data & 13 & 10.8 & & \\
\hline Single & 1 & 0.8 & & \\
\hline Married & 120 & 100 & & \\
\hline Separated & \multicolumn{1}{|l|}{} & & \\
\hline Total & 68 & 56.7 & & \\
\hline Year/Level & 52 & 43.3 & & \\
\hline 200 & 120 & 100 & & \\
\hline 300 & 3 & 2.5 & & \\
\hline Total & 23 & 19.2 & & \\
\hline Residential Status & 94 & 78.3 & & \\
\hline Missing Data & 120 & 100 & & \\
\hline On Campus & & & 1.69 & 1.54 \\
\hline Off Campus & & & \\
\hline Total & & & \\
\hline Cumulative GPA & & & \\
\hline
\end{tabular}

Table 1 indicates that $47 \%$ of respondents were males, while $53 \%$ were females. The mean age was 24.63 years, while the standard deviation was 7.08 years. $95.8 \%$ were Christians, $1.7 \%$ belonged to the Islamic religion, and $0.8 \%$ belonged to other religions. Again $87.5 \%$ were single, while $10.8 \%$ were married, and $0.8 \%$ were separated. Also, $56.7 \%$ were in level 200, whiles $43.3 \%$ were in level 300. Under residential status, $19.2 \%$ lived on campus, while $78.3 \%$ lived off-campus. The mean for the cumulative grade point average was 1.69 , and the standard deviation was 1.54 .

Table 2. Mean and Standard Deviation for Social Support, Academic Self-efficacy, and Resilience

\begin{tabular}{|l|l|l|}
\hline Variables & M & SD \\
\hline Social Support & 65.64 & 15.81 \\
\hline Academic Self-Efficacy & 43.01 & 11.37 \\
\hline Resilience & 137.73 & 23.45 \\
\hline
\end{tabular}

Table 2 indicates the mean and standard

Testing of Hypotheses: Hypothesis One; A deviations of social support (Mean=65.64, $\mathrm{SD}=15.81), \quad$ academic self-efficacy significant positive correlation exists between (Mean=43.01, $\mathrm{SD}=11.37$ ), and resilience (Mean=137.73, $\mathrm{SD}=23.45)$ 
Table 3. Pearson Product Moment Correlation Coefficient Test Results on the Relationship between Social Support and Academic Self-Efficacy

\begin{tabular}{|l|l|l|l|l|}
\hline Variables & M & SD df & r & P \\
\hline Social Support & 65.64 & 15.81 & & \\
\hline Academic Self -Efficacy & 43.01 & 11.37 & & \\
\hline & & & .184 & .022 \\
\hline
\end{tabular}

Table 3 indicates that the mean for social assistance $(M=65.64, S D=15.81)$ and academic self-efficacy/performance

$(\mathrm{M}=43.01$, $\mathrm{SD}=11.37$ ) were administered to the Pearson Product Moment Correlation Coefficient test to determine whether a significant positive relationship exists between social support and academic self-efficacy. Results ( $\mathrm{r}-.184, \mathrm{p}=.022)$ indicated that the correlation between social support and academic self-efficacy/performance is significantly positive. This implies that social support predicts academic self-efficacy. Hypothesis one is supported. Hypothesis Two: Females will report higher levels of social assistance compared to their male counterparts. The results are presented in Table 4.

Table 4. Independent T-Test Result between Females Social Assistance and Males Social Support

\begin{tabular}{|l|l|l|l|l|l|l|}
\hline Group & N & M & SD & df & t & P \\
\hline Females Social Assistance Scores & 67 & 65.96 & 17.00 & 115 & -17 & .86 \\
\hline Males Social- Assistance Scores & 50 & 65.44 & 14.50 & & & \\
\hline$* p<0.05$ &
\end{tabular}

Results indicate no significant difference in the amount of social assistance received by females $(\mathrm{M}=65.96, \quad \mathrm{SD}=17.00)$ and males $(\mathrm{M}=65.44, \quad \mathrm{SD}=14.50) ; \quad(115)=-.17, \mathrm{p}=.86$. Therefore, the hypothesis that females will report higher levels of social assistance compared to male counterparts was not supported. Hypothesis three: There will be a significant influence of social assistance and psychological distress on academic selfefficacy. The results are presented in Table 5.

Table 5. Linear Regression on how Social Assistance and Psychological Distress (Resilience) can Predict Academic Self-efficacy

\begin{tabular}{|l|l|l|l|l|}
\hline Variables & B & SE & $\boldsymbol{\beta}$ & $\boldsymbol{P}$ \\
\hline (Constant) & 19.07 & 6.60 & - & .005 \\
\hline Social Assistance & .090 & .065 & .12 & .170 \\
\hline Resilience & .131 & .044 & .271 & .003 \\
\hline $\mathrm{R}^{2}=.104$ & \multicolumn{4}{|l}{} \\
\hline
\end{tabular}

The analysis in Table 5 shows that social assistance does not influence academic selfefficacy but resilience (psychological distress) does influence academic performance/selfefficacy; social assistance $(\mathrm{t}=1.381, \mathrm{p}=.170)$, and resilience $(\mathrm{t}=3.016, \mathrm{p}=.003)$.

\section{Conclusion}

It was found that high social assistance predicted high academic performance. No significant difference in the amount of social assistance and academic performance of female and male's students. It was also found that high resilience (low level of psychological distress) predicted high academic self-efficacy.

\section{Discussion}

The results from the data analysis revealed that there is no difference in the level of social support and academic performance by both men and women. A study conducted by [7] compared the academic performance of primary school children with behavioral disorders. More males than females had behavioral disorders in 
this study. The result indicated that the relationship between social assistance and psychological problems was a negative one. This confirms the findings of [19-21] that parental school involvement improves the academic performance of children. The findings of this study indicated that social assistance was positively correlated to academic self-efficacy or performance. As such, the more social support students receive, the more their academic self-efficacy/performance increases. There is no significant difference in the amount of social assistance received by males and females. The study indicates that social support does not influence academic self-efficacy, but resilience (psychological distress) does influence academic performance. The study reveals that there might be more issues surrounding students' poor academic selfefficacy/performance. Therefore, different variables could be examined to ascertain their influence on the academic selfefficacy/performance on students. The study revealed that social assistance and resilience predict the academic performance of students. Good social assistance predicts good academic performance.

\section{References}

[1] Pidgeon, A., Rowe, N. F., Stapleton, P., Magyar, H. B. \& Lo, B. C. Y. (2014). Examining Characteristics of Resilience among University Students: An International Study.Open Journal of Social Sciences, 2 (11), 14-22. Retrieved from https://epublications.bond.edu.au/fsd_papers/176/.

[2] Dollete, M., Steese, S., Phillips, W., Taormina, G., \& Matthews, G. (2004). Understanding girls' circle as an intervention on perceived social support, body image, self-efficacy, locus of control and selfesteem. The Journal of Psychology,90 (2), $204-215$. [3] Thawabieh, A.M., \& Qaisy, L.M. (2012). Assessing Stress among University Students. American International Journal of Contemporary Research, 2. Retrieved from https://www.aijcrnet.com/journals/Vol_2_No_2_Feb ruary_2012/13.pdf.

\section{Conflict of Interest}

Author declares that there is no conflict of interest.

\section{Implications and Recommendations}

The existence of the counseling centers on university campuses and their benefits to the students should be explained to students during orientation programmes. Mental health professionals should place emphasis on being more empathetic in their practice to boost the social assistance they give to their clients. Also, the mental health professionals should also identify clients who have adequate psychological resilience and guide them in coping skills they could use.

\section{Acknowledgement}

The study was conducted in the academic institution that the researcher works, but all ethical standards were followed. There were some missing data when cumulative grade point was being collated to serve as confirmation of academic self-efficacy. Acknowledgement to all sources cited in this work and respondents consulted.

[4] Stallman. (2010). Psychological distress in university students: A comparison with general population data. Australian Psychologist, 45(4).

[5] Mirowsky, J. Ross, C. E.1996. Social patterns of distress. Annual Review of Socialogy, 12, 23-45.

[6] Chohan, B.I., \& Khan R.M. (2010). Impact of Parental Support on the Academic Performance and Self-Concept of the Student. Journal of Research and Reflections in Education, 4. 14-26. Retrieved from

https://www.researchgate.net/publication/216035869 _Impact_of_Parental_Support_on_the_Academic_P erformance_and_Self_Concept_of_the_Student.

[7] Akpan, M.U., Ojinnaka, N.C., \& Ekanem, E.E. (2010). Academic performance of school children with behaviour disorders in Uyo, Nigeria. African Health Sciences, 10 (2), 154-158. 
[8] Shakir, M. [2014]. Academic Anxiety as a correkate of Academic Achievement. Journal of Education and Practice5, Retrieved from http://citeseerx.ist.psu.edu/viewdov/download?doi10 .1.1.840.7365\&rep=rep1\&type-pdf.

[9] Abomah, P. W. (2013). Student's attitudes towards examination malpractices: A case study of Methodist University College Ghana. International Journal of Research in Education. (10) 1.

[10] Yu, L. Shek, D. T. L. Zhu, X. [2018]. The influence of personal well-being on learning achievement in university students over time: Mediating or moderating effects of internal and external University engagement. Frontiers of $\begin{array}{lllll}\text { Psychology } & 9 & \text { [8] } & 2287 & \text { Retrieved from }\end{array}$ https://www.nebi.Nih.gov/pulmed/2937521.

[11] Tuner, D. P. Thompson, M. E. Huber, L. R. B. $\&$ Arif A. A. $\{2012\}$ Depressive Symptoms and Academic Performance of North Carolina College Students. North Carolina Medical Journal, 73 \{3\} 169-175.

[12]Cao, W. Fang, Z. Hou, G. Han, M. Xu, X. Dong, J. et al [2020]. The psychological impact of the COVID-19 epidemic on college students in China. Psychiatry Research 2020:112934. Doi:10. 1016/j. psycgres.2020.112934.

[13] Maslow, A. H. \{1943\}. The theory of human motivation Psychological Review 50, 370-396.

[14] Judel, L. \{2014\}. Perception regarding the role of social support in the Academic Achievement of Adolescents Exposed to Violence. North West University. Potchefstroom Campus.

[15]OECD. $\{2008\}$ Tertiary Education for the Knowledge Society. OECD Thematic Review of Education: Synthesis Report. April 2008.
[16] Chemers M, Martin \& Hu, Li-tze \&Garcia F, B. (2001). Academic self-efficacy and first-year college student performance and adjustment. Journal of Educational Psychology. 93. 55-64. 10.1037/00220663.93.1.55. Retrieved from https://www.researchgate.net/publication/232450523 _Academic_self-efficacy_and_firstyear_college_student_performance_and_adjustment. [17] Wagnild, G.M., \& Young, H, M. (1987) How Resilient Are You? Retrieved from http://www.resiliencescale.com/en/rstest/rstest_25_e n.html.

[18] Wagnild, G.M., \& Young, H, M. (2009). Resilience Scale - A Reliable and Valid tool to Measure Resilience. Retrieved from http://www.resiliencescale.com.

[19]Duncan-Williams, B. (2015). Academic stress, academic performance and the psychological wellbeing of senior high school remedial students in the Greater-Accra region of Ghana. (Unpublished master's thesis). University of Ghana Legon.

[20]Nyarko, K. $\{2011\}$ Parental School Involvement: The case of Ghana. Journal of Emergency Trendsin Educational Research and Policy Studies. 2\{5\},378-381.

[21] Ye, Y, Huang, X. \& Liu, Y. [2021] Social support and academic burnout among university students: A mediation model. Journal of Psychology Research and Behaviour Management. [14] 335344. 


\title{
Assessing the Challenges of Pharmaceutical Practices during COVID-19 Pandemic in Nigeria
}

\author{
Nnenna Genevieve Ekechukwu', Kenneth Anele Agu ${ }^{2}$ \\ ${ }^{1}$ Bristol Pharmacy, Gwarimpa, Abuja, Nigeria \\ ${ }^{2}$ Associate Director, Howard University Global Initiative Nigeria, Abuja, Nigeria
}

\begin{abstract}
Pharmacies are the frontline of the pandemic and critical to maintaining public health. The emergence of COVID-19 brought unprecedented challenges and changes to all nations of the world. In the light of this, this study assessed the challenges of pharmaceutical practices in Nigeria during COVID-19. A descriptive cross-sectional survey design was adopted, and the data were collected from 1,200 respondents through the interview schedule and structured questionnaire using a systematic random sampling technique. A total of 1,118 copies of the questionnaire were retrieved, coded, and analysed using descriptive and inferential statistics aided by the SPSS software version 23. The study discovered different factors that influenced the effective practice of pharmacists during the COVID-19 pandemic. The findings of this study revealed that the majority, 591(52.9\%) of the pharmacists, encountered difficulties on the road with security personnel while on essential duty and also found it 'somewhat difficult to work during the pandemic. The results of Factor Analysis grouped the major challenges into material and financial constraints. The results showed two orthogonal factors pharmaceutical practices, which were derived with the total explanation of $65.35 \%$ of the variance. Only variables with constraints loadings of 0.70 and above were used in naming the constraints. The material constraint has the greatest impact on effective practices of pharmacists to provide treatment for illnesses during COVID-19 with a $44.16 \%$ contribution. There is a need for government and institution supports for better and effective pharmaceutical practices before, during, and after any sort of pandemic, especially in drugs supplies and financial assistance.
\end{abstract}

Keywords: Assessment, Challenges, COVID-19 Pandemic, Pharmaceutical Practices, Nigeria.

\section{Introduction}

The Coronavirus disease 2019 (COVID-19), declared and recognized as a global health emergence and a global pandemic by [1-3], is a communicable disease caused by the newly discovered Severe Acute Respiratory Syndrome Coronavirus 2 (SARS-CoV-2). Coronaviruses are also described as zoonotic, as they are usually transmitted between animals and man through direct contact with an infected person $[4,5]$. COVID-19 pandemic was primarily discovered in Wuhan, China, and reported to World Health Organization (WHO) in December 2019 [6, 7]. In December 2019, the emerging infectious disease called the novel coronavirus (COVID-19) outbreak, began and spread worldwide [8]. The emergence of novel Coronavirus disease (COVID-19) since late 2019 introduced a global health crisis that has revealed the present-day health systems limits globally [6]. Though, studies have stated that coronavirus was first identified in 1937 as an infectious bronchitis virus with which birds suffered that devastated poultry stocks [5]. In the past 70 years, studies have found camels, cattle, cats, dogs, horses, mice, pigs, rats, and turkeys that were infected with coronaviruses [5]. Respiratory syndrome coronavirus (MERS$\mathrm{CoV})[\mathrm{WHO}, 2020]$ and Severe Acute 
Respiratory Syndrome (SARS) are mainly caused by coronaviruses [WHO, 2020]. The most common symptoms of coronavirus in patients are fever, dry cough, and respiratory problems [8]. It was reported that $80 \%$ of the infected cases are mild or asymptomatic [8]. The descriptions of clinical signs and symptoms of coronavirus disease and advice on preventive behaviors have historically been passed from one generation to another, helping to shape many religious and socio-cultural conventions [7].

The increasing numbers of infectious cases overwhelmed the workload in healthcare sectors in different countries [11]. The pandemic brought unprecedented challenges and changes to all the nations of the world (including Nigeria). For example, unprecedented mortality, distress, and mental resilience are some of the challenges posed by the COVID-19 pandemics [3, 12, 13]. In Africa, it was reported that confirmed cases of COVID-19 rose to $1,203,769$ and 28,289 deaths as of $25^{\text {th }}$ August 2020 [14]. The Federal Ministry of Health reported the first case of COVID-19 in Nigeria on February 27, 2020, in Lagos [15]. Since that period, there has been a drastic increase in the number of daily reported cases in the country, with 166,682 confirmed cases and 2,117 deaths as of June 3, 2021 [16]. In spite of the fact that Nigeria is the most populous country in Africa, the country had about $2.7 \%$ confirmed cases and $1.8 \%$ death of COVID-19 in the region as of the second quarter of 2020 [17].

Since Nigeria solely depends on importation to meet its demands, the country suffered a huge blow to several sectors, including the pharmaceutical industry. Even though the local industry in Nigeria fairs better when compared to its counterparts in other developing countries in Sub-Saharan African [15]. In March 2020, when the COVID-19 pandemic had a tremendous effect on every sector of the economy, especially the pharmaceutical sector and practices as well as the health and market economy, strict measures were taken, most importantly the lockdown measure. Consequently, the pandemic affected the economy by directly affecting production in major countries that are sole manufacturers of raw materials, intermediate products, and consumer goods, thereby creating supply chain and market disruption, and by its financial impact on firms and the financial markets.

As part of the emergency response activities across all States in Nigeria, health education campaigns were directed at members of the public [17, 18]. In spite of all the basic precautionary and/or preventive measures put in place to curb the spread of COVID-19, pharmaceutical practices and other health care professionals faced some challenges in one way or the other during the pandemic. Studies have shown the impacts of COVID-19 in every region and/or continent of the world, especially in America, Europe, and Asia [19, 20].

In Nigeria, studies have been conducted on COVID-19 [15, 17, 21-27]. From these previous studies, little or no studies have been conducted on the challenges facing pharmaceutical practices during COVID-19 in Nigeria. This study filled this gap by assessing the challenges of pharmaceutical practices in Nigeria during COVID-19 with a view to illuminating areas of strengths and weaknesses for future improvement.

\section{Pharmacy and Pharmaceutical Practices}

Pharmacists are critical for attaining the goal of universal health coverage and equitable access to essential health services, particularly in relation to access to medicines and medicines expertise [28]. Pharmacists, the third largest and most accessible healthcare professionals in the world [2, 29], are often the first point of contact with the health system in many countries [30, 31]. Pharmacists are central to attaining the goal of equitable access and rational use of medicines - a key objective of universal health coverage [32]. 
Pharmacies are regarded as the frontline of the pandemic and critical to maintaining public health. Pharmacy and Pharmacy Practice. In recent years, pharmacy, like other health professions, has undergone a change in the way it is practiced because of technological advances and the changes in the nature of health care delivery [33]. Pharmacy practice serves to facilitate the appropriate use of medicines. In traditional approaches to clinical pharmacy, it was thought that this could be achieved by helping to ensure that individual patients received the 'correct medicine in the correct dose at the correct time'.

\section{Materials and Methods}

The study area is Nigeria. It lies between latitudes $4 \mathrm{o}$ and $14 \mathrm{o}$ North of the equator and longitudes 20 42' and $15^{\circ} 00^{\prime}$ East of the Greenwich Meridian (Figure 1) [34]. In 2016, the population of the study area was put at 193,392,517 [35]. The study area comprises the Federal Capital Territory (FCT, Abuja) and 36 states that are subdivided into 774 Local Government Areas (LGAs) [36]. The study area was based on the six geo-political regions (including FCT) (Figure 1). Infectious diseases such as malaria, HIV/AIDs, and tuberculosis are leading causes of death in the country [37]. Although current estimates indicate improvement in under-five and maternal mortality rates between 1990 and 2012 in Nigeria, these are still significantly high at $117 / 1000$ and 560/100,000 live births, respectively, compared to other countries in the SSA region [37].

Evidence also indicates an increasing prevalence of non-communicable and chronic diseases, including diabetes, hypertension, cardiovascular diseases, and stroke in the country [38-40]. Overall health status and access to healthcare vary across the different regions in the country, with existing reports suggesting that health indicators are generally worse in the northern region compared to the Southern [41].
The study adopted a descriptive crosssectional survey designed specifically to elicit information from the respondents among the targeted population. The research instrument was a standardized structured (close-ended) and unstructured (open-ended) self-administered and electronic questionnaire to collect data. The questionnaire was tested to establish its validity and reliability. The researcher passed the questionnaire through experts and public health professional researchers to appraise the relevance of the questions in relation to the topic to determine if it would test what it was intended for. This tool was furthermore pretested before being administered. 1,200 professional and practice pharmacists in hospital practice, community practice, and industrial practice were systematically and randomly selected across the six geo-political zones in Nigeria. A total of 1,118 copies of the questionnaire were retrieved, coded, and analyzed using descriptive and inferential statistics, while the Statistical Package for Social Sciences (SPSS) software version 23 was used to run the analyses. Descriptive statistics include the use of frequency, percentages, mean, and standards deviation, while inferential statistics include exploratory factor analysis. The researcher ensured that all the administered copies of the questionnaire were collected, checked, and coded in an excel Microsoft package. The reliability coefficient of the questionnaire was assessed. Mean scores and standard deviations analysis procedures were used for the challenges facing pharmaceutical practices in the study area. The challenges facing pharmaceutical practices were further subjected to exploratory factor analysis. Factor analysis is a technique of data reduction used to collate a huge quantity of observed items statistically into a lesser set of latent variables termed factors due to their fundamental bivariate correlation patterns [42, 43]. Exploratory factor analysis procedure using the principal factor model with iteration and varimax rotation was further employed in 
grouping the constraints variables into major of 0.70 and above were used in naming the factors. However, only variables with loadings factors.

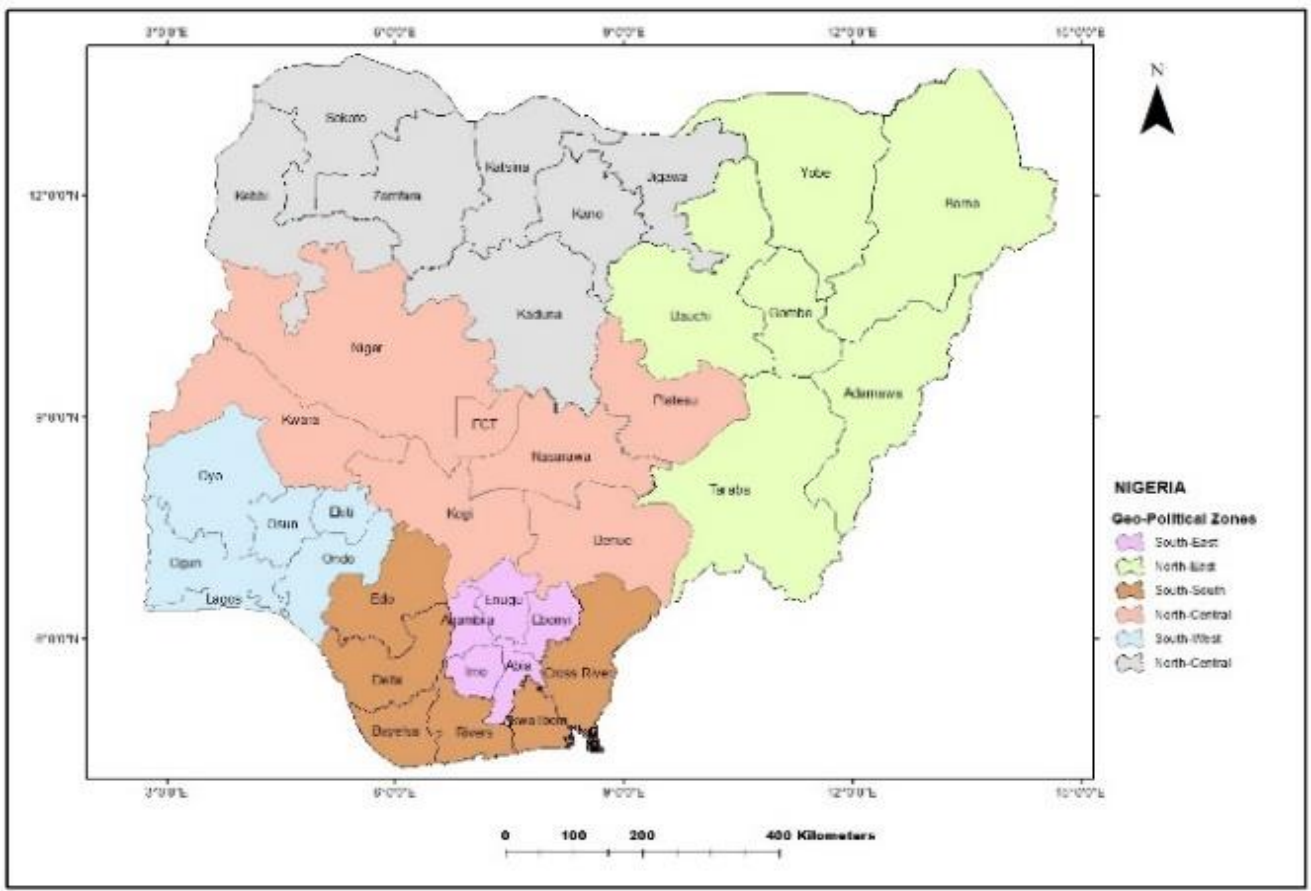

Figure.1. Map of the Study Area, Nigeria

\section{Results}

\section{Demographic Characteristics of the Respondents}

Table 1 presents the socio-demographic characteristics of the respondents in the study area are presented.51.4\% of the respondent were male.

The respondents between 30 and 59 years constituted the larger population of $84 \% .81 .2 \%$ of the respondents were married in the study area, while all the respondents were professional pharmacists with university educational qualifications; $42.5 \%$ with Bachelor of Pharmacy, 25.8\% with Master degree, and
6.3\% with Ph.D. degrees. Hospital practice, community practice, and industrial, pharmaceutical practice constituted the larger population of the respondents of $51.2 \%, 1.9 \%$, and $7.2 \%$, respectively.

Health insurance, marketing/production, administrative, political, and non-Governmental organizations were other areas of pharmaceutical practice. Those pharmacists (respondents) who had spent between 20 and 24 years constituted $21.3 \%$ (Table 1). The majority, $722(64.6 \%)$ of the respondents (Pharmacists) in the study area, worked for 6-8 hours per day.

Table 1. Demographic Characteristics of the Respondents

\begin{tabular}{|l|l|l|l|}
\hline Variables & Frequency & Percent (\%) \\
\hline \multirow{4}{*}{ Gender } & Male & 575 & 51.4 \\
\cline { 2 - 4 } & Female & 513 & 45.9 \\
\cline { 2 - 4 } & Prefer not to say & 30 & 2.7 \\
\cline { 2 - 4 } & Total & $\mathbf{1 1 1 8}$ & $\mathbf{1 0 0 . 0}$ \\
\hline \multirow{4}{*}{ gge Bracket } & $18-29$ & 130 & 11.6 \\
\cline { 2 - 4 } & $30-39$ & 256 & 22.9 \\
\cline { 2 - 4 } & $40-49$ & 357 & 31.9 \\
\hline
\end{tabular}




\begin{tabular}{|c|c|c|c|}
\hline & $50-59$ & 326 & 29.2 \\
\hline & $60-69$ & 49 & 4.4 \\
\hline & Total & 1118 & 100.0 \\
\hline \multirow[t]{4}{*}{ Marital Status } & Single & 200 & 17.9 \\
\hline & Married & 908 & 81.2 \\
\hline & Separated & 10 & 0.9 \\
\hline & Total & 1118 & 100.0 \\
\hline \multirow[t]{6}{*}{ Educational Level } & B. Pharm & 475 & 42.5 \\
\hline & Masters & 288 & 25.8 \\
\hline & Postgraduate Fellowship & 255 & 22.8 \\
\hline & $\mathrm{PhD}$ & 70 & 6.3 \\
\hline & Others & 30 & 2.7 \\
\hline & Total & 1118 & 100.0 \\
\hline \multirow[t]{7}{*}{ Area of Practice } & Academia & 10 & 0.9 \\
\hline & Hospital & 572 & 51.2 \\
\hline & Community & 357 & 31.9 \\
\hline & Industrial & 80 & 7.2 \\
\hline & Public Health & 69 & 6.2 \\
\hline & Others & 30 & 2.7 \\
\hline & Total & 1118 & 100.0 \\
\hline \multirow[t]{8}{*}{ Other Areas of Practice } & Do not practice in any other area & 1008 & 90.2 \\
\hline & NGO & 10 & 0.9 \\
\hline & Health Insurance & 40 & 3.6 \\
\hline & Marketing/Production & 20 & 1.8 \\
\hline & Academia & 20 & 1.8 \\
\hline & Administrative & 10 & 0.9 \\
\hline & Politics & 10 & 0.9 \\
\hline & Total & 1118 & 100.0 \\
\hline \multirow[t]{8}{*}{ Years of Practice } & Less the 5 Years & 179 & 16.0 \\
\hline & $5-9$ Years & 79 & 7.1 \\
\hline & $10-14$ Years & 268 & 24.0 \\
\hline & $15-19$ Years & 108 & 9.7 \\
\hline & $20-24$ Years & 238 & 21.3 \\
\hline & $25-29$ Years & 157 & 14.0 \\
\hline & 30 Years and above & 89 & 8.0 \\
\hline & Total & 1118 & 100.0 \\
\hline \multirow{5}{*}{$\begin{array}{l}\text { Average number of } \\
\text { daily hours of work }\end{array}$} & $3-5$ Hours & 20 & 1.8 \\
\hline & $6-8$ Hours & 722 & 64.6 \\
\hline & $9-11$ Hours & 277 & 24.8 \\
\hline & 12 Hours and Above & 99 & 8.9 \\
\hline & Total & 1118 & 100.0 \\
\hline
\end{tabular}




\section{Challenges Faced by Pharmacists and Pharmaceutical Practices during Covid- 19}

Table 2 and Figure 2 present the difficulties encountered by pharmacists during COVID-19 in the study area. The results showed that $52.9 \%$ of the pharmacists encountered difficulties on the road with security personnel while on essential duty. As a result, only $8.1 \%$ of the respondents indicated that it was very difficult for them to work during the COVID19 pandemic, while the majority 513(45.9\%) indicated 'somewhat difficult to work during COVID-19 pandemic in the study area (Table $3)$.

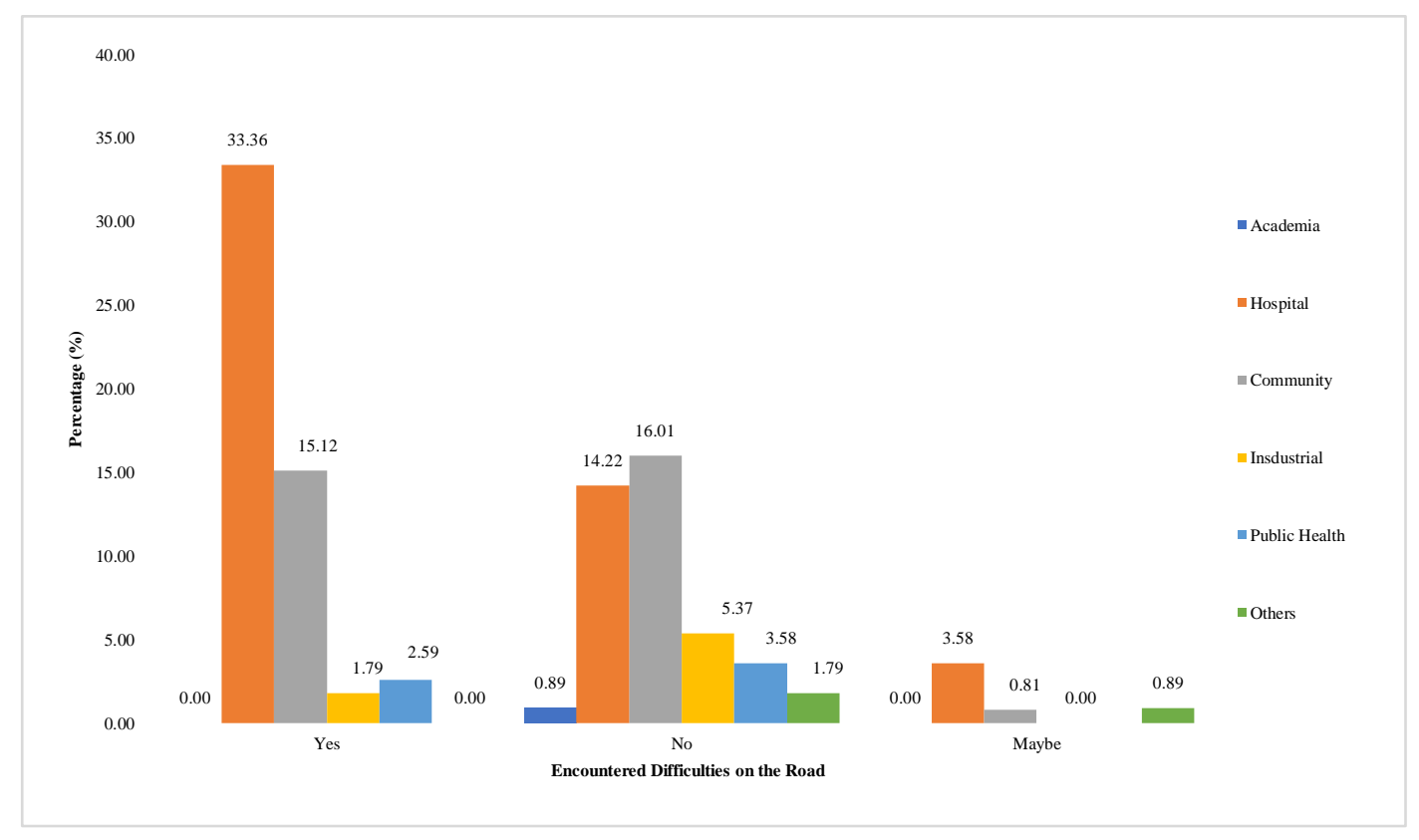

Figure 2. Difficulties Encountered on the Road by the Respondents during COVID-19 Pandemic

Table 2. Statistics of the Difficulties Encountered on the Road during COVID-19

\begin{tabular}{|l|l|l|l|l|l|l|l|}
\hline & \multicolumn{4}{|l|}{ Area of Practice } & \multirow{2}{*}{ Total } \\
\cline { 2 - 7 } & Academia & Hospital & Community & Industrial & $\begin{array}{l}\text { Public } \\
\text { Health }\end{array}$ & Others & \\
\hline Yes & $0(0.0)$ & $373(33.36)$ & $169(15.12)$ & $20(1.79)$ & $29(2.59)$ & $0(0.0)$ & $591(52.86)$ \\
\hline No & $10(0.89)$ & $159(14.22)$ & $179(16.01)$ & $60(5.37)$ & $40(3.58)$ & $20(1.79)$ & $468(41.86)$ \\
\hline Maybe & $0(0.0)$ & $40(3.58)$ & $9(0.81)$ & $0(0.0)$ & $0(0.0)$ & $10(0.89)$ & $59(5.28)$ \\
\hline Total & $10(0.89)$ & $572(51.16)$ & $357(31.93)$ & $80(7.16)$ & $69(6.17)$ & $30(2.68)$ & $1118(100)$ \\
\hline
\end{tabular}

Table 3. How Difficult it was to Work during COVID-19 in Pharmaceutical Practices

\begin{tabular}{|l|l|l|l|l|l|l|l|}
\hline & \multicolumn{2}{|l|}{ Area of Practice } & Total \\
\cline { 2 - 7 } & Academia & Hospital & Community & Industrial & $\begin{array}{l}\text { Public } \\
\text { Health }\end{array}$ & Others & \\
\hline $\begin{array}{l}\text { Very } \\
\text { Difficult }\end{array}$ & 0.0 & $50(4.47)$ & $20(1.79)$ & 0.0 & $20(1.79)$ & 0.0 & $90(8.05)$ \\
\hline Very Easy & 0.0 & $29(2.59)$ & $49(4.38)$ & 0.0 & 0.0 & $20(1.79)$ & $98(8.77)$ \\
\hline $\begin{array}{l}\text { Somewhat } \\
\text { Easy }\end{array}$ & $10(0.89)$ & $109(9.75)$ & $109(9.75)$ & $20(1.79)$ & $40(3.58)$ & 0.0 & $288(25.76)$ \\
\hline
\end{tabular}




\begin{tabular}{|c|c|c|c|c|c|c|c|}
\hline & & & & & & & \\
\hline & & & & & & & \\
\hline 100 & & & & & & & \\
\hline \multicolumn{4}{|c|}{$\begin{array}{l}\text { A larger percentage }(86.6 \%) \text { of the } \\
\text { respondents encountered poor patronage, } \\
\text { shortage of cash flow }(85.7 \%) \text {, and shortage of } \\
\text { drugs/medication, and the high cost of raw } \\
\text { materials as well as other consumables with a } \\
\text { percentage of } 83.98 \% \text { (Figure } 3 \text { ). The mean and } \\
\text { standard deviation results of the challenges are } \\
\text { also presented in Table } 4 \text {, where a shortage of } \\
\text { raw materials (mean }=1.31 \text { ), high cost of raw }\end{array}$} & \multicolumn{4}{|c|}{$\begin{array}{l}\text { materials (mean }=1.21 \text { ), shortage of } \\
\text { drugs/medications (mean=1.21), and shortage } \\
\text { of cash flow (1.20) are the major challenges } \\
\text { faced by pharmaceutical practices in the study } \\
\text { area. Other challenges encountered by the } \\
\text { respondents during the COVID-19 pandemic } \\
\text { include food and house maintenance supplies, } \\
\text { restriction from teaching and research, and the } \\
\text { fear of getting the infection. }\end{array}$} \\
\hline
\end{tabular}

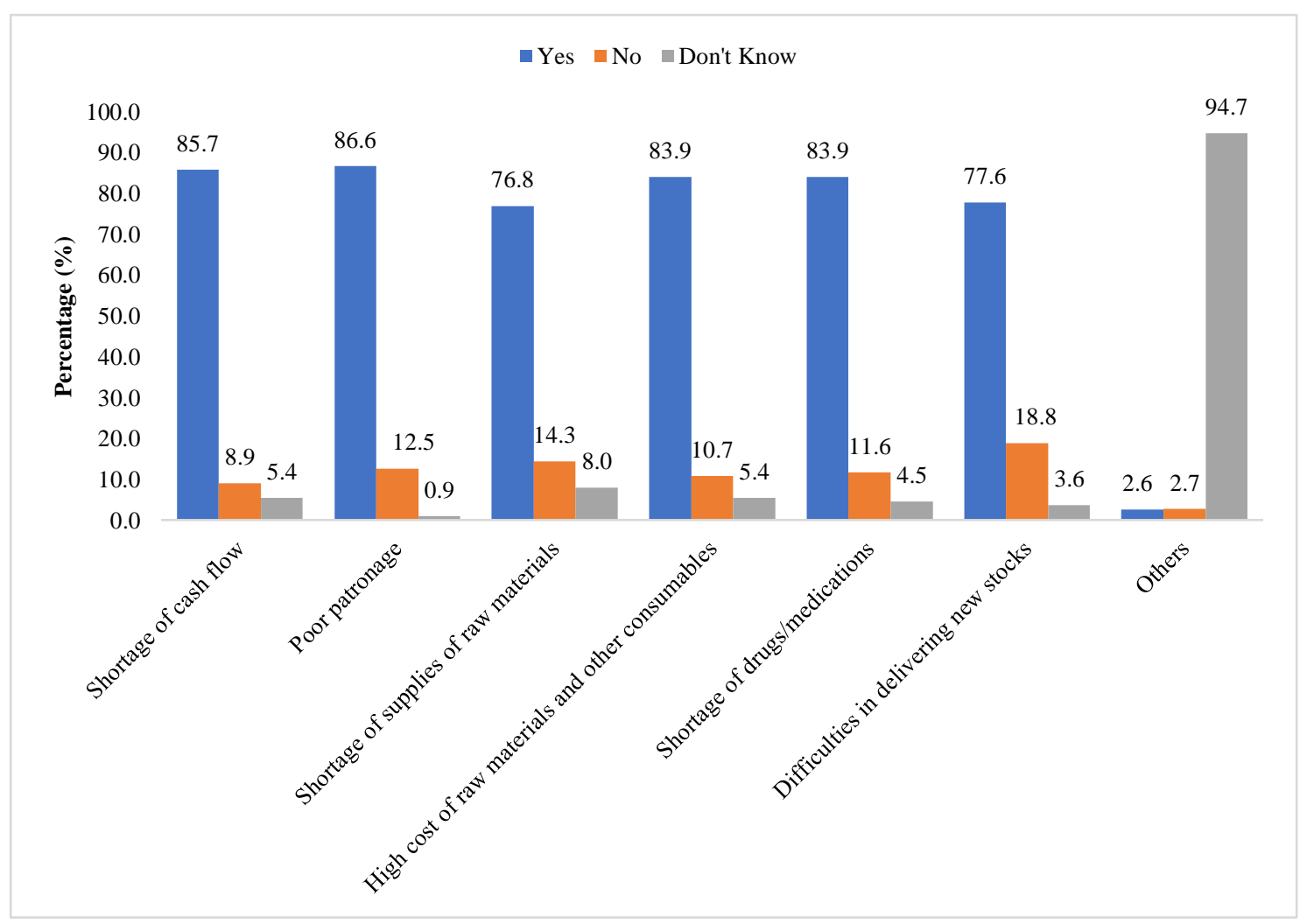

Figure 3. Challenges Faced by Pharmaceutical Practices during COVID-19 Pandemic

Table 4. Statistics of the Challenges Faced by Pharmaceutical Practices $(n=1118)$

\begin{tabular}{|l|l|l|}
\hline Challenges Encountered & Mean & Std. Deviation \\
\hline Shortage of cash flow & 1.1968 & 0.51539 \\
\hline Poor patronage & 1.1431 & 0.37503 \\
\hline Shortage of supplies of raw materials & 1.3051 & 0.61072 \\
\hline High cost of raw materials and other consumables & 1.2147 & 0.52552 \\
\hline Difficulties in delivering new stocks & 1.2594 & 0.51371 \\
\hline Shortage of drugs/medications & 1.2057 & 0.50306 \\
\hline
\end{tabular}

${ }^{1}$ Ranged from 1 "Yes" to 3 "Don't Know." 
The results of the rotated component matrix showing the extracted factors based on the responses of respondents are shown in Table 5. The results showed two orthogonal factors in the challenges faced by pharmaceutical practices in the study area, which were derived with the total explanation of $65.35 \%$ of the variance. Only variables with constraints loadings of 0.70 and above were used in naming the constraints. The Eigenvalues, percentage of variance, and cumulative percentage of the variance explained are also presented in Table 5.

Table 5. Challenges Encountered during COVID-19 Pandemic

\begin{tabular}{|l|l|l|}
\hline Items Description & Factor 1 & Factor 2 \\
\hline Shortage of supplies of raw materials & 0.839 & -0.004 \\
\hline Shortage of drugs/medications & 0.8 & 0.146 \\
\hline $\begin{array}{l}\text { High cost of raw materials and other } \\
\text { consumables }\end{array}$ & 0.745 & 0.227 \\
\hline Shortage of cash flow & -0.103 & 0.874 \\
\hline Poor patronage & 0.286 & 0.78 \\
\hline Difficulties in delivering new stocks & 0.438 & 0.54 \\
\hline Factor Description & Materials & Financial \\
\hline Eigenvalues & 2.650 & 1.271 \\
\hline \% of Variance & 44.161 & 21.191 \\
\hline Cumulative \% of Variance Explained & 44.161 & 65.352 \\
\hline
\end{tabular}

Extraction Method: Principal Component Analysis

Rotation Method: Varimax with Kaiser Normalization

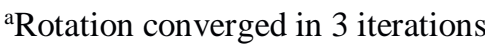

The factor I is tagged "materials constraint". These two factors or constraints have an impact on pharmacists and/or pharmaceutical practices in Nigeria. The eigenvalue of Factor I is 2.65, with $44.16 \%$ of the variance. The factor I have very high significant loading on the variable 'shortage of supplies of raw materials (0.84), "shortage of drugs/medications" (0.80), and moderately high loading on the variables 'high cost of raw materials and other consumables (0.75).

Factor II, which is tagged "financial constraint", has an Eigenvalue of 1.23 and contributed $21.19 \%$ to the variance in the challenges of pharmaceutical practices in the study area. Factor II has the highest loading on 'shortage of cash flow' and 'Poor patronage' with loading points 0.87 and 0.78 respectively.

The finding of this study further showed that $46.06 \%$ of the respondents in the pharmaceutical practices faced a shortage of staff/personnel in the study area (Table 6). Hospital pharmaceutical practice faced a $31.84 \%$ shortage of staff/personnel; community practice faced a $9.75 \%$ shortage of staff, while industrial practice, public health practice, and academia faced smaller percentages of shortage of staff during COVID-19 in the study area.

The rationale behind the shortage of staff/personnel in the pharmaceutical practices during COVID-19 is presented in Figure 4. 'Staff infected with COVID-19' was indicated by the majority $(26.0 \%)$ of the respondents as the main reason for the shortage of staff during COVID-19.

Furthermore, respondents revealed that 'government directives/orders for junior staff to stay at home, 'family pressure to stay at home, and 'the anxiety among the staff of being infected with the viruses were indicated as the minor reasons for the shortage of staff during COVID-29. The restriction of staff to move 
around during the COVID-19 pandemic was pharmaceutical practices during COVID-19, as not a reason for the shortage of staff in the indicated by the respondents.

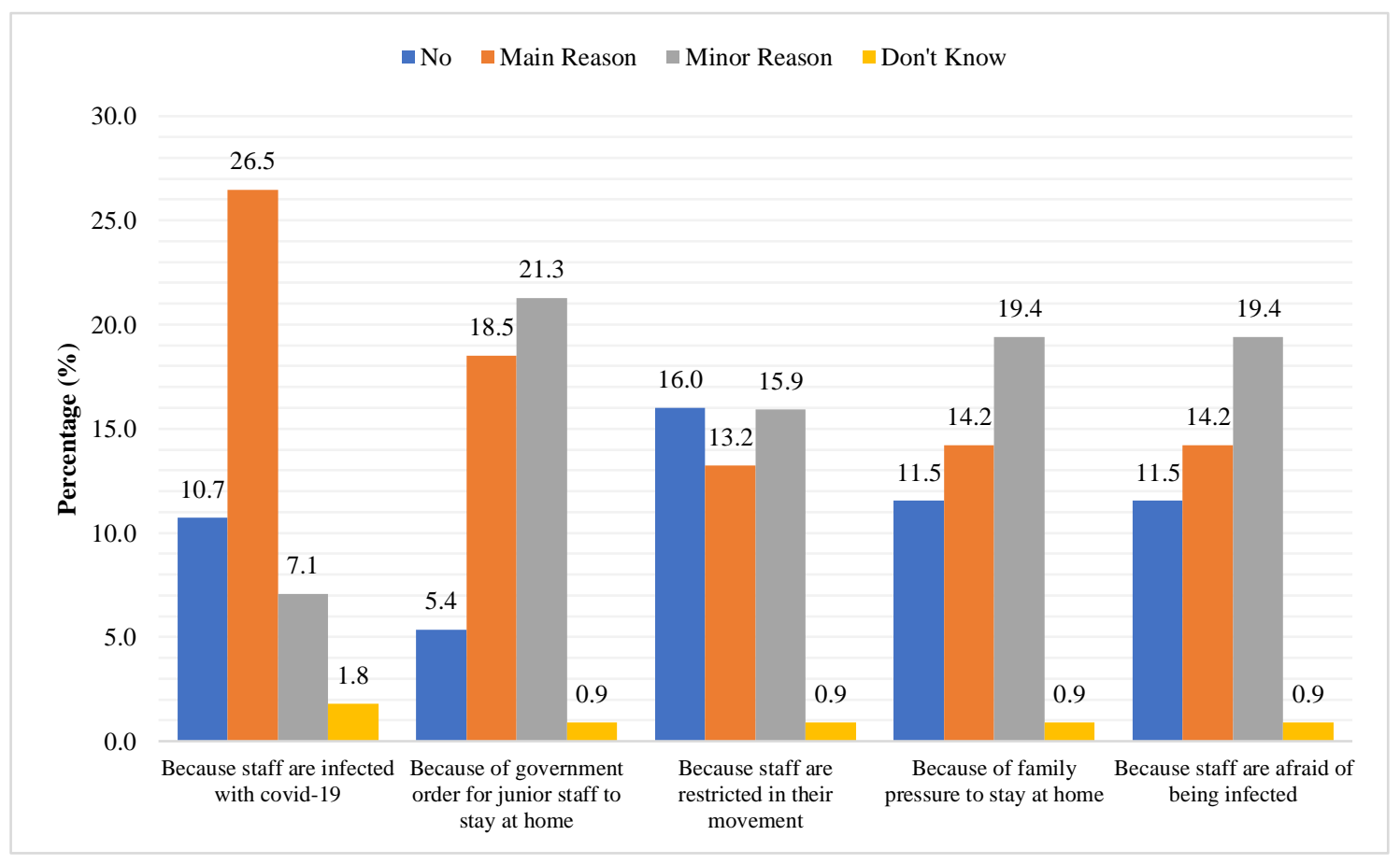

Figure 4. Perception on the Major Reasons for the Shortage of Staff/Personnel in the Pharmaceutical Practices during COVID-19

Table 6. Shortage of Staff in Pharmaceutical Practices during COVID-19

\begin{tabular}{|l|l|l|l|l|}
\hline & Yes & No & Maybe & \\
\hline Academia & 0.0 & $10(0.89)$ & 0.0 & $10(0.89)$ \\
\hline Hospital & $356(31.84)$ & $196(17.53)$ & $20(1.79)$ & $572(51.16)$ \\
\hline Community & $109(9.75)$ & $248(22.18)$ & 0.0 & $357(31.93)$ \\
\hline Industrial & $10(0.89)$ & $70(6.26)$ & 0.0 & $80(7.16)$ \\
\hline Public Health & $20(1.79)$ & $49(4.38)$ & 0.0 & $69(6.17)$ \\
\hline Others & $20(1.79)$ & $10(0.89)$ & 0.0 & $30(2.68)$ \\
\hline Total & $515(46.06)$ & $583(52.15)$ & $20(1.79)$ & $1118(100)$ \\
\hline
\end{tabular}

\section{Discussion}

Findings of this study revealed that pharmacists encountered difficulties on the road with security personnel while on essential duty, and only $8.1 \%$ of the respondents indicated that it was very difficult for them to work during the COVID-19 pandemic. The difficulties encountered on the road while on essential duties might be attributed to the directives given by the government to the law enforcement agencies during the lockdown approach in the study area. In contrast to the findings of a previous study, two-third of the respondents found it somewhat difficult or very difficult to work effectively during the COVID19 pandemic [25].

Studies suggest that healthcare workers are at higher risk of infection when treating patients with COVID-19 [8]. They are also vulnerable to physical and emotional exhaustion [44] as well as the development of various mental health disorders [8]. This fact is confirmed by the higher grades of mental health symptoms reported throughout the pandemic [45]. Some of the challenges faced by the pharmaceutical practices include poor patronage, shortages of cash flow, shortage of drugs/medication, and 
the high cost of raw materials. The challenges faced by the pharmaceutical practices could be a result of the restrictions of the economic activities and other contributing factors. The most common challenges that pharmacy professionals faced during COVID-19 were general anxiety about the impact of coronavirus on their life, and difficulties with communication with their co-workers, issues with internet connectivity, social isolation, to mention but a few $[3,8,11,12,25]$. All these afore-mentioned challenges faced by the pharmacists and/or pharmaceutical practices during the COVID-19 pandemic were grouped into two constraints factors, namely 'material constraints' and 'financial constraints'.

Hospital and community pharmaceutical practices faced the larger percentages of shortage of staff/personnel, which might be a result of the impact of the COVID-19 pandemic in the study area. The shortage of staff/personnel was due to the fear that some staff got infected with the virus, 'government directives/orders for junior staff to stay at home, 'family pressure to stay at home, and 'the anxiety of being infected with the viruses was indications of the shortage of staff in the study area.

The need for organizational and government supports is imperative for improving pharmaceutical practices in the study area. The ranking of 'online personnel training'; 'advice on how to prevent infections while maintaining all business operations and interstate movement'; 'adequate provision of work tools; training on diversification of products, services, and sales channels; and 'online management training' as their 1st priority needed as organizational supports is to better improve the profession and pharmaceutical practices to respond to the COVID-19 pandemic and other infectious diseases in the study area. This finding is similar to the findings, which stated that webinars on COVID-19, access to a community of support to share questions and concerns, and signposting to information are also important supports to better improve the pharmaceutical practices in the study area [25]. Not only organizational supports are needed for better improvement but also government supports.

\section{Conclusion}

The pharmaceutical practices and pharmaceutical healthcare professionals of Nigeria have shown to be contributing to the healthcare sector, especially with the emergence of COVID-19, which negatively affected pharmacists and pharmaceutical practices in the country. Many factors also affect the quality of health services provided by pharmacists, which include but are not limited to human resources, materials, and finances. As human resource is a vital component in delivering health services, pharmacists play significant roles in improving the health status of Nigerians. In this respect, the challenges of pharmaceutical practices during the COVID-19 Pandemic in Nigeria were assessed. This work has thrown more light on the difficulties and/or challenges faced by the pharmacists during COVID-19 and the needed supports for better improvement of pharmaceutical practices and lives of pharmaceutical professionals in Nigeria. This study recommends that government efforts should be made to lessen the total manufacturing and distribution costs of drugs; make access to cash/short-term finances available to pharmacists without all the bottleneck processes and long protocols; approving and implementing friendly production and distribution policies during and after COVID19 pandemic is very crucial.

\section{Conflict of Interest}

We have no conflict of interest to declare.

\section{Acknowledgements}

The author expresses his gratitude to all pharmacists and/or professionals for their willingness and cooperation to participate in this study. 


\section{References}

[1] Ramzy, A., and McNeil, D.G., 2020, World Health Organisation declares global emergency as Wuhan coronavirus spreads. The New York Times. Accessed: 30/01/2020. https://nyti.ms/2RER70M.

[2] The New York Times, 2020, Nigeria Responds to First Coronavirus Case in Sub-Saharan Africa. 28 March 2020.

[3] Roy, R.M. et al. 2021, Psychological distress during pandemic Covid-19 among adult general population: Result across 13 countries. Clinical Epidemiology and Global Health, 10 (2021), 100708, 1-6.

https://doi.org/10.1016/j.cegh.2021.100708.

[4] Weiner, L.P., 1987, Coronaviruses: A historical perspective. In Michael, M.C.L. and Stephen, A.S. (Eds), Corona Viruses: Advances in Experimental Medicine and Biology (pp. 1-4), volume 28, Plenum Press: New York and London.

[5] International Medical Aids-IMA, 2020, Coronavirus: What you need to know. 21 April 2020. Retrieved 25 April 2020 at https://medicalaid.org/.

[6] World Health Organisation, 2020, Infection prevention and control for the safe management of a dead body in the context of COVID-19 Interim guidance 24 March 2020.

[7] Shakespeare, M., 2002, Zoonoses. London, U.K.: Pharmaceutical Press, Division of the Royal Pharmaceutical Society.

[8] Lai, J., Ma, S., Wang, Y., Cai, Z., Hu, J., Wei, N., et al. 2020, Factors associated with mental health outcomes among health care workers exposed to coronavirus disease 2019. JAMA Netw Open, 3: e203976.

Doi:10.1001/ jamanetworkopen.2020.3976.

[9] World Health Organization, 2020, Middle East respiratory syndrome coronavirus (MERS-CoV). Available: https://www.who.int/emergencies/merscov/en/ Accessed: 8 September 2021.

[10]WHO, 2020, Severe Acute Respiratory Syndrome (SARS) Available: https://www.who.int/csr/sars/en/ Accessed: 7 September 2021.

[11] Mila, N.N.H., Roy, R.M., Ayesha, A., Fatjona, K., Radwa, A.E., Jeldah, M.N., and Adinegara, L.A.,
2020, Immediate impact of COVID-19 on mental health and its associated factors among healthcare workers: A global perspective across 31 countries. Viewpoints, 10(2), 020381, 1-6. doi: 10.7189/jogh.10.020381.

[12]WHO, 2020, Mental health and psychosocial considerations during the COVID-19 outbreak. https://www.who.int/docs/default-

source/coronaviruse/mental-healthconsiderations.pdf?sfvrsn=6d3578af_2;2020.

[13]Zhu N, Zhang D, Wang W, et al. A novel coronavirus from patients with pneumonia in China, 2019. N Engl J Med., ;382(8):727-733. https://doi.org/10.1056/NEJMoa2001017.

[14] African Centre for Disease Control-ACDC, 2020, Coronavirus disease 2019 (COVID-19): Africa centre for disease control. Accessed: 25 August 2020. https://africacdc.org/\%20covid-19/.

[15] Akande-Sholabi, W., Adebisi, Y.A., Bello, A., and Ilesanmi, O.S., 2020, COVID-19 in Nigeria: Is the pharmaceutical sector spared? Public Health in Practice, 1, 100044.

https://doi.org/10.1016/j.puhip.2020.100044.

[16] Nigeria Centre for Disease Control-NCDC, 2021, First case of corona virus disease confirmed in Nigeria. 28 February 2020. Retrieved 5 June 2021.

[17] Oni, B.O., 2021b, Mitigating strategies and its challenges of COVID-19 pandemic in Ogun State, Nigeria. Texila International Journal of Public Health, 1-11. DOI: 10.21522/TIJPH.2013.09.01. Art007.

[18] Nigeria Centre for Disease and Control NCDC, 2020a, COVID-19 Nigeria-Nigeria centre for disease control. Accessed: 11 August 2020. https://covid19.ncdc.gov.ng/.

[19] Thomson, L.A., et al., 2007, Systematic review of the incidence and characteristics of preventable adverse drug events in ambulatory care. Annals of Pharmacotherapy, 41(9), 1411-1426.

[20] Shanmugam, S., et al., 2011, impact of pharmaceutical care on quality of life in patients with type 2 diabetes mellitus. Journal of Royal Medical Society, 16(1), 412-418.

[21] Oni, O.B., 2021a, Cost-effectiveness analysis during lockdown and health belief model of COVID-19 pandemic in Ogun State, South-western 
Nigeria. Texila International Journal of Public Health, 1-11.

[22]Erah, P.O., and Nwazuoke, J.C., 2002, Identification of standards for pharmaceutical care in Benin City. Tropical Journal of Pharmaceutical Research, 1(2), 55-66.

[23] Oparah, C.A., and Eferakeya, A.E., 2005, Attitude of Nigerian pharmacists towards pharmaceutical care. Pharmacy World and Science, 27(3), 208-214.

[24] David, K.B., and Adebisi, Y.A., 2020, Proposed model for hospital and community pharmacy services during COVID-19 pandemic in Nigeria. Int. J. Pharm. Pract. (2020 Jul 4). https://doi.org/10.1111/ijpp.12652,10.1111/ijpp.126 52.

[25] Ashiru-Oredope, D., Chan, A.H.Y., Olaoye, O., Rutter, V., Babar, Z. and the C.P.A. COVID-19 Action Team, 2020, Needs assessment and impact of COVID-19 on pharmaceutical professionals in 31 commonwealth countries. J of Pharm Policy and Pract 13, 72, 1-11. https://doi.org/10.1186/s40545020-00275-7.

[26] Ayati, N., Saiyarsarai, P. \& Nikfar, S., 2020-, Short- and long-term impacts of COVID-19 on the pharmaceutical sector. DARU J Pharm Sci, 28, 799805. https://doi.org/10.1007/s40199-020-00358-5. [27] Chukwuorji J.C., and Iorfa, S.K., 2020, Commentary on the coronavirus pandemic: Nigeria. Psychological Trauma: Theory, Research, Practice, and Policy, 12(S1), S188- S190. DOI $10.1037 / \operatorname{tra} 0000786$.

[28]Ekpenyong, A., Udoh, A., Kpokiri, E., and Bates, I., 2018, An analysis of pharmacy workforce capacity in Nigeria. Journal of Pharmaceutical Policy and Practice, 11:20. https://doi.org/10.1186/s40545-018-0147-9.

[29] International Pharmaceutical Federation-IPF, 2006, Global pharmacy workforce and migration report: A call for action. The Hague: International Pharmaceutical Federation; 2006. Available from: http://www.fip.org/files/fip/HR/FIP\%20Global\%20P harmacy\%20and\%20Migration\%20report\%2007042 006.PDF.

[30] Smith, F., 2009, Private local pharmacies in low- and middle-income countries: a review of interventions to enhance their role in public health. Tropical Med Int Health. 2009, 14(3), 362-72.

[31] Stenson, B., Syhakhang, L., Eriksson, B., and Tomsom, G., 2001, Real world pharmacy: Assessing the quality of private pharmacy practice in the Lao People's Democratic Republic. Soc Sci Med. 2001, 52, 393-404.

[32] International Pharmaceutical Federation (IPF), 2015, Global pharmacy workforce intelligence: trends report. The Hague: International Pharmaceutical Federation; 2015. Available from: https://www.fip.org/files/fip/PharmacyEducation/Tr ends/FIPEd_Trends_report_2015_web_v3.pdf.

[33]Duggan, C., 2001, Primary and secondary care pharmacy. In: K. Taylor, and G. Harding (Eds.), Pharmacy practice (pp. 43-49). London and New York.

[34] Salami, A.A., Olorunfemi, J.F., and Olanrewaju, R.M., 2020, Geo-spatial analysis of rainfall amounts and rainy days using satellites and ground-based data in Nigeria. Journal of Meteorology and Climate Science, 18 (1).

[35] National Population Commission, 2016, 2016 Projected population of Federal Republic of Nigeria 2006 Population and Housing Census, Priority Tables, Vol. VII Abuja, Nigeria.

[36]Eze, T.C., Okpala, C.S., and Ogbodo, J.C., 2014, Patterns of inequality in human development across Nigeria's six geo-political zones. J Dev Ctries Stud., 4(8), 97-101.

[37] World Health Organization, 2015, Nigeria: WHO statistical profile 2015. Available from: http://www.who.int/gho/countries/nga.pdf?ua=1.

[38]Ansa, V., Ekott, J., and Bassey, E., 2008, Profile and outcome of cardiovascular admissions at the University of Uyo Teaching Hospital, Uyo: A five-year review. Niger J Clin Pr., 11(3), 290.

[39]Ukoh, V., 2007, Admission of hypertensive patients at the University of Benin Teaching Hospital. Nigeria East Afr Med J., 84(7), 329-35.

[40] Onwuchekwa, A.C., and Chinenye, S., 2010, Clinical profile of hypertension at a university teaching Hospital in Nigeria. Vasc Health Risk Manag, 6, 511-6.

[41] Chankova, S., Ha, N., Chipanta, D., Kombe, G., Onoja, A., and Ogungbemi, K., 2006, A situation 
assessment of human resources in the public health sector in Nigeria. Bethesda: USAID and Abt Associates InC; 2006. Available from: http://pdf.usaid.gov/pdf_docs/PNADH422.pdf.

Accessed 06/10/2020.

[42] Salami, A.A., 2018, Constraints to effective climate change adaptation policies and programmes in Osun State, Nigeria. Journal of Social Sciences and Humanities, 1(1), 9-14.

[43] Anol, B., 2012, Social science research: Principles, methods, and practices (2nd Edition). University of South Florida Tampa, Florida, USA. Published under the Creative Commons Attribution-
Non-Commercial-Share Alike 3.0 Unported License. 135-136. Retrieved 9th February, 2015 from http://scholarcommons.usf.edu/cgi/viewcontent.cgi? article $=1002 \&$ context $=$ oa_textbooks.

[44]Liu, Q., Luo, D., Haase, J.E., et al, 2020, The experiences of healthcare providers during the COVID-19 crisis in China: a qualitative study. The Lancet. Global health. 8(6), e790-e798.

[45] Ayanian, J.Z., 2020, Mental health needs of health care workers providing frontline COVID- 19 care. JAMA Health Forum. 2020. https://doi.org/10.1001/jamahealthforum.2020.0397 Published online April 1. 


\title{
Attitude, Knowledge, and Use of Self-Medication with Antibiotics by Outpatients of Gbagada General Hospital Gbagada Lagos.
}

\author{
Odis Adaora Isabella \\ School of Public Health, Texila American University, Guyana
}

\begin{abstract}
Self-medication with antibiotics is a threat to global health and becoming increasingly common due to multiple factors. The aim of our study was to evaluate the attitudes, knowledge, and use of selfmedication with antibiotics among outpatients of Gbagada General Hospital Gbagada - Lagos, Nigeria. The objective of this research was to access the attitudes, knowledge and use among the Patients that use Self-medication with antibiotics. The study design was a cross-sectional descriptive study. A pretest of a closed-ended questionnaire was distributed to the respondents, corrections were made, and data was collected in February 2021. 402 Outpatients of the Gbagada General Hospital Gbagada city area of Lagos was recruited for the study in the aforementioned time period through multi-stage probability sampling. Thirty-three percent of respondents said antibiotics could cure all infections. Forty-eight percent of respondents said antibiotics might be effective even if they don't complete their dosage. $94.78 \%$ of our respondents have taken antibiotics, and $71.89 \%$ have selfmedicated with antibiotics. Forty-eight percent of respondents said antibiotics might be effective even if they don't complete their dosage, Not completing the dosage (49.25\%), Using antibiotics repeatedly (43.28\%), and Self - medication (34.08\%). The percentage of the respondent that have taken antibiotics once and twice between March 2020 and February 2021, which was during the COVID 19 First and second wave in Nigeria, were (36.07\%) and (25.87\%) respectively. We recommend the use of media to discourage the masses from self-medication with antibiotics.
\end{abstract}

Keywords: Antimicrobial resistance, Antibiotics, Self-medication.

\section{Introduction}

Self-medication with antibiotics is a threat to global health and becoming increasingly common due to multiple factors. Selfmedication as defined by WHO is the utilization of drugs to treat self-diagnosed disorders or symptoms, or the irregular or continuous use of a prescribed drug for chronic or repeated diseases or symptoms without Doctor's description [1].

The absence of clinical assessment of the condition by a qualified medical doctor is a result to self-medication, which could result in overlooked diagnosis and hindrances in appropriate treatments [2]. The research discovered that the Chemotherapy of bacterial infections depends on the isolation of the aberrant agent, categorization of the agent's antibiotic susceptibility, and bringing the suitable antibiotic to the site of infection in adequate quantities to either kill the bacteria (bactericidal) or modify it to allow the body's immune response to drug and eventually kill it [3]. Previous researchers defined selfmedication defined as "taking of drugs, herbs or home remedies on one's own initiative, or on the advice of another person, without consulting a doctor" [4]. This procedure includes the use of medication by oneself or giving it to family members, friends, colleagues, including children or the elderly [5]. Previous literature revealed that the prevalence of self-medication is comparatively greater in 
developing countries as compared to developed countries $[6,7]$. The researchers also found out that regions of Eastern and Southern Europe had comparatively higher rates of selfmedication than northern and western areas of Europe [7].

The prevalence was 3\% in northern Europe [7]. An increase in self-medication practices has also been observed in Latin America [8]. While there is a huge increase in Asia, with the values being reported to be around $4-75 \%$ [9]. A previous study carried out in Karachi discovered that the self-medication rate in university students was $80.4 \%$ and that in the urban population was $68.1 \%[10,11]$.

Two decades ago, the World Health Organization (WHO) encouraged the use of self-medication without medical council in order to prevent and treat diseases in a faster and more efficient manner and also to reduce the load on healthcare centers in the rural areas $[12,13]$. The recent WHO reports on antimicrobial resistance states that it is a current global health threat [1]. It has been discovered that the use of medicines has led to problems in the short and long term. Self-medication is becoming increasingly common due to multiple factors. With information easily accessed through the internet, people are exposed to a greater amount of information, and they want to make independent decisions regarding their lives, which includes medications too [14]. Another important reason is the increased access to antibiotics in countries like Nigeria, where they are sold without a prescription, giving people a chance to ignore the Doctor and use their own opinion or the advice of others to self-medicate [15-18]. The causes of increased use of self-medication with antibiotics are because of an attitude of medical/health care providers, financial problems, illiteracy, inadequate healthcare facilities, or even a lack of time [12]. Studies carried out in Argentina, Brazil, Chile, Colombia, Costa Rica, and Nicaragua linked the high self-medication rates to a lack of access to healthcare facilities [8].
Another interesting discovering in Honduras was that self-medication was connected to urban dwellers. However, no association was built with socio-economic status [19].

Individuals indulging in the act of using antibiotics do not have adequate information regarding their proper use, dosage, and any side effects $[20,21]$. Abuse of such drugs may cause harm to the patients. There is a perception amongst the masses that common respiratory infections can be cured by antibiotics [22]. This has led to increased uninstructed use of antibiotics that has resulted in many pathogens becoming resistant to them. Strains of $S$. pneumonia, S. Typhi, Neisseria gonorrhoeae, and Shigella species have been found that are now resistant to common antibiotics [23-26]. [27] also found a direct relationship between inappropriate drug use and antibiotic resistance. In Pakistan, pharmacies are under a legal requirement to sell specific drugs only on prescription from a registered medical professional [28, 29]. However, the adherence to the law by these pharmacies is not encouraging, resulting to the high rates of selfmedication [28, 30]. In Lome, Togo, pharmacies do not sell any drug without Doctor's prescription.

In the research conducted in Nigeria by [31] out of the 1230 respondents from undergraduate students and community members, prescription of antibiotics by a physician was $33 \%$ and $57 \%$, respectively, amongst undergraduate students and community members. The researchers tested the respondent's knowledge of antibiotic resistance (ABR) and found that undergraduate students displayed less knowledge that selfmedication could lead to ABR $(32.6 \%$ and $42.2 \%$, respectively).

The study also discovered that selfmedication with antibiotics is highly prevalent in Northwest Nigeria, with most medicines being purchased from un-licensed stores without a prescription from a physician. This is very rampant in Nigeria as Pharmacies have no regulation or restriction of the sale of drugs. 
[31] also observed a significant gap in respondents' knowledge of ABR.

\section{Research Questions for this Study}

Does the individuals indulging in the act of using antibiotics do not have adequate information regarding their proper use, dosage, and any side effects. What are the multiple factors that lead to or result to increase of Self medication with antibiotics?

\section{Assumptions}

The assumption in this study is that there is the probability of self-medication with antibiotics, the effectiveness of antibiotics, lack of knowledge, and cost that leads to increased self-medication with antibiotics.

However, due to the high economic cost of hospital care, lack of time to visit the hospital, and often personal beliefs, and the fear of going to the hospital after-effects like contracting diseases like COVID - 19, people usually regard Doctor's clinical assessment and prescription as a voluntary rather than compulsive measure.

\section{Hypothesis}

Lack of knowledge of awareness of antibiotics resistance and high cost gives rise to Self - medication with antibiotics, and there may be other multiple factors or significant determinants that are difficult to measure and quantify, which determine causes of Self medication with antibiotics.

\section{Aim}

The aim of our study was to evaluate the attitudes, knowledge, and use of selfmedication with antibiotics among outpatients of Gbagada General Hospital Gbagada - Lagos, Nigeria.

\section{Specific Objectives}

a) To examine the level of knowledge and use of antibiotics among outpatients of Gbagada General Hospital Gbagada Lagos b) To find out the frequency and reasons of Self - medication with antibiotics among outpatients of Gbagada General Hospital Gbagada - Lagos

c) To assess the adverse effects in the outpatients that use Self - medication with antibiotics

d) To examine the association of sociocultural factors with antibiotics use.

\section{Literature Review}

According to [32], 39.3\% had practiced Selfmedication with antibiotics (SMA). The main reason for taking antibiotics is for runny nose, nasal congestion, cough, sore throat, fever, aches and pains, vomiting, diarrhea, and skin wounds. There was no significant difference between the medical or non-medical students regarding whether they had ever taken antibiotics $(p=0.082)$, but a significantly higher percentage of non-medical students had selfmedicated with antibiotics compared to medical students $(p<0.001)$. Responses from another research conducted by [31] discovered that the undergraduate students identified that the commonly self-diagnosed illnesses treated with antibiotics were malaria (14.5\%), typhoid (13.1\%), stomach pains (12.7\%), diarrhea $(11.9 \%)$, cold $(0.8 \%)$, ear and throat pain (1.2\%), asthma (1.6\%), sinusitis (2.2\%), dental caries $(2.8 \%)$, and fever $(3.9 \%)$. On the other hand, the community members were more likely to use antibiotics for illnesses such as dysentery (19\%), infection (17\%), typhoid $(13 \%)$, sinusitis $(1.8 \%)$, asthma (2.2\%), food poisoning $(3.1 \%)$, and ear and throat pain (3.2\%) [31]. Another research discovered that Antibiotics were used to treat self-perceived sore throat, fever, pain, cough, vaginal discharge, eye problems, common influenza, urinary infections, respiratory tract infections, wounds, and toothaches [33].

The frequency of SMA taken by medical students have significantly lower than the nonmedical students with a Chi-square of $p<0.001$ the significant differences regarding reasons for 
SMA between medical and non-medical students [31]. The research [31] discovered that the frequency of antibiotic used among undergraduate students and community members were reported as $43 \%$ and $26 \%$ weekly, respectively. Undergraduate students were more likely to use antibiotics as reported in the weekly usage of antibiotics (43\%) compared to community members $(26 \%)$.

Another research found out that antibiotics were purchased by referring to the scientific or generic name, which was one of the most common patterns of SMA used by the participants from the middle and high socioeconomic pharmacies. The names of antibiotics were known by the participants since most indicated previous use of, prescribed by a health care professional (HCP) when they had sought help at the hospital or clinic. The researchers discovered that participants who requested an antibiotic using a previous prescription pattern named amoxicillin with clavulanic acid, azithromycin, and cotrimoxazole as the most purchased NPA. They also found out that the participants did not know precisely the uses and adverse effects of the requested antibiotics; they believed that the antibiotics were useful in treating certain diseases in 2 to 3 days. [34].

In the research [34], the majority of the pharmacy clients interviewed, 30 (93.75\%) admitted frequent use of Non prescribed antibiotics (NPAs), 15 (88.2\%) out of the 17 pharmacists interviewed admitted dispensing NPAs [34]. While the majority of the participants (16) mentioned the use of amoxicillin, also known as 'two colours medicine', 14 participants mentioned the use of cotrimoxazole, and seven mentioned amoxicillin with clavulanic acid. Two to five participants also used tetracycline, ciprofloxacin, azithromycin, doxycycline, erythromycin, metronidazole, and phenoxymethylpenicillin [34]. The researchers questioned the manner customers request NPA, pharmacists unanimously admitted that SMA is a frequent practice among customers. Another pharmacist admitted SMA is a widespread and rampant practice and that most customers seem to be very well informed [34]. [31] also discovered that the distribution pattern of most commonly used antibiotics among undergraduate students were metronidazole (18\%), amoxicillin/clavulanic acid (16.8\%), ampicillin/cloxacillin (14.8\%), cotrimoxazole (12\%), and tetracycline (11\%). Meanwhile, the community members reported the highest use of ampicillin/cloxacillin (23.5\%), ciprofloxacin (18.7\%), ampicillin (12.5\%), tetracycline $(11.4 \%)$, and amoxicillin/clavulanic acid (10.6\%). \%).

[32] found out that most practiced SMA because of its Convenience (42.3\%) [Medical $(41.7 \%)$ and non-medical students $(42.5 \%)]$ or cost savings [Medical (37.5\%) and non-medical students $(35.2 \%)$, though not much difference, were seen between both groups. Differences were found relating to lack of trust in the prescribing doctors as one of the reasons for SMA, where none of the medical students had a lack of trust in their prescribing doctors as compared to non-medical students (8.9\%). Furthermore, more non-medical students gave "other reasons" as their reason $(9.5 \%)$, while more medical students gave multiple answers to these questions (16.7\%). However, there was no significant difference between the medical and non-medical students regarding the diseases, the basis for SMA, nor the reasons they stopped antibiotics during SMA ( $p=0.052$, 0.428 , and 0.684 , respectively). The common disease or condition for SMA was due to fever (25.5\%); SMA was mainly practiced based on a previous doctor's prescription (35.9\%), and the majority stopped the antibiotics once their symptoms disappeared (31.2\%). No medical students stated a lack of trust in prescribing doctors, whereas (8.9\%) non-medical students stated that was a reason for SMA (Chi-square $p=0.005$ ).

[32] found out that the main decision for choosing amoxicillin during SMA as the type 
of antibiotics (37.1\%); obtaining their antibiotics from community pharmacies was $(66.0 \%)$; knowing the dosage after consulting a doctor was (27.8\%) and taking only one type of antibiotic during an illness was (55.1\%). Haque discovered that, there was no significant difference between medical and non-medical students regarding the dosage and the maximum number of antibiotics taken during an illness. However, significant differences were observed between the two groups regarding the consideration for SMA and where they obtained the antibiotics for SMA [32]. A higher percentage of medical students gave either multiple answers or the brand and price of the antibiotics as their main consideration compared to non-medical students, who were more concerned about the type or an adverse reaction from the antibiotics [32].

[32] also found out that practices regarding the use of antibiotics during SMA, very few participants "always" change the dosage or switch antibiotics during SMA were $8.1 \%$, though quite a number "sometimes" did were $41.3 \%$. The majority that did not fully understand the instruction on the antibiotic package were $60.2 \%$, and somewhat concerned about taking counterfeit antibiotics were $46.4 \%$, the respondents that did not experience any adverse effects during SMA were $71.3 \%$, those that thought that SMA was an acceptable practice were $61.3 \%$ and those that were not sure whether they could successfully treat the infection on their own were $64.3 \%$. Less than half of the participants had taken the same antibiotics with different names during a course of antibiotics $(40.1 \%)$.

[32] did a comparison between medical and non-medical students regarding the use of antibiotics with SMA showed a significant difference for understanding the instruction on the antibiotics package, whereas as expected, a higher percentage of medical students understood the instruction fully $(p=0.015)$. In addition, a higher percentage of medical students switched antibiotics during SMA
( $p=0.004)$ and did not think that they could successfully treat themselves $(p=0.011)$. A higher percentage of non-medical students were more concerned about taking counterfeit antibiotics $(p=0.011)$ and thinking that SMA is a good or acceptable practice $(p=0.002)$ [32].

A study conducted by [31] found out that prescription of antibiotics for use by a clinician, nurse, or pharmacist were $33.5 \%, 29 \%$, and $25 \%$, respectively, among undergraduate students and were 57\%, 20.4\%, and $15.5 \%$ among the community members. It was discovered that antibiotics purchases mostly took place at patent medicine stores (40\%) among the undergraduate students, unlike the community members whose main source of Purchase was at a local chemist or pharmacy (48.4\%). However, a substantial number of the undergraduate students compared to community members reported that they patronized local drug hawkers (22.7\% and 9.4\%, respectively). Regarding compliance with the prescribed duration of use of the antibiotics indicated that $85 \%$ of undergraduate students and $84 \%$ of community members completed the course of antibiotic prescription. Similarly, the majority of the respondents $(72.5 \%$ undergraduate students and $60.4 \%$ community members) suggested that antibiotic use was devoid of any side effects. In contrast, respondents reported different levels of satisfaction from the use of antibiotics. Undergraduate students mostly rated antibiotic use as good (43\%), while the community members mostly rated it as satisfactory $(40 \%)$ in resolving illnesses. The chi-square tests indicate a significant association between frequency of antibiotic use, prescribing personnel, place of Purchase, and efficacy of antibiotics in resolving illnesses with self-medication with antibiotics among the undergraduate students and community residents ( $p$-value < 0.001) [31].

In the research conducted by [33] found out that the pharmacists observed that most customers knew exactly the name and dosage of the antibiotics (how many milligrams, e.g. If 
$250 \mathrm{mg}$ or $500 \mathrm{mg}$ ), and occasionally, they referred to the name of the laboratory of origin of the antibiotics if a German, Portuguese or Indian-made antibiotics. [34].

[34] discovered that pharmacists agree SMA is an individual practice, they were of the opinion that the doctors and/or qualified health professionals were also to blame for the widespread abuse of the use of antibiotics since they are quick to prescribe for symptoms or health problems that do not necessarily require antibiotics treatment.

Moreover, pharmacists believed doctors' prescribing practices contributed to SMA since they frequently prescribe the same antibiotic for different conditions, and patients learn to recognize those antibiotics. This, according to pharmacists, led patients to overuse and didn't feel the need to seek medical help since patients who can afford to pay go straight to the pharmacy. [34]

The study also highlighted that both customers and pharmacists mentioned the practice of sharing antibiotics with family, friends, and/other people from the social network are common. Such behavior was, according to the pharmacists, influenced by the behavior of not finishing the complete course of treatment and/or stopping medications when symptoms disappear. This attitude led patients to do home storage of left-over antibiotics that are later used either for the same patient or others within the social network or family. Participants from FGD, customers, and a pharmacist agreed and explained [34]. From the study, pharmacists admitted with concern that some customers used old prescriptions to purchase antibiotics.

According to the pharmacists, it is also becoming common for customers to come with an old prescription as a picture saved in their smartphone or even shared by someone else. Normally old patients, people above 60 years old, use a lot of old prescriptions. People also got information from the internet without Doctor's prescription. [34].

\section{Methodology}

\section{Study Design}

A descriptive cross-sectional study was carried out to assess the knowledge, use, frequency, and reasons of self-medication with antibiotics among patients at Gbagada General Hospital Gbagada from February $14^{\text {th }}-19^{\text {th }}$, 2021. Gbagada General Hospital is the largest tertiary care hospital run by the government. It is one of the major suppliers of free-of-cost healthcare for the community of Gbagada for patients who cannot afford to pay for their treatment. Four hundred people were recruited from the Outpatient Department (OPD) of the hospital. This study was approved by the review board of Lagos state health service commission and Lagos University Teaching Hospital Health Research Committee.

\section{Study Area}

This study was be conducted in Kosofe Local Government Area in Lagos State, Nigeria. Kosofe means "nothing is free". This underscores the diverse commercial activities which characterized the indigenes and early settlers of the area in the mid-nineteenth century, the people were noted for massive trade in vegetables, fruits, maize, cassava, and fish. Its location at the gateway to the metropolitan Lagos further entrenches Kosofe as an important name in commerce in modernday Nigeria [35].

Kosofe is located at the Northern part of Lagos State. It is bounded by (3) other Local Governments, namely: Ikeja, Ikorodu, and Somolu. It also shares a boundary with Ogun State. Its jurisdiction comprises of seven wards and encompasses an area of about $17.85 \mathrm{sq} / \mathrm{km}$. Its headquarters is at Ogudu Road, Ojota, Lagos; presently, Kosofe falls under the East Senatorial District [35].

Self-medication with antibiotics occurs everywhere in the world, including Kosefe Local government. Where our research was conducted (General Hospital Gbagada) was a 
good place to study and capture the knowledge and use of self-medication with antibiotics.

\section{Study population}

The population comprised of all the residents in Kosofe LGA, and study subjects were out patients that use General Hospital. This comprised of those that use self-medication with antibiotics, as well as track the adverse effects in the patients that used self-medication with antibiotics.

\section{Inclusion Criteria}

Outpatient Department (OPD) of Gbagada General Hospital Gbagada Lagos. The definition of self-medication was set as the use of any antibiotics within the last 12 months, without the prescription of a doctor. This time limit of 12 months was set to eliminate the possible recall bias among the participants. Antibiotics are the medications consumed to treat bacterial and protozoal infections and that are depicted on the World Health Organization's (WHO) model list of necessary medicines [36] [37]

\section{Exclusion Criteria}

Outpatient Department (OPD) that do not use General Hospital.

\section{Sample Size Determination}

The Cochran formula is [38] - The sample size was determined in order to have $95 \%$ confidence limits of $5 \%$ maximum error of the estimate when the probability is $46 \%$ [30]. This leads to a requirement of 402 residents. For a non-response expectation, the sample size was increased to 402 Outpatient Department (OPD) of the hospital. 402 Outpatients of the Gbagada General Hospital Gbagada city area of Lagos will be recruited for the study in the aforementioned time period through probability sampling.

\section{Sampling Technique}

The technique of multi-stage sampling was used to obtain cross-sectional data for this study in Lagos state. The Lagos state was divided geographically into 37 Local governments Area.

Stage 1: The balloting method of simple random sampling was used to select a government hospital (Gbagada general Hospital) from the list of hospitals in the Local governments of Lagos state, Nigeria. Therefore, the sample sizes of 402 outpatients were distributed according to the number of patients that use a government hospital.

Stage 2: Simple random sampling method using outpatient registers was used to select the patients that would be sampled in the hospital.

Stage 3: All outpatients using selfmedication with antibiotics in the hospitals were sampled in the hospital picked.

\section{Method of Data Collection}

Informed consent was obtained from every participant, both verbal and written. Questionnaire was developed for this study based on the previous research questions related to knowledge and use of self-medication with antibiotics. A pretest was carried out for 20 outpatients of Gbagada General Hospital, and necessary modifications were carried out. Participants were given the option of answering the questionnaire themselves or having the researcher fill it based on verbal responses. The questionnaire contained five sections. The first is the demographic section, which contained questions regarding age, gender, marital status, education level, household income, occupation, and health insurance. Section B assessed the different antibiotics that the participants bought for self-administration. Section $\mathrm{C}$ gauged the reasons for self-medication and its frequency, the location for obtaining medicines, and the people they approached for advice. Section D determined the knowledge of adverse effects caused by antibiotics. Section E asked about the knowledge of inadequate use of antibiotics on antibiotic resistance. The investigator explained the study to the participants, including the conditions for participating, as well as privacy 
and confidentiality for data collection. Although the study was free from any serious ethical issues, the researcher designed a participant's information sheet that explained the voluntary nature of the study in details, and the anonymity and confidentiality in the study. Necessary translation of the contents of the tools for this research was done to assist the less-learned but with care not to influence or distort the judgment of the participants. The researcher, through trained health workers for data collection, gave the participant's information sheet and questionnaire to eligible and willing participants at the various places designated for data collection.

\section{Ethical Considerations}

Ethical approval was obtained from the Research and Ethics Committee of Lagos University Teaching Hospital. Permission was also obtained and the Chairman of Lagos State Health service commission before the commencement of the study. Participation was voluntary; all the participants were required to provide written informed consent, and they were assured of the confidentiality regarding information collected from them.

Section A was the demographic section, which will contain questions regarding age, gender, marital status, education level, household income, occupation, and health insurance. Section B assessed the different antibiotics that the participants bought for selfadministration. Section $C$ was gauged the reasons for self-medication and its frequency, the location for obtaining medicines, and the people they approached for advice. Section D was determined the knowledge of adverse effects caused by antibiotics. Section E asked about the knowledge of inadequate use of antibiotics on antibiotic resistance. Each participant was asked at the start of the questionnaire whether they self-medicated. Those who did were required to fill the whole questionnaire while the rest only filled sections $\mathrm{A}, \mathrm{D}$ and $\mathrm{E}$. The questionnaire was compiled from the already validated versions used by [37, $39,40]$ in their studies.

\section{Results}

This section presents the major findings from the study. The results are divided into five subsections, namely: Socio-demographic characteristics of respondents, The different antibiotics that the participants bought for selfadministration, The reasons for self-medication and its frequency, the location for obtaining medicines, and the people they approached for advice and the knowledge of adverse effects caused by antibiotics.

\section{Section A: Socio-Demographic Data}

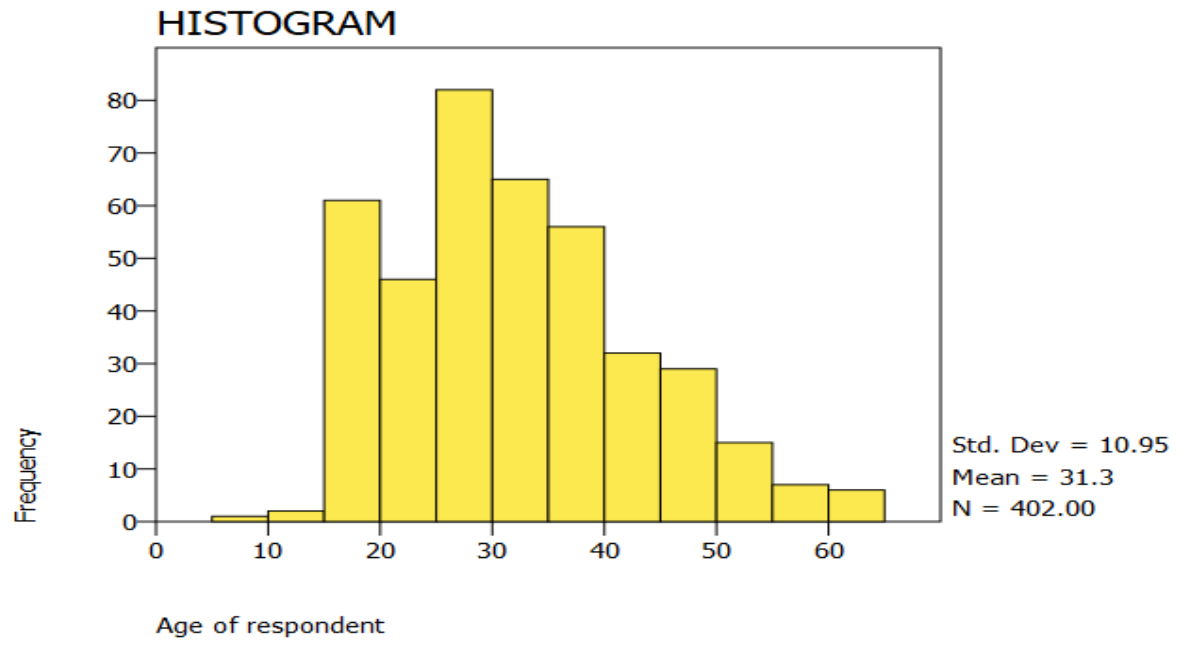

Figure 1. Socio-Demographic Data 
The mean, modal ages, and standard deviation of respondents, were 31.29 years, 30 years old, and 10.95. The youngest respondent was 8 years old, and the oldest respondent was 64.

Table 1. Socio-demographic Characteristics of Respondents

\begin{tabular}{|c|c|c|}
\hline Respondents & Frequency $n=402$ & Percentage $(\%)$ \\
\hline \multicolumn{3}{|c|}{ Have you ever taken antibiotics? } \\
\hline Yes & 381 & 94.78 \\
\hline No & 21 & 5.22 \\
\hline \multicolumn{3}{|c|}{ Have you treated yourself (self-medicated) with antibiotics } \\
\hline Yes & 289 & 71.89 \\
\hline No & 113 & 5.22 \\
\hline \multicolumn{3}{|c|}{ Sex of respondent } \\
\hline Male & 155 & 38.56 \\
\hline Female & 247 & 61.44 \\
\hline \multicolumn{3}{|l|}{ Marital Status } \\
\hline Single & 204 & 50.75 \\
\hline Married & 180 & 44.78 \\
\hline Divorced & 9 & 2.24 \\
\hline Separated & 9 & 2.24 \\
\hline \multicolumn{3}{|l|}{ Education } \\
\hline $\begin{array}{l}\text { No formal } \\
\text { education }\end{array}$ & 2 & 0.50 \\
\hline Primary & 5 & 1.24 \\
\hline Secondary & 129 & 32.09 \\
\hline Tertiary & 266 & 66.17 \\
\hline \multicolumn{3}{|l|}{ Religion } \\
\hline Christian & 307 & 76.37 \\
\hline Islam & 95 & 23.63 \\
\hline Others & 0 & 0.00 \\
\hline \multicolumn{3}{|c|}{ Employment Status } \\
\hline Employed & 156 & 38.81 \\
\hline Unemployed & 101 & 25.12 \\
\hline Self employed & 145 & 36.07 \\
\hline \multicolumn{3}{|l|}{ Income } \\
\hline$<50,000$ Naira & 193 & 48.01 \\
\hline $50,000-99,999$ & 72 & 17.91 \\
\hline $\begin{array}{l}100,000- \\
150,000\end{array}$ & 81 & 20.15 \\
\hline$>150,000$ & 56 & 13.93 \\
\hline \multicolumn{3}{|c|}{ Health Insurance status } \\
\hline Yes & 136 & 33.83 \\
\hline No & 266 & 66.17 \\
\hline
\end{tabular}


Respondents that are females were $61.44 \%$, and $38.56 \%$ were males. Half of our respondents were single $(50.75 \%)$ while $44.78 \%$ were married, $2.24 \%$ were divorced and separated, respectively.

The majority of parents/guardians were Christians (76.37\%), Muslims were 23.63\%. The respondents (parents/guardians) interviewed that had secondary education were $33.09 \%, 66.17 \%$ had tertiary education, while $1.24 \%$ had primary education and $0.50 \%$ had no formal education.

The majority of our respondents were employed $(38.81 \%$ ), about $36.07 \%$ of our respondents were Self - employed $25.12 \%$ of our respondents were unemployed. It was interesting to discover that $48.01 \%$ of our respondents earn below 50,000 Naira monthly, $17.91 \%$ earn between 50,000 naira, and 99,999 naira monthly, $20.15 \%$ earn between $100,000-$ 150,000 naira monthly, and $13.93 \%$ earn above 150,000 Naira monthly respectively.

The majority of respondents $(66.17 \%)$ do not have health insurance, while only $33.83 \%$ of respondents have health insurance, $94.78 \%$ of our respondents have taken antibiotics, while $5.22 \%$ have not taken antibiotics before.

The majority of our respondents (71.89\%) have self-medicated with antibiotics, while $28.11 \%$ do not self-medicate with antibiotics.

\section{Section B: The Different Antibiotics that the Participants Bought for Self- administration}

Ampicillin (53.23\%), Penicillin (51,24\%), chloroquine $(45.77 \%)$, and Amoxycillin $(40.05 \%)$ are the antibiotics our respondents used most for Self - medication.

\section{Section C: The Reasons for Self-medication and its Frequency, the Location for Obtaining Medicines and the People they Approached for Advice}

Table 2. The Reasons for Self-medication and its Frequency, the Location for Obtaining Medicines

\begin{tabular}{|l|l|l|}
\hline Reasons & Frequency $\mathbf{n = 4 0 2}$ & Percentage (\%) \\
\hline What is your frequency of antibiotics use? & 18 & 448 \\
\hline Weekly & 44 & 10.95 \\
\hline Monthly & 41 & 10.20 \\
\hline Once in two months & 48 & 11.94 \\
\hline Every 3 months & 251 & 62.44 \\
\hline Others & 170 & \multicolumn{2}{|l|}{} \\
\hline Who prescribed the antibiotics? & 51 & 42.29 \\
\hline Doctor & 139 & 12.69 \\
\hline Nurse & 42 & 34.58 \\
\hline Pharmacist & 10.45 \\
\hline Others & 186 & \multicolumn{2}{|l|}{} \\
\hline Place of antibiotics purchase & 168 & 46.27 \\
\hline Local Chemist & 4 & 41.79 \\
\hline Patent Medicine store & 44 & 1.00 \\
\hline Local drug hawkers & \multicolumn{2}{|l|}{} \\
\hline Others & \multicolumn{2}{|l|}{} \\
\hline Did you comply with the duration of use of antibiotics? & 79.95 \\
\hline Yes & 319 & 20.65 \\
\hline No & 83 & 36.07 \\
\hline Were there any side effects? & 145 \\
\hline Yes & \multicolumn{2}{|l|}{} \\
\hline
\end{tabular}




\begin{tabular}{|l|l|l|}
\hline No & 257 & 63.93 \\
\hline Was the antibiotics effective in resolving the illness? & 39.30 \\
\hline Excellent & 158 & 43.53 \\
\hline Satisfactory & 175 & 15.17 \\
\hline Good & 61 & 1.99 \\
\hline No results & 8 & 72.64 \\
\hline How much did you understand the instructions? & 24.88 \\
\hline Fully understood & 292 & 2.49 \\
\hline Partly understood & 100 & \\
\hline Did not understand at all & 10 & 33.08 \\
\hline $\begin{array}{l}\text { Have you ever found out that you had taken the same antibiotics with different } \\
\text { names at the same time? }\end{array}$ & 66.92 \\
\hline Yes & 133 & 22.64 \\
\hline No & 269 & 77.36 \\
\hline $\begin{array}{l}\text { Have you ever had adverse reaction when you took antibiotics for Self - } \\
\text { medication? }\end{array}$ & 91 \\
\hline Yes & 311 \\
\hline No &
\end{tabular}

For frequency of antibiotics use majority of our respondents fall in the category of others (62.44\%). Doctor's and Pharmacist prescription for our respondents was $42.29 \%$ and $34.58 \%$, respectively. It is worthy to note that some patient calls their health care providers on the phone or use telemedicine which has come to stay.

The place of Purchase of antibiotics our respondents use for Self - medication were Local chemist (46.27\%) and Patent Medicine stores $(41.79 \%)$. It was amazing that $79.35 \%$ of our respondents complied with the duration of the use of the antibiotics, which is good, and $63.93 \%$ of our respondents reported that they had no side effects while $36.07 \%$ had side effects.

Surprisingly, $98.01 \%$ of our respondents stated that the antibiotics was effective to resolving their illness. Our respondents indicated that $36.07 \%$ and $25.87 \%$ have taken antibiotics once and twice, respectively, between March 2020 and February 2021, which was during the COVID - 19 First and second wave in Nigeria. It is worthy to note $11.69 \%$ didn't take antibiotics in the last one year, and an 8-years-old child took antibiotics 24 times within one year because of a medical history of infection in the leg. (Bone joint).

Long delays in hospital (43.03\%), Convenience (26.37\%), Cost saving (20.90\%), and attitude of hospital staff (18.16\%) were mostly the reasons our respondents were selfmedicating with antibiotics. Our respondents self-medicated with antibiotics for Infection (40.55\%), Fever (38.31\%), Sore throat (27.36\%), Cough (26.62\%), Malaria (26.12\%), Typhoid (19.40\%), Diarrhea (16.92\%), Aches and pains (16.67\%).

Respondent's selections of antibiotics were based on Recommendation by a Doctor (41.29\%), Based on my own experience and knowledge of antibiotics (30.85\%), recommendation by community Pharmacist (28.36\%), Previous Doctor's prescription $(23.13 \%)$, and recommendation by Nurse (16.42\%). Our respondents that Fully understood the instruction of the antibiotics they used to self-medicate were $72.64 \%$.

The majority of our respondents $(77.11 \%)$ took only one type of antibiotics when they were ill, $19.25 \%$ took two types of antibiotics, while $2.99 \%$ took three types of antibiotics, and only 0.25 took four types of antibiotics. 
Our respondents that found out that they had taken the same antibiotics with different names at the same time were $33.08 \%$.

Our respondents stopped taking antibiotics after completion of the course (35.82\%), a few days after recovery (30.85\%), After symptoms disappeared $(29.60 \%$ ), while $9.45 \%$ stopped after antibiotics finished/ran out, $7.46 \%$ stopped after a few days regardless of the outcome. Our respondents that had an adverse reaction when they self-medicate with antibiotics were $22.64 \%$, and $11.94 \%$ stopped taking antibiotics when they experienced an adverse reaction, while $9.20 \%$ and $4.98 \%$ consulted a Doctor and Pharmacy staff, respectively.

\section{Section D: The Knowledge of Adverse Effects Caused by Antibiotics and Section E: The Knowledge of Inadequate use of Antibiotics on Antibiotic Resistance}

Table 3. The Knowledge of Adverse Effects Caused by Antibiotics and the Knowledge of Inadequate use of Antibiotics on Antibiotic Resistance

\begin{tabular}{|c|c|c|}
\hline Section D: & Frequency $n=402$ & Percentage $(\%)$ \\
\hline \multicolumn{3}{|c|}{ Do you know what antibiotics are? } \\
\hline Yes & 360 & 89.55 \\
\hline No & 42 & 10.45 \\
\hline \multicolumn{3}{|c|}{ Antibiotics can cure all infections } \\
\hline True & 132 & 32.59 \\
\hline False & 271 & 67.41 \\
\hline \multicolumn{3}{|c|}{ Antibiotics might be effective even if I don't complete my dosage } \\
\hline Yes & 194 & 48.26 \\
\hline No & 208 & 51.74 \\
\hline \multicolumn{3}{|c|}{ Level of awareness of antibiotics resistance } \\
\hline Low & 79 & 19.65 \\
\hline Moderate & 257 & 63.93 \\
\hline High & 66 & 16.42 \\
\hline \multicolumn{3}{|c|}{$\begin{array}{l}\text { Do you use left-over antibiotics from friends and family members without } \\
\text { Doctor's prescription? }\end{array}$} \\
\hline Always & 13 & 3.23 \\
\hline Sometimes & 147 & 36.57 \\
\hline Never & 242 & 60.20 \\
\hline \multicolumn{3}{|l|}{ Section E: } \\
\hline \multicolumn{3}{|c|}{ Do you use another family members antibiotics? } \\
\hline Always & 17 & 4.23 \\
\hline Sometimes & 127 & 31.59 \\
\hline Never & 258 & 64.18 \\
\hline \multicolumn{3}{|c|}{ Unnecessary use of antibiotics makes them ineffective } \\
\hline True & 277 & 68.91 \\
\hline False & 125 & 31.09 \\
\hline \multicolumn{3}{|c|}{ Have you heard of resistance to antibiotics? } \\
\hline Yes & 205 & 51.00 \\
\hline No & 197 & 49.00 \\
\hline
\end{tabular}

Respondents knew what antibiotics are were $89.55 \%$ while $32.59 \%$ of our respondents said antibiotics can cure all infections, and $48.26 \%$ of our respondents said antibiotics might be 
effective even if they don't complete their dosage. Level of awareness of antibiotic resistance amongst our respondents for were moderate (66.93\%), Low (19.65\%), and High (16.42\%).

Respondents that use left-over antibiotics from friends and family members without Doctor's prescription sometimes and always were $36.57 \%$ and $3.23 \%$, respectively.

The common adverse reaction of antibiotics experienced by respondents were Nausea (26.87\%), Rash (24.13\%), Vomiting (13.68\%), Drug resistance (12.19, Diarrhea (11.19\%), and Vaginal thrush 93.235).

Our respondents said that Intravenous is better than oral medication (27.36\%), Higher doses result in faster recovery (15.67\%), Lower doses result in less adverse reactions (17.91\%), Switching antibiotics enhances drug effects (17.66\%), Broad-spectrum antibiotics are better than narrow-spectrum ones (25.12\%) and Switching antibiotics reduces adverse reactions (14.93\%). $64.18 \%$ of our respondents have never used another family member's antibiotics. 68.91 of our respondents agree that the unnecessary use of antibiotics makes them ineffective. $51 \%$ of our respondents have heard of resistance to antibiotics.

Respondents knew that resistance to antibiotics can be caused by Not completing the dosage $(49.25 \%)$, Using antibiotics repeatedly (43.28\%), and Self - medication (34.08\%). Respondents knew that antibiotics is used for treating Bacteria infection (85.32\%), viral infection (17.66\%), and others (8.21\%).

\section{Discussion}

Between March 2020 and February 2021, which was during the COVID - 19 First and second wave in Nigeria, $36.07 \%$ and $25.87 \%$ of outpatients of Gbagada General Hospital took antibiotics once and twice, respectively. Long delays in hospital $(43.03 \%$, Convenience (26.37\%), Cost saving (20.90\%), and attitude of hospital staff $(18.16 \%)$ were mostly the reasons our respondents were self-medicating with antibiotics. This is similar to the discovery of [31], those reasons reported for engaging in self-medication among undergraduate students and community members were due to long delays in the hospital, it being cheaper not to go to the hospital, and the distance to the hospital" [31]. Respondents self-medicated with antibiotics for Infection (40.55\%), Fever (38.31\%), Sore throat (27.36\%), Cough (26.62\%), Malaria (26.12\%), Typhoid $(19.40 \%)$, Diarrhea (16.92\%), Aches and pains $(16.67 \%)$. The majority of respondents (66.17\%) do not have health insurance, while only $33.83 \%$ of respondents have health insurance. Level of awareness of antibiotic resistance amongst our respondents for were moderate $(66.93 \%)$, Low (19.65\% and Hight $(16.42 \%)$. This justifies $[31,32]$ findings stating that" the most common reasons for selfadministration of antibiotics were sore throat, fever, running nose and cough [31] [32]. Other reasons were dental infection, rheumatism, and fatigue, nasal congestion, fever, aches and pains, vomiting, diarrhea, and skin wounds.

Respondents that had tertiary education were $66.17 \%$, Chi-Square showed that there was a significant association between level of education and use of antibiotics. Level of education had an effect in the level of knowledge and use of Self - medication with antibiotics. $25.12 \%$ of our respondents were unemployed, and the majority of respondents (66.17\%) do not have health insurance righting to an increase in self-medication with antibiotics. As discovered by [31] that being unemployed and having no health insurance resulted to the self-administration of antibiotics. Most elderly outpatients at Gbagada General hospital do not self-medicate with antibiotics, unlike the young adult outpatients of Gbagada General hospital Gbagada. According to similar research conducted earlier, the most common self-medicating group were adults aged 40-49 while the least self-usage was in the 60-69 age groups, unlike a study carried out by [33] that discovered old patients, people above 60 years 
old use a lot of old prescriptions for selfmedication with antibiotics. People also get information form the internet without Doctor's prescription [34].

Doctor's and Pharmacist prescriptions for our respondents were $42.29 \%$ and $34.58 \%$, respectively. For frequency of antibiotics use, the majority of our respondents fall in the category of others $(62.44 \%)$, meaning that they only use antibiotics when needed and not weekly, monthly, bimonthly, or once in 3 months. The place of Purchase of antibiotics our respondents use for Self - medication were Local chemists (46.27\%) and Patent Medicine stores $(41.79 \%)$. $32.59 \%$ of our respondents said antibiotics can cure all infections. $48.26 \%$ of our respondents said antibiotics might be effective even if they don't complete their dosage. $36.57 \%$ and $3.23 \%$ of our respondents use left-over antibiotics from friends and family members without Doctor's prescription sometimes and always, respectively. The common adverse reaction of antibiotics experienced by respondents were Nausea (26.87\%), Rash (24.13\%), Vomiting (13.68\%), Drug resistance (12.19\%), Diarrhea (11.19\%), and Vaginal thrush 93.235). $64.18 \%$ of our respondents have never used another family member's antibiotics. 68.91 of our respondents agree that the unnecessary use of antibiotics makes them ineffective. This is similar to a survey conducted by [31] those undergraduate students who showed that suggestions from family and friends (34.3\%) were the most common explanation for self-medication of self-diagnosed illnesses. While in the community, prescription by physicians $(33.5 \%)$ were the highest response for choice of antibiotics, followed by previous experience with the antibiotic (18\%) and knowledge of the antibiotic (11\%) [31]. The researchers discovered that undergraduate students were more likely than the community residents to subscribe to using left-over antibiotics from friends or family members without doctor's prescription; most times $(12.5 \%$ and $8.5 \%$, respectively) and sometimes $(57.4 \%$ and $40.3 \%$ ) [31]. Similarly, the undergraduate students were more likely than the community residents to use antibiotics based on relative's advice; always ( $25.4 \%$ and $18.3 \%$, respectively) and sometimes (61.4\% and 37.7\%) [31].

Knowledge of ABR varied among the respondents. Our respondents said that Intravenous is better than oral medication (27.36\%), Higher doses result in faster recovery (15.67\%), Lower doses result in less adverse reactions $(17.91 \%)$, Switching antibiotics enhances drug effects (17.66\%), Broadspectrum antibiotics are better than narrowspectrum ones $(25.12 \%)$ and Switching antibiotics reduces adverse reactions (14.93\%). Respondents knew that resistance to antibiotics can be caused by Not completing the dosage $(49.25 \%)$, Using antibiotics repeatedly (43.28\%), and Self - medication (34.08\%). Respondents knew that antibiotics is used for treating Bacteria infection (85.32\%), viral infection $(17.66 \%)$, and others $(8.21 \%)$. This justifies [31] findings that the undergraduate students, compared to the community residents displayed more knowledge of the fact that antibiotics cannot cure all infections (53\% and $42.4 \%$ ), that antibiotics are not used for cold $(57.5 \%$ and $55.3 \%)$, and that unnecessary use of antibiotics could make them ineffective $(68.4 \%$ and $62.9 \%$ ) In contrast, community residents displayed better knowledge compared to undergraduate students when asked if antibiotics can be used for body pains $(59.1 \%$ and $37.2 \%$ ) and if antibiotics might be effective without completing the dosage $(52.9 \%$ and $43.9 \%$ ); the correct response was false. The undergraduate students, compared to the community residents, displayed less knowledge of the fact that self-medication could lead to the development of Antibiotics resistance (32.6\% and $42.2 \%$, respectively), but undergraduate students showed more knowledge that indiscriminate antibiotic use could cause Antibiotics resistance (51.3\% and 41.8\%) [31]. 
We are therefore accepting our hypothesis that lack of knowledge of awareness of antibiotics resistance $\mathrm{p}=0.024$ and high cost gives rise to Self - medication with antibiotics and there are other multiple factors or significant determinants like COVID-19 lockdown restrictions, long delays in hospital, the attitude of hospital staff and lack of health insurance determine causes of Self medication with antibiotics.

\section{Conclusion}

The emergence and spread of drug-resistant pathogens have acquired new resistance mechanisms, which has led to antimicrobial resistance and has continued to threaten our ability to treat common infections. The most alarming is the rapid global trend of multi- and pan-resistant bacteria (also known as "superbugs") that cause infections that are not treatable with existing antimicrobial medicines such as antibiotics [1].

In 2019 WHO discovered 32 antibiotics in clinical development that address the WHO list of priority pathogens, six were classified as innovative. A major concern was the lack of access to quality antimicrobials. Antibiotic shortages are currently affecting countries of all levels of development and especially in healthcare systems [1].

Antibiotics are becoming increasingly ineffective as drug resistance increases globally, making it more difficult to treat infections and death. New antibacterial are really vital - for example, to treat carbapenem-resistant gramnegative bacterial infections as identified in the WHO priority pathogen list [1]. The outpatients of Gbagada General Hospital who are using these antibiotics generally do not have full information regarding their proper use. However, if the outpatients of Gbagada General Hospital do not stop self-medication with antibiotics now, these new antibiotics will suffer the same fate as the current ones and become ineffective.

\section{Recommendation}

a) There is pressing importance for public health agencies, professionals, and the Federal Ministry of Health in Nigeria to enforce existing laws on antibiotics sales by Pharmacies, drug hawkers and enlighten the people on the dangers of ABR.

b) We recommend the use of media (television, radio, newspaper, magazine, billboards, Facebook, Twitter, Instagram, Linkedin, Telegram, Tik Tok, Whatsapp etc.) to discourage the masses from selfmedication with antibiotics.

c) The Public should be encouraged to stop the misused and overuse of antimicrobials.

d) The Public should ensure that they drink clean water and practice proper sanitation and adequate infection prevention and control to mitigate the spread of microbes.

\section{Acknowledgement}

All praises to God for the gift of life, mercy, and good health that enabled me to complete this research. My sincere gratitude to Lagos State Health Service Commission and Gbagada General Hospital for the permission, support, and opportunity given to me to carry out this study.

I would like to express my gratitude to Dr. Ann Ogbenna (a senior lecturer at College of the Medicine University of Lagos), who was instrumental to getting ethical approval for this research, data collector, Oluwatosin Adewumi, Mentor, Ms. Jesna, my lecturers, and its Management of Texila American University. I am highly thankful for the kind support bestowed on me by my Husband Mr. Noris Chimezie Odis, children (Chimuanya, Ogechukwu, Chisimudi), Sweet Mum, Mrs. Bibiana Anyichie, Siblings, family, friends, and all respondents in this study.

\section{Conflicts of Interest}

The author declares no conflict of interest. 


\section{References}

[1] World Health Organization, 2020, Antimicrobial resistance, https://www.who.int/news-room/factsheets/detail/antimicrobial-resistance.

[2] Hamel MJ, Odhacha A, Roberts JM, Deming MS. Malaria control in Bungoma District, Kenya: a survey of home treatment of children with fever, bed net use and attendance at antenatal clinics. Bull World Health Organ 2001;79(11):1014-1023 [PMC free article] [PubMed] [Google Scholar].

[3] Behrman RE, Kliegman RM, Jenson HB. Nelson Essentials Textbook of pediatrics third edition W.B. Saunders company Philidelphia. 2000. [Google Scholar].

[4] Hernandez-Juyol M, Job-Quesada JR., 2002 Dentistry, and self-medication: a current challenge. Med Oral, 7(5):344-47.

[5] Kiyingi KS, Lauwo JA., 1993 Drugs in the home: danger and waste. World Health Forum, 14(4):381-84

[6] Napolitano F, Izzo MT, Di Giuseppe G, Angelillo IF. 2013, Public knowledge, attitudes, and experience regarding the use of antibiotics in Italy. PLoS One, 8(12): e84177.

[7] Grigoryan L， Burgerhof JG， Degener JE, Deschepper R, Lundborg CS, Monnet DL, et al., 2008, Self-Medication with Antibiotics and Resistance (SAR) Consortium. Determinants of selfmedication with antibiotics in Europe: the impact of beliefs, country wealth and the healthcare system. $J$ Antimicrob Chemother, 61:1172-79.

[8] Drug Utilization Research Group, 1996, Latin America WHO. Multicenter study on selfmedication and self-prescription in six Latin American Countries. Clin Pharmacol Ther. 61:48893.

[9] Kafle KK, Gartoulla RP., 1993, Self-Medication and its Impact on Essential Drugs Schemes in Nepal: A Socio-Cultural Research Project: Action Programme on Essential Drugs. Geneva: World Health Organization.

[10] Mumtaz Y, Jahangeer SA, Mujtaba T, Zafar S, Adnan S., 2011, Self-medication among university students of Karachi. JLUMHS, 10(03):102-05.
[11]Ali SM, Fatima M, Ali L, 2015, SelfMedication among Downtown Urban Population of Karachi, Pakistan. Indian Journal of Medical Research and Pharmaceutical Sciences, 2(4).

[12] Phalke VD, Phalke DB, Durgawale PM., 2006, Self-medication practices in rural Maharashtra. Indian J Community Med, 31:34-35.

[13]WHO, 1998, World Health Organization: The role of the pharmacist in self-care and selfmedication. In Report of the 4th WHO Consultative Group on the Role of the Pharmacist in Health Care System. Geneva.

[14]Laporte JR, Castel JM., 1992, [The physician and self-medication]. Med Clin (Barc), 99(11):41416.

[15] Stratchounski LS, Andreeva IV, Ratchina SA, Galkin DV, Petrotchenkova NA, Demin AA, et al., 2003, The inventory of antibiotics in Russian home medicine cabinets. Clin Infect Dis. 37(4):498-505.

[16] Okumura J, Wakai S, Umenai T., 2002, Drug utilization and self-medication in rural communities in Vietnam. Soc Sci Med, 54(12):1875-86.

[17] Calva J, Bojalil R., 1996, Antibiotic use in a periurban community in Mexico: a household and drugstore survey. Soc Sci Med., 42(8):1121-28.

[18]Lansang MA, Lucas-Aquino R, Tupasi TE, Mina VS, Salazar LS, Juban N, et al., 1990, Purchase of antibiotics without prescription in Manila, the Philippines. Inappropriate choices and doses. J Clin Epidemiol, 43(1):61-7.

[19] Crigger NJ, Holcomb L, Grogan RL, Vasquez M, Parchment C, Almendares J, et al., 2004, Development of the choices and acquisition of antibiotics model from a descriptive study of a lay Honduran population. Int J Nurs Stud., 41(7):74553.

[20] Arul Prakasam K, Senthil NK, Ramesh J., 2011, Students' knowledge of antibiotics: a cross-sectional study of students in Tamil Nadu. Int J Pharm Pharm Sci., 3(1).

[21]Balbuena FR, Aranda AB, Figueras A., 2009, Self-medication in older urban Mexicans: an observational, descriptive, cross-sectional study. Drugs Aging, 26(1):51-60.

[22] Chan G, Tang S., 2006, Parental knowledge, attitudes and antibiotic use for acute upper 
respiratory tract infection in children attending a primary healthcare clinic in Malaysia. Singapore Med J., 47(4):266-70.

[23] Brown S, Warnnissorn T, Biddle J, Panikabutra K, Traisupa A., 1982, Antimicrobial resistance of Neisseria gonorrhoea in Bangkok: is single-drug treatment passe. Lancet., 2(8312):1366-68.

[24] Appelbaum PC, Bhamjee A, Scragg JN, Hallett AF, Bowen AJ, Cooper RC., 1977, Streptococcus pneumonia resistant to penicillin and chloramphenicol. Lancet., ii:995-97.

[25]Farrar WE, Eidson M., 1971, R factors in strains of Shigella dysenteriae type 1 isolated in the western hemisphere during 1969-1970. J Infect Dis., 124(3):327-29.

[26] Olarte J, Galindo E., 1973, Salmonella typhi resistant to chloramphenicol, ampicillin, and other antimicrobial agents: strains isolated during an extensive typhoid fever epidemic in Mexico. Antimicrob Agents Chemother, 4(6):597-601.

[27] Sturm AW, van der Pol R, Smits AJ, van Hellemondt FM, Mouton SW, Jamil B, et al., 1997, Over-the-counter availability of antimicrobial agents, self-medication and patterns of resistance in Karachi, Pakistan. J Antimicrob Chemother, 39(4):543-47.

[28] Butt ZA, Gilani AH, Nanan D, Sheikh AL, White F., 2005, Quality of pharmacies in Pakistan: a cross-sectional survey. Int $J$ Qual Health Care, 17(4):307-13.

[29] Qidwai W, Krishanani MK, Hashmi S, Afridi M, Ali RA, et al., 2006, Private drug seller's education in improving prescribing practices. $J$ Coll Physicians Surg Pak., 16:743-46.

[30] Rabbani F, Cheema FH, Talati N, Siddiqui S, Syed S, Bashir S, et al., 2001, Behind the counter: pharmacies and dispensing patterns of pharmacy attendants in Karachi. J Pak Med Assoc., 51:149-54. https://www.ncbi.nlm.nih.gov/pmc/articles/PMC602 $3284 /$.

[31] Ajibola, O., Omisakin, O. A., Eze, A. A., \& Omoleke, S. A. (2018). Self-Medication with Antibiotics, Attitude, and Knowledge of Antibiotic Resistance among Community Residents and Undergraduate Students in Northwest Nigeria.
Diseases (Basel, Switzerland), 6(2), 32. https://doi.org/10.3390/diseases6020032.

[32] Haque M, Rahman NAA, McKimm J, Kibria GM, Azim Majumder MA, Haque SZ, Islam MZ, Binti Abdullah SL, Daher AM, Zulkifli Z, Rahman S, Kabir R, Lutfi SNNB, Aishah Binti Othman NS. Self-medication of antibiotics: investigating practice among university students at the Malaysian National Defence University. Infect Drug Resist. 2019; 12:1333-1351 https://doi.org/10.2147/IDR.S203364. [33] Torres NF, Solomon VP, Middleton LE, 2020, Identifying the commonly used antibiotics for selfmedication in urban Mozambique: a qualitative study BMJ Open 2020;10: e041323. doi: 10.1136/bmjopen-2020-041323.

[34] Torres, N.F., Solomon, V. \& Middleton, L.E. Patterns of self-medication with antibiotics in Maputo City: a qualitative study. Antimicrobe Resist $\begin{array}{llllll}\text { Infect } & \text { Control } & \mathbf{8}, & 161 & \text { (2019). }\end{array}$ https://doi.org/10.1186/s13756-019-0618-z.

[35] Kosofe Local Government Area, 2017, About Kosofe http://kosofelocalgovtarea.blogspot.com/2017/09/ab out-kosofe.html?m=1.

[36] WHO, 2013, Model List of Essential Medicines 18th list. Geneva Switzerland: WHO Press.

[37] Ramay BM, Lambour P, Ceron A., 2015, Comparing antibiotic self-medication in two socioeconomic groups in Guatemala City: a descriptive cross-sectional study. BMC Pharmacol Toxicol., 16:11.

[38] Araoye, M. O., 2003, Research methodology with statistics for health and social sciences. First edition Nathadex Publisher Ilorin Nigeria. pp 119.

[39] Shah SJ, Ahmad H, Rehan RB, Najeeb S, Mumtaz M, Jilani MH, et al., 2014, Self-medication with antibiotics among non-medical university students of Karachi: a cross-sectional study. BMC Pharmacol Toxicol., 15:74.

[40] Ilhan Mustafa N, Durukan Elif, Ilhan Sevil Ozger, Aksakal F Nur, Ozkan Seçil, Bumin Mehmet Ali, 2009, Self-medication With Antibiotics: Questionnaire Survey Among Primary Care Center Attendants, 18(12):1150-1157. doi:10.1002/pds.1829 https://pubmed.ncbi.nlm.nih.gov/19827009/. 
